TESIS DOCTORAL

PROGRAMA DOCTORADO DE EDUCACIÓN

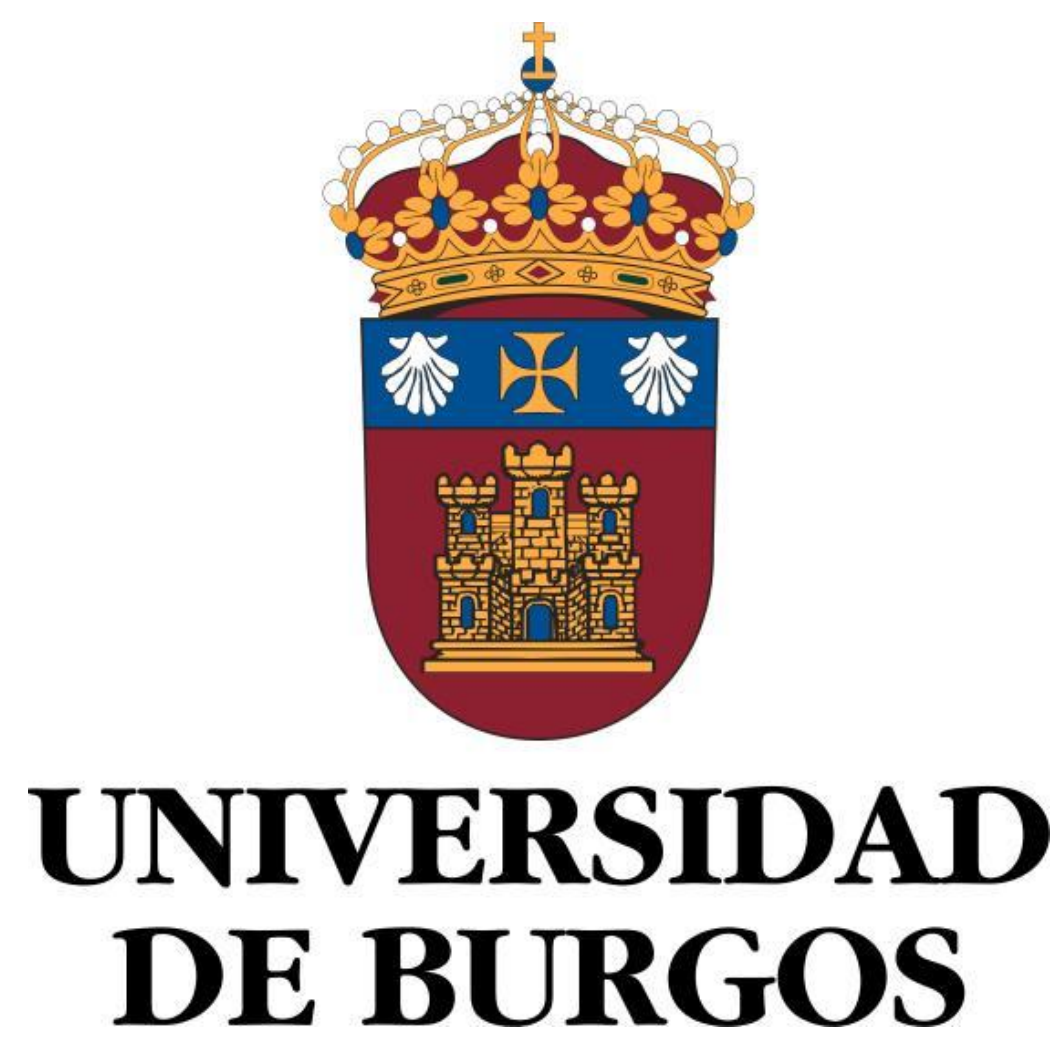

\title{
ANÁLISIS TÁCTICO DEL FIELD GOAL EN BALONCESTO. IMPLICACIONES TEÓRICAS Y APLICACIONES PRÁCTICAS.
}

Autor: Rodrigo Cubillo León

Directores: Dr. Alfredo Jiménez Eguizábal

Dra. Carmen Palmero Cámara

2020 
TESIS DOCTORAL

PROGRAMA DOCTORADO DE EDUCACIÓN

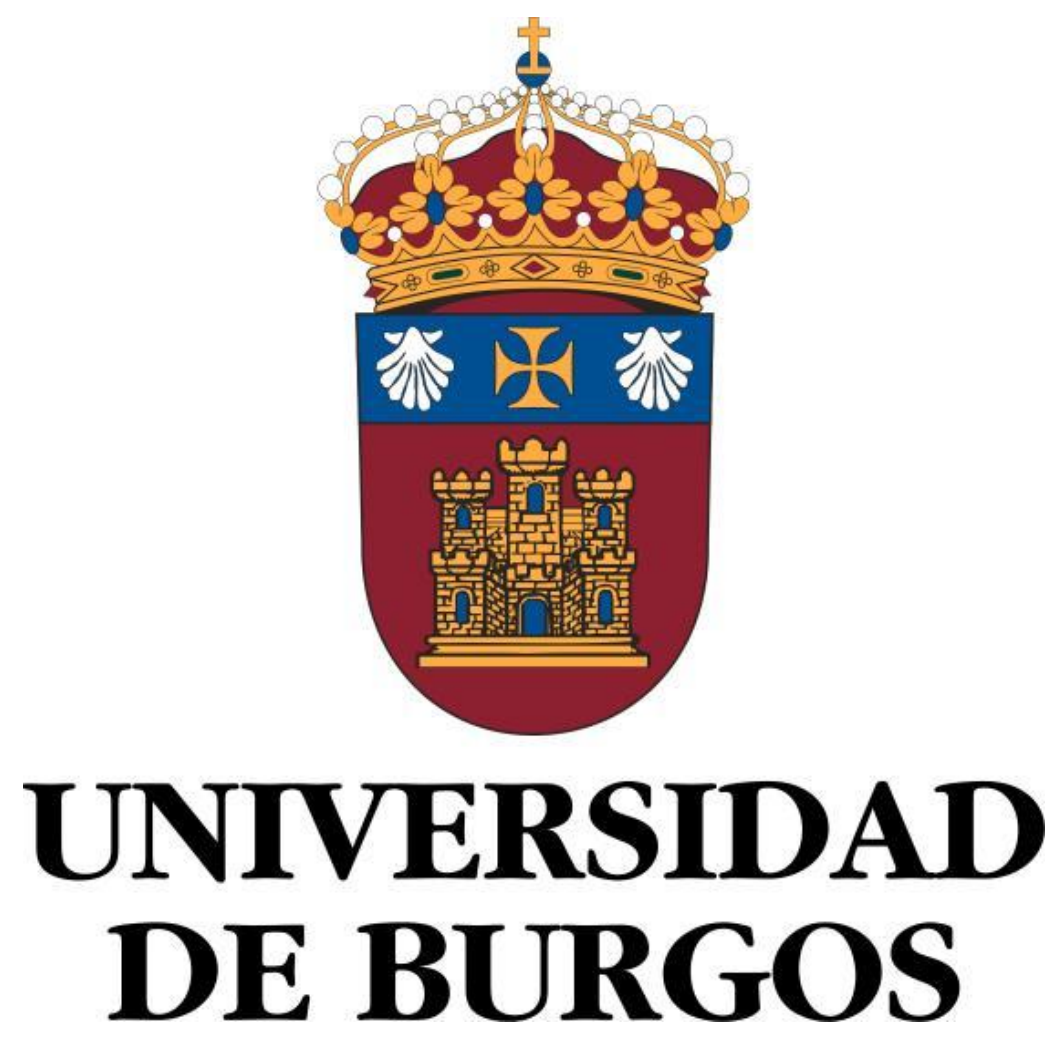

\section{ANÁLISIS TÁCTICO DEL FIELD GOAL EN BALONCESTO. IMPLICACIONES TEÓRICAS Y APLICACIONES PRÁCTICAS.}

Autor: Rodrigo Cubillo León

Directores: Dr. Alfredo Jiménez Eguizábal Dra. Carmen Palmero Cámara 


\section{INFORME DEL DIRECTOR DE LA TESIS.}

(Art. 16.1 del Reglamento de Doctorado de la Universidad de Burgos. BOCYL 18/03/2014)

\section{Dra. Carmen Palmero Cámara y Dr. Alfredo Jiménez Eguizábal,} Catedráticos de Universidad, adscritos al Departamento de Ciencias de la Educación de la Universidad de Burgos

\section{HACE CONSTAR:}

Que el trabajo de investigación titulado "Análisis Táctico del Field Goal en Baloncesto. Implicaciones teóricas y aplicaciones prácticas" que presenta el doctorando D. Rodrigo Cubillo León, para la colación del Grado de Doctor por la Universidad de Burgos, ha sido realizado bajo su dirección en el marco del Programa de Doctorado en Educación y que hallándose finalizado y cumpliendo con los requisitos formales y el rigor científico exigidos, autorizan su depósito, dado que reúne las condiciones necesarias para su presentación y defensa ante el Tribunal correspondiente que ha de juzgarlo en la Universidad de Burgos

Para que así conste y surta los oportunos efectos, firmo en Burgos, a uno de noviembre de dos mil veinte

\section{DIRECTOR DE TESIS}

\begin{tabular}{l|l} 
PALMERO & $\begin{array}{l}\text { Firmado digitalmente } \\
\text { por PALMERO CAMARA }\end{array}$ \\
CAMARA MARIA & MARIA DEL CARMEN - \\
DEL CARMEN - & 16507063D \\
16507063D & Fecha: 2020.11 .01 \\
$18: 50: 59+01^{\prime} 00^{\circ}$
\end{tabular}

Fdo.: Carmen Palmero Cámara

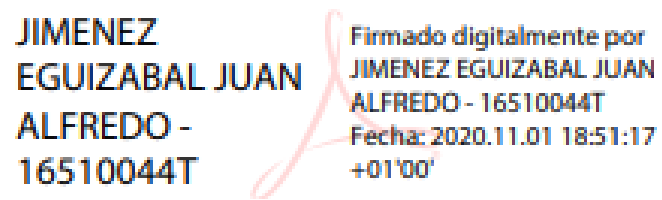

Fdo.: Alfredo Jiménez Eguizábal 


\section{AGRADECIMIENTOS}

En primer lugar me gustaría agradecer a la Universidad de Burgos y especialmente a mis directores, los doctores Carmen Palmero Cámara y Alfredo Jiménez Eguizábal, por sus orientaciones y apoyo para culminar este apasionante proyecto personal y académico.

En este mismo sentido no puedo olvidarme de la Universidad de León, concretamente de Alejando Vaquera y Juan Carlos Morante. Sin sus consejos y ayuda me habría sido imposible realizar este estudio.

Me resulta obligatorio nombrar a José Luis, mi padre. El doctorado es algo que siempre he tenido en mente, pero por unas razones u otras siempre había encontrado una excusa, porque es lo que eran, para posponerlo. Ver su fuerza, su lucha y sus ganas de vivir me hizo replantearme mi forma de ver la vida y me decidí a dar este gran paso. No por motivos laborales o económicos, tan solo por mi (y en parte por él), por disfrutar del proceso, por aprender, por conocerme un poco mejor, por saber gestionar mi tiempo, por aprender a afrontar la frustración, el cansancio... en definitiva, por crecer como persona.

Gracias a Esther por ser mi apoyo, en lo bueno y en lo malo. Por saber frenarme cuando me acelero y por ser esa mano que me empuja cuando ya no quedan fuerzas para seguir adelante. Ella me da ese equilibrio y, sobre todo, me hace feliz, el verdadero objetivo de esta vida, pues el resto de aspectos son medios para llegar a ella.

También quiero dedicar unas palabras para todos esos grandes profesores que en distintas áreas del conocimiento y etapas de mi vida me han aportado algo más allá de valiosos conocimientos teóricos y prácticos. Hablo de esos profesores que fomentan tu espíritu crítico, tu curiosidad y te hacen madurar integralmente.

Para acabar, creo que los éxitos en la vida se consiguen con esfuerzo y dedicación, no hay duda, pero me habría sido imposible sin todas esas personas que me han hecho ser lo que soy. No he escrito sus nombres en estas líneas, pero os aseguro que buena parte de este éxito es suyo.

"La razón por la que las personas fracasan realmente no es porque pusieron sus metas muy altas y no llegaron, sino porque las pusieron muy bajas y las alcanzaron” Jordan Belfort 


\section{ÍNDICE GENERAL}

I. Índice de figuras

II. Índice de tablas

III. Glosario de términos y simbología

IV. Resumen/Abstract

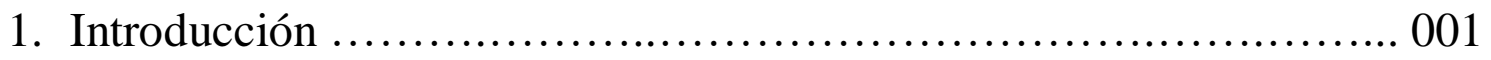

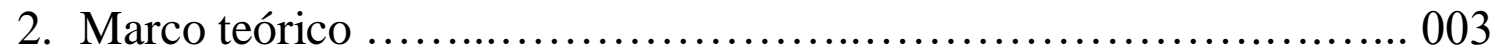

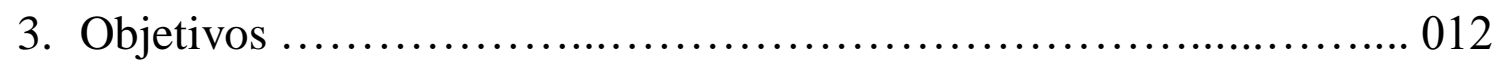

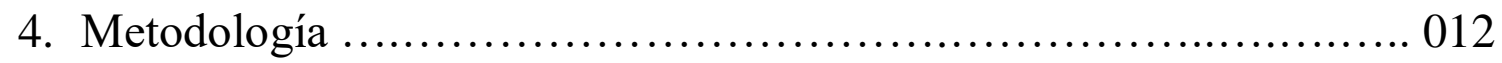

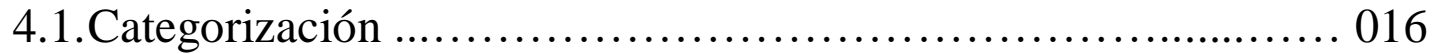

4.1.1. Nivel conductual ....................................... 017

4.1.2. Nivel contextual ...................................... 017

4.1.2.1.Zona del campo .................................. 018

4.1.2.2.Periodo de juego ..................................... 020

4.1.2.3.Tiempo de posesión .................................... 020

4.1.2.4.Precedente ...................................... 021

4.1.2.5.Jugadores implicados ............................... 022

4.1.2.6.Ventaja / desventaja .............................. 022

4.1.2.7.Tipo de tiro ................................... 023

4.1.2.8.Momento especial ................................... 025

4.1.3. Nivel evaluativo ...................................... 026

4.2.Constancia intersesional ..................................... 027

4.3.Constancia intrasesional ..................................... 028

4.4.Fiabilidad y validez ...................................... 028

5. Reflexión previa a los resultados y su aplicación ......................... 032

6. Resultados .................................................. 033

6.1.Zona del campo ........................................... 036

6.1.1. Zona del campo y resultado ................................ 037

6.1.2. Zona del campo y tiempo de posesión ........................ 041 
6.1.3. Zona del campo y tipo de tiro ............................ 044

6.1.4. Zona del campo y ventaja/desventaja ........................ 047

6.1.5. Zona del campo y precedente ............................... 048

6.1.6. Zona del campo y jugadores implicados ..................... 050

6.1.7. Zona del campo y QT ...................................... 052

6.1.8. Zona del campo y momento especial ......................... 054

6.2.Resultado .................................................... 055

6.2.1. Resultado y tiempo de posesión .............................. 056

6.2.2. Resultado y tipo de tiro .................................. 059

6.2.3. Resultado y ventaja/desventaja ......................... 062

6.2.4. Resultado y precedente .................................. 064

6.2.5. Resultado y jugadores implicados ........................... 067

6.2.6. Resultado y QT ........................................... 068

6.2.7. Resultado y momento especial ............................ 071

6.3.Tiempo de posesión ........................................... 073

6.3.1. Tiempo de posesión y tipo de tiro ........................... 073

6.3.2. Tiempo de posesión y ventaja/desventaja ................... 076

6.3.3. Tiempo de posesión y precedente .......................... 077

6.3.4. Tiempo de posesión y jugadores implicados ................. 080

6.3.5. Tiempo de posesión y QT ................................ 082

6.3.6. Tiempo de posesión y momento especial ................. 083

6.4.Tipo de tiro ............................................... 084

6.4.1. Tipo de tiro y ventaja/desventaja ...................... 085

6.4.2. Tipo de tiro y precedente .............................. 086

6.4.3. Tipo de tiro y jugadores implicados .......................... 089

6.4.4. Tipo de tiro y QT ........................................ 090

6.4.5. Tipo de tiro y momento especial ............................ 092

6.5.Ventaja/desventaja ...................................... 093

6.5.1. Ventaja/desventaja y precedente ......................... 095 
6.5.2. Ventaja/desventaja y jugadores implicados 096

6.5.3. Ventaja/desventaja y QT ................................ 097

6.5.4. Ventaja/desventaja y momento especial ..................... 097

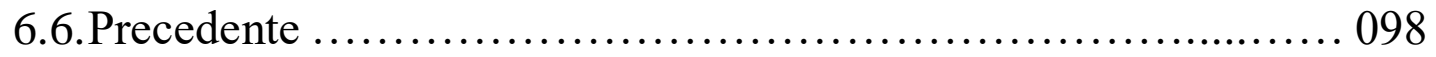

6.6.1. Precedente y jugadores implicados ........................ 099

6.6.2. Precedente y QT ..................................... 101

6.6.3. Precedente y momento especial .......................... 103

6.7.Jugadores implicados ...................................... 105

6.7.1. Jugadores implicados y QT ............................ 105

6.7.2. Jugadores implicados y momento especial ................. 107

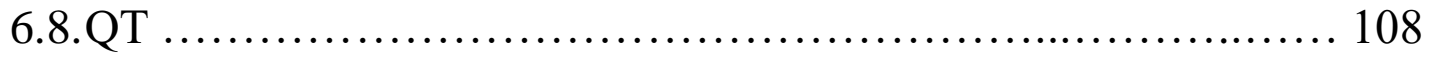

6.8.1. QT y momento especial .............................. 108

6.9.Momento especial ......................................... 109

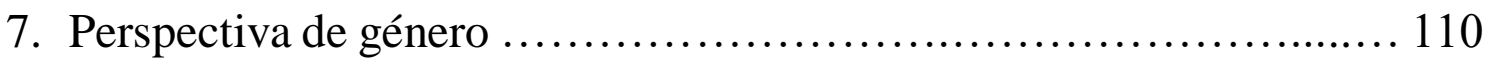

7.1.Comparativa baloncesto masculino y femenino .................. 110

7.2. Comparativa baloncesto europeo y americano .................. 113

7.2.1. Baloncesto masculino y femenino en EU .................. 117

7.2.2. Baloncesto masculino y femenino en EEUU ............... 119

7.2.3. Baloncesto masculino en EU y EEUU .................... 122

7.2.4. Baloncesto femenino en EU y EEUU ...................... 124

8. Síntesis de resultados ......................................... 127

9. Discusión de los resultados ..................................... 150

10. Aplicación práctica ........................................... 158

10.1. Ejercicios prácticos ...................................... 161

10.1.1. Ficha $\mathrm{N}^{\mathrm{o}} 1$ : Trabajo de rebote y FG tras pase ............... 163

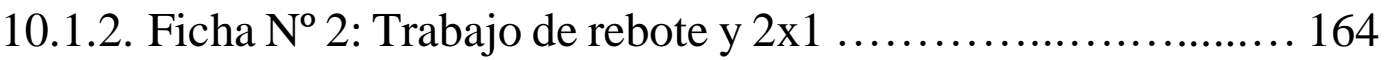

10.1.3. Ficha $\mathrm{N}^{\mathrm{o}} 3$ : Toma de decisiones y bloqueos ................... 165

10.1.4. Ficha $\mathrm{N}^{\mathrm{o}}$ 4: Fintas de recepción y líneas de pase ............. 166

10.1.5. Ficha $\mathrm{N}^{\circ}$ 5: Ayudas defensivas y ataque en superioridad ...... 167 
10.1.6. Ficha $\mathrm{N}^{\mathrm{o}}$ 6: Pase 168

10.1.7. Ficha $\mathrm{N}^{\mathrm{o}}$ 7: FG tras pase .................................... 169

10.1.8. Ficha $\mathrm{N}^{\mathrm{o}}$ 8: Pase interior y trabajo en poste bajo ................. 170

10.1.9. Ficha $\mathrm{N}^{\circ}$ 9: $1 \mathrm{x} 1 \mathrm{y} 1 \mathrm{x} 1$ con pasador ........................... 171

10.1.10. Ficha $\mathrm{N}^{\mathrm{o}} 10$ : $1 \mathrm{x} 1 \mathrm{y}$ dribling ............................. 172

10.1.11. Ficha $\mathrm{N}^{\mathrm{o}}$ 11: $1 \mathrm{x} 1$ y recuperación defensiva .................. 173

10.1.12. Ficha $\mathrm{N}^{\mathrm{o}} 12$ : 2x1 y bloqueo directo ........................ 174

10.1.13. Ficha $\mathrm{N}^{\mathrm{o}} 13: 2 \mathrm{x} 2$ y balance defensivo ..................... 175

10.1.14. Ficha $\mathrm{N}^{\mathrm{o}} 14: 2 \mathrm{x} 2$ libre y balance defensivo .................. 176

10.1.15. Ficha $\mathrm{N}^{\mathrm{o}} 15: 2 \mathrm{x} 2$ y defensa en tándem ..................... 177

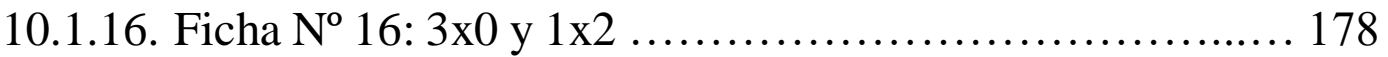

10.1.17. Ficha $\mathrm{N}^{\mathrm{o}} 17: 3 \mathrm{x} 2$ y defensa en tándem ..................... 179

10.1.18. Ficha $\mathrm{N}^{\mathrm{o}} 18: 3 \times 2$ continuo y defensa en tándem .............. 180

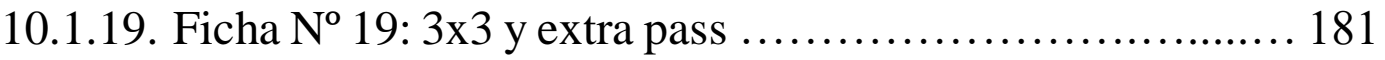

10.1.20. Ficha $\mathrm{N}^{\mathrm{o}} 20: 3 \times 3$ pasando y cortando ...................... 182

10.1.21. Ficha $\mathrm{N}^{\mathrm{o}} 21: 3 \times 3$ continuo ............................. 183

10.1.22. Ficha $\mathrm{N}^{\mathrm{o}} 22$ : Pasar y cortar $+5 \mathrm{x} 5 \ldots \ldots \ldots \ldots \ldots \ldots \ldots \ldots \ldots \ldots \ldots \ldots \ldots \ldots$

10.1.23. Ficha $\mathrm{N}^{\mathrm{o}}$ 23: Juego libre con premisas .................... 185

10.1.24. Ficha $\mathrm{N}^{\mathrm{o}} 24$ : Contraataque con zonas defensivas ........... 185

10.1.25. Ficha $\mathrm{N}^{\mathrm{o}} 25$ : Pase largo para contraataque .................... 186

10.1.26. Ficha $\mathrm{N}^{\mathrm{o}}$ 26: Presión todo el campo y trap ................... 187

10.1.27. Ficha $\mathrm{N}^{\circ} 27$ : Ataque en últimos segundos (cuernos) ......... 188

10.1.28. Ficha $\mathrm{N}^{\circ}$ 28: Ataque en últimos segundos (aclarado) ........ 189

10.1.29. Ficha $\mathrm{N}^{\circ}$ 29: Ataque en últimos segundos campo entero .... 190

10.1.30. Ficha $\mathrm{N}^{\mathrm{o}}$ 30: Preparación física (circuito) ................. 191

10.1.31. Ficha $\mathrm{N}^{\circ}$ 31: Preparación física y dribling (1) ............... 192

10.1.32. Ficha $\mathrm{N}^{\mathrm{o}}$ 32: Preparación física y dribling (2) ................ 193

10.1.33. Ficha $\mathrm{N}^{\mathrm{o}}$ 33: Preparación física (líneas) .................... 193

10.1.34. Ficha $\mathrm{N}^{\circ}$ 34: Preparación física (trenzas) ................... 194 
10.1.35. Ficha $\mathrm{N}^{\mathrm{o}} 35$ : Preparación física y finalizaciones ............. 195

10.1.36. Ficha № 36: Preparación física (palmeos) ................. 196

11. Bibliografía .................................................. 197

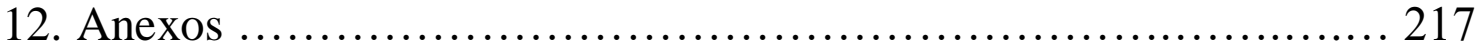

12.1. Tablas intraobservador ................................. 217

12.2. Tablas interobservador .................................... 219

12.3. Encuentros analizados ..................................... 221

12.4. Datos obtenidos ......................................... 228

12.4.1. Totales ............................................. 228

12.4.2. Baloncesto masculino (ACB, Euroliga y NBA) .............. 233

12.4.3. Baloncesto femenino (L.Fem., WEuroliga y WNBA) ....... 239

12.4.4. Europa (Euroliga y WEuroliga) ........................... 244

12.4.5. EEUU (NBA y WNBA) ................................. 249

12.4.6. Baloncesto masculino europeo (ACB Y Euroliga) ......... 255

12.4.7. Baloncesto femenino europeo (L.Fem. y WEuroliga) ....... 261

12.4.8. Baloncesto masculino EEUU (NBA) .................... 267

12.4.9. Baloncesto femenino EEUU (WNBA) ................... 274 


\section{I. ÍNDICE DE FIGURAS}

Figura 1.- Complementariedad cualitativa - cuantitativa en la metodología observacional: elementos del proceso.

Adaptación de Anguera et al. (2018, p.11) ................... 006

Figura 2.- Representación gráfica de los 8 diseños observacionales.

Adaptación de Anguera et al. $(2011$, p.66) ................... 007

Figura 3.- Diseño observacional utilizado en este estudio ............... 007

Figura 4.- Licencias deportivas por federaciones en 2019 .............. 009

Figura 5.- Componentes de la acción en deportes colectivos.

Adaptación de Patiño y López-Barrajón (1998, p.38) .............. 011

Figura 6.- Selección de fuente de imágenes ............................... 013

Figura 7.- Fijación de variables de análisis ............................. 014

Figura 8.- Software VA-Sports ................................... 015

Figura 9.- Variables de análisis aplicadas al estudio del FG .............. 016

Figura 10.- Campogramas de otros estudios .......................... 018

Figura 11.- Campograma definitivo ................................. 019

Figura 12.- Campograma original ................................... 019

Figura 13.- Consecuencias de la disminución del tiempo de posesión ..... 020

Figura 14.- \% de FG según zona del campo ............................ 036

Figura 15.- Resultado del FG dentro de cada zona del campo ............. 037

Figura 16.- \% FG según resultado dentro de cada zona del campo .......... 039

Figura 17.- \% FG según zona del campo de cada resultado ................ 040 
Figura 18.- Franja de posesión del FG dentro de cada zona del campo .... 041

Figura 19.- \% franja de posesión del FG dentro de cada zona del campo 042

Figura 20.- \% de FG de la franja de posesión 17-24 según zona del campo 043

Figura 21.- \% de FG de la franja de posesión 9-16 según zona del campo 043

Figura 22.- \% de FG de la franja de posesión 0-8 según zona del campo 043

Figura 23.- \% tipo de FG dentro de cada zona del campo 045

Figura 24.- \% buenos FG según zona del campo 045

Figura 25.- \% malos FG según zona del campo ........................ 046

Figura 26.- \% FG con el marcador en contra según zona del campo ...... 047

Figura 27.- \% FG con el marcador a favor según zona del campo ......... 047

Figura 28.- \% FG entre las variables zona del campo y precedente ....... 048 Figura 29.- \% de FG acumulado entre las variables zona del campo y jugadores implicados 051

Figura 30.- FG según QT dentro de cada zona del campo ................. 052

Figura 31.- \% de FG tras t.muerto según zona del campo ................. 054

Figura 32.- \% de FG en última jugada según zona del campo .............. 054

Figura 33.- $\%$ de FG en función del resultado ........................... 055

Figura 34.- \% de FG según resultado positivo y negativo ................... 055 
Figura 35.- \% de FG de cada resultado según tiempo de posesión 057

Figura 36.- \% de FG según resultado dentro de cada franja de posesión 057

Figura 37.- \% de FG con resultado (+) y (-) de cada franja de posesión 058

Figura 38.- \% de FG con resultado (+) y (-) dentro de cada tipo de tiro 059

Figura 39.- \% de buenos FG según resultado 060

Figura 40.- \% de malos FG según resultado 060

Figura 41.- \% de FG de cada tipo de tiro según resultado 061

Figura 42.- $\%$ de tipos de FG dentro de cada posible resultado 062

Figura 43.- \% de resultados (+) y (-) del FG según el marcador 063

Figura 44.- $\%$ de los resultados del FG dentro de cada precedente 065

Figura 45.- $\%$ de los precedentes del FG para cada resultado 066 Figura 46.- \% de FG acumulado entre las variables resultado y jugadores implicados 067

Figura 47.- \% de FG según resultado dentro de cada QT 069

Figura 48.- \% de FG según QT dentro de cada resultado 070

Figura 49.- \% de FG según resultado dentro de cada QT .................. 070

Figura 50.- \% de FG según resultado tras t.muerto 071

Figura 51.- \% de FG según resultado en última jugada 071 
Figura 52.- \% de FG según resultado dentro de cada momento especial 072

Figura 53.- \% de FG en función del tiempo de posesión 073

Figura 54.- \% de FG según tiempo de posesión dentro de cada tipo

de tiro 074

Figura 55.- $\%$ de FG según tipo de tiro dentro de 0-8 075

Figura 56.- \% de FG según tipo de tiro dentro de 9-16 075

Figura 57.- $\%$ de FG según tipo de tiro dentro de 17-24 075

Figura 58.- \% de FG según tiempo de posesión dentro de cada situación del marcador 076

Figura 59.- \% de FG según precedente dentro de cada franja de posesión

Figura 60.- \% de FG según franja de posesión dentro de cada precedente 079

Figura 61.- \% de FG según $\mathrm{n}^{\circ}$ de jugadores dentro de cada franja de posesión 081

Figura 62.- \% de FG según franja de posesión dentro de cada QT 082

Figura 63.- \% de FG según QT dentro de cada franja de posesión 083

Figura 64.- \% de FG según franja de posesión en última jugada 083

Figura 65.- \% de FG según franja de posesión tras t. muerto 084

Figura 66.- \% de FG según tipo de tiro 084 
Figura 67.- \% de FG según tipo de tiro dentro de cada situación del marcador 085

Figura 68.- \% de FG según tipo de tiro dentro de cada precedente 087

Figura 69.- \% de FG según precedente dentro de cada tipo de tiro 088

Figura 70.- \% de FG acumulado entre las variables tipo de tiro y jugadores implicados 089

Figura 71.- \% de FG según $n^{\circ}$ de jugadores dentro de cada tipo de tiro 089

Figura 72.- \% de FG según tipo de tiro dentro de cada QT 091

Figura 73.- \% de FG según QT dentro de cada tipo de tiro 091

Figura 74.- \% de FG según tipo de tiro dentro de cada m.especial 092

Figura 75.- \% de FG según marcador

Figura 76.- \% de FG según precedente dentro de cada situación del marcador 095

Figura 77.- \% de FG según jugadores implicados dentro de cada situación del marcador 096

Figura 78.- \% de FG según marcador tras t.muerto 097

Figura 79.- \% de FG según marcador en última jugada 098

Figura 80.- \% de FG según precedente 098

Figura 81.- \% de FG acumulado entre las variables precedente y jugadores implicados 099 
Figura 82.- \% de FG según jugadores implicados dentro de cada precedente 100

Figura 83.- \% de FG según precedente dentro de cada QT .............. 101

Figura 84.- \% de FG según QT dentro de cada precedente ............... 103

Figura 85.- \% de FG según precedente tras t.muerto ..................... 103

Figura 86.- \% de FG según precedente en última jugada ................ 104

Figura 87.- \% de FG según jugadores implicados ....................... 105

Figura 88.- \% de FG según jugadores implicados dentro de cada QT ... 106

Figura 89.- \% de FG según jugadores implicados tras t.muerto ........... 107

Figura 90.- \% de FG según jugadores implicados en última jugada ....... 107

Figura 91.- \% de FG según QT ..................................... 108

Figura 92.- \% de FG según QT tras t.muerto ............................ 109

Figura 93.- \% de FG según QT en última jugada ........................ 109

Figura 94.- \% de FG según momento normal o especial .................. 109 


\section{II. ÍNDICE DE TABLAS}

Tabla 1.- Nivel conductual. Variable lanzamientos ...................... 017

Tabla 2.- Nivel contextual. Variable precedente .......................... 021

Tabla 3.- Nivel contextual. Variable ventaja/desventaja .................. 023

Tabla 4.- Nivel contextual. Variable tipo de tiro ......................... 024

Tabla 5.- Nivel evaluativo. Variable resultado de la acción ............... 026

Tabla 6.- Valoración del coeficiente Kappa (Landis y Koch, 1977) ........ 029

Tabla 7.- Concordancia intraobservador. Variable ventaja/desventaja .... 030

Tabla 8.- Concordancia interobservador. Variable tipo de tiro ............. 030

Tabla 9.- Índice Kappa Intraobservador .............................. 030

Tabla 10.- Índice Kappa Interobservador ........................... 030

Tabla 11.- Índice Kappa de niveles de respuesta ...................... 031

Tabla 12.- Esquema de combinación de dos variables .................... 033

Tabla 13.- Análisis sobre el total de combinaciones entre las variables

precedente y posesión ........................................ 034

Tabla 14.- Análisis de cada categoría de la variable precedente en

función del tiempo de posesión ..................................... 035

Tabla 15.- Análisis de cada categoría de la variable posesión en función

del precedente ............................................... 035

Tabla 16.- \% de FG entre las variables zona del campo y resultado ........ 037 
Tabla 17.- \% FG con resultado positivo y negativo dentro de cada zona del campo 038

Tabla 18.- \% FG según zona del campo y efectividad en cada una ....... 038

Tabla 19.- \% FG según resultado dentro de cada zona del campo ........... 039

Tabla 20.- \% FG según zona del campo de cada resultado .................. 040

Tabla 21.- \% de FG entre las variables zona del campo y tiempo de posesión 041

Tabla 22.- \% franja de posesión del FG dentro de cada zona del campo 042

Tabla 23.- \% de FG entre las variables zona del campo y tipo de tiro ...... 044

Tabla 24.- \% tipo de FG dentro de cada zona del campo .................. 044

Tabla 25.- \% de cada tipo de FG según zona del campo ................... 046

Tabla 26.- \% de FG con el marcador a favor, igualado y en contra según zona del campo ........................................ 047

Tabla 27.- $\%$ de FG entre las variables zona del campo y precedente ...... 048

Tabla 28.- \% de precedente del FG dentro de cada zona del campo ...... 049

Tabla 29.- \% de cada precedente del FG según zona del campo ........... 049

Tabla 30.- \% de FG entre las variables zona del campo y jugadores implicados 050

Tabla 31.- \% de FG dentro de cada zona del campo según jugadores implicados 051

Tabla 32.- \% de FG entre las variables zona del campo y QT 052 
Tabla 33.- \% de FG según QT dentro de cada zona del campo 053

Tabla 34.- \% de FG de cada m. especial según zona del campo 054

Tabla 35.- \% de FG entre las variables resultado y tiempo de posesión ... 056

Tabla 36.- \% de FG de cada resultado según tiempo de posesión 056

Tabla 37.- \% de FG según resultado dentro de cada franja de posesión ... 057

Tabla 38.- \% de FG con resultado (+) y (-) de cada franja de posesión .... 058

Tabla 39.- \% de FG entre las variables resultado y tipo de tiro 059

Tabla 40.- \% de FG con resultado (+) y (-) dentro de cada tipo de tiro .... 060

Tabla 41.- \% de FG de cada tipo de tiro según resultado ................. 061

Tabla 42.- \% de FG de cada posible resultado según tipo de tiro 062

Tabla 43.- \% de resultados del FG según el marcador 063

Tabla 44.- \% de FG entre las variables resultado y precedente 064

Tabla 45.- \% de FG según resultado dentro de cada precedente 064

Tabla 46.- \% de los resultados del FG dentro de cada precedente 065

Tabla 47.- \% de los precedentes del FG para cada resultado 066

Tabla 48.- \% de FG con resultado (+) y (-) según jugadores implicados .. 067

Tabla 49.- \% de FG según jugadores implicados dentro de cada

Resultado 068

Tabla 50.- \% de FG entre las variables resultado y QT 068

Tabla 51.- \% de FG según resultado dentro de cada QT 068

Tabla 52.- \% de FG según QT dentro de cada resultado 069

Tabla 53.- \% de FG según resultado dentro de cada QT 070 
Tabla 54.- \% de FG según resultado tras t.muerto 071

Tabla 55.- \% de FG según resultado dentro de cada momento especial ... 072 Tabla 56.- \% de FG entre las variables tiempo de posesión y tipo de tiro 073

Tabla 57.- \% de FG según tiempo de posesión dentro de cada tipo de tiro 074

Tabla 58.- \% de FG según tipo de tiro dentro de cada franja de posesión 075

Tabla 59.- \% de FG según tiempo de posesión dentro de cada situación del marcador 076

Tabla 60.- \% de FG entre las variables tiempo de posesión y precedente 077

Tabla 61.- \% de FG según precedente dentro de cada franja de posesión 078

Tabla 62.- \% de FG según franja de posesión dentro de cada precedente 078

Tabla 63.- \% de FG entre las variables tiempo de posesión y jugadores implicados 080

Tabla 64.- \% de FG según $\mathrm{n}^{\circ}$ de jugadores dentro de cada franja de posesión 080

Tabla 65.- \% de FG según franja de posesión dentro de cada QT 082

Tabla 66.- \% de FG según QT dentro de cada franja de posesión 082 
Tabla 67.- \% de FG según tipo de tiro dentro de cada situación del marcador 086

Tabla 68.- \% de FG entre las variables tipo de tiro y precedente 086

Tabla 69.- \% de FG según tipo de tiro dentro de cada precedente 087

Tabla 70.- \% de FG según precedente dentro de cada tipo de tiro 088

Tabla 71.- \% de FG según jugadores implicados dentro de cada tipo de tiro 090

Tabla 72.- \% de FG entre las variables tipo de tiro y QT 090

Tabla 73.- \% de FG según QT dentro de cada tipo de tiro 091

Tabla 74.- \% de FG según tipo de tiro dentro de cada m.especial

Tabla 75.- Análisis sobre el total de combinaciones entre la variable A y ventaja/desventaja

Tabla 76.- Análisis de cada categoría de la variable A en función de la variable ventaja/desventaja 094

Tabla 77.- Análisis de cada categoría de la variable ventaja/desventaja en función de la variable A 094

Tabla 78.- \% de FG según precedente dentro de cada situación del marcador 095

Tabla 79.- \% de FG según jugadores implicados dentro de cada situación del marcador 096

Tabla 80.- \% de FG según QT dentro de cada situación del marcador 097 
Tabla 81.- \% de FG entre las variables precedente y jugadores implicados 099

Tabla 82.- \% de FG según jugadores implicados dentro de cada precedente 100

Tabla 83.- \% de FG entre las variables precedente y QT 101

Tabla 84.- \% de FG según precedente dentro de cada QT 102

Tabla 85.- \% de FG según QT dentro de cada precedente 102

Tabla 86.- \% de FG según precedente dentro de cada m.especial 103

Tabla 87.- \% de FG entre las variables jugadores implicados y QT 105

Tabla 88.- \% de FG según jugadores implicados dentro de cada QT 106

Tabla 89.- \% de FG según jugadores implicados dentro de cada m.especial 107

Tabla 90.- de FG según QT dentro de cada m.especial 108

Tabla 91.- \% de FG según zona del campo por género 111

Tabla 92.- \% de FG según resultado por género 111

Tabla 93.- \% de FG según tiempo de posesión por género

Tabla 94.- \% de FG según tipo de tiro por género

Tabla 95.- \% de FG según ventaja/desventaja por género

Tabla 96.- \% de FG según precedente por género

Tabla 97.- \% de FG según jugadores implicados por género 113

Tabla 98.- \% de FG según periodo de juego por género 113

Tabla 99.- \% de FG según zona del campo por localización 114 
Tabla 100.- \% de FG según resultado por localización

Tabla 101.- \% de FG según tiempo de posesión por localización 115

Tabla 102.- \% de FG según tipo de tiro por localización 115

Tabla 103.- \% de FG según ventaja/desventaja por localización 115

Tabla 104.- \% de FG según precedente por localización 116

Tabla 105.- \% de FG según jugadores implicados por localización 116

Tabla 106.- \% de FG según periodo de juego por localización 117

Tabla 107.- \% de FG según zona del campo por género en EU .......... 117

Tabla 108.- \% de FG según resultado por género en EU ................. 117

Tabla 109.- \% de FG según tiempo de posesión por género en EU ........ 118

Tabla 110.- \% de FG según tipo de tiro por género en EU ................ 118

Tabla 111.- \% de FG según ventaja/desventaja por género en EU ......... 118

Tabla 112.- \% de FG según precedente por género en EU ................. 119

Tabla 113.- \% de FG según jugadores implicados por género en EU ...... 119

Tabla 114.- \% de FG según periodo de juego por género en EU .......... 119

Tabla 115.- \% de FG según zona del campo por género en EEUU ......... 120

Tabla 116.- \% de FG según resultado por género en EEUU .............. 120

Tabla 117.- \% de FG según tiempo de posesión por género en EEUU .... 120

Tabla 118.- \% de FG según tipo de tiro por género en EEUU ............ 120

Tabla 119.- \% de FG según ventaja/desventaja por género en EEUU ..... 121

Tabla 120.- \% de FG según precedente por género en EEUU ............ 121

Tabla 121.- \% de FG según jugadores implicados por género en EEUU .. 121 
Tabla 122.- \% de FG según periodo de juego por género en EEUU

Tabla 123.- \% de FG según zona del campo por localización

en B.Masculino

Tabla 124.- \% de FG según resultado por localización

en B.Masculino

Tabla 125.- \% de FG según tiempo de posesión por

localización en B.Masculino

Tabla 126.- \% de FG según tipo de tiro por localización

en B.Masculino 123

Tabla 127.- \% de FG según ventaja/desventaja por

localización en B.Masculino

Tabla 128.- \% de FG según precedente por localización

en B.Masculino

Tabla 129.- \% de FG según jugadores implicados por

localización en B.Masculino

Tabla 130.- \% de FG según periodo de juego por

localización en B.Masculino

Tabla 131.- \% de FG según zona del campo por localización

en B.Femenino

Tabla 132.- \% de FG según resultado por localización

en B.Femenino 
Tabla 133.- \% de FG según tiempo de posesión por localización en B.Femenino

Tabla 134.- \% de FG según tipo de tiro por localización

en B.Femenino

Tabla 135.- \% de FG según ventaja/desventaja por

localización en B.Femenino

Tabla 136.- \% de FG según precedente por localización

en B.Femenino 126

Tabla 137.- \% de FG según jugadores implicados por

localización en B.Femenino 126

Tabla 138.- \% de FG según periodo de juego por

localización en B.Femenino 126 


\section{GLOSARIO DE TERMINOS Y SIMBOLOGÍA}

Bloqueo: situación técnico/táctica donde un atacante sin balón se sitúa estáticamente en el campo tratando de obstaculizar al defensor de un compañero. Puede ser indirecto, cuando se realiza sobre un jugador sin balón, o directo, cuando se realiza sobre un jugador con balón.

- Pick and roll: se trata de un bloqueo directo en el cual el bloqueador continua, pivotando sobre el pie más cercano al aro, orientándose así de nuevo al balón a la vez que saca ventaja al bloqueado al interponerse entre él y el balón, de tal modo, que pueda recibir y atacar el aro.

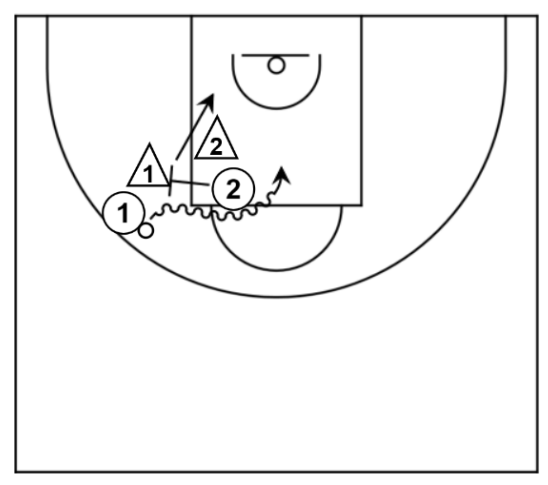

- Pick and pop: podríamos traducirlo por bloqueo y apertura, es similar al pick and roll, pero en este caso se pivota sobre el pie más alejado al aro, de tal modo que se abre hacía el exterior (alejándose del aro) para recibir. Suele utilizarse para bloqueadores con buen tiro.

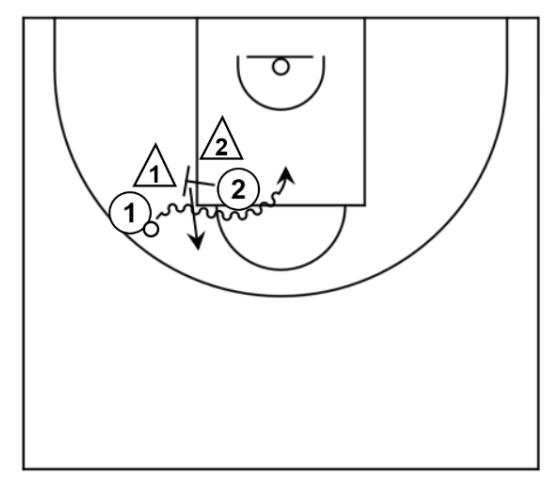

- Pasar de segundo: El defensor bloqueado (defensor del balón) pasa el bloqueo entre el balón y el bloqueador. Evitamos que el atacante con balón puede realizar un FG cómodo, pero si al pasar se "engancha" con el bloqueador el atacante con balón tendría una fácil penetración. Ideal contra equipos con buenos tiradores.

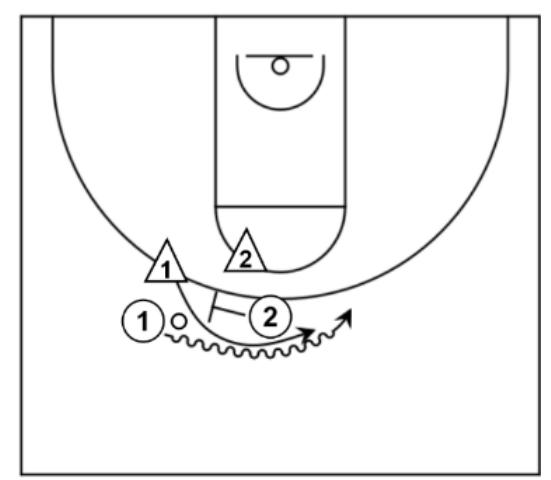


- Pasar como tercero: El defensor bloqueado (defensor del balón) pasa el bloqueo entre el bloqueador y el defensor del bloqueador. En esta defensa evitamos la penetración del hombre con balón, pero se le deja la posibilidad de un tiro cómodo tras el bloqueador. Ideal contra equipos con malos tiradores.

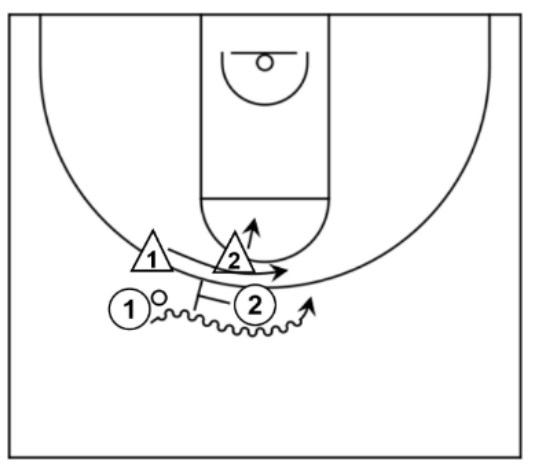

- Pasar como cuarto o defensa push: El defensor bloqueado (defensor del balón) pasa el bloqueo por detrás del bloqueador y del defensor del bloqueador. En este caso el defensor del bloqueador debe "empujar" tratando de

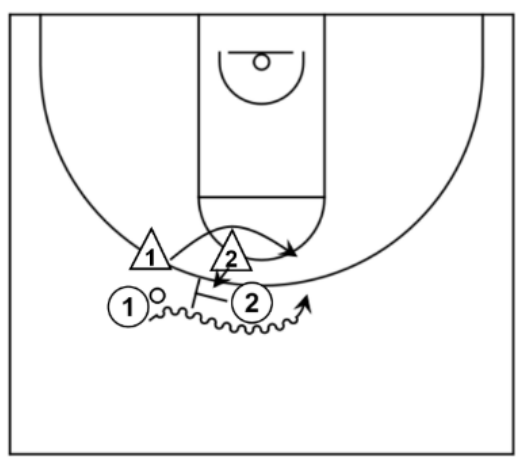
minimizar la ventaja del atacante con balón y facilitando el paso al defensor del balón. Ideal contra equipos con malos tiradores. Además, se tiene un mayor control del bloqueador al tener un defensor realizando “push”, dificultando así su continuación.

- Cambio entre defensores: Se trata de la opción más sencilla de realizar, pero en caso de que no se produzca entre jugadores de características similares se produciría un miss mach, dando ventaja al equipo atacante.

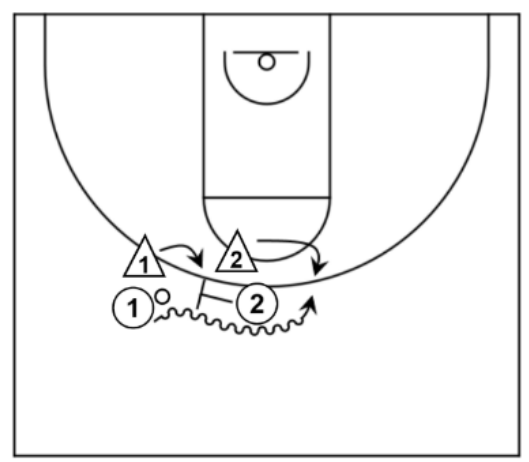


- Negación de bloqueo: Se trata de evitar que este se produzca. Lo cual se consigue a través de la ubicación y posición del defensor del hombre con balón. El defensor del bloqueador se hunde ligeramente para una posible ayuda a la penetración del atacante con balón.
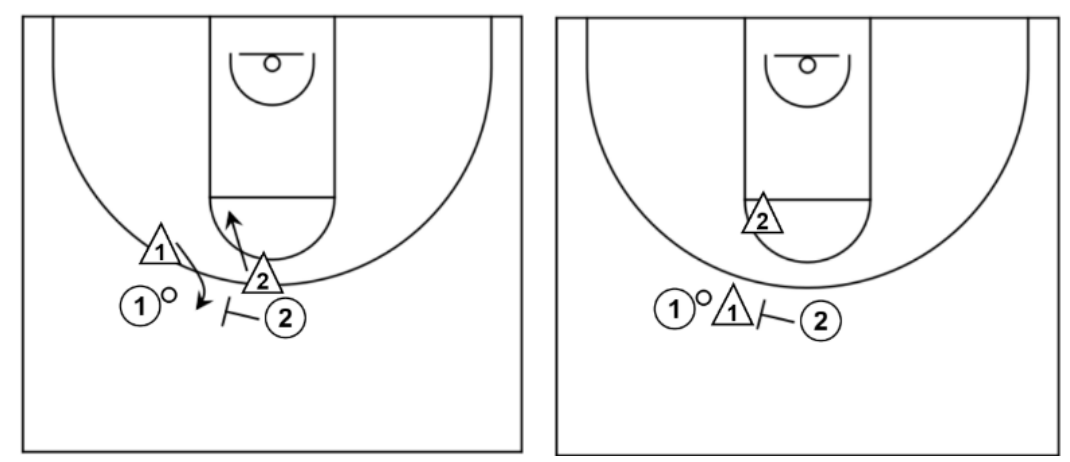

- Flash: Defensa consistente en un movimiento vertical u horizontal por parte del defensor del bloqueador para frenar o ralentizar el avance del atacante con balón, pudiendo así recuperar el defensor del hombre con balón.

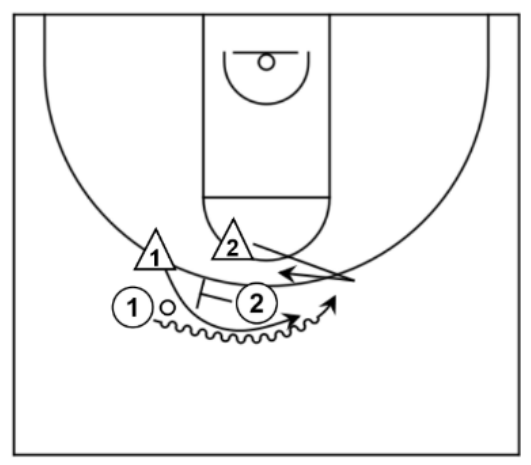

- Trap (2x1): Aprovechando la cercanía de dos defensores al jugador con balón generada por el bloqueo, el defensor del bloqueador saltará en flash y realizará un $2 x 1$ con el defensor del balón una vez este recupere. Se trata de una defensa muy agresiva, con el consiguiente peligro de dejar al bloqueador solo para una posible continuación en caso de que llegue el pase. 
$\bigcirc \underline{\text { Corte en } V \text { o finta de recepción: acción }}$ ofensiva en la que el jugador atacante hunde a su defensor hacia canasta para después arrancar súbitamente hacia el perímetro para recibir.

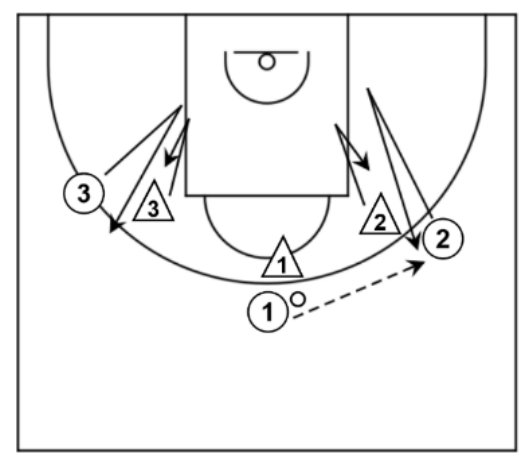

Crossover: gesto técnico ofensivo que consiste en un quiebro o cambio rápido de dirección y mano.

Defensa en tándem: tipo de defensa dentro de una transición defensiva en la que dos jugadores se colocan en línea de aro-aro, uno tras el otro, comunicándose para salir a parar el balón y remplazándose continuamente entre ellos, tratando así de impedir la canasta y ganar tiempo para la recuperación del resto de defensores.

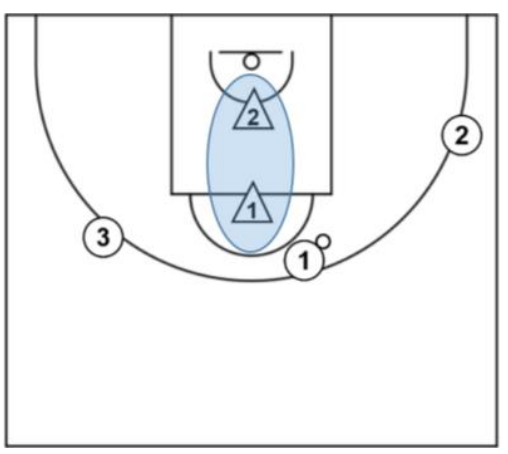

Dentro-fuera: termino que hace referencia al pase interior al poste bajo (dentro), tras el cual el pasador se abre para generar espacio al jugador con balón. En caso de que la defensa se cierre sobre el hombre con balón, creando espacio al jugador exterior, el balón se vuelve a sacar mediante un pase para aprovechar el espacio generado (fuera).

Dribbling: desplazamiento en bote del jugador con balón.

Oxtra pass: literalmente, "pase extra". Se trata de la realización de un pase más para generar la mejor posición ofensiva en la realización del lanzamiento. 
Finta: se trata de la realización de un movimiento de engaño simulando que se va a realizar una acción sin llegar a realizarla, tratando así de confundir al defensor y sacar ventaja.

Home advantage: término que hace referencia a la ventaja del equipo local sobre el visitante por el hecho de jugar en su propio campo.

Lado débil y lado fuerte: tras trazar una línea imaginaria aro-aro, se denomina lado débil a la mitad del campo donde no se encuentra el balón, y lado fuerte a la mitad donde se encuentra. Es un término de vital importancia de cara al posicionamiento defensivo.

En el lado fuerte el defensor debe ejercer la máxima presión sobre su atacante, cubriendo muy bien las líneas de pase y a corta distancia, mientras que en el lado débil se puede limitar esa presión, dando cierta distancia al atacante para colocarse en una posición de ayuda por si un compañero pudiera necesitarla.

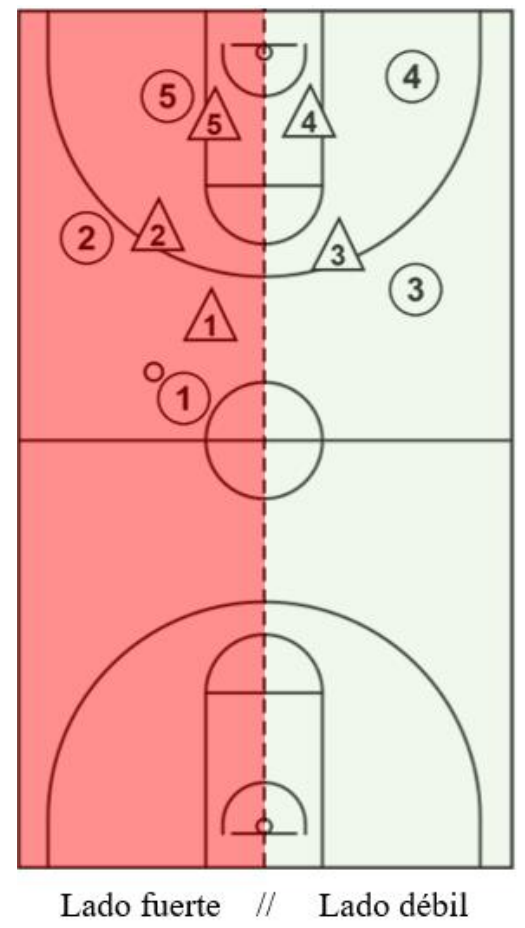

Línea de pase: dícese de la recta imaginaria entre el atacante con balón y el resto de los atacantes.

Miss mach: desajuste defensivo en el cual se da un desequilibrio entre las características del emparejamiento del atacante y el defensor.

Palmeo: lanzamiento a canasta mediante un toque con una o dos manos sin llegar a agarrar el balón. Suele ejecutarse tras rebote. 
Pivote: Movimiento técnico que consiste en el giro del cuerpo sobre un apoyo (pie de pivote), el cual se mantiene en contacto con la cancha.

Poste repetidor: función que realiza generalmente un jugador grande, el cual se coloca de tal modo que facilite o desahogue el ataque a través de la recepción y el pase del balón.

Puerta atrás: acción ofensiva en la que el jugador atacante saca al defensor hacia el perímetro para después arrancar súbitamente hacia canasta para recibir y encestar. Se trata de un corte en V invertido.

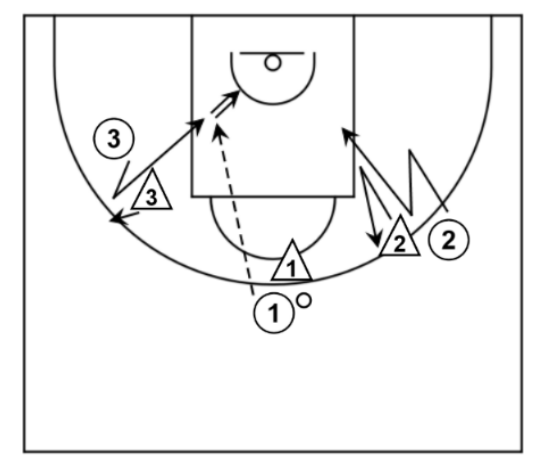

Reverso: gesto técnico en el que el atacante pivota sobre el pie más cercano al defensor de tal forma que gira sobre él, arrastrando el balón con la mano más alejada y protegiéndolo con el cuerpo, para cambiarlo una vez superado a la otra mano, que pasa a ser la más alejada del defensor.

Skipping: elevación de las rodillas de forma alterna por encima de la cintura.

Tempo: ritmo de las posesiones de los equipos.

Timing: coordinación espacio-temporal entre el balón y los jugadores.

Trailer: dícese del jugador que va a remolque o por detrás de la jugada.

Transición: puede ser ofensiva o defensiva, y hace referencia al cambio de una 
situación a otra. En el caso de cambio de ataque a defensa sería transición defensiva, y en el caso contrario ofensiva.

Trap: término defensivo que se utiliza para denominar a la defensa en 2x1 al jugador con balón. Tiende a utilizarse aprovechando también las líneas del campo y las limitaciones reglamentarias como los 8 segundos para pasar de medio campo o la norma de campo atrás.

Trenzas: transición ofensiva mediante pases en la que las trayectorias de los atacantes se van cruzando entre sí buscando la amplitud del ataque.

Triple amenaza: concepto que hace referencia a la posición básica del atacante con balón desde la cual puede realizar tres acciones: pase, lanzamiento o bote.

\begin{tabular}{|c|c|c|}
\hline \multicolumn{3}{|c|}{ SIMBOLOGÍA DEL BALONCESTO } \\
\hline $\begin{array}{c}423 \\
45 \\
45 \\
\text { Jugadores atacantes }\end{array}$ & $\begin{array}{c}11.213 \\
\text { Jugadores defensores }\end{array}$ & $\begin{array}{l}1 \\
\text { Jugador con balón }\end{array}$ \\
\hline Desplazamiento sin balón & Pase & Finta de pase \\
\hline $\begin{array}{l}\text { Conducción de balón } \\
\text { (dribling) }\end{array}$ & $\begin{array}{c}\longrightarrow \\
\text { Lanzamiento }\end{array}$ & $\stackrel{\Longrightarrow}{\Longrightarrow}$ \\
\hline Bloqueo & Pivote & $\begin{array}{c}\mathbf{R} \\
\text { Rebote }\end{array}$ \\
\hline Obstáculos & (0) & \\
\hline $\begin{array}{c}\mathbf{E} \\
\text { Entrenador }\end{array}$ & Medio campo & Campo completo \\
\hline
\end{tabular}




\section{RESUMEN}

En el baloncesto, como deporte de colaboración-oposición, numerosos factores inciden en el resultado, pero el tiro de campo -field goal, FD- es sin duda el gesto y aspecto decisivo por excelencia. Esto es debido a que, junto con el tiro libre, es la forma de consecución de puntos, y por tanto, un medio indispensable para la victoria.

El presente trabajo de investigación expone el problema, los análisis -pretendiendo superar la dimensión cuantitativa- y los resultados de la investigación llevada a cabo para conocer y explicar la influencia de las variables intervinientes en las dimensiones tácticas del tiro de campo, incluyendo la perspectiva de género, con el propósito de contribuir a mejorar la teoría y práctica del baloncesto. La muestra consta de 15.485 sucesos analizados pertenecientes a 212 encuentros de 6 ligas (NBA, WNBA, ACB, Liga Femenina, Euroleague y Euroleague Women) durante las temporadas 2017/2018 y 2018/2019. El análisis cuenta con variables a nivel conductual, contextual y evaluativo, recogiendo así toda la información relevante respecto al gesto analizado. El método de observación se ha demostrado válido y fiable a través del cálculo del índice kappa a nivel inter e intraoberservador.

Tras el análisis, combinación y comparación de las distintas variables (zona del campo, periodo de juego, tiempo de posesión, precedente, jugadores implicados, ventaja/desventaja, tipo de tiro, momento especial y resultado de la acción) se han obtenido resultados con gran importancia táctica. Las zonas centrales del campo son desde las que más FG se ejecutan, siendo la zona 1 la que mayor porcentaje de tiros y eficacia muestra. En cuanto a la posesión, la franja intermedia (9-16) es la más utilizada por ser el equilibrio entre la precipitación y la presión por el límite temporal, de hecho, en la última franja de posesión (0-8) es donde peores porcentajes de eficacia se observan. Según avanzan los periodos se van realizando menos FG y el ritmo de juego se enlentece realizando posesiones más largas. Por otro lado, los precedentes más efectivos para la realización de un FG son el contraataque, el robo y el rebote; a pesar de lo cual, los más utilizados son la jugada personal, el pase y el bloqueo directo. En cuanto a la intervención directa con el balón, el baloncesto actual podría resumirse en acciones de 2x2 o 3x3.

Nuestro estudio quiere caracterizarse por el rigor de sus implicaciones teóricas, pero al mismo tiempo y de modo convergente también por una extraordinaria sensibilidad y 
atención investigadora en torno a sus aplicaciones prácticas. Por ello, estos resultados de primera magnitud, junto con otros hallazgos científicos mostrados a lo largo de todo el estudio, han sido posteriormente aplicados en una batería de ejercicios para mejorar aquellos puntos clave o más determinantes dentro del juego en relación al tiro de campo. El modelo de enseñanza utilizado deberá ser constructivista, buscando con ello el entendimiento de la lógica interna del juego mediante una intervención reflexiva, lo cual generará jugadores más autónomos con una buena capacidad de adaptación y toma de decisión ante situaciones variables o distintos estímulos. Estos ejercicios deben ser entendidos como un planteamiento teórico-práctico para la adquisición de unos conocimientos y/o habilidades, no siendo por tanto inmutables, sino una base o idea inicial sobre la que podremos "jugar" a través de distintas premisas o modificaciones en busca de los objetivos que deseemos trabajar. 


\section{ABSTRACT}

In basketball, as a collaboration-opposition sport, numerous factors affect the result, but the field goal -FD- is undoubtedly the decisive move and most fundamental aspect. This is because, together with the free shot, it is the way to achieve points, and therefore, an indispensable mean for victory.

The present thesis exposes the problem, the analysis - trying to overcome the quantitative dimension - and the results of the research carried out to find out and explain the influence of the variables involved in the tactical dimensions of field goal, including the perspective of gender, with the purpose of contributing to improve the theory and practice of basketball. The sample consists of 15,485 analyzed events belonging to 212 matches of 6 leagues (NBA, WNBA, ACB, Women's League, Euroleague and Euroleague Women) during the 2017/2018 and 2018/2019 seasons. Variables at the behavioral, contextual and evaluative level were evaluated, thus collecting all the relevant information regarding the analyzed move. The observation method has been proven valid and reliable through the calculation of the kappa index at the inter and intra-observer level.

After the analysis, combination and comparison of the different variables (area of the field, playing period, time of possession, precedent, players involved, advantage/disadvantage, type of shot, special moment and result of the action), results with great tactical importance have been obtained. Most FG are executed from the central areas of the field, being zone 1 the one that shows the highest percentage of shots and efficiency. Regarding possession, the intermediate time interval (9-16) is the most used as it is the balance between precipitation and pressure due to the time limit, in fact, the last possession interval (0-8) is where the worst efficacy percentages are observed. As the periods progress, less FG are attempted and the pace of the game slows down with longer possessions. On the other hand, the most effective plays that precede a successful FG are the counterattack, interception and the rebound; despite this, the most common are the personal play, the pass and the direct block. As for direct intervention with the ball, current basketball could be summarized in actions of $2 \times 2$ or $3 \times 3$.

Our study wants to be characterized by the rigor of its theoretical implications, but concurrently by an extraordinary sensitivity and a thorough investigation regarding its practical applications. For this reason, these first-rate results, along with other scientific 
findings shown throughout the study, have been subsequently applied in a battery of exercises to improve those key or most determining points in the game in relation to field goal. The teaching model applied must be constructivist, thereby seeking an understanding of the internal logic of the game through a reflective intervention, which will generate more autonomous players with a better adaptation and decision-making capacity when faced with variable situations or different stimuli. These exercises should be understood as a theoretical-practical approach for the acquisition of knowledge and/or skills, not being therefore immutable, but a base or initial idea on which we can "play" through different premises or modifications in search of the objectives we want to work on. 


\section{INTRODUCCIÓN}

El baloncesto en España se ha consolidado como el segundo deporte más practicado y uno de los más populares, en gran parte, debido a los grandes éxitos deportivos de clubes y selecciones, situando a España como uno de los grandes referentes mundiales de este deporte. Dentro de este creciente interés que se ha mostrado por el baloncesto me siento obligado a mencionar a la ciudad de Burgos, y no solo hablo de un crecimiento a nivel competitivo, sino un auténtico movimiento social e impacto económico digno de estudio.

Este contexto de relevancia social, e incluso económica, ha puesto de manifiesto la oportunidad y relevancia de acometer diferentes análisis científicos de la práctica del baloncesto. Considerando estas circunstancias, así como la oportunidad y necesidad de contribuir a intensificar un campo de estudio tan atrayente como es el baloncesto, nuestra investigación doctoral se propone analizar la influencia de las variables intervinientes en las dimensiones tácticas del tiro de campo a través de una metodología observacional valida y fiable de 6 ligas profesionales de baloncesto, tanto masculinas como femeninas, durante dos temporadas consecutivas. Aspectos que bajo la óptica de la investigación educativa se hallan poco estudiados monográficamente y a los que no se les ha prestado la debida atención. Planteamos llevar a cabo un estudio multifactorial en busca de la captación de toda la información táctica inherente al juego, pudiendo así posteriormente encontrar unos patrones o dinámicas de juego aplicables al entrenamiento de cualquier categoría.

Somos conscientes de que estos patrones o dinámicas no son imperecederos, pues con el paso del tiempo la propia evolución del baloncesto, ya sea por cambios normativos, por las mayores capacidades técnico-tácticas de los jugadores, las variaciones antropométricas de los mismos u otros factores influyentes en el juego, derivarán en otros patrones o dinámicas. Lo que es evidente es que estos cambios no serán inmediatos, ni drásticos, pero debemos de ser conscientes de su existencia para poder avanzar en su estudio de forma paralela a la evolución que el deporte sufra.

Además de la relevancia científica, me parece importante aludir a motivaciones personales y exponer brevemente mi percepción acerca del impacto del deporte en la sociedad. A lo largo de toda mi vida, el deporte, de una forma u otra, ha estado presente, 
apreciando sus aspectos más positivos y también los más negativos. Considero que el deporte en el ámbito educativo es una herramienta con un tremendo valor, ayudando en la transmisión de valores y en el desarrollo físico, psíquico y social de las personas. Debemos recuperar esta esencia educativa y lúdica del deporte, y alejarnos de las contaminaciones económicas o políticas que se dan en la élite, y cuyas raíces van extendiéndose por todo el tejido estructural del deporte como si de una infección se tratara. Como recoge Gómez (2013), "El riesgo de politización del deporte, debido al gran impacto social que éste tiene en el imaginario colectivo, es que se acrecienten las diferencias nacionales y regionales, pudiendo derivar en conflictos violentos entre las aficiones" (p.610).

En este mismo sentido, la Unión Europea ya reconoció la influencia positiva del deporte en la salud, la educación y la cohesión social, convirtiéndolo en un instrumento valiosísimo para la formación de una sociedad mejor. A través de la Comisión Europea (2007) se redactó el Libro blanco del deporte, el cual sirve como orientación estratégica para evitar el racismo y la violencia en el deporte, aprovechando su potencial cultural e integrador. A estas motivaciones responde, en definitiva, el planteamiento y trazado final de nuestro trabajo. 


\section{MARCO TEÓRICO}

Uno de los primeros escollos que hemos tenido que solventar y que queremos plantear con todo tipo de cautelas, se refiere a la precisión conceptual del deporte y a sus obligadas relaciones con el ambiente social, cultural e incluso político en el que se practica. La palabra deporte es usada indiscriminadamente para hacer referencia a cualquier actividad física, ejercicio o deporte, y la cuestión es que hay diferencias claras entre cada uno de esos términos. Actividad física hace referencia a cualquier movimiento musculo esquelético que conlleva un gasto energético más allá del metabolismo basal, mientras que el ejercicio físico necesita de una planificación, estructuración y repetición en busca de un objetivo concreto. Por su parte, la definición de deporte presenta una gran complejidad por la gran cantidad de aspectos de los que consta, de hecho, autores como Olivera (2006) defienden la indefinibilidad de este concepto dada su dimensión cultural, realidad social y complejidad simbólica a pesar de los muchos intentos por parte de distintas entidades o autores de definirlo. Su definición más aceptada advierte de la necesidad de competición, reglamentación y clasificación para determinar un ganador, incluso hay quien considera que debe de estar institucionalizado a través de una federación para considerase como tal.

Superada la ultradeterminación homérica, diferentes enfoques científicos han operado a lo largo de veinticinco siglos tratando de entender, mediante el recurso al logos, el comportamiento humano. Las denominadas ciencias del deporte, de aparición más reciente, no pueden obviamente permanecer ajenas a esta tendencia universal, participando intensamente de la indagación entorno a un mayor conocimiento de todos los aspectos relacionados con el comportamiento, como los factores psicológicos, tácticos, biomecánicos, de salud y muchos otros que, en mayor o menor grado, forman parte del deporte. Pero sus inicios no fueron sencillos, pues como afirma Cagigal (1975), el deporte se basaba en unos principios teórico-prácticos obsoletos muy arraigados que impedían que floreciese el abundante interés científico en él, dándose así un desconocimiento que invadía todas las esferas del deporte, desde los aficionados hasta los altos cargos, muchos de los cuales carecían de una formación acorde al puesto ocupado.

Lo cierto es que el deporte y el ocio han sido una herramienta clave en el proceso de civilización (Elias y Dunning, 1992), aumentando progresivamente el interés en su 
estudio, convirtiéndose indiscutiblemente en la actualidad en una herramienta clave a nivel social, cultural y educativo. Se trata de una pieza esencial en el entramado social, prueba de ello es su presencia en la Constitución española, donde se recoge "Los poderes públicos fomentarán la educación sanitaria, la educación física y el deporte. Asimismo facilitarán la adecuada utilización del ocio" (art. $43.3 \mathrm{CE}$ ), recogiéndose también competencias por parte de las CCAA dentro de esta importante materia con la "promoción del deporte y de la adecuada utilización del ocio" (art. 148.1.19 CE). En el caso concreto del deporte en España he de destacar los trabajos de Otero (2003) y García (2006), los cuales recogen la evolución del deporte en España durante el primer tercio del siglo XX; y finales del XX y comienzo del XXI respectivamente.

Cagigal (1975) diferenciaba entre tipos de deporte haciendo referencia a términos como deporte-espectáculo, deporte-juego y deporte-salud entre otros, dejando ver cómo pueden darse distintas perspectivas del deporte en función de los resultados buscados con la práctica del mismo. Dentro del denominado deporte-espectáculo señalaba que tiene unas funciones básicas como el ocio pasivo y el contacto social, la profesionalización, el trabajo y rendimiento, y por último, una función política. El deporte ha sido utilizado como herramienta política, siendo moldeado y adaptado por todos los sistemas políticos en función de sus intereses (Olivera, 2006), usado en ocasiones como cortina de humo para situaciones de inestabilidad social, económica o política; una versión moderna del pan y circo.

La politización, por tanto, del deporte está en los orígenes del mismo. Este el caso que queremos analizar. Los gobiernos descubrieron en el deporte un potente canalizador propagandístico de sus ideologías y los medios de comunicación que cubren la actualidad deportiva emplean connotaciones políticas en sus informaciones. (Gómez, 2013, p.603)

Pero más allá de toda esta complejidad, su estudio, al igual que en todas las ciencias, y sea cual sea el paradigma en el que se sustente, debe basarse en el método científico con una metodología adecuada al área de análisis. Según la RAE (s.f.) un paradigma es una "teoría o conjunto de teorías cuyo núcleo central se acepta sin cuestionar y que suministra la base y modelo para resolver problemas y avanzar en el conocimiento" (definición 2), 
y si nos basamos en un ámbito más específico, Bonvecchio de Aruani y Maggioni (2006) recogen: "Kuhn, T. S. (1962) define paradigma como "un conjunto de suposiciones interrelacionadas respecto del mundo social, que proporciona un marco filosófico para el estudio organizado de este mundo"' (p.28).

En la perspectiva que aquí más nos interesa de concreción en el ámbito de la investigación, nos encontramos con un marco general en el cual se organizan y aglutinan las tendencias y puntos de vista de un grupo de científicos entorno a un área de estudio concreto. Consecuentemente, en función del paradigma adoptado, todos los conceptos relativos a la investigación, como el ¿qué?, el ¿cómo? y el ¿para qué?, pueden ser conceptualmente distintos (Rivera, 2010).

Hoy en día son tres los más aceptados, el paradigma cuantitativo, el cualitativo y un tercero que es la mezcla de ambos. El paradigma cuantitativo, está más destinado a una rigurosa recopilación de datos sobre la cual poder generalizar un resultado. Un claro ejemplo de esto sería la estadística, la cual ha sido la tendencia más utilizada en baloncesto, y aún lo sigue siendo. Por el contrario, el paradigma cualitativo ya no busca cuantificar, medir, registrar; si no analizar el contexto, extrayendo una interpretación lo más veraz posible del hecho en sí.

Estas dos teorías tienen puntos débiles. En cuanto a la primera, se trata de simples datos, números en frio sin ningún contexto. Estos datos "deslavados" omiten cierta información, la cual puede ser de vital importancia, más aún si hablamos del ámbito deportivo, concretamente de un deporte de oposición-colaboración como es el baloncesto. Morante (2009) afirma que para realizar un buen análisis táctico no debe de usarse la estadística convencional, pues en la mayoría de ocasiones su análisis se centra en indicadores que carecen de significación táctica, o al menos, esta es cuestionable.

Por otro lado, el paradigma cualitativo plantea el problema de la subjetividad, poniendo en entredicho la rigurosidad del método científico, y por tanto de los resultados. Dados estos inconvenientes, no sería lógico tener que usar uno de ellos de forma exclusiva, por ello, el investigador puede utilizar un método mixto entre ambos de tal forma que se adapte lo mejor posible al objetivo de su estudio (Tashakkori y Creswell, 2007, 2008; Castañer et al., 2013), aprovechando las virtudes y solventando las carencias de cada uno. Por todo esto, este "mixed method" será el utilizado en nuestro estudio. 
Instalados en este paradigma mixto, afrontamos el diseño o modelo de observación. Anguera (1988) define la metodología observacional como:

Procedimiento encaminado a articular una percepción deliberada de la realidad manifiesta con su adecuada interpretación, captando su significado, de forma que mediante un registro objetivo, sistemático y especifico de la conducta generada de forma espontánea en un determinado contexto, y una vez se ha sometido a una adecuada codificación y análisis, nos proporcione resultados válidos dentro de un marco especifico de conocimiento. (p.7)

En la figura 1 encontramos los distintos elementos del proceso de la metodología observacional, complementándose, como comentamos anteriormente, las vertientes cualitativa y cuantitativa.

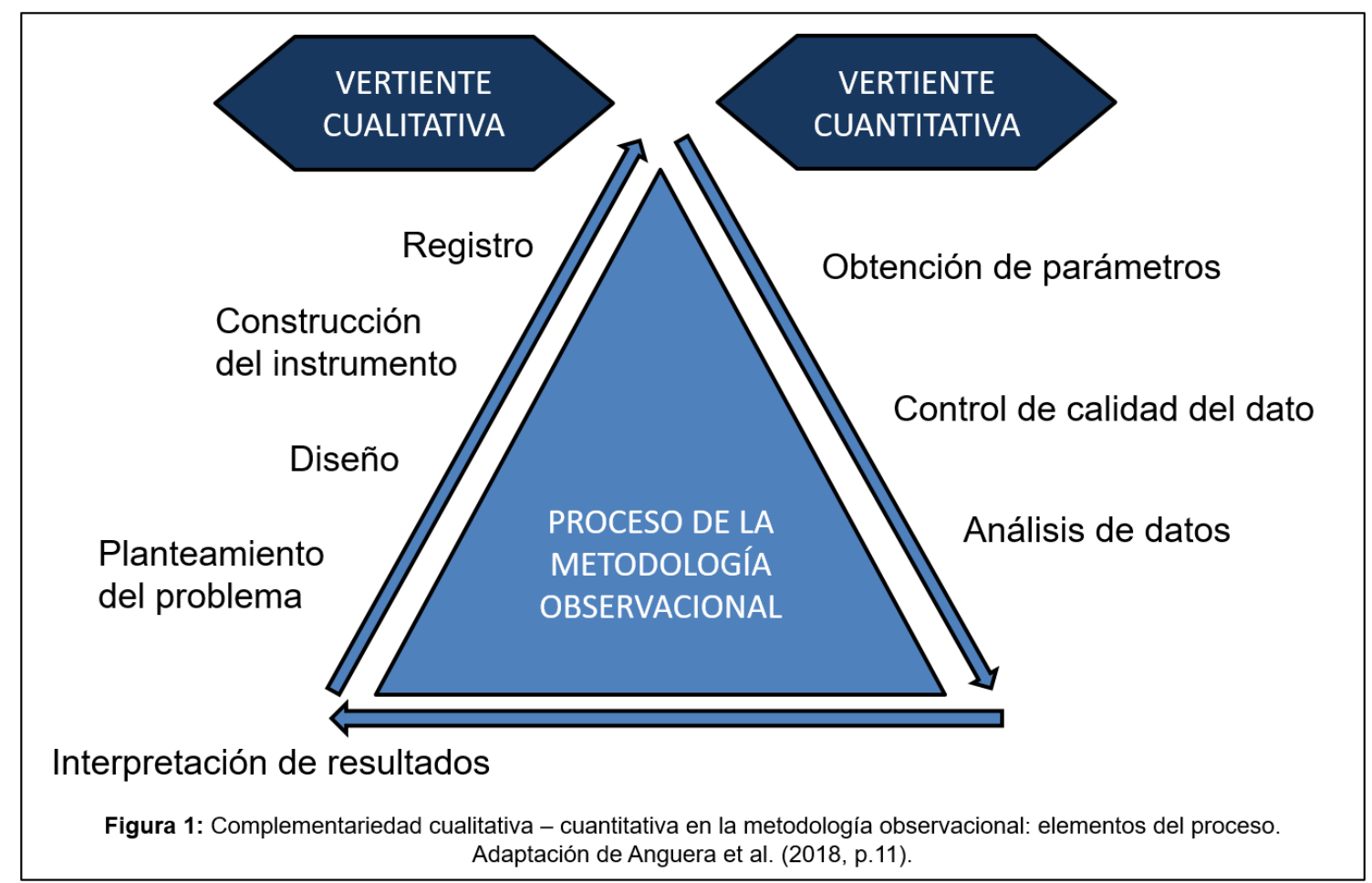

Anguera et al. (2011) recogen 8 posibles diseños (figura 2) en función de dos diámetros y dos circunferencias. El diámetro horizontal hace referencia a la temporalidad, desde algo puntual hasta un seguimiento a lo largo del tiempo; el vertical, a las unidades objetivo, desde una unidad concreta como podría ser un jugador, hasta todos los intervinientes en una jugada; y por último, las circunferencias a la dimensionalidad, diferenciando entre estudios con tan solo un nivel de respuesta como objetivo, con otros 
en los que se da más de uno.

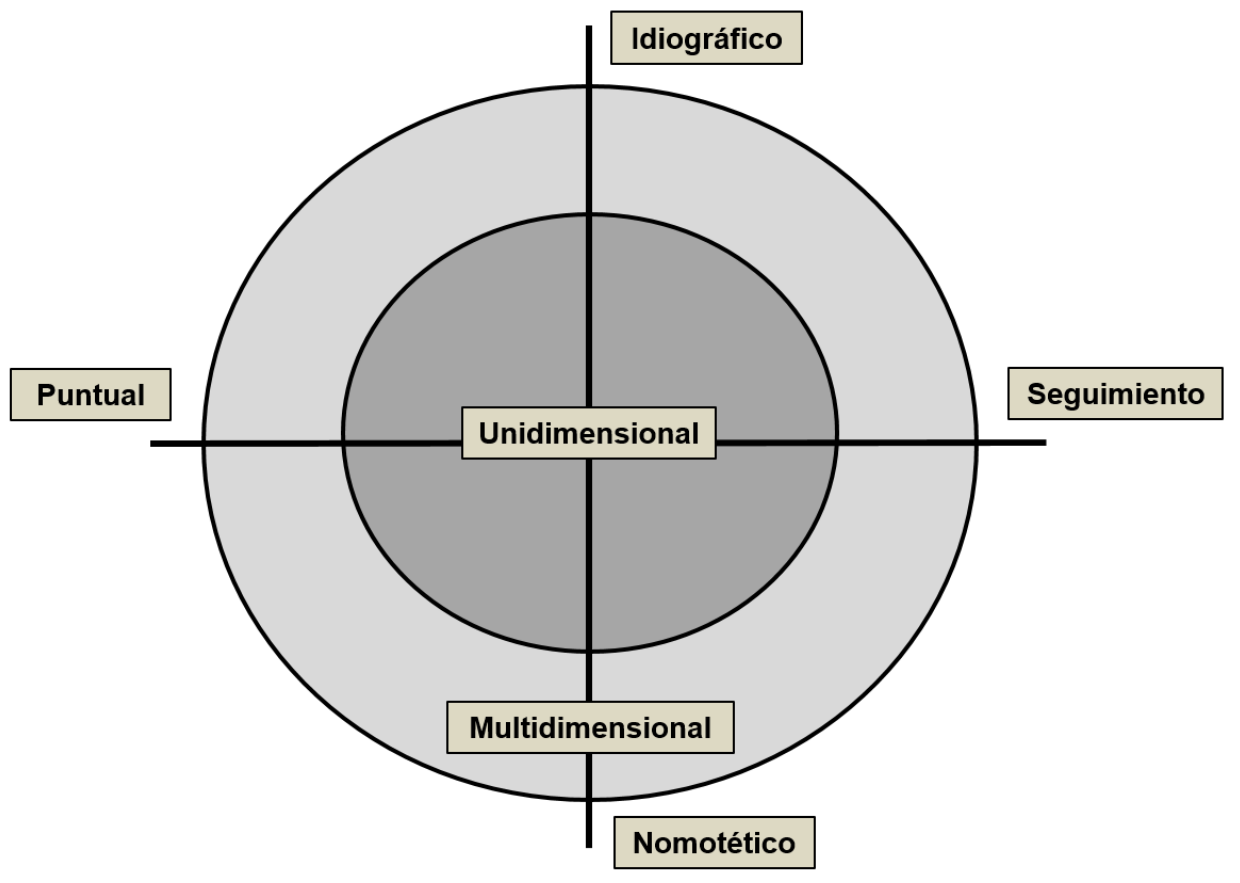

Figura 2: Representación gráfica de los 8 diseños observacionales. Adaptación de Anguera et al. (2011, p.66).

En el caso concreto de este trabajo, el diseño observacional utilizado (figura 3) ha sido de seguimiento (se analizan dos temporadas), nomotético (se obtienen resultados generalizables) y multidimensional (se recogen varios niveles de respuesta).

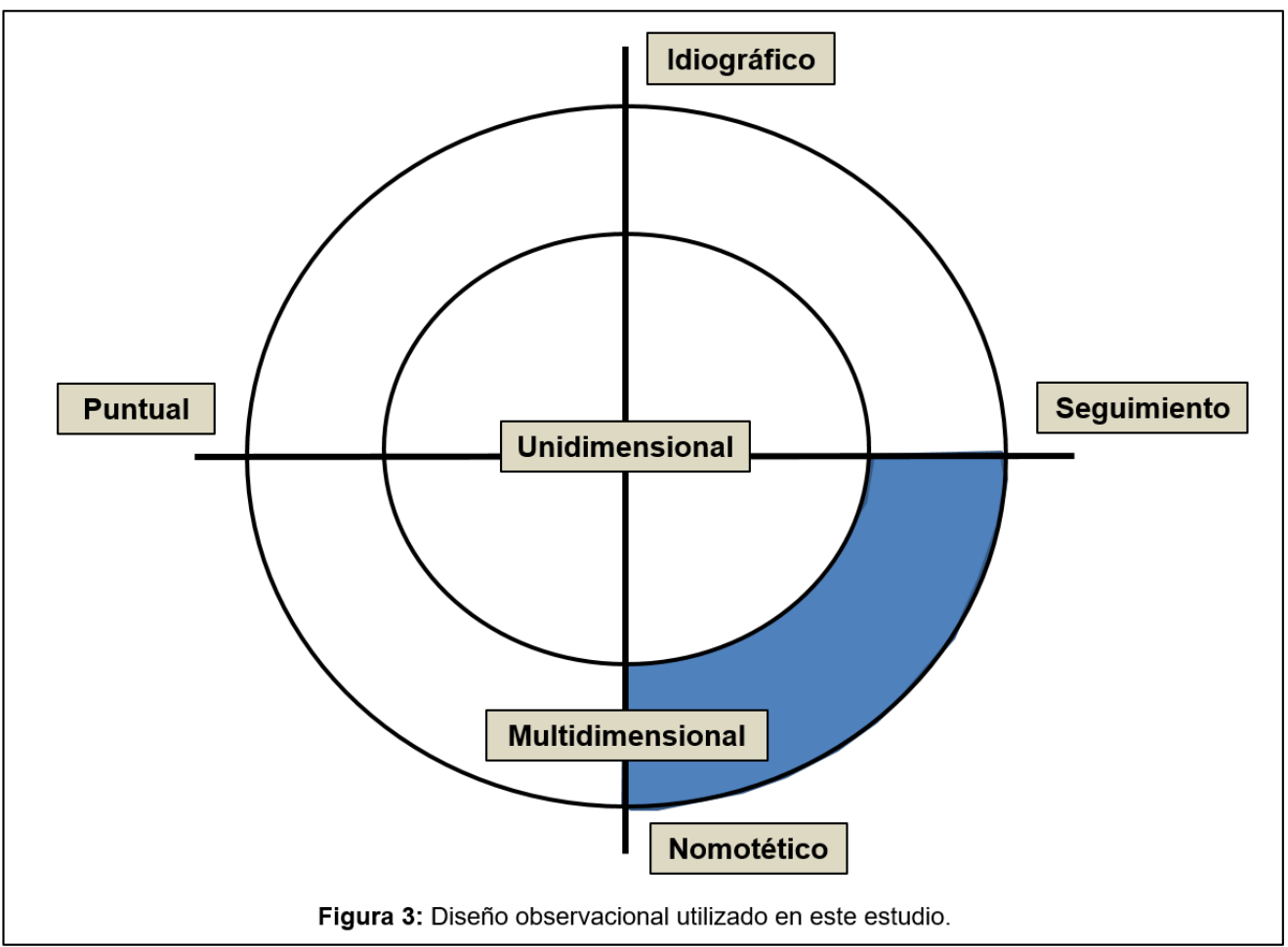


A la hora de usar un determinado paradigma o diseño observacional en el ámbito deportivo debemos de tener en cuenta si se trata de una modalidad individual o colectiva. Las diferencias entre los deportes individuales y colectivos han sido estudiadas desde distintas perspectivas, principalmente psicológicas (García et al., 2013a; Benítez et al., 2013; García, 2016; González-García y Pelegrín, 2016; Almeida, 2017; Sáez y Ocampo, 2019), pero también desde otras como técnicas (Pradas y Reverter, 2011) o fisiológicas (Prieto, 2015). En cuanto al estudio de la táctica, no se da esa diferenciación, pues en los deportes colectivos también se da la táctica individual. Para Patiño y López-Barrajón (1998) todas las acciones en deportes colectivos están determinadas por una respuesta táctica, pues el jugador debe dar solución a la conducta de ejecución, al ajuste mecánico en cuanto a eficacia y eficiencia, y a la conducta de decisión en función de las variables o estímulos intervinientes.

Según ha ido aumentado el interés deportivo en la sociedad, se ha aplicado de forma gradual el desarrollo tecnológico en su estudio. Algunos autores como Dabnichki y Baca (2008) sitúan los primeros estudios mediante aplicación informática para el deporte en la década de los 60, centrándose en análisis biomecánicos y documentación de tareas. Otros autores como Perl (2006) y Link y Lames (2009) los sitúan ya en la década de los 70. Desde esos inicios, y a la vez que los equipos informáticos y la tecnología se han ido haciendo más comunes y económicos, su aplicación en el deporte no ha dejado de crecer, incidiendo no solo en la práctica o el estudio, si no también es su difusión y globalización como producto de consumo. A día de hoy hay numerosos softwares deportivos, algunos centrados en componentes técnicos o biomecánicos mediante el análisis del movimiento como el Dartfish o el Kinovea, y otros más orientados a la interpretación táctica como el Nacsport, LongoMatch o ERIC Sport. Una muestra de este avance tecnológico es el uso de la realidad virtual, la cual ya ha demostrado una mayor eficacia y eficiencia para el entrenamiento deportivo en comparación a otras herramientas ya asentadas como el uso de imágenes o video (Vignais et al., 2015; Pagé et al., 2019). 
Centrándonos en el baloncesto, este se encuentra entre los deportes más practicados del mundo, y en el caso concreto de España, se trata del segundo deporte con más licencias deportivas tras el futbol (figura 4). Según los datos extraídos de la base de datos del MUCD, en 2019 en España había 385.635 deportistas federados en baloncesto, de los cuales 252.708 eran hombres $y$ 132.927 mujeres. Resulta curioso que, a pesar de esta gran diferencia entre el número de federados según sexos, el número de deportistas de alto nivel (DAN) no difiere tanto,

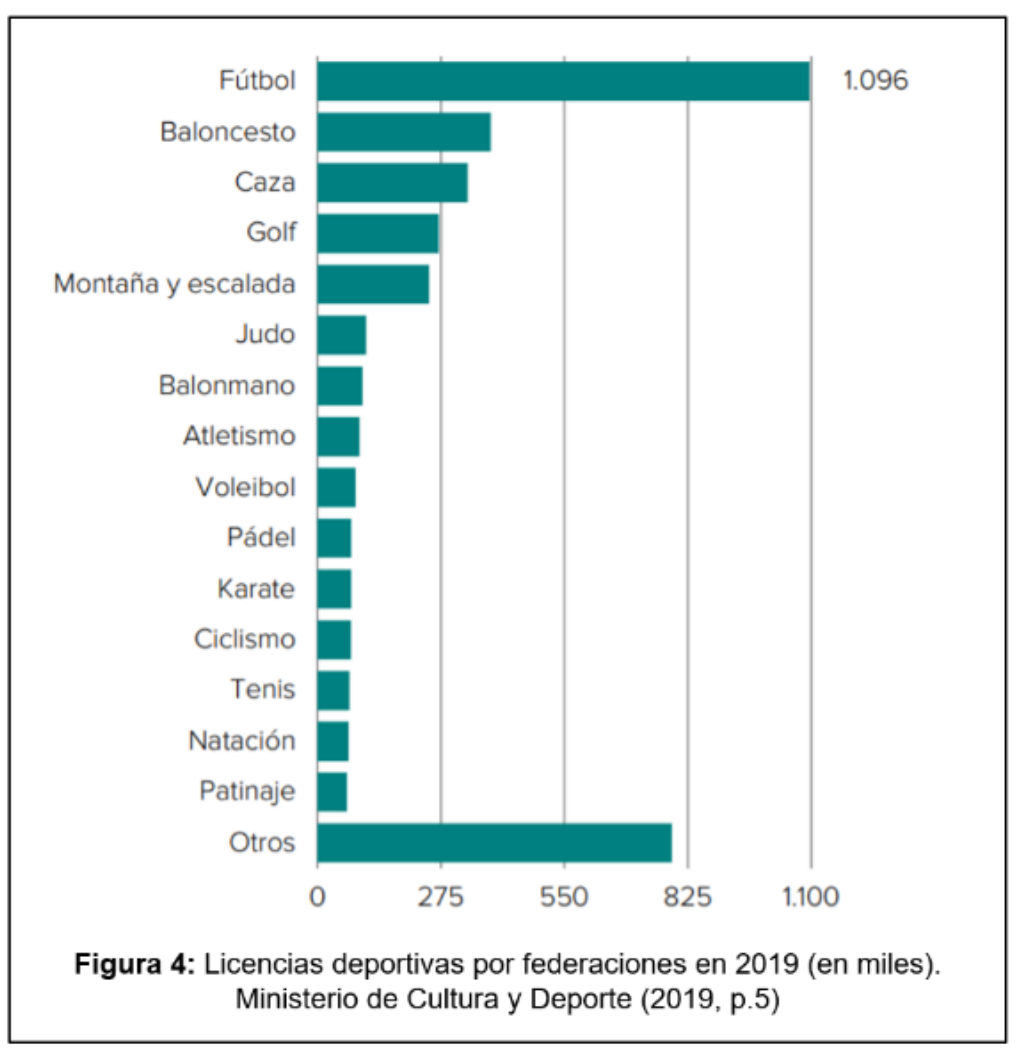
sumando 145 en el caso de los hombres y 136 en el caso de las mujeres.

Se trata de un deporte que ha experimentado profundas transformaciones, adaptándose no solo a las nuevas tendencias de juego y características antropométricas de los jugadores, sino también a los gustos y demandas del espectador. Un claro ejemplo es como se ha tratado de aumentar el dinamismo y espectacularidad del juego mediante la implantación, modificación y adaptación de reglas (aumento de distancias, reducciones de tiempo, introducción del semicírculo de no carga, etcétera) sin alterar su espíritu original.

Esta evolución ha generado una complejidad normativa, que junto con la poca dificultad en la consecución del objetivo (canasta), limita enormemente la intervención de la casualidad en el juego. En los deportes con tanteo bajo y una normativa más laxa, como podría ser el caso del futbol, la influencia de la casualidad toma mayor importancia (Ferreira et al., 2009). Esta complejidad en el juego ha hecho que el baloncesto sea uno de los deportes colectivos más estudiados, pero, históricamente, la mayoría de estos estudios se han centrado en un análisis puramente estadístico. Se han dado estudios en 
relación a numerosas temáticas como aspectos biomecánicos (Rojas et al., 2000; Vaquera et al., 2002; Guerra et al., 2018 ), de preparación y acondicionamiento físico (Sánchez, 2007; Freyre y Fernández, 2009), fisiológicos (Vaquera et al., 2008, 2018; CallejaGonzález et al., 2016), del home advantage (De Rose, 2004; Carron et al., 2005; Gómez et al., 2007b; Pojskić et al., 2011), del tiro libre (Garzón et al., 2011; López y Jiménez, 2013; Pinto et al., 2018; Collado-Mateo et al., 2019), de los momentos críticos (Sampaio et al., 2006; Navarro et al., 2009, 2012, 2017), de las lesiones (Sánchez y Gómez, 2008; Teramoto et al., 2017; Bonato et al., 2018; Policastro et al., 2019), de la toma de decisiones (Iglesias et al., 2005; Gómez y Lorenzo, 2006; Jiménez, 2007, 2017) y muchos otros áreas de interés. La consecución de la victoria es el objetivo principal en todo deporte, por lo que muchos de los estudios realizados buscan los factores influyentes en el resultado final a través de la comparación entre los equipos ganadores y perdedores (Trninić et al., 2002; Gómez et al., 2007b; Gómez et al., 2008; Csataljay et al., 2009; Lorenzo et al., 2010; García et al., 2013b).

El baloncesto, pues, ha sido analizado recientemente desde diversas perspectivas y una intención generalizadora (Piñar et al., 2004; Gómez et al., 2007a; Lorenzo et al., 2010). Sin embargo, se requieren trabajos monográficos como el que nosotros planteamos que puedan enriquecer los ámbitos más generales al permitir una mayor profundización en las líneas medulares del objeto de estudio. Además, interpretando las nuevas tendencias que enfatizan los análisis eminentemente tácticos, trataremos de analizar los sucesos junto con su contexto, extrayendo así una información completa y evitando el "falseamiento" por carencias de información. Consecuentemente, centramos nuestro objeto de estudio en el tiro de campo -fiel goal, a partir de ahora FG- que engloba todo lanzamiento realizado con el reloj en marcha, ya sea de dos o tres puntos, acotación que ya predetermina, aún dentro de un marco total de libertad, la articulación del trabajo. Se trata de todo gesto que permita obtener puntos, a excepción de los tiros libres, los cuales no están englobados en este término. A pesar de conocer la importancia que los tiros libres tienen en el juego, ya habiendo sido estudiada por otros autores (Cárdenas y Rojas, 1997; Sampaio, 1998; Tran y Silverberg, 2008; Jiménez y López, 2012; López y Jiménez, 2013), se ha decidido no añadirlos al estudio dado su predominante carácter técnico y biomecánico puesto que su contexto es fijo, inmutable y controlado, solo viéndose influenciado, y en un bajo grado, por la fatiga y la presión ambiental (Alarcón et al., 2017; Pinto et al., 2018; Morales et 
al., 2018).

El FG, como acción necesaria para la consecución de puntos, y por tanto factor directamente relacionado con la victoria, ha sido la acción del juego más estudiada en baloncesto. Como recogen Ibáñez et al. (2009a), ha sido estudiado desde diferentes enfoques, "biomecánicos (Robbins, Wheat, Irwin \& Bartlett, 2006; Rojas, Cepero, Oña \& Gutiérrez, 2000), psicológicos (Al-Abood, Bennett, Hernández, Ashford \& Davids, 2002; Dezman, Trninic \& Dizdar, 2001; Geisler \& Leith, 2001) y hasta fisiológicos (Woolstenhulme, Bailey \& Allsen, 2004)" (p.40). Todos ellos siguen una línea muy analítica, girando en torno a una única categoría o variable influyente en el lanzamiento. Por ello, ciertos autores, entre los que se encuentra Ibáñez, tratan de abordar el estudio de los FG de forma más global, de forma multifactorial, teniendo así en cuenta factores temporales, espaciales, grados de oposición... (Ibáñez et al., 2007; Ibáñez et al., 2009a).

"El lanzamiento a canasta es el gesto supremo del baloncesto y constituye el punto final de una serie de actos motores, individuales y/o colectivos, destinados casi siempre a conseguir realizarlo con las mejores condiciones posibles" (Patiño y López-Barrajón, 1998, p.39). Esa dimensión multifactorial inherente a los deportes colectivos de colaboración-oposición, al tratarse de situaciones variables, hace necesario que al gesto técnico vaya acompañado de una toma de decisión que trata de dar la mejor respuesta posible a las distintas incógnitas surgidas: ¿cómo?, ¿cuándo?, ¿dónde?...

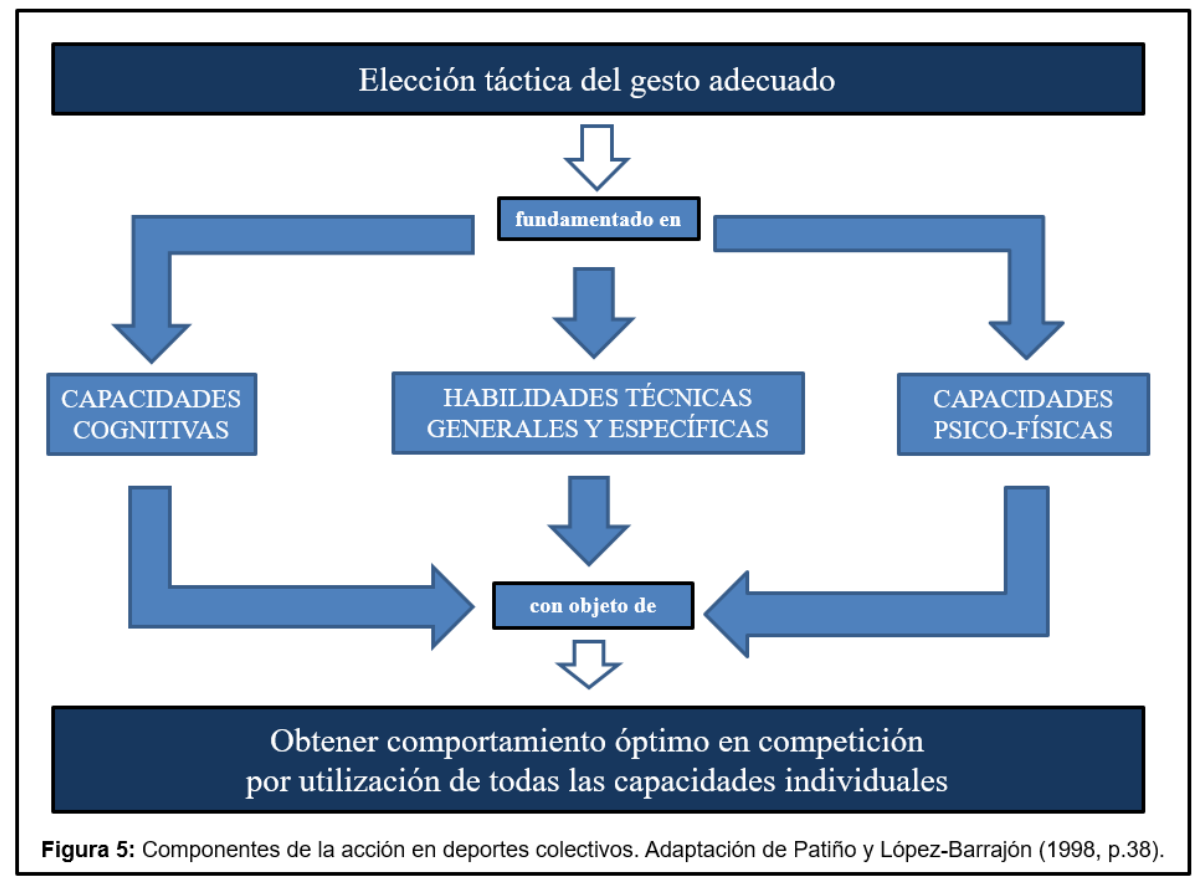




\section{OBJETIVOS}

El objetivo principal del presente estudio es identificar y analizar todas aquellas variables a nivel contextual y evaluativo influyentes en los FG en baloncesto para así poder inferir el grado y el modo de influencia de estas, considerando también, cuando resulta pertinente, la perspectiva de género.

Con carácter aplicado, asumimos también como objetivo el diseño y elaboración de una batería de ejercicios útil y práctica mediante la cual los entrenadores podrán entrenar los factores influyentes clave en los FG. Serán ejercicios que buscan la complejidad contextual de una situación real de partido, mejorando así la toma de decisión y la eficiencia del jugador, pues como recogen Ibáñez et al. (2009a) tras su análisis multifactorial del lanzamiento en la NBA:

Estos resultados ponen de manifiesto la necesidad de realizar el entrenamiento de forma más real, adecuándolo a las características de la competición analizada. Conocer las acciones que permiten conseguir una mayor eficacia en el lanzamiento a canasta en cada competición facilitará a los entrenadores el diseño de las sesiones de entrenamiento. (Ibáñez et al., 2009a, p.39)

De igual modo, se podrá utilizar para mejorar aspectos defensivos, tratando de llevar al atacante hacia todas aquellas variables directamente relacionadas con el fallo.

\section{METODOLOGÍA}

Por las razones anteriormente expuestas y de modo coherente con el estado de la cuestión y los objetivos planteados, intentamos alcanzar el rigor necesario en nuestras decisiones metodológicas.

Para el análisis de la muestra se ha utilizado un software deportivo, el VA-Sports, más concretamente su versión destinada al video análisis en baloncesto. Se trata de una herramienta tremendamente útil, capaz de cortar, visionar, almacenar archivos de video, definir e introducir en dichos archivos niveles de respuesta y categorías de análisis para su posterior tratamiento. 
Siguiendo el modelo metodológico de Anguera y Hernández (2013) para aumentar el control sobre las disrupciones temporales durante la sesión de observación, todas las unidades de observación analizadas (posesiones de cada equipo y situaciones de FG) son completamente observables.

En la figura 6 podemos observar los diferentes pasos dentro del programa antes del análisis de los niveles de respuesta en cada uno de los partidos. Estos pasos son la cumplimentación de los datos generales del análisis (1), definición de las características de la competición (2), selección de la fuente de imágenes (3), fijación de referencias o marco temporal (4), definición de equipos y jugadores (5), fijación de variables de análisis y sus categorías (6), definición de parámetros de dibujo sobre la cancha de juego (7), ajuste de parámetros del cronograma de resultados (8), definición de opciones relacionadas con los eventos registrados (9), y por último, la estrategia de competición (10).

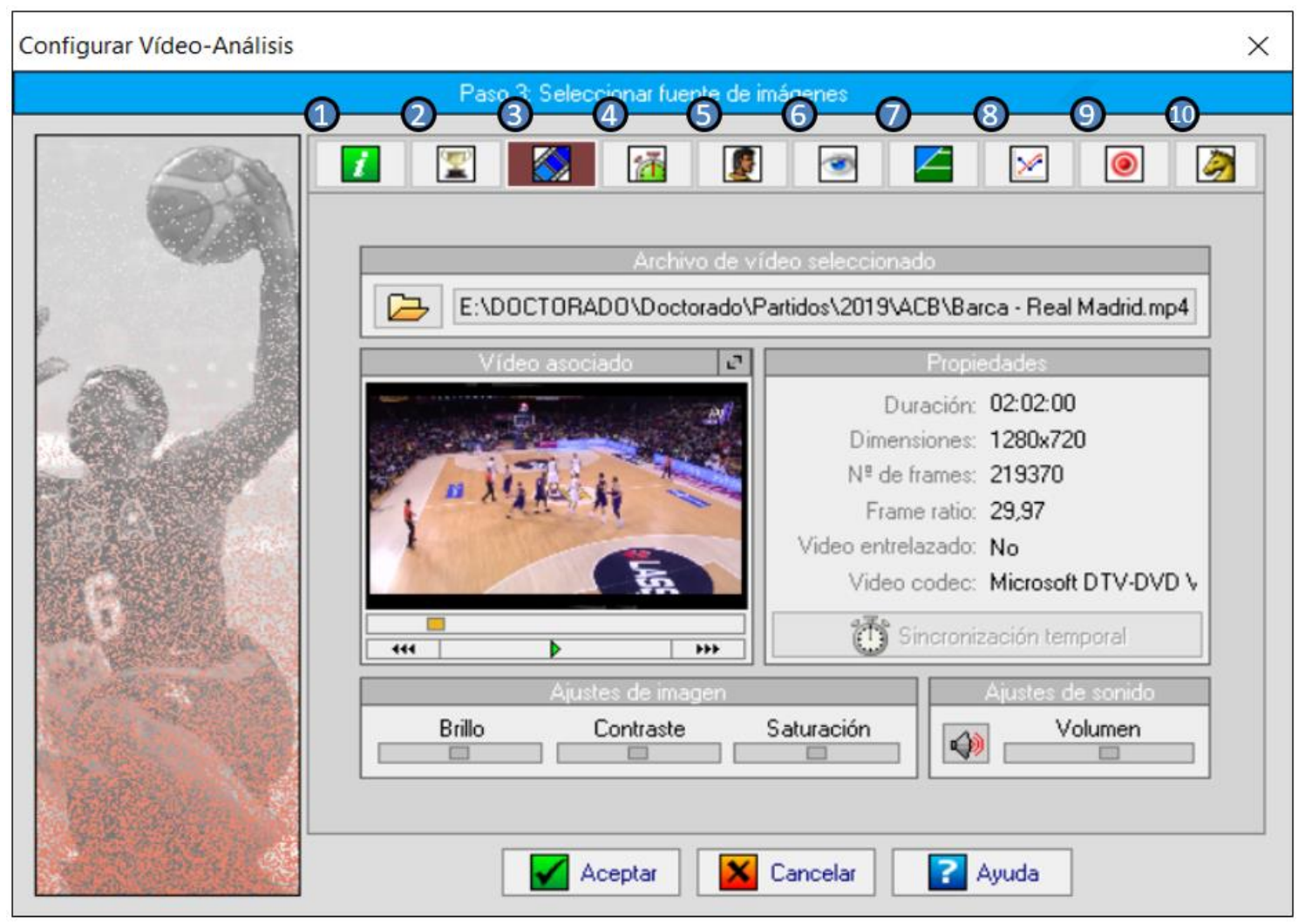

Figura 6: Selección de fuente de imágenes. 
El sexto paso, la fijación de variables o niveles de respuesta (figura 7), es uno de los pasos más importantes, pues en él se define y se desglosa cada una de ellas en distintas categorías.

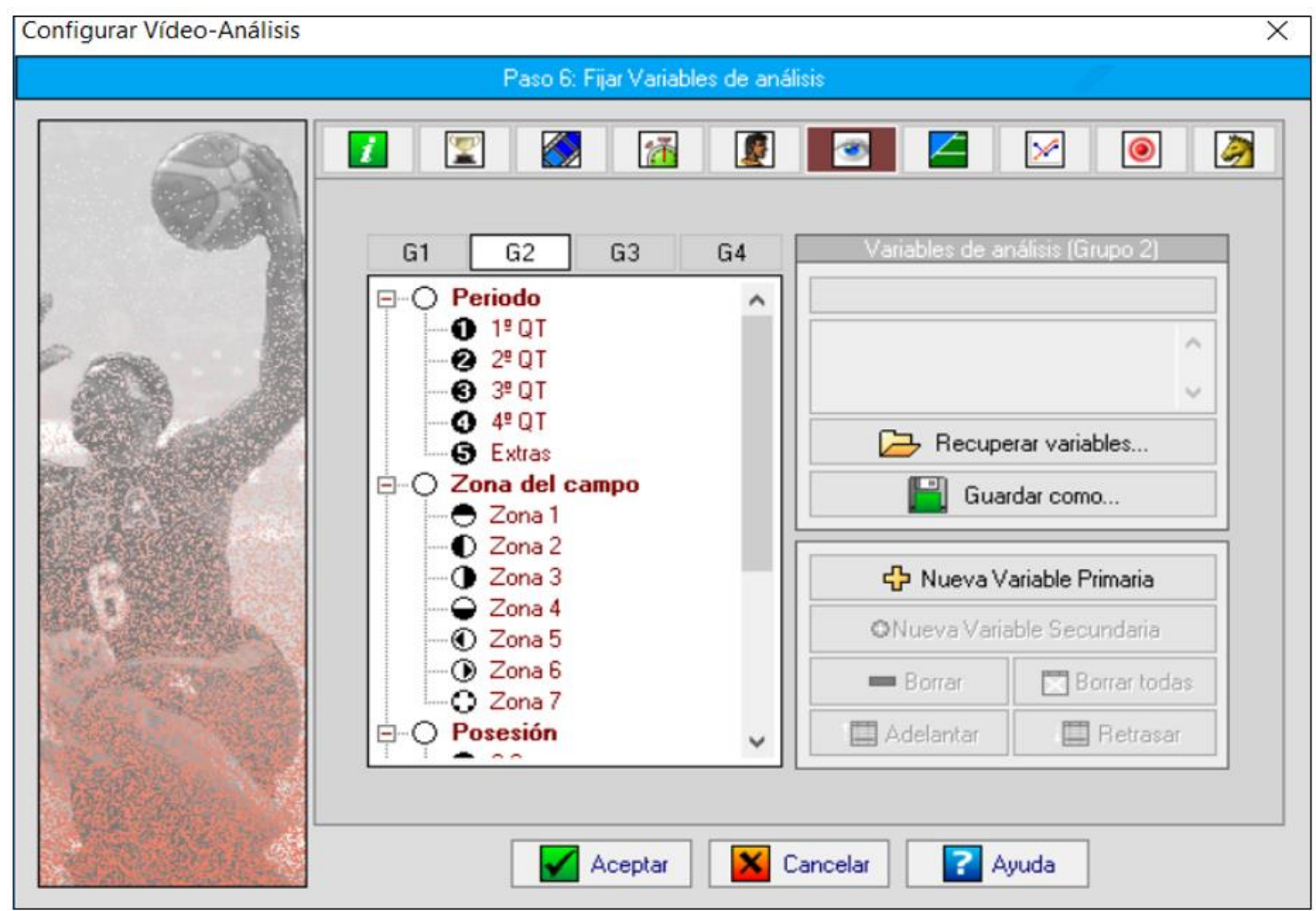

Figura 7: Fijación de variables de análisis.

Una vez completados todos los pasos tendremos acceso al "core" del software (figura 8), donde podremos observar, etiquetar y analizar los elementos de estudio. En el contamos con una panel de identificación de jugadores y equipos (1), un sistema configurable de variables de análisis (2), información gráfica de contextualización espacial (3), imágenes de video y herramientas para su corte en secuencias (4), estadísticas de las posesiones por equipo (5), secuencias de competición con referencias temporales y de marcador, donde se introducen las variables y categorías de estudio (6), y una cronología de la evolución del juego (7). 


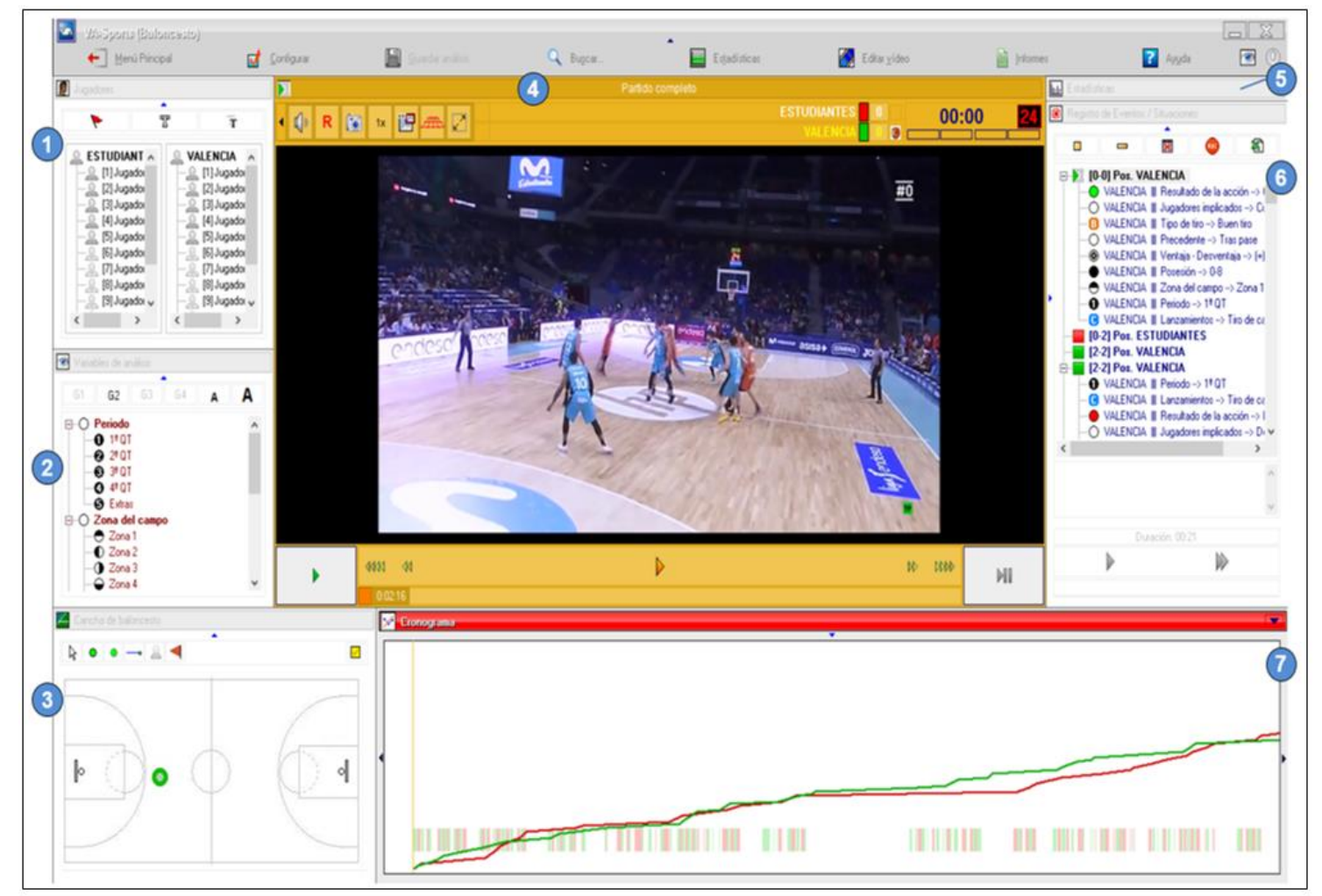

Figura 8: Software VA-Sports.

La muestra consta de 15.485 posesiones pertenecientes a 212 partidos de baloncesto de 6 ligas, masculinas y femeninas (NBA, WNBA, ACB, Liga Femenina, Euroleague y Euroleague Women), durante las temporadas 2017/2018 y 2018/2019. En busca de una homogeneidad de muestra, las 6 ligas analizadas son profesionales, pues como demostraron Kioumourtzoglou et al. (1998), existe un mayor dominio en la predicción y atención selectiva en los jugadores profesionales en comparación con los amateur. En esta línea, Ibáñez et al. (2009b) también encontraron diferencias entre los equipos amateur y profesionales a la hora de efectuar los lanzamientos en función del tipo de tiro, la distancia desde donde se efectúan, su precedente y la presión defensiva.

Dentro de la metodología observacional debemos ser especialmente cuidadosos con cuatro etapas: (I) Delimitación del problema y propuesta del diseño observacional, (II) recogida, gestión y optimización de datos, (III) análisis de datos e (IV) interpretación de los resultados (Anguera y Hernández, 2013). 


\subsection{CATEGORIZACIÓN}

Tras una exhaustiva revisión teórica y un consenso con diferentes expertos en el ámbito del análisis táctico y el baloncesto, se definieron las variables o niveles de respuesta de estudio y sus subdivisiones en categorías, lo cual vemos recogido en la figura 9.

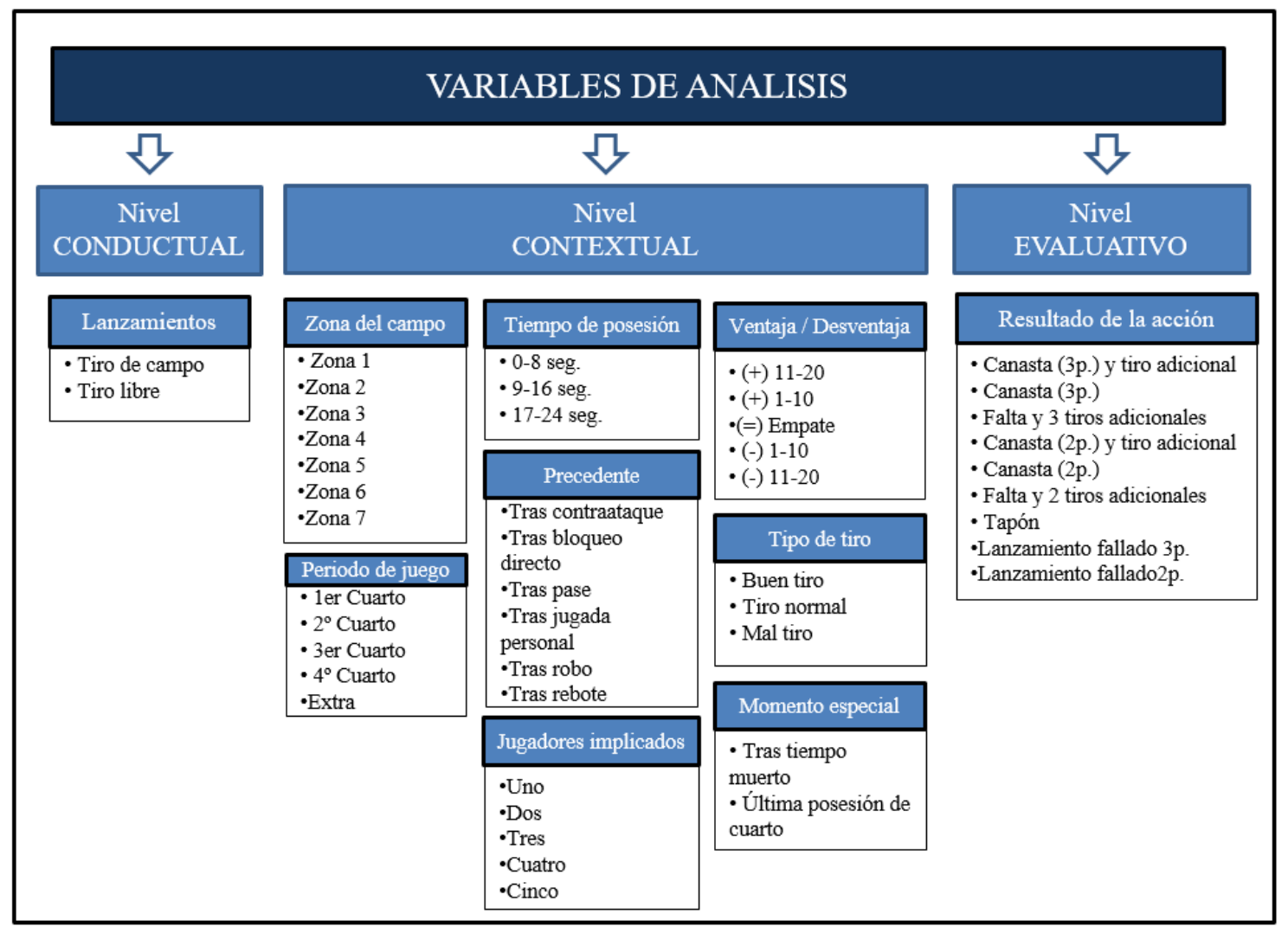

Figura 9 : Variables de análisis aplicadas al estudio del FG.

Tras esto, se realizó un estudio piloto en el cual se visionaron 6 partidos completos para verificar que no se daba ninguna conducta no contemplada en dichas variables, o que alguna de estas no recogiera de forma clara y fidedigna la realidad analizada. Esto es lo que Anguera y Hernández (2013) denominan prueba de cautela.

El proceso de categorización realizado es de vital importancia, pues al tratarse de datos cualitativos necesitamos un buen desarrollo y definición de las categorías y niveles de respuesta con todos sus matices, en caso de no ser así, nos sería imposible recoger de forma valida y fiable los sucesos estudiados (Anguera, 1986).

Con la categorización se pretende una homogeneidad interna entre los diferentes ítems clasificados en cada categoría y una homogeneidad externa entre categorías, 
cumpliéndose las condiciones de exhaustividad con relación a los aspectos seleccionados como objetivo (de ahí la gran importancia de su perfecta delimitación) y de mutua exclusividad, que implica garantía de no solapamiento. (Anguera, 1986, p.32)

\subsubsection{Nivel Conductual}

Dentro de la definición de las variables de análisis, a nivel conductual podemos diferenciar entre un FG (objeto de estudio) y un tiro libre, siendo tan solo esas dos opciones las variables existentes en el ámbito conductual del lanzamiento en baloncesto.

\begin{tabular}{|c|c|}
\hline \multicolumn{2}{|c|}{ Lanzamientos } \\
\hline Categorías & \multicolumn{1}{|c|}{ Explicación } \\
\hline Tiro de campo (FG) & $\begin{array}{c}\text { Todo lanzamiento realizado con el reloj en marcha, ya sea de dos o tres } \\
\text { puntos. Se trata de toda gesto que permite obtener puntos (palmeos, } \\
\text { mates, bandejas, tiros), a excepción de los tiros libres, los cuales no se } \\
\text { consideran como tal. }\end{array}$ \\
\hline$>$ Tiro libre & $\begin{array}{c}\text { Lanzamiento a canasta realizado siempre en las mismas condiciones } \\
\text { (proceso, distancia, restricciones) y sin que corra el reloj. Se produce como } \\
\text { consecuencia de una sanción arbitral y su puntuación es de un punto. }\end{array}$ \\
\hline
\end{tabular}

Tabla 1: Nivel conductual. Variable lanzamientos.

\subsubsection{Nivel Contextual}

Análisis de todos los factores influyentes en la ejecución de la conducta FG. Estos factores son: zona del campo, periodo de juego, tiempo de posesión, precedente, jugadores implicados, ventaja/desventaja, tipo de tiro y momento especial. 


\subsubsection{Zona del campo:}

En todo estudio de la táctica deportiva, sea cual sea el deporte, la contextualización espacial es de vital importancia. En baloncesto se han utilizado tantos campogramas como interpretaciones o intereses de estudio se han dado por parte de los autores. En la figura 10 mostramos algunos de ellos, desde divisiones espaciales muy sencillas como las de Fernández et al. (2009) u Ortega y García (2009), hasta algunas tan complejas como las de Ibáñez et al. (2002) o Nunes et al. (2016).

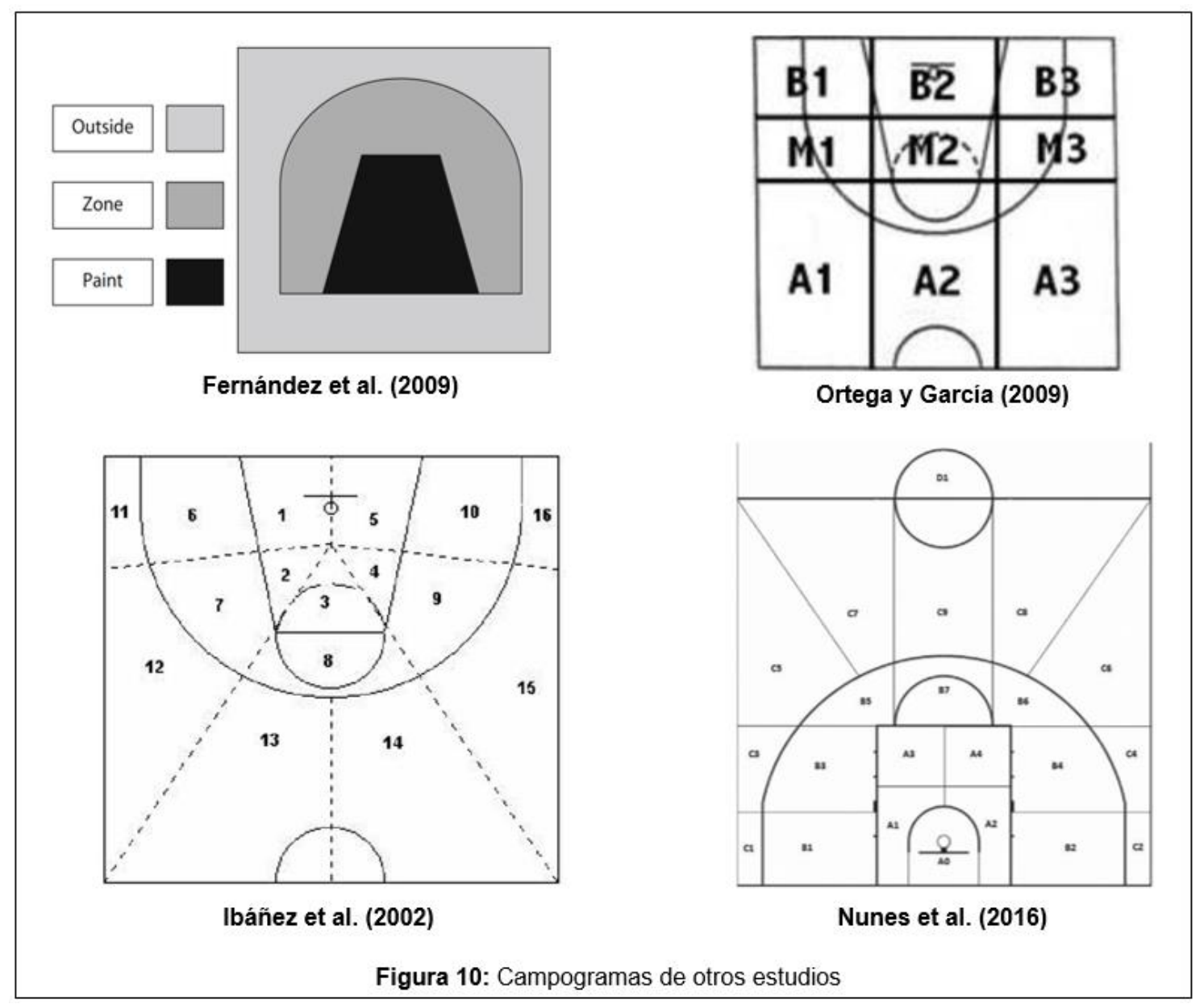


En este estudio, en cuanto al análisis de la variable espacial, se han utilizado las propias líneas del campo y la prolongación de una de ellas (tiro libre), tratando así de facilitar la identificación a la hora de visualizar las acciones (figura 11).

En origen se optó por la división espacial recogida en otro modelo (figura 12) en el cual, además de las propias líneas del campo, se utilizaban dos líneas que unían la esquina del tiro libre con la esquina de medio campo. Esta

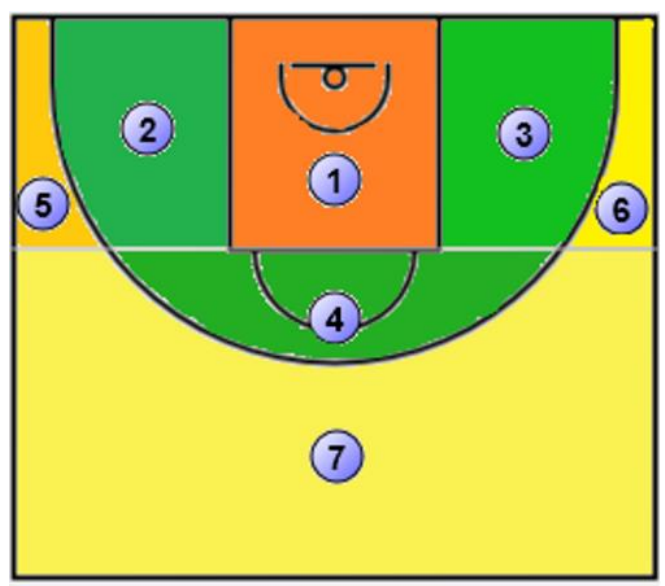

Figura 11: Campograma definitivo. primera idea se tomó pensando en una distribución más equitativa del área de cada zona, pero tras la realización del estudio piloto anteriormente descrito, se observó como a la hora de la visualización de la acción no siempre eran visibles ambos puntos de referencia (esquina del tiro libre y esquina del medio campo), dando lugar a duda y quedando en manos de la interpretación subjetiva del observador en que zona se encontraba. Por esta razón se decidió descartar, ya que se busca un método objetivo, fiable y válido.

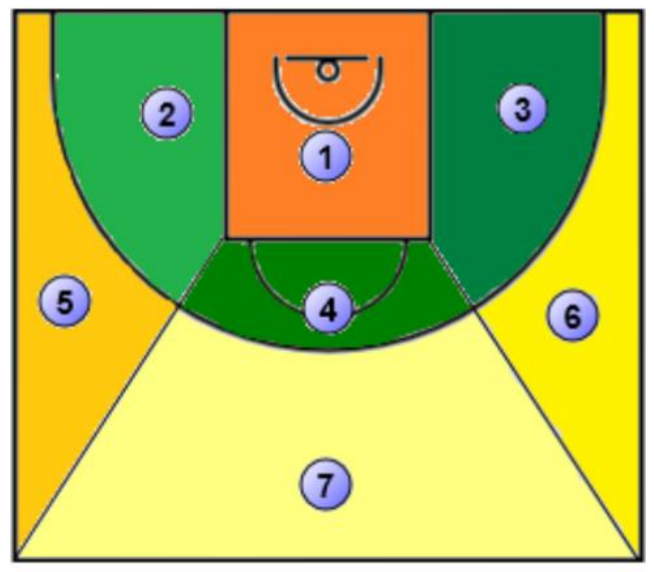

Figura 12: Campograma original. Aun así, con el nuevo modelo (figura 11) podría darse la situación en la cual el jugador que ejecuta elFG justo se encuentre en la línea. En caso de ser sobre la línea de tres puntos siempre pasará a considerarse zona interior (zona 2, 3 o 4), pues la línea está incluida en dichas zonas por reglamento. Si se tratara de otras líneas, será la ubicación del balón como objeto prioritario en la consecución de la canasta el que determine la zona que ha de asignarse. 


\subsubsection{Periodo de juego:}

Con esta variable se asocia la ejecución del FG con el periodo (QT) en el cual se realiza, es decir, primer, segundo, tercer o cuarto QT, ya que en los encuentros analizados no hay ninguno con periodos extras en busca de una homogeneidad de la muestra. Con ello se busca una posible detección de patrones, dinámicas o tendencias de juego en función del QT.

\subsubsection{Tiempo de posesión:}

El tiempo es un factor claramente influyente sobre la dinámica del juego en todo deporte. "Uno de los aspectos que está siempre contemplado en los reglamentos deportivos es el referido al control del tiempo de juego en varias de sus vertientes, como uno de los determinantes de la lógica interna" (Lorenzo, 2000, p.13).

En baloncesto, la variable temporal está muy acotada y su normativa ha sufrido una evolución en favor del dinamismo y la espectacularidad. Muestra de ello es como en la temporada 2000-2001 la FIBA redujo el tiempo de posesión de 30" a 24". Esto produjo un aumento en el número de FG de 2 y 3 puntos, del número de acciones y de la velocidad de estas (Barrios, 2003), a pesar de lo cual, la diferencia de puntos en el marcador entre ganadores y perdedores se mantuvo constante. (Piñar et al., 2004)

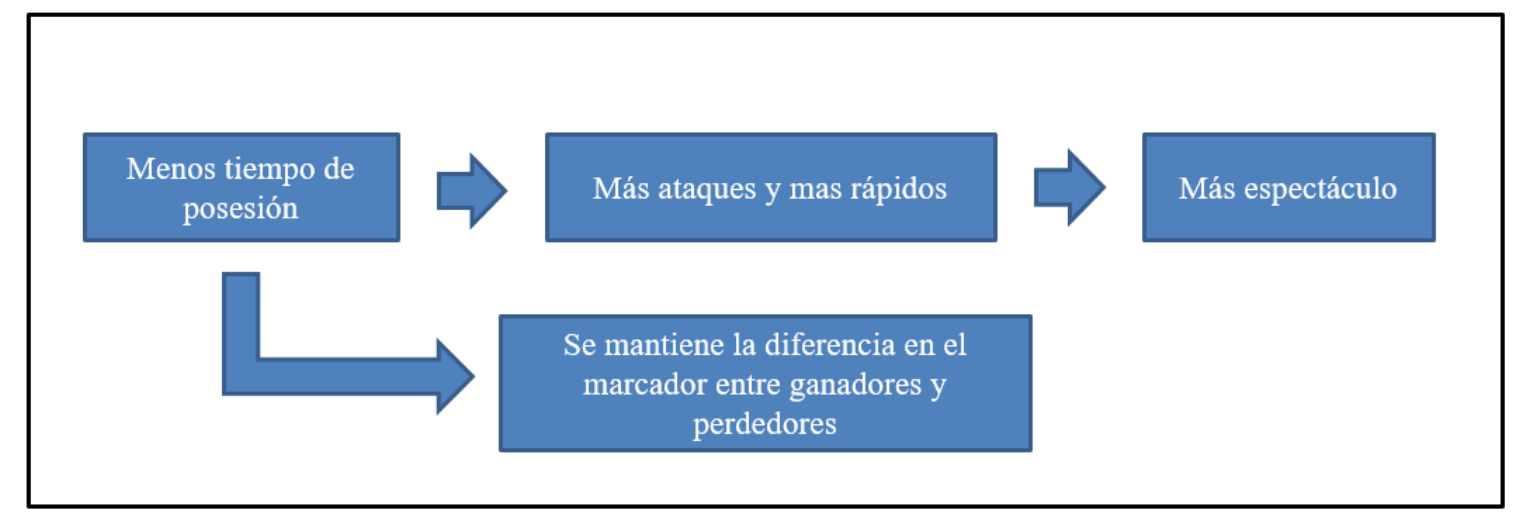

Figura 13: Consecuencias de la disminución del tiempo de posesión.

En este estudio, siguiendo el modelo usado por Vaquera et al. (2013), se ha usado la división de la posesión en tres franjas o intervalos. Los intervalos de tiempo en los que se han dividido las posesiones son 0-8, 9-16 y 17-24. Hemos de tener en cuenta que las 
posesiones empiezan en el segundo 24, siguiendo así la dinámica del reloj de posesión para facilitar el análisis. Otros autores como Lorenzo et al. (2003), Madejón (2002) y Nunes et al. (2016) han realizado particiones de la posesión muy similares al modelo aquí utilizado.

\subsubsection{Precedente:}

Busca identificar la acción técnico/táctica que precede al FG para, posteriormente, analizar como influye en los patrones o resto de variables que afectan al mismo.

\begin{tabular}{|c|c|}
\hline \multicolumn{2}{|r|}{ Precedente } \\
\hline Categorías & Explicación \\
\hline$>$ Tras contraataque & $\begin{array}{c}\text { Acciones de tiro de campo ejecutadas tras un contraataque } \\
\text { (transición muy rápida con superioridad). }\end{array}$ \\
\hline$>$ Tras bloqueo directo & $\begin{array}{l}\text { Acciones de tiro de campo ejecutadas tras un bloque directo } \\
\text { realizado por un compañero. }\end{array}$ \\
\hline$>$ Tras pase & $\begin{array}{l}\text { Acciones de tiro de campo ejecutadas tras recibir un pase de un } \\
\text { compañero. }\end{array}$ \\
\hline$>$ Tras jugada personal & $\begin{array}{c}\text { Acciones de tiro de campo ejecutadas sin colaboración alguna } \\
\text { por parte de los compañeros. }\end{array}$ \\
\hline$>$ Tras robo & $\begin{array}{l}\text { Acciones de tiro de campo ejecutadas tras hacerse con la } \\
\text { posesión del balón, la cual estaba en manos del oponente. }\end{array}$ \\
\hline$>$ Tras rebote & $\begin{array}{c}\text { Acciones de tiro de campo ejecutadas tras recibir el balón } \\
\text { procedente de un rebote de un lanzamiento previo. }\end{array}$ \\
\hline
\end{tabular}

Tabla 2: Nivel contextual. Variable precedente.

De las seis categorías de la variable precedente, tres de ellas están ligadas a una rápida ejecución del FG. Estamos hablando del contraataque, el robo y el rebote. La primera de ellas viene ligada por definición, mientras que las otras dos van unidas a una rápida ejecución debido a que en caso de demorarse la realización del FG dejarían de ser el precedente o causa directa del mismo, pasando a serlo otras categorías. 


\subsubsection{Jugadores implicados:}

Se refiere al número de jugadores por los que pasa la posesión del balón en el campo de ataque antes de un FG. Si bien es cierto que puede darse que un jugador por el que no pasa la posesión del balón genere, directa o indirectamente, ventajas para la consecución del objetivo a través de bloqueos directos, indirectos, aclarados u otros recursos técnico/tácticos, se trata de algo inherente al juego por tratarse de un deporte de colaboración-oposición, por lo que no se ha tenido en cuenta en busca de una claridad identificativa.

En los precedentes "contraataque" y "robo" también se tienen en cuenta los jugadores que han entrado en contacto con el balón en el campo defensivo, pues en estos dos casos, como acabamos de explicar en el apartado anterior, su influencia sobre el FG va unida a una rápida ejecución tras ellos, ya que de no ser así, perderían esa influencia sobre el lanzamiento, recayendo en otras categorías de la variable precedente. De este modo, en estos dos casos concretos son importantes todos los jugadores en contacto con el balón independientemente de la mitad del campo.

\subsubsection{Ventaja / Desventaja:}

Esta variable contextual es muy importante, pues la diferencia en el tanteo del marcador es algo, a priori, muy influyente, lo cual trataremos de demostrar en este estudio.

En la dialéctica del baloncesto, es común escuchar hablar de términos como "se han ido del partido" o "se ha roto el partido", términos referentes a ciertas ocasiones en que la diferencia en el marcador crea un punto de inflexión en el partido, a partir del cual, la dinámica y patrones de juego de los equipos cambian totalmente. Al igual ocurre con términos como "se le ha encogido la mano", el cual hace referencia a lanzamientos en momentos críticos del encuentro, ya sea por una presión temporal, del marcador u otros factores. Por todo ello, esta variable mostrará la dinámica de los FG según se tenga ventaja o desventaja sobre el luminoso, pudiendo así identificar las diferencias existentes en los patrones de juego. 


\begin{tabular}{|l|r|}
\hline \multicolumn{2}{|c|}{ Diferencia en el marcador } \\
\hline Categorías & Explicación \\
\hline$>(+)$ 11-20 & $\begin{array}{r}\text { Acciones de tiro de campo ejecutadas con una ventaja en el } \\
\text { marcador de entre 11 y 20 puntos. }\end{array}$ \\
\hline$>(+)$ 1-10 & $\begin{array}{r}\text { Acciones de tiro de campo ejecutadas con una ventaja en el } \\
\text { marcador de entre 1 y 10 puntos. }\end{array}$ \\
\hline$>(-)$ Empate $1-10$ & Acciones de tiro de campo ejecutadas con igualdad en el marcador. \\
\hline$>(-)$ 11-20 & Acciones de tiro de campo ejecutadas con una desventaja en el \\
& $\begin{array}{r}\text { marcador de entre 1 y 10 puntos. } \\
\text { marcador de entre 11 y 20 puntos. }\end{array}$ \\
\hline
\end{tabular}

Tabla 3: Nivel contextual. Variable ventaja/desventaja.

\subsubsection{Tipo de tiro:}

En muchas ocasiones un FG ejecutado en condiciones óptimas (buen tiro) no acaba en canasta, al igual que, lanzamientos en condiciones altamente desfavorables (mal tiro) finalizan en canasta. Por esto se ha creado un "rating scale" en el cual se analiza la ejecución del FG definiéndola como: mal tiro, tiro normal o buen tiro.

En muchas ocasiones, se sobrevalora un resultado positivo, aunque no necesariamente sea fruto de acciones tácticas adecuadas. Por el contrario, se menosprecia a buenas actuaciones tácticas cuando, como es lógico que ocurra a menudo, no conllevan la consecución del objetivo: victoria, clasificación, gol... (Riera, 1995, p.48) 


\begin{tabular}{|c|l|}
\hline \multicolumn{2}{|c|}{ Tipo de tiro } \\
\hline Categorías & \multicolumn{1}{c|}{ Explicación } \\
\hline Buen tiro & $\begin{array}{l}\text { Acciones de tiro de campo ejecutadas en situación muy ventajosa. } \\
\text { Ejemplos: } \\
\text { ○ Ventaja espacial (tiro sin oposición y/o desde una zona cómoda) }\end{array}$ \\
\hline Tiro normal & $\begin{array}{l}\text { Es toda acción ejecutada en una situación relativamente normal dentro de lo que } \\
\text { supone un deporte de colaboración - oposición. }\end{array}$ \\
\hline$>$ Mal tiro & $\begin{array}{l}\text { Acciones de tiro de campo ejecutadas bien el gesto técnico situación de clara desventaja. } \\
\text { Ejemplos: } \\
\text { o Desventaja espacial (tiro con clara oposición y/o desde una zona muy alejada o } \\
\text { sin ángulo) } \\
\text { o Desventaja temporal (sin tiempo para ejecutar bien el gesto técnico) }\end{array}$ \\
\hline
\end{tabular}

Tabla 4: Nivel contextual. Variable tipo de tiro.

Esta clasificación se ha hecho analizando la ejecución del FG desde un punto de vista de táctica individual, es decir, es un buen tiro porque las condiciones para su ejecución son óptimas, no teniendo en cuenta nada más allá de ese FG. Para tratar de clarificar esta idea pondré un ejemplo. Imaginemos que en mitad de un contraataque en el que tenemos una superioridad de tres contra uno, el jugador con balón se detiene en la línea de tres puntos, lógicamente, totalmente solo, y ejecuta el FG. Según nuestra definición esto sería un buen tiro, pues las condiciones son óptimas, pero si lo observamos desde la táctica colectiva, sin duda hubiera sido mejor finalizar con una bandeja o FG bajo el aro aprovechándonos de la superioridad, teniendo así mucha mayor probabilidad de éxito. 


\subsubsection{Momento especial:}

Un momento especial o crítico es aquel que incide decisivamente en el resultado final de un encuentro. Normalmente son múltiples y heterogéneos, siendo el sumatorio e interacción entre ellos el factor decisivamente influyente en la consecución del triunfo o la derrota. Por ello, estos momentos suponen unas exigencias para los jugadores que en caso de no ser bien gestionadas pueden desencadenar en una "crisis psicológica" (Bar-Eli y Tractinsky, 2000).

Si extrapolamos esto a pequeña escala, el momento especial sería un momento que incide decisivamente en la ejecución de un FG, ya sea porque en el tiempo muerto se ha diseñado una jugada, o por que al tratarse de la última posesión de cuarto se juega de modo distinto. Se trata de una perturbación que rompe la dinámica del juego.

En esta línea, algunos autores afirman que el resultado final del partido no es más que el balance de rendimientos parciales de "pequeños partidos". Álvaro et al. (1995) y Orta et al. (2000), entre otros, proponen dividir los encuentros en unidades de competición más pequeñas, más concretamente en ciclos de ataque-defensa.

Un momento crítico o situación especial no deja de ser una circunstancia influyente en el resultado final, ya sea de acción o de encuentro, de la cual se puede extraer una mayor información táctica (Chicote et al., 2009). De los momentos críticos señalados por Chicote et al. (2009), en este estudio se han tenido en cuenta la gran mayoría: primeras acciones tras interrupción de juego, situaciones de igualdad o inversión de la evolución del marcador, y acciones finales de cuarto.

En cuanto a las acciones tras interrupción de juego, estas son de gran importancia, pues como señalan Lorenzo et al. (2013), se da un mayor contenido táctico y cantidad de información elaborada durante las pausas de los encuentros en comparación a los momentos de juego. 


\subsubsection{Nivel evaluativo}

A nivel evaluativo, la variable registrada tiene como fin la identificación del resultado del FG. Para ello se han descrito todos los posibles sucesos finales tras la ejecución de este, tratando de ser claros, precisos y obviamente excluyentes.

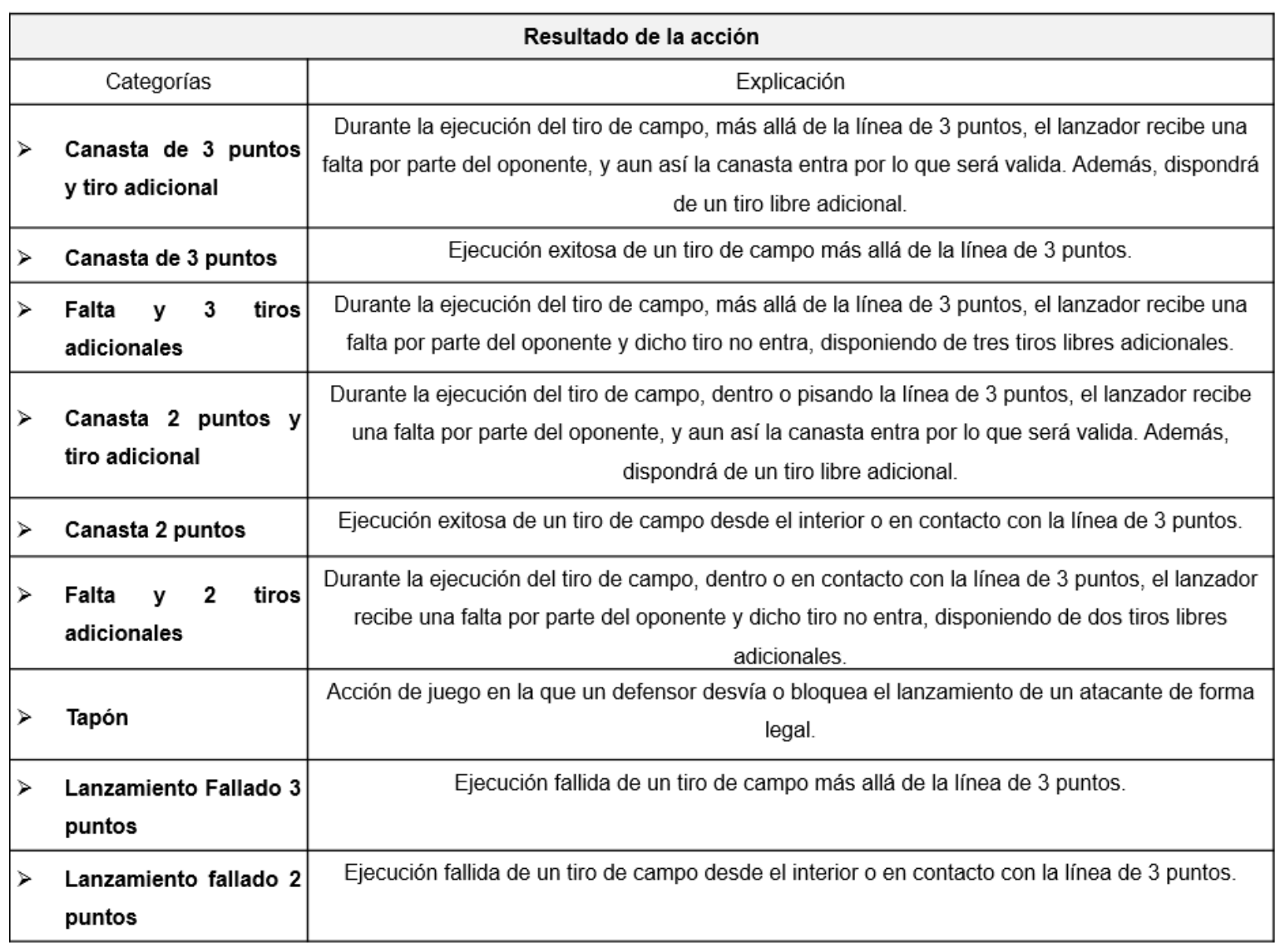

Tabla 5: Nivel evaluativo. Variable resultado de la acción. 


\subsection{CONSTANCIA INTERSESIONAL}

Se ha buscado una constancia intersesional a través de la selección de encuentros con ciertas características que la favorezcan. Debe diferenciarse el rendimiento de los equipos según la competición, el hecho de jugar en casa o fuera y la diferencia final del marcador, no siendo lo mismo partidos ajustados que partidos con grandes diferencias (Sampaio, 2001; citado por Gómez et al., 2007a).

La influencia del "home advantage effect" ha sido objeto de estudio en diferentes deportes (Sampedro y Prieto, 2012; Hoffmann et al., 2017; Koning, 2011), dándose también en el caso del baloncesto numerosos estudios sobre el tema (Carron et al., 2005; Gómez et al., 2007b; Pojskić et al., 2011). Los equipos locales tienden a ganar, siendo el porcentaje de victorias superior al 50\% (Courneya y Carron, 1992; García et al., 2009), lo cual es probablemente debido como afirman Bray y Widmeyer (2000) a factores como el apoyo del público y la mayor motivación.

Si nos centramos en el objeto de estudio de esta tesis, los FG, son factores discriminantes entre equipos locales y visitantes (García et al., 2009; Navarro et al., 2012), cosa que como señalan Cárdenas y Rojas (1997) no ocurre con los tiros libres, pues no parece influir en el porcentaje de aciertos el hecho de jugar en casa o fuera. A razón de esto se decidió que todos los partidos de los equipos analizados tuvieran la condición de visitante, lo cual homogeniza la muestra de estudio, aumentando la calidad del método de observación.

Siguiendo con esa homogeneización, ninguno de los encuentros analizados cuenta con periodos extras, dándose así un equilibrio en cuanto al tiempo de juego entre los distintos partidos. Además, como recogieron Martínez y García (2017) el factor cancha también influye en los periodos extras, pues en caso de que el equipo visitante convierta la última posesión del tiempo ordinario y empate, es más probable que acabe ganando el encuentro, cosa que no ocurre con los equipos locales. También recoge la influencia positiva de ser el primero en convertir un FG en la prórroga, pero esta independientemente de la condición de visitante o local. Sin duda, en los periodos extras, la condición física, el trabajo motivacional y el control del estrés es básico. 


\subsection{CONSTANCIA INTRASESIONAL}

En ciertas ocasiones dentro de un encuentro se producen diferencias en el marcador que modifican la tendencia del partido. Se trata de una diferencia en el tanteo que provoca un punto de inflexión en el transcurso del juego, una ruptura del flujo conductual, muchas veces debido a factores emocionales y/o psicológicos. Podríamos decir que el partido cambia totalmente, pues ambos equipos modifican su visión del encuentro, y por tanto, su línea de juego. Para evitar esta ruptura de la constancia intrasesional, y tras el debate con varios entrenadores, jugadores y expertos, se ha concluido que para este estudio tal diferencia sea de más de 20 puntos. Por ello, en ninguno de los encuentros analizados se dará una diferencia mayor a 20 puntos entre ambos equipos.

\subsection{FIABILIDAD Y VALIDEZ}

La fiabilidad y la validez son dos términos que no tienen por qué ir unidos, algo puede ser válido y no fiable, o al revés. Pongamos por caso que tras dar unas pautas a unos observadores independientes, todos registraran la misma variable. Esto demostraría la fiabilidad del método, pues todos coinciden en señalar lo mismo, pero no su validez, pues podría ser que la variable marcada no refleje verazmente el objeto de estudio, es decir, que no analice lo que pretendía analizar.

Fiabilidad es el grado en que las respuestas son independientes de las circunstancias accidentales de la investigación, y validez la medida en que la respuesta se interpreta de forma correcta. No son simétricas, ya que es fácil lograr una fiabilidad perfecta sin validez, mientras que ésta implica fiabilidad. (Anguera, 1986, p.34)

Dentro de todo estudio estos términos son de crucial importancia, pues sin un método de observación fiable y válido todos los resultados obtenidos carecerán de valor. Todos los observadores del presente estudio han recibido un riguroso entrenamiento de comprensión, observación e identificación de las variables. A pesar de ello siempre es necesario el cálculo de la concordancia inter e intraobservador con el coeficiente Kappa (Cohen, 1960) para determinar su fiabilidad. 
$\mathrm{K}=(\mathrm{Po}-\mathrm{Pe}) /(1-\mathrm{Pe})$, donde "Po" es la proporción de acuerdos observados y "Pe" es la proporción de acuerdos esperados por azar. Explicado de forma simple, este coeficiente contabiliza las concordancias entre observaciones de una muestra de " $N$ " ítems, a la vez que excluye la concordancia atribuible al azar. En función del valor de dicho coeficiente, el cual puede variar entre $-1 \mathrm{y}+1$, se define la fuerza de concordancia. El valor $\mathrm{k}=0$ representa la concordancia atribuible puramente al azar.

\begin{tabular}{|c|c|}
\hline Coeficiente Kappa & Fuerza de concordancia \\
\hline$<0,00$ & Pobre \\
\hline $0,00-0,20$ & Leve \\
\hline $0,21-0,40$ & Aceptable \\
\hline $0,41-0,60$ & Moderada \\
\hline $0,61-0,80$ & Considerable \\
\hline $0,81-1,00$ & Casi perfecta \\
\hline
\end{tabular}

Tabla 6: Valoración del coeficiente Kappa (Landis y Koch, 1977).

Debemos tener en cuenta que este indice solo mide la concordancia entre dos observadores. En caso de querer analizar la concordancia entre más observadores deberiamos utilizar el coeficiente kappa de Fleiss (Fleiss, 1971).

En este estudio se realizó un análisis intraobservador dejando un periodo de tiempo de un mes entre ambas observaciones, e interobservador llevado a cabo por dos observadores independientes, calculando así los índices Kappa de cada uno de los niveles de respuesta. Como podemos ver en la tabla 7, la diagonal sombreada marca las coincidencias entre los dos análisis realizados con un mes de diferencia por parte de un observador. En ella, debido a que mide un nivel de respuesta objetivo al venir definido por el marcador, la concordancia es absoluta. Sin embargo, en la tabla 8 , la cual muestra los análisis de dos observadores independientes, podemos ver como hay dos mediciones discordantes. Todas las tablas de concordancia intra e inter observador de cada variable están recogidas en el anexo 12.1 y 12.2 respectivamente. 


\begin{tabular}{|c|c|c|c|c|c|c|c|}
\hline \multirow[t]{2}{*}{$N=61$} & & \multicolumn{6}{|c|}{ OBERVADOR A* } \\
\hline & & (+) $11-20$ & (+) $1-10$ & Empate & $(-) 1-10$ & (-) $11-20$ & Total \\
\hline \multirow{6}{*}{ OBERVADOR A } & (+) $11-20$ & 0 & 0 & 0 & 0 & 0 & 0 \\
\hline & $(+) 1-10$ & 0 & 5 & 0 & 0 & 0 & 5 \\
\hline & Empate & 0 & 0 & 3 & 0 & 0 & 3 \\
\hline & $(-) 1-10$ & 0 & 0 & 0 & 53 & 0 & 53 \\
\hline & (-) $11-20$ & 0 & 0 & 0 & 0 & 0 & 0 \\
\hline & Total & 0 & 5 & 3 & 53 & 0 & 61 \\
\hline
\end{tabular}

Tabla 7: Concordancia intraobservador. Variable ventaja/desventaja.

\begin{tabular}{|c|c|c|c|c|c|}
\hline \multirow[t]{2}{*}{$N=61$} & & \multicolumn{4}{|c|}{ OBERVADOR B } \\
\hline & & Buen tiro & Tiro normal & Mal tiro & Total \\
\hline \multirow{4}{*}{ OBERVADOR A } & Buen tiro & 12 & 1 & 0 & 13 \\
\hline & Tiro normal & 1 & 36 & 0 & 37 \\
\hline & Mal tiro & 0 & 0 & 11 & 11 \\
\hline & Total & 13 & 37 & 11 & 61 \\
\hline
\end{tabular}

Tabla 8: Concordancia interobservador. Variable tipo de tiro.

A continuación (tabla 9 y 10) se muestran los índices Kappa intra e inter observador, observándose una mayor concordancia entre un mismo evaluador que entre dos evaluadores independientes, lo cual era de esperar. A pesar de esto, la diferencia es mínima, demostrándose

\begin{tabular}{|c|c|}
\hline Nivel de respuesta & Índice de Kappa Intraobservador \\
\hline Zona del campo & 1 \\
\hline Periodo de juego & 1 \\
\hline Tiempo de posesión & 1 \\
\hline Precedente & 1 \\
\hline Jugadores implicados & 1 \\
\hline Ventaja/Desventaja & 0,970 \\
\hline Tipo de tiro & 1 \\
\hline Momento especial & $\mathbf{0 , 9 9 6}$ \\
\hline Resultado de la acción & TOTAL \\
\hline
\end{tabular}

Los índices totales obtenidos (tabla 11) en los distintos niveles de respuesta demuestran una alta fuerza de concordancia, en gran medida debido a que algunos de estos niveles están cerrados y bien definidos por la reglamentación o su objetividad (periodo de juego, número de jugadores

\begin{tabular}{|c|c|}
\hline Nivel de respuesta & Índice de Kappa Interobservador \\
\hline Zona del campo & 0,970 \\
\hline Periodo de juego & 0,974 \\
\hline Tiempo de posesión & 0,976 \\
\hline Precedente & 1 \\
\hline Jugadores implicados & 1 \\
\hline Ventaja/Desventaja & 0,941 \\
\hline Tipo de tiro & 1 \\
\hline Momento especial & $\mathbf{0 , 9 8 4}$ \\
\hline Resultado de la acción & Tabla 10: Índice Kappa Interobservador. \\
\hline TOTAL & \\
\hline
\end{tabular}


implicados, ventaja/desventaja...). Otros, como pueden ser por ejemplo la zona del campo o el tiempo de posesión pueden ser más conflictivos. En el caso de la zona del campo, a pesar de estar bien definido y basarse en las líneas de la cancha, en determinados lanzamientos se efectúa justo en la transición entre una zona y otra, pudiendo generar alguna duda en los observadores en caso de no tener una buena visión o perspectiva. En el caso del tiempo de posesión sería algo similar, pues en ocasiones el lanzamiento se produce entre dos intervalos de medición, siendo casi imposible saber en qué momento exacto el balón deja de estar en contacto con la mano. Pero sin duda alguna el nivel de respuesta más conflictivo es el tipo de tiro, pues a pesar de haberse definido lo más estrictamente posible y haber entrenado a los observadores a través de distintos ejemplos clarificadores siempre contendrá un valor subjetivo. Quizás debido a ese intenso entrenamiento y definición de este nivel de respuesta más conflictivo se haya conseguido contener esa posible discordancia.

\begin{tabular}{|c|c|}
\hline Nivel de respuesta & Índice de Kappa \\
\hline Zona del campo & 0,985 \\
\hline Periodo de juego & 1 \\
\hline Tiempo de posesión & 0,987 \\
\hline Precedente & 0,988 \\
\hline Jugadores implicados & 1 \\
\hline Ventaja/Desventaja & 1 \\
\hline Tipo de tiro & 0,955 \\
\hline Momento especial & 1 \\
\hline Resultado de la acción & 1 \\
\hline TOTAL & 0,99 \\
\hline
\end{tabular}

Tabla 11: Índice Kappa de niveles de respuesta. 


\section{REFLEXIÓN PREVIA A LOS RESULTADOS Y SU APLICACIÓN}

Con carácter previo a la exposición de resultados, resulta relevante aludir a su vertebración que pretende proporcionar, casi normativizar, el marco interpretativo general del conjunto de resultados y de su posterior aplicación.

En todo estudio es necesaria una fragmentación e interpretación de los datos para realizar una inferencia de los resultados, pues sin esta selección y simplificación nos "ahogaríamos" en un mar de información sin saber hacia dónde remar. No debemos obsesionarnos con el mayor volumen de datos posible, sino buscar la calidad de estos. Consecuentemente, centraremos nuestra atención investigadora priorizando todos aquellos datos que puedan aportar información relevante para el estudio y el propósito aplicado de mejorar la eficacia en el FG mediante el uso de situaciones de entrenamiento lo más similares posibles al juego real, tratando así de conseguir una transferencia de las condiciones de competición en todos sus aspectos (tiempo, espacio, oposición, fatiga,...)

Con estos modelos de entrenamiento se podrá mejorar la toma de decisión y con ello la eficacia de los jugadores en la ejecución del FG, minimizando la ansiedad competitiva y otras emociones, factores siempre presentes dada la naturaleza multidimensional del baloncesto como deporte de oposición-colaboración. Control de las emociones y su influencia en el rendimiento, cuya importancia ya fue puesta de manifiesto por distintos autores como Arent y Landers (2003) y Abénza et al. (2009). Y en la perspectiva que guarda relación con la aplicabilidad de los resultados, también conviene subrayar la utilidad del recurso al constructivismo que facilita descubrir y entender la lógica interna del juego mediante una intervención reflexiva del jugador. Así conseguiremos una autentica mejora en la toma de decisión (Gréhaigne et al. 1999, 2005). 


\section{RESULTADOS}

Provisto de este eje de coordenadas, mostramos los resultados obtenidos tras 2 temporadas, 6 ligas, 212 encuentros (anexo 12.3) y 15.485 FG analizados. Todas las tablas donde se recogen los FG en función de variables están recogidas en el anexo 12.4.1. Estos resultados no son un fin en sí mismo, si no su estudio para una posterior aplicación práctica. Iremos desgranando los resultados en función de las variables de análisis a nivel contextual y evaluativo, así como sus posibles combinaciones.

Si analizamos una variable por sí sola tan solo obtendremos el reparto de FG dentro de cada una de sus categorías, sin embargo, si combinamos variables por pares podremos ver la relación directa entre ambas, lo cual utilizaremos posteriormente para diseñar ejercicios de entrenamiento o crear premisas para modificar los mismos en busca del objetivo deseado.

En la tabla 12 se muestra un esquema de las combinaciones de las distintas categorías de dos variables.

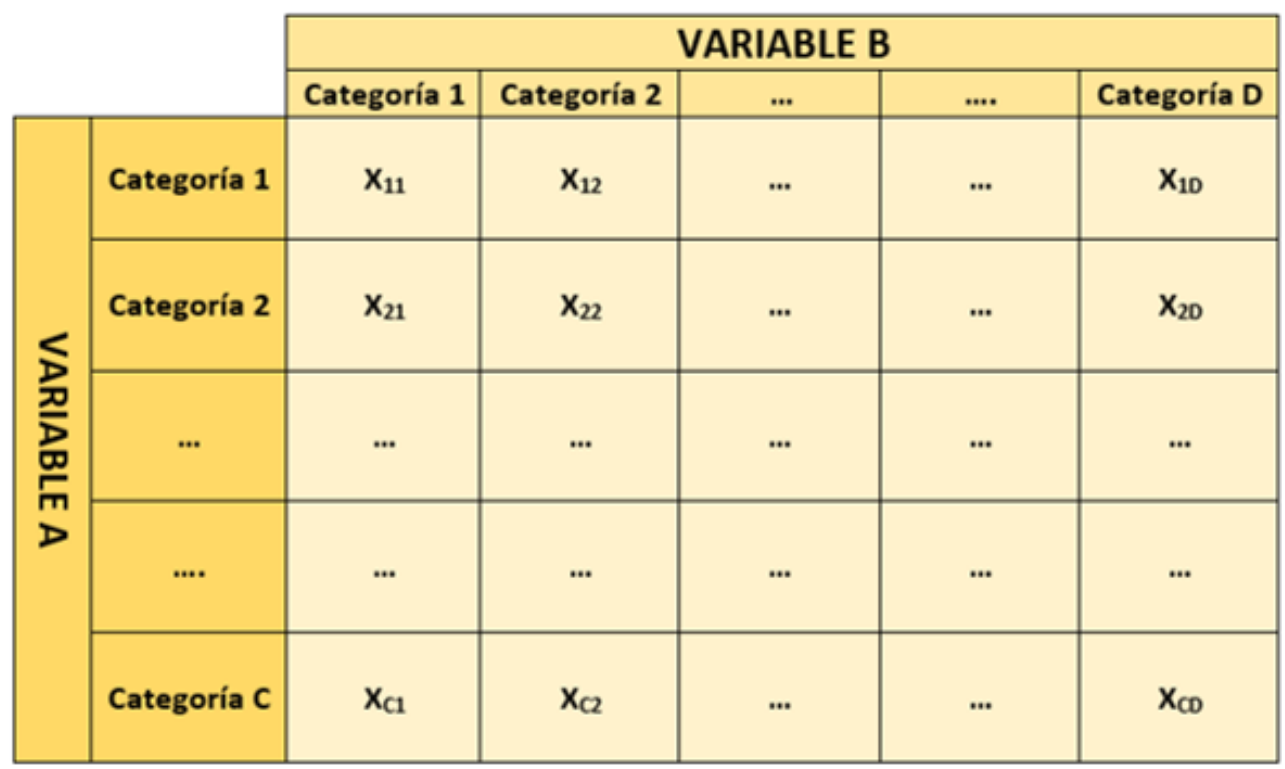

Tabla 12: Esquema de combinación de dos variables.

Una vez extraídos los datos, nos encontramos ante distintas posibilidades de interpretación. Una posibilidad sería analizar la combinación de variables sobre el total de FG, es decir, que porcentaje sobre el total de FG pertenece a cada combinación de categorías de dos variables distintas. 


\begin{tabular}{|c|c|c|c|c|}
\cline { 3 - 5 } \multicolumn{2}{c|}{} & \multicolumn{3}{c|}{ TIEMPO DE POSESIÓN } \\
\cline { 3 - 5 } \multicolumn{2}{c|}{} & $\mathbf{0 - 8}$ & $\mathbf{9 - 1 6}$ & $\mathbf{1 7 - 2 4}$ \\
\hline \multirow{3}{*}{$\underset{\mathrm{m}}{\mathrm{m}}$} & Contraataque & $0,06 \%$ & $0,01 \%$ & $2,34 \%$ \\
\cline { 2 - 5 } & Bloqueo Directo & $4,73 \%$ & $9,87 \%$ & $1,76 \%$ \\
\cline { 2 - 5 } & Pase & $12,02 \%$ & $18,47 \%$ & $5,15 \%$ \\
\cline { 2 - 5 } & Jugada Personal & $15,65 \%$ & $16,58 \%$ & $5,18 \%$ \\
\cline { 2 - 5 } & Robo & $0,09 \%$ & $0,04 \%$ & $2,71 \%$ \\
\cline { 2 - 5 } & Rebote & $0,64 \%$ & $3,86 \%$ & $0,84 \%$ \\
\hline
\end{tabular}

Tabla 13: Análisis sobre el total de combinaciones entre las variables precedente y posesión.

En la tabla 13 podemos ver un ejemplo de esta interpretación entre las variables precedente y tiempo de posesión. El sumatorio de todas las combinaciones entre categorías es el 100\%. Esta interpretación busca unos patrones o conductas más globales con la influencia directa de dichas combinaciones sobre el juego, pues se trata del porcentaje de que se produzca dicha combinación en el FG. Podríamos decir que cuanto mayor porcentaje exista entre dos categorías, más incidencia tendrán en el FG, y por tanto, más importancia en su análisis para la aplicación práctica.

Las otras dos perspectivas son más analíticas. En ellas se busca ver la influencia de las distintas categorías de una de las variables sobre cada una de las categorías de la otra. Además, hemos de tener en cuenta que los porcentajes obtenidos ya no son sobre el total de los FG ejecutados, si no sobre el total de los FG ejecutados dentro de esa categoría en la que nos centramos. Pongamos como ejemplo la categoría "robo" de la variable "precedente". Su porcentaje sobre el total es muy bajo, pues se ejecutan muy pocos en comparación al resto de precedentes, pero si nos centramos en la combinación de esa categoría con las categorías de la otra variable, ya solo nos estamos centrando en el "robo", y por tanto tomamos como "N" el número de FG realizados en esa categoría, no teniendo en cuenta el resto.

En la tabla 14 se muestra a modo de ejemplo el análisis del FG dentro de cada categoría de la variable "precedente" según en qué categoría de la variable "tiempo de posesión" se encuentre, es decir, es una interpretación horizontal, donde se ve como se reparte el total de cada categoría de la variable "precedente" entre las categorías de la variable “tiempo de posesión”. 


\begin{tabular}{|c|c|c|c|c|c|}
\hline & & \multicolumn{4}{|c|}{ TIEMPO DE POSESIÓN } \\
\hline & & $0-8$ & $9-16$ & $17-24$ & TOTAL \\
\hline \multirow{6}{*}{ 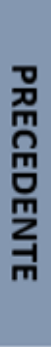 } & Contraataque & $2,41 \%$ & $0,53 \%$ & $97,06 \%$ & $100,00 \%$ \\
\hline & Bloqueo Directo & $28,90 \%$ & $60,32 \%$ & $10,78 \%$ & $100,00 \%$ \\
\hline & Pase & $33,73 \%$ & $51,81 \%$ & $14,46 \%$ & $100,00 \%$ \\
\hline & Jugada Personal & $41,83 \%$ & $44,32 \%$ & $13,85 \%$ & $100,00 \%$ \\
\hline & Robo & $3,19 \%$ & $1,37 \%$ & $95,44 \%$ & $100,00 \%$ \\
\hline & Rebote & $11,97 \%$ & $72,31 \%$ & $15,72 \%$ & $100,00 \%$ \\
\hline
\end{tabular}

Tabla 14: Análisis de cada categoría de la variable precedente en función del tiempo de posesión.

Si por el contrario hacemos un análisis vertical, analizaremos como se reparte el total de cada categoría de la variable "tiempo de posesión" entre las categorías de la variable "precedente". La tabla 15 es un ejemplo de esta interpretación.

\begin{tabular}{|c|c|c|c|c|}
\hline & \multicolumn{3}{|c|}{ TIEMPO DE POSESIÓN } \\
\hline & & $0-8$ & $9-16$ & $17-24$ \\
\hline \multirow{7}{*}{ 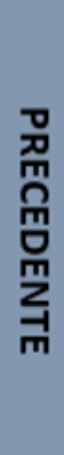 } & Contraataque & $0,18 \%$ & $0,03 \%$ & $13,03 \%$ \\
\hline & Bloqueo Directo & $14,24 \%$ & $20,21 \%$ & $9,80 \%$ \\
\hline & Pase & $36,23 \%$ & $37,83 \%$ & $28,65 \%$ \\
\hline & Jugada Personal & $47,15 \%$ & $33,95 \%$ & $28,80 \%$ \\
\hline & Robo & $0,27 \%$ & $0,08 \%$ & $15,04 \%$ \\
\hline & Rebote & $1,93 \%$ & $7,91 \%$ & $4,67 \%$ \\
\hline & TOTAL & $100,00 \%$ & $100,00 \%$ & $100,00 \%$ \\
\hline
\end{tabular}

Tabla 15: Análisis de cada categoría de la variable posesión en función del precedente.

La diferencia entre el análisis horizontal o vertical se basa en que variable, y por tanto sus categorías, estamos tomando como objeto principal de estudio, pudiendo ver así como le afectan las categorías de la otra variable, es decir, nos aportan informaciones distintas.

Imaginemos que queremos analizar los FG de la última franja de posesión, de 0 a 8 segundos, para su aplicación práctica. Entonces nos interesará saber, dentro de esa franja, en qué porcentaje se da cada precedente, viendo así la importancia de estos de cara a trabajarlos en los entrenamientos. Sin embargo, si nuestro objetivo es trabajar el bloqueo directo, ya sea defensiva u ofensivamente, debemos conocer cuando tienden a producirse, interesándonos por tanto saber como se reparten dentro de cada franja de posesión. 
Conociendo estas tres posibles interpretaciones emplearemos las necesarias dentro de cada variable o combinación de estas para extraer la mayor información posible del FG. Hemos de ser conscientes de que no para todas las variables serán útiles las tres.

\subsection{ZONA DEL CAMPO}

En la figura 14 observamos como la zona 1 del campograma es donde mayor número de FG se ejecuta con un 49,5\% del total. De igual modo podemos ver como las zonas de tiro más centradas respecto del aro tienen un mayor número de lanzamientos que las zonas laterales. Es decir, dentro del perímetro, en las zona 1 y 4, se realizan más lanzamientos que en la zona 2 y 3 , que son laterales. Lo mismo ocurre desde el exterior del perímetro, ejecutándose más lanzamientos en la zona 7 que en la zona 5 y 6.

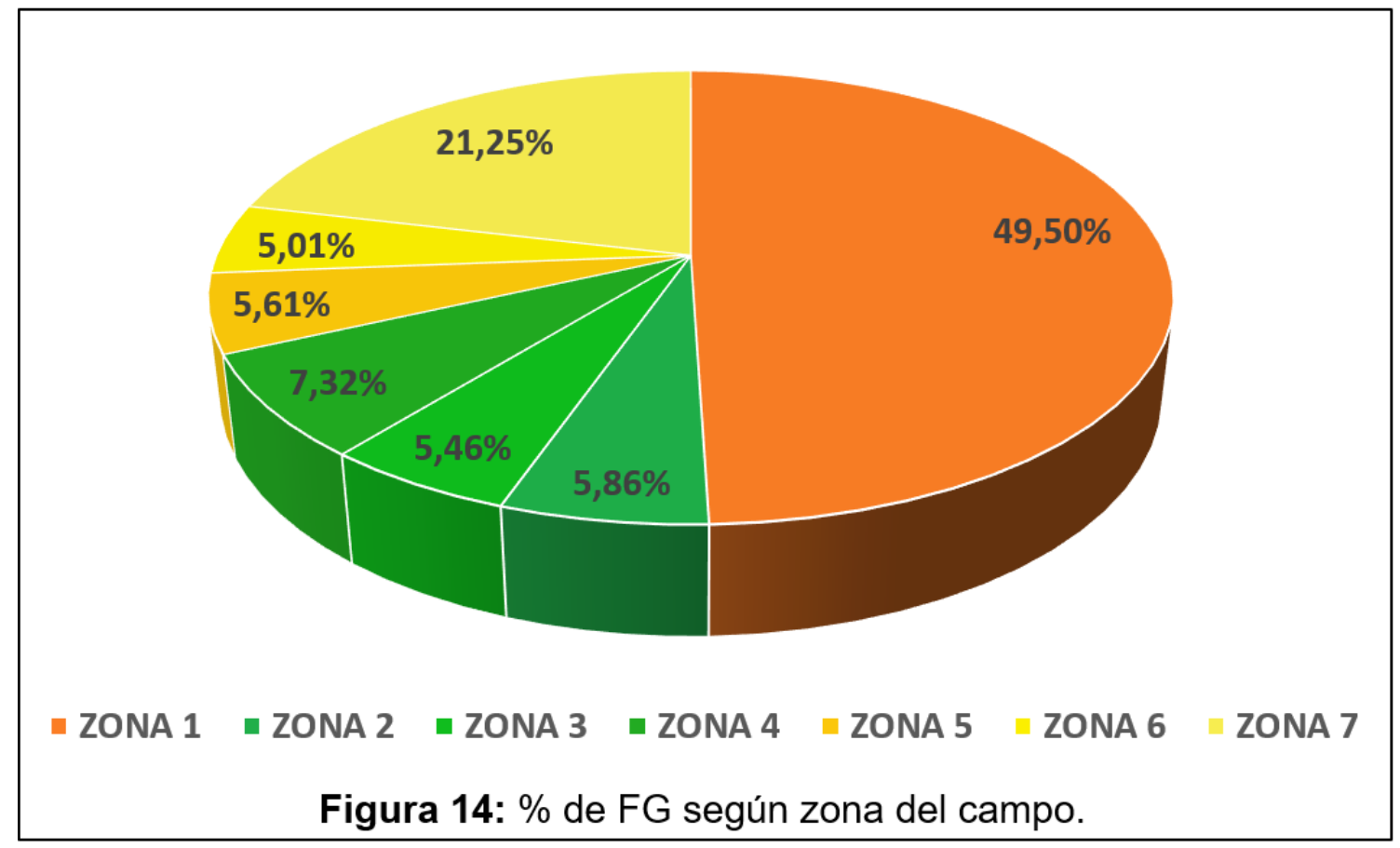

En relación a la lateralidad de los lanzamientos podemos observar como si enfrentamos las zonas 2 y 5 , con las zonas 3 y 6 , se ejecutan un mayor número de FG desde el lado izquierdo. El orden de mayor a menor \% de FG dentro de cada zona sería el siguiente: Zona 1, Zona 7, Zona 4, Zona 2, Zona 5, Zona 3 y Zona 6. 


\subsubsection{Zona del campo y resultado}

Analizando la combinación de este par de variables de forma global (tabla 16) vemos como tan solo la combinación de 5 pares de categorías suponen más de un $5 \%$ sobre el total. En la zona 1 tanto las canastas de 2 puntos como sus fallos tienen un porcentaje considerable. En la zona 7 destacan también las canastas y fallos de 3, pero con una clara predominancia de los fallos. Por último, en la zona 1 se producen un 5,82\% de FG cuyo resultado es una falta y adicional.

\begin{tabular}{|c|c|c|c|c|c|c|c|}
\cline { 2 - 7 } \multicolumn{1}{c|}{} & ZONA 1 & ZONA 2 & ZONA 3 & ZONA 4 & ZONA 5 & ZONA 6 & ZONA 7 \\
\hline 3p. + adicional & $0 \%$ & $0 \%$ & $0 \%$ & $0 \%$ & $0,03 \%$ & $0,02 \%$ & $0,05 \%$ \\
\hline 3puntos & $0 \%$ & $0 \%$ & $0 \%$ & $0 \%$ & $1,99 \%$ & $1,70 \%$ & $6,92 \%$ \\
\hline Falta + 3 adic. & $0 \%$ & $0 \%$ & $0 \%$ & $0 \%$ & $0,06 \%$ & $0,06 \%$ & $0,24 \%$ \\
\hline 2p. + adicional & $2,00 \%$ & $0,12 \%$ & $0,05 \%$ & $0,01 \%$ & $0 \%$ & $0 \%$ & $0 \%$ \\
\hline 2puntos & $21,23 \%$ & $1,76 \%$ & $1,83 \%$ & $2,75 \%$ & $0 \%$ & $0 \%$ & $0 \%$ \\
\hline Falta + 2 adic. & $5,82 \%$ & $0,21 \%$ & $0,21 \%$ & $0,19 \%$ & $0 \%$ & $0 \%$ & $0 \%$ \\
\hline Tapón & $3,37 \%$ & $0,14 \%$ & $0,09 \%$ & $0,06 \%$ & $0,03 \%$ & $0,08 \%$ & $0,08 \%$ \\
\hline Fallo 3p. & $0 \%$ & $0 \%$ & $0 \%$ & $0 \%$ & $3,50 \%$ & $3,15 \%$ & $13,96 \%$ \\
\hline Fallo 2p. & $17,08 \%$ & $3,63 \%$ & $3,29 \%$ & $4,31 \%$ & $0 \%$ & $0 \%$ & $0 \%$ \\
\hline
\end{tabular}

Tabla 16: \% de FG entre las variables zona del campo y resultado.

Si nos fijamos en la importancia del resultado respecto a la lógica interna del juego podemos dividir los resultados en positivos (3p.+adic., 3p., falta+3adic., 2p.+adic., 2p., falta+2adic.) o negativos (tapón, fallo $3 p$. y fallo 2 p.). Evaluando el resultado del FG en función de la zona del campo (figura 15) se muestra como la única zona donde se dan más resultados positivos que negativos es la zona 1 .

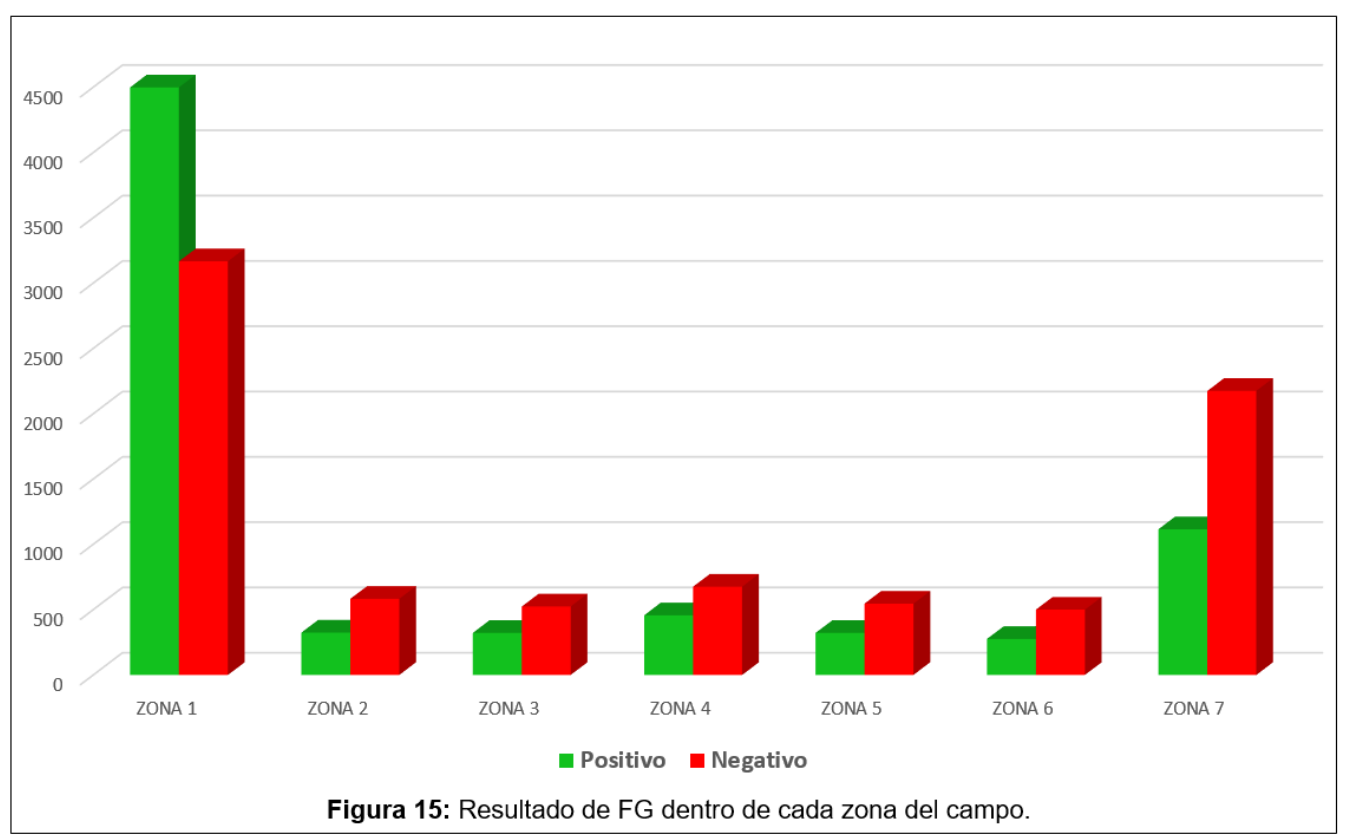


La tabla 17 nos muestra porcentualmente la eficacia de cada zona, observando como las dos peores zonas dentro de la línea de 3 puntos son la 2 y la 3 , lo cual podría ser la causa, en relación al apartado anterior, de que se efectúen un menor número de FG desde dichas zonas. Sin embargo, esta dinámica se ve rota en el exterior del perímetro, no teniendo la zona 7 , desde la cual se ejecutan más FG, mejor efectividad que la 5 y 6 , sino que es ligeramente menos efectiva. El orden de mayor a menor eficacia dentro de cada zona sería el siguiente: Zona 1, Zona 4, Zona 3, Zona 5, Zona 2, Zona 6 y Zona 7.

\begin{tabular}{|c|c|c|c|c|c|c|c|}
\cline { 2 - 8 } \multicolumn{1}{c|}{} & ZONA 1 & ZONA 2 & ZONA 3 & ZONA 4 & ZONA 5 & ZONA 6 & ZONA 7 \\
\hline Resultado positivo & $58,68 \%$ & $35,72 \%$ & $38,06 \%$ & $40,34 \%$ & $37,10 \%$ & $35,57 \%$ & $33,89 \%$ \\
\hline Resultado negativo & $41,32 \%$ & $64,28 \%$ & $61,94 \%$ & $59,66 \%$ & $62,90 \%$ & $64,43 \%$ & $66,11 \%$ \\
\hline TOTAL & $100,00 \%$ & $100,00 \%$ & $100,00 \%$ & $100,00 \%$ & $100,00 \%$ & $100,00 \%$ & $100,00 \%$ \\
\hline
\end{tabular}

Tabla 17: \% FG con resultado positivo y negativo dentro de cada zona del campo.

En cuanto a la lateralidad, en el caso del exterior del perímetro si coincide el lado desde donde más se tira, como vimos en el apartado anterior, con el más efectivo, el lado izquierdo. Sin embargo, en el interior del perímetro tiene mayor efectividad el lado derecho.

La tabla 18 recoge de forma clara el \% de FG según zona del campograma así como la efectividad dentro de cada zona. Estos datos son muy importantes de cara a su futura aplicación práctica. En ella podemos ver como la zona 4 es la segunda más efectiva, a pesar de lo cual, se mantiene como tercera zona desde la que más se lanza y claramente alejada de las dos primeras.

La tabla 19 y la figura 16 recogen los porcentajes de los posibles resultados del FG dentro de cada zona.

\begin{tabular}{|c|c|c|c|}
\hline \multicolumn{2}{|c|}{ ZONA DEL CAMPO } & \multirow{2}{*}{$\begin{array}{c}\% \text { de lanzamientos } \\
49,50 \%\end{array}$} & \multirow{2}{*}{$\begin{array}{c}\% \text { resultado + } \\
58,68 \%\end{array}$} \\
\hline Zona 1 & & & \\
\hline Zona 2 & & $5,86 \%$ & $35,72 \%$ \\
\hline Zona 3 & $=$ & $5,46 \%$ & $38,06 \%$ \\
\hline Zona 4 & & $7,32 \%$ & $40,34 \%$ \\
\hline Zona 5 & & $5,61 \%$ & $37,10 \%$ \\
\hline Zona 6 & $=$ & $5,01 \%$ & $35,57 \%$ \\
\hline Zona 7 & $\checkmark$ & $21,25 \%$ & $33,89 \%$ \\
\hline
\end{tabular}

Tabla 18: \% FG según zona del campo y efectividad en cada una 


\begin{tabular}{|c|c|c|c|c|c|c|c|}
\cline { 2 - 8 } \multicolumn{1}{c|}{} & ZONA 1 & ZONA 2 & ZONA 3 & ZONA 4 & ZONA 5 & ZONA 6 & ZONA 7 \\
\hline 3p. + adicional & $0 \%$ & $0 \%$ & $0 \%$ & $0 \%$ & $0,46 \%$ & $0,39 \%$ & $0,21 \%$ \\
\hline 3puntos & $0 \%$ & $0 \%$ & $0 \%$ & $0 \%$ & $35,48 \%$ & $34,02 \%$ & $32,55 \%$ \\
\hline Falta + 3 adic. & $0 \%$ & $0 \%$ & $0 \%$ & $0 \%$ & $1,15 \%$ & $1,16 \%$ & $1,12 \%$ \\
\hline 2p. + adicional & $4,04 \%$ & $2,09 \%$ & $0,83 \%$ & $0,18 \%$ & $0 \%$ & $0 \%$ & $0 \%$ \\
\hline 2puntos & $42,88 \%$ & $29,99 \%$ & $33,45 \%$ & $37,60 \%$ & $0 \%$ & $0 \%$ & $0 \%$ \\
\hline Falta + 2 adic. & $11,75 \%$ & $3,64 \%$ & $3,78 \%$ & $2,56 \%$ & $0 \%$ & $0 \%$ & $0 \%$ \\
\hline Tapón & $6,81 \%$ & $2,32 \%$ & $1,65 \%$ & $0,79 \%$ & $0,46 \%$ & $1,55 \%$ & $0,40 \%$ \\
\hline Fallo 3p. & $0 \%$ & $0 \%$ & $0 \%$ & $0 \%$ & $62,44 \%$ & $62,89 \%$ & $65,71 \%$ \\
\hline Fallo 2p. & $34,51 \%$ & $61,96 \%$ & $60,28 \%$ & $58,87 \%$ & $0 \%$ & $0 \%$ & $0 \%$ \\
\hline TOTAL & $100,00 \%$ & $100,00 \%$ & $100,00 \%$ & $100,00 \%$ & $100,00 \%$ & $100,00 \%$ & $100,00 \%$ \\
\hline
\end{tabular}

Tabla 19: \% FG según resultado dentro de cada zona del campo.

La zona 1 es proporcionalmente, en comparación al resto de zonas, donde mayor número de tapones y faltas con dos tiros adicionales se producen, lo cual era de esperar debido a la cercanía del aro y por ende, una mayor presencia de defensores y de un modo más agresivo.

Entre las zonas exteriores la dinámica es casi idéntica, cabiendo destacar como la zona 7 , a pesar de ser la zona exterior desde la que más se lanza, es la zona con menor porcentaje de canasta de 3 puntos y la que mayor de fallo de 3 puntos.

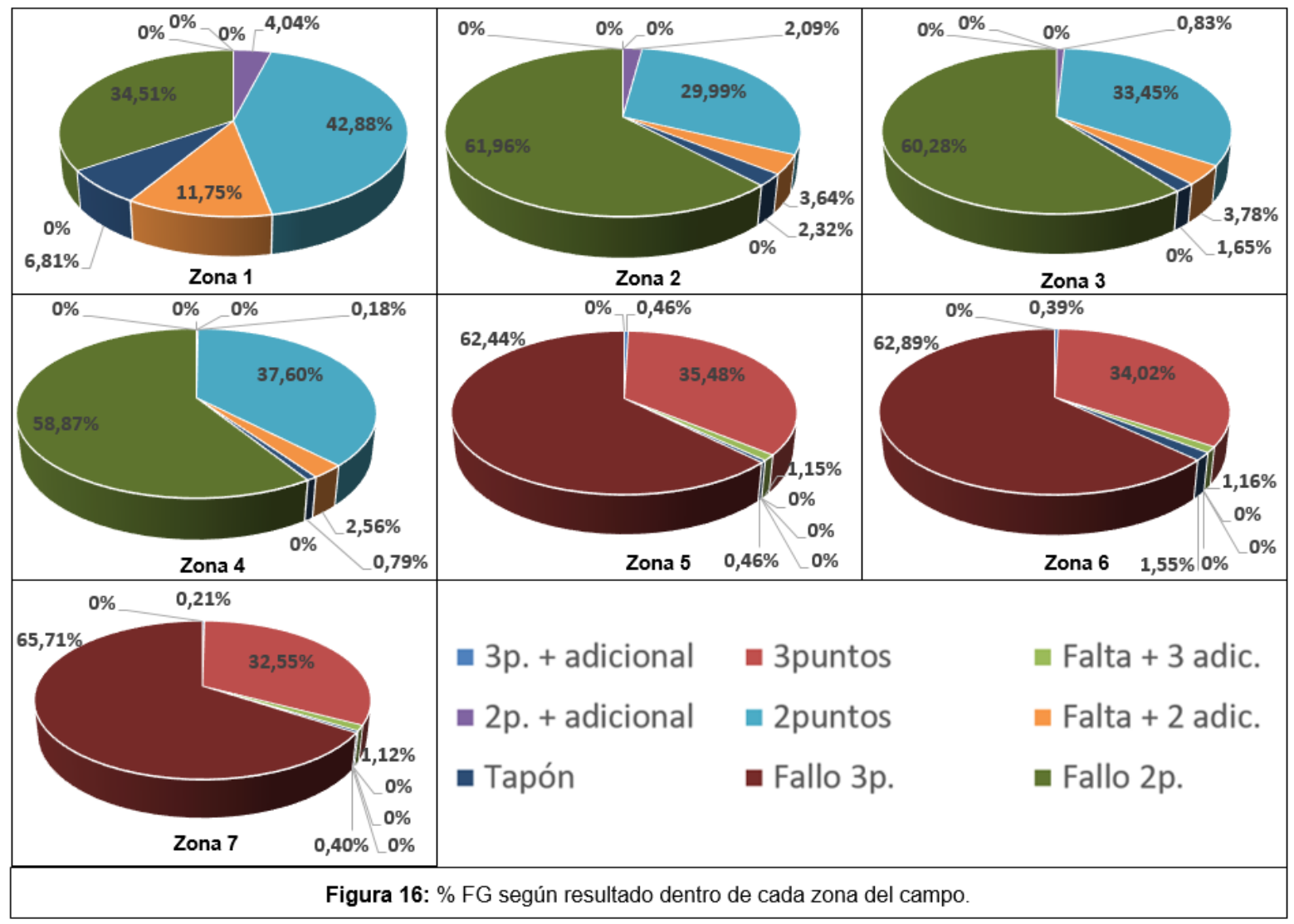


Si por el contrario analizamos los porcentajes de cada posible resultado del FG según zona, hemos de apoyarnos en la tabla 20 y la figura 17.

\begin{tabular}{|c|c|c|c|c|c|c|c|c|}
\cline { 2 - 9 } \multicolumn{1}{c|}{} & ZONA 1 & ZONA 2 & ZONA 3 & ZONA 4 & ZONA 5 & ZONA 6 & ZONA 7 & TOTAL \\
\hline 3p. + adicional & $0 \%$ & $0 \%$ & $0 \%$ & $0 \%$ & $28,57 \%$ & $21,43 \%$ & $50,00 \%$ & $100 \%$ \\
\hline 3puntos & $0 \%$ & $0 \%$ & $0 \%$ & $0 \%$ & $18,75 \%$ & $16,07 \%$ & $65,19 \%$ & $100 \%$ \\
\hline Falta + 3 adic. & $0 \%$ & $0 \%$ & $0 \%$ & $0 \%$ & $17,86 \%$ & $16,07 \%$ & $66,07 \%$ & $100 \%$ \\
\hline 2p. + adicional & $91,72 \%$ & $5,62 \%$ & $2,07 \%$ & $0,59 \%$ & $0 \%$ & $0 \%$ & $0 \%$ & $100 \%$ \\
\hline 2puntos & $77,01 \%$ & $6,37 \%$ & $6,63 \%$ & $9,98 \%$ & $0 \%$ & $0 \%$ & $0 \%$ & $100 \%$ \\
\hline Falta + 2 adic. & $90,55 \%$ & $3,32 \%$ & $3,22 \%$ & $2,91 \%$ & $0 \%$ & $0 \%$ & $0 \%$ & $100 \%$ \\
\hline Tapón & $87,73 \%$ & $3,53 \%$ & $2,35 \%$ & $1,51 \%$ & $0,67 \%$ & $2,02 \%$ & $2,18 \%$ & $100 \%$ \\
\hline Fallo 3p. & $0 \%$ & $0 \%$ & $0 \%$ & $0 \%$ & $16,98 \%$ & $15,29 \%$ & $67,73 \%$ & $100 \%$ \\
\hline Fallo 2p. & $60,33 \%$ & $12,82 \%$ & $11,63 \%$ & $15,21 \%$ & $0 \%$ & $0 \%$ & $0 \%$ & $100 \%$ \\
\hline
\end{tabular}

Tabla 20: \% FG según zona del campo de cada resultado.

En ellos podemos ver como los cuatro resultados relativos al triple se producen en un mayor porcentaje desde la zona 7 , lo cual está directamente influenciado por ser la zona exterior desde la que más se lanza. Lo mismo pasaría con los resultados relativos al FG de 2 puntos, dándose en mayor proporción en la zona 1, zona desde donde más se lanza.

En cuanto a los tapones, resultado vinculado a todos los FG, cuenta con un altísimo porcentaje en la zona 1, siendo su presencia en el resto de zonas casi anecdótica.

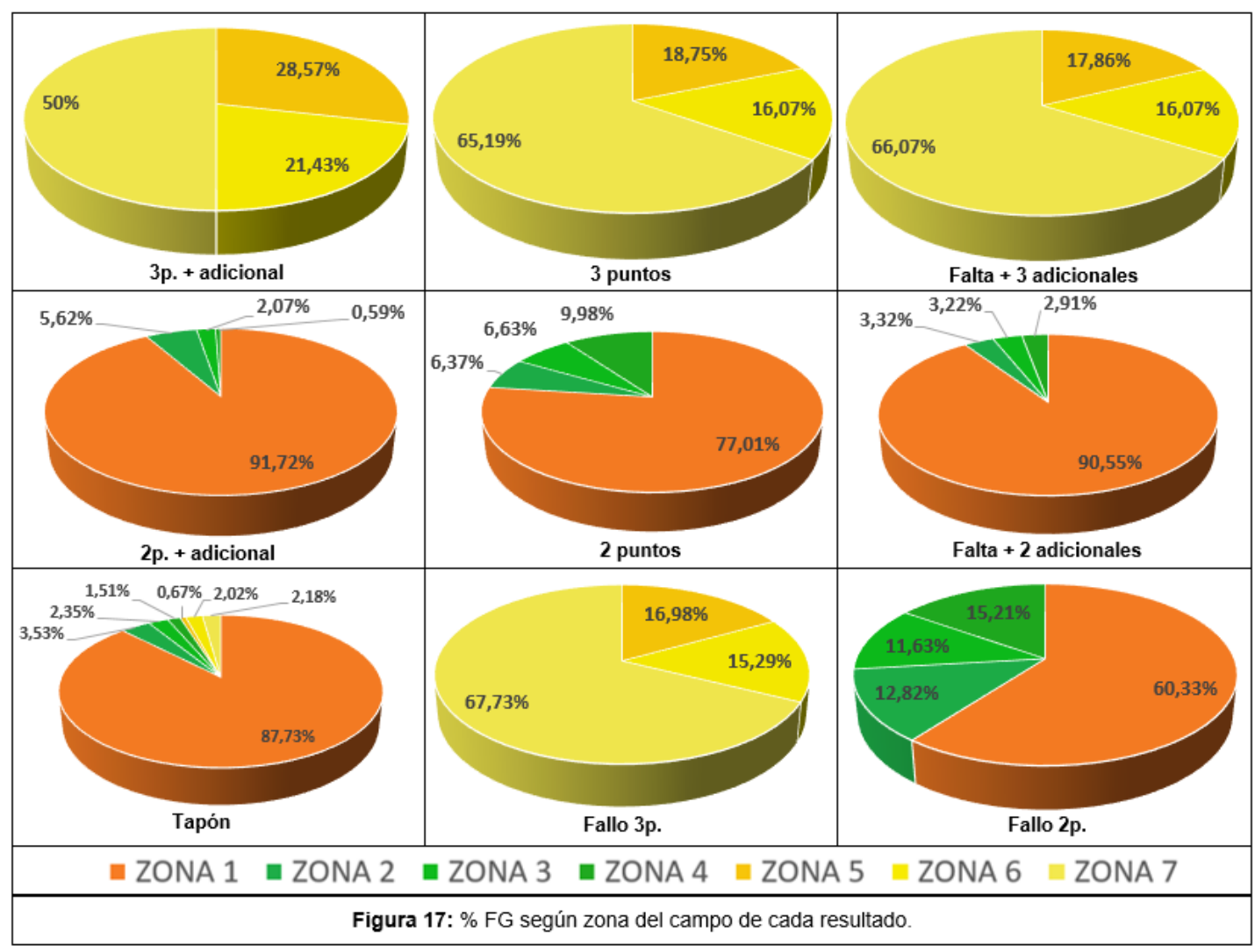




\subsubsection{Zona del campo y tiempo de posesión}

Si analizamos de forma global las combinaciones de estas dos variables (tabla 21) vemos como los mayores porcentajes siguen apareciendo en las zonas 1 y 7, reforzando aún más la importancia de estas dos zonas del campograma. La combinación de las categorías “zona 1" y "9-16" es la que más incide sobre el FG, pues cuenta con más de un $24 \%$ del total. Tras esta combinación, la seguirían esa misma zona con la categoría " $0-8$ " y "1724 ” respectivamente. En la zona 7 cabe destacar su combinación con "9-16” y "0-8”.

\begin{tabular}{|c|c|c|c|c|c|c|c|}
\cline { 2 - 8 } \multicolumn{1}{c|}{} & ZONA 1 & ZONA 2 & ZONA 3 & ZONA 4 & ZONA 5 & ZONA 6 & ZONA 7 \\
\hline $\mathbf{0 - \mathbf { 8 }}$ & $14,71 \%$ & $2,51 \%$ & $2,23 \%$ & $2,46 \%$ & $1,83 \%$ & $1,98 \%$ & $7,47 \%$ \\
\hline $\mathbf{9}-\mathbf{1 6}$ & $24,35 \%$ & $2,81 \%$ & $2,56 \%$ & $4,04 \%$ & $2,79 \%$ & $2,22 \%$ & $10,05 \%$ \\
\hline $\mathbf{1 7}-\mathbf{2 4}$ & $10,44 \%$ & $0,54 \%$ & $0,67 \%$ & $0,81 \%$ & $0,99 \%$ & $0,82 \%$ & $3,72 \%$ \\
\hline
\end{tabular}

Tabla 21: \% de FG entre las variables zona del campo y tiempo de posesión.

Por tanto, los resultados nos muestran como como la zona 1 domina en todas las franjas de posesión; y dentro de la zona 7 lo hace más la franja media y final, teniendo menos incidencia la franja inicial de posesión.

La figura 18 nos muestra los FG realizados dentro de cada zona del campo y en que franja temporal de la posesión se han realizado. En todas las zonas destaca la posesión entre los

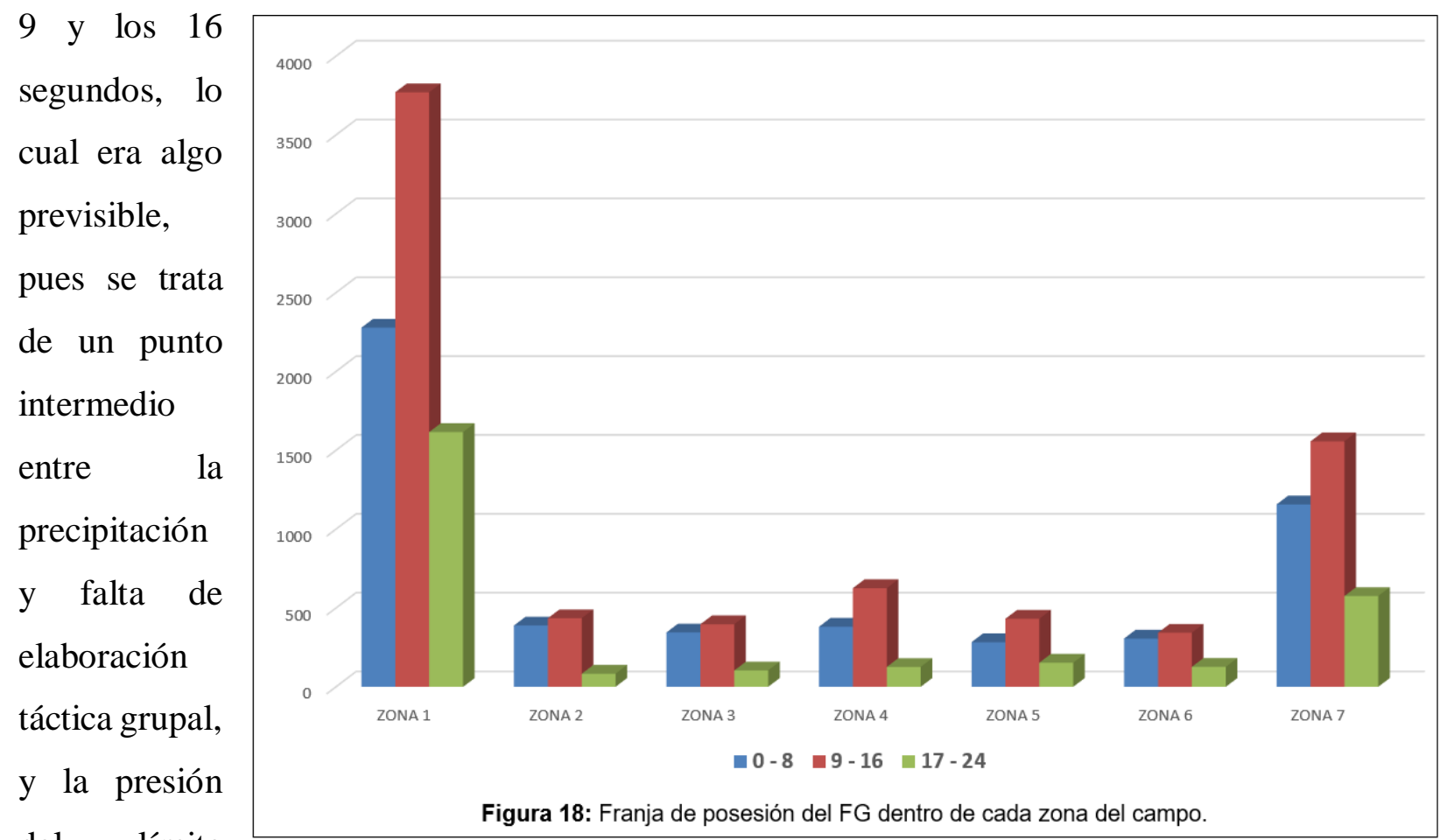

del límite

Figura 18: Franja de posesión del FG dentro de cada zona del campo.

temporal reglamentario para realizar el lanzamiento. 
Valiéndonos de la tabla 22, la cual nos ofrece de forma porcentual los datos de cada zona según franja de posesión, observamos ciertas correlaciones. A pesar de que todas las zonas tienen una dinámica semejante (figura 19), podemos observar como la zona 1 rompe ese patrón con un reparto más similar entre la franja de posesión 0-8 y 17-24, algo que no ocurre en ninguna de las otras zonas.

\begin{tabular}{|c|c|c|c|c|c|c|c|}
\cline { 2 - 8 } \multicolumn{1}{c|}{} & ZONA 1 & ZONA 2 & ZONA 3 & ZONA 4 & ZONA 5 & ZONA 6 & ZONA 7 \\
\hline $\mathbf{0 - 8}$ & $29,72 \%$ & $42,89 \%$ & $40,78 \%$ & $33,63 \%$ & $32,60 \%$ & $39,43 \%$ & $35,17 \%$ \\
\hline $\mathbf{9 - 1 6}$ & $49,20 \%$ & $47,96 \%$ & $46,93 \%$ & $55,25 \%$ & $49,77 \%$ & $44,20 \%$ & $47,33 \%$ \\
\hline $\mathbf{1 7}-\mathbf{2 4}$ & $21,08 \%$ & $9,15 \%$ & $12,29 \%$ & $11,12 \%$ & $17,63 \%$ & $16,37 \%$ & $17,51 \%$ \\
\hline TOTAL & $100,00 \%$ & $100,00 \%$ & $100,00 \%$ & $100,00 \%$ & $100,00 \%$ & $100,00 \%$ & $100,00 \%$ \\
\hline
\end{tabular}

Tabla 22: \% franja de posesión del FG dentro de cada zona del campo.

Esto podría ser debido a que los contraataques y transiciones ofensivas rápidas tienden a finalizarse cerca del aro por la superioridad o ventaja inherente; lo mismo que ocurre con los últimos segundos donde la elaboración de la jugada tiende a acercar al finalizador al aro. De hecho, si nos fijamos en las zonas 2 y 3, zonas cercanas al aro, tienen un mayor porcentaje de FG en la franja 0-8, lo cual apoya la idea de que se tiende a buscar la cercanía del aro en los últimos segundos, ya sea por una jugada elaborada o por una jugada personal.

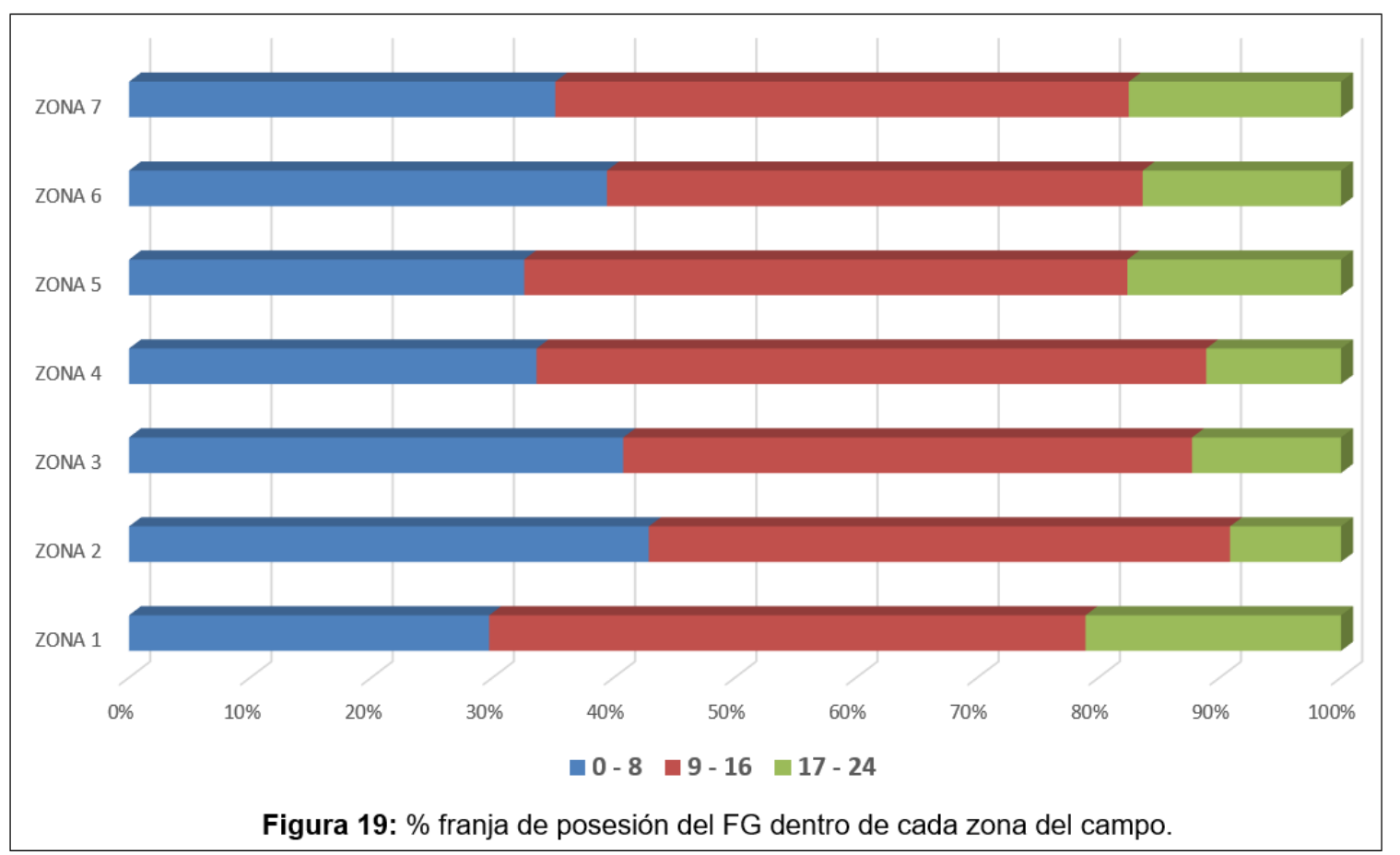


Si observamos el reparto dentro de cada franja de posesión según zona (figuras 20, 21 y

22) podemos ver como el mayor número de lanzamientos de las tres franjas temporales se ejecutan en la zona 1, lo cual es lógico dado que, como ya hemos demostrado, es la zona desde donde más se lanza y también la más efectiva, por lo que se busca finalizar en ella. Las tres franjas coinciden también, y en un porcentaje similar, en cuanto a la

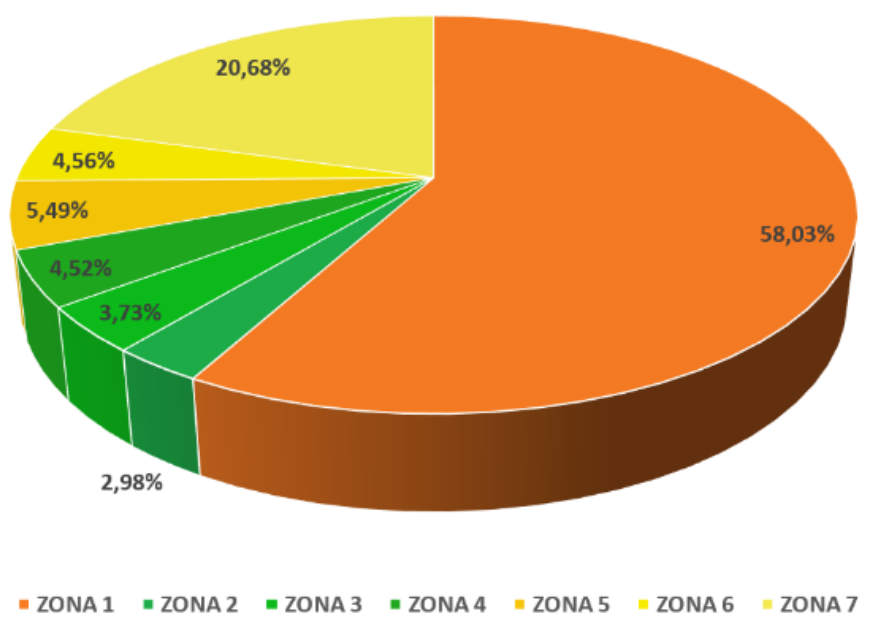

Figura 20: \% de FG de la franja de posesión 17-24 según zona del campo. zona 7 , la segunda zona desde donde más se lanza.
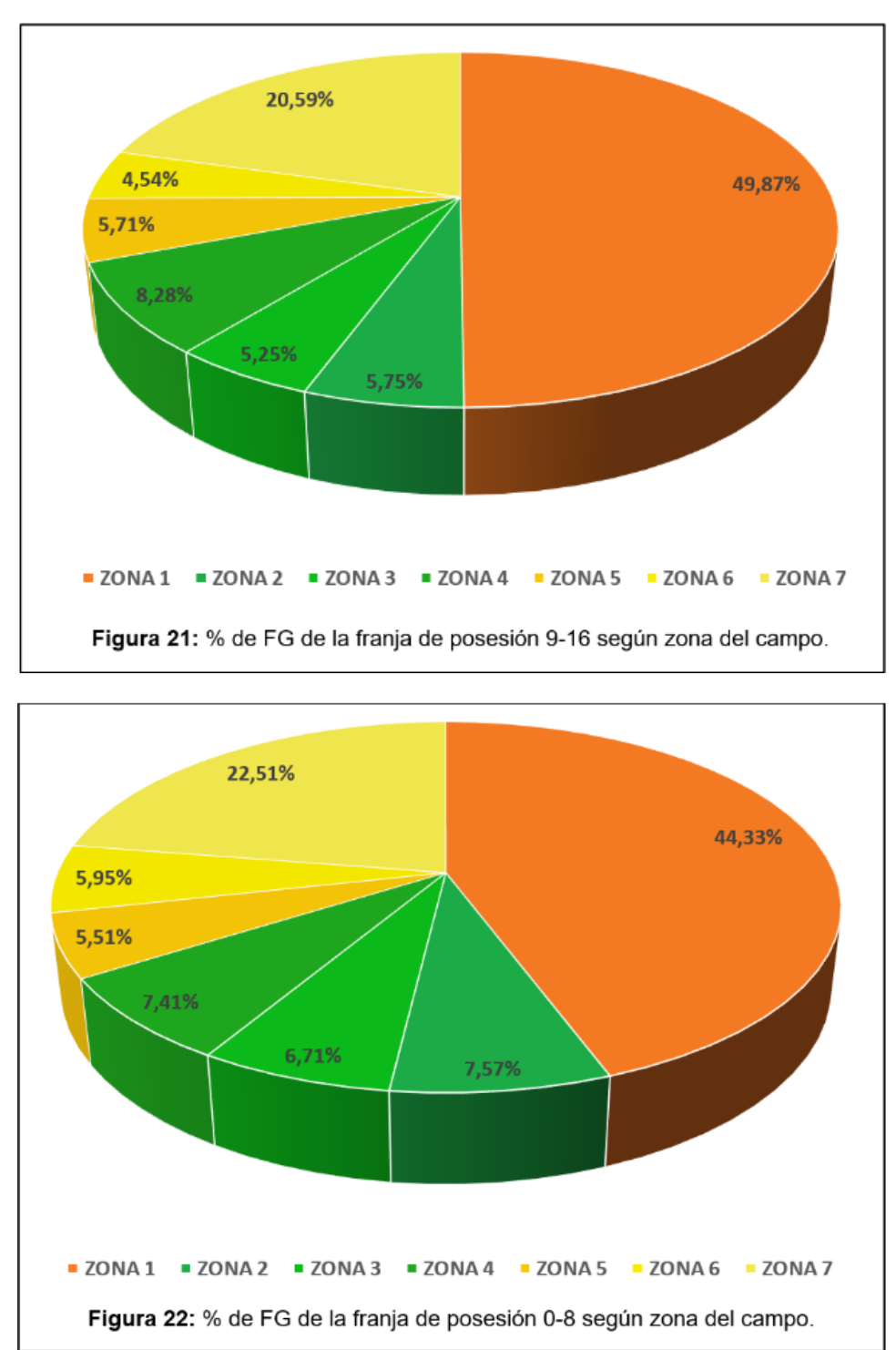


\subsubsection{Zona del campo y tipo de tiro}

El análisis de este par de variables desde una perspectiva global, sobre el total de FG (tabla 23), nos muestra como la ejecución de los tiros normales y buenos en las zonas 1 y 7 dominan de forma destacada sobre cualquier otro tipo de combinación de categorías.

\begin{tabular}{|c|c|c|c|c|c|c|c|}
\cline { 2 - 8 } \multicolumn{1}{c|}{} & ZONA 1 & ZONA 2 & ZONA 3 & ZONA 4 & ZONA 5 & ZONA 6 & ZONA 7 \\
\hline Buen tiro & $12,30 \%$ & $1,35 \%$ & $1,32 \%$ & $3,58 \%$ & $3,85 \%$ & $3,36 \%$ & $11,98 \%$ \\
\hline Tiro normal & $31,11 \%$ & $3,05 \%$ & $3,00 \%$ & $3,20 \%$ & $1,52 \%$ & $1,40 \%$ & $6,46 \%$ \\
\hline Mal tiro & $6,09 \%$ & $1,45 \%$ & $1,14 \%$ & $0,53 \%$ & $0,24 \%$ & $0,25 \%$ & $2,80 \%$ \\
\hline
\end{tabular}

Tabla 23: \% de FG entre las variables zona del campo y tipo de tiro.

En ambas zonas también se dan mayores porcentajes de malos tiros que en el resto, especialmente en la zona 1 , siendo donde mayor número de malos tiros se producen.

La tabla 24 y la figura 23 nos muestran los porcentajes de los tipos de tiro dentro de cada zona, viendo como las zonas 1, 2 y 3 tienen los porcentajes más bajos de buenos tiros, lo cual sigue la logica de que en las zonas cercanas al aro siempre hay una mayor oposición y un menor espacio de juego. Esto lleva a que en las zonas 2 y 3 se den los porcentajes más altos de malos tiros. La zona 1 tiene un porcentaje más bajo en este aspecto, seguramente debido a que una gran parte de los lanzamientos son tras un rebote, generando así en la mayoría de ocasiones un tiro normal.

\begin{tabular}{|c|c|c|c|c|c|c|c|}
\cline { 2 - 8 } \multicolumn{1}{c|}{} & ZONA 1 & ZONA 2 & ZONA 3 & ZONA 4 & ZONA 5 & ZONA 6 & ZONA 7 \\
\hline Buen tiro & $24,84 \%$ & $23,04 \%$ & $24,23 \%$ & $48,98 \%$ & $68,66 \%$ & $67,01 \%$ & $56,38 \%$ \\
\hline Tiro normal & $62,86 \%$ & $52,15 \%$ & $54,96 \%$ & $43,78 \%$ & $27,07 \%$ & $27,96 \%$ & $30,43 \%$ \\
\hline Mal tiro & $12,30 \%$ & $24,81 \%$ & $20,80 \%$ & $7,24 \%$ & $4,26 \%$ & $5,03 \%$ & $13,19 \%$ \\
\hline TOTAL & $100,00 \%$ & $100,00 \%$ & $100,00 \%$ & $100,00 \%$ & $100,00 \%$ & $100,00 \%$ & $100,00 \%$ \\
\hline \multicolumn{7}{c|}{ Tabla 24: \% tipo de FG dentro de cada zona del campo. }
\end{tabular}

La zona 4 sigue mostrandose como una muy buena zona con un porcentaje de buenos tiros de casi el $49 \%$ y con tan solo un 7,24\% de malos tiros. Debemos recordar que era la zona con segundo mejor porcentaje de efectividad, por lo que sin duda será un área del campo muy importante de cara a la aplicación practica.

En cuanto al exterior del perímetro observamos como en las tres zonas se da un muy buen porcentaje de buenos tiros, siendo en las zonas laterales significativamente mayor, al igual que cuentan con un porcentaje de malos tiros menor. Esto es debido a que en la zona 7 se realizan un mayor número de malos tiros a causa de las últimas jugadas o últimos 
segundos de posesión, donde habitualmente se acaba con tiros forzados tras jugada personal, pase o bloqueo directo.

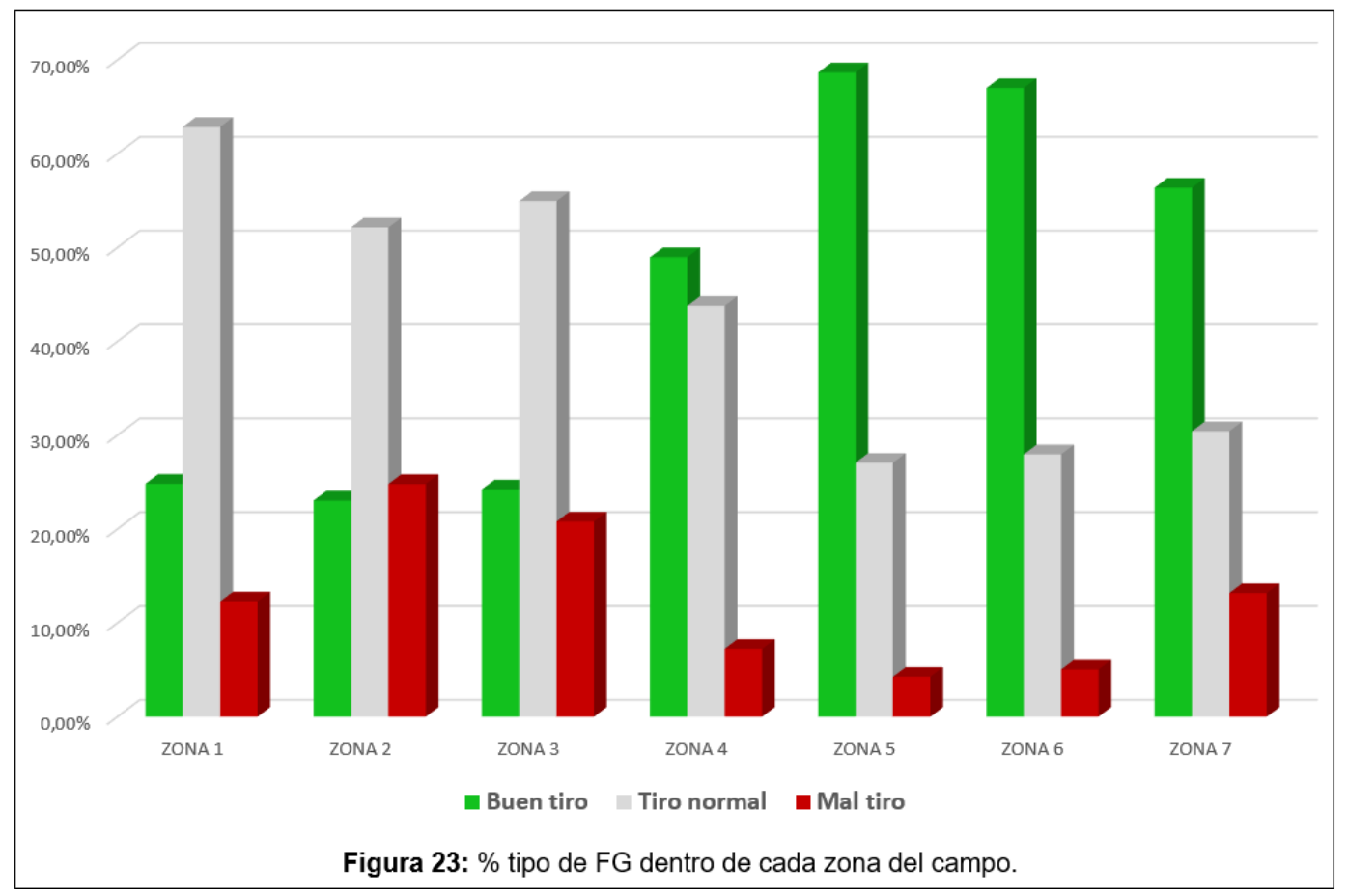

El orden de mayor a menor porcentaje de buenos y malos FG según zona es el siguiente:

Buen tiro: Zona 5, Zona 6, Zona 7, Zona 4, Zona 1, Zona 3 y Zona 2.

Mal tiro: Zona 2, Zona 3, Zona 7, Zona 1, Zona 4, Zona 6 y Zona 5.

Si nos centramos en como se reparten el total de buenos o malos FG por las zonas del campograma (figuras 24 y 25; tabla 25) observamos como en los buenos tiros se sigue la dinámica de las zonas centrales (zona 1, 4, y 7), aunque en este caso las zonas laterales del exterior del perímetro son muy similares a la zona 4. Lo que si destaca claramente, y con unos porcentajes casi idénticos, son las zonas 1 y 7 como zonas con mayor número de buenos FG.

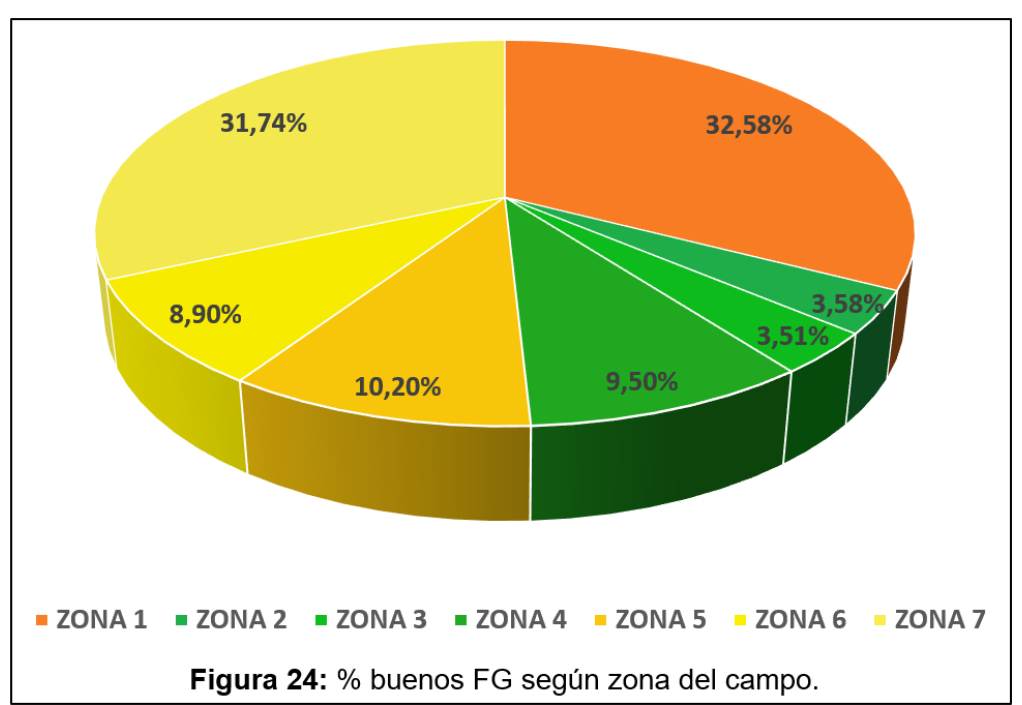


También se mantiene la superioridad de $\mathrm{n}^{\mathrm{o}}$ de lanzamientos del lado izquierdo sobre el derecho (zona 2 > zona 3; zona 5 > zona 6). Debemos destacar como en las zonas 2 y 3 apenas se ejecutan buenos tiros.

\begin{tabular}{|c|c|c|c|c|c|c|c|c|}
\cline { 2 - 8 } \multicolumn{1}{c|}{} & ZONA 1 & ZONA 2 & ZONA 3 & ZONA 4 & ZONA 5 & ZONA 6 & ZONA 7 & TOTAL \\
\hline Buen tiro & $32,58 \%$ & $3,58 \%$ & $3,51 \%$ & $9,50 \%$ & $10,20 \%$ & $8,90 \%$ & $31,74 \%$ & $100,00 \%$ \\
\hline Tiro normal & $62,53 \%$ & $6,14 \%$ & $6,04 \%$ & $6,44 \%$ & $3,05 \%$ & $2,82 \%$ & $12,99 \%$ & $100,00 \%$ \\
\hline Mal tiro & $48,71 \%$ & $11,62 \%$ & $9,09 \%$ & $4,24 \%$ & $1,91 \%$ & $2,01 \%$ & $22,42 \%$ & $100,00 \%$ \\
\hline
\end{tabular}

Tabla 25: \% de cada tipo de FG según zona del campo.

Centrándonos en los malos tiros podemos ver como en la zona 1 es donde en mayor porcentaje se dan y de forma muy superior, pues dobla a la siguiente zona que sería la 7. Cabe destacar el mínimo porcentaje de malos tiros de las zonas 5 y 6 , seguidas de cerca por la zona 4.

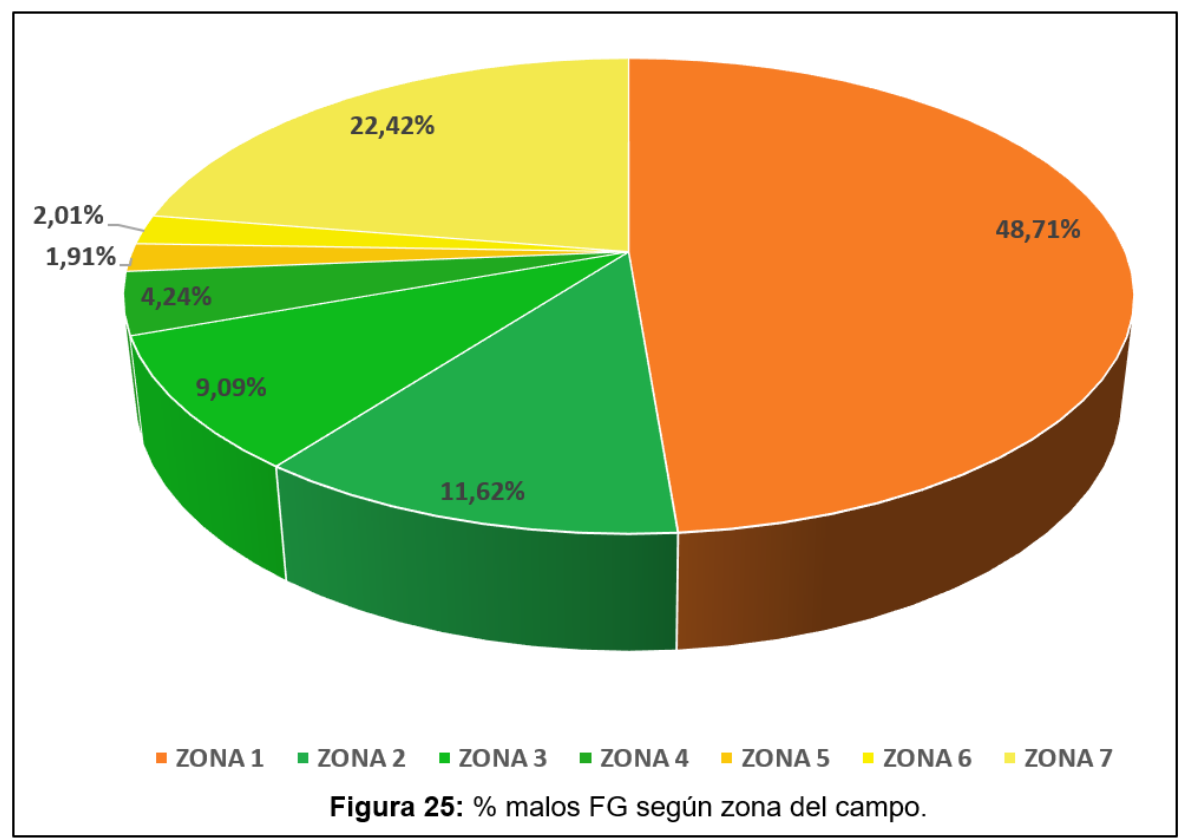




\subsubsection{Zona del campo y ventaja/desventaja}

En qué zonas del campo se efectúan los lanzamientos en función de si se va por encima

o por debajo en el marcador son unos resultados con un gran potencial para su aplicación práctica, pero tras extraer los datos, no se han obtenido diferencias significativas como podemos apreciar en las figuras 26 y 27.

En la tabla 26 vemos como tanto cuando se va por encima, empate o por debajo en el marcador se sigue una misma dinámica, siendo las zonas 1, 7 y 4, en ese orden, las

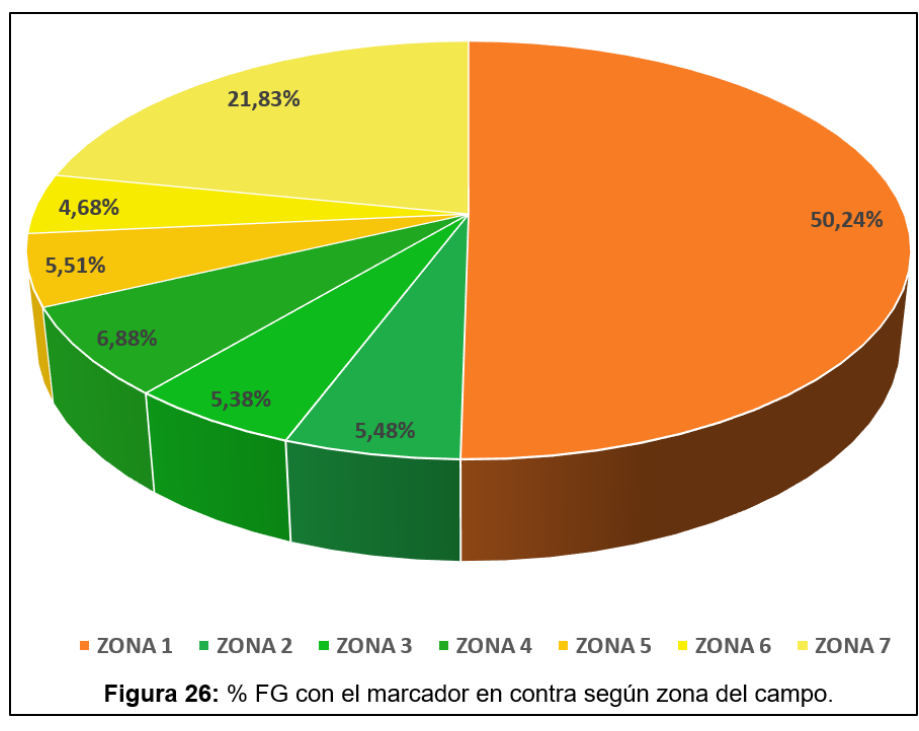
más utilizadas.

Aunque sea de forma mínima, si se observa un aumento de la zona 1 y 7 cuando se va perdiendo en comparación a las otras posibles situaciones del marcador, lo cual es lógico, pues por un lado se trata de la zona más cercana al aro, y como ya hemos demostrado antes, la más efectiva; y por otro lado, se trata de la zona centrada del exterior del perímetro y con mayor espacio para sumar 3 puntos y acercarse en el marcador.

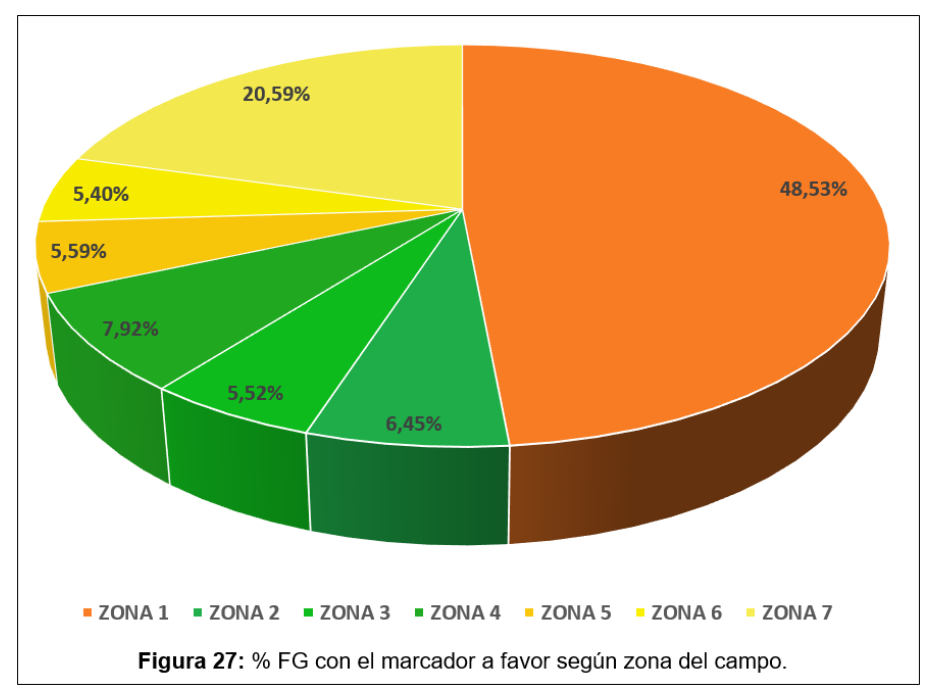

Figura 27: \% FG con el marcador a favor según zona del campo.

\begin{tabular}{|c|c|c|c|c|c|c|c|c|}
\cline { 2 - 9 } \multicolumn{1}{c|}{} & ZONA 1 & ZONA 2 & ZONA 3 & ZONA 4 & ZONA 5 & ZONA 6 & ZONA 7 & TOTAL \\
\hline Marcador (+) & $48,53 \%$ & $6,45 \%$ & $5,52 \%$ & $7,92 \%$ & $5,59 \%$ & $5,40 \%$ & $20,59 \%$ & $100,00 \%$ \\
\hline Empate & $48,73 \%$ & $5,77 \%$ & $5,77 \%$ & $7,61 \%$ & $6,39 \%$ & $5,60 \%$ & $20,12 \%$ & $100,00 \%$ \\
\hline Marcador (-) & $50,24 \%$ & $5,48 \%$ & $5,38 \%$ & $6,88 \%$ & $5,51 \%$ & $4,68 \%$ & $21,83 \%$ & $100,00 \%$ \\
\hline
\end{tabular}

Tabla 26: \% de FG con el marcador a favor, igualado y en contra según zona del campo. 


\subsubsection{Zona del campo y precedente}

La tabla 27 y la figura 28 nos muestran el análisis de estas dos variables de forma global, viendo así como la mayor incidencia la tiene la combinación de la categoría "zona 1" con todas las categorías de la variable "precedente", a excepción de la categoría "pase", que se da más en la zona 7.

\begin{tabular}{|c|c|c|c|c|c|c|c|}
\cline { 2 - 8 } \multicolumn{1}{c|}{} & ZONA 1 & ZONA 2 & ZONA 3 & ZONA 4 & ZONA 5 & ZONA 6 & ZONA 7 \\
\hline Contraataque & $2,00 \%$ & $0,01 \%$ & $0,04 \%$ & $0,03 \%$ & $0,08 \%$ & $0,07 \%$ & $0,18 \%$ \\
\hline Bloqueo Directo & $7,27 \%$ & $0,90 \%$ & $0,94 \%$ & $2,63 \%$ & $0,21 \%$ & $0,11 \%$ & $4,29 \%$ \\
\hline Pase & $8,90 \%$ & $1,45 \%$ & $1,59 \%$ & $1,98 \%$ & $4,66 \%$ & $4,26 \%$ & $12,82 \%$ \\
\hline Jugada Personal & $23,88 \%$ & $3,39 \%$ & $2,80 \%$ & $2,65 \%$ & $0,54 \%$ & $0,50 \%$ & $3,65 \%$ \\
\hline Robo & $2,41 \%$ & $0,04 \%$ & $0,05 \%$ & $0,02 \%$ & $0,10 \%$ & $0,03 \%$ & $0,19 \%$ \\
\hline Rebote & $5,04 \%$ & $0,06 \%$ & $0,05 \%$ & $0,02 \%$ & $0,01 \%$ & $0,04 \%$ & $0,12 \%$ \\
\hline
\end{tabular}

Tabla 27: \% de FG entre las variables zona del campo y precedente.

También podemos ver como teniendo en cuenta todas las zonas, la jugada personal y el pase tienen la mayor incidencia, sumando cada una más de un $35 \%$ sobre el total, seguidas del bloqueo con algo más de un $16 \%$.

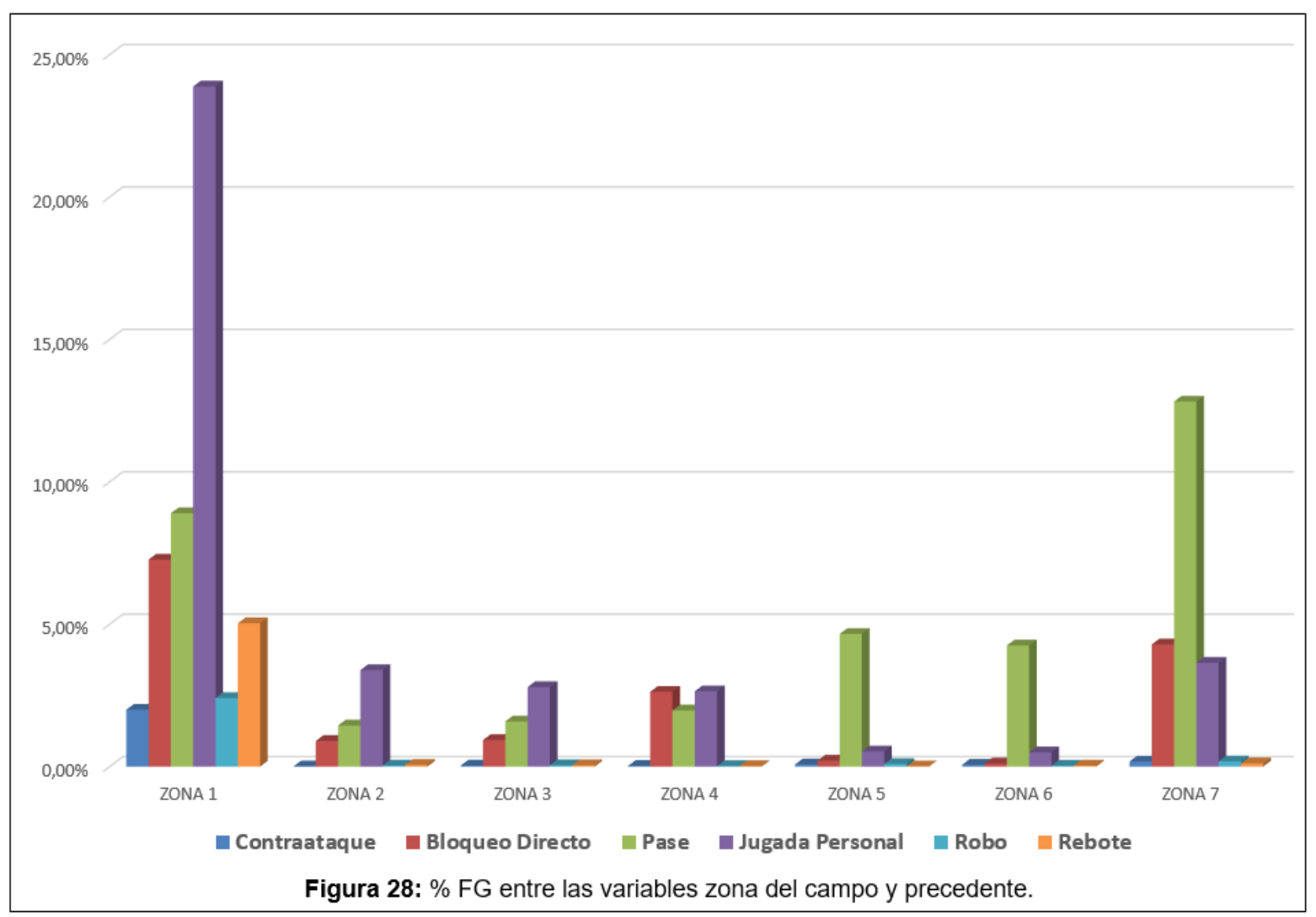


Si nos centramos en la incidencia de los precedentes dentro de cada zona (tabla 28) observamos como en las zonas 1, 2 y 3 destaca categóricamente la jugada personal como precedente. El pase y el bloqueo directo ocupan el segundo y tercer lugar respectivamente en dichas zonas.

\begin{tabular}{|c|c|c|c|c|c|c|c|}
\cline { 2 - 8 } \multicolumn{1}{c|}{} & ZONA 1 & ZONA 2 & ZONA 3 & ZONA 4 & ZONA 5 & ZONA 6 & ZONA 7 \\
\hline Contraataque & $4,04 \%$ & $0,22 \%$ & $0,71 \%$ & $0,35 \%$ & $1,50 \%$ & $1,42 \%$ & $0,85 \%$ \\
\hline Bloqueo Directo & $14,69 \%$ & $15,44 \%$ & $17,14 \%$ & $35,92 \%$ & $3,80 \%$ & $2,19 \%$ & $20,21 \%$ \\
\hline Pase & $17,98 \%$ & $24,70 \%$ & $29,08 \%$ & $27,01 \%$ & $83,18 \%$ & $84,92 \%$ & $60,33 \%$ \\
\hline Jugada Personal & $48,25 \%$ & $57,88 \%$ & $51,18 \%$ & $36,19 \%$ & $9,56 \%$ & $10,05 \%$ & $17,17 \%$ \\
\hline Robo & $4,87 \%$ & $0,66 \%$ & $0,95 \%$ & $0,26 \%$ & $1,73 \%$ & $0,64 \%$ & $0,88 \%$ \\
\hline Rebote & $10,18 \%$ & $1,10 \%$ & $0,95 \%$ & $0,26 \%$ & $0,23 \%$ & $0,77 \%$ & $0,55 \%$ \\
\hline TOTAL & $100,00 \%$ & $100,00 \%$ & $100,00 \%$ & $100,00 \%$ & $100,00 \%$ & $100,00 \%$ & $100,00 \%$ \\
\hline
\end{tabular}

Tabla 28: \% de precedente del FG dentro de cada zona del campo.

Por el contrario, vemos como en el exterior del perímetro predomina de forma clara el pase como precedente. La zona 7, en comparación a sus zonas exteriores contiguas, cuenta con un mayor porcentaje de bloqueo directo y jugada personal.

La zona 4 se muestra como una zona más equilibrada entre tres precedentes de forma casi exclusiva, desmarcándose ligeramente el bloqueo directo y la jugada personal por encima del pase.

En cuanto a como se reparte el total de cada precedente en función de la zona del campo (tabla 29), vemos como casi todos los precedentes se efectúan en mayor porcentaje en la zona 1. La única excepción se muestra en el pase, el cual se efectúa más en la zona 7. Esto tiene sentido, pues por la lógica interna del baloncesto siempre será más complejo un pase al interior de la zona, como área de alta efectividad, que un pase hacia el exterior alejándose del aro.

\begin{tabular}{|c|c|c|c|c|c|c|c|c|}
\cline { 2 - 9 } \multicolumn{1}{c|}{} & ZONA 1 & ZONA 2 & ZONA 3 & ZONA 4 & ZONA 5 & ZONA 6 & ZONA 7 & TOTAL \\
\hline Contraataque & $82,89 \%$ & $0,53 \%$ & $1,60 \%$ & $1,07 \%$ & $3,48 \%$ & $2,94 \%$ & $7,49 \%$ & $100,00 \%$ \\
\hline Bloqueo Directo & $44,45 \%$ & $5,53 \%$ & $5,72 \%$ & $16,07 \%$ & $1,30 \%$ & $0,67 \%$ & $26,25 \%$ & $100,00 \%$ \\
\hline Pase & $24,96 \%$ & $4,06 \%$ & $4,46 \%$ & $5,54 \%$ & $13,08 \%$ & $11,94 \%$ & $35,96 \%$ & $100,00 \%$ \\
\hline Jugada Personal & $63,85 \%$ & $9,06 \%$ & $7,48 \%$ & $7,08 \%$ & $1,43 \%$ & $1,35 \%$ & $9,75 \%$ & $100,00 \%$ \\
\hline Robo & $84,97 \%$ & $1,37 \%$ & $1,82 \%$ & $0,68 \%$ & $3,42 \%$ & $1,14 \%$ & $6,61 \%$ & $100,00 \%$ \\
\hline Rebote & $94,32 \%$ & $1,21 \%$ & $0,97 \%$ & $0,36 \%$ & $0,24 \%$ & $0,73 \%$ & $2,18 \%$ & $100,00 \%$ \\
\hline
\end{tabular}

Tabla 29: \% de cada precedente del FG según zona del campo. 
Siguiendo con el pase, podemos observar como en la zona exterior del perímetro se ejecuta con más asiduidad en comparación con las zonas interiores, a excepción de la pintura. En cuanto a las jugadas personales y bloqueos directos como precedente, su realización en las zonas 5 y 6 es casi anecdótico. La falta de espacio en dichas zonas podría ser la razón. Otro dato que podemos entrever de los resultados extraídos es como el bloqueo directo tiende a usarse en mayor medida en las zonas centrales (zona 1, 4 y 7).

\subsubsection{Zona del campo y jugadores implicados}

El número de jugadores que entran en contacto con el balón en cada jugada es muy interesante para la posterior aplicación práctica, pues los ejercicios, ya sean ofensivos o defensivos, los podremos acercar a la realidad del juego limitando los jugadores involucrados.

La siguiente tabla (tabla 30) recoge los porcentajes de la combinación de las variables “zona del campo" y “jugadores implicados” sobre el total de FG realizados. En ella vemos como el porcentaje de combinación de la zona 1 con todas las categorías de la variable "jugadores implicados" es superior al resto. Tan solo la zona 7 la sigue, aunque de lejos.

\begin{tabular}{|c|c|c|c|c|c|c|c|}
\cline { 2 - 8 } \multicolumn{1}{c|}{} & ZONA 1 & ZONA 2 & ZONA 3 & ZONA 4 & ZONA 5 & ZONA 6 & ZONA 7 \\
\hline Uno & $13,70 \%$ & $0,76 \%$ & $0,96 \%$ & $1,23 \%$ & $0,12 \%$ & $0,19 \%$ & $2,74 \%$ \\
\hline Dos & $15,57 \%$ & $1,92 \%$ & $1,74 \%$ & $2,38 \%$ & $2,14 \%$ & $1,74 \%$ & $8,43 \%$ \\
\hline Tres & $13,12 \%$ & $1,98 \%$ & $1,76 \%$ & $2,44 \%$ & $1,93 \%$ & $1,66 \%$ & $6,21 \%$ \\
\hline Cuatro & $5,88 \%$ & $0,99 \%$ & $0,84 \%$ & $1,05 \%$ & $1,14 \%$ & $1,21 \%$ & $3,27 \%$ \\
\hline Cinco & $1,23 \%$ & $0,19 \%$ & $0,16 \%$ & $0,22 \%$ & $0,27 \%$ & $0,21 \%$ & $0,61 \%$ \\
\hline
\end{tabular}

Tabla 30: \% de FG entre las variables zona del campo y jugadores implicados.

La suma de las categorías "dos" y "tres" jugadores en combinación con todas las categorías de la variable "zona" nos indica su gran incidencia sobre el juego con casi un $34 \%$ y algo más de un $29 \%$ respectivamente.

En la figura 29 se muestra el porcentaje acumulado sobre el total de FG realizados en función de ambas variables, pudiendo ver su mayor o menor incidencia y como escalan. 


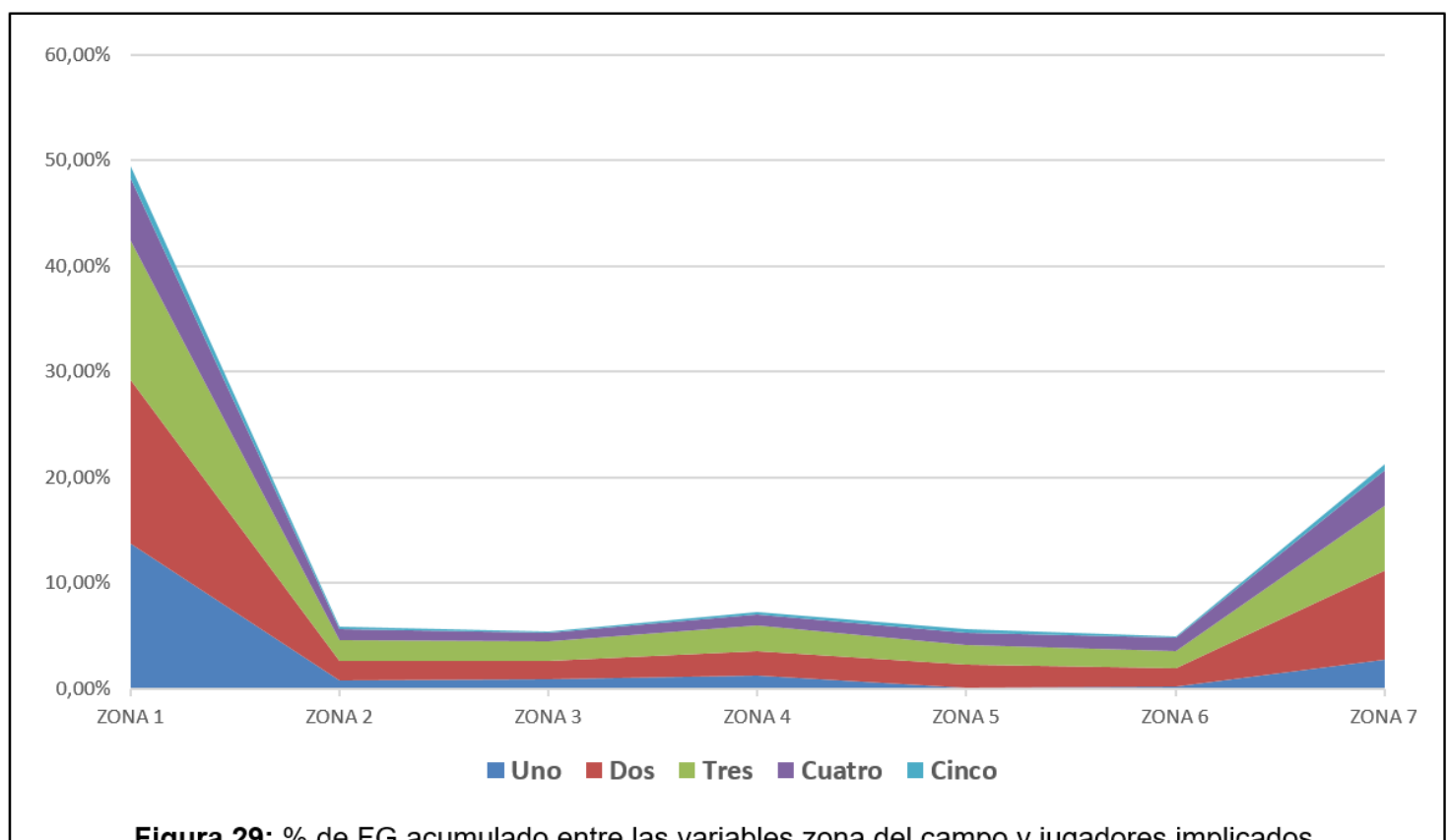

Figura 29: \% de FG acumulado entre las variables zona del campo y jugadores implicados.

Centrándonos en los jugadores implicados dentro de cada zona (tabla 31) podemos ver de forma clara como en todas las zonas del campo el número de jugadores que suelen entrar en contacto con el balón son dos o tres. Esto significa que el ataque en baloncesto podría resumirse en acciones de $2 \times 2$ o $3 \times 3$.

En la zona 1, además de dos y tres, también la participación de un solo jugador tiene un porcentaje muy alto. Esto es debido a los FG realizados tras rebote, los cuales normalmente se producen en la zona 1.

\begin{tabular}{|c|c|c|c|c|c|c|c|}
\cline { 2 - 8 } \multicolumn{1}{c|}{} & ZONA 1 & ZONA 2 & ZONA 3 & ZONA 4 & ZONA 5 & ZONA 6 & ZONA 7 \\
\hline Uno & $27,68 \%$ & $13,01 \%$ & $17,61 \%$ & $16,86 \%$ & $2,07 \%$ & $3,74 \%$ & $12,89 \%$ \\
\hline Dos & $31,45 \%$ & $32,86 \%$ & $31,80 \%$ & $32,48 \%$ & $38,25 \%$ & $34,79 \%$ & $39,67 \%$ \\
\hline Tres & $26,50 \%$ & $33,85 \%$ & $32,27 \%$ & $33,36 \%$ & $34,45 \%$ & $33,12 \%$ & $29,21 \%$ \\
\hline Cuatro & $11,87 \%$ & $16,98 \%$ & $15,37 \%$ & $14,30 \%$ & $20,39 \%$ & $24,23 \%$ & $15,38 \%$ \\
\hline Cinco & $2,49 \%$ & $3,31 \%$ & $2,96 \%$ & $3,00 \%$ & $4,84 \%$ & $4,12 \%$ & $2,86 \%$ \\
\hline TOTAL & $100,00 \%$ & $100,00 \%$ & $100,00 \%$ & $100,00 \%$ & $100,00 \%$ & $100,00 \%$ & $100,00 \%$ \\
\hline
\end{tabular}

Tabla 31: \% de FG dentro de cada zona del campo según jugadores implicados.

En cuanto a las zonas 5 y 6, podemos ver como apenas se dan FG en los que solo haya intervenido un jugador. Por otro lado, si nos fijamos dentro de cada zona en las acciones en las que intervienen 5 jugadores, estas son muy escasas en comparación al resto. 


\subsubsection{Zona del campo y QT}

La influencia de los periodos de juego sobre la dinamica del partido es debida a que se trata de una localización temporal respecto del final del encuentro. La tabla 32 muestra la distribución porcentual sobre el total de FG de las variables "zona del campo" y "QT", mostrando como hay un reparto similar a lo largo del encuentro. Aún así, podemos observar como según avanzan los cuartos se van produciendo menos FG desde la zona 1. Este descenso es observable en todas las zonas interiores del perímetro. En las zonas exteriores se mantiene relativamente constante, dandose en la zona 7 una mayor incidencia en los segundos cuartos de cada mitad, más especialmente en el último cuarto.

\begin{tabular}{|c|c|c|c|c|c|c|c|}
\cline { 2 - 8 } \multicolumn{1}{c|}{} & ZONA 1 & ZONA 2 & ZONA 3 & ZONA 4 & ZONA 5 & ZONA 6 & ZONA 7 \\
\hline 10 QT & $12,94 \%$ & $1,65 \%$ & $1,48 \%$ & $2,37 \%$ & $1,61 \%$ & $1,24 \%$ & $4,73 \%$ \\
\hline 20 QT & $12,52 \%$ & $1,55 \%$ & $1,41 \%$ & $1,77 \%$ & $1,39 \%$ & $1,25 \%$ & $5,41 \%$ \\
\hline 3 QT & $12,13 \%$ & $1,41 \%$ & $1,32 \%$ & $1,74 \%$ & $1,29 \%$ & $1,29 \%$ & $5,24 \%$ \\
\hline 40 QT & $11,92 \%$ & $1,24 \%$ & $1,25 \%$ & $1,44 \%$ & $1,30 \%$ & $1,23 \%$ & $5,87 \%$ \\
\hline
\end{tabular}

Tabla 32: \% de FG entre las variables zona del campo y QT.

Al centrarnos en el porcentaje de FG según QT dentro de cada zona (figura 30 y tabla 33) vemos como en todas ellas el reparto es similar, no observándose diferencias significativas. Pero si nos fijamos detenidamente, se corroboran las apreciaciones del análisis sobre el total, viéndose como en todas las zonas interiores del perímetro disminuye progresivamente el porcentaje de FG según avanzan los QT, no siendo extensible dicho patrón al exterior del perímetro.

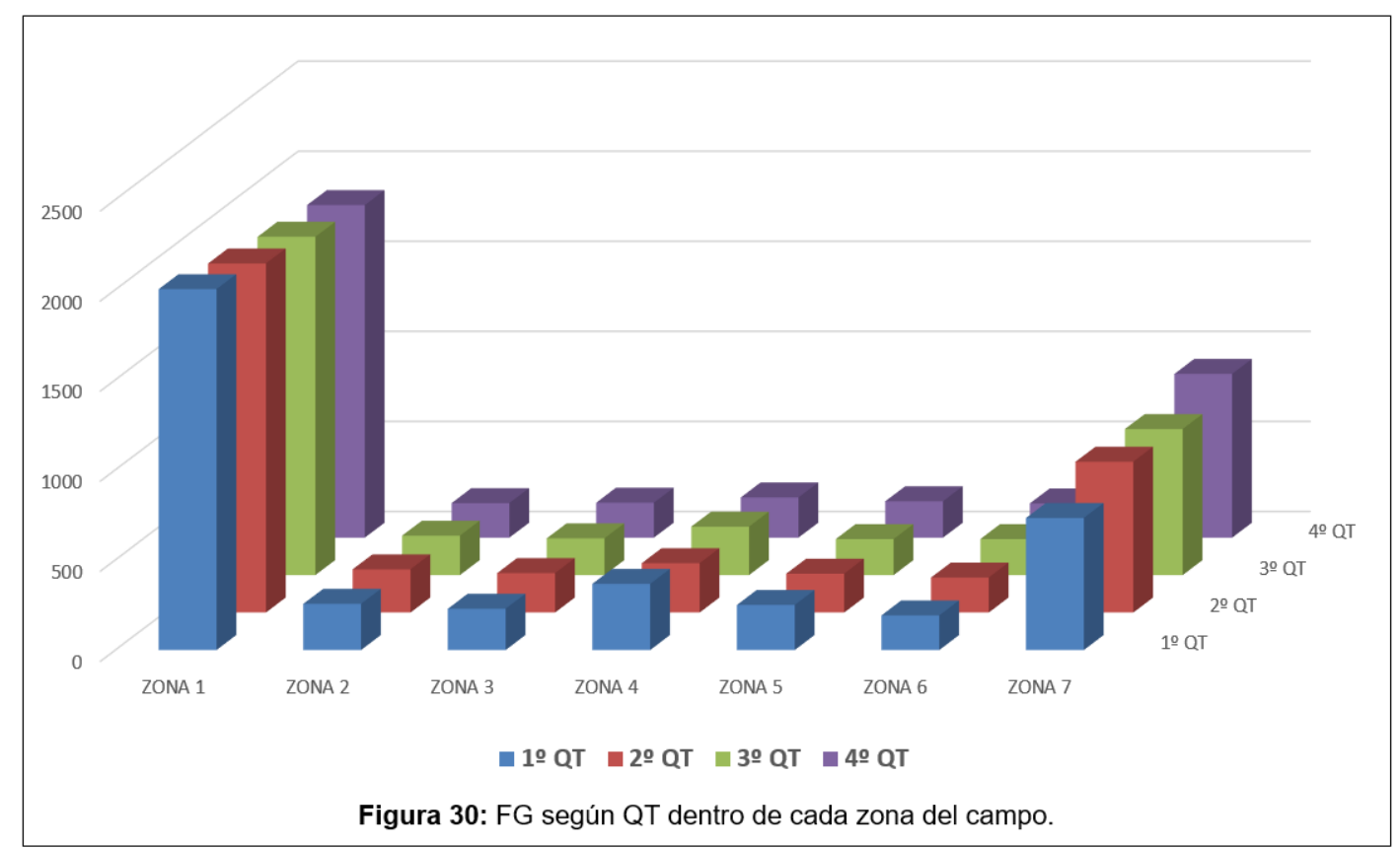


En la zona 7 observamos como en los segundos cuartos de cada mitad ( $2^{\circ} \mathrm{QT}$ y $\left.4^{\circ} \mathrm{QT}\right)$ el porcentaje de FG supera al de los primeros. Además, se da una gran diferencia entre el $1^{\circ}$ y $4^{\circ}$ QT. En el primero se realizan menos lanzamientos desde esa zona, quizás por no estar aún inmersos al $100 \%$ en el partido, lo que se compensa con mayor porcentaje de FG desde la zona 4 que en otros cuartos; mientras que en la fase definitiva del encuentro se aumenta el porcentaje desde la zona 7.

\begin{tabular}{|l|c|c|c|c|c|c|c|}
\cline { 2 - 8 } \multicolumn{1}{c|}{} & ZONA 1 & ZONA 2 & ZONA 3 & ZONA 4 & ZONA 5 & ZONA 6 & ZONA 7 \\
\hline 10 QT & $26,13 \%$ & $28,22 \%$ & $27,07 \%$ & $32,39 \%$ & $28,80 \%$ & $24,74 \%$ & $22,28 \%$ \\
\hline 20 QT & $25,28 \%$ & $26,46 \%$ & $25,89 \%$ & $24,18 \%$ & $24,88 \%$ & $25 \%$ & $25,44 \%$ \\
\hline 39 QT & $24,50 \%$ & $24,15 \%$ & $24,11 \%$ & $23,74 \%$ & $23,04 \%$ & $25,77 \%$ & $24,65 \%$ \\
\hline 4\% QT & $24,08 \%$ & $21,17 \%$ & $22,93 \%$ & $19,68 \%$ & $23,27 \%$ & $24,48 \%$ & $27,63 \%$ \\
\hline TOTAL & $100,00 \%$ & $100,00 \%$ & $100,00 \%$ & $100,00 \%$ & $100,00 \%$ & $100,00 \%$ & $100,00 \%$ \\
\hline
\end{tabular}

Tabla 33: \% de FG según QT dentro de cada zona del campo. 


\subsubsection{Zona del campo y momento especial}

Como podemos ver en las figuras 31 y 32 , las zonas desde las que se ejecutan los FG tras un tiempo muerto o una última jugada parecen a priori muy distintos, pero si observamos los datos en la tabla 34 , estos son muy similares en todas las zonas, de hecho, en ambos momentos las zonas desde donde más FG se ejecutan son la zona 1 y la 7 con gran diferencia sobre el resto, pero los porcentajes entre esas dos zonas y momentos especiales parecen estar invertidos.

Tras un tiempo muerto, y su correspondiente charla táctica, se ejecutan más FG desde la zona 1, pues es la más cercana al aro y por tanto la más efectiva. Le seguiría la zona 7 , zona más allá de la línea de tres, central y espaciosa para finalizar la posesión con un buen lanzamiento de 3 puntos.
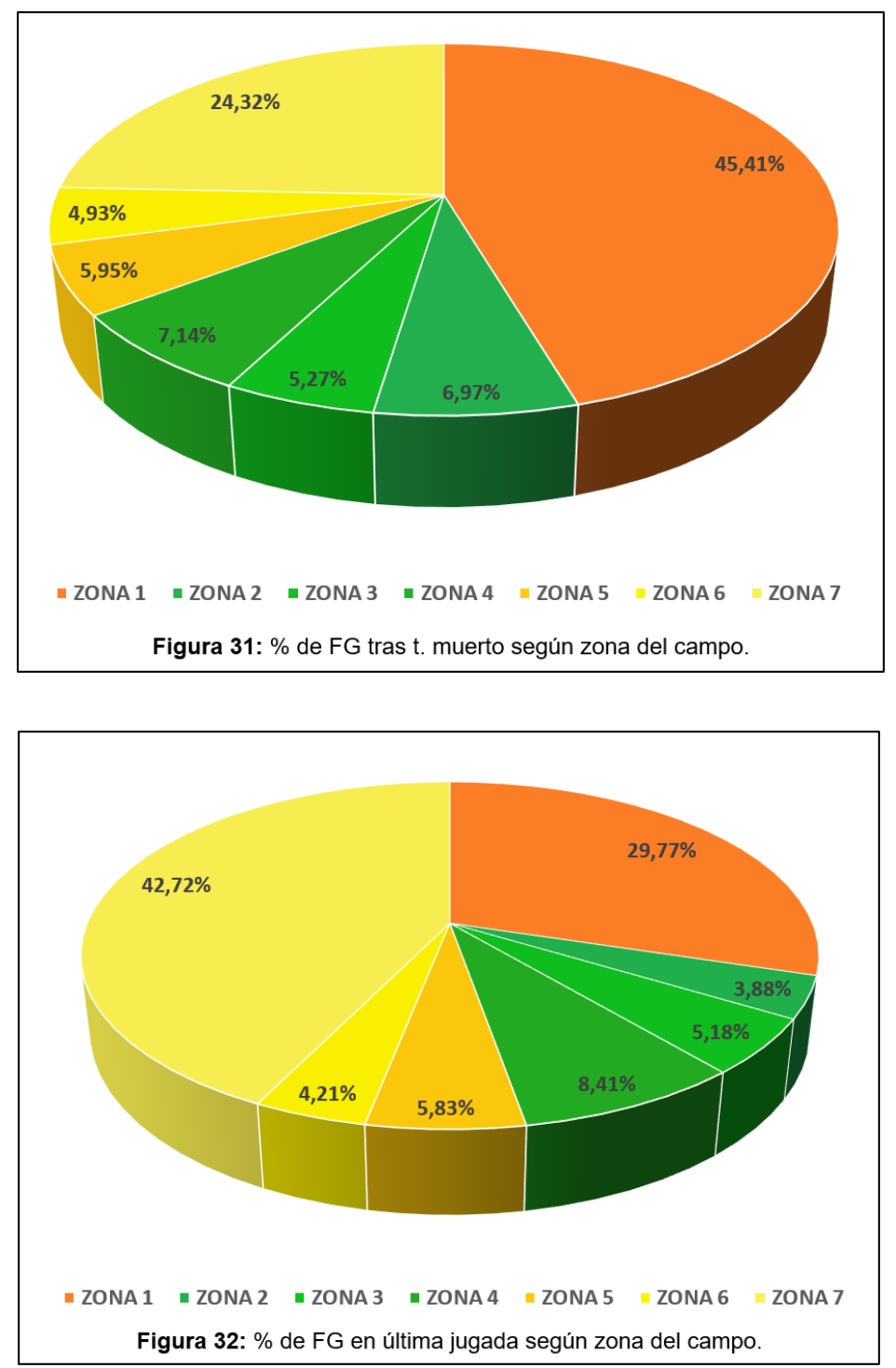

En las últimas jugadas de cuarto, la zona desde la que más se finaliza es la 7, tras la cual estaría la zona 1 y 4 respectivamente, zonas centrales.

\begin{tabular}{|c|c|c|c|c|c|c|c|c|}
\cline { 2 - 9 } \multicolumn{1}{c|}{} & ZONA 1 & ZONA 2 & ZONA 3 & ZONA 4 & ZONA 5 & ZONA 6 & ZONA 7 & TOTAL \\
\hline Tiempo Muerto & $45,41 \%$ & $6,97 \%$ & $5,27 \%$ & $7,14 \%$ & $5,95 \%$ & $4,93 \%$ & $24,32 \%$ & $100,00 \%$ \\
\hline Última Jugada & $29,77 \%$ & $3,88 \%$ & $5,18 \%$ & $8,41 \%$ & $5,83 \%$ & $4,21 \%$ & $42,72 \%$ & $100,00 \%$ \\
\hline
\end{tabular}

Tabla 34: \% de FG de cada m. especial según zona del campo. 


\subsection{RESULTADO}

A la hora de hablar exclusivamente de los resultados de los FG, la figura 33 nos muestra su reparto porcentualmente. En el vemos como los fallos y las canastas de 2 puntos son las más comunes, seguidas de los fallos y las canastas de 3 puntos en ese orden. Las canastas y adicional tienen, como era de esperar, unos porcentajes muy bajos, siendo casi anecdóticos los resultados de 3 puntos y adicional.

Las faltas+2 adic. son más comunes, lo cual es lógico dado que cualquier falta cuando el equipo tiene

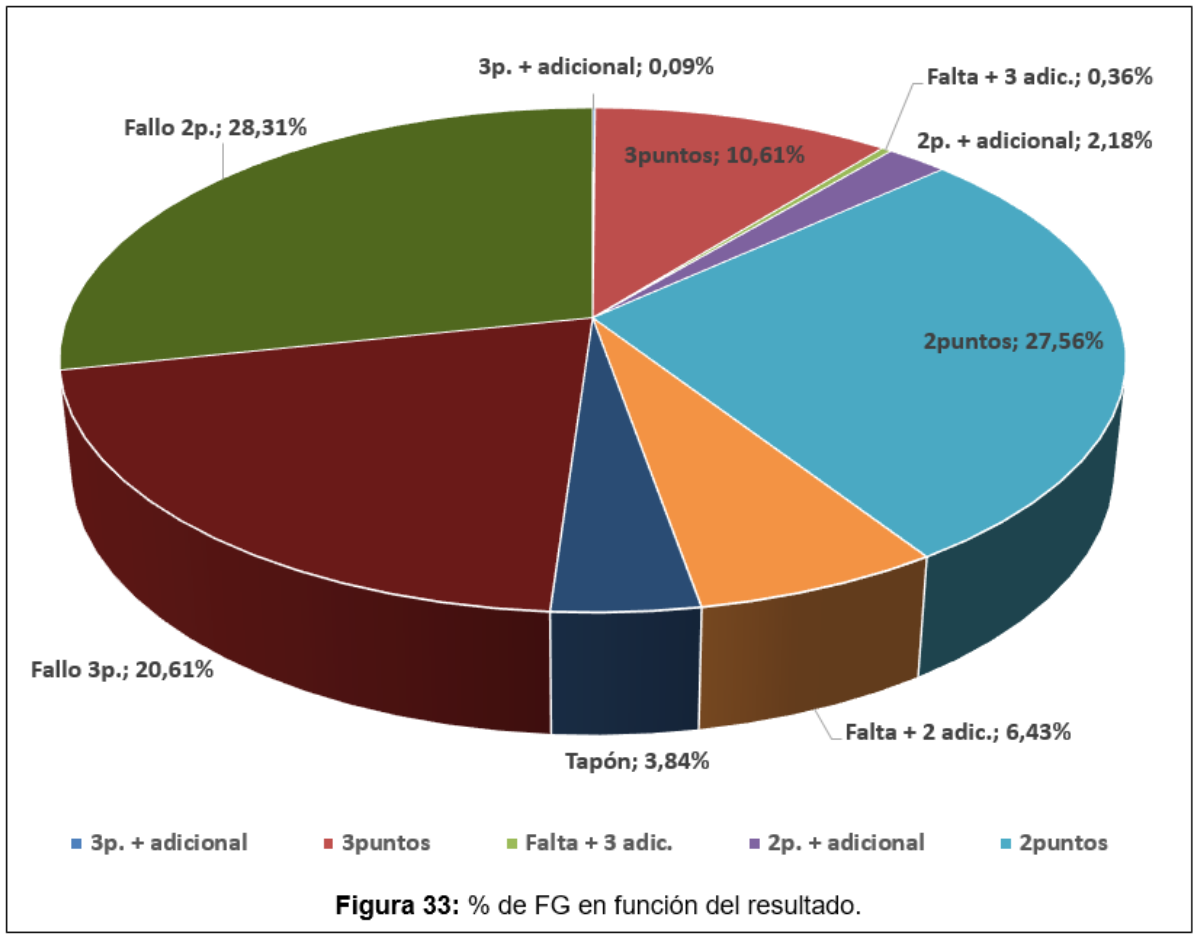
cuatro acumuladas en ese cuarto desemboca en ello, además, en las defensas es relativamente común que suceda, incluso en ocasiones es un recurso, pues en caso de tener que realizar la falta, esta se efectúa de forma contundente para evitar cualquier opción de canasta y adicional.

Si nos fijamos en la positividad o negatividad del resultado del FG (figura 34) vemos como a pesar de haber el doble de posibles resultados positivos, los resultados negativos prevalecen, lo cual era previsible como deporte colectivo de colaboraciónoposición.

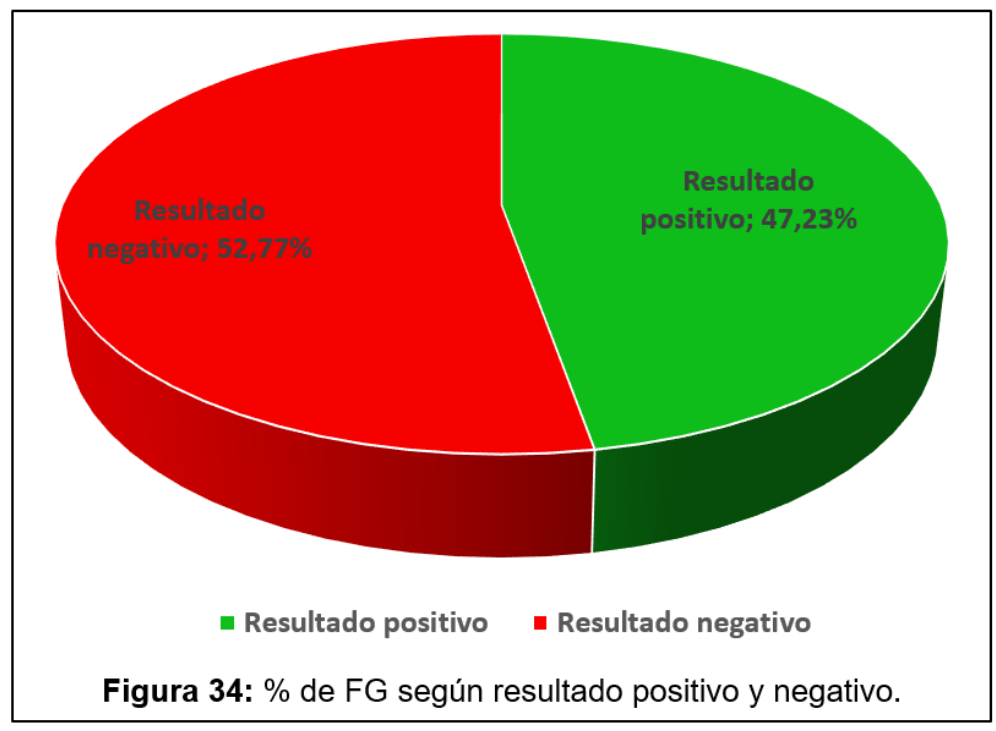




\subsubsection{Resultado y tiempo de posesión}

A continuación podemos ver como se reparten los porcentajes sobre el total de FG realizados en función de las variables "tiempo de posesión" y "resultado" (tabla 35), siendo las combinaciones de dichas variables con porcentajes más altos las relacionadas con las canastas y fallos de 2 y 3 puntos. Cabe destacar como, en comparación con sus contiguas, la franja de posesión 9-16 es la que mayor porcentaje tiene en todos los posibles resultados.

\begin{tabular}{|c|c|c|c|c|c|c|c|c|c|}
\cline { 2 - 9 } \multicolumn{1}{c|}{} & 3p. + adicional & 3puntos & Falta + 3 adic. & 2p. + adicional & 2puntos & Falta + 2 adic. & Tapón & Fallo 3p. & Fallo 2p. \\
\hline $\mathbf{0 - \mathbf { 8 }}$ & $0,01 \%$ & $3,38 \%$ & $0,10 \%$ & $0,52 \%$ & $8,06 \%$ & $1,87 \%$ & $1,25 \%$ & $7,68 \%$ & $10,31 \%$ \\
\hline $\mathbf{9 - 1 6}$ & $0,06 \%$ & $5,19 \%$ & $0,19 \%$ & $1,14 \%$ & $13,57 \%$ & $3,17 \%$ & $1,81 \%$ & $9,55 \%$ & $14,13 \%$ \\
\hline $\mathbf{1 7}-\mathbf{2 4}$ & $0,01 \%$ & $2,03 \%$ & $0,06 \%$ & $0,52 \%$ & $5,93 \%$ & $1,38 \%$ & $0,78 \%$ & $3,38 \%$ & $3,87 \%$ \\
\hline
\end{tabular}

Tabla 35: \% de FG entre las variables resultado y tiempo de posesión.

La tabla 36 y la figura 35 nos muestran los porcentajes de cada resultado en función del tiempo de posesión, de lo que podemos extraer varios hallazgos tácticamente relevantes.

\begin{tabular}{|c|c|c|c|c|c|c|c|c|c|}
\cline { 2 - 10 } \multicolumn{1}{c|}{} & 3p. + adicional & 3puntos & Falta + 3 adic. & 2p. + adicional & 2puntos & Falta + 2 adic. & Tapón & Fallo 3p. & Fallo 2p. \\
\hline $\mathbf{0 - 8}$ & $14,29 \%$ & $31,89 \%$ & $28,57 \%$ & $23,67 \%$ & $29,24 \%$ & $29,15 \%$ & $32,44 \%$ & $37,25 \%$ & $36,43 \%$ \\
\hline $\mathbf{9 - 1 6}$ & $71,43 \%$ & $48,93 \%$ & $53,57 \%$ & $52,37 \%$ & $49,23 \%$ & $49,35 \%$ & $47,23 \%$ & $46,33 \%$ & $49,91 \%$ \\
\hline $\mathbf{1 7 - 2 4}$ & $14,29 \%$ & $19,17 \%$ & $17,86 \%$ & $23,96 \%$ & $21,53 \%$ & $21,51 \%$ & $20,34 \%$ & $16,42 \%$ & $13,66 \%$ \\
\hline TOTAL & $100,00 \%$ & $100,00 \%$ & $100,00 \%$ & $100,00 \%$ & $100,00 \%$ & $100,00 \%$ & $100,00 \%$ & $100,00 \%$ & $100,00 \%$ \\
\hline
\end{tabular}

Tabla 36: \% de FG de cada resultado según tiempo de posesión.

Todos los resultados se dan en mayor proporción en la posesión media, pues es, como ya comentamos anteriormente, la posesión entre la precipitación y el ataque bajo presión temporal, además de, como veremos más adelante, tratarse de la franja de posesión donde más FG se realizan. Los resultados de 3p.+adic. se dan entre los segundos 9-16 de posesión en el 71,43\% de las ocasiones, repartiéndose por igual entre las otras dos franjas el restante.

Hemos de destacar como los resultados negativos (tapón, fallo 2p. y fallo 3p.) tienen mayor presencia en la franja 0-8 que el resto de resultados, lo cual es debido a las malas decisiones o al contexto adverso en el que se realizan los FG frente a la exigencia de finalizar la acción por el límite temporal reglamentario. En un porcentaje similar podemos encontrar el resultado de 3 puntos, lo cual podría explicarse con los FG realizados tras una jugada táctica, moviendo el balón y creando buenas opciones de tiro en la última franja de posesión. 


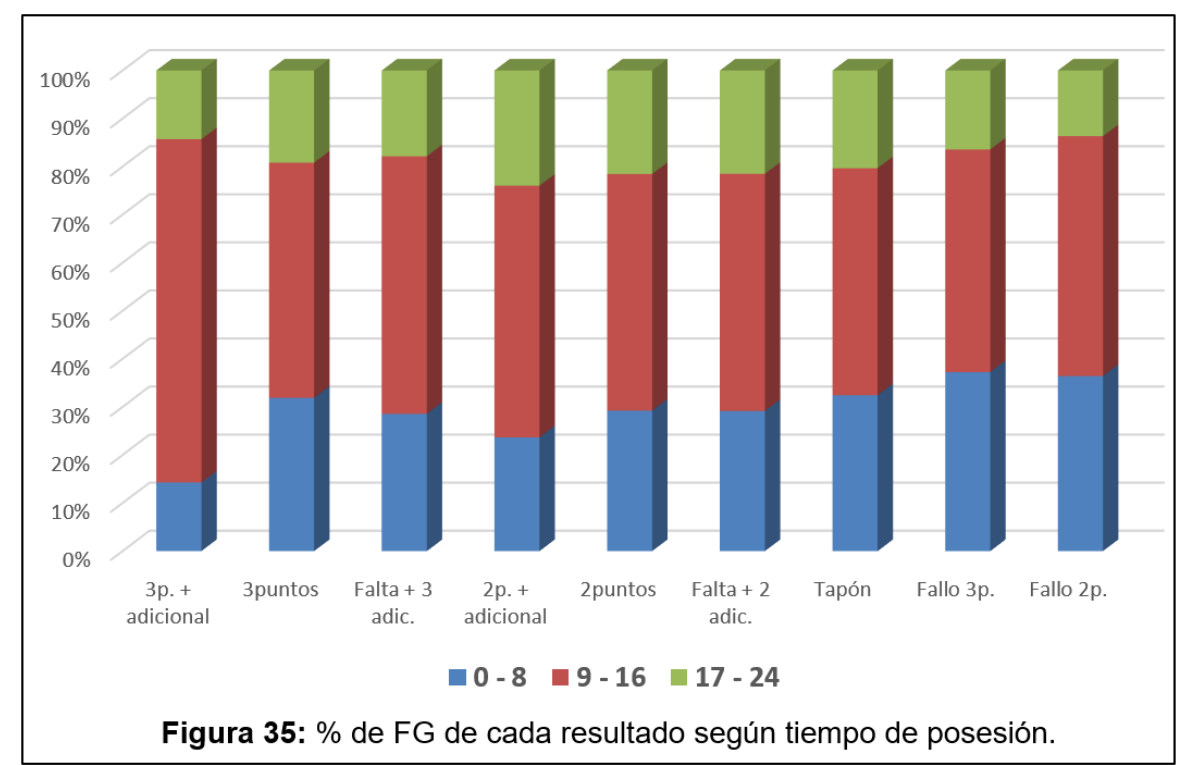

También es destacable como los 2 p.+adic., los 2 p., las falta +2 adic. y los tapones tiene un alto porcentaje en la franja 17-24. Esto es debido a los contraataques o transiciones rápidas, donde dichos resultados son comunes.

\begin{tabular}{|c|c|c|c|c|c|c|c|c|c|c|}
\cline { 2 - 12 } \multicolumn{1}{c|}{} & 3p. + adicional & 3puntos & Falta + 3 adic. & 2p. + adicional & 2puntos & Falta + 2 adic. & Tapón & Fallo 3p. & Fallo 2p. & TOTAL \\
\hline $\mathbf{0 - 8}$ & $0,04 \%$ & $10,20 \%$ & $0,31 \%$ & $1,56 \%$ & $24,28 \%$ & $5,64 \%$ & $3,76 \%$ & $23,14 \%$ & $31,08 \%$ & $100,00 \%$ \\
\hline $\mathbf{9 - 1 6}$ & $0,13 \%$ & $10,63 \%$ & $0,40 \%$ & $2,34 \%$ & $27,79 \%$ & $6,49 \%$ & $3,72 \%$ & $19,56 \%$ & $28,94 \%$ & $100,00 \%$ \\
\hline $\mathbf{1 7 - 2 4}$ & $0,07 \%$ & $11,31 \%$ & $0,36 \%$ & $2,91 \%$ & $33,00 \%$ & $7,68 \%$ & $4,34 \%$ & $18,82 \%$ & $21,51 \%$ & $100,00 \%$ \\
\hline
\end{tabular}

Tabla 37: \% de FG según resultado dentro de cada franja de posesión.

El en tabla 37 se muestra el reparto porcentual de los resultados dentro de cada franja de posesión. Si comparamos el reparto de las tres franjas temporales entre ellas, observamos ciertas dinámicas ascendentes $\mathrm{y}$ descendentes (figura 36). En resultados como $3 \mathrm{p}$., 2p.+adic., 2p., y falta +2 adic. observamos un mayor porcentaje en cuanto mayor es el tiempo de posesión del que se dispone

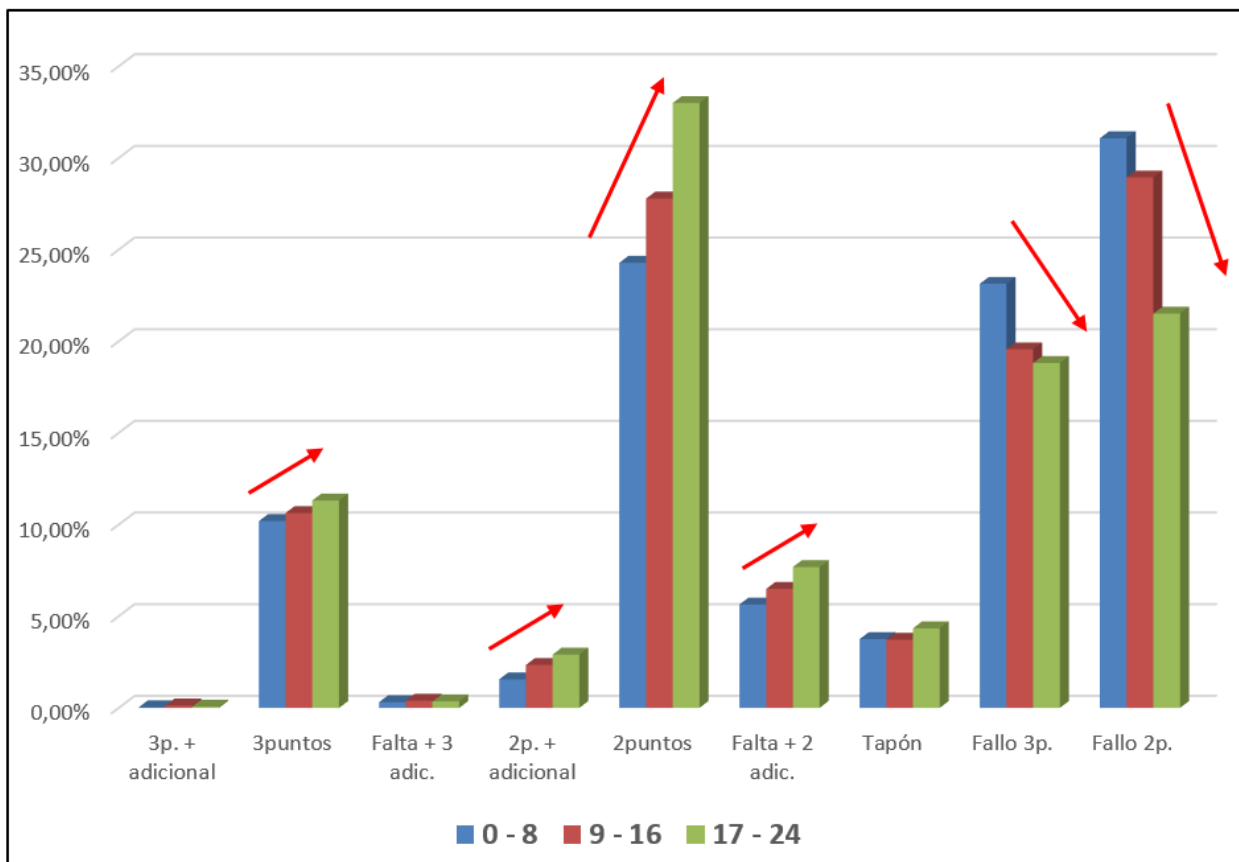

Figura 36: \% de FG según resultado dentro de cada franja de posesión. 
(directamente proporcional); mientras que en resultados como los fallos de 3 y 2 puntos el porcentaje es inversamente proporcional al tiempo de posesión. Los tapones demuestran cierta constancia en todas las franjas de posesión.

Si abordamos el resultado desde su positividad o negatividad dentro de cada franja de posesión (tabla 38), observamos como la única franja con mayor positividad que negatividad es la de 17-24, debido en gran parte a los contraataques y transiciones rápidas.

\begin{tabular}{|c|c|c|c|}
\cline { 2 - 4 } \multicolumn{1}{c|}{} & RESULTADO (+) & RESULTADO (-) & TOTAL \\
\hline $\mathbf{0 - \mathbf { 8 }}$ & $\mathbf{4 2 , 0 3 \%}$ & $57,97 \%$ & $100,00 \%$ \\
\hline $\mathbf{9 - 1 6}$ & $\mathbf{4 7 , 7 8 \%}$ & $52,22 \%$ & $100,00 \%$ \\
\hline $\mathbf{1 7}-\mathbf{2 4}$ & $55,33 \%$ & $44,67 \%$ & $100,00 \%$ \\
\hline
\end{tabular}

Tabla 38: \% de FG con resultado (+) y (-) de cada franja de posesión.

Si lo observamos en la figura 37 , vemos con en la franja 0-8 se da una dinámica más negativa, en la franja intermedia tiende a ser más neutra y en la franja 17-24 más positiva.

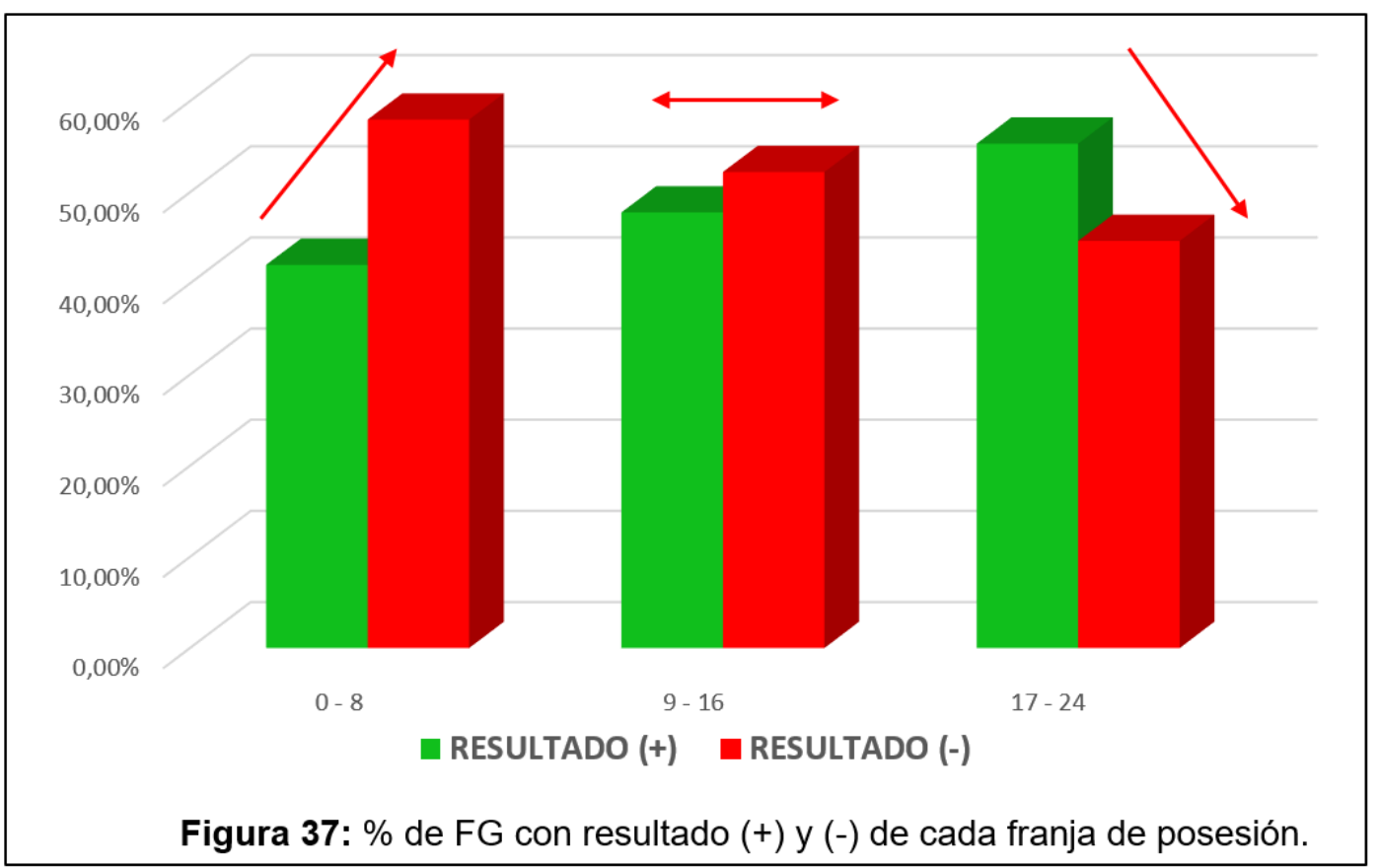




\subsubsection{Resultado y tipo de tiro}

Si enfrentamos la variable "resultado" y "tipo de tiro" (tabla 39) podemos ver como a excepción del fallo de 2 puntos en un mal tiro, todos los porcentajes elevados, es decir, combinaciones con mayor incidencia en el juego, tienen que ver con los tiros normales o buenos.

\begin{tabular}{|c|c|c|c|c|c|c|c|c|c|}
\cline { 2 - 10 } \multicolumn{1}{c|}{} & 3p. + adicional & 3puntos & Falta + 3 adic. & 2p. + adicional & 2puntos & Falta + 2 adic. & Tapón & Fallo 3p. & Fallo 2p. \\
\hline Buen tiro & $0,03 \%$ & $7,75 \%$ & $0,07 \%$ & $0,49 \%$ & $13,08 \%$ & $0,23 \%$ & $0,06 \%$ & $11,33 \%$ & $4,70 \%$ \\
\hline Tiro normal & $0,05 \%$ & $2,44 \%$ & $0,25 \%$ & $1,58 \%$ & $13,40 \%$ & $5,55 \%$ & $2,73 \%$ & $6,54 \%$ & $17,22 \%$ \\
\hline Mal tiro & $0,01 \%$ & $0,42 \%$ & $0,05 \%$ & $0,12 \%$ & $1,08 \%$ & $0,65 \%$ & $1,05 \%$ & $2,74 \%$ & $6,39 \%$ \\
\hline
\end{tabular}

Tabla 39: \% de FG entre las variables resultado y tipo de tiro.

Todos los resultados con lanzamientos adicionales se dan en mayor medida en los tiros normales, lo cual tiene cierta lógica, pues en un buen tiro se dispone de una ventaja sobre el defensor que evita que pueda llegar, y por tanto hacer falta; y en los malos tiros, el defensor no tiene necesidad de arriesgar en la defensa sobre el lanzador.

Los porcentajes de la combinación de las categorías "canasta de 2 puntos" y tiros "buenos" o "normales" es similar, mientras que en el caso de los triples los "buenos tiros" triplican el porcentaje de "tiros normales".

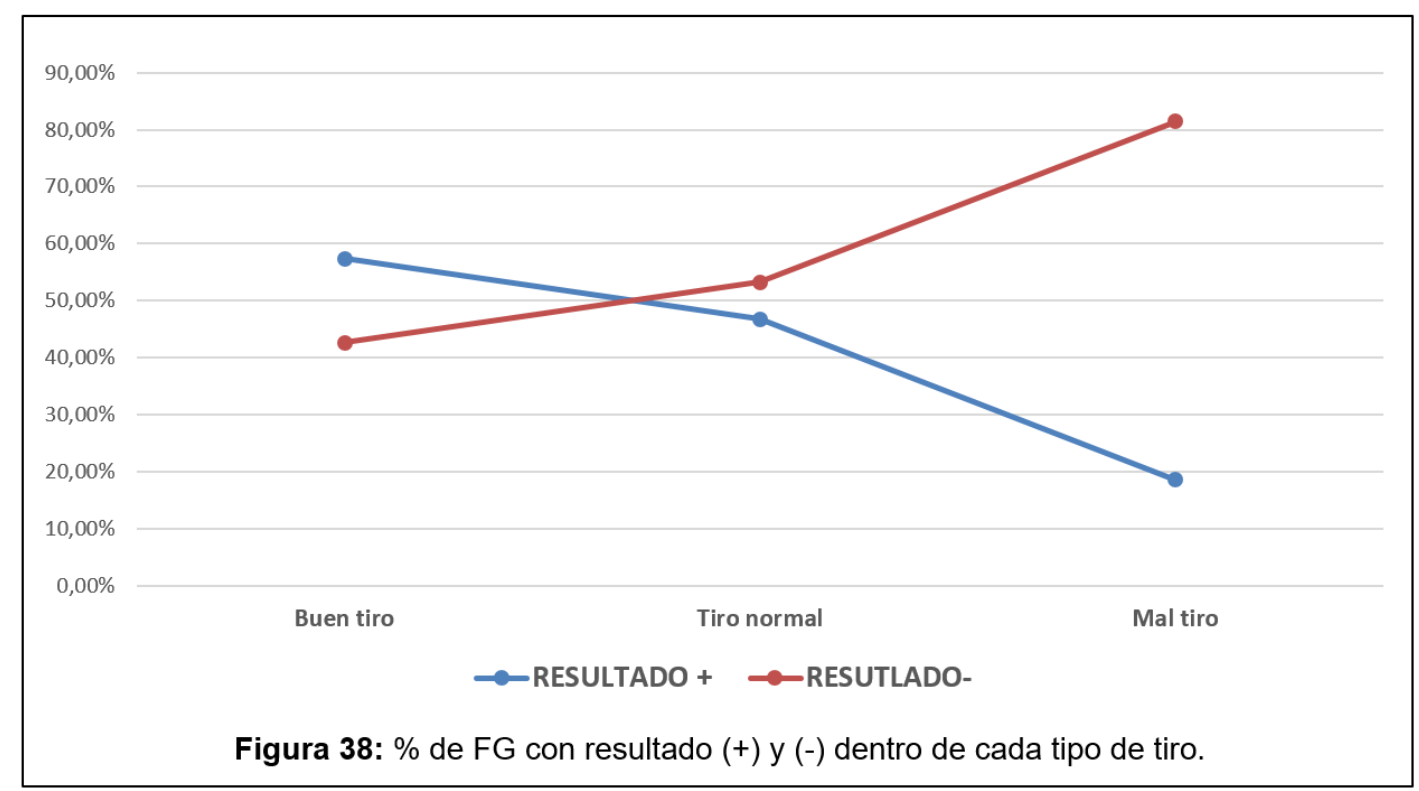

En la figura 38 y la tabla 40 podemos ver la relación entre el tipo de tiro y el resultado de este. Como era de esperar, los buenos tiros tienen un mayor porcentaje de resultados positivos, el cual desciende en los tiros normales, y en mucha mayor medida en los malos tiros; ocurriendo lo contrario con los resultados negativos. 


\begin{tabular}{|c|c|c|c|}
\cline { 2 - 4 } \multicolumn{1}{c|}{} & RESULTADO + & RESUTLADO - & TOTAL \\
\hline Buen tiro & $57,36 \%$ & $42,64 \%$ & $100,00 \%$ \\
\hline Tiro normal & $46,76 \%$ & $53,24 \%$ & $100,00 \%$ \\
\hline Mal tiro & $18,54 \%$ & $81,46 \%$ & $100,00 \%$ \\
\hline
\end{tabular}

Tabla 40: \% de FG con resultado (+) y (-) dentro de cada tipo de tiro.

Si nos centramos en como se reparte cada resultado dentro de cada tipo de tiro (figuras 39 y 40) podemos ver diferencias significativas entre los buenos y malos tiros, lo cual se recoge de forma más clara en la tabla 41.
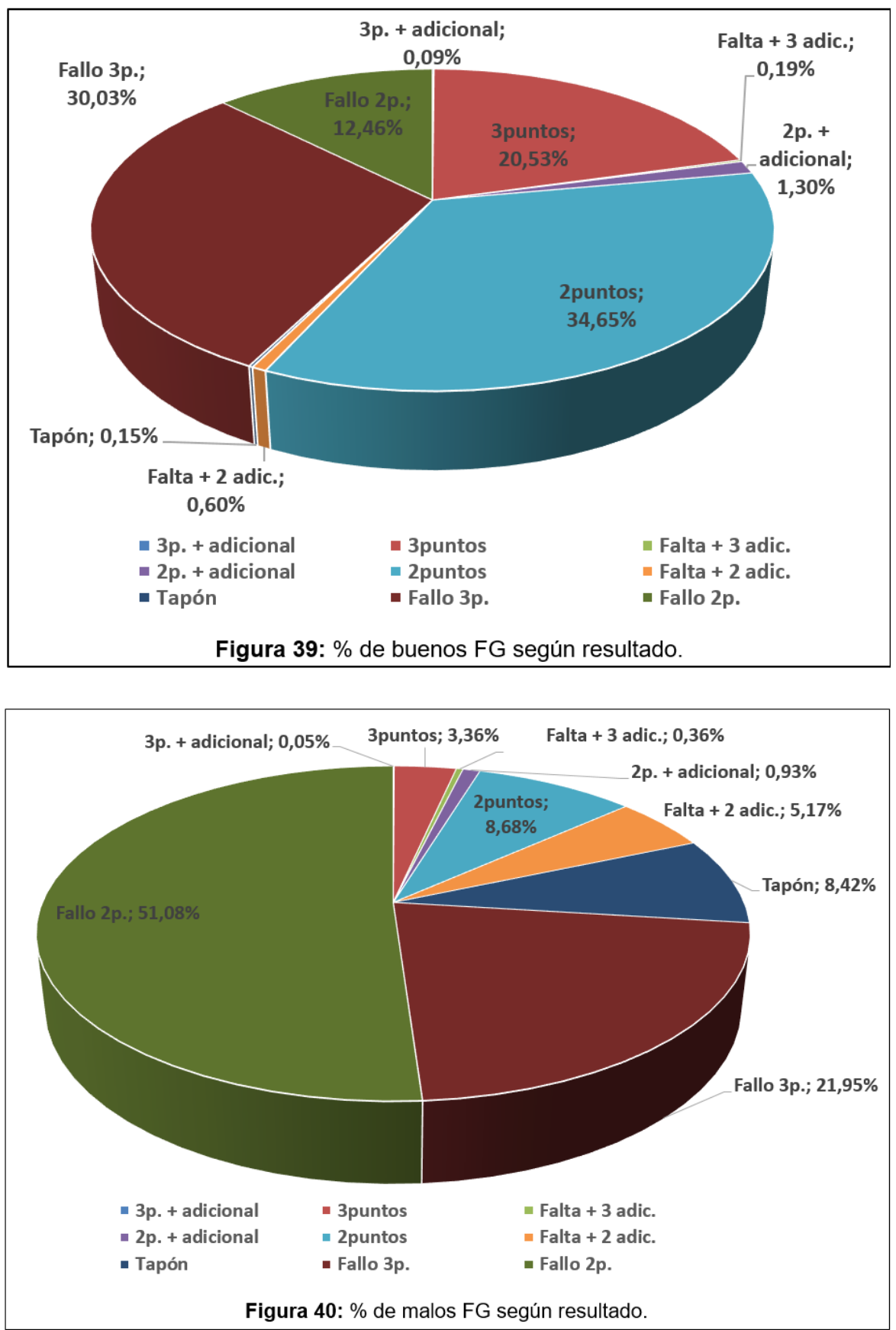
Los malos tiros en su mayoría acaban en fallo de 3 y 2 puntos con más del $70 \%$ entre ambos, mientras que en los buenos tiros no pasa del 43\%. Es destacable como los malos tiros tienen un porcentaje mucho mayor de tapones y menor de canastas de 2 y 3 puntos en comparación con los buenos tiros.

\begin{tabular}{|c|c|c|c|c|c|c|c|c|c|c|}
\hline & 3p. + adicional & 3puntos & Falta +3 adic. & 2p. + adicional & 2puntos & Falta +2 adic. & Tapón & Fallo 3p. & Fallo 2p. & TOTAL \\
\hline Buen tiro & $0,09 \%$ & $20,53 \%$ & $0,19 \%$ & $1,30 \%$ & $34,65 \%$ & $0,60 \%$ & $0,15 \%$ & $30,03 \%$ & $12,46 \%$ & $100,00 \%$ \\
\hline Tiro normal & $0,10 \%$ & $4,91 \%$ & $0,49 \%$ & $3,17 \%$ & $26,93 \%$ & $11,16 \%$ & $5,49 \%$ & $13,13 \%$ & $34,61 \%$ & $100,00 \%$ \\
\hline Mal tiro & $0,05 \%$ & $3,36 \%$ & $0,36 \%$ & $0,93 \%$ & $8,68 \%$ & $5,17 \%$ & $8,42 \%$ & $21,95 \%$ & $51,08 \%$ & $100,00 \%$ \\
\hline
\end{tabular}

Tabla 41: \% de FG de cada tipo de tiro según resultado.

A modo de resumen de lo anterior disponemos de la siguiente figura (figura 41).

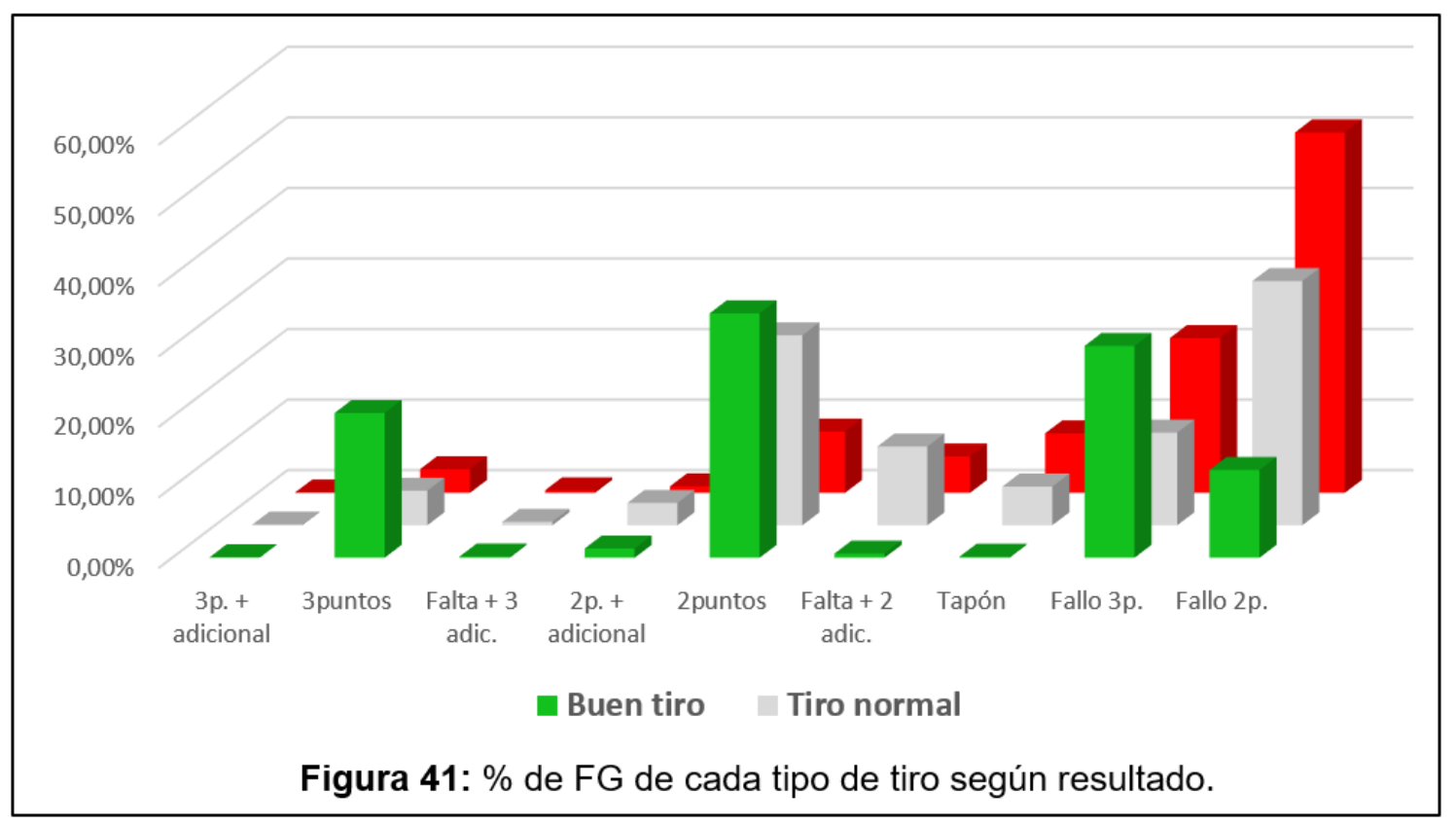

Si nos fijamos dentro de cada resultado en qué porcentaje se da cada tipo de tiro (tabla 42; figura 42), vemos como la mayoría de resultados se dan en mayor medida en los tiros normales, lo cual es lógico, pues son los que mayor " $\mathrm{N}$ " tienen, sin embargo, en las canastas de 3 puntos es muy superior en buenos tiros, y en 2 puntos casi idéntico. Por otro lado, los tapones y fallos de 2 puntos tienen un mayor porcentaje en los malos tiros en comparación al resto. Estas relaciones demuestran la importancia de obtener ventajas para realizar lanzamientos cómodos, u obstaculizarlos en el caso de la defensa. 


\begin{tabular}{|c|c|c|c|c|c|c|c|c|c|}
\hline & 3p. + adicional & 3puntos & Falta +3 adic. & 2 p. + adicional & 2puntos & Falta +2 adic. & Tapón & Fallo 3p. & Fallo 2p. \\
\hline Buen tiro & $35,71 \%$ & $73,04 \%$ & $19,64 \%$ & $22,49 \%$ & $47,45 \%$ & $3,52 \%$ & $1,51 \%$ & $54,98 \%$ & $16,61 \%$ \\
\hline Tíro normal & $57,14 \%$ & $23,01 \%$ & $67,86 \%$ & $72,19 \%$ & $48,62 \%$ & $86,43 \%$ & $71,09 \%$ & $31,70 \%$ & $60,83 \%$ \\
\hline Mal tiro & $7,14 \%$ & $3,96 \%$ & $12,50 \%$ & $5,33 \%$ & $3,94 \%$ & $10,05 \%$ & $27,39 \%$ & $13,31 \%$ & $22,56 \%$ \\
\hline TOTAL & $100,00 \%$ & $100,00 \%$ & $100,00 \%$ & $100,00 \%$ & $100,00 \%$ & $100,00 \%$ & $100,00 \%$ & $100,00 \%$ & $100,00 \%$ \\
\hline
\end{tabular}

Tabla 42: \% de FG de cada posible resultado según tipo de tiro.

El fallo de 3 puntos rompe con lo explicado anteriormente, teniendo su mayor porcentaje en el buen tiro, lo cual tiene su explicación en que la mayoría de lanzamientos de 3 se producen con un buen tiro, por lo cual, tanto su acierto como su fallo tienen mayor porcentaje en este. Además, a pesar de realizarse en unas condiciones favorables, los tiros desde más allá de la línea de 3 puntos siempre implican dificultad por la distancia al aro.

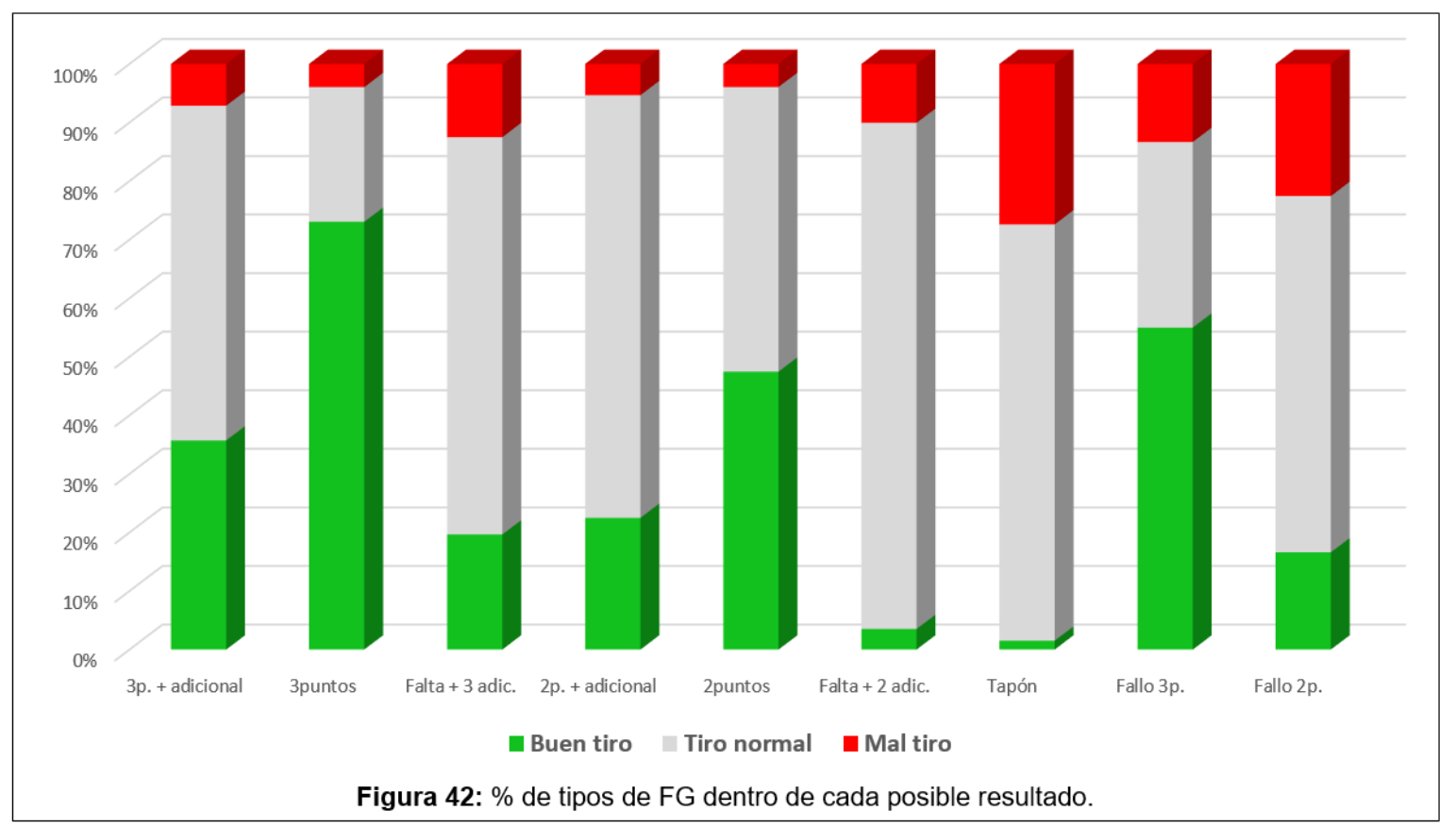

\subsubsection{Resultado y ventaja/desventaja}

En la figura 43 vemos como cuando se va por encima en el marcador hay mayor diferencia entre el resultado positivo y el negativo, mientras que cuando se va empate o por debajo en el marcador esta diferencia se ve reducida. Es posible que esto se vea influenciado por la presión de mantener la superioridad en el marcador cuando se va ganando, la oportunidad de adelantarse (elemento motivador) cuando reinan las tablas o la necesidad de sumar cuando se va por debajo.

Sería muy interesante profundizar en el estudio de estas variables a través de distintas escalas de valoración de estrés en jugadores profesionales. Existen muchos cuestionarios 
específicos de evaluación de la ansiedad en el deporte, cuyo precursor inicial fue Martens (1977) con la creación del test Sport Competition Anxiety (SCAT). De ahí se han ido generando distintos test o escalas, con sus respectivas revisiones y adaptaciones, algunas de ellas al español como la adaptación del CSAI-2R de Andrade et al. (2007), o de la escala de ansiedad competitiva SAS-2 de Ramis et al. (2010), tomando así mucha importancia la resiliencia y el "coping", que no deja de ser una forma o estrategia de afrontamiento ante episodios, sucesos o situaciones estresantes.

Respecto a estas estrategias de afrontamiento en el deporte podemos encontrar numerosos autores y trabajos como Belem et al. (2014) y su estudio en vóley playa profesional, o Rosado et al. (2012) y su trabajo en baloncesto de alta competición, pero me gustaría destacar el trabajo de Nicholls y Polman (2007) con una exhaustiva revisión de la literatura en esta área.

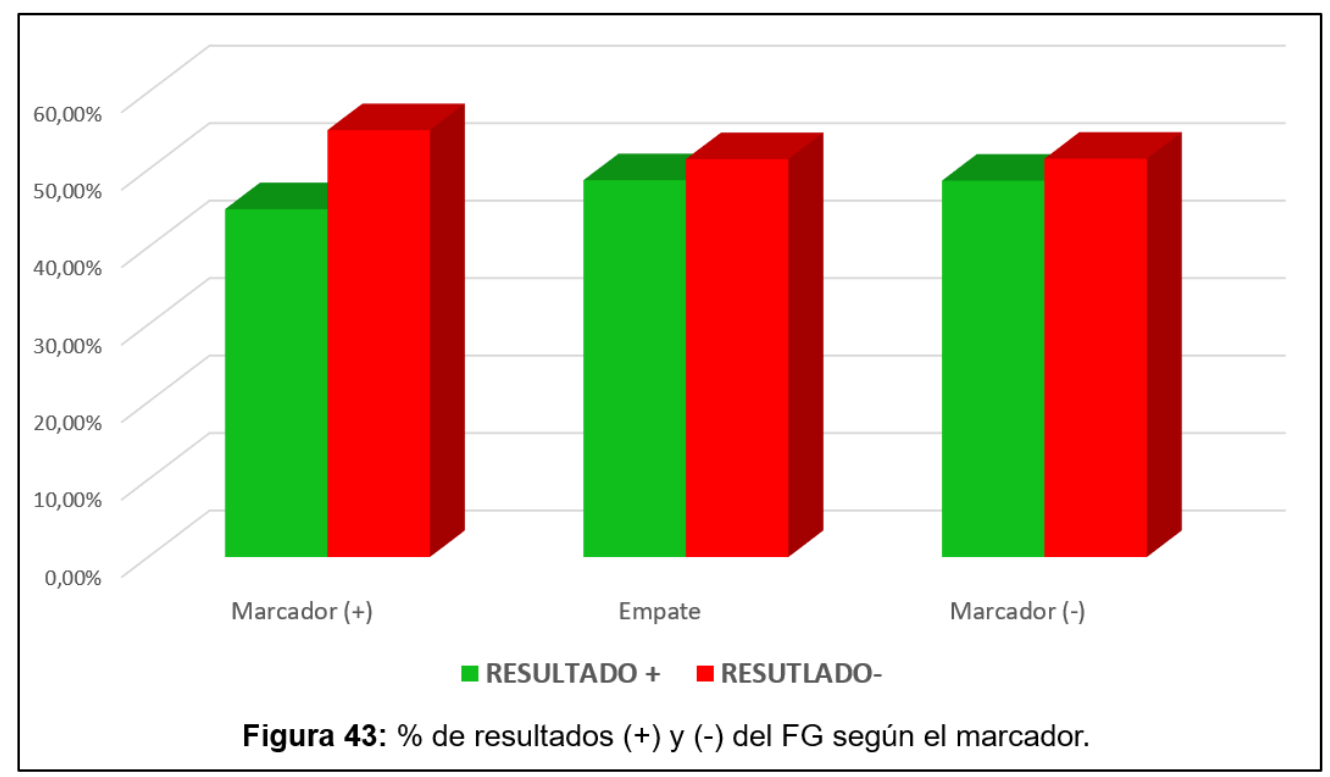

Si nos fijamos detenidamente en los porcentajes de resultados de los FG según la superioridad, igualdad o desventaja en el marcador (tabla 43), podemos ver como a pesar de que las dinámicas son muy similares, se observan ciertas pequeñas diferencias. Proporcionalmente se meten menos triples y canastas, se reciben más tapones y se falla más de 2 y 3 puntos cuando se va por encima en el marcador.

\begin{tabular}{|c|c|c|c|c|c|c|c|c|c|c|}
\hline & 3p. + adicional & 3puntos & Falta +3 adic. & 2p. + adicional & 2puntos & Falta +2 adic. & Tapón & Fallo 3p. & Fallo 2p. & TOTAL \\
\hline Marcador (+) & $0,05 \%$ & $9,39 \%$ & $0,40 \%$ & $1,63 \%$ & $26,69 \%$ & $6,73 \%$ & $4,28 \%$ & $21,49 \%$ & $29,34 \%$ & $100,00 \%$ \\
\hline Empate & $0,17 \%$ & $11,90 \%$ & $0,17 \%$ & $2,01 \%$ & $29,13 \%$ & $5,25 \%$ & $3,06 \%$ & $19,86 \%$ & $28,43 \%$ & $100,00 \%$ \\
\hline Marcador (-) & $0,10 \%$ & $11,24 \%$ & $0,36 \%$ & $2,57 \%$ & $27,93 \%$ & $6,38 \%$ & $3,66 \%$ & $20,14 \%$ & $27,62 \%$ & $100,00 \%$ \\
\hline
\end{tabular}

Tabla 43: \% de resultados del FG según el marcador. 


\subsubsection{Resultado y precedente}

El conocimiento de la relación entre el resultado y su precedente es altamente valioso, pues con ello se identifica la efectividad de estos. Si analizamos la combinación de estas dos variables sobre el total de los FG realizados (tabla 44) vemos como tan solo el pase tiene un porcentaje significativo en el FG de 3 puntos, tanto en el acierto como en el fallo. En cuanto a los tiros de dos, son respectivamente la jugada personal, el pase y el bloqueo directo los que mayor porcentaje tienen.

\begin{tabular}{|c|c|c|c|c|c|c|c|c|c|}
\cline { 2 - 9 } \multicolumn{1}{c|}{} & 3p. + adicional & 3puntos & Falta + 3 adic. & 2p. + adicional & 2puntos & Falta + 2 adic. & Tapón & Fallo 3p. & Fallo 2p. \\
\hline Contraataque & $0 \%$ & $0,14 \%$ & $0 \%$ & $0,13 \%$ & $1,30 \%$ & $0,18 \%$ & $0,07 \%$ & $0,20 \%$ & $0,40 \%$ \\
\hline Bloqueo Directo & $0,01 \%$ & $1,56 \%$ & $0,09 \%$ & $0,21 \%$ & $4,66 \%$ & $1,12 \%$ & $0,52 \%$ & $2,93 \%$ & $5,26 \%$ \\
\hline Pase & $0,06 \%$ & $7,36 \%$ & $0,19 \%$ & $0,43 \%$ & $6,73 \%$ & $0,87 \%$ & $0,67 \%$ & $14,01 \%$ & $5,33 \%$ \\
\hline Jugada Personal & $0,03 \%$ & $1,39 \%$ & $0,08 \%$ & $1,16 \%$ & $11,01 \%$ & $3,45 \%$ & $2,14 \%$ & $3,16 \%$ & $15,00 \%$ \\
\hline Robo & $0 \%$ & $0,12 \%$ & $0 \%$ & $0,08 \%$ & $1,50 \%$ & $0,24 \%$ & $0,18 \%$ & $0,19 \%$ & $0,52 \%$ \\
\hline Rebote & $0 \%$ & $0,04 \%$ & $0 \%$ & $0,19 \%$ & $2,36 \%$ & $0,56 \%$ & $0,26 \%$ & $0,13 \%$ & $1,80 \%$ \\
\hline
\end{tabular}

Tabla 44: \% de FG entre las variables resultado y precedente.

Si nos centramos en los resultados según su aportación al equipo, es decir, en resultados positivos y negativos de cada precedente (tabla 45), podemos ver como tan solo tres de los seis tienen un porcentaje de resultados positivos superiores al 50\% (el contraataque, el robo y el rebote), convirtiéndose por ello en factores determinantes para el resultado de los encuentros, y por lo tanto, un punto muy importante a tener en cuenta de cara a la futura aplicación práctica.

\begin{tabular}{|c|c|c|c|}
\cline { 2 - 4 } \multicolumn{1}{c|}{} & RESULTADO + & RESUTLADO- & TOTAL \\
\hline Contraataque & $72,19 \%$ & $27,81 \%$ & $100,00 \%$ \\
\hline Bloqueo Directo & $46,74 \%$ & $53,26 \%$ & $100,00 \%$ \\
\hline Pase & $43,88 \%$ & $56,12 \%$ & $100,00 \%$ \\
\hline Jugada Personal & $45,74 \%$ & $54,26 \%$ & $100,00 \%$ \\
\hline Robo & $68,56 \%$ & $31,44 \%$ & $100,00 \%$ \\
\hline Rebote & $59,01 \%$ & $40,99 \%$ & $100,00 \%$ \\
\hline
\end{tabular}

Tabla 45: \% de FG según resultado dentro de cada precedente.

Tanto el robo como el contraataque tienen un alto porcentaje de resultados positivos, seguramente debido a la superioridad que lleva implícita el contraataque y que en ocasiones se produce tras robo. En cuanto al rebote, se trata de una situación generalmente muy cercana al aro, lo cual repercute en esa positividad del resultado. 
Es curioso ver, como descubriremos más adelante, como los tres precedentes más utilizados son los que tienen un porcentaje de efectividad inferior al $50 \%$.

\begin{tabular}{|c|c|c|c|c|c|c|c|c|c|c|}
\hline & 3p. + adicional & 3puntos & Falta +3 adic. & 2 p. + adicional & 2puntos & Falta +2 adic. & Tapón & Fallo 3p. & Fallo 2p. & TOTAL \\
\hline Contraataque & $0 \%$ & $5,61 \%$ & $0 \%$ & $5,35 \%$ & $53,74 \%$ & $7,49 \%$ & $2,94 \%$ & $8,29 \%$ & $16,58 \%$ & $100 \%$ \\
\hline Bloqueo Directo & $0,04 \%$ & $9,55 \%$ & $0,55 \%$ & $1,26 \%$ & $28,46 \%$ & $6,87 \%$ & $3,16 \%$ & $17,92 \%$ & $32,18 \%$ & $100 \%$ \\
\hline Pase & $0,16 \%$ & $20,65 \%$ & $0,54 \%$ & $1,20 \%$ & $18,88 \%$ & $2,45 \%$ & $1,88 \%$ & $39,29 \%$ & $14,95 \%$ & $100 \%$ \\
\hline Jugada Personal & $0,07 \%$ & $3,71 \%$ & $0,21 \%$ & $3,09 \%$ & $29,44 \%$ & $9,22 \%$ & $5,73 \%$ & $8,44 \%$ & $40,09 \%$ & $100 \%$ \\
\hline Robo & $0 \%$ & $4,33 \%$ & $0 \%$ & $2,73 \%$ & $53,08 \%$ & $8,43 \%$ & $6,38 \%$ & $6,61 \%$ & $18,45 \%$ & $100 \%$ \\
\hline Rebote & $0 \%$ & $0,73 \%$ & $0 \%$ & $3,51 \%$ & $44,26 \%$ & $10,52 \%$ & $4,84 \%$ & $2,42 \%$ & $33,74 \%$ & $100 \%$ \\
\hline
\end{tabular}

Tabla 46: \% de los resultados del FG dentro de cada precedente.

La tabla 46 y la figura 44 nos muestran el reparto porcentual de resultados de cada precedente. En los contraataques, robos y rebotes se observa como de forma destacada son los FG de 2 puntos, con sus correspondientes canastas o fallos, los que acumulan la mayor parte de las ejecuciones. Esto se extiende a la jugada personal, pero a diferencia de la dinámica de los anteriores (mayor porcentaje de acierto de 2 puntos que fallo) en esta ocurre lo contrario, menos canastas de 2 puntos y más fallos.

Los bloqueos directos y los pases, además de en los fallos y aciertos de 2 puntos, también tienen un porcentaje considerable desde la línea de 3.

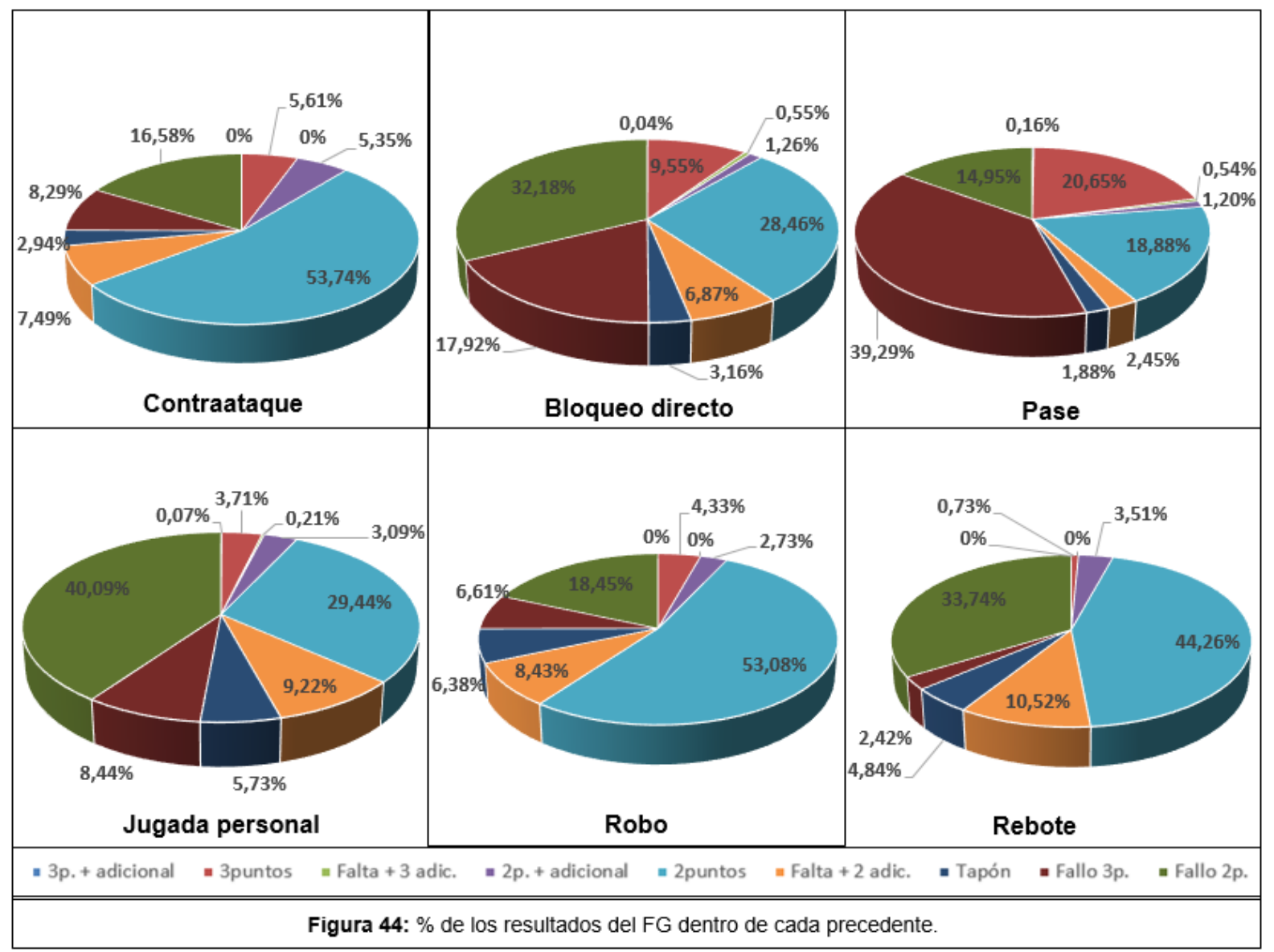


En cuanto a como se reparte cada posible resultado entre los precedentes (tabla 47, figura 45), podemos ver como en todos destacan el pase, el bloqueo directo y la jugada personal.

\begin{tabular}{|c|c|c|c|c|c|c|c|c|c|}
\hline & 3p. + adicional & 3 puntos & Falta +3 adic. & 2p. + adicional & 2puntos & Falta +2 adic. & Tapón & Fallo 3p. & Fallo 2p. \\
\hline Contraataque & $0 \%$ & $1,28 \%$ & $0 \%$ & $5,92 \%$ & $4,71 \%$ & $2,81 \%$ & $1,85 \%$ & $0,97 \%$ & $1,41 \%$ \\
\hline Bloqueo Directo & $7,14 \%$ & $14,73 \%$ & $25 \%$ & $9,47 \%$ & $16,89 \%$ & $17,49 \%$ & $13,45 \%$ & $14,22 \%$ & $18,59 \%$ \\
\hline Pase & $64,29 \%$ & $69,39 \%$ & $53,57 \%$ & $19,53 \%$ & $24,41 \%$ & $13,57 \%$ & $17,48 \%$ & $67,95 \%$ & $18,82 \%$ \\
\hline Jugada Personal & $28,57 \%$ & $13,09 \%$ & $21,43 \%$ & $52,96 \%$ & $39,95 \%$ & $53,67 \%$ & $55,80 \%$ & $15,32 \%$ & $52,97 \%$ \\
\hline Robo & $0 \%$ & $1,16 \%$ & $0 \%$ & $3,55 \%$ & $5,46 \%$ & $3,72 \%$ & $4,71 \%$ & $0,91 \%$ & $1,85 \%$ \\
\hline Rebote & $0 \%$ & $0,37 \%$ & $0 \%$ & $8,58 \%$ & $8,58 \%$ & $8,74 \%$ & $6,72 \%$ & $0,63 \%$ & $6,36 \%$ \\
\hline TOTAL & $100 \%$ & $100 \%$ & $100 \%$ & $100 \%$ & $100 \%$ & $100 \%$ & $100 \%$ & $100 \%$ & $100 \%$ \\
\hline
\end{tabular}

Tabla 47: \% de los precedentes del FG para cada resultado.

En los resultados de las zonas exteriores al perimetro destaca el pase como precedente con mayor porcentaje, sin embargo, en las zonas interiores es la jugada personal quien ocupa ese lugar.

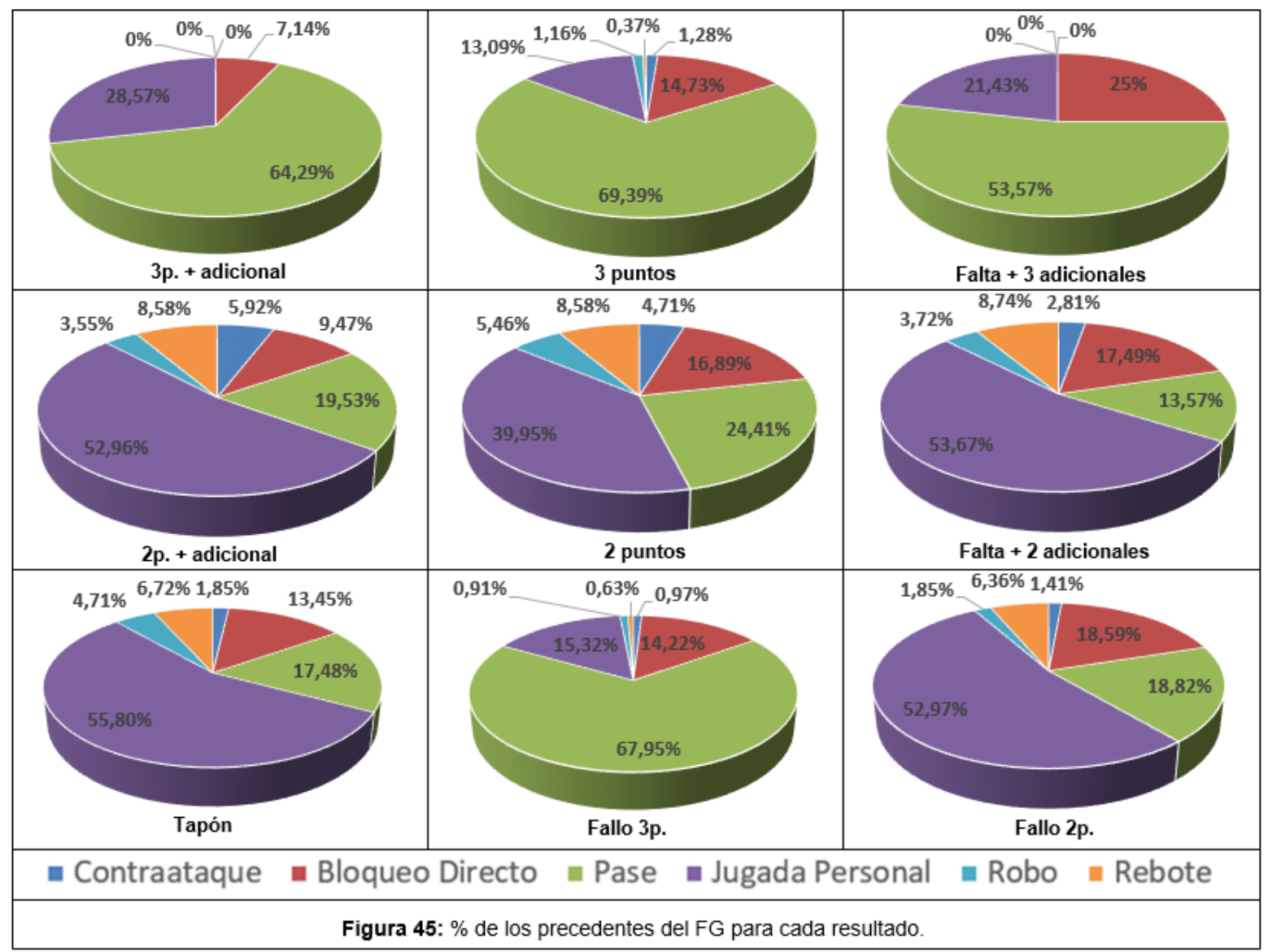




\subsubsection{Resultado y jugadores implicados}

La combinación de estas dos variables sobre el total de los FG realizados se recoge en la figura 46. En ella podemos apreciar de forma acumulada los porcentajes de cada resultado en función del número de jugadores que han entrado en contacto con el balón.

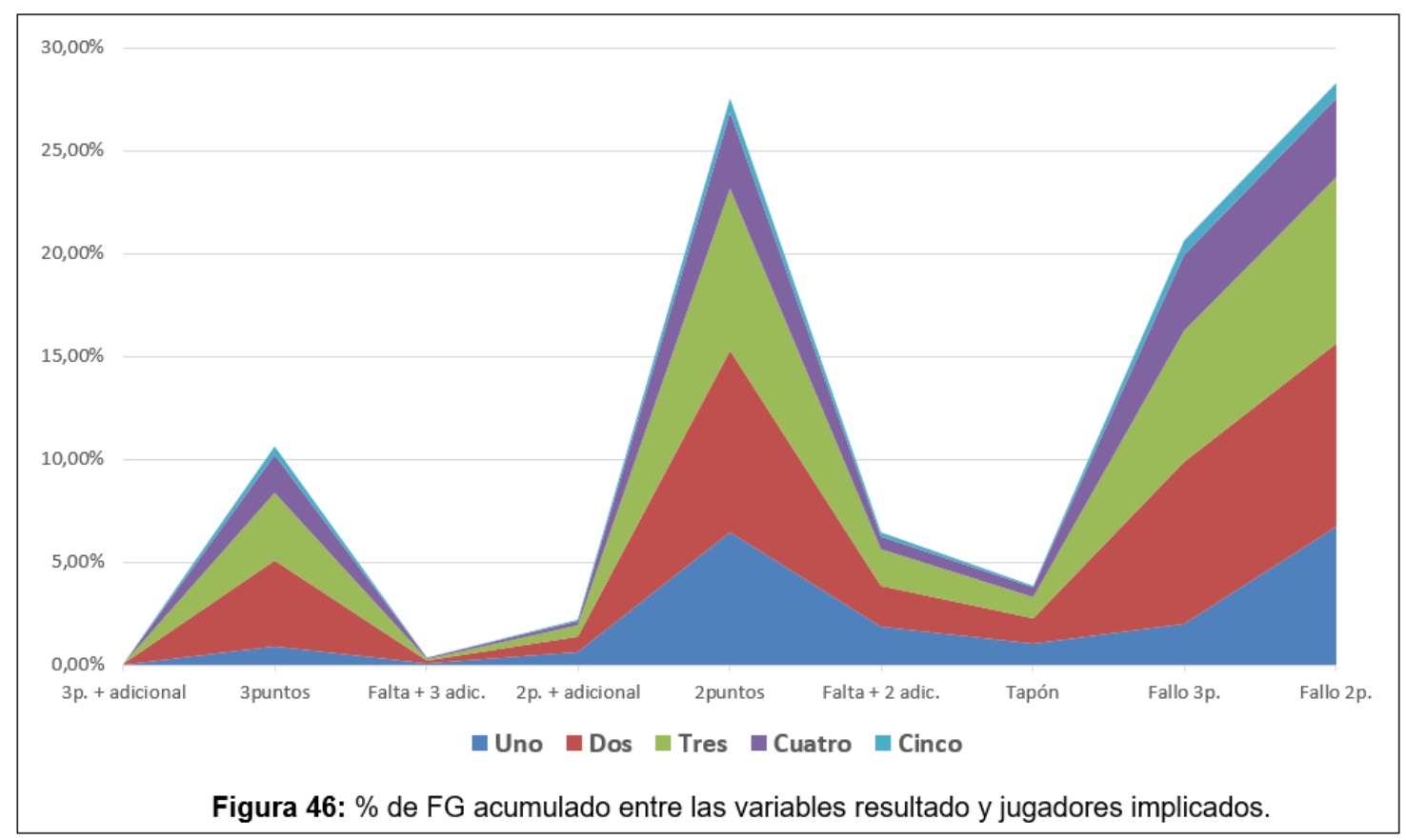

Si observamos los resultados del FG en relación al número de jugadores que entran en contacto con el balón (tabla 48), vemos como las jugadas donde intervienen uno, tres o dos jugadores son las más efectivas en ese orden, existiendo diferencias apreciables con las jugadas en las que intervienen cuatro o cinco, con los peores resultados respectivamente. El hecho de que las jugadas en las que tan solo interviene un jugador tengan tan buen porcentaje está directamente relacionado con el rebote, pues como acabamos de ver en el apartado anterior, tiene un 59,01\% de resultados positivos.

\begin{tabular}{|c|c|c|c|}
\cline { 2 - 4 } \multicolumn{1}{c|}{} & RESULTADO + & RESUTLADO- & TOTAL \\
\hline Uno & $50,48 \%$ & $49,52 \%$ & $100,00 \%$ \\
\hline Dos & $46,83 \%$ & $53,17 \%$ & $100,00 \%$ \\
\hline Tres & $46,87 \%$ & $53,13 \%$ & $100,00 \%$ \\
\hline Cuatro & $44,86 \%$ & $55,14 \%$ & $100,00 \%$ \\
\hline Cinco & $45,31 \%$ & $54,69 \%$ & $100,00 \%$ \\
\hline
\end{tabular}

Tabla 48: \% de FG con resultado (+) y (-) según jugadores implicados. 
Si vamos más allá y nos centramos en que número de jugadores tienen un mayor porcentaje dentro de cada posible resultado, lo cual se recoge en la tabla 49, vemos como en todos los resultados es anecdótico el hecho de que intervengan 5 jugadores. En el resto de resultados se da un mayor porcentaje en los FG con intervención de dos o tres jugadores. Hemos de remarcar como todos los resultados relacionados con el FG de 2 puntos (fallo, falta+2 adic., canasta, canasta+adic.), y el tapón, relacionado con el FG en general, tienen también un elevado porcentaje en los FG en cuya jugada ha entrado en contacto con el balón tan solo un jugador.

\begin{tabular}{|c|c|c|c|c|c|c|c|c|c|}
\cline { 2 - 10 } \multicolumn{1}{c|}{} & 3p. + adicional & 3puntos & Falta + 3 adic. & 2p. + adicional & 2puntos & Falta + 2 adic. & Tapón & Fallo 3p. & Fallo 2p. \\
\hline Uno & $14,29 \%$ & $8,64 \%$ & $19,64 \%$ & $27,51 \%$ & $23,45 \%$ & $29,25 \%$ & $27,39 \%$ & $9,77 \%$ & $23,63 \%$ \\
\hline Dos & $35,71 \%$ & $39,26 \%$ & $42,86 \%$ & $34,62 \%$ & $31,89 \%$ & $30,95 \%$ & $31,60 \%$ & $38,22 \%$ & $31,59 \%$ \\
\hline Tres & $35,71 \%$ & $30,86 \%$ & $23,21 \%$ & $26,63 \%$ & $28,77 \%$ & $27,04 \%$ & $27,39 \%$ & $30,83 \%$ & $28,44 \%$ \\
\hline Cuatro & $14,29 \%$ & $17,65 \%$ & $12,50 \%$ & $7,99 \%$ & $13,43 \%$ & $10,05 \%$ & $11,09 \%$ & $17,79 \%$ & $13,55 \%$ \\
\hline Cinco & $0,00 \%$ & $3,59 \%$ & $1,79 \%$ & $3,25 \%$ & $2,46 \%$ & $2,71 \%$ & $2,52 \%$ & $3,38 \%$ & $2,78 \%$ \\
\hline TOTAL & $100,00 \%$ & $100,00 \%$ & $100,00 \%$ & $100,00 \%$ & $100,00 \%$ & $100,00 \%$ & $100,00 \%$ & $100,00 \%$ & $100,00 \%$ \\
\hline
\end{tabular}

Tabla 49: \% de FG según jugadores implicados dentro de cada resultado.

\subsubsection{Resultado y QT}

La relación del resultado de los FG y el QT en que se ejecutan nos ayudará a entender un poco más los patrones de juego en baloncesto. En la tabla 50 podemos ver el porcentaje de incidencia de la combinación de las categorías de ambas variables sobre el total de FG.

\begin{tabular}{|c|c|c|c|c|c|c|c|c|c|}
\cline { 2 - 9 } \multicolumn{1}{c|}{} & 3p. + adicional & 3puntos & Falta + 3 adic. & 2p. + adicional & 2puntos & Falta + 2 adic. & Tapón & Fallo 3p. & Fallo 2p. \\
\hline 19 QT & $0,02 \%$ & $2,58 \%$ & $0,10 \%$ & $0,54 \%$ & $8,05 \%$ & $1,40 \%$ & $0,92 \%$ & $4,86 \%$ & $7,54 \%$ \\
\hline 20 QT & $0,02 \%$ & $2,69 \%$ & $0,06 \%$ & $0,52 \%$ & $6,90 \%$ & $1,73 \%$ & $0,87 \%$ & $5,23 \%$ & $7,27 \%$ \\
\hline 3우 QT & $0,01 \%$ & $2,62 \%$ & $0,10 \%$ & $0,56 \%$ & $6,59 \%$ & $1,49 \%$ & $0,95 \%$ & $5,04 \%$ & $7,05 \%$ \\
\hline 40 QT & $0,04 \%$ & $2,71 \%$ & $0,10 \%$ & $0,56 \%$ & $6,03 \%$ & $1,80 \%$ & $1,10 \%$ & $5,48 \%$ & $6,45 \%$ \\
\hline
\end{tabular}

Tabla 50: \% de FG entre las variables resultado y QT.

Analizando los resultados de los FG dentro de cada cuarto (tabla 51, figura 47) podemos ver como en todos los cuartos se da una dinámica similar, acumulando los mayores porcentajes en las mismas categorías de resultados.

\begin{tabular}{|c|c|c|c|c|c|c|c|c|c|c|}
\cline { 2 - 11 } \multicolumn{1}{c|}{} & 3p. + adicional & 3puntos & Falta + 3 adic. & 2p. + adicional & 2puntos & Falta + 2 adic. & Tapón & Fallo 3p. & Fallo 2p. & TOTAL \\
\hline 19 QT & $0,07 \%$ & $9,93 \%$ & $0,40 \%$ & $2,08 \%$ & $30,92 \%$ & $5,38 \%$ & $3,55 \%$ & $18,68 \%$ & $28,98 \%$ & $100,00 \%$ \\
\hline 20 QT & $0,08 \%$ & $10,64 \%$ & $0,26 \%$ & $2,07 \%$ & $27,26 \%$ & $6,84 \%$ & $3,45 \%$ & $20,67 \%$ & $28,74 \%$ & $100,00 \%$ \\
\hline 30 QT & $0,05 \%$ & $10,74 \%$ & $0,40 \%$ & $2,30 \%$ & $27,00 \%$ & $6,11 \%$ & $3,89 \%$ & $20,66 \%$ & $28,85 \%$ & $100,00 \%$ \\
\hline 4은 QT & $0,16 \%$ & $11,18 \%$ & $0,40 \%$ & $2,29 \%$ & $24,84 \%$ & $7,43 \%$ & $4,53 \%$ & $22,58 \%$ & $26,60 \%$ & $100,00 \%$ \\
\hline
\end{tabular}

Tabla 51: \% de FG según resultado dentro de cada QT. 


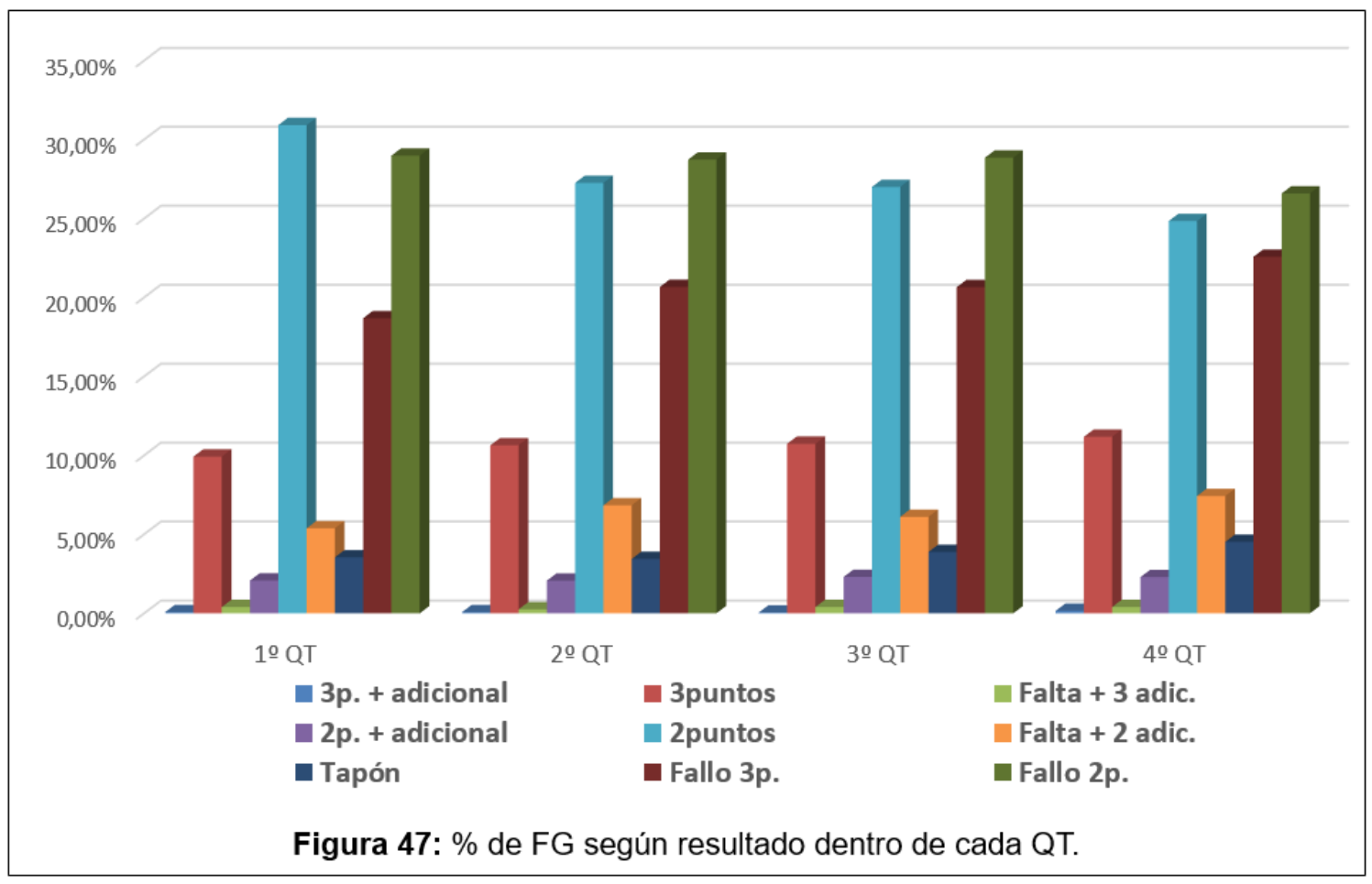

En cuanto a como se reparte cada resultado según los cuartos, la tabla 52, y de forma más clara la figura 48 , nos muestran ciertas dinámicas a tener en cuenta. Los 3p.+adic. se producen mayormente, y con gran diferencia, en el último cuarto del partido. Se trata del último, y por tanto, decisivo periodo de los encuentros, produciéndose defensas más agresivas que desembocan en este resultado.

\begin{tabular}{|c|c|c|c|c|c|c|c|c|c|}
\cline { 2 - 9 } \multicolumn{1}{c|}{} & 3p. + adicional & 3puntos & Falta + 3 adic. & 2p. + adicional & 2puntos & Falta + 2 adic. & Tapón & Fallo 3p. & Fallo 2p. \\
\hline 10 QT & $21,43 \%$ & $24,35 \%$ & $28,57 \%$ & $24,85 \%$ & $29,20 \%$ & $21,81 \%$ & $24,03 \%$ & $23,59 \%$ & $26,64 \%$ \\
\hline 20 QT & $21,43 \%$ & $25,38 \%$ & $17,86 \%$ & $23,97 \%$ & $25,02 \%$ & $26,93 \%$ & $22,69 \%$ & $25,38 \%$ & $25,68 \%$ \\
\hline 39 QT & $14,28 \%$ & $24,71 \%$ & $26,79 \%$ & $25,74 \%$ & $23,92 \%$ & $23,22 \%$ & $24,71 \%$ & $24,47 \%$ & $24,89 \%$ \\
\hline 49 QT & $42,86 \%$ & $25,56 \%$ & $26,79 \%$ & $25,45 \%$ & $21,86 \%$ & $28,04 \%$ & $28,57 \%$ & $26,57 \%$ & $22,79 \%$ \\
\hline TOTAL & $100,00 \%$ & $100,00 \%$ & $100,00 \%$ & $100,00 \%$ & $100,00 \%$ & $100,00 \%$ & $100,00 \%$ & $100,00 \%$ & $100,00 \%$ \\
\hline
\end{tabular}

Tabla 52: \% de FG según QT dentro de cada resultado.

En los aciertos y fallos de 3 puntos, y en las faltas+2 adic. se da una misma dinámica, aumentando su porcentaje en los segundos cuartos de cada mitad. Podemos observar otra dinámica, en este caso descendente, desde el primer al último periodo en los resultados de acierto y fallo de 2 puntos. 


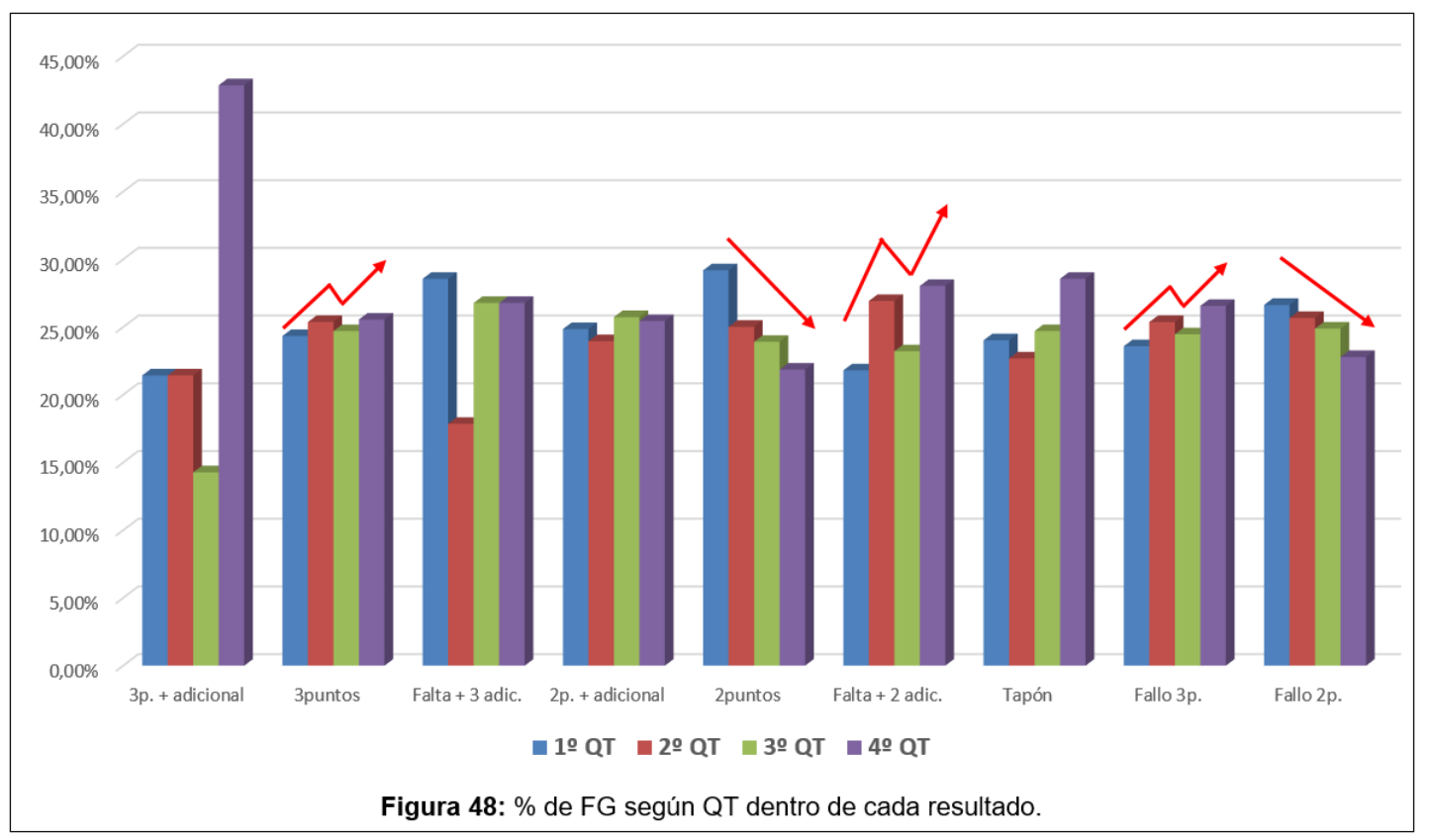

En cuanto a eficacia, es decir, la comparación de resultados con algún valor positivo y los resultados con valor negativo dentro de cada cuarto, debemos fijarnos en la tabla 53 y figura 49. La proporción de resultados positivos dentro de cada cuarto va disminuyendo según avanza

\begin{tabular}{|c|c|c|c|}
\cline { 2 - 4 } \multicolumn{1}{c|}{} & RESULTADO + & RESUTLADO- & TOTAL \\
\hline 10 QT & $48,78 \%$ & $51,22 \%$ & $100,00 \%$ \\
\hline 20 QT & $47,14 \%$ & $52,86 \%$ & $100,00 \%$ \\
\hline 3 QT & $46,60 \%$ & $53,40 \%$ & $100,00 \%$ \\
\hline 4 QT & $46,30 \%$ & $53,70 \%$ & $100,00 \%$ \\
\hline
\end{tabular}
Tabla 53: \% de FG según resultado dentro de cada QT. el encuentro. Esto seguramente este influenciado por el cansancio físico y la presión mental ejercida por la cercanía al momento decisivo del encuentro.

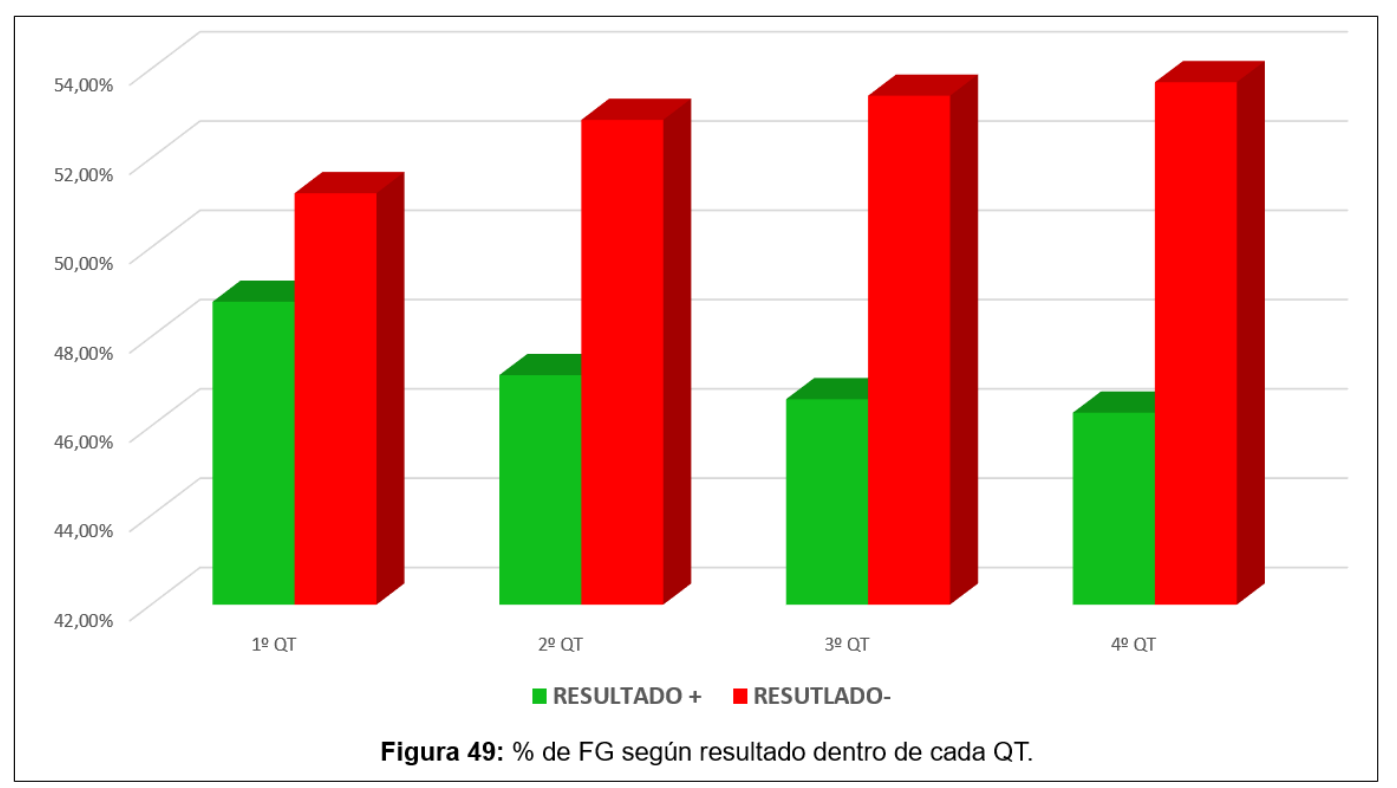




\subsubsection{Resultado y momento especial}

En qué proporción se reparten los resultados de los FG tras momentos especiales nos desvela mucho acerca de la importancia de los mismos (tabla 54).

\begin{tabular}{|c|c|c|c|c|c|c|c|c|c|c|}
\hline & 3p. + adicional & 3puntos & Falta +3 adic. & 2p. + adicional & 2puntos & Falta +2 adic. & Tapón & Fallo 3p. & Fallo 2p. & TOTAL \\
\hline Tiempo Muerto & $0,17 \%$ & $10,71 \%$ & $0,51 \%$ & $2,72 \%$ & $24,49 \%$ & $5,27 \%$ & $3,74 \%$ & $23,30 \%$ & $29,08 \%$ & $100,00 \%$ \\
\hline Última Jugada & $0 \%$ & $7,44 \%$ & $0,32 \%$ & $0,97 \%$ & $17,15 \%$ & $2,27 \%$ & $4,85 \%$ & $44,34 \%$ & $22,65 \%$ & $100,00 \%$ \\
\hline
\end{tabular}

Tabla 54: \% de FG según resultado tras t.muerto.

Los resultados tras un tiempo muerto (figura 50) son en su mayoría lanzamientos de 2 y

3 puntos, produciéndose más fallos que aciertos, pero con unos buenos porcentajes de eficacia.

En cuanto a las últimas jugadas (figura 51) es totalmente distinto, produciéndose en su mayoría fallos de 2 y 3 puntos debido a la presión ejercida por el límite temporal de las mismas, además de, en muchas ocasiones, tratarse de FG muy forzados sin tiempo para mover el balón o generar ventaja para el tirador.
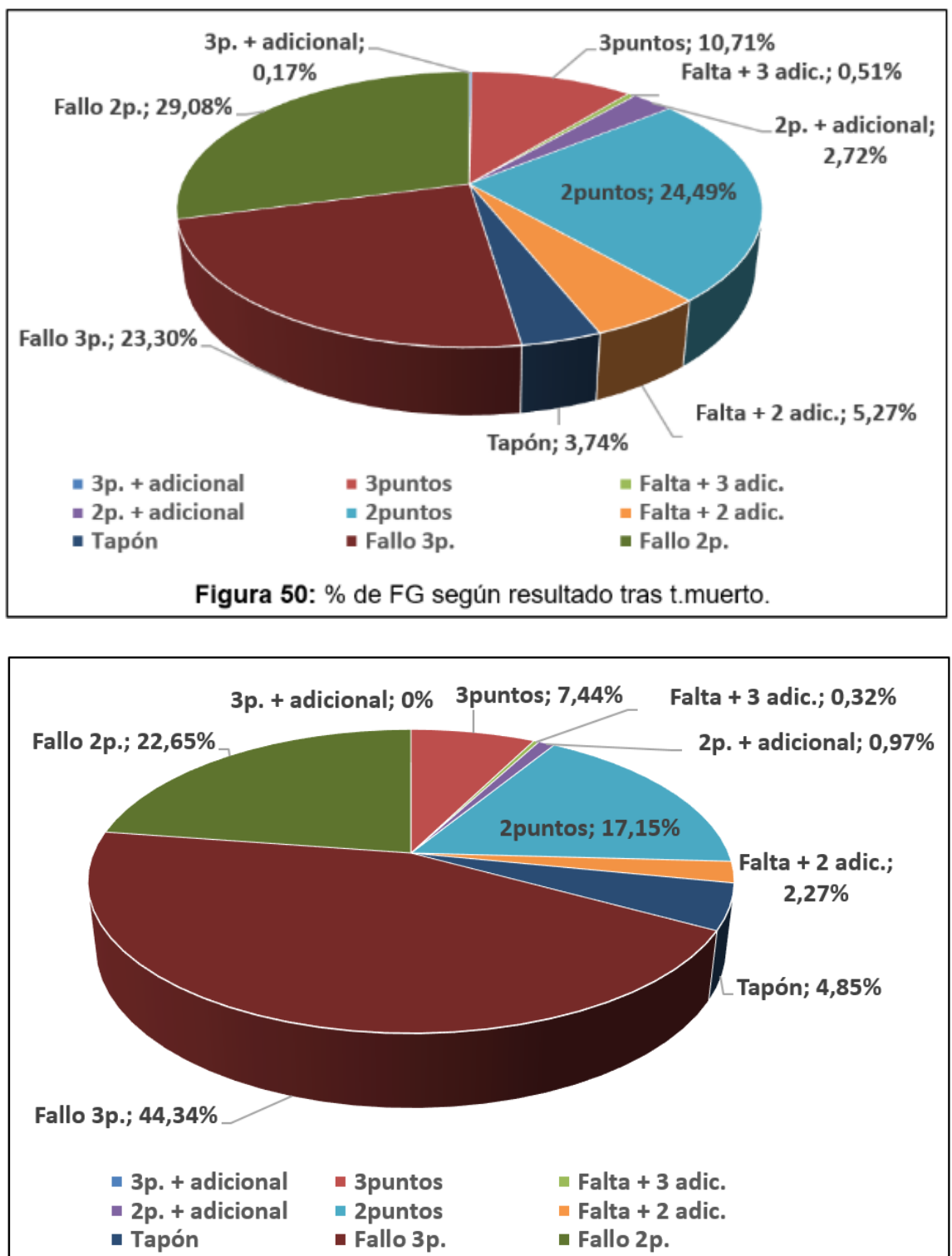

Figura 51: \% de FG según resultado en última jugada. 
Homogenizando todos los resultados dentro de positivos o negativos (tabla 55 y figura 52) vemos como en el caso de los tiempos muertos el porcentaje de resultados positivos en más que aceptable, estando relativamente cerca del 47,23\% que se da de media en los FG.

\begin{tabular}{|c|c|c|c|}
\cline { 2 - 4 } \multicolumn{1}{c|}{} & RESULTADO + & RESUTLADO - & TOTAL \\
\hline Tiempo Muerto & $43,88 \%$ & $56,12 \%$ & $100,00 \%$ \\
\hline Última Jugada & $28,16 \%$ & $71,84 \%$ & $100,00 \%$ \\
\hline
\end{tabular}

Tabla 55: \% de FG según resultado dentro de cada momento especial.

En cuanto a las últimas jugadas, el resultado negativo sobrepasa descaradamente al positivo, lo cual como ya hemos explicado, es algo lógico.

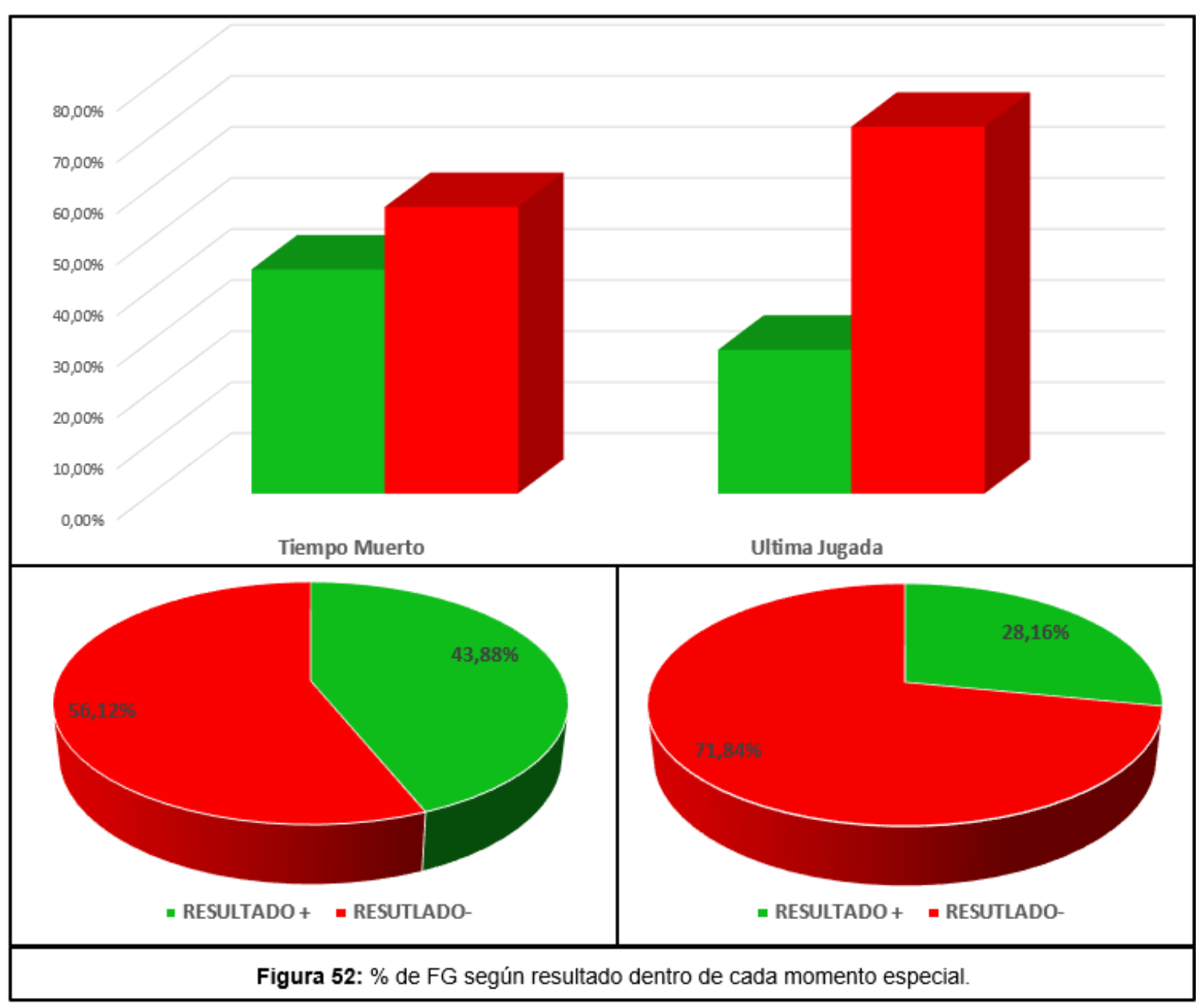




\subsection{TIEMPO DE POSESIÓN}

En la figura 53 se recoge el reparto porcentual de los FG en las franjas de posesión estudiadas, pudiendo ver como la posesión intermedia es la más utilizada con casi un $50 \%$, lo cual, como dijimos anteriormente, es lógico por ser el punto medio entre la precipitación y la presión del límite temporal.

En cuanto a las otras dos franjas, la de 17-24 es en la que menos FG se producen, lo cual es debido a que tan solo en contrataques o

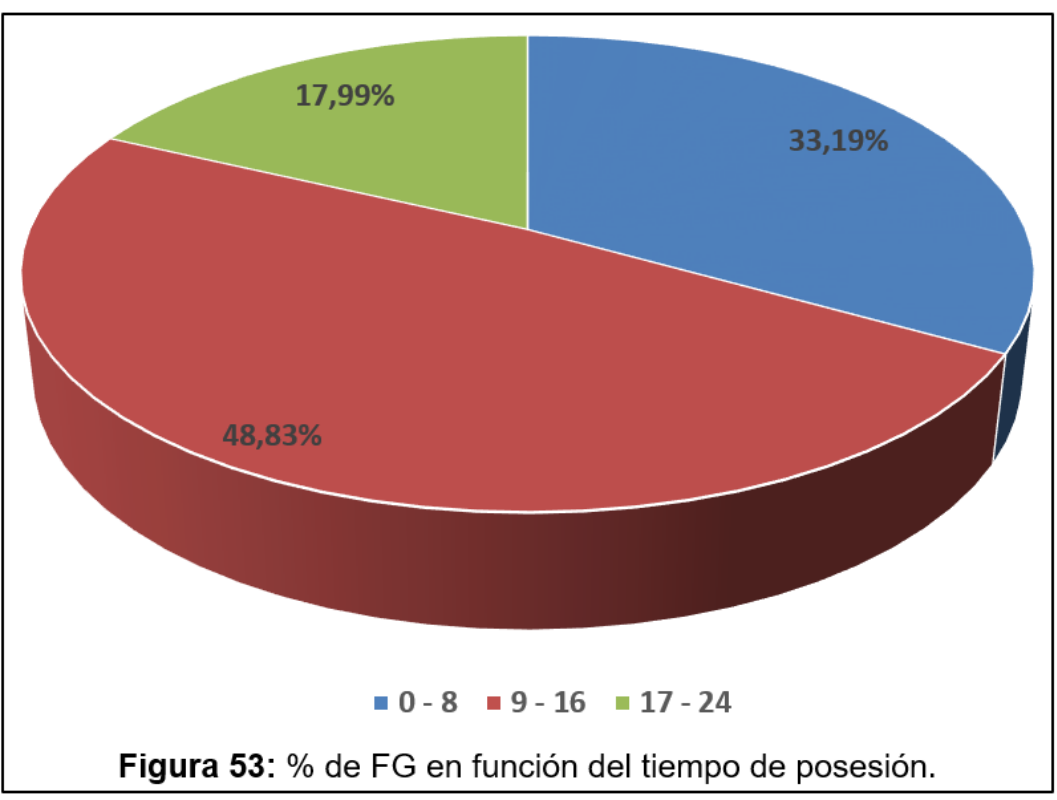

Figura 53: \% de FG en función del tiempo de posesión. transiciones rápidas se pueden dar. No es algo común, pues los equipos suelen "subir" el balón mientras el base organiza o inicia la jugada.

\subsubsection{Tiempo de posesión y tipo de tiro}

La relación entre el tipo de FG y la franja de posesión en que estos se realizan nos facilitará la compresión de los patrones de juego para su posterior aplicación práctica. Como podemos ver en la tabla 56, las combinaciones de categorías con más porcentaje sobre el total, y por tanto, mayor incidencia en el juego, son los tiros normales y buenos en la franja de posesión 9-16. Debemos destacar también como los malos tiros tienen su mayor porcentaje en la última franja de posesión, existiendo una gran diferencia con el resto de franjas.

\begin{tabular}{|c|c|c|c|}
\cline { 2 - 4 } \multicolumn{1}{c|}{} & $\mathbf{0 - 8}$ & $\mathbf{9 - 1 6}$ & $\mathbf{1 7 - 2 4}$ \\
\hline Buen tiro & $9,67 \%$ & $18,92 \%$ & $9,14 \%$ \\
\hline Tiro normal & $16,51 \%$ & $25,66 \%$ & $7,58 \%$ \\
\hline Mal tiro & $7,00 \%$ & $4,24 \%$ & $1,26 \%$ \\
\hline
\end{tabular}

Tabla 56: \% de FG entre las variables tiempo de posesión y tipo de tiro. 
El reparto porcentual entre las franjas de posesión de los FG de cada tipo de tiro (tabla 57, figura 54) nos deja ver diferencias significativas. El mayor porcentaje de malos tiros se produce en la franja 0-8, la cual somete al jugador a una presión temporal por el límite de este, obligando a finalizar la jugada independientemente de las condiciones bajo las que se encuentre.

\begin{tabular}{|c|c|c|c|c|}
\cline { 2 - 5 } \multicolumn{1}{c|}{} & $\mathbf{0 - 8}$ & $\mathbf{9 - 1 6}$ & $\mathbf{1 7}-\mathbf{2 4}$ & TOTAL \\
\hline Buen tiro & $25,63 \%$ & $50,14 \%$ & $24,23 \%$ & $100,00 \%$ \\
\hline Tiro normal & $33,19 \%$ & $51,58 \%$ & $15,24 \%$ & $100,00 \%$ \\
\hline Mal tiro & $55,99 \%$ & $33,94 \%$ & $10,07 \%$ & $100,00 \%$ \\
\hline
\end{tabular}

Tabla 57: \% de FG según tiempo de posesión dentro de cada tipo de tiro.

En cuanto a los FG buenos y normales, vemos como tienden a realizarse en la posesión intermedia, donde hay tiempo suficiente para valorar y decidir cómo, cuándo y dónde finalizar. En los buenos tiros, tras el dominio de la franja intermedia, se mantienen un equilibrio entre las otras dos. Esto es debido a, por un lado, los contraataques y transiciones rápidas donde se generan ventajas, $\quad \mathrm{y}$ por otro lado, \begin{tabular}{|l|l|}
\hline Buen tiro \\
\hline $30,00 \%$
\end{tabular} los últimos segundos donde se finalizan jugadas tras mover el balón y/o la defensa, generando con ello ciertas ventajas.

En relación al reparto de los tipos de FG dentro de cada franja de posesión (tabla 58 y figuras 55, 56 y 57) vemos como se producen proporcionalmente más buenos tiros en la primera franja, disminuyendo en la segunda y más aún en la última; dándose la dinámica opuesta para los malos tiros. 


\begin{tabular}{|c|c|c|c|}
\cline { 2 - 4 } \multicolumn{1}{c|}{} & $\mathbf{0 - 8}$ & $\mathbf{9 - 1 6}$ & $\mathbf{1 7 - 2 4}$ \\
\hline Buen tiro & $29,15 \%$ & $38,75 \%$ & $50,84 \%$ \\
\hline Tiro normal & $49,76 \%$ & $52,56 \%$ & $42,15 \%$ \\
\hline Mal tiro & $21,09 \%$ & $8,69 \%$ & $7,00 \%$ \\
\hline TOTAL & $100,00 \%$ & $100,00 \%$ & $100,00 \%$ \\
\hline
\end{tabular}

Tabla 58: \% de FG según tipo de tiro dentro de cada franja de posesión.

De lo anterior se extrae que la franja 17-24 es en la que mejores situaciones de tiro se generan. Esto es debido a la superioridad en el ataque y/o la falta de tiempo del equipo defensor para ejecutar una buena transición defensiva.

En las otras dos franjas el mayor porcentaje de tiros es de tipo normal, el más común como demostraremos en apartados posteriores.
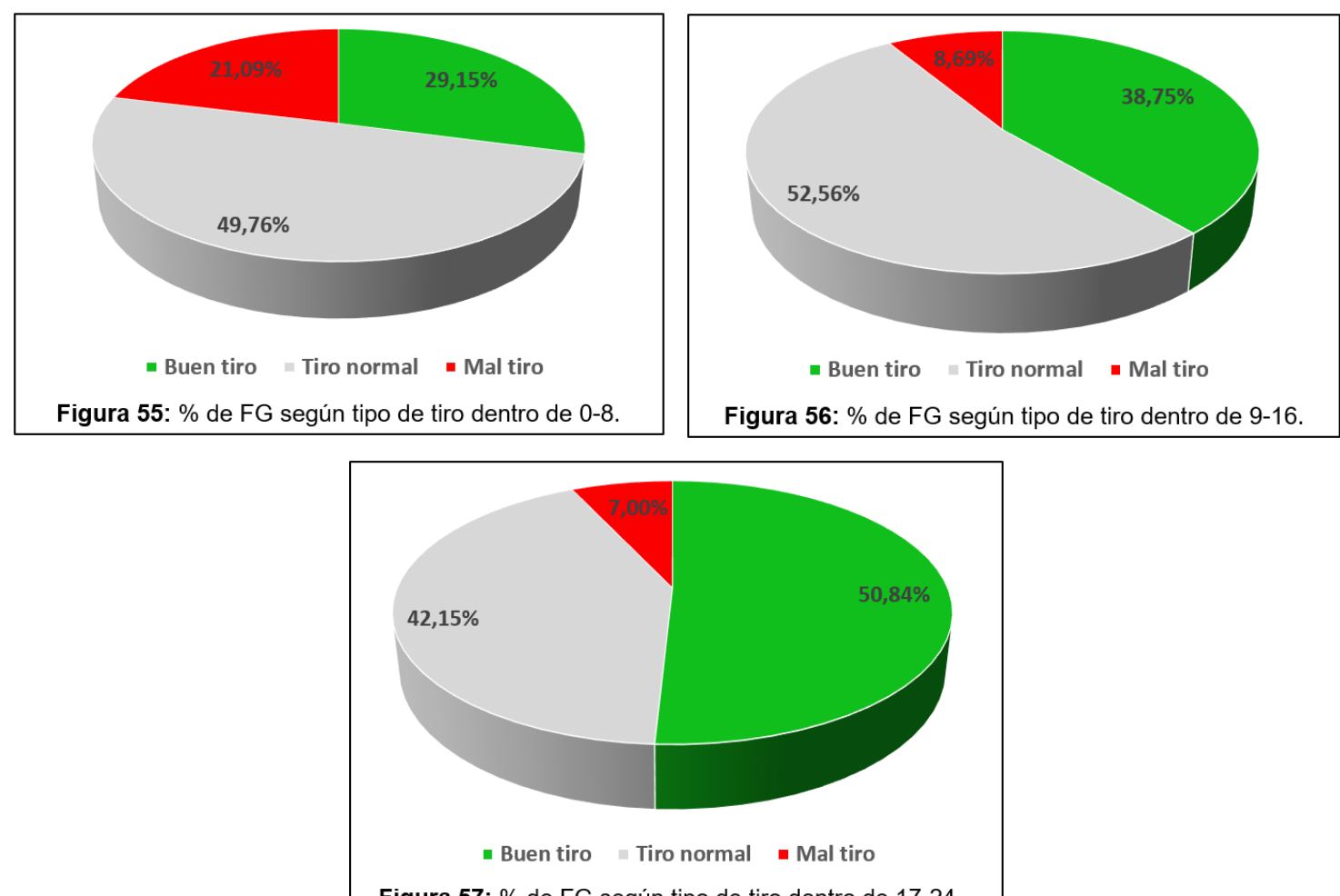

Figura 57: \% de FG según tipo de tiro dentro de 17-24. 


\subsubsection{Tiempo de posesión y ventaja/desventaja}

El hecho de ir igualados, por encima, o por debajo en el marcador influye sobre el juego de los equipos. La siguiente tabla (tabla 59) nos muestra como se reparte el porcentaje de FG dentro de cada situación del marcador según la franja de posesión.

\begin{tabular}{|c|c|c|c|c|}
\cline { 2 - 5 } \multicolumn{1}{c|}{} & $\mathbf{0 ~ - ~ 8}$ & $\mathbf{9 - 1 6}$ & $\mathbf{1 7}-\mathbf{2 4}$ & TOTAL \\
\hline Marcador (+) & $34,77 \%$ & $47,23 \%$ & $18,00 \%$ & $100,00 \%$ \\
\hline Empate & $34,38 \%$ & $47,77 \%$ & $17,85 \%$ & $100,00 \%$ \\
\hline Marcador (-) & $31,98 \%$ & $50,02 \%$ & $17,99 \%$ & $100,00 \%$ \\
\hline
\end{tabular}

Tabla 59: \% de FG según tiempo de posesión dentro de cada situación del marcador.

En todas las situaciones del marcador la franja de posesión más utilizada es la intermedia, seguida de la 0-8, y por último, la 17-24 como menos utilizada. Las franjas de posesión en las que se realizan los FG cuando se va empatados o por encima en el marcador son muy similares, casi idénticas. Donde si encontramos diferencias en el reparto es cuando se va por debajo en el marcador.

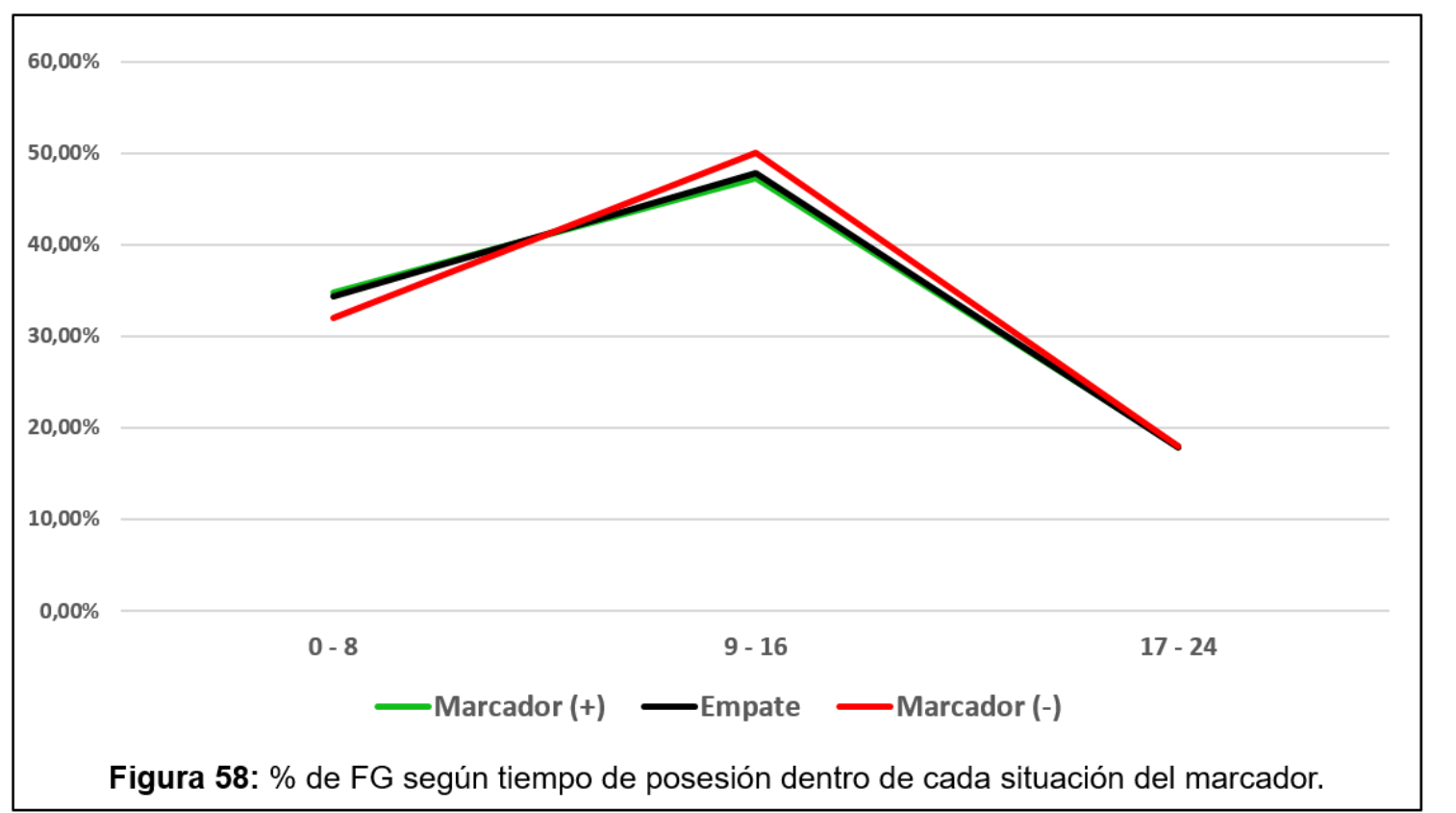

Como podemos ver en la figura anterior (figura 58), la diferencia cuando se va por debajo en el marcador reside en que se aumenta el porcentaje de posesiones intermedias y disminuye el de 0-8, pues se busca revertir la situación en el luminoso realizando FG sin precipitarse y sin dejar correr demasiado el tiempo. 


\subsubsection{Tiempo de posesión y precedente}

La tabla 60 muestra los porcentajes de cada par de categorías de las variables "tiempo de posesión" y "precedente" sobre el total de FG realizados. En ella podemos ver como la mayor repercusión sobre el juego la tienen el pase y la jugada personal. Tras estas dos categorías, el bloqueo directo dispone de un porcentaje considerable en la franja de posesión intermedia.

\begin{tabular}{|c|c|c|c|}
\cline { 2 - 4 } \multicolumn{1}{c|}{} & $\mathbf{0 - 8}$ & $\mathbf{9 - 1 6}$ & $\mathbf{1 7}-\mathbf{2 4}$ \\
\hline Contraataque & $0,06 \%$ & $0,01 \%$ & $2,34 \%$ \\
\hline Bloqueo Directo & $4,73 \%$ & $9,87 \%$ & $1,76 \%$ \\
\hline Pase & $12,02 \%$ & $18,47 \%$ & $5,15 \%$ \\
\hline Jugada Personal & $15,65 \%$ & $16,58 \%$ & $5,18 \%$ \\
\hline Robo & $0,09 \%$ & $0,04 \%$ & $2,71 \%$ \\
\hline Rebote & $0,64 \%$ & $3,86 \%$ & $0,84 \%$ \\
\hline
\end{tabular}

Tabla 60: \% de FG entre las variables tiempo de posesión y precedente.

La figura 59 recoge el porcentaje de FG tras los precedentes dentro de cada franja de posesión. En ella podemos ver como en todas las franjas de posesión los precedentes que más se dan son el pase y la jugada personal, aunque hay diferencias en la superioridad del uno sobre el otro. Mientras que en la franja 17-24 se da un equilibrio entre ambos, y en la intermedia se producen más FG tras pase que tras jugada personal; en la franja 0-8 se producen más jugadas personales que pases, lo cual es debido a que, ante la presión del límite temporal, el jugador debe buscarse/crearse la opción de tiro de forma individual.

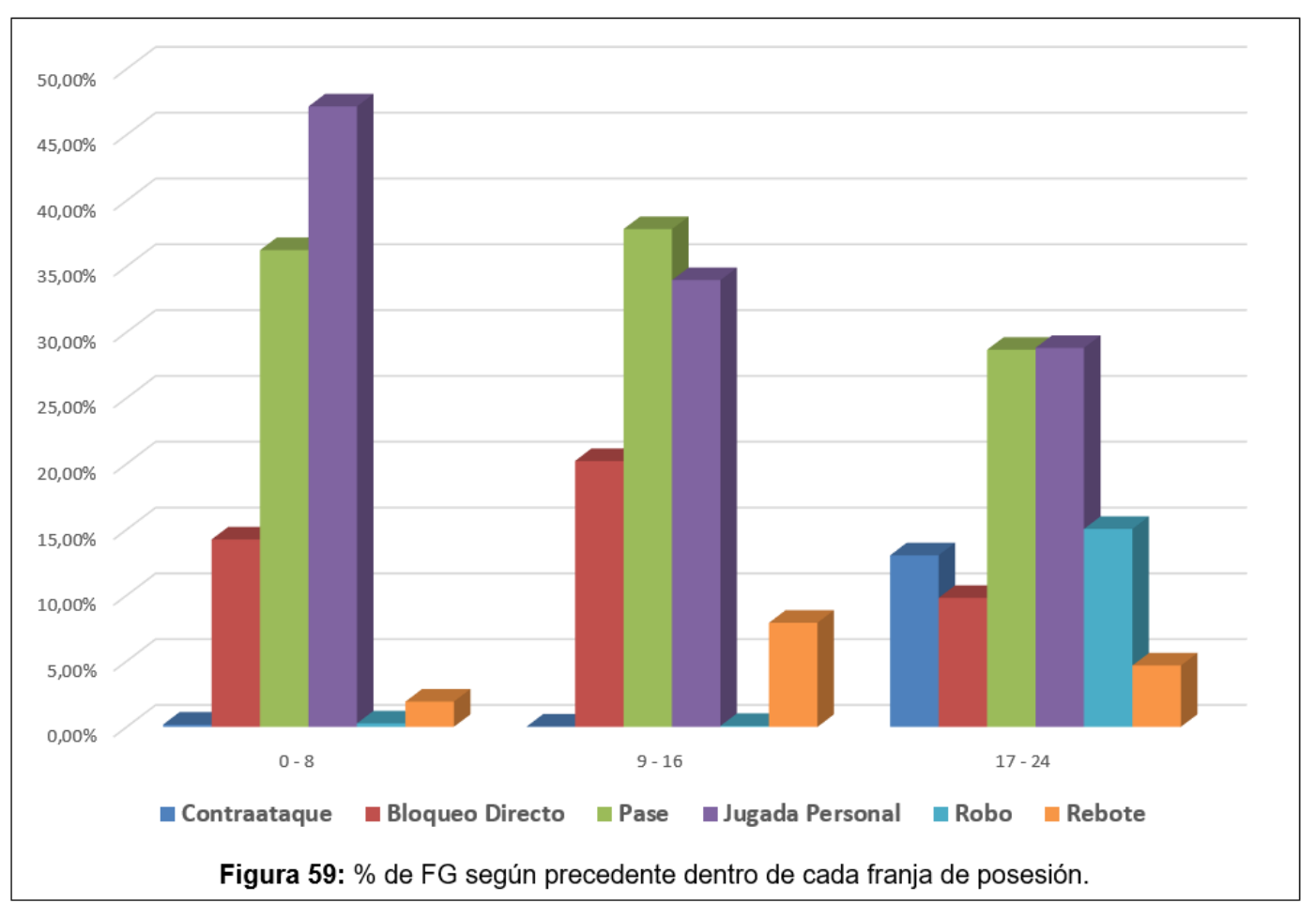


Analizando mejor los datos con la tabla 61 vemos como en las franjas 0-8 y 9-16 el bloqueo directo ocupa el tercer lugar, teniendo también un porcentaje considerable en la franja 17-24, pero siendo relegado en esta a un $5^{\circ}$ puesto, pues los FG tras robo y contraataque lo superan.

\begin{tabular}{|c|c|c|c|}
\cline { 2 - 4 } \multicolumn{1}{c|}{} & $\mathbf{0 - 8}$ & $\mathbf{9 - 1 6}$ & $\mathbf{1 7 - 2 4}$ \\
\hline Contraataque & $0,18 \%$ & $0,03 \%$ & $13,03 \%$ \\
\hline Bloqueo Directo & $14,24 \%$ & $20,21 \%$ & $9,80 \%$ \\
\hline Pase & $36,23 \%$ & $37,83 \%$ & $28,65 \%$ \\
\hline Jugada Personal & $47,15 \%$ & $33,95 \%$ & $28,80 \%$ \\
\hline Robo & $0,27 \%$ & $0,08 \%$ & $15,04 \%$ \\
\hline Rebote & $1,93 \%$ & $7,91 \%$ & $4,67 \%$ \\
\hline TOTAL & $100,00 \%$ & $100,00 \%$ & $100,00 \%$ \\
\hline
\end{tabular}

Tabla 61: \% de FG según precedente dentro de cada franja de posesión.

Apoyándonos sobre los datos mostrados en la tabla 62 y la figura 60, las cuales nos muestran el reparto entre las franjas de posesión de cada precedente, podemos remarcar varios resutlados. Por un lado, el contraataque se produce

\begin{tabular}{|c|c|c|c|c|}
\cline { 2 - 5 } \multicolumn{1}{c|}{} & $\mathbf{0 - 8}$ & $\mathbf{9 - 1 6}$ & $\mathbf{1 7 - 2 4}$ & TOTAL \\
\hline Contraataque & $2,41 \%$ & $0,53 \%$ & $97,06 \%$ & $100,00 \%$ \\
\hline Bloqueo Directo & $28,90 \%$ & $60,32 \%$ & $10,78 \%$ & $100,00 \%$ \\
\hline Pase & $33,73 \%$ & $51,81 \%$ & $14,46 \%$ & $100,00 \%$ \\
\hline Jugada Personal & $41,83 \%$ & $44,32 \%$ & $13,85 \%$ & $100,00 \%$ \\
\hline Robo & $3,19 \%$ & $1,37 \%$ & $95,44 \%$ & $100,00 \%$ \\
\hline Rebote & $11,97 \%$ & $72,31 \%$ & $15,72 \%$ & $100,00 \%$ \\
\hline
\end{tabular}

Tabla 62: \% de FG según franja de posesión dentro de cada precedente. es un resultado

esperable, pues en la propia definición de contraataque se especifica que, además de la superioridad numérica, debe realizarse de forma rápida sin dar tiempo a la transición defensiva del rival. El hecho de que se dé, aunque sea mínimamente, dentro de las otras franjas, es debido a ocasiones especiales en las que el tiempo del cuarto es inferior a 24", haciendo por tanto que las posesiones se ajusten al tiempo del que se dispone. Algo muy similar ocurre con el robo, dándose casi exclusivamente en la franja 17-24.

En cuanto al bloqueo directo, el pase y la jugada personal, todos tienen un mayor porcentaje en la franja intermedia, pero en el caso de la jugada personal, mantiene un equilibrio con la franja 0-8. 


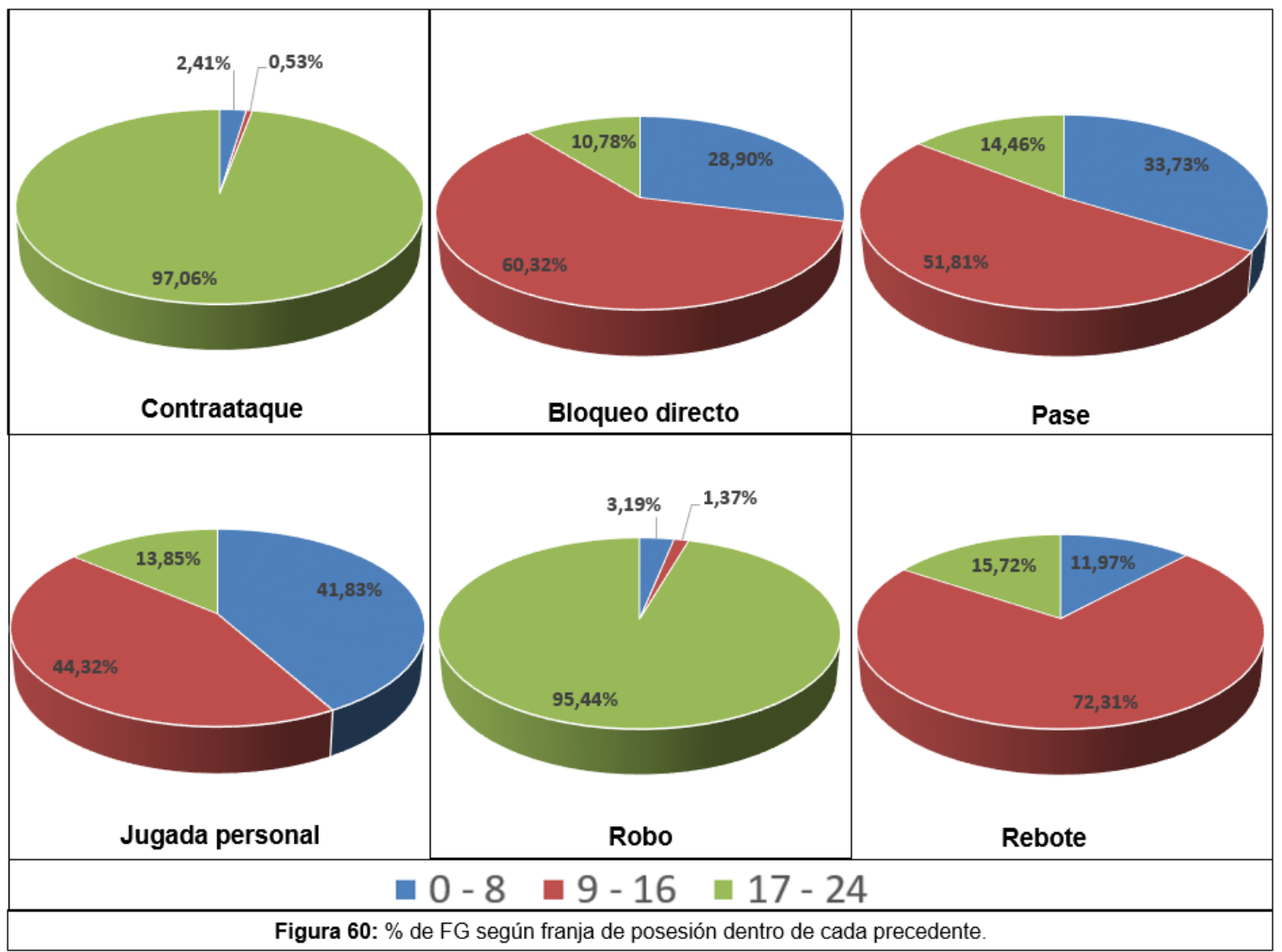

Antes de dar por finalizado este apartado me gustaría explicar ciertos datos que a priori podrían parecer erróneos, concretamente estoy hablando de los relativos al rebote. En el baloncesto, como en todos los deportes, se van produciendo evoluciones técnicas y tácticas, lo cual obliga al reglamento a evolucionar con ellas. Podríamos poner como ejemplo clarificador el aumento de la distancia de la línea de 3 puntos adoptado por la FIBA desde el 1 de octubre de 2010. No se trata de una medida aleatoria, si no que busca una adaptación del reglamento a las características del baloncesto actual. Por un lado buscaba "encarecer" las canastas de 3 puntos, y por otro lado, ante el aumento del tamaño medio de los jugadores, facilitar más espacio al juego interior. En relación al rebote, hay una regla que se ha impuesto en temporadas diferentes dentro de las ligas analizadas. Esta regla consiste en que tras un rebote ofensivo el marcador de posesión no se reinicia desde los 24 segundos, si no desde 14, favoreciendo así el dinamismo del juego, un mayor número de posesiones, y por tanto, más espectáculo, pues no debemos olvidarnos de que el deporte como espectáculo es un negocio que busca una rentabilidad.

Esta regla se aplicó en la FIBA en la temporada 2014-2015, en la WNBA desde 2016 y en la NBA en la temporada 2018-2019. Dado que las temporadas analizadas en este 
estudio son la 2017-2018 y la 2018-2019, el cambio en la NBA afectó al estudio, siendo esta la razón de la mayor parte de los FG tras rebote producidos en la franja de posesión 17-24. La otra parte, que es mínima, se debe a los FG realizados en esa franja tras un rebote ofensivo cuyo lanzamiento previo no ha tocado el aro, no reiniciándose por tanto desde 14 segundos, si no que continua de forma normal. Su porcentaje en la franja 0-8 es debido a los FG tras lanzamientos previos que no tocan aro, dejando esa franja de posesión al lanzamiento; y los realizados en los últimos segundos de cuarto, no disponiendo de la posibilidad de reinicio.

\subsubsection{Tiempo de posesión y jugadores implicados}

La siguiente tabla (tabla 63) muestra la combinación de estas dos variables sobre el total de FG realizados, pudiendo observar como los mayores porcentajes se dan en la combinación de la categoría " $0-8$ " con tres, cuatro y dos jugadores; la franja 9-16 con dos y tres; y por último, la categoría "17-24" con dos y un jugador. Estos resultados son lógicos, pues a mayor tiempo de posesión transcurrido, mayor número

\begin{tabular}{|c|c|c|c|}
\cline { 2 - 4 } \multicolumn{1}{c|}{} & $\mathbf{0 - \mathbf { 8 }}$ & $\mathbf{9 - 1 6}$ & $\mathbf{1 7}-\mathbf{2 4}$ \\
\hline Uno & $3,02 \%$ & $9,38 \%$ & $7,30 \%$ \\
\hline Dos & $7,83 \%$ & $17,84 \%$ & $8,25 \%$ \\
\hline Tres & $11,47 \%$ & $15,40 \%$ & $2,23 \%$ \\
\hline Cuatro & $8,61 \%$ & $5,59 \%$ & $0,19 \%$ \\
\hline Cinco & $2,25 \%$ & $0,63 \%$ & $0,01 \%$ \\
\hline
\end{tabular}

Tabla 63: \% de FG entre las variables tiempo de posesión y jugadores implicados. de jugadores implicados.

Como demostraremos más adelante, para la realización de un FG lo más común es que entren en contacto con el balón dos o tres jugadores, pero como vemos en la tabla 64, existen diferencias según la franja de posesión en la que se ejecuten. En la franja 0-8 lo más común es tres jugadores, seguida de cuatro y dos respectivamente. El hecho de que en esta franja se dé el mayor porcentaje de cuatro y cinco jugadores es lógico, pues cuanto más tiempo de posesión

\begin{tabular}{|c|c|c|c|}
\cline { 2 - 4 } \multicolumn{1}{c|}{} & $\mathbf{0 - 8}$ & $\mathbf{9 - 1 6}$ & $\mathbf{1 7 - 2 4}$ \\
\hline Uno & $9,11 \%$ & $19,20 \%$ & $40,61 \%$ \\
\hline Dos & $23,60 \%$ & $36,53 \%$ & $45,89 \%$ \\
\hline Tres & $34,56 \%$ & $31,54 \%$ & $12,39 \%$ \\
\hline Cuatro & $25,94 \%$ & $11,44 \%$ & $1,04 \%$ \\
\hline Cinco & $6,79 \%$ & $1,28 \%$ & $0,07 \%$ \\
\hline TOTAL & $100,00 \%$ & $100,00 \%$ & $100,00 \%$ \\
\hline
\end{tabular}

Tabla 64: \% de FG según $n^{\circ}$ de jugadores dentro de cada franja de posesión. ha transcurrido de forma previa al FG, más posibilidades de que entren mayor número de 
jugadores en contacto con el balón. En la franja 9-16 destacan claramente sobre el resto la intervención de dos y tres jugadores, pero en la franja 17-24 lo hacen dos y un jugador respectivamente, lo cual es debido a que en esos pocos segundos de posesión transcurridos no es fácil que intervengan muchos atacantes, de hecho, la intervención de cuatro o cinco jugadores en esta franja es casi inexistente.

En la figura 61, donde se comparan proporcionalmente las tres franjas de tiempo de posesión, podemos ver como el porcentaje de que intervengan uno o dos jugadores va disminuyendo según avanza el tiempo de posesión. Por el contrario, el porcentaje de que intervengan tres, cuatro o cinco va aumentando.

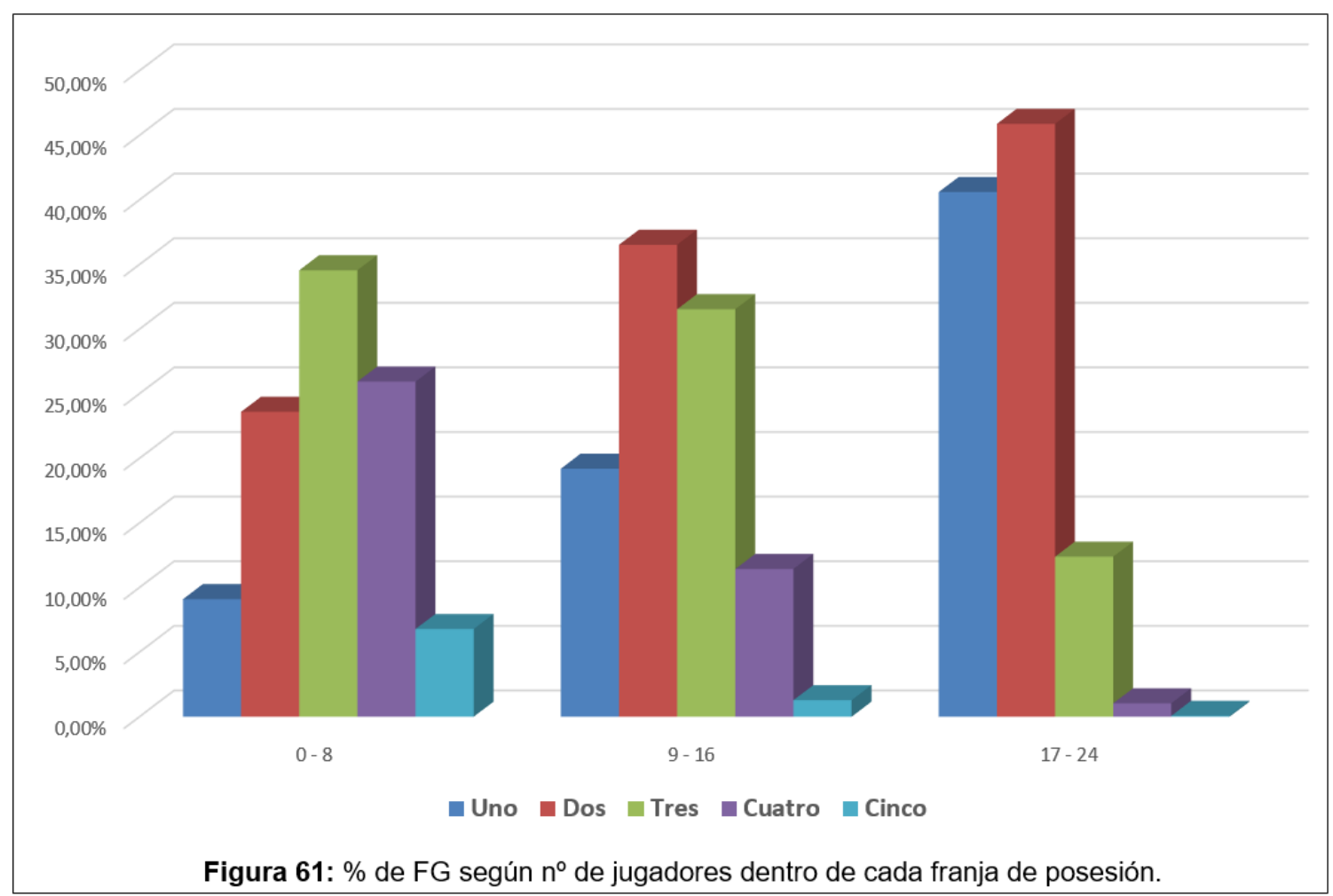




\subsubsection{Tiempo de posesión y QT}

La figura 62 y la tabla 65 muestran los porcentajes de los FG según franja de posesión dentro de cada QT, y en ellas podemos observar como según avanzan los cuartos se van realizando proporcionalmente más lanzamientos en la franja de posesión 0-8. También se aprecia

\begin{tabular}{|c|c|c|c|c|}
\cline { 2 - 5 } \multicolumn{1}{c|}{} & $\mathbf{0 - 8}$ & $\mathbf{9 - 1 6}$ & $\mathbf{1 7}-\mathbf{2 4}$ & TOTAL \\
\hline 10 QT & $30,10 \%$ & $50,67 \%$ & $19,23 \%$ & $100,00 \%$ \\
\hline 29 QT & $33,15 \%$ & $48,88 \%$ & $17,97 \%$ & $100,00 \%$ \\
\hline 3 QT & $34,44 \%$ & $47,21 \%$ & $18,35 \%$ & $100,00 \%$ \\
\hline 40 QT & $35,28 \%$ & $48,43 \%$ & $16,29 \%$ & $100,00 \%$ \\
\hline
\end{tabular}

Tabla 65: \% de FG según franja de posesión dentro de cada QT. como en el $1^{\circ}$ y $3^{\circ} \mathrm{QT}$, primeros cuartos de cada mitad, se realizan más FG en la franja 17-24.

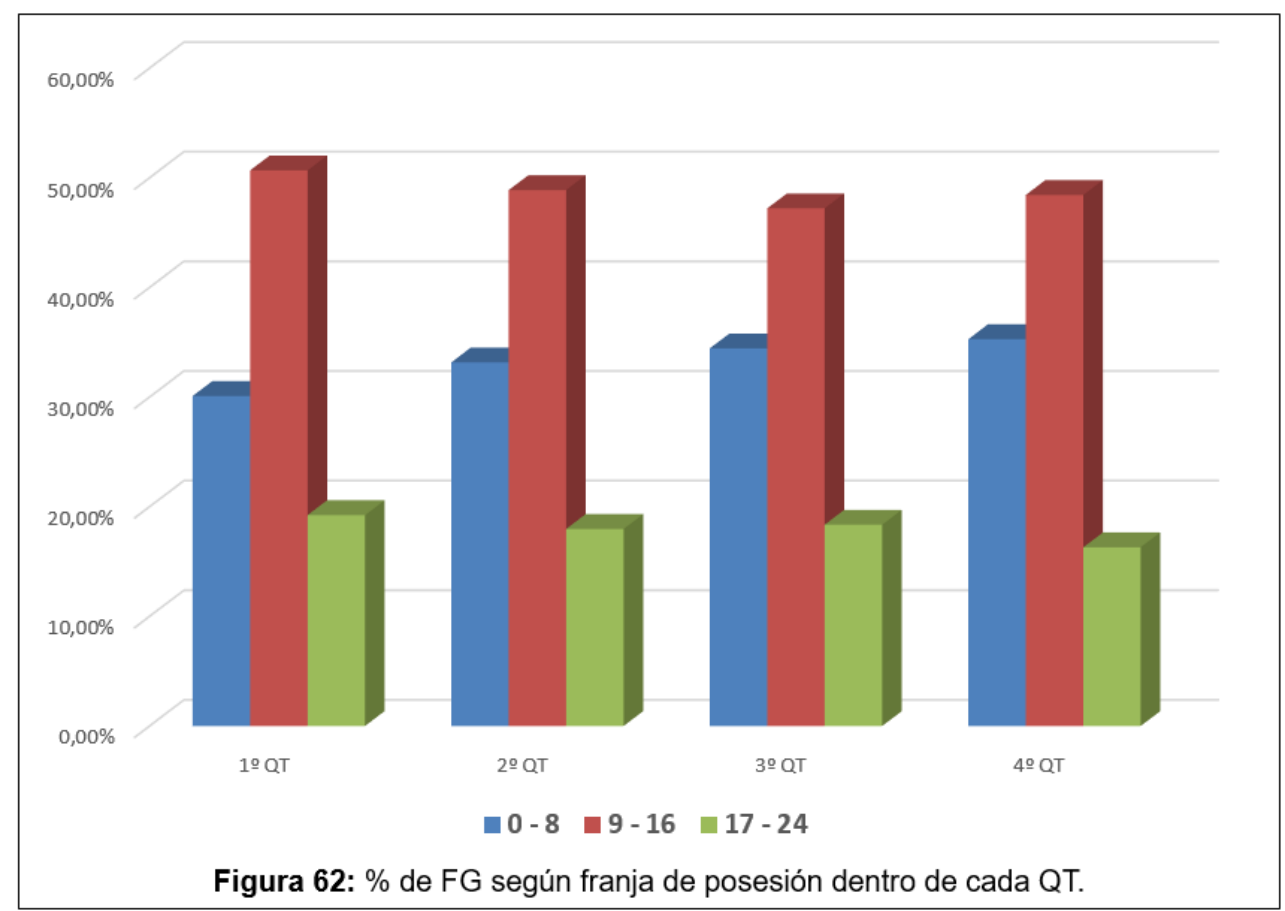

Si nos fijamos en como se reparten los porcentajes de cada franja de posesión según cuartos (tabla 66), observamos una dinámica ascendente según avanza el encuentro en la franja 0-8, mientras que, en la franja 17-24 se da una dinámica descendente. Esto se observa de forma clara en la figura 63, y su traducción al juego es que, según avanza el partido, el juego se enlentece aumentando la duración de

\begin{tabular}{|c|c|c|c|}
\cline { 2 - 4 } \multicolumn{1}{c|}{} & $\mathbf{0 - 8}$ & $\mathbf{9 - 1 6}$ & $\mathbf{1 7}-\mathbf{2 4}$ \\
\hline 19 QT & $23,60 \%$ & $27,01 \%$ & $27,83 \%$ \\
\hline 20 QT & $25,28 \%$ & $25,33 \%$ & $25,28 \%$ \\
\hline 3 QT & $25,34 \%$ & $23,61 \%$ & $24,92 \%$ \\
\hline 40 QT & $25,78 \%$ & $24,06 \%$ & $21,97 \%$ \\
\hline TOTAL & $100,00 \%$ & $100,00 \%$ & $100,00 \%$ \\
\hline
\end{tabular}

Tabla 66: \% de FG según QT dentro de cada franja de posesión. 
las posesiones. En la franja intermedia se observa un descenso en los dos primeros QT y un equilibrio en los dos últimos.

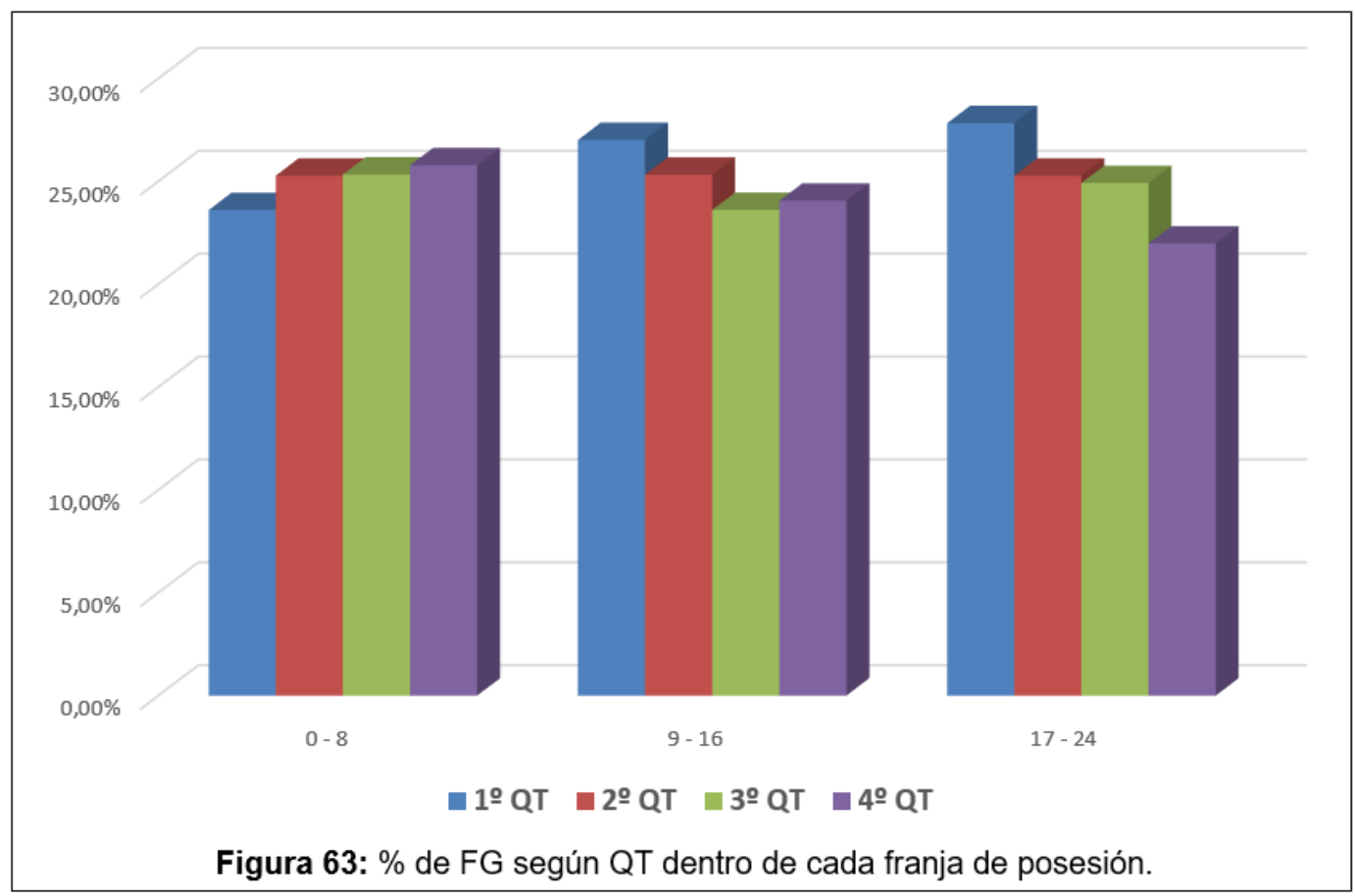

\subsubsection{Tiempo de posesión y momento especial}

En cuanto a los momentos especiales, uno de ellos, la última jugada, está directamente relacionado con la franja de posesión 0-8, por lo que la totalidad de los mismos se producen en ella (figura 64).

El otro momento especial, el tiempo muerto, no tiene una relación directa con ninguna franja de posesión, lo cual hace que se pueda dar en todas las

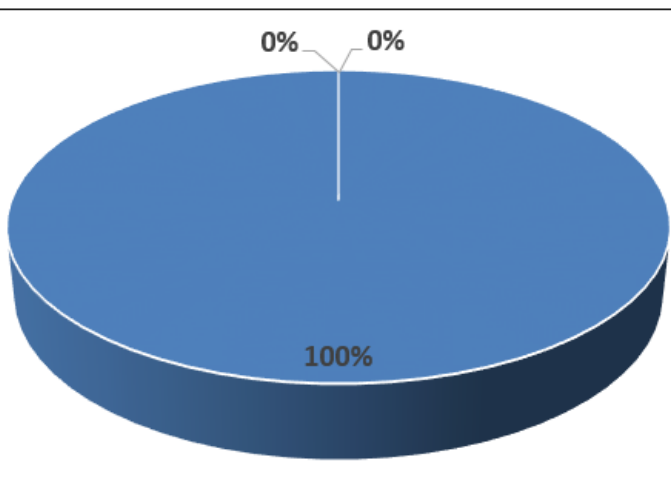

$$
=0-8=9-16=17-24
$$

Figura 64: \% de FG según franja de posesión en última jugada. franjas, pero como observamos en la figura 65, en la franja de 17-24 se da mucho menos, lo cual es debido a que generalmente tras un tiempo muerto se aportan unas pautas para sacar una ventaja, requiriendo movimientos de balón o jugadores, transcurriendo así el tiempo. Además, el tiempo muerto puede producirse cuando ya se halla consumido parte 
de la posesión o se reinicie desde 14". En las otras dos franjas, el reparto es similar, estando ligeramente por encima los FG en la última franja de posesión, quizás debido a esos movimientos de pizarra explicados anteriormente y su correspondiente consumo de tiempo.

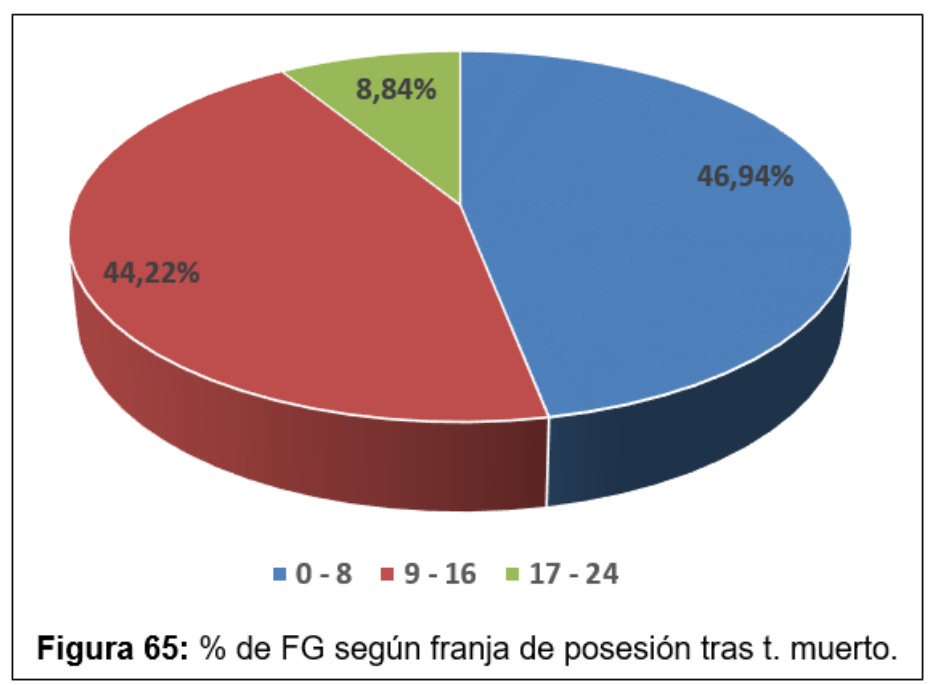

\subsection{TIPO DE TIRO}

El mayor porcentaje de FG ejecutados en un encuentro se da bajo unas condiciones normales, seguido de los FG realizados bajo unas condiciones ventajosas y favorables, y por último, los malos tiros (figura 66).

Todos los equipos trabajan para crear y mejorar sus FG, pues son un factor determinante en el resultado de un encuentro. Pero el hecho de que se trate de un deporte de colaboraciónoposición implica el mismo trabajo por parte del equipo defensor, el cual trata de evitar toda ventaja. De ahí que lo más común sea un punto intermedio, lo que

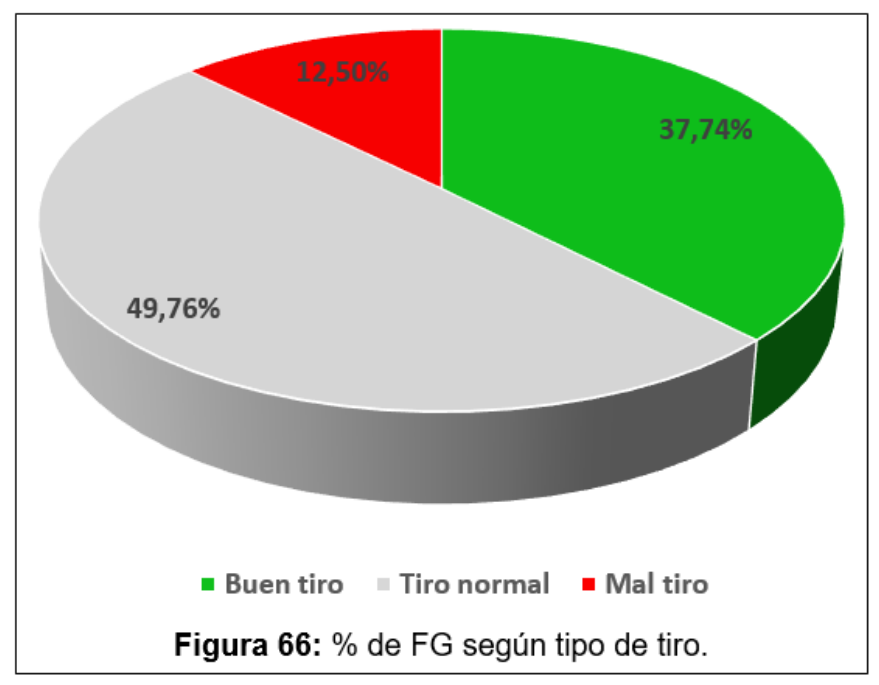
hemos denominado "tiros normales". 


\subsubsection{Tipo de tiro y ventaja/desventaja}

El tipo de FG realizado en función del marcador nos ayuda a ver las diferencias en el juego según se vaya por encima, por debajo o empatados, pues como es lógico, no se juega de igual modo en cada una de dichas situaciones.

La figura 67 muestra la repartición porcentual de cada una de las situaciones del marcador según el tipo de tiro que se realice.

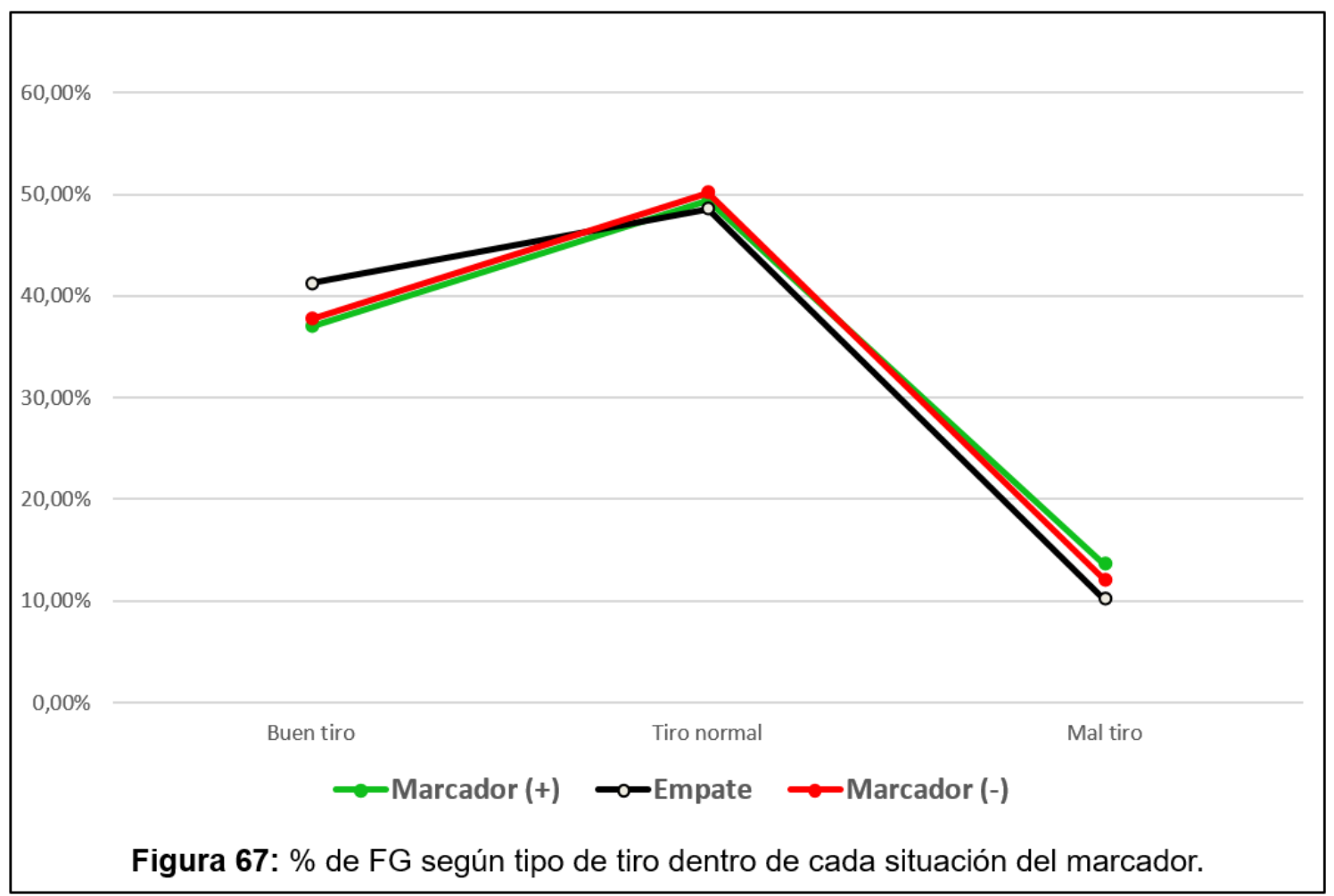

En ella se observan diferencias entre las tres situaciones. En comparación con el resto de marcadores, cuando se va empatados se realizan más buenos tiros, menos tiros normales y muchos menos malos tiros. Cuando las tablas reinan en el marcador los equipos mueven el balón y buscan la mejor opción de tiro para adelantarse.

Apoyándonos en la tabla 67 y comparando como se distribuyen los tiros en la situación de ventaja y desventaja en el marcador, vemos como cuando se va por debajo se realizan mayor porcentaje de buenos tiros y tiros normales, además de reducir el porcentaje de los malos tiros. 


\begin{tabular}{|c|c|c|c|c|}
\cline { 2 - 5 } \multicolumn{1}{c|}{} & Buen tiro & Tiro normal & Mal tiro & TOTAL \\
\hline Marcador (+) & $37,01 \%$ & $49,40 \%$ & $13,58 \%$ & $100,00 \%$ \\
\hline Empate & $41,29 \%$ & $48,56 \%$ & $10,15 \%$ & $100,00 \%$ \\
\hline Marcador (-) & $37,75 \%$ & $50,15 \%$ & $12,10 \%$ & $100,00 \%$ \\
\hline
\end{tabular}

Tabla 67: \% de FG según tipo de tiro dentro de cada situación del marcador.

El hecho de ir por debajo en el marcador ejerce una presión motivadora y necesidad de anotar que favorece el juego, mientras que el equipo que va por encima tiene una situación más cómoda y relajada. No hemos de olvidar que en todos los partidos analizados nunca se ha dado una diferencia mayor a 20 puntos (constancia intrasesional), pues se considera que diferencias tan amplias en el marcador hacen que las dinámicas de juego se desvirtúen por una sensación de ausencia de posibilidades de revertir el resultado, entrando así en una dinámica de "dejarse llevar".

\subsubsection{Tipo de tiro y precedente}

En la tabla 68 vemos como se relacionan las categorías de las variables "tipo de tiro" y "precedente" sobre el total de FG ejecutados. En ella observamos como la mayor incidencia se da en el pase y la jugada personal con valores totales casi idénticos. La diferencia la encontramos en su reparto sobre las categorías de la variable "tipo de tiro", donde el precedente "pase" acumula la mayoría de su porcentaje entre los tiros normales y buenos, mientras que, en el caso de la jugada personal, lo acumula entre los normales y malos.

\begin{tabular}{|c|c|c|c|}
\cline { 2 - 4 } \multicolumn{1}{c|}{} & Buen tiro & Tiro normal & Mal tiro \\
\hline Contraataque & $1,70 \%$ & $0,66 \%$ & $0,06 \%$ \\
\hline Bloqueo Directo & $6,69 \%$ & $8,28 \%$ & $1,39 \%$ \\
\hline Pase & $21,66 \%$ & $11,77 \%$ & $2,22 \%$ \\
\hline Jugada Personal & $4,47 \%$ & $24,46 \%$ & $8,47 \%$ \\
\hline Robo & $1,80 \%$ & $0,93 \%$ & $0,11 \%$ \\
\hline Rebote & $1,43 \%$ & $3,66 \%$ & $0,25 \%$ \\
\hline
\end{tabular}

Tabla 68: \% de FG entre las variables tipo de tiro y precedente.

Como tercer precedente con mayor incidencia encontramos al bloqueo directo. Tras el precedente "pase", es el que más incidencia de ejecución de FG en condiciones ventajosas muestra. 
Centrándonos en el estudio del reparto de los tipos de tiro dentro de cada precedente (tabla 69 y figura 68) vemos que precedentes son los que ayudan en la consecución de buenos o malos tiros, lo cual es un punto clave para la futura aplicación práctica.

\begin{tabular}{|c|c|c|c|c|}
\cline { 2 - 5 } \multicolumn{1}{c|}{} & Buen tiro & Tiro normal & Mal tiro & TOTAL \\
\hline Contraataque & $70,32 \%$ & $27,27 \%$ & $2,41 \%$ & $100,00 \%$ \\
\hline Bloqueo Directo & $40,90 \%$ & $50,61 \%$ & $8,49 \%$ & $100,00 \%$ \\
\hline Pase & $60,76 \%$ & $33,01 \%$ & $6,23 \%$ & $100,00 \%$ \\
\hline Jugada Personal & $11,95 \%$ & $65,40 \%$ & $22,65 \%$ & $100,00 \%$ \\
\hline Robo & $63,33 \%$ & $32,80 \%$ & $3,87 \%$ & $100,00 \%$ \\
\hline Rebote & $26,72 \%$ & $68,56 \%$ & $4,72 \%$ & $100,00 \%$ \\
\hline
\end{tabular}

Tabla 69: \% de FG según tipo de tiro dentro de cada precedente.

Los contraataques, los robos y los pases tienen un gran porcentaje de buenos tiros, en todos por encima del $60 \%$. En los dos primeros era de esperar, pues en los contraataques siempre existe esa rapidez y superioridad numérica que la definición del mismo lleva implícita, y en el caso del robo, generalmente va asociado a ataques rápidos sin dar tiempo a la transición defensiva de los oponentes. El pase sin embargo se muestra como la mejor herramienta por sí misma, es decir, sin situaciones ya de por si ventajosas, para generar buenas opciones de FG.

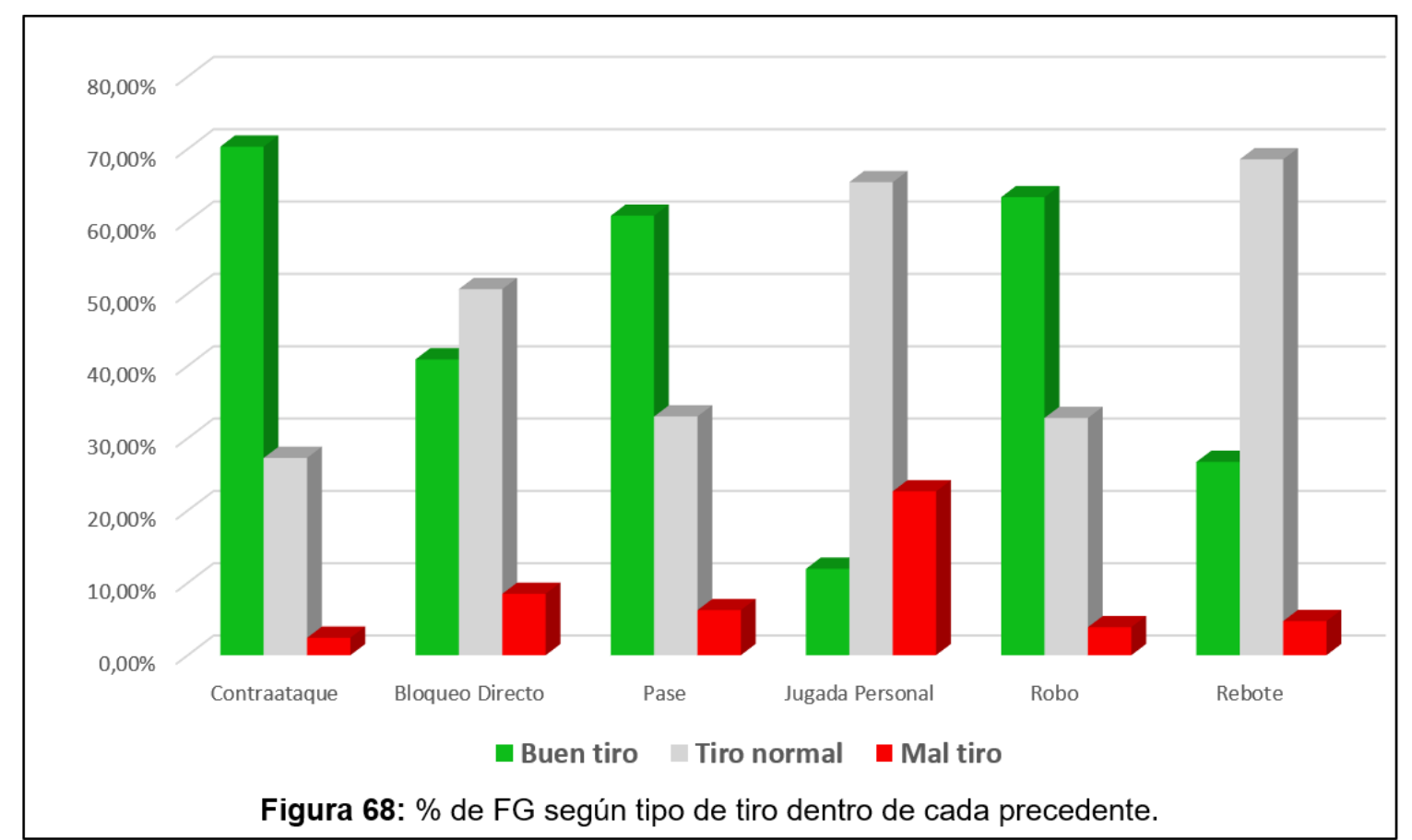

Tras rebote, jugada personal y bloqueo directo se dan los mayores porcentajes en tiros normales, pero en el caso de las jugadas personales también se da el mayor porcentaje, en 
comparación al resto de precedentes, de malos tiros con un 22,65\%. Las jugadas personales son por tanto el peor precedente para un FG con el menor porcentaje de buenos tiros y el mayor de malos tiros.

\begin{tabular}{|c|c|c|c|}
\cline { 2 - 4 } \multicolumn{1}{c|}{} & Buen tiro & Tiro normal & Mal tiro \\
\hline Contraataque & $4,50 \%$ & $1,32 \%$ & $0,46 \%$ \\
\hline Bloqueo Directo & $17,73 \%$ & $16,64 \%$ & $11,11 \%$ \\
\hline Pase & $57,39 \%$ & $23,65 \%$ & $17,77 \%$ \\
\hline Jugada Personal & $11,84 \%$ & $49,16 \%$ & $67,77 \%$ \\
\hline Robo & $4,76 \%$ & $1,87 \%$ & $0,88 \%$ \\
\hline Rebote & $3,78 \%$ & $7,36 \%$ & $2,01 \%$ \\
\hline TOTAL & $100,00 \%$ & $100,00 \%$ & $100,00 \%$ \\
\hline
\end{tabular}

Tabla 70: \% de FG según precedente dentro de cada tipo de tiro.

Si nos fijamos en como se reparten porcentualmente cada tipo de tiro entre los posibles precedentes (tabla 70 y figura 69) seguimos obteniendo datos en la misma línea. Por un lado, el mayor porcentaje de buenos tiros se realiza tras pase, y por el otro, el mayor porcentaje de malos tiros tras jugada personal.

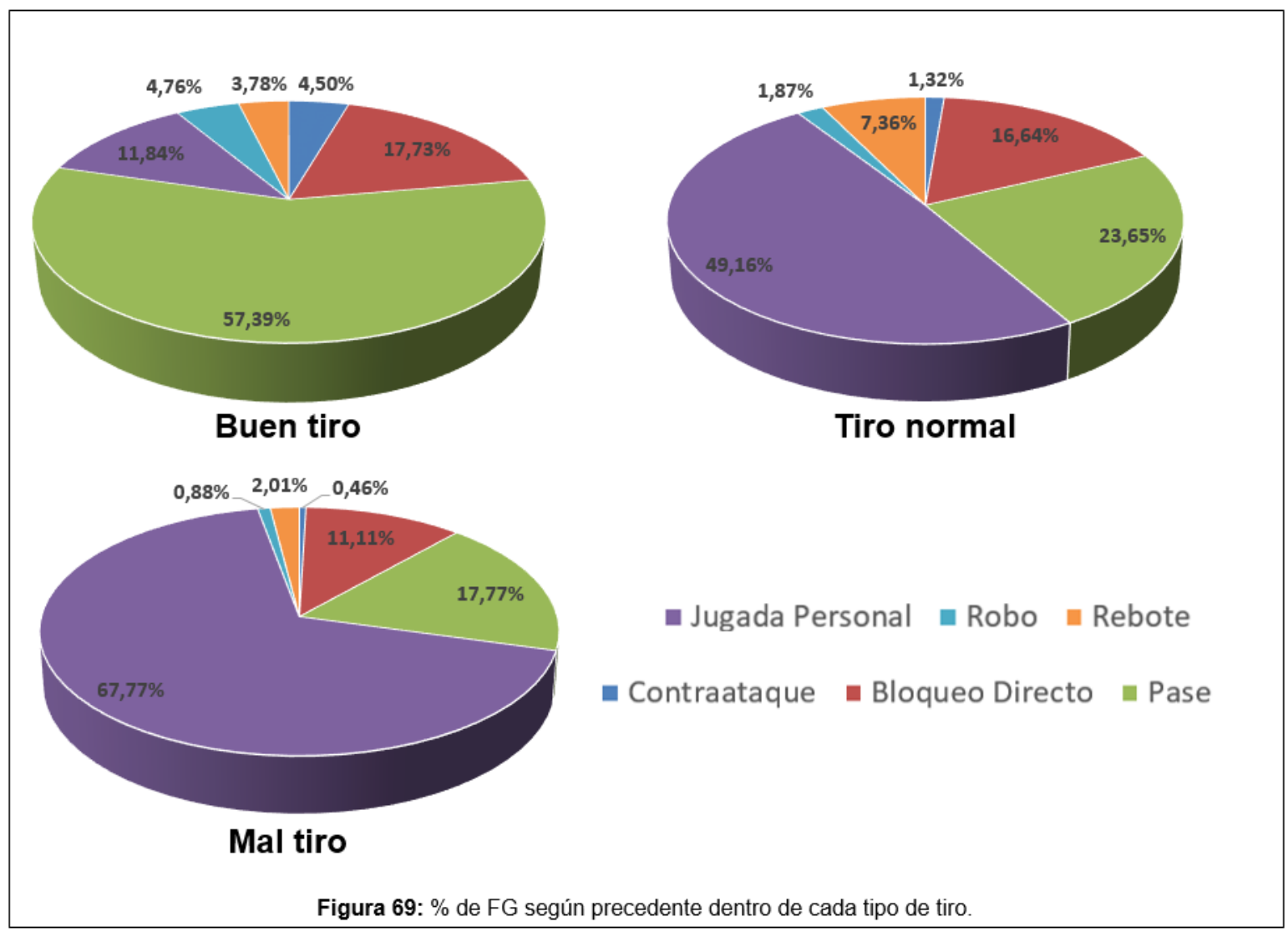




\subsubsection{Tipo de tiro y jugadores implicados}

En la siguiente figura (figura 70) podemos ver el porcentaje acumulado entre las categorías de las variables "tipo de tiro" y "jugadores implicados". Se observa de forma clara como los malos tiros apenas tienen incidencia en el juego, siendo el tiro normal y el buen tiro respectivamente los que más tienen.

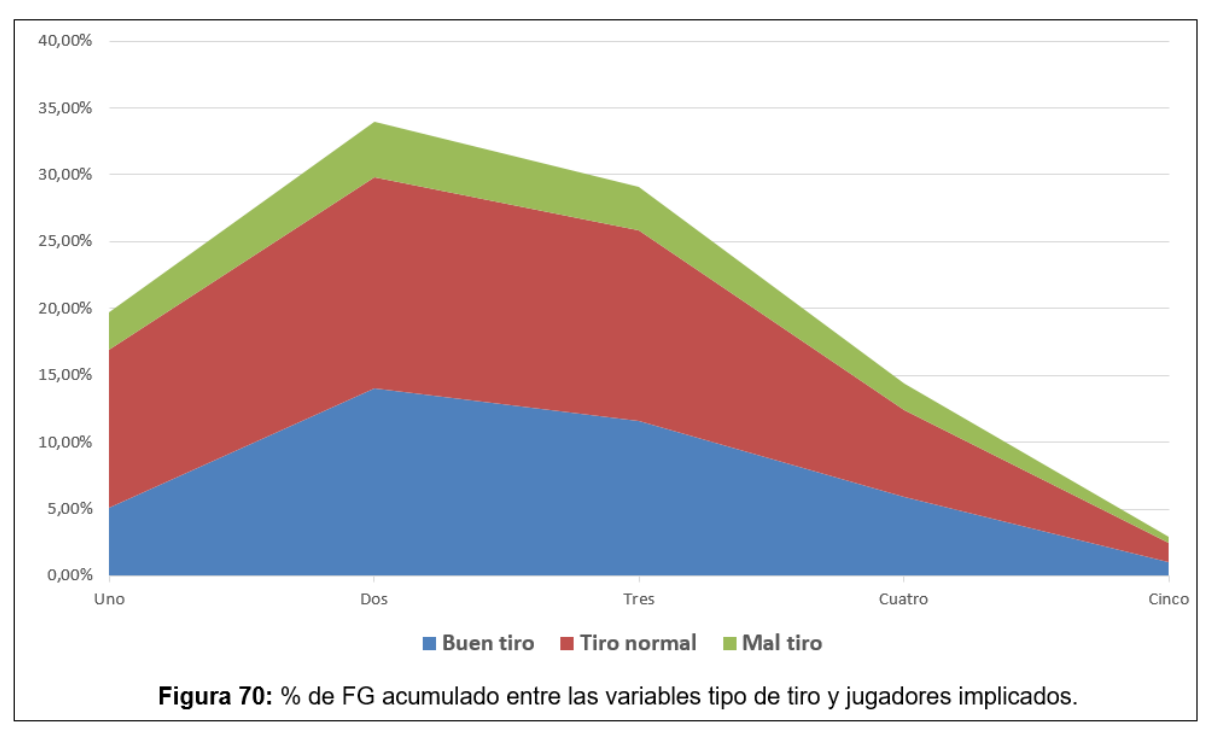

Entre las tres categorías del "tipo de tiro" se sigue una misma dinamica respecto de las categorias de la variable "jugadores implicados". Sus porcentajes ascienden hasta los dos jugadores implicados, pico de mayor incidencia, a partir del cual descienden, siendo ese descenso más pronunciado a partir de la implicación de tres jugadores.

En cuanto al tipo de tiro en función de los jugadores que entran en contacto con el balón de forma previa al FG (figura 71), podemos observar como en los tres tipos de tiros destaca por encima de los demás la implicación de dos y tres jugadores.

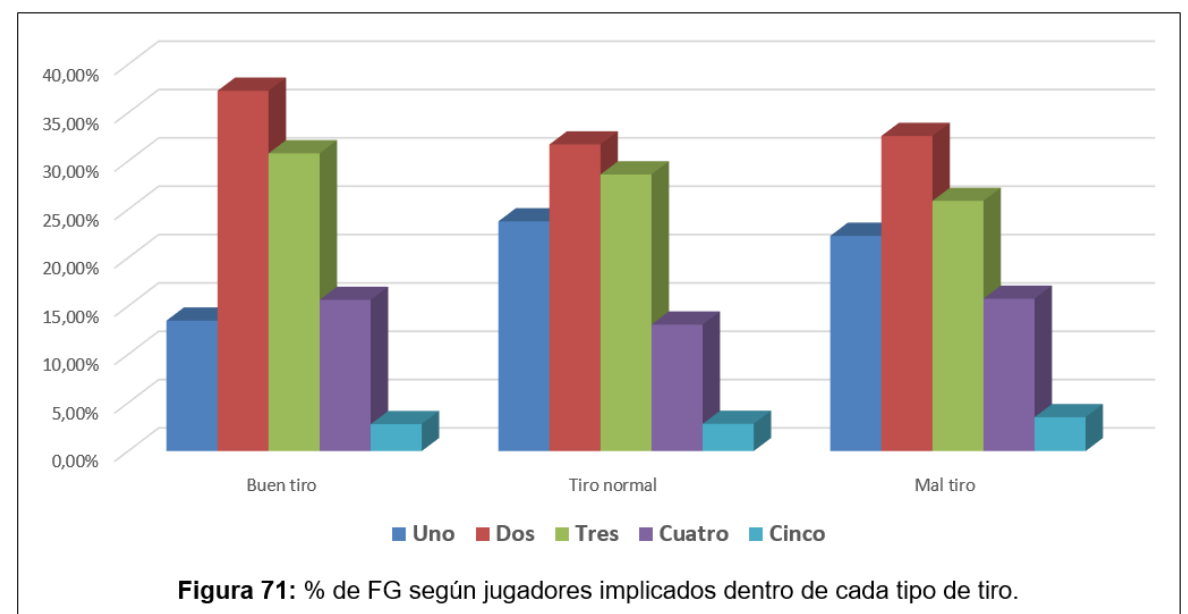


La tabla 71 nos muestra los datos numéricamente, y en ella vemos como los malos tiros y tiros normales también tienen un elevado porcentaje de jugadas con un solo jugador. En cuanto a los buenos tiros, más de un $68 \%$ se producen con dos y tres jugadores, dándose tras ellos un equilibrio entre cuatro, un poco por encima, y un jugador. La intervención por parte de todos los jugadores es realmente baja en todos los casos.

\begin{tabular}{|c|c|c|c|}
\cline { 2 - 4 } \multicolumn{1}{c|}{} & Buen tiro & Tiro normal & Mal tiro \\
\hline Uno & $13,50 \%$ & $23,76 \%$ & $22,26 \%$ \\
\hline Dos & $37,27 \%$ & $31,72 \%$ & $32,59 \%$ \\
\hline Tres & $30,80 \%$ & $28,62 \%$ & $25,88 \%$ \\
\hline Cuatro & $15,64 \%$ & $13,08 \%$ & $15,75 \%$ \\
\hline Cinco & $2,79 \%$ & $2,82 \%$ & $3,51 \%$ \\
\hline TOTAL & $100,00 \%$ & $100,00 \%$ & $100,00 \%$ \\
\hline
\end{tabular}

Tabla 71: \% de FG según jugadores implicados dentro de cada tipo de tiro.

\subsubsection{Tipo de tiro y QT}

Al observar los porcentajes de combinación de estas dos variables sobre el total de FG (tabla 72) vemos como la incidencia de los buenos tiros y los tiros normales va disminuyendo según avanza el encuentro. En cuanto a los malos tiros observamos como tienen un repunte en los segundos cuartos de cada mitad.

\begin{tabular}{|c|c|c|c|}
\cline { 2 - 4 } \multicolumn{1}{c|}{} & Buen tiro & Tiro normal & Mal tiro \\
\hline 10 QT & $10,26 \%$ & $13,02 \%$ & $2,75 \%$ \\
\hline 20 QT & $9,71 \%$ & $12,35 \%$ & $3,24 \%$ \\
\hline 30 QT & $9,24 \%$ & $12,19 \%$ & $2,99 \%$ \\
\hline 4o QT & $8,53 \%$ & $12,20 \%$ & $3,53 \%$ \\
\hline
\end{tabular}

Tabla 72: \% de FG entre las variables tipo de tiro y QT.

Si nos centramos dentro de cada QT en que porcentaje se dan los distintos tipos de tiro (figura 72), observamos como comparando los cuartos todos tienen una dinámica similar. 


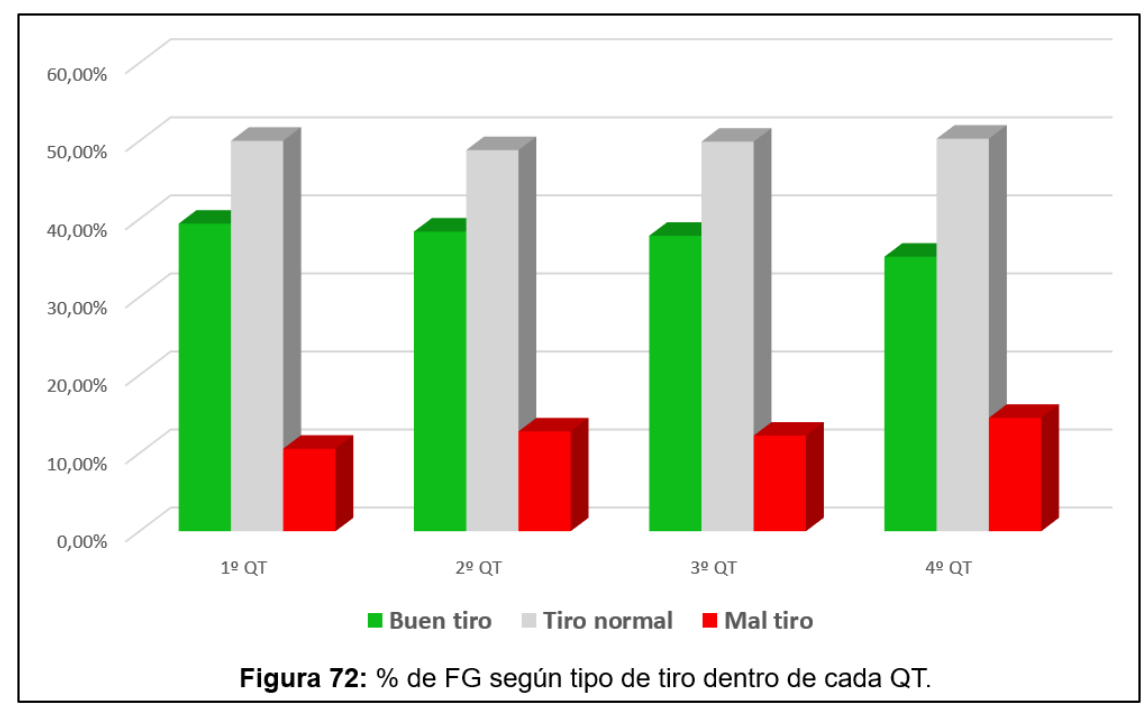

Pero al fijarnos en la distribución de cada tipo de tiro según el cuarto (tabla 73 y figura 73) podemos ver de forma más clara las dinámicas en los encuentros. El número de buenos tiros va disminuyendo según avanza el encuentro, mientras que los tiros

\begin{tabular}{|c|c|c|c|}
\cline { 2 - 4 } \multicolumn{1}{c|}{} & Buen tiro & Tiro normal & Mal tiro \\
\hline 19 QT & $27,17 \%$ & $26,16 \%$ & $22,00 \%$ \\
\hline 2\% QT & $25,74 \%$ & $24,83 \%$ & $25,88 \%$ \\
\hline 3\% QT & $24,49 \%$ & $24,49 \%$ & $23,92 \%$ \\
\hline 4\% QT & $22,60 \%$ & $24,52 \%$ & $28,20 \%$ \\
\hline TOTAL & $100,00 \%$ & $100,00 \%$ & $100,00 \%$ \\
\hline
\end{tabular}

Tabla 73: \% de FG según QT dentro de cada tipo de tiro. normales, tras un pequeño bajón después del primer cuarto, se estabilizan. Por su parte, los malos tiros aumentan en los segundos cuartos de cada parte.

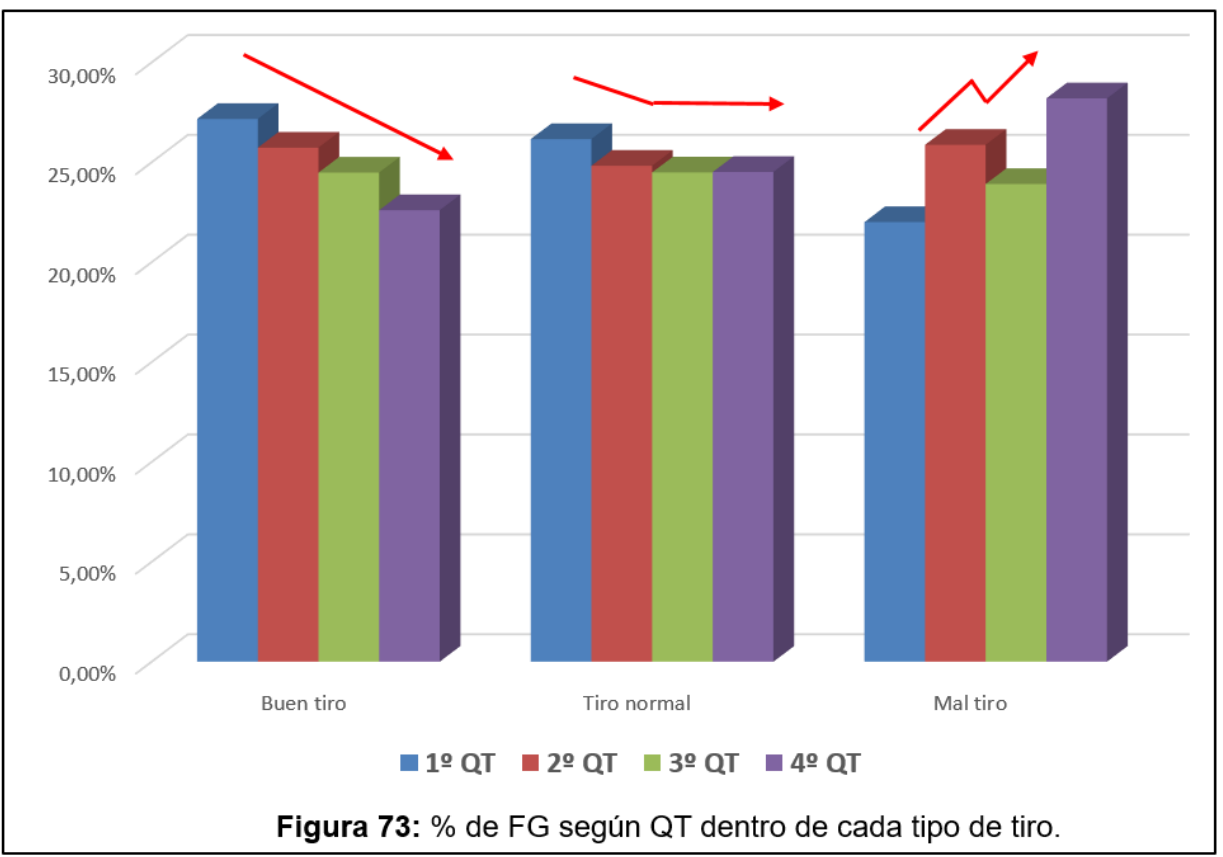




\subsubsection{Tipo de tiro y momento especial}

Los porcentajes de tipos de tiro realizados tras cada momento especial son recogidos en la siguiente figura (figura 74). En ella podemos ver la gran diferencia entre ambos, predominando tras un tiempo muerto los tiros normales y en las últimas jugadas los malos tiros.

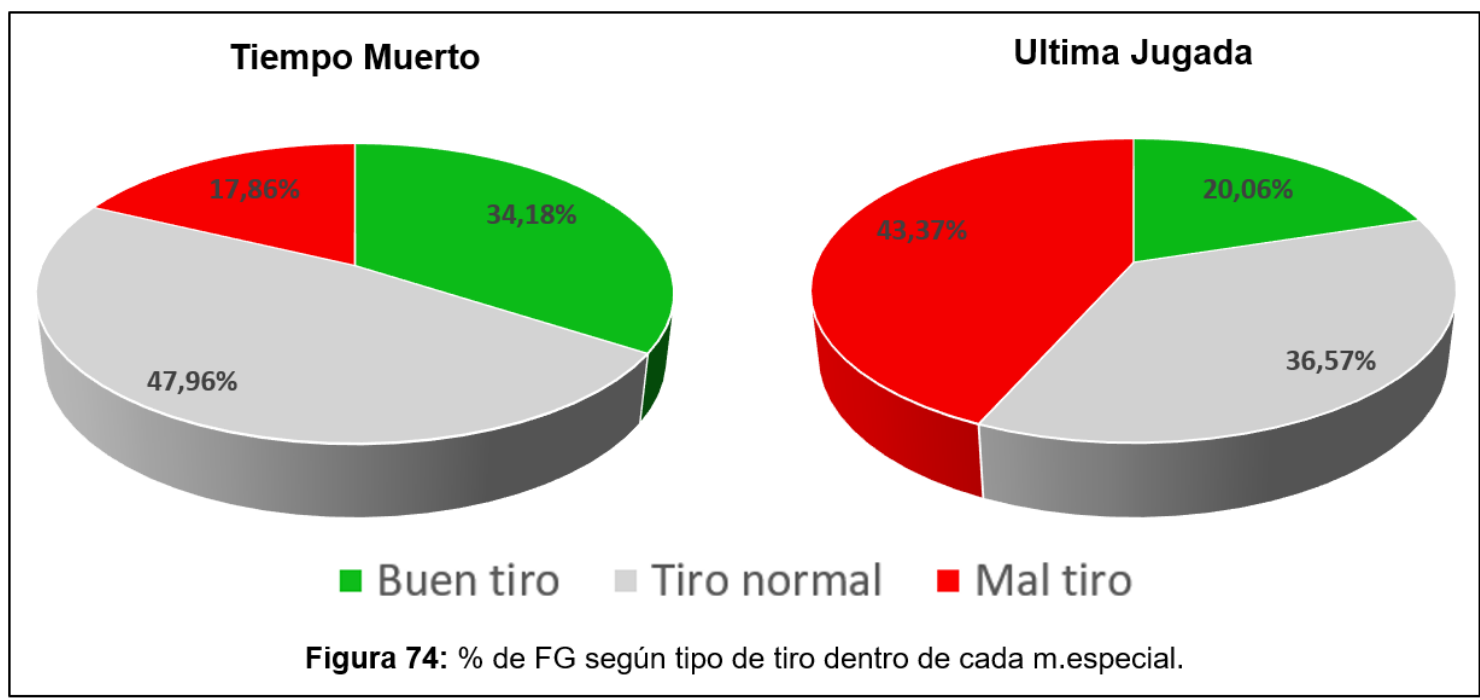

Si nos centramos en los porcentajes (tabla 74), podemos observar como tras tiempo muerto, a pesar de que predominan los tiros normales, hay un buen porcentaje de buenos tiros. Aún así, este porcentaje esta por debajo de la media de buenos tiros descrita anteriormente, la cual se situa en 37,74\%. De aquí podemos deducir de forma genérica que los tiempos muertos no se centran en el diseño de la jugada inmediata tras este, si no que se usan para realizar mejoras y ajustes más generales y globales sobre el juego, tratando de minimizar los fallos que se están cometiendo y sacar ventajas de los puntos débiles del rival.

En cuanto a las últimas jugadas, destacan con un elevado porcentaje los malos tiros, lo cual era de esperar, pues son jugadas donde el límite temporal somete al jugador a la necesidad de ejecutar el FG sin importar la situación, tanto en cuanto a lugar del campo, como a la oposición del defensor.

\begin{tabular}{|c|c|c|c|c|}
\cline { 2 - 5 } \multicolumn{1}{c|}{} & Buen tiro & Tiro normal & Mal tiro & TOTAL \\
\hline Tiempo Muerto & $34,18 \%$ & $47,96 \%$ & $17,86 \%$ & $100,00 \%$ \\
\hline Última Jugada & $20,06 \%$ & $36,57 \%$ & $43,37 \%$ & $100,00 \%$ \\
\hline
\end{tabular}

Tabla 74: \% de FG según tipo de tiro dentro de cada m.especial. 


\subsection{VENTAJA/DESVENTAJA}

En la siguiente figura (figura 75) se muestra el porcentaje de FG realizados en cada situación del marcador, es decir, ganando, empatando o perdiendo. En el podemos ver como el $55,7 \%$ de los FG analizados se han realizado cuando se iba por debajo en el marcador, frente al $36,85 \%$ cuando se iba ganando. Estos resultados no aportan datos relevantes, pues en función de los partidos analizados podría verse una gran variación, por tanto la aportación de estos datos al

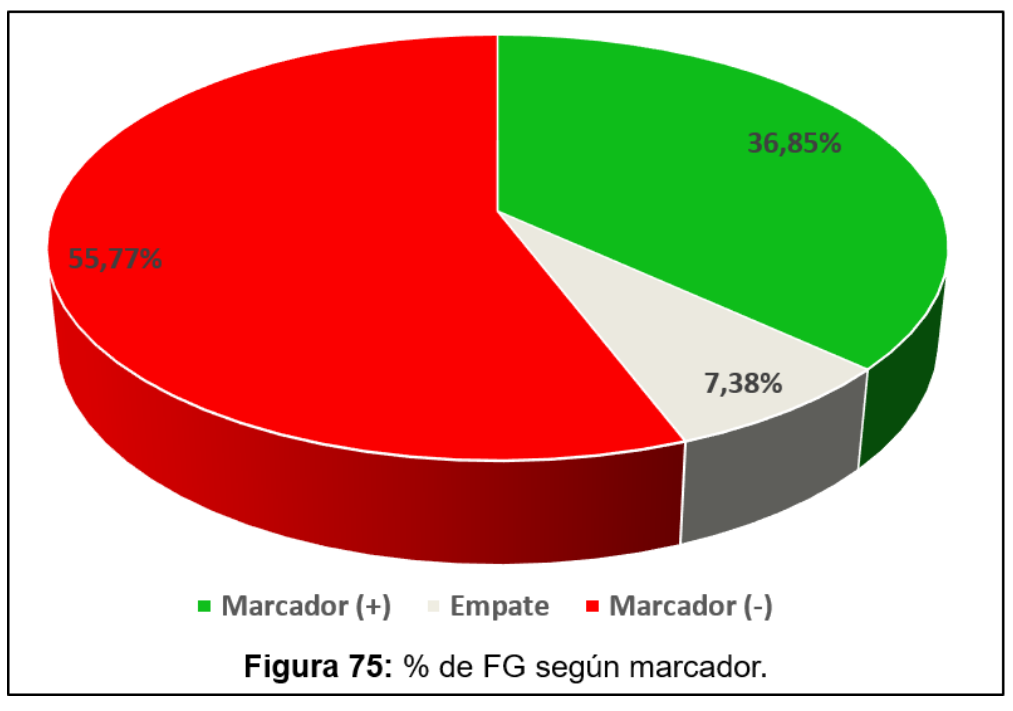
estudio es nula.

El hecho de que en la muestra analizada se ejecuten más FG en situaciones de desventaja que de ventaja hace que en el análisis de esta variable solo sea válida una perspectiva de las tres explicadas anteriormente. En cuanto a la perspectiva global (tabla 75), el hecho de que se produzcan más FG en la categoría de desventaja en el marcador hace que los porcentajes de esta categoría tengan una muestra mayor, aumentando por tanto sus porcentajes sobre el total.

\begin{tabular}{|c|c|c|c|c|}
\hline & \multicolumn{3}{|c|}{ VARIABLE VENTAJA / DESVENTAJA } \\
\hline & & Marcador (+) & Empate & Marcador (-) \\
\hline \multirow{6}{*}{ 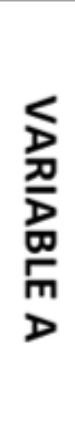 } & Categoría 1 & $\mathrm{X}_{1+} \%$ & $X_{1=} \%$ & $\mathrm{X}_{1-} \%$ \\
\hline & Categoría 2 & $x_{2+} \%$ & $X_{2=} \%$ & $x_{2-} \%$ \\
\hline & Categoría ... & $X \ldots+\%$ & $X_{\ldots}=\%$ & X... $\%$ \\
\hline & Categoría ... & $X \ldots+\%$ & $X_{\ldots=}=\%$ & X... $\%$ \\
\hline & Categoría ... & $X \ldots+\%$ & $X_{\ldots}=\%$ & X... $\%$ \\
\hline & Categoría C & $x_{C+} \%$ & $X_{C=} \%$ & $\mathrm{X}_{\mathrm{C}-} \%$ \\
\hline & & & $=\operatorname{suma}\left(\mathrm{X}_{1+}: \mathrm{X}_{\mathrm{C}-}\right)$ & $100,00 \%$ \\
\hline
\end{tabular}

Tabla 75: Análisis sobre el total de combinaciones entre la variable A y ventaja/desventaja. 
Lo mismo ocurriría en la perspectiva horizontal (tabla 76), pues el análisis de como se reparte cada categoría de la variable A en función de la ventaja/desventaja en el marcador está directamente influenciado por el hecho de que la muestra cuente con más FG ejecutados en desventaja.

\begin{tabular}{|c|c|c|c|c|c|}
\hline & & \multicolumn{3}{|c|}{ VARIABLE VENTAJA / DESVENTAJA } & \\
\hline & & Marcador (+) & Empate & Marcador (-) & \\
\hline \multirow{6}{*}{$\begin{array}{l}\underset{D}{D} \\
\text { 备 } \\
\text { 思 } \\
\text { 而 } \\
\text { D }\end{array}$} & Categoría 1 & $\mathrm{X}_{1+} \%$ & $X_{1=} \%$ & $\mathrm{X}_{1-} \%$ & $100,00 \%$ \\
\hline & Categoría 2 & $X_{2+} \%$ & $X_{2=} \%$ & $X_{2-} \%$ & $100,00 \%$ \\
\hline & Categoría ... & $X_{\ldots+} \%$ & $X_{\ldots}=\%$ & $X \ldots$ & $100,00 \%$ \\
\hline & Categoría ... & $X_{\ldots+} \%$ & $X_{\ldots=} \%$ & $X \ldots$ & $100,00 \%$ \\
\hline & Categoría ... & $X_{\ldots+} \%$ & $X_{\ldots=} \%$ & $X \ldots$ & $100,00 \%$ \\
\hline & Categoría C & $\mathrm{X}_{\mathrm{C}+} \%$ & $\mathrm{X}_{\mathrm{C}=} \%$ & $\mathrm{x}_{\mathrm{C}-} \%$ & $100,00 \%$ \\
\hline
\end{tabular}

Tabla 76: Análisis de cada categoría de la variable A en función de la variable ventaja/desventaja.

Tras descartar estas dos primeras perspectivas, llegamos a la vertical, la cual es la única válida para la variable ventaja/desventaja, pues analiza cada categoría de la variable ventaja/desventaja sobre ella misma, viendo como se reparten los porcentajes sobre el total de esta, con las categorías de la variable A (tabla 77).

\begin{tabular}{|c|c|c|c|c|}
\hline & \multicolumn{3}{|c|}{ VARIABLE VENTAJA / DESVENTAJA } \\
\hline & & Marcador (+) & Empate & Marcador (-) \\
\hline \multirow{6}{*}{ 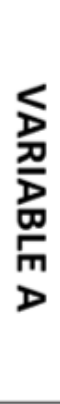 } & Categoría 1 & $\mathrm{X}_{1+} \%$ & $X_{1=} \%$ & $X_{1-} \%$ \\
\hline & Categoría 2 & $\mathrm{X}_{2+} \%$ & $X_{2=} \%$ & $X_{2-} \%$ \\
\hline & Categoría ... & $X \ldots+\%$ & $X_{\ldots}=\%$ & $X \ldots$ \\
\hline & Categoría ... & $X \ldots+\%$ & $X \ldots=\%$ & X... $\%$ \\
\hline & Categoría ... & $X \ldots+\%$ & $X \ldots=\%$ & $X \ldots$ \\
\hline & Categoría C & $\mathrm{X}_{\mathrm{C}+} \%$ & $\mathrm{X}_{\mathrm{C}=} \%$ & $\mathrm{X}_{\mathrm{C}-} \%$ \\
\hline & & $100,00 \%$ & $100,00 \%$ & $100,00 \%$ \\
\hline
\end{tabular}

Tabla 77: Análisis de cada categoría de la variable ventaja/desventaja en función de la variable A.

Es decir, las categorías ventaja, igualdad y desventaja se están analizando de forma independiente sobre el número de FG ejecutados en cada una, no influyendo por tanto que los encuentros analizados tengan una muestra mayor de FG cuando se va por debajo en el marcador. 


\subsubsection{Ventaja/desventaja y precedente}

En el punto anterior veíamos como el marcador por sí solo no aporta datos útiles de cara a su interpretación, pero en el momento que lo analizamos junto a otra variable, y desde una perspectiva correcta, los datos extraíbles cogen sentido.

En la figura 76 se muestra el porcentaje de FG según el precedente dentro de cada situación del marcador. Como podemos observar, en las tres situaciones se reparten de forma similar los precedentes del FG, siendo los más utilizados la jugada personal y el pase respectivamente, ocupando el bloqueo directo el tercer lugar.

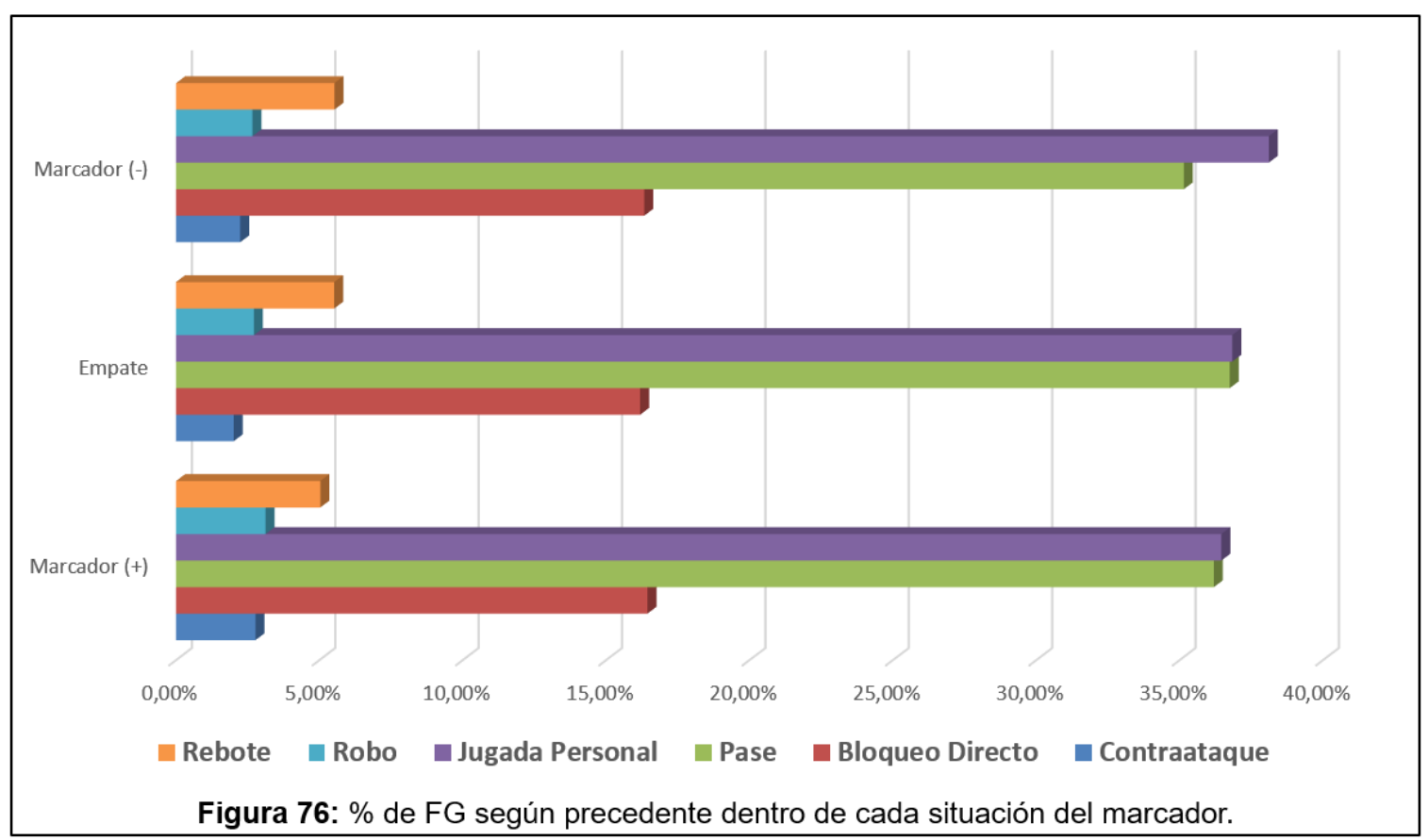

Se pueden observar ciertas diferencias si comparamos el reparto entre las tres categorías de la variable ventaja/desventaja (tabla 78). Cuando se va por debajo en el marcador se realizan proporcionalmente menos FG con el pase y más con la jugada personal que cuando se va empate o ganando. Cuando se va ganando se producen proporcionalmente más FG tras contraataques y robos, pero menos tras rebote. Los porcentajes de FG tras bloqueo son casi idénticos en las tres.

\begin{tabular}{|c|c|c|c|}
\cline { 2 - 4 } \multicolumn{1}{c|}{} & Marcador (+) & Empate & Marcador (-) \\
\hline Contraataque & $2,77 \%$ & $2,01 \%$ & $2,23 \%$ \\
\hline Bloqueo Directo & $16,44 \%$ & $16,19 \%$ & $16,33 \%$ \\
\hline Pase & $36,19 \%$ & $36,75 \%$ & $35,14 \%$ \\
\hline Jugada Personal & $36,45 \%$ & $36,83 \%$ & $38,11 \%$ \\
\hline Robo & $3,12 \%$ & $2,71 \%$ & $2,66 \%$ \\
\hline Rebote & $5,03 \%$ & $5,51 \%$ & $5,52 \%$ \\
\hline TOTAL & $100,00 \%$ & $100,00 \%$ & $100,00 \%$ \\
\hline
\end{tabular}

Tabla 78: \% de FG según precedente dentro de cada situación del marcador. 


\subsubsection{Ventaja/desventaja y jugadores implicados}

Como podemos ver en la figura 77 , en las tres posibles situaciones del marcador la intervención de dos y tres jugadores es la que más se da, pero en el caso del empate se tiende más a tres que a dos; mientras que con ventaja y desventaja en el marcador se invierte, prevaleciendo la intervención de dos sobre la de tres.

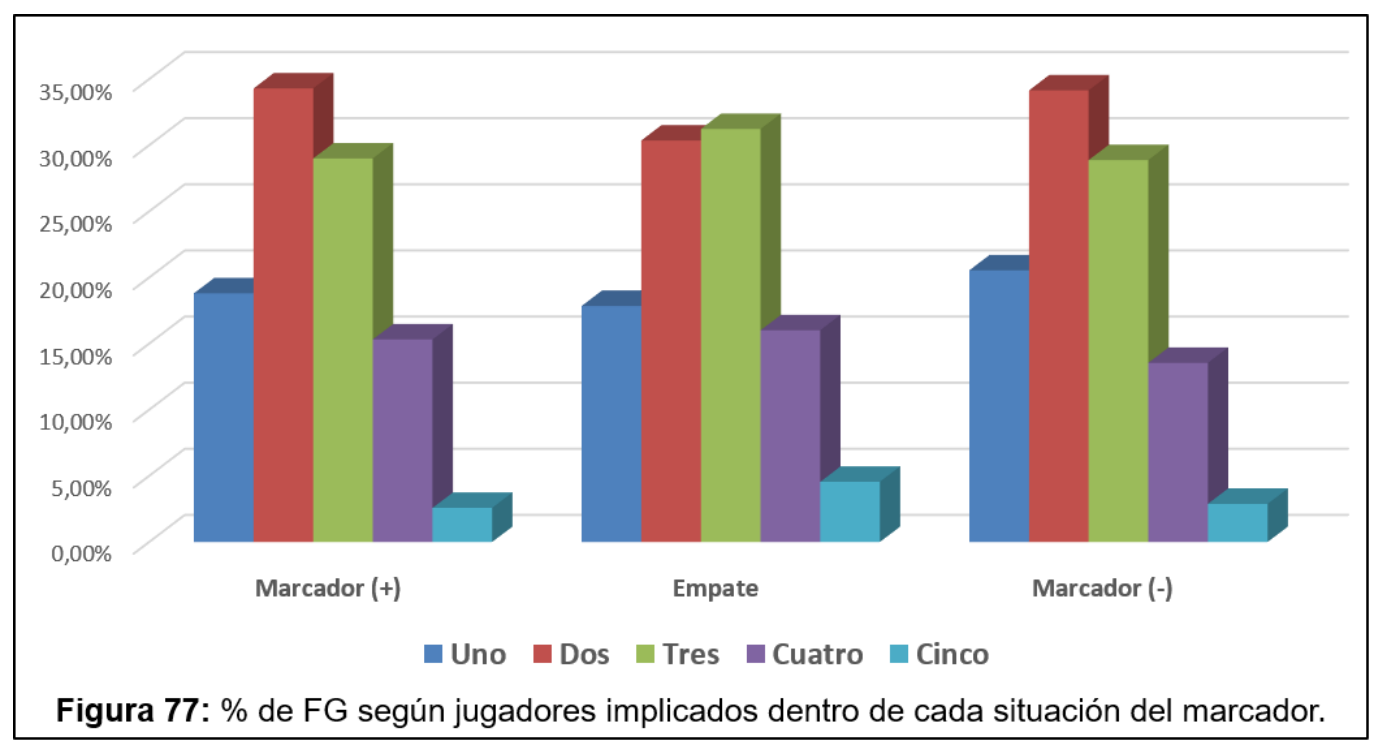

Apoyándonos en la tabla 79 vemos como cuando se va por debajo en el marcador se dan proporcionalmente, en comparación al resto de situaciones, más jugadas con un solo jugador y menos de cuatro. La necesidad de encestar no favorece la tranquilidad en el juego, por lo que no se da tanto pase de balón, siendo menor el número de jugadores intervinientes

\begin{tabular}{|c|c|c|c|}
\cline { 2 - 4 } \multicolumn{1}{c|}{} & Marcador (+) & Empate & Marcador (-) \\
\hline Uno & $18,80 \%$ & $17,85 \%$ & $20,54 \%$ \\
\hline Dos & $34,30 \%$ & $30,36 \%$ & $34,15 \%$ \\
\hline Tres & $29,00 \%$ & $31,23 \%$ & $28,88 \%$ \\
\hline Cuatro & $15,32 \%$ & $16,01 \%$ & $13,55 \%$ \\
\hline Cinco & $2,58 \%$ & $4,55 \%$ & $2,88 \%$ \\
\hline TOTAL & $100,00 \%$ & $100,00 \%$ & $100,00 \%$ \\
\hline
\end{tabular}

Tabla 79: \% de FG según jugadores implicados dentro de cada situación del marcador. antes de cada FG.

Es destacable como los FG ejecutados con tablas en el marcador tienen proporcionalmente menor porcentaje en la intervención de uno y dos jugadores, y más en la de tres, cuatro y cinco, que cuando se va por encima o por debajo. Cuando reinan las tablas, se mueve más el balón en busca de la mejor opción para adelantarse en el marcador. 


\subsubsection{Ventaja/desventaja y QT}

La combinación de estas dos variables no aporta información especialmente útil. La tabla 80 recoge los FG ejecutados dentro de cada situación del marcador en función del QT en el que se realizan. Si nos fijamos en los FG ejecutados cuando reinan las tablas, observamos como partiendo desde un porcentaje muy alto en el primer cuarto, este va descendiendo. Es decir, desde el primer QT, donde debido al inicio del encuentro son lógicas esas situaciones de empate, las diferencias sobre el luminoso van haciéndose más comunes según se acercan al momento decisivo del encuentro.

\begin{tabular}{|c|c|c|c|}
\cline { 2 - 4 } \multicolumn{1}{c|}{} & Marcador (+) & Empate & Marcador (-) \\
\hline 19 QT & $25,53 \%$ & $44,27 \%$ & $23,93 \%$ \\
\hline 20 QT & $28,23 \%$ & $24,15 \%$ & $23,52 \%$ \\
\hline 39 QT & $23,52 \%$ & $18,72 \%$ & $25,76 \%$ \\
\hline 4\% QT & $22,71 \%$ & $12,86 \%$ & $26,78 \%$ \\
\hline TOTAL & $100,00 \%$ & $100,00 \%$ & $100,00 \%$ \\
\hline
\end{tabular}

Tabla 80: \% de FG según QT dentro de cada situación del marcador.

También se observa una disminución de los porcentajes de FG en los dos últimos cuartos cuando se va ganando, produciéndose simultáneamente un aumento por parte de los equipos con el marcador en contra.

\subsubsection{Ventaja/desventaja y momento especial}

Si analizamos los FG realizados tras un momento especial fijándonos en que porcentaje se producen dentro de cada posibilidad del marcador (figura 78 y 79), observamos como un gran porcentaje $(67,86 \%)$ de los FG tras tiempo muerto se ejecutan cuando se va perdiendo. Esto puede ser debido a que en la mayoría de ocasiones se piden los tiempos muertos para cambiar o modificar el juego táctico del equipo, y esto sucede de forma más común cuando se va perdiendo; o podría deberse a que, como hemos

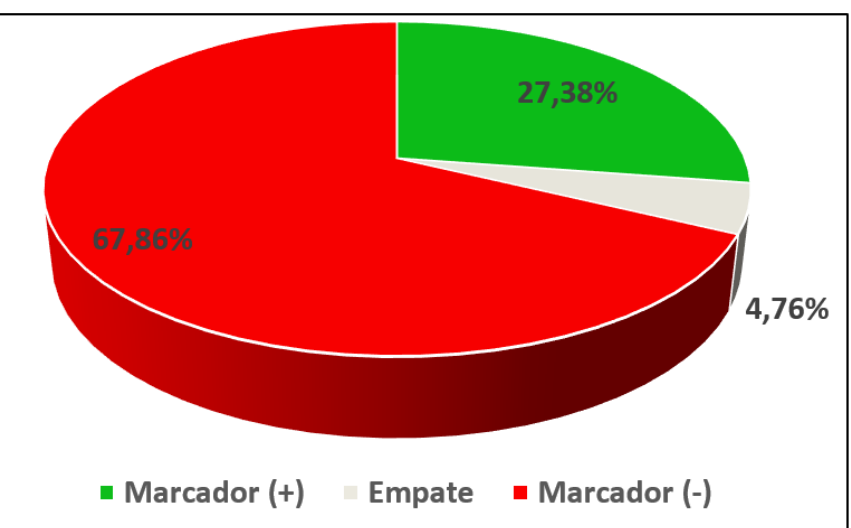

Figura 78: \% de FG según marcador tras t.muerto. 
explicado anteriormente, estos datos están "contaminados" por la mayor muestra de FG ejecutados cuando se va por debajo en el marcador, por lo que no podemos extraer resultados fiables.

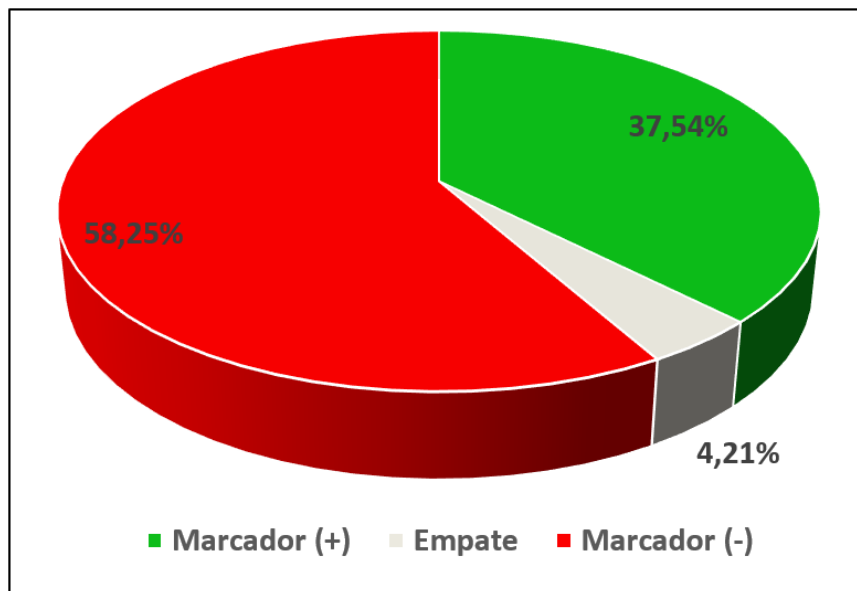

Figura 79: \% de FG según marcador en última jugada.

\subsection{PRECEDENTE}

Analizar en qué porcentaje se da cada posible precedente antes de un FG es de gran valor para su futura aplicación práctica, pues podremos ver su importancia sobre el juego como factor relacionado con el FG. La figura 80 nos muestra el porcentaje en que se da cada precedente, y en el podemos ver como la jugada personal y el pase, respectivamente, están muy por encima del resto de precedentes, sumando entre ambos más de un $73 \%$. Por tanto, sin duda alguna son los precedentes a tener más en cuenta para el trabajo práctico.

El bloqueo se desmarca como tercer precedente en importancia, seguido del rebote, y de forma mucho menos relevante, del robo y el contraataque.

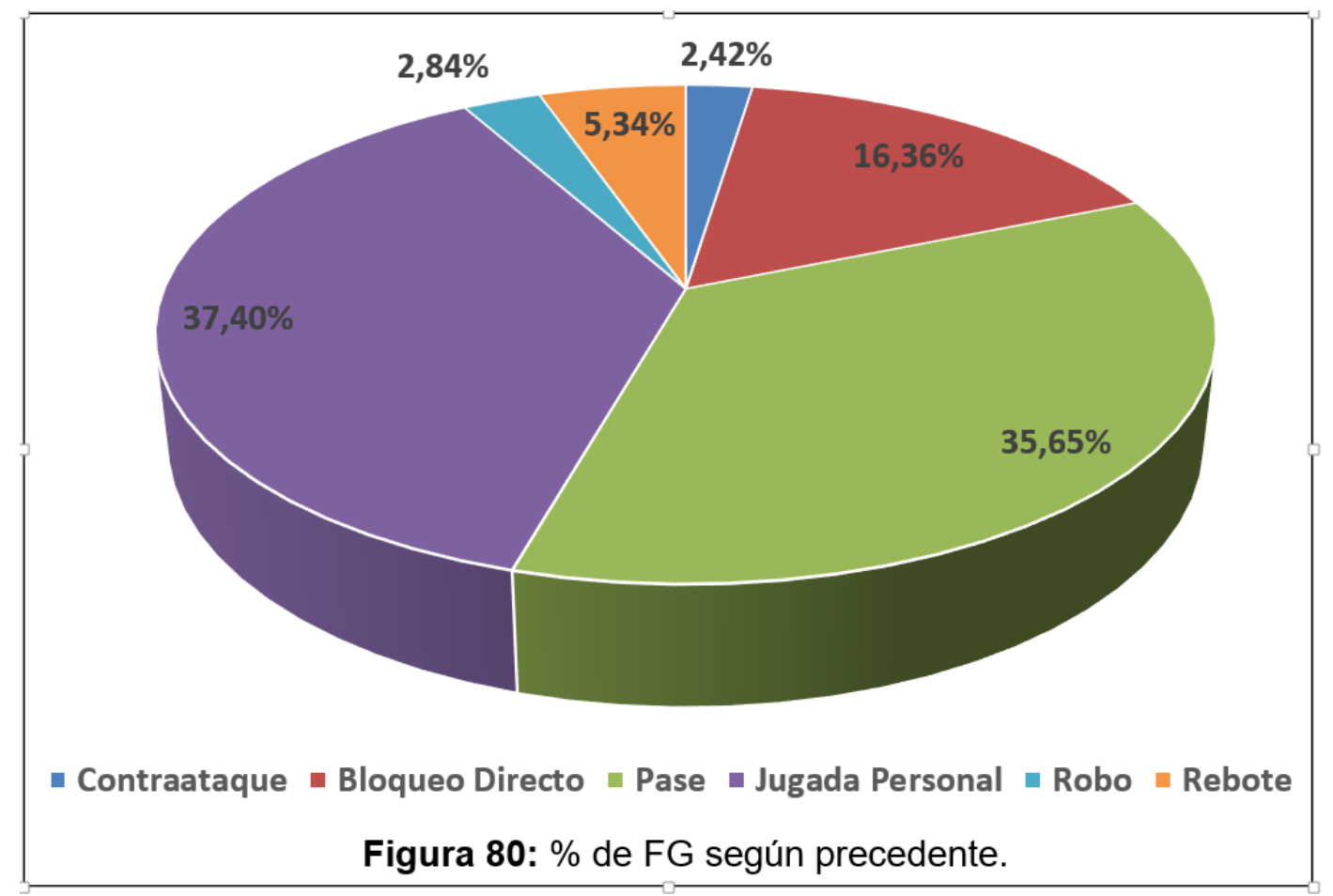




\subsubsection{Precedente y jugadores implicados}

Los porcentajes de incidencia por pares de categorías de estas dos variables se muestran en la tabla 81, y de forma acumulada en la figura 81.

\begin{tabular}{|c|c|c|c|c|c|c|}
\cline { 2 - 7 } \multicolumn{1}{c|}{} & Contraataque & Bloqueo Directo & Pase & Jugada Personal & Robo & Rebote \\
\hline Uno & $0,19 \%$ & $3,82 \%$ & $0 \%$ & $9,10 \%$ & $1,25 \%$ & $5,34 \%$ \\
\hline Dos & $1,45 \%$ & $6,01 \%$ & $13,73 \%$ & $11,42 \%$ & $1,30 \%$ & $0 \%$ \\
\hline Tres & $0,69 \%$ & $4,66 \%$ & $12,70 \%$ & $10,78 \%$ & $0,26 \%$ & $0 \%$ \\
\hline Cuatro & $0,08 \%$ & $1,56 \%$ & $7,48 \%$ & $5,23 \%$ & $0,02 \%$ & $0 \%$ \\
\hline Cinco & $0 \%$ & $0,30 \%$ & $1,73 \%$ & $0,87 \%$ & $0 \%$ & $0 \%$ \\
\hline
\end{tabular}

Tabla 81: \% de FG entre las variables precedente y jugadores implicados.

Las combinaciones con mayor incidencia se tienden a dar con la intervención de dos y tres jugadores, teniendo los mayores porcentajes el pase con dos y tres respectivamente, seguido de la jugada personal con dos, tres y uno.

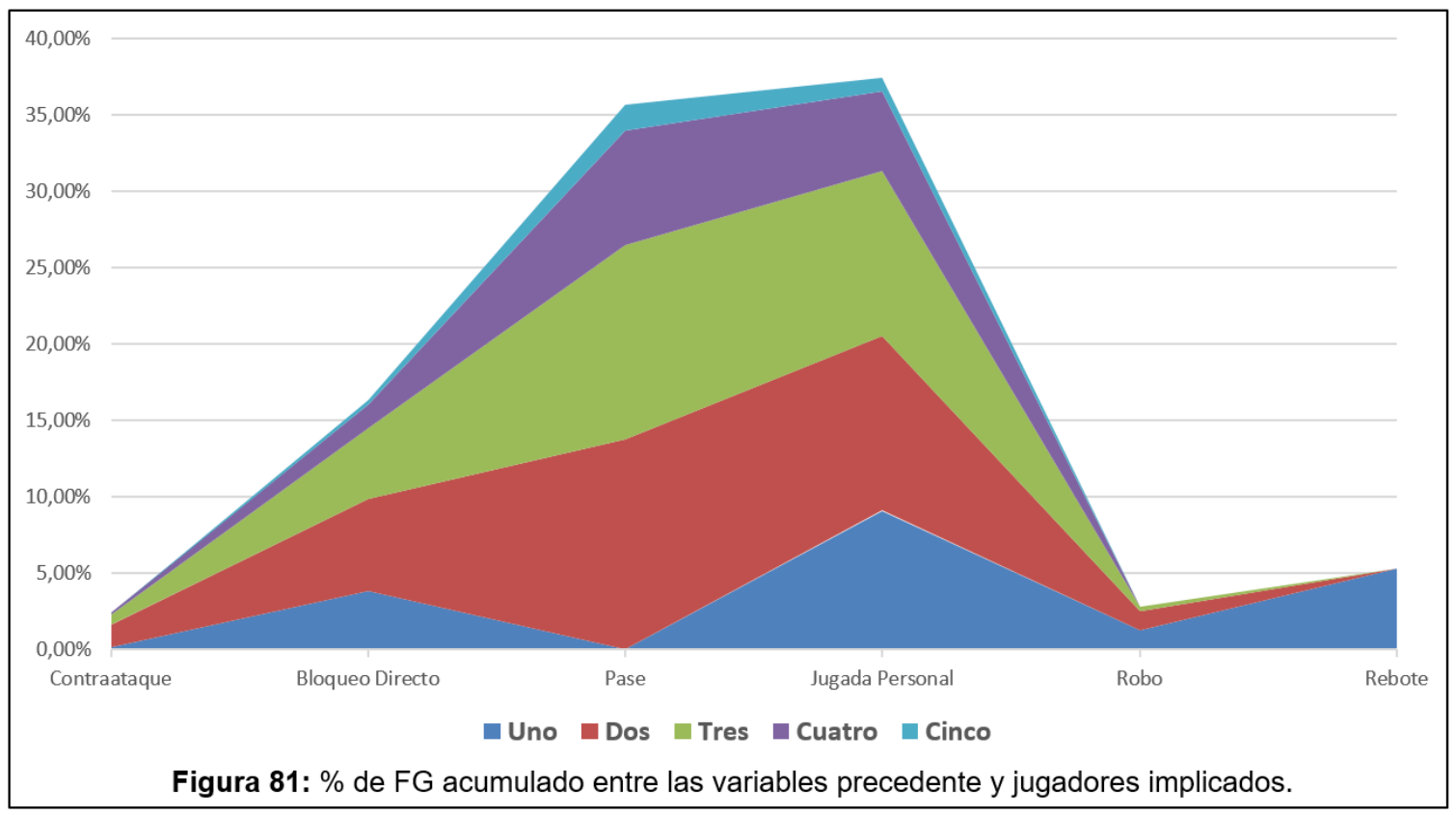

En cuanto al bloqueo directo, el porcentaje más alto se da en combinación con la intervención de dos y tres jugadores respectivamente. El rebote por su parte, acumula todos sus porcentajes con tan solo un jugador, pues es intrínseco a su definición.

La figura 82 muestra los jugadores que han entrado en contacto con el balón antes del FG dentro de cada precedente, y en ella podemos observar grandes diferencias. Si bien es cierto que en la mayoría de precedentes dominan por encima del resto la intervención de 
dos o tres jugadores, esto no se da en todos, y en los que se da, no se produce de igual modo, prevaleciendo de forma distinta el uno sobre el otro.

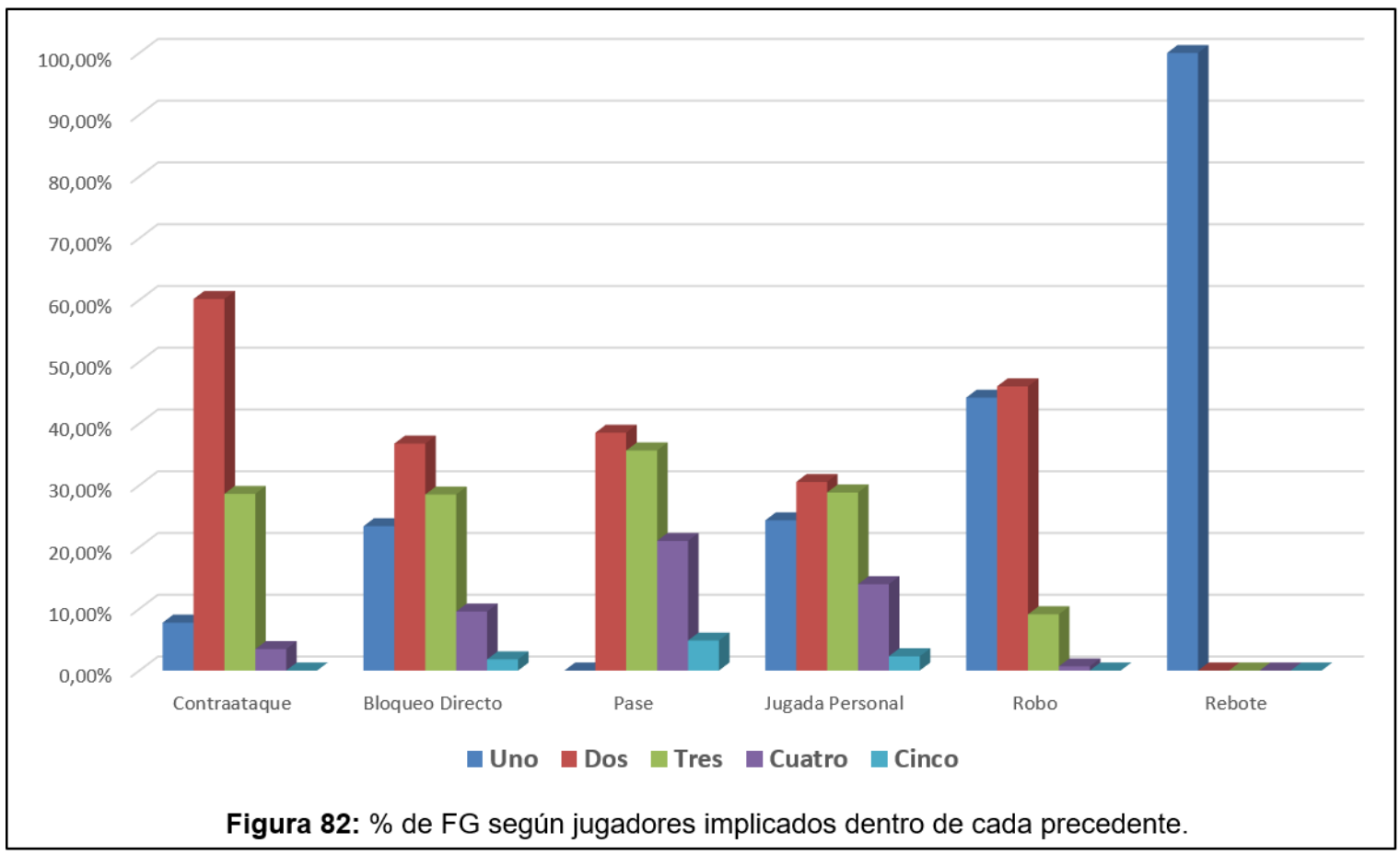

La tabla 82 nos ayudará a analizar cada precedente de forma más clara. En el contraataque casi la totalidad de los FG se dan con dos o tres jugadores, especialmente con dos, con más de un $60 \%$. Es igualmente remarcable como nunca entran en contacto cinco jugadores y casi nunca cuatro.

\begin{tabular}{|c|c|c|c|c|c|c|}
\cline { 2 - 7 } \multicolumn{1}{c|}{} & Contraataque & Bloqueo Directo & Pase & Jugada Personal & Robo & Rebote \\
\hline Uno & $7,75 \%$ & $23,37 \%$ & $0 \%$ & $24,33 \%$ & $44,19 \%$ & $100,00 \%$ \\
\hline Dos & $60,16 \%$ & $36,75 \%$ & $38,51 \%$ & $30,54 \%$ & $46,01 \%$ & $0 \%$ \\
\hline Tres & $28,61 \%$ & $28,50 \%$ & $35,63 \%$ & $28,83 \%$ & $9,11 \%$ & $0 \%$ \\
\hline Cuatro & $3,48 \%$ & $9,55 \%$ & $21,00 \%$ & $13,98 \%$ & $0,68 \%$ & $0 \%$ \\
\hline Cinco & $0 \%$ & $1,82 \%$ & $4,86 \%$ & $2,31 \%$ & $0 \%$ & $0 \%$ \\
\hline TOTAL & $100,00 \%$ & $100,00 \%$ & $100,00 \%$ & $100,00 \%$ & $100,00 \%$ & $100,00 \%$ \\
\hline
\end{tabular}

Tabla 82: \% de FG según jugadores implicados dentro de cada precedente.

En cuanto al bloqueo directo y la jugada personal, se reparten entre dos, tres y uno respectivamente, sumando entre ellos más del $80 \%$. En relación al pase observamos como se reparte entre dos, tres y cuatro, siendo el precedente con mayor incidencia de cuatro jugadores. El 0\% en un jugador es lógico, pues para un pase se requiere de al menos dos jugadores. El robo se reparte casi totalmente entre dos y un jugador, pues por la definición del mismo se trata de FG realizados directamente por la ventaja ocasionada con el robo, 
por lo que debe finalizarse rápido, evitando así que el número de jugadores intervinientes sea muy alto. Por último, en cuanto al rebote, por definición solo puede intervenir un jugador, de ahí su $100 \%$.

\subsubsection{Precedente y QT}

La tabla 83 nos muestra como los mayores porcentajes sobre el total de FG se dan en la combinación de los distintos QT con el pase y la jugada personal, siendo el bloqueo directo la tercera categoría con mayores porcentajes.

\begin{tabular}{|c|c|c|c|c|c|c|}
\cline { 2 - 7 } \multicolumn{1}{c|}{} & Contraataque & Bloqueo Directo & Pase & Jugada Personal & Robo & Rebote \\
\hline 10 QT & $0,72 \%$ & $4,53 \%$ & $9,17 \%$ & $9,48 \%$ & $0,78 \%$ & $1,34 \%$ \\
\hline 2\% QT & $0,68 \%$ & $3,98 \%$ & $8,98 \%$ & $9,58 \%$ & $0,67 \%$ & $1,42 \%$ \\
\hline 3 QT & $0,57 \%$ & $3,83 \%$ & $8,98 \%$ & $9,04 \%$ & $0,74 \%$ & $1,25 \%$ \\
\hline 4\% QT & $0,44 \%$ & $4,01 \%$ & $8,52 \%$ & $9,31 \%$ & $0,65 \%$ & $1,33 \%$ \\
\hline
\end{tabular}

Tabla 83: \% de FG entre las variables precedente y QT.

Si observamos como se reparten los distintos precedentes dentro de cada QT (figura 83 y tabla 84) vemos como en todos se da la misma dinámica, no habiendo diferencias considerables entre ninguno de ellos.

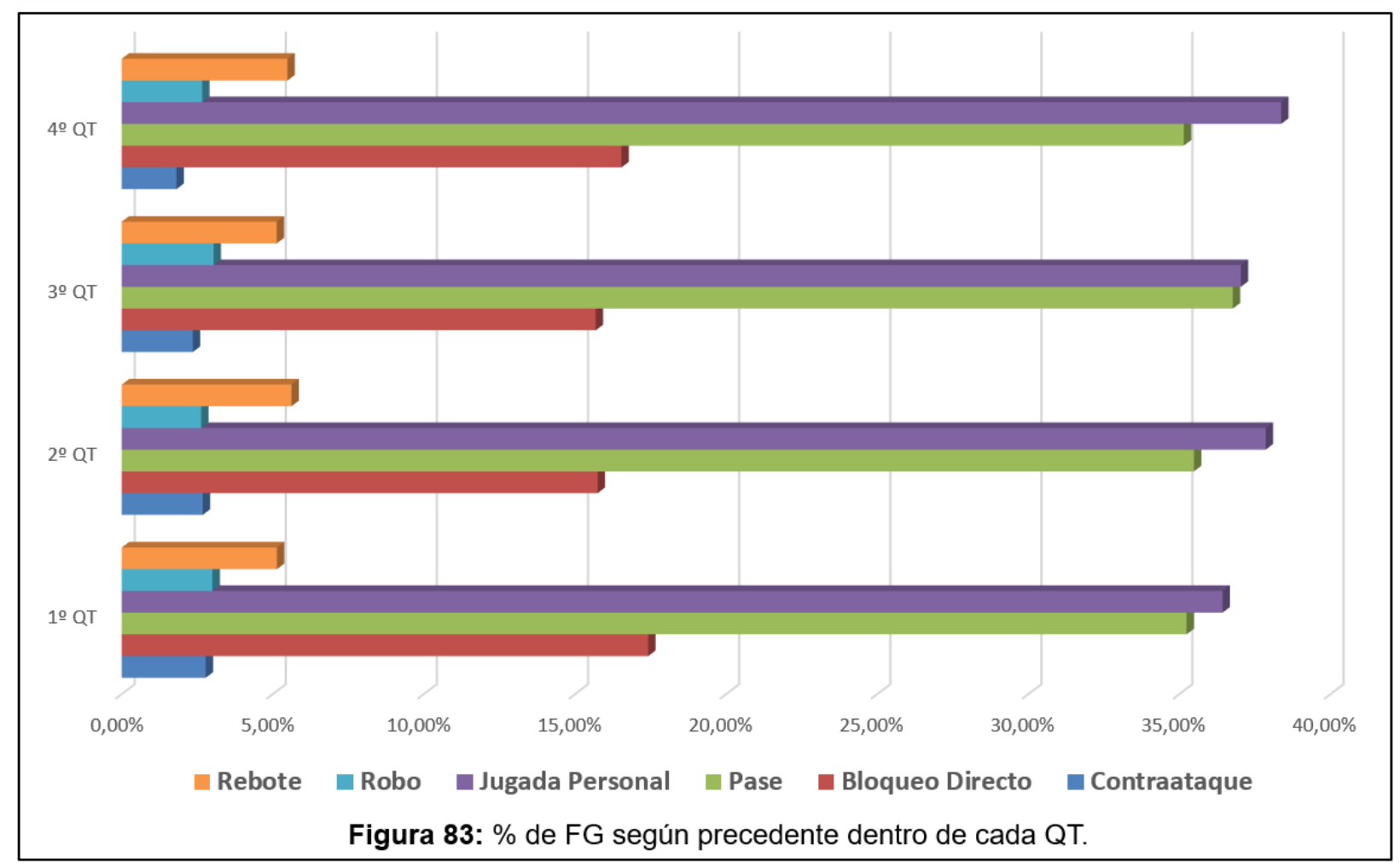


En todos los QT el precedente del FG que más se da es la jugada personal y el pase respectivamente, sumando entre ambos más del 70\%. Como tercer precedente más utilizado estaría el bloqueo directo.

\begin{tabular}{|c|c|c|c|c|c|c|c|}
\cline { 2 - 8 } \multicolumn{1}{c|}{} & Contraataque & Bloqueo Directo & Pase & Jugada Personal & Robo & Rebote & TOTAL \\
\hline 19 QT & $2,78 \%$ & $17,42 \%$ & $35,24 \%$ & $36,43 \%$ & $3,00 \%$ & $5,14 \%$ & $100,00 \%$ \\
\hline 2\% QT & $2,68 \%$ & $15,75 \%$ & $35,48 \%$ & $37,85 \%$ & $2,63 \%$ & $5,62 \%$ & $100,00 \%$ \\
\hline 3 QT & $2,35 \%$ & $15,68 \%$ & $36,76 \%$ & $37,03 \%$ & $3,04 \%$ & $5,13 \%$ & $100,00 \%$ \\
\hline 4 QT & $1,81 \%$ & $16,53 \%$ & $35,14 \%$ & $38,37 \%$ & $2,66 \%$ & $5,48 \%$ & $100,00 \%$ \\
\hline
\end{tabular}

Tabla 84: \% de FG según precedente dentro de cada QT.

Si nos centramos en como se reparte cada precedente entre los distintos cuartos (tabla 85) vemos como el porcentaje de contraataques va reduciéndose a medida que avanza el encuentro, existiendo una gran diferencia entre el primer y el último cuarto. Según va pasando esa frescura inicial de los jugadores, el ritmo del partido va disminuyendo, produciéndose, como demostraremos más adelante, un menor número de FG. Además, el último QT como momento decisivo del encuentro provoca que las jugadas sean más trabajadas, y por ello menos rápidas.

Lo mismo ocurre con el pase, aunque de forma mucho más gradual y sin tanta diferencia entre cuartos. En cuanto al bloque directo, en el primer cuarto se realizan más, manteniendo una estabilidad en los otros tres.

\begin{tabular}{|c|c|c|c|c|c|c|}
\cline { 2 - 7 } \multicolumn{1}{c|}{} & Contraataque & Bloqueo Directo & Pase & Jugada Personal & Robo & Rebote \\
\hline 19 QT & $29,95 \%$ & $27,71 \%$ & $25,72 \%$ & $25,35 \%$ & $27,56 \%$ & $25,03 \%$ \\
\hline 20 QT & $28,07 \%$ & $24,36 \%$ & $25,18 \%$ & $25,60 \%$ & $23,46 \%$ & $26,60 \%$ \\
\hline 3 QT & $23,80 \%$ & $23,41 \%$ & $25,18 \%$ & $24,17 \%$ & $26,20 \%$ & $23,46 \%$ \\
\hline 4 QT & $18,18 \%$ & $24,52 \%$ & $23,91 \%$ & $24,88 \%$ & $22,78 \%$ & $24,91 \%$ \\
\hline TOTAL & $100,00 \%$ & $100,00 \%$ & $100,00 \%$ & $100,00 \%$ & $100,00 \%$ & $100,00 \%$ \\
\hline
\end{tabular}

Tabla 85: \% de FG según QT dentro de cada precedente.

En relación a la jugada personal, se produce un poco más en los dos primeros, pero sus porcentajes son similares en todos los cuartos. También observamos como en los segundos cuartos de cada mitad el porcentaje es algo más elevando que en los primeros. Esta dinámica, y de forma más clara, se observa también en el rebote. Sin embargo, el robo sigue la dinámica opuesta, produciéndose más en los primeros cuartos de cada mitad y con una diferencia significativa. Todo esto lo podemos observar de forma más visual en la figura 84 . 


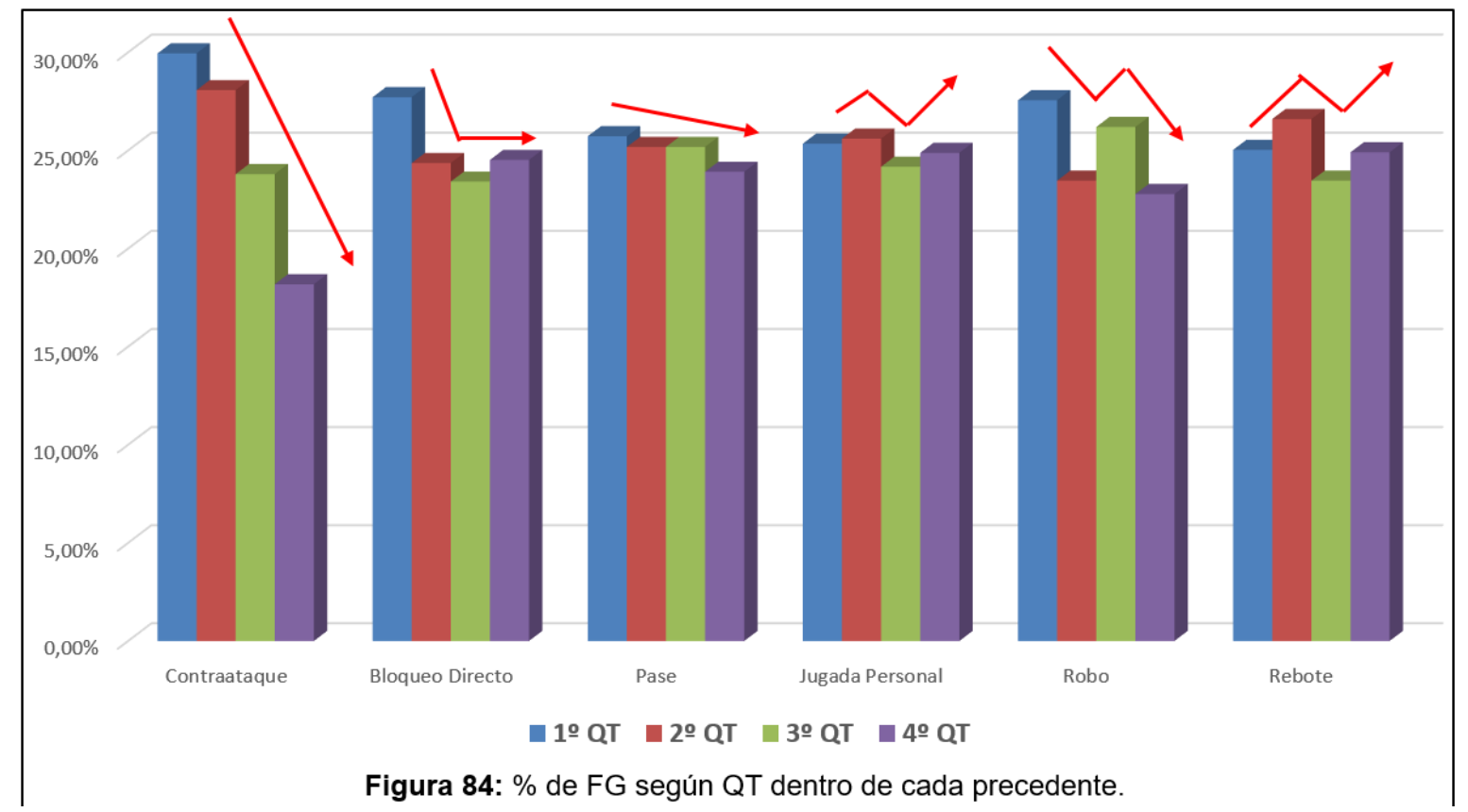

\subsubsection{Precedente y momento especial}

El precedente al FG en los momentos especiales (tabla 86) nos ayudará a descubrir cuál es el más utilizado en cada uno de ellos, extrayendo de ahí los resultados más determinantes para su aplicación práctica.

\begin{tabular}{|c|c|c|c|c|c|c|c|}
\cline { 2 - 8 } \multicolumn{1}{c|}{} & Contraataque & Bloqueo Directo & Pase & Jugada Personal & Robo & Rebote & TOTAL \\
\hline Tiempo Muerto & $0 \%$ & $15,31 \%$ & $40,48 \%$ & $44,22 \%$ & $0 \%$ & $0 \%$ & $100 \%$ \\
\hline Última Jugada & $1,94 \%$ & $11,65 \%$ & $30,42 \%$ & $52,43 \%$ & $3,56 \%$ & $0 \%$ & $100 \%$ \\
\hline
\end{tabular}

Tabla 86: \% de FG según precedente dentro de cada m.especial.

A pesar de que en ambos momentos especiales los mayores porcentajes se den en los mismos precedentes, existen grandes diferencias como observamos en las figuras $85 \mathrm{y}$ 86. Por un lado, tras el tiempo muerto no se puede producir ni el contraataque, ni el rebote, ni el robo como precedente, lo cual reduce a tres las posibilidades. En él se producen casi por igual la jugada personal y el pase,

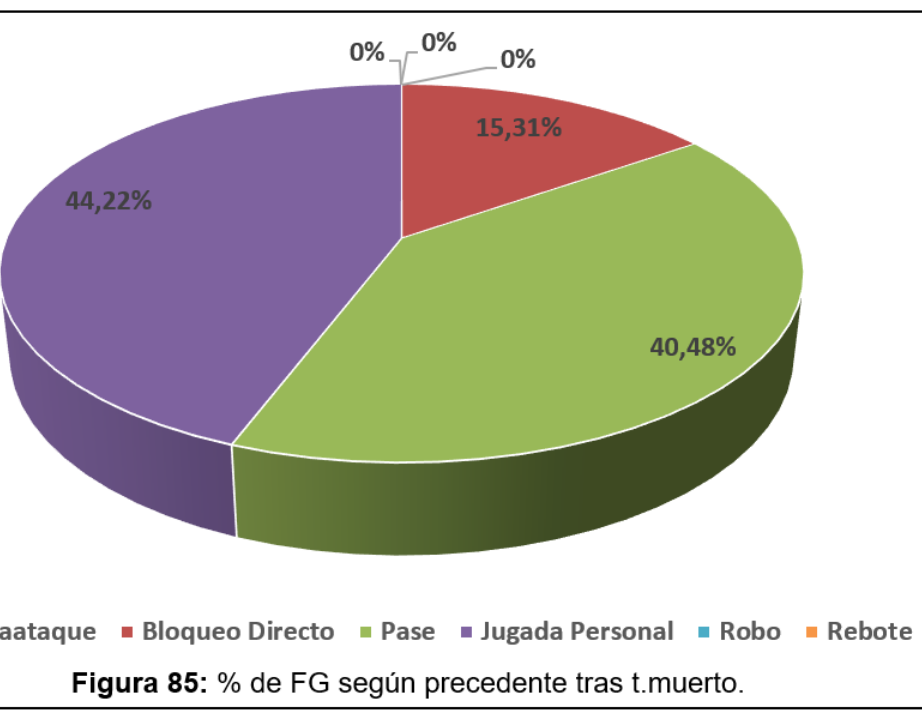


estando un poco por encima la primera. El bloqueo directo queda relegado a la tercera y última posición. Por tanto, tras un tiempo muerto, en más del $84 \%$ de las ocasiones el último recurso utilizado para generar el FG es el pase o la jugada personal.

En cuanto a la última jugada, todos los precedentes son posibles a excepción del rebote, pues estos no se han considerado como jugada al no tener un trasfondo táctico. Al igual que tras tiempo muerto, los precedentes con mayor porcentaje son la jugada personal y el pase, siguiendo como tercera opción el bloqueo directo. Pero es destacable como en esta ocasión más del $52 \%$ de las ocasiones recaen sobre la jugada personal. Esto suele

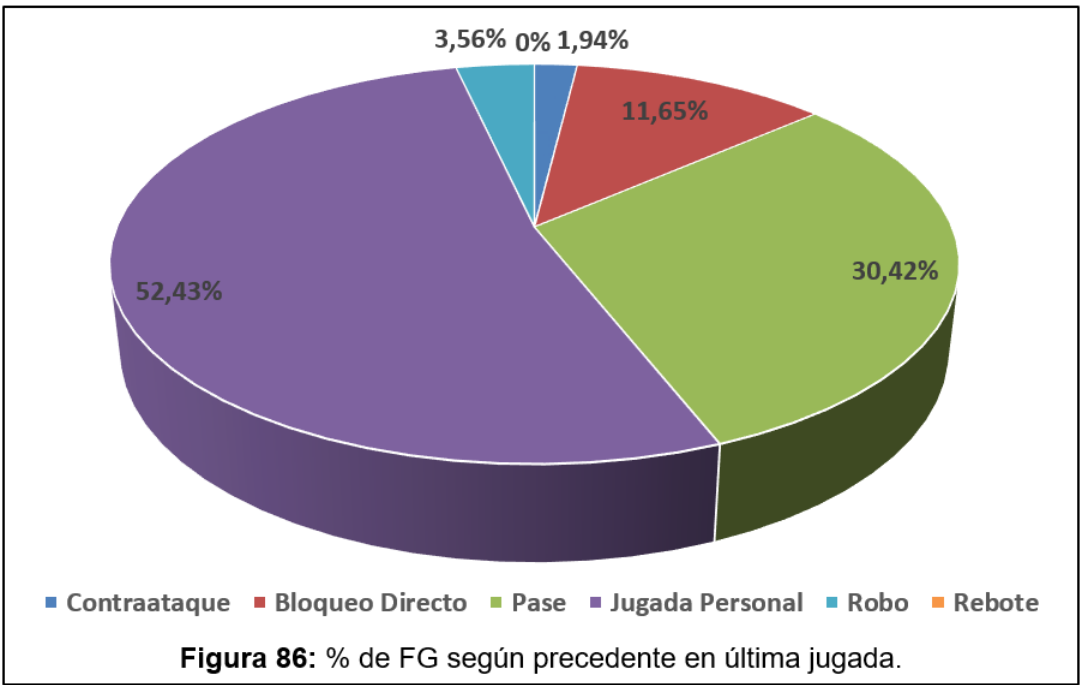

Figura 86: \% de FG según precedente en última jugada.

deberse a dos situaciones, por un lado cuando el jugador que sube el balón a falta de pocos segundos para finalizar el QT debe crearse una opción de tiro, no habiendo tiempo para la ejecución de pases, bloqueos u otros recursos, y por otro lado, ocasiones en las que se apura el tiempo del que dispone para no conceder una posesión más al equipo contrario. 


\subsection{JUGADORES IMPLICADOS}

Si nos fijamos en como se reparte el porcentaje de número de jugadores que entran en contacto con el balón antes de un FG (figura 87) vemos como en más del $63 \%$ de las ocasiones interactúan dos o tres jugadores, seguidos de la intervención de uno y cuatro. La razón de que se dé un porcentaje relativamente alto de un jugador $(19,7 \%)$ es el rebote. De forma muy eventual, con menos de un $3 \%$, entran los cinco jugadores en contacto con el balón.

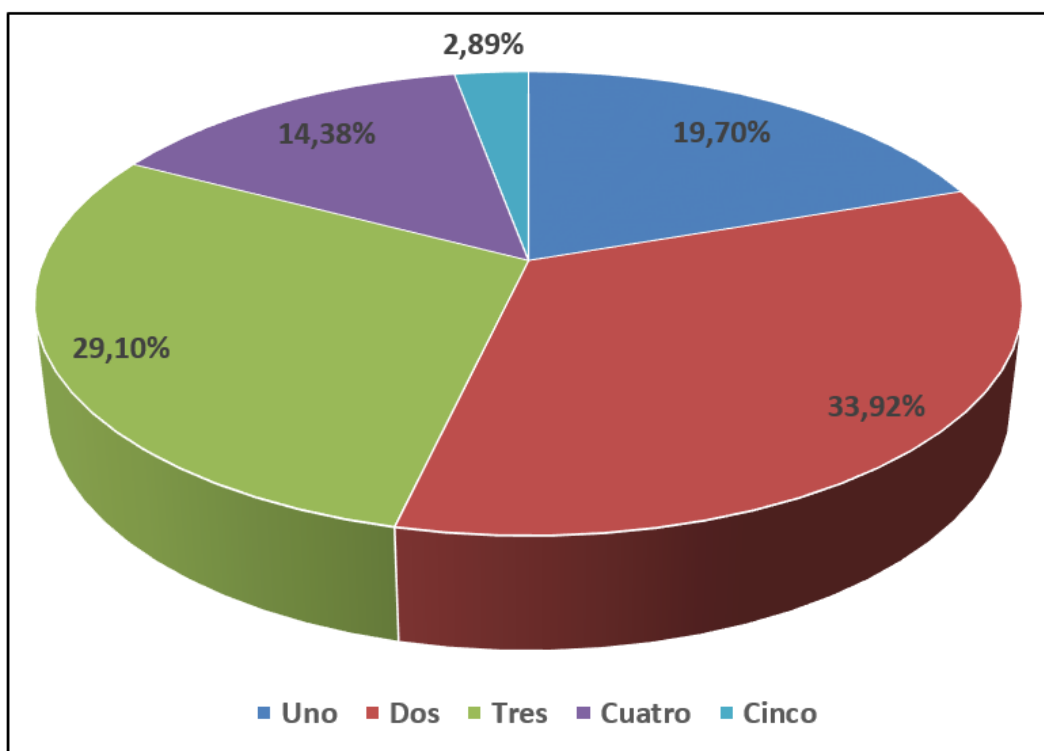

Figura 87: \% de FG según jugadores implicados.

Podría decirse que el baloncesto moderno basa su juego en acciones con intervención directa sobre el balón de dos o tres jugadores, siendo muy raro que los cinco intervengan.

\subsubsection{Jugadores implicados y QT}

La combinación de estas variables sobre el total de FG (tabla 87) nos muestra como el número de jugadores en contacto con el balón con mayor incidencia son respectivamente dos, tres, uno, cuatro y cinco.

\begin{tabular}{|c|c|c|c|c|c|}
\cline { 2 - 6 } \multicolumn{1}{c|}{} & Uno & Dos & Tres & Cuatro & Cinco \\
\hline 19 QT & $4,91 \%$ & $8,69 \%$ & $7,85 \%$ & $3,81 \%$ & $0,77 \%$ \\
\hline 20 QT & $4,88 \%$ & $8,47 \%$ & $7,51 \%$ & $3,74 \%$ & $0,70 \%$ \\
\hline 39 QT & $4,90 \%$ & $7,99 \%$ & $7,12 \%$ & $3,69 \%$ & $0,72 \%$ \\
\hline 40 QT & $5,01 \%$ & $8,78 \%$ & $6,63 \%$ & $3,14 \%$ & $0,70 \%$ \\
\hline
\end{tabular}

Tabla 87: \% de FG entre las variables jugadores implicados y QT.

La tabla 88, la cual recoge el porcentaje de jugadores implicados antes de efectuar un FG dentro de cada QT, nos deja ver una vez más como en todos los cuartos la intervención 
de dos y tres jugadores acumulan los mayores porcentajes, muy por encima del resto, seguidos de la intervención de uno y cuatro.

\begin{tabular}{|c|c|c|c|c|c|c|}
\cline { 2 - 7 } \multicolumn{1}{c|}{} & Uno & Dos & Tres & Cuatro & Cinco & TOTAL \\
\hline 10 QT & $18,86 \%$ & $33,40 \%$ & $30,15 \%$ & $14,64 \%$ & $2,95 \%$ & $100,00 \%$ \\
\hline 20 QT & $19,30 \%$ & $33,46 \%$ & $29,68 \%$ & $14,78 \%$ & $2,78 \%$ & $100,00 \%$ \\
\hline 3o QT & $20,07 \%$ & $32,72 \%$ & $29,15 \%$ & $15,13 \%$ & $2,94 \%$ & $100,00 \%$ \\
\hline 40 QT & $20,66 \%$ & $36,18 \%$ & $27,32 \%$ & $12,94 \%$ & $2,90 \%$ & $100,00 \%$ \\
\hline
\end{tabular}

Tabla 88: \% de FG según jugadores implicados dentro de cada QT.

Si hacemos una comparación entre el reparto dentro de cada cuarto, podemos ver como en el tercer y cuarto QT se da un mayor porcentaje de un jugador. De hecho, según avanzan los cuartos se producen proporcionalmente más FG con un solo jugador.

En cuanto a tres jugadores, vemos como en cada cuarto va descendiendo su porcentaje, siendo el $4^{\circ}$ QT el que menos FG con tres jugadores tiene. Este último y decisivo QT también tiene el menor porcentaje de intervención de cuatro jugadores, pero el que más en dos. Es decir, en este QT las jugadas de uno y dos jugadores tienen una mayor incidencia que en el resto de cuartos, mientras que las jugadas de tres y cuatro la ven disminuida. Por último, la intervención de los 5 jugadores es muy escasa en todos los QT.

Todo lo anterior lo podemos ver claramente en la figura 88 .

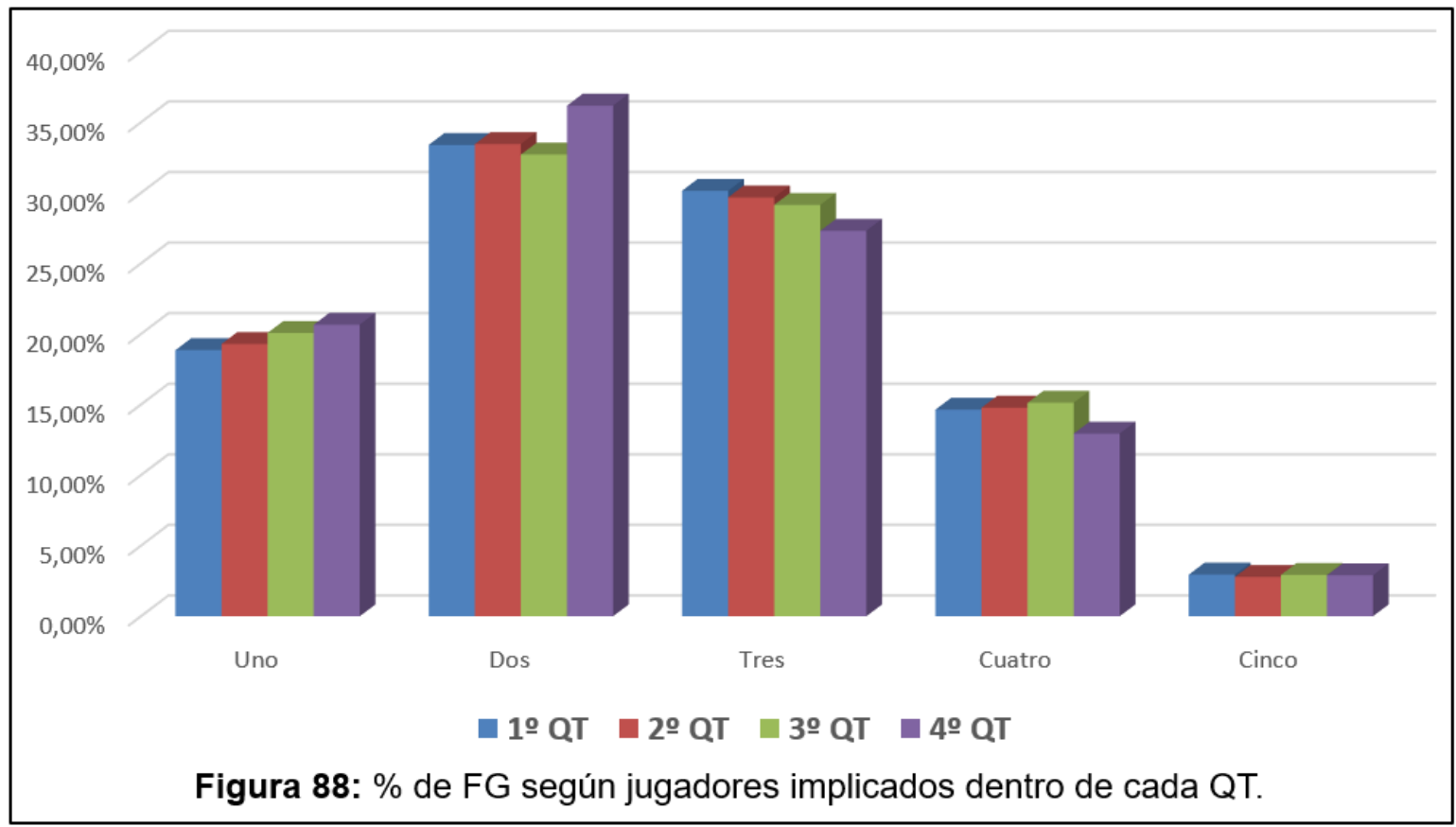




\subsubsection{Jugadores implicados y momento especial}

En las figuras 89 y 90 observamos las grandes diferencias entre el número de jugadores que entran en contacto con el balón antes del FG dentro de cada momento especial.

Como vemos en la tabla 89 , los FG tras tiempo muerto tienen un mayor porcentaje en la intervención de dos y tres jugadores, seguidos de lejos por cuatro y uno

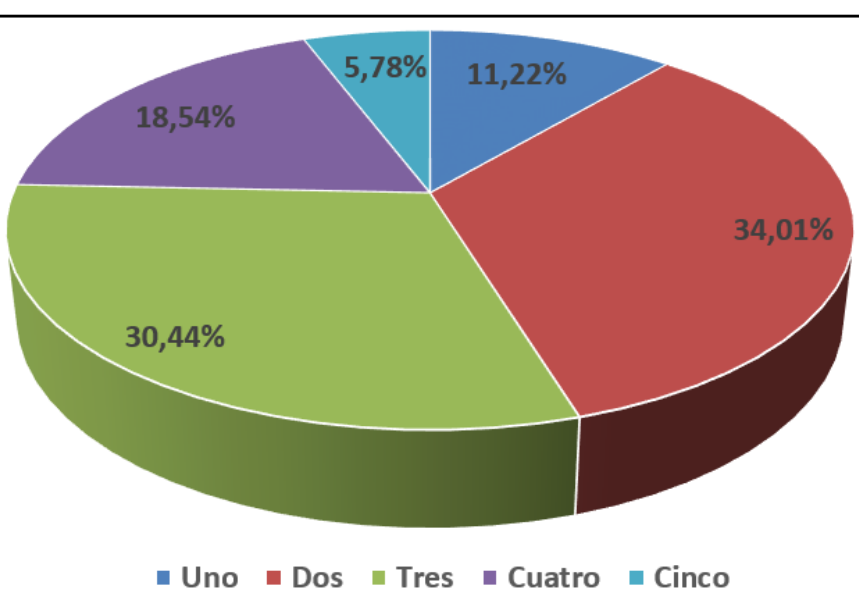

Figura 89: \% de FG según jugadores implicados tras t.muerto. respectivamente, y acumulando tan solo un 5,78\% en la intervención de cinco jugadores.

Sin embargo, en los FG en última jugada, más del $82 \%$ se reparte entre uno y dos jugadores, disminuyendo el porcentaje según se suman jugadores, incluso dándose un $0 \%$ para cinco. Es muy remarcable como el FG en última jugada tiene casi un $44 \%$ de ejecuciones en las que tan solo un jugador ha entrado en contacto con el balón.

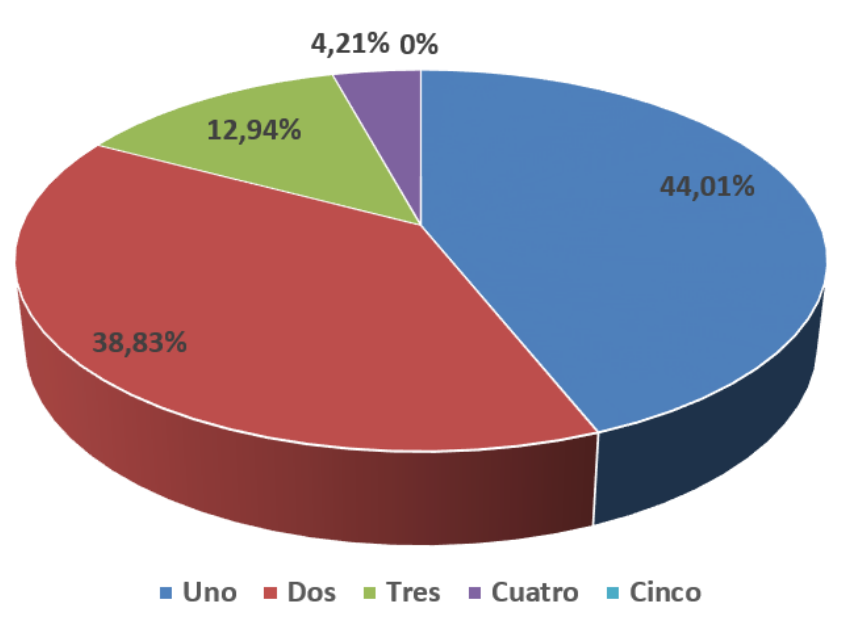

Figura 90: \% de FG según jugadores implicados en última jugada.

\begin{tabular}{|c|c|c|c|c|c|c|}
\cline { 2 - 7 } \multicolumn{1}{c|}{} & Uno & Dos & Tres & Cuatro & Cinco & TOTAL \\
\hline Tiempo Muerto & $11,22 \%$ & $34,01 \%$ & $30,44 \%$ & $18,54 \%$ & $5,78 \%$ & $100,00 \%$ \\
\hline Última Jugada & $44,01 \%$ & $38,83 \%$ & $12,94 \%$ & $4,21 \%$ & $0 \%$ & $100,00 \%$ \\
\hline
\end{tabular}

Tabla 89: \% de FG según jugadores implicados dentro de cada m.especial. 


\section{8. $Q T$}

El QT como división temporal del partido tiene un importante valor para su análisis, pues muestra la evolución o dinámica en el juego según en qué fracción del encuentro se está.

En la figura 91 podemos ver como se producen más FG en el primer cuarto que en el resto. Además, se van reduciendo progresivamente el número de los mismos según avanzan los cuartos. Por tanto, en los primeros compases de los encuentros, dado la frescura física y mental de los equipos, sumada a la falta de presión ejercida por la relación del marcador y el tiempo hasta el final del partido, se dan un mayor número de FG.

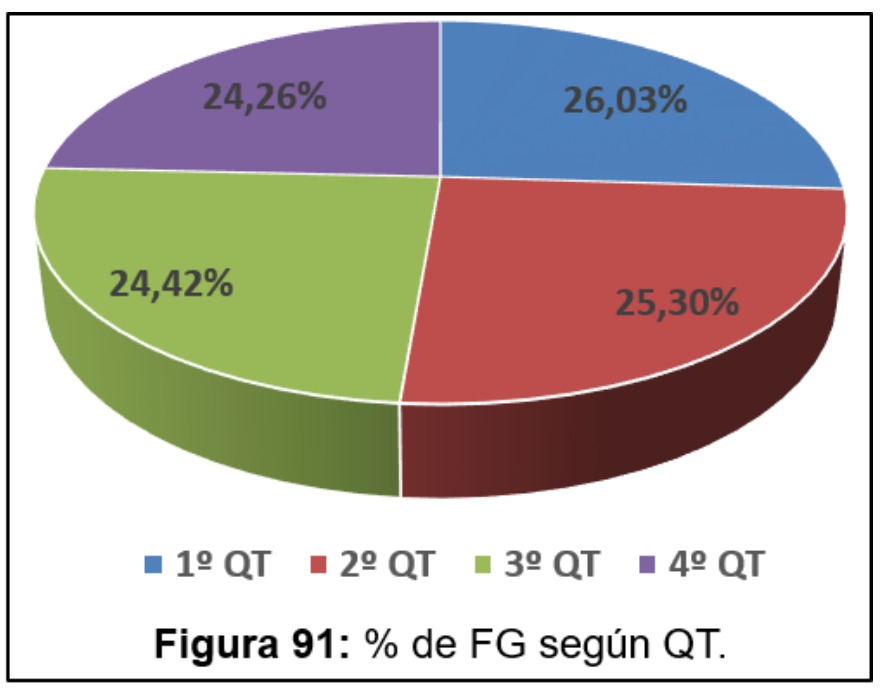

Según va desapareciendo esa frescura, las situaciones de lanzamiento van siendo más difíciles de generar, y la relación entre resultado en el marcador y el tiempo hasta el final del encuentro va siendo más determinante, pues va quedando menos tiempo para mantener o invertir el marcador, por lo que las jugadas son más reflexivas y trabajadas.

\subsubsection{QT y momento especial}

La tabla 90 nos muestra como se reparte proporcionalmente cada momento especial analizado según el QT.

\begin{tabular}{|c|c|c|c|c|c|}
\cline { 2 - 6 } \multicolumn{1}{c|}{} & 19 QT & 20 QT & 39 QT & 49 QT & TOTAL \\
\hline Tiempo Muerto & $14,97 \%$ & $24,83 \%$ & $17,18 \%$ & $43,03 \%$ & $100,00 \%$ \\
\hline Última Jugada & $26,21 \%$ & $25,57 \%$ & $31,07 \%$ & $17,15 \%$ & $100,00 \%$ \\
\hline
\end{tabular}

Tabla 90: \% de FG según QT dentro de cada m.especial.

La diferencia entre ambos momentos, como vemos en las figuras 92 y 93, es evidente. Los FG tras tiempo muerto se producen más en los segundos cuartos de cada mitad, existiendo gran diferencia con los primeros. Además, el último cuarto aucumula un 
porcentaje muy alto, más de un $43 \%$, lo cual se debe a tratarse del cuarto decisivo del encuentro.

Los FG en las últimas jugadas no tienen un patrón claro. Tan solo se observa un fuerte descenso en el último cuarto.

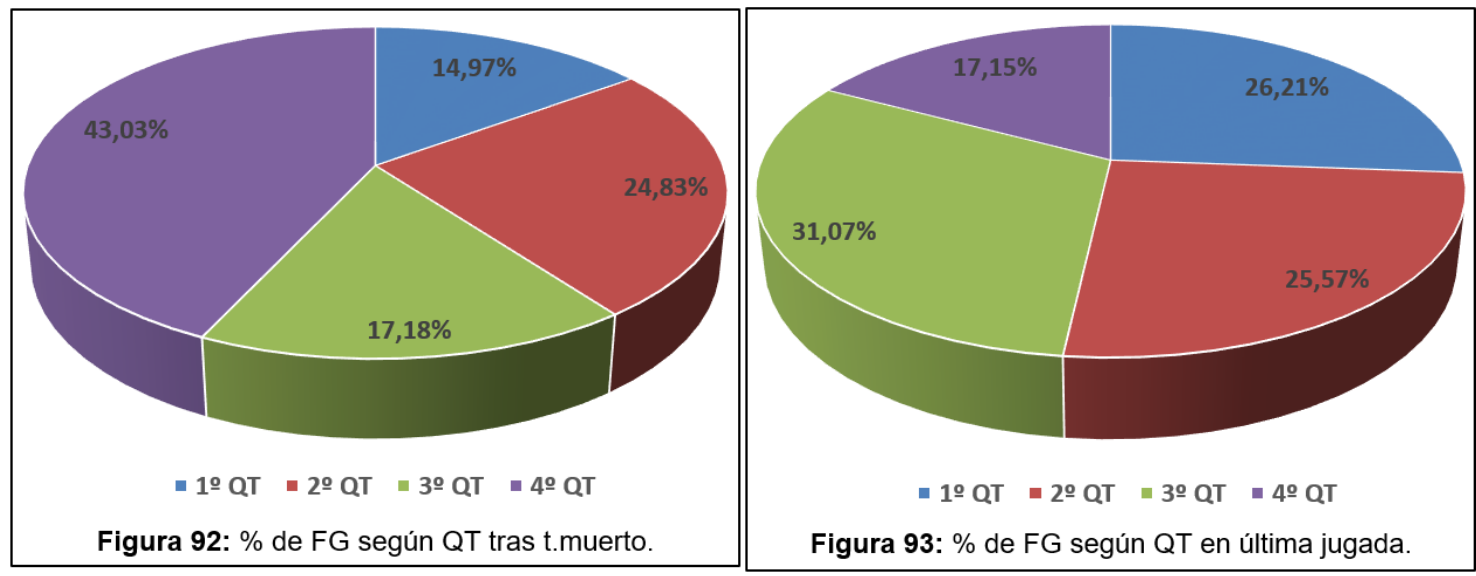

\subsection{MOMENTO ESPECIAL}

Si nos fijamos en la proporción entre FG tras un momento especial y tras el resto de momentos (figura 94), podemos ver como estos momentos especiales son escasos, sin llegar siquiera a un $6 \%$ del total, por lo que su importancia sobre el resultado final no es especialmente significativa.

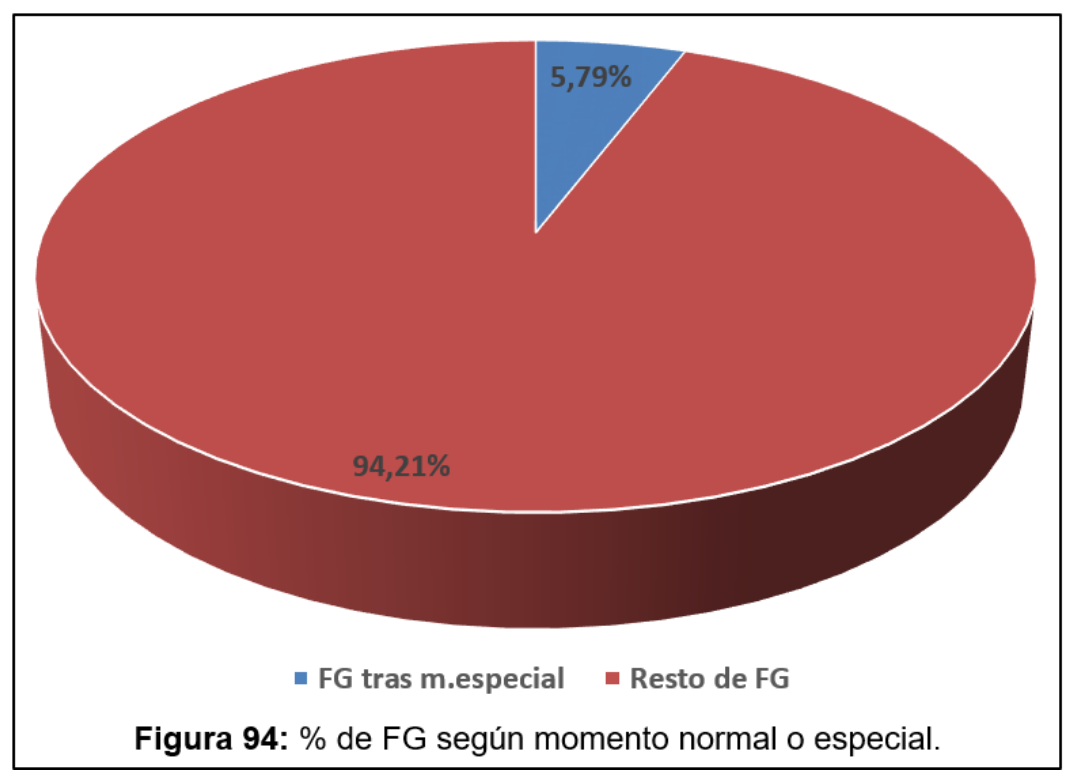




\section{PERSPECTIVA DE GÉNERO}

Valiéndonos de todos los datos extraídos aprovecharemos para hacer un pequeño análisis en función del género (WNBA, liga Día y WEuroliga / NBA, ACB y Euroliga) y de la localización (Euroliga y WEuroliga / NBA y WNBA). Además, dentro de la localización volveremos a confrontar los datos por género, analizando los datos de las seis ligas en cuatro subapartados: 1) Baloncesto masculino y femenino en EU, 2) Baloncesto masculino y femenino en EEUU, 3) Baloncesto masculino en EU y EEUU, y 4) Baloncesto femenino en EU y EEUU.

Todas las tablas están recogidas en el anexo 12.4, desde el subapartado 2 hasta el 9, y contienen información muy completa para un estudio que debería afrontarse por sí mismo, no teniendo cabida dentro de este. Por ello, nos limitaremos a rascar la superficie de toda la información obtenida buscando analizar las diferencias genéricas más destacables.

\subsection{COMPARATIVA BALONCESTO MASCULINO Y FEMENINO}

El análisis de las diferencias deportivas según el género ha sido estudiado por diversos autores como Thibault et al. (2010) que se centraron en las diferencias de género en atletismo, natación, patinaje de velocidad, ciclismo en pista y levantamiento de pesas; $\mathrm{u}$ otros más específicos del baloncesto como Ibáñez et al. (2003), Sampaio et al. (2004), Refoyo et al. (2009), Gómez et al. (2013), incluso analizando las diferencias en el tipo de lesiones según el género como Zuckerman et al. (2018).

En este apartado se comparan las tablas del reparto del porcentaje de FG en las distintas categorías dentro de cada variable en función del sexo, tratando de extraer a partir de las diferencias significativas halladas, diferencias en los patrones de juego.

En la tabla 91 podemos ver claramente como en el baloncesto femenino se da una mayor incidencia en las zonas interiores del perímetro (zona1, 2, 3 y 4), mientras que en el baloncesto masculino se ejecutan porcentualmente mayor número de FG desde las zonas exteriores (zona 5, 6 y 7).

La mayor diferencia se da en la zona 7, desde donde en el baloncesto femenino se lanza casi un $7 \%$ menos. En cuanto al interior del perímetro, la mayor diferencia, aunque no 
muy elevada, se da en la zona 4, desde donde las mujeres ejecutan algo más de un $3 \%$ de FG que los hombres.

\begin{tabular}{|l|c|c|c|c|c|c|c|c|}
\cline { 2 - 9 } \multicolumn{1}{c|}{} & ZONA 1 & ZONA 2 & ZONA 3 & ZONA 4 & ZONA 5 & ZONA 6 & ZONA 7 & TOTAL \\
\hline B.FEMENINO & $50,77 \%$ & $7,27 \%$ & $6,79 \%$ & $9,27 \%$ & $4,75 \%$ & $4,20 \%$ & $16,94 \%$ & $100,00 \%$ \\
\hline B.MASCULINO & $48,76 \%$ & $5,04 \%$ & $4,69 \%$ & $6,18 \%$ & $6,10 \%$ & $5,48 \%$ & $23,74 \%$ & $100,00 \%$ \\
\hline
\end{tabular}

Tabla 91: \% de FG según zona del campo por género.

En cuanto a los resultados (tabla 92), el baloncesto masculino tiene mayores porcentajes de FG en las categorías relativas al lanzamiento de 3 puntos. En las categorías relativas a los lanzamientos de 2 puntos los porcentajes son más similares, excepto en el número de fallos, donde las mujeres tienen algo más de un $9 \%$ más.

En relación a los tapones, en contra de lo que se podría pensar dada la diferencia de físicos, la diferencia no es significativa.

\begin{tabular}{|l|c|c|c|c|c|c|c|c|c|c|}
\cline { 2 - 10 } \multicolumn{1}{c|}{} & 3p. + adicional & 3puntos & Falta + 3 adic. & 2p. + adicional & 2puntos & Falta + 2 adic. & Tapón & Fallo 3p. & Fallo 2p. & TOTAL \\
\hline B.FEMENINO & $0,09 \%$ & $7,71 \%$ & $0,09 \%$ & $2,11 \%$ & $27,89 \%$ & $6,44 \%$ & $3,71 \%$ & $17,84 \%$ & $34,13 \%$ & $100,00 \%$ \\
\hline B.MASCULINO & $0,09 \%$ & $12,29 \%$ & $0,52 \%$ & $2,22 \%$ & $27,37 \%$ & $6,42 \%$ & $3,92 \%$ & $22,22 \%$ & $24,94 \%$ & $100,00 \%$ \\
\hline
\end{tabular}

Tabla 92: \% de FG según resultado por género.

En la siguiente tabla (tabla 93) se recoge el reparto porcentual en función de la variable "tiempo de posesión". Los datos obtenidos en ambos sexos son muy similares, dandose en comparación un mayor porcentaje por parte de los hombres en las categorías " $0-8$ " y “17-24"; y por parte de las mujeres en la "9-16". Es decir, por un lado los hombres realizan más ataques rápidos, pero a su vez, tambien tienden a agotar las posesiones más que las mujeres, las cuales se mueven más en posesiones intermedias.

\begin{tabular}{|l|c|c|c|c|}
\cline { 2 - 5 } \multicolumn{1}{c|}{} & $\mathbf{0 - 8}$ & $\mathbf{9 - 1 6}$ & $\mathbf{1 7 - 2 4}$ & TOTAL \\
\hline B.FEMENINO & $32,88 \%$ & $49,56 \%$ & $17,56 \%$ & $100,00 \%$ \\
\hline B.MASCULINO & $33,36 \%$ & $48,40 \%$ & $18,23 \%$ & $100,00 \%$ \\
\hline
\end{tabular}

Tabla 93: \% de FG según tiempo de posesión por género.

En la variable "tipo de tiro" (tabla 94) no encontramos diferencias significativas entre ambos sexos. Las diferencias son minimas, observando un ligero mayor porcentaje por parte de las mujeres en los buenos y malos FG, teniendo por tanto los hombres algo más de porcentaje en los tiros normales. 


\begin{tabular}{|l|c|c|c|c|}
\cline { 2 - 5 } \multicolumn{1}{c|}{} & Buen tiro & Tiro normal & Mal tiro & TOTAL \\
\hline B.FEMENINO & $37,88 \%$ & $49,42 \%$ & $12,70 \%$ & $100,00 \%$ \\
\hline B.MASCULINO & $37,66 \%$ & $49,95 \%$ & $12,39 \%$ & $100,00 \%$ \\
\hline
\end{tabular}

Tabla 94: \% de FG según tipo de tiro por género.

La tabla 95 recoge los resultados en función del marcador, pero como ya explicamos anteriormente, no podemos extraer una información útil de ellos.

\begin{tabular}{|l|c|c|c|c|c|c|}
\cline { 2 - 7 } \multicolumn{1}{c|}{} & $(\mathbf{+}) \mathbf{1 1}-\mathbf{2 0}$ & $\mathbf{( + )} \mathbf{1}-\mathbf{1 0}$ & Empate & $\mathbf{( - )} \mathbf{1}-\mathbf{1 0}$ & $\mathbf{( - )} \mathbf{1 1}-\mathbf{2 0}$ & TOTAL \\
\hline B.FEMENINO & $1,94 \%$ & $35,10 \%$ & $7,58 \%$ & $48,06 \%$ & $7,32 \%$ & $100,00 \%$ \\
\hline B.MASCULINO & $2,15 \%$ & $34,59 \%$ & $7,26 \%$ & $46,77 \%$ & $9,22 \%$ & $100,00 \%$ \\
\hline
\end{tabular}

Tabla 95: \% de FG según ventaja/desventaja por género.

Comparando el reparto porcentual en los distintos precedentes del FG (tabla 96) entre los dos géneros podemos ver como como el baloncesto femenino utiliza más el contraataque, el pase y el rebote; mientras que los hombres utilizan más el bloqueo directo y la jugada personal. Los valores de robo son muy similares.

Las mayores diferencias se dan en el bloqueo directo, pase y jugada personal, como ya vimos, los tres precedentes más utilizados. Mientras que el baloncesto femenino se basa más en la creación de situaciones de lanzamiento a traves del pase, muy seguido de la jugada personal, en el baloncesto masculino la jugada personal supera al pase como forma de generar el FG.

\begin{tabular}{|l|c|c|c|c|c|c|c|}
\cline { 2 - 8 } \multicolumn{1}{c|}{} & Contraataque & Bloqueo Directo & Pase & Jugada Personal & Robo & Rebote & TOTAL \\
\hline B.FEMENINO & $2,90 \%$ & $15,01 \%$ & $37,35 \%$ & $36,08 \%$ & $2,85 \%$ & $5,81 \%$ & $100,00 \%$ \\
\hline B.MASCULINO & $2,13 \%$ & $17,14 \%$ & $34,66 \%$ & $38,17 \%$ & $2,83 \%$ & $5,07 \%$ & $100,00 \%$ \\
\hline
\end{tabular}

Tabla 96: \% de FG según precedente por género.

El cuanto al número de jugadores implicados en la ejecución de los FG (tabla 97) tambien encontramos diferencias según género. A pesar de que ambos sexos tienen su mayor porcentaje en dos y tres jugadores, las mujeres tienen mayores porcentajes de tres, cuatro y cinco; mientras que los hombres tienen mayores porcentajes en uno y dos. El hecho de que, como vimos en la tabla anterior, las mujeres se basen más en el pase, puede favorecer la implicación de mayor número de jugadoras, pero esto solo es una hipotesis que habría que estudiar con detenimiento. 


\begin{tabular}{|l|c|c|c|c|c|c|}
\cline { 2 - 7 } \multicolumn{1}{c|}{} & Uno & Dos & Tres & Cuatro & Cinco & TOTAL \\
\hline B.FEMENINO & $17,70 \%$ & $31,47 \%$ & $30,42 \%$ & $16,38 \%$ & $4,03 \%$ & $100,00 \%$ \\
\hline B.MASCULINO & $20,87 \%$ & $35,34 \%$ & $28,33 \%$ & $13,22 \%$ & $2,23 \%$ & $100,00 \%$ \\
\hline
\end{tabular}

Tabla 97: \% de FG según jugadores implicados por género.

Por último, en cuanto al reparto porcentual de FG según el perido de juego (tabla 98), vemos como los resultados son muy similares, siendo las únicas diferencias, minimamente significativas, el mayor porcentaje de las mujeres en los dos primeros QT, y de los hombres el el tercero.

\begin{tabular}{|l|c|c|c|c|c|}
\cline { 2 - 6 } \multicolumn{1}{c|}{} & 10 QT & 20 QT & 30 QT & 4\% QT & TOTAL \\
\hline B.FEMENINO & $26,25 \%$ & $25,56 \%$ & $23,91 \%$ & $24,28 \%$ & $100,00 \%$ \\
\hline B.MASCULINO & $25,90 \%$ & $25,15 \%$ & $24,71 \%$ & $24,24 \%$ & $100,00 \%$ \\
\hline
\end{tabular}

Tabla 98: \% de FG según periodo de juego por género.

\subsection{COMPARATIVA BALONCESTO EUROPEO VS AMERICANO}

Las diferencias entre el deporte europeo y el americano han sido ya estudiadas por autores como Fort (2000, 2019) y Van Bottenburg (2011) entre otros. Si nos centramos en el baloncesto, el modelo europeo y el americano siempre han tenido grandes diferencias en varios áreas fundamentales para el juego, como por ejemplo, a nivel normativo, a nivel espacial (líneas del campo), a nivel temporal (distinta duración de los cuartos), a nivel organizativo (más encuentros y menos descanso entre los mismos), etcétera. Pero a su vez, uno se ha ido influenciado del otro, buscando ambos la evolución lógica del deporte para poder adaptarse a las exigencias competitivas y sociales que se demandan.

Una de sus mayores diferencias es el modelo de negocio, contando la NBA con un mayor impacto económico y una mayor expansión mundial. Además de esto, uno de sus mayores logros ha sido el control de la competencia a través de techos salariales y drafts. Con ello han conseguido una liga equilibrada en la que los equipos campeones, o al menos, que optan a serlo, no son constantes a lo largo de los años.

Si nos centramos en lo meramente deportivo, Fierro (2002) recoge en su estudio como aunque en los partidos de la NBA se anoten más puntos, si estos los ajustamos proporcionalmente a los 40 minutos que se juegan en $\mathrm{ACB}$, la anotación media tiene 
valores similares. También recoge como la ACB cuenta con mejores porcentajes de efectividad en triples y canastas de dos, mientras que en la NBA, mucho más física, destacan los tapones y los rebotes. En la NBA observa como hay una mayor correlación negativa entre los puntos en contra y la victoria, que correlación entre los puntos conseguidos y la victoria, siendo por tanto más determinante para la consecución de la victoria la defensa.

A continuación, como en el apartado anterior, vamos a realizar una comparación entre las tablas del reparto del porcentaje de FG en las categorías dentro de cada variable en función de la localización, tratando de extraer a partir de las diferencias significativas halladas, diferencias en los patrones de juego.

En la tabla 99, que recoge el reparto de los porcentajes de FG según zona del campo, podemos ver como los datos obtenidos son muy similares, dándose unas variaciones mínimas. En cuanto a la zona exterior del perímetro, en el baloncesto europeo se ejecutan más FG desde las zonas laterales (zona 5 y 6) y menos desde la zona central (zona 7). Respecto al interior de la línea de 3 puntos, el baloncesto norteamericano realiza más FG desde la zona 2 y 4 , mientras que el europeo, desde la zona 1 y 3.

\begin{tabular}{|l|c|c|c|c|c|c|c|c|}
\cline { 2 - 9 } \multicolumn{1}{c|}{} & ZONA 1 & ZONA 2 & ZONA 3 & ZONA 4 & ZONA 5 & ZONA 6 & ZONA 7 & TOTAL \\
\hline B.EUROPEO & $49,30 \%$ & $5,17 \%$ & $6,05 \%$ & $7,54 \%$ & $5,64 \%$ & $5,64 \%$ & $20,66 \%$ & $100,00 \%$ \\
\hline B.NORTE AMERICANO & $48,63 \%$ & $6,82 \%$ & $5,33 \%$ & $8,15 \%$ & $5,57 \%$ & $4,27 \%$ & $21,24 \%$ & $100,00 \%$ \\
\hline
\end{tabular}

Tabla 99: \% de FG según zona del campo por localización.

Si nos centramos en los resultados tras FG (tabla 100) se sigue manteniendo una misma dinámica entre ambos, dándose al igual que en la tabla anterior, pequeñas diferencias. Lo más destacable es como en el baloncesto europeo hay mayores porcentajes de fallo de 2 y 3 puntos que en el norteamericano, manteniendo esa superioridad en los triples, pero no en las canastas de dos puntos. En cuanto a los tapones, se da una ligera superioridad en las ligas norteamericanas.

\begin{tabular}{|c|c|c|c|c|c|c|c|c|c|c|}
\hline & 3p. + adicional & 3puntos & Falta +3 adic. & 2p. + adicional & 2puntos & Falta +2 adic. & Tapón & Fallo 3p. & Fallo 2p. & TOTAL \\
\hline B.EUROPEO & $0,10 \%$ & $10,91 \%$ & $0,29 \%$ & $2,24 \%$ & $27,45 \%$ & $5,98 \%$ & $3,83 \%$ & $20,57 \%$ & $28,64 \%$ & $100,00 \%$ \\
\hline B.NORTE AMERICANO & $0,10 \%$ & $10,60 \%$ & $0,42 \%$ & $2,18 \%$ & $28,19 \%$ & $6,90 \%$ & $3,95 \%$ & $19,74 \%$ & $27,93 \%$ & $100,00 \%$ \\
\hline
\end{tabular}

Tabla 100: \% de FG según resultado por localización.

En relación al tiempo de posesión en el que se ejecutan los FG (tabla 101) si encontramos mayores diferencias. Aunque para ambos el orden según mayores porcentajes en cuanto 
a las categorías de tiempo de posesión son 9-16, 0-8 y 17-24, los porcentajes de estas franjas son muy distintos.

En cuanto a la franja de posesión intermedia, los porcentajes son similares, dándose cierta superioridad en las ligas norteamericanas. Las mayores diferencias se encuentran en las otras dos franjas, y al ser comparadas vemos como en la franja 17-24 se da un porcentaje mucho más alto en las ligas norteamericanas, y en la franja 0-8 en las ligas europeas. De estos datos podríamos concluir que el baloncesto norteamericano es mucho más rápido y físico, pues acumula más del 73\% de sus FG entre las dos primeras franjas de posesión, mientras que el baloncesto europeo es más táctico y pausado, acumulando más del $85 \%$ entre las dos últimas franjas.

\begin{tabular}{|l|c|c|c|c|}
\cline { 2 - 5 } \multicolumn{1}{c|}{} & $\mathbf{0 - 8}$ & $\mathbf{9 - 1 6}$ & $\mathbf{1 7 - 2 4}$ & TOTAL \\
\hline B.EUROPEO & $39,62 \%$ & $47,08 \%$ & $13,30 \%$ & $100,00 \%$ \\
\hline B.NORTE AMERICANO & $26,39 \%$ & $51,44 \%$ & $22,17 \%$ & $100,00 \%$ \\
\hline
\end{tabular}

Tabla 101: \% de FG según tiempo de posesión por localización.

Respecto al tipo de tiro (tabla 102) encontramos diferencias que podrían estar relacionadas con lo anterior. En cuanto a malos tiros, los porcentajes son similares, encontrado las diferencias en las otros dos categorias. En el baloncesto norteamericano se producen menos buenos tiros que en el europeo, y más tiros normales. Esto podría deberse a ese juego más pausado y tactico del baloncesto europeo para generar ventajas y ejecutar los FG en las mejores condiciones posibles.

\begin{tabular}{|l|c|c|c|c|}
\cline { 2 - 5 } \multicolumn{1}{c|}{} & Buen tiro & Tiro normal & Mal tiro & TOTAL \\
\hline B.EUROPEO & $41,25 \%$ & $46,65 \%$ & $12,10 \%$ & $100,00 \%$ \\
\hline B.NORTE AMERICANO & $35,51 \%$ & $51,95 \%$ & $12,54 \%$ & $100,00 \%$ \\
\hline
\end{tabular}

Tabla 102: \% de FG según tipo de tiro por localización.

Al igual que en la compración por género, los resultados en función del marcador (tabla 103) no nos aportan datos fiables, por lo que nos los analizaremos.

\begin{tabular}{|l|c|c|c|c|c|c|}
\cline { 2 - 7 } \multicolumn{1}{c|}{} & $(\mathbf{+}) \mathbf{1 1}-\mathbf{2 0}$ & $\mathbf{( + )} \mathbf{1}-\mathbf{1 0}$ & Empate & $(\mathbf{-}) \mathbf{1}-\mathbf{1 0}$ & $\mathbf{( - )} \mathbf{1 1}-\mathbf{2 0}$ & TOTAL \\
\hline B.EUROPEO & $2,44 \%$ & $33,18 \%$ & $7,17 \%$ & $48,89 \%$ & $8,32 \%$ & $100,00 \%$ \\
\hline B.NORTE AMERICANO & $2,34 \%$ & $36,09 \%$ & $7,68 \%$ & $45,53 \%$ & $8,37 \%$ & $100,00 \%$ \\
\hline
\end{tabular}

Tabla 103: \% de FG según ventaja/desventaja por localización. 
En la tabla 104 se recogen los FG en función del precendete, y en ella podemos observar como las diferencias se dan en los 3 precedentes más utilizados: el bloqueo directo, el pase y la jugada personal. En el baloncesto europeo se ejecutan algo más de un $5 \%$ más de FG tras pase, y en el norteamericano, algo más de un $6 \%$ más tras jugada personal. Para ambas localizaciones los precedentes más utilizados son el pase y la jugada personal, pero se da una superioridad inversa del uno sobre el otro. En el baloncesto europeo la incidencia del pase esta por encima de la jugada personal, mientras en en el norteamericano es al contrario. En cuanto al bloqueo directo, se utiliza ligeramente más en el baloncesto europeo.

\begin{tabular}{|l|c|c|c|c|c|c|c|}
\cline { 2 - 7 } \multicolumn{1}{c|}{} & Contraataque & Bloqueo Directo & Pase & Jugada Personal & Robo & Rebote & TOTAL \\
\hline B.EUROPEO & $2,20 \%$ & $17,37 \%$ & $37,94 \%$ & $34,18 \%$ & $2,88 \%$ & $5,44 \%$ & $100,00 \%$ \\
\hline B.NORTE AMERICANO & $2,31 \%$ & $16,76 \%$ & $32,34 \%$ & $40,57 \%$ & $2,66 \%$ & $5,36 \%$ & $100,00 \%$ \\
\hline
\end{tabular}

Tabla 104: \% de FG según precedente por localización.

$\mathrm{Si}$ comparamos los porcentajes de las categorias de la variable "jugadores implicados"(tabla 105) vemos como en ambas localizaciones el número de jugadores más común es dos, tres y uno respectivamente. A pesar de coincidir en esto, si comparamos los porcentajes entre el baloncesto europeo y el norteamericano en cada categoria, vemos como en las ligas europeas los porcentajes de FG tras entrar en contacto con el balón tres, cuatro y cinco jugadores son mayores; mientras que en las ligas norteamericanas los porcentajes en uno y dos estan por encima.

\begin{tabular}{|l|c|c|c|c|c|c|}
\cline { 2 - 7 } \multicolumn{1}{c|}{} & Uno & Dos & Tres & Cuatro & Cinco & TOTAL \\
\hline B.EUROPEO & $17,76 \%$ & $32,15 \%$ & $30,89 \%$ & $15,88 \%$ & $3,32 \%$ & $100,00 \%$ \\
\hline B.NORTE AMERICANO & $22,83 \%$ & $35,55 \%$ & $27,33 \%$ & $12,22 \%$ & $2,06 \%$ & $100,00 \%$ \\
\hline
\end{tabular}

Tabla 105: \% de FG según jugadores implicados por localización.

Podríamos concluir que, a pesar de que para el baloncesto europeo y norteamericano el número de jugadores más utilizado sea dos y tres, si existe una tendencia por parte de Europa a utilizar más jugadores, y por parte de América a utilizar menos. Esto podría ir ligado a la utilización del tiempo de posesión estudiado anteriormente, pues en Europa tiende a usarse más, siendo por tanto más facil que entren más jugadores en contacto con el balón.

Por último, en cuanto al reparto de porcentajes entre las categorias de la variable "periodo de juego" (tabla 106), vemos una dinamica muy similar. Las diferencias son mínimas, 
siendo la más destacable como el baloncesto europeo tiende ha realizar más FG en el primer QT en comparacion con las ligas norteamericanas.

\begin{tabular}{|l|c|c|c|c|c|}
\cline { 2 - 5 } \multicolumn{1}{c|}{} & 19 QT & 20 QT & 3\% QT & 4\% QT & TOTAL \\
\hline B.EUROPEO & $26,54 \%$ & $25,10 \%$ & $24,13 \%$ & $24,23 \%$ & $100,00 \%$ \\
\hline B.NORTE AMERICANO & $25,88 \%$ & $25,49 \%$ & $24,54 \%$ & $24,09 \%$ & $100,00 \%$ \\
\hline
\end{tabular}

Tabla 106: \% de FG según periodo de juego por localización.

\subsubsection{Baloncesto masculino y femenino en EU}

En este apartado se muestran las diferencias entre ambos géneros dentro de una especificidad y limitación en cuanto a localización, centrándose tan solo en las ligas europeas.

La tabla 107 recoge los porcentajes según zona del campo, y en ella observamos como el baloncesto femenino efectúa proporcionalmente más FG desde las zonas interiores, mientras que en el masculino se producen más FG desde el exterior del perímetro. Las mayores diferencias dentro del perímetro se dan en la zona 4, con una superioridad femenina de 4,13\%. En cuanto al exterior del perímetro, es la zona 7 la que muestra mayor diferencia con una superioridad masculina de $7,85 \%$.

\begin{tabular}{|l|c|c|c|c|c|c|c|c|}
\cline { 2 - 9 } \multicolumn{1}{c|}{} & ZONA 1 & ZONA 2 & ZONA 3 & ZONA 4 & ZONA 5 & ZONA 6 & ZONA 7 & TOTAL \\
\hline B.FEM. (EU) & $51,63 \%$ & $6,52 \%$ & $6,75 \%$ & $8,76 \%$ & $4,63 \%$ & $4,58 \%$ & $17,13 \%$ & $100 \%$ \\
\hline B.MASC. (EU) & $49,02 \%$ & $3,66 \%$ & $4,52 \%$ & $4,63 \%$ & $6,55 \%$ & $6,64 \%$ & $24,98 \%$ & $100 \%$ \\
\hline
\end{tabular}

Tabla 107: \% de FG según zona del campo por género en EU.

En cuanto a los resultados del FG (tabla 108), el baloncesto masculino muestra mayor incidencia en los resultados relativos al lanzamiento de 3 puntos, a excepción del resultado "3p.+adicional”, el cual se da ligeramente más en el femenino. En cuanto a los lanzamientos relativos a 2 puntos, los datos obtenidos son mucho más similares, dándose tan solo una excepción, el fallo de 2, en el que las mujeres muestran un mayor porcentaje. En cuanto al porcentaje de tapones, la diferencia es mínima, pero dicha diferencia es algo mayor que la encontrada en la comparación entre sexos a nivel global.

\begin{tabular}{|l|c|c|c|c|c|c|c|c|c|c|}
\cline { 2 - 9 } \multicolumn{1}{c|}{} & 3p. + adicional & 3puntos & Falta + 3 adic. & 2p. + adicional & 2puntos & Falta + 2 adic. & Tapón & Fallo 3p. & Fallo 2p. & TOTAL \\
\hline B.FEM. (EU) & $0,13 \%$ & $7,66 \%$ & $0,10 \%$ & $1,96 \%$ & $27,75 \%$ & $5,86 \%$ & $3,54 \%$ & $18,33 \%$ & $34,67 \%$ & $100 \%$ \\
\hline B.MASC. (EU) & $0,05 \%$ & $13,30 \%$ & $0,51 \%$ & $2,40 \%$ & $26,34 \%$ & $6,15 \%$ & $3,94 \%$ & $24,13 \%$ & $23,19 \%$ & $100 \%$ \\
\hline
\end{tabular}

Tabla 108: \% de FG según resultado por género en EU. 
En la siguiente tabla (109) se recogen los porcentajes de FG en relación al tiempo de posesión. En comparación, el baloncesto masculino ejecuta más FG en la última franja de posesión, mientras que el femenino lo hace en las dos primeras franjas, es decir, en Europa el baloncesto femenino tiende a ser más rápido, mientras que el masculino tiende a agotar más las posesiones antes de realizar el FG. Esto difiere de los datos obtenidos al comparar géneros sin distinción de localización (apartado 7.1), donde solo se daba una superioridad femenina en la franja intermedia, y las diferencias en las otras dos franjas eran menores.

\begin{tabular}{|l|c|c|c|c|}
\cline { 2 - 5 } \multicolumn{1}{c|}{} & $\mathbf{0 - \mathbf { 8 }}$ & $\mathbf{9 - 1 6}$ & $\mathbf{1 7 - 2 4}$ & TOTAL \\
\hline B.FEM. (EU) & $36,07 \%$ & $47,94 \%$ & $15,99 \%$ & $100 \%$ \\
\hline B.MASC. (EU) & $41,88 \%$ & $45,29 \%$ & $12,84 \%$ & $100 \%$ \\
\hline
\end{tabular}

Tabla 109: \% de FG según tiempo de posesión por género en EU.

En la variable "tipo de tiro" (tabla 110) observamos como el baloncesto femenino ejecuta proporcionalmente más FG en condiciones normales, mientras que el masculino ejecuta más buenos y malos tiros. Estos resultados son muy distintos de los obtenidos en el análisis global de género, donde los porcentajes eran más similares y era en el baloncesto femenino donde se producían mayores porcentajes de buenos y malos tiros.

\begin{tabular}{|l|c|c|c|c|}
\cline { 2 - 5 } \multicolumn{1}{c|}{} & Buen tiro & Tiro normal & Mal tiro & TOTAL \\
\hline B.FEM. (EU) & $38,72 \%$ & $49,57 \%$ & $11,71 \%$ & $100 \%$ \\
\hline B.MASC. (EU) & $40,56 \%$ & $46,28 \%$ & $13,16 \%$ & $100 \%$ \\
\hline
\end{tabular}

Tabla 110: \% de FG según tipo de tiro por género en EU.

La tabla 111 recoge los resultados en función del marcador. Pero como ya se ha mencionado a lo largo de este trabajo, estos datos no aportan información relevante.

\begin{tabular}{|l|c|c|c|c|c|c|}
\cline { 2 - 7 } \multicolumn{1}{c|}{} & $(\mathbf{+}) \mathbf{1 1}-\mathbf{2 0}$ & $\mathbf{( + )} \mathbf{1}-\mathbf{1 0}$ & Empate & $(-) \mathbf{1}-\mathbf{1 0}$ & $\mathbf{( - )} \mathbf{1 1}-\mathbf{2 0}$ & TOTAL \\
\hline B.FEM. (EU) & $1,91 \%$ & $36,89 \%$ & $7,59 \%$ & $47,45 \%$ & $6,16 \%$ & $100 \%$ \\
\hline B.MASC. (EU) & $1,77 \%$ & $30,68 \%$ & $6,71 \%$ & $49,92 \%$ & $10,92 \%$ & $100 \%$ \\
\hline
\end{tabular}

Tabla 111: \% de FG según ventaja/desventaja por género en EU.

En relación a los precedentes, la tabla 112 recoge los porcentajes de cada uno de ellos, observando como en comparación, en el baloncesto femenino se ejecutan más FG tras contraataque, jugada personal, pase y rebote; mientras que en el masculino lo hacen tras bloqueo directo y robo. Para ambos sexos los precedentes más utilizados son el pase, la jugada personal y el bloqueo directo respectivamente. 


\begin{tabular}{|l|c|c|c|c|c|c|c|}
\cline { 2 - 8 } \multicolumn{1}{c|}{} & Contraataque & Bloqueo Directo & Pase & Jugada Personal & Robo & Rebote & TOTAL \\
\hline B.FEM. (EU) & $2,70 \%$ & $13,98 \%$ & $39,10 \%$ & $35,36 \%$ & $2,90 \%$ & $5,96 \%$ & $100 \%$ \\
\hline B.MASC. (EU) & $2,33 \%$ & $17,84 \%$ & $38,03 \%$ & $33,99 \%$ & $3,07 \%$ & $4,75 \%$ & $100 \%$ \\
\hline
\end{tabular}

Tabla 112: \% de FG según precedente por género en EU.

En cuanto al número de jugadores que entran en contacto con el balón antes del FG (tabla 113), los mayores porcentajes de ambos sexos se dan con la intervención de dos y tres jugadores, con una superioridad de tres jugadores sobre dos para las mujeres, y al contario para los hombres. Proporcionalmente, en el baloncesto masculino se ejecutan más FG con la intervención de uno y dos jugadores, mientras que en el caso de las mujeres lo hacen con la intervención de tres, cuatro y cinco. Es decir, en el baloncesto masculino se tiende a realizar FG con menos jugadores implicados que en el femenino.

\begin{tabular}{|l|c|c|c|c|c|c|}
\cline { 2 - 7 } \multicolumn{1}{c|}{} & Uno & Dos & Tres & Cuatro & Cinco & TOTAL \\
\hline B.FEM. (EU) & $16,37 \%$ & $29,76 \%$ & $31,06 \%$ & $18,13 \%$ & $4,68 \%$ & $100 \%$ \\
\hline B.MASC. (EU) & $17,52 \%$ & $34,99 \%$ & $30,26 \%$ & $14,59 \%$ & $2,65 \%$ & $100 \%$ \\
\hline
\end{tabular}

Tabla 113: \% de FG según jugadores implicados por género en EU.

Por último, la tabla 114 recoge el reparto porcentual entre los distintos QT. Los datos obtenidos son muy similares, apreciándose una pequeña superioridad en el porcentaje de FG en la primera mitad del encuentro por parte de las mujeres, y en la segunda mitad por parte de los hombres.

\begin{tabular}{|l|c|c|c|c|c|}
\cline { 2 - 6 } \multicolumn{1}{c|}{} & 10 QT & 20 QT & 3\% QT & 40 QT & TOTAL \\
\hline B.FEM. (EU) & $26,50 \%$ & $25,66 \%$ & $23,80 \%$ & $24,03 \%$ & $100 \%$ \\
\hline B.MASC. (EU) & $25,84 \%$ & $24,66 \%$ & $24,78 \%$ & $24,73 \%$ & $100 \%$ \\
\hline
\end{tabular}

Tabla 114: \% de FG según periodo de juego por género en EU.

\subsubsection{Baloncesto masculino y femenino en EEUU}

A continuación se muestran los datos obtenidos para el baloncesto femenino y masculino en Norteamérica, pudiendo así comparar los resultados de ambos. La primera tabla (tabla 115) recoge los porcentajes relativos a la zona del campo desde la que han sido ejecutados los FG. En ella apreciamos como hay una mayor incidencia de las zonas interiores para el baloncesto femenino, y de las exteriores para el masculino, dándose de nuevo las mayores diferencias en las zonas 7 y 4 . 


\begin{tabular}{|l|c|c|c|c|c|c|c|c|}
\cline { 2 - 9 } \multicolumn{1}{c|}{} & ZONA 1 & ZONA 2 & ZONA 3 & ZONA 4 & ZONA 5 & ZONA 6 & ZONA 7 & TOTAL \\
\hline B.FEM. (EEUU) & $48,86 \%$ & $8,94 \%$ & $6,89 \%$ & $10,42 \%$ & $5,01 \%$ & $3,36 \%$ & $16,51 \%$ & $100 \%$ \\
\hline B.MASC. (EEUU) & $48,55 \%$ & $6,13 \%$ & $4,83 \%$ & $7,41 \%$ & $5,75 \%$ & $4,56 \%$ & $22,76 \%$ & $100 \%$ \\
\hline
\end{tabular}

Tabla 115: \% de FG según zona del campo por género en EEUU.

En cuanto a los resultados del FG (tabla 116), el baloncesto masculino tiene mayores porcentajes en todos los FG relativos al lanzamiento de 3 puntos, mientras que el baloncesto femenino los tiene en los relativos al lanzamiento de 2 puntos, dándose una igualdad en cuanto al número de canastas. Referente a los tapones, al contrario de lo que cabría esperar, las mujeres ejecutan proporcionalmente más tapones que los hombres.

\begin{tabular}{|l|c|c|c|c|c|c|c|c|c|c|}
\cline { 2 - 10 } \multicolumn{1}{c|}{} & 3p. + adicional & 3puntos & Falta + 3 adic. & 2p. + adicional & 2puntos & Falta + 2 adic. & Tapón & Fallo 3p. & Fallo 2p. & TOTAL \\
\hline B.FEM. (EEUU) & $0 \%$ & $7,80 \%$ & $0,06 \%$ & $2,45 \%$ & $28,19 \%$ & $7,74 \%$ & $4,10 \%$ & $16,74 \%$ & $32,92 \%$ & $100 \%$ \\
\hline B.MASC. (EEUU) & $0,13 \%$ & $11,50 \%$ & $0,53 \%$ & $2,09 \%$ & $28,19 \%$ & $6,63 \%$ & $3,90 \%$ & $20,71 \%$ & $26,33 \%$ & $100 \%$ \\
\hline
\end{tabular}

Tabla 116: \% de FG según resultado por género en EEUU.

En la siguiente tabla (tabla 117) se recogen los porcentajes de FG ejecutados dentro de cada franja de posesión. Como podemos observar, el baloncesto masculino tiene, en comparación con el femenino, mayores porcentajes en la primera y última franja. Es decir, los hombres realizan más ataques rápidos y también más ataques agotando la posesión, mientras que las mujeres inciden más en las posesiones intermedias.

\begin{tabular}{|l|c|c|c|c|}
\cline { 2 - 5 } \multicolumn{1}{c|}{} & $\mathbf{0 - 8}$ & $\mathbf{9 - 1 6}$ & $\mathbf{1 7 - 2 4}$ & TOTAL \\
\hline B.FEM. (EEUU) & $25,74 \%$ & $53,19 \%$ & $21,07 \%$ & $100 \%$ \\
\hline B.MASC. (EEUU) & $26,60 \%$ & $50,88 \%$ & $22,52 \%$ & $100 \%$ \\
\hline
\end{tabular}

Tabla 117: \% de FG según tiempo de posesión por género en EEUU.

En relación al tipo de tiro (tabla 118), el baloncesto femenino cuanto con mayores porcentajes en los malos y buenos tiros, siendo en los últimos mínima la diferencia; mientras que el baloncesto masculino destaca por su incidencia en tiros normales.

\begin{tabular}{|l|c|c|c|c|}
\cline { 2 - 5 } \multicolumn{1}{c|}{} & Buen tiro & Tiro normal & Mal tiro & TOTAL \\
\hline B.FEM. (EEUU) & $35,99 \%$ & $49,09 \%$ & $14,92 \%$ & $100 \%$ \\
\hline B.MASC. (EEUU) & $35,35 \%$ & $52,87 \%$ & $11,77 \%$ & $100 \%$ \\
\hline
\end{tabular}

Tabla 118: \% de FG según tipo de tiro por género en EEUU.

La tabla 119 recoge los porcentajes en función del marcador, lo cual, como explicamos anteriormente, no nos aporta datos fiables. 


\begin{tabular}{|l|c|c|c|c|c|c|}
\cline { 2 - 7 } \multicolumn{1}{c|}{} & $(\mathbf{+}) \mathbf{1 1}-\mathbf{2 0}$ & $\mathbf{( + )} \mathbf{1}-\mathbf{1 0}$ & Empate & $\mathbf{( - )} \mathbf{1}-\mathbf{1 0}$ & $(-) \mathbf{1 1}-\mathbf{2 0}$ & TOTAL \\
\hline B.FEM. (EEUU) & $1,99 \%$ & $31,09 \%$ & $7,57 \%$ & $49,43 \%$ & $9,91 \%$ & $100 \%$ \\
\hline B.MASC. (EEUU) & $2,45 \%$ & $37,70 \%$ & $7,71 \%$ & $44,27 \%$ & $7,87 \%$ & $100 \%$ \\
\hline
\end{tabular}

Tabla 119: \% de FG según ventaja/desventaja por género en EEUU.

En cuanto a los precedentes del FG utilizados (tabla 120), observamos como el baloncesto femenino tiene una superioridad porcentual en todos los precedentes a excepción de la jugada personal, la cual se da en mayor grado en el baloncesto masculino. Para ambos sexos los precedentes más utilizados son la jugada personal, el pase y el bloqueo directo en ese orden.

\begin{tabular}{|l|c|c|c|c|c|c|c|}
\cline { 2 - 8 } \multicolumn{1}{c|}{} & Contraataque & Bloqueo Directo & Pase & Jugada Personal & Robo & Rebote & TOTAL \\
\hline B.FEM. (EEUU) & $3,36 \%$ & $17,31 \%$ & $33,43 \%$ & $37,70 \%$ & $2,73 \%$ & $5,47 \%$ & $100 \%$ \\
\hline B.MASC. (EEUU) & $1,98 \%$ & $16,59 \%$ & $31,98 \%$ & $41,49 \%$ & $2,64 \%$ & $5,33 \%$ & $100 \%$ \\
\hline
\end{tabular}

Tabla 120: \% de FG según precedente por género en EEUU.

La tabla 121 recoge los porcentajes de los FG en función del número de jugadores que han entrado en contacto con el balón. Para ambos sexos la intervención de dos y tres jugadores respectivamente es la más común. Si comparamos los porcentajes entre ambos, observamos una superioridad femenina en la intervención de tres, cuatro y cinco jugadores; y masculina en la intervención de uno y dos.

\begin{tabular}{|l|c|c|c|c|c|c|}
\cline { 2 - 6 } \multicolumn{1}{c|}{} & Uno & Dos & Tres & Cuatro & Cinco & TOTAL \\
\hline B.FEM. (EEUU) & $20,67 \%$ & $35,31 \%$ & $28,99 \%$ & $12,47 \%$ & $2,56 \%$ & $100 \%$ \\
\hline B.MASC. (EEUU) & $23,53 \%$ & $35,63 \%$ & $26,80 \%$ & $12,14 \%$ & $1,90 \%$ & $100 \%$ \\
\hline
\end{tabular}

Tabla 121: \% de FG según jugadores implicados por género en EEUU.

Por último, en cuanto al reparto de los FG entre los QT (tabla 122), observamos datos muy similares, dándose una ligera superioridad por parte de los hombres en el número de FG en los tres primeros QT, y de las mujeres en el último.

\begin{tabular}{|l|c|c|c|c|c|}
\cline { 2 - 6 } \multicolumn{1}{c|}{} & 10 QT & 20 QT & 3\% QT & 40 QT & TOTAL \\
\hline B.FEM. (EEUU) & $25,68 \%$ & $25,34 \%$ & $24,15 \%$ & $24,83 \%$ & $100 \%$ \\
\hline B.MASC. (EEUU) & $25,94 \%$ & $25,54 \%$ & $24,66 \%$ & $23,86 \%$ & $100 \%$ \\
\hline
\end{tabular}

Tabla 122: \% de FG según periodo de juego por género en EEUU. 


\subsubsection{Baloncesto masculino en EU y EEUU}

En este apartado se recogen los datos obtenidos para el baloncesto masculino en función de su localización, pudiendo así apreciar las diferencias existentes entre EU y EEUU. La primera tabla (tabla 123) recoge los porcentajes por zona del campo desde donde se han ejecutado los FG. Comparando ambas localizaciones, se observa una mayor incidencia por parte del baloncesto europeo en la zona 1 y en las tres zonas exteriores, mientras que los norteamericanos muestran una mayor utilización de las zonas 2, 3 y 4.

\begin{tabular}{|l|c|c|c|c|c|c|c|c|}
\cline { 2 - 9 } \multicolumn{1}{c|}{} & ZONA 1 & ZONA 2 & ZONA 3 & ZONA 4 & ZONA 5 & ZONA 6 & ZONA 7 & TOTAL \\
\hline B.MASC. (EU) & $49,02 \%$ & $3,66 \%$ & $4,52 \%$ & $4,63 \%$ & $6,55 \%$ & $6,64 \%$ & $24,98 \%$ & $100 \%$ \\
\hline B.MASC. (EEUU) & $48,55 \%$ & $6,13 \%$ & $4,83 \%$ & $7,41 \%$ & $5,75 \%$ & $4,56 \%$ & $22,76 \%$ & $100 \%$ \\
\hline
\end{tabular}

Tabla 123: \% de FG según zona del campo por localización en B.Masculino.

Centrándonos en los resultados del FG (tabla 124) podemos ver como proporcionalmente en Europa se anota y falla más desde el exterior del perímetro, y se anota y falla menos desde el interior. El baloncesto europeo también muestra una mayor incidencia en los tapones, aunque esta diferencia es mínima.

\begin{tabular}{|l|c|c|c|c|c|c|c|c|c|c|}
\cline { 2 - 9 } \multicolumn{1}{c|}{} & 3p. + adicional & 3puntos & Falta + 3 adic. & 2p. + adicional & 2puntos & Falta + 2 adic. & Tapón & Fallo 3p. & Fallo 2p. & TOTAL \\
\hline B.MASC. (EU) & $0,05 \%$ & $13,30 \%$ & $0,51 \%$ & $2,40 \%$ & $26,34 \%$ & $6,15 \%$ & $3,94 \%$ & $24,13 \%$ & $23,19 \%$ & $100 \%$ \\
\hline B.MASC. (EEUU) & $0,13 \%$ & $11,50 \%$ & $0,53 \%$ & $2,09 \%$ & $28,19 \%$ & $6,63 \%$ & $3,90 \%$ & $20,71 \%$ & $26,33 \%$ & $100 \%$ \\
\hline
\end{tabular}

Tabla 124: \% de FG según resultado por localización en B.Masculino.

En relación al tiempo de posesión en el que se ejecutan los FG (tabla 125) encontramos grandes diferencias. A pesar de que tanto para el europeo como para el norteamericano el orden de las franjas más utilizadas es el mismo, siendo la más utilizada la intermedia, seguida de la última y la primera respectivamente, la diferencia de porcentajes dentro de las mismas franjas es muy alta. El baloncesto masculino europeo muestra ser más lento, teniendo mucho mayor porcentaje en la última franja que el americano, y acumulando más del $87 \%$ de sus FG entre las dos últimas franjas. Por su parte, el norteamericano muestra una mayor verticalidad, acumulando más del 73\% de sus FG en las dos primeras franjas.

\begin{tabular}{|l|c|c|c|c|}
\cline { 2 - 5 } \multicolumn{1}{c|}{} & $\mathbf{0 - \mathbf { 8 }}$ & $\mathbf{9 - 1 6}$ & $\mathbf{1 7 - 2 4}$ & TOTAL \\
\hline B.MASC. (EU) & $41,88 \%$ & $45,29 \%$ & $12,84 \%$ & $100 \%$ \\
\hline B.MASC. (EEUU) & $26,60 \%$ & $50,88 \%$ & $22,52 \%$ & $100 \%$ \\
\hline
\end{tabular}

Tabla 125: \% de FG según tiempo de posesión por localización en B.Masculino. 
Respecto al tipo de tiro (tabla 126) podemos ver como el baloncesto europeo cuenta proporcionalmente con mayores porcentajes en los buenos y malos tiros, lo cual podría estar relacionado con, como vimos en el apartado anterior, el alto porcentaje de FG en la última franja de posesión $(41,88 \%)$, pues por un lado los equipos han dispuesto de muchos segundos para mover el balón y buscar una buena opción de lanzamiento, y por otro lado, puede que hayan llegado al final del tiempo reglamentario sin haber creado esa buena opción, por lo que han de ejecutar el FG sin importar las condiciones en las que se encuentre el tirador, produciéndose en muchas ocasiones malos tiros.

\begin{tabular}{|l|c|c|c|c|}
\cline { 2 - 5 } \multicolumn{1}{c|}{} & Buen tiro & Tiro normal & Mal tiro & TOTAL \\
\hline B.MASC. (EU) & $40,56 \%$ & $46,28 \%$ & $13,16 \%$ & $100 \%$ \\
\hline B.MASC. (EEUU) & $35,35 \%$ & $52,87 \%$ & $11,77 \%$ & $100 \%$ \\
\hline
\end{tabular}

Tabla 126: \% de FG según tipo de tiro por localización en B.Masculino.

La tabla 127 nos muesta los datos en función del marcador, no siendo dichos datos fiables para el análisis.

\begin{tabular}{|l|c|c|c|c|c|c|}
\cline { 2 - 7 } \multicolumn{1}{c|}{} & $(\mathbf{+}) \mathbf{1 1}-\mathbf{2 0}$ & $\mathbf{( + )} \mathbf{1}-\mathbf{1 0}$ & Empate & $(-) \mathbf{1}-\mathbf{1 0}$ & $(-) \mathbf{1 1}-\mathbf{2 0}$ & TOTAL \\
\hline B.MASC. (EU) & $1,77 \%$ & $30,68 \%$ & $6,71 \%$ & $49,92 \%$ & $10,92 \%$ & $100 \%$ \\
\hline B.MASC. (EEUU) & $2,45 \%$ & $37,70 \%$ & $7,71 \%$ & $44,27 \%$ & $7,87 \%$ & $100 \%$ \\
\hline
\end{tabular}

Tabla 127: \% de FG según ventaja/desventaja por localización en B.Masculino.

El reparto porcentual de los FG en función de su precedente (tabla 128) nos muestra como en el baloncesto masculino, tanto en Europa como en Norteamérica, el pase y la jugada personal son los precedentes más usados. En Europa se ejecutan más pases que jugadas personales, mientras que en Norteamérica ocurre lo contrario. Estamos hablando de porcentajes muy altos, un 38,03\% de FG tras pase en EU y un 41,49\% de FG tras jugada personal en EEUU. El tercer precedente más usado es para ambos el bloqueo directo, dándose una ligera mayor incidencia en el baloncesto europeo, en el cual también se dan más FG tras contraataque y robo, pero menos tras rebote.

\begin{tabular}{|l|c|c|c|c|c|c|c|}
\cline { 2 - 8 } \multicolumn{1}{c|}{} & Contraataque & Bloqueo Directo & Pase & Jugada Personal & Robo & Rebote & TOTAL \\
\hline B.MASC. (EU) & $2,33 \%$ & $17,84 \%$ & $38,03 \%$ & $33,99 \%$ & $3,07 \%$ & $4,75 \%$ & $100 \%$ \\
\hline B.MASC. (EEUU) & $1,98 \%$ & $16,59 \%$ & $31,98 \%$ & $41,49 \%$ & $2,64 \%$ & $5,33 \%$ & $100 \%$ \\
\hline
\end{tabular}

Tabla 128: \% de FG según precedente por localización en B.Masculino. 
En cuanto al número de jugadores implicados (tabla 129) vemos como para las dos localizaciones el orden de mayor a menor incidencia es el mismo, primero las categorías “dos" y "tres" jugadores, con porcentajes más altos, seguidas de "uno", "cuatro" y "cinco" jugadores respectivamente. Comparando los porcentajes de las categorías de ambos observamos como en Europa se da proporcionalmente más la implicación de tres, cuatro y cinco jugadores, mientras que en Norteamérica se da más la de uno y dos. Esto podría estar relacionado con el uso de posesiones más largas por parte del baloncesto europeo.

\begin{tabular}{|l|c|c|c|c|c|c|}
\cline { 2 - 7 } \multicolumn{1}{c|}{} & Uno & Dos & Tres & Cuatro & Cinco & TOTAL \\
\hline B.MASC. (EU) & $17,52 \%$ & $34,99 \%$ & $30,26 \%$ & $14,59 \%$ & $2,65 \%$ & $100 \%$ \\
\hline B.MASC. (EEUU) & $23,53 \%$ & $35,63 \%$ & $26,80 \%$ & $12,14 \%$ & $1,90 \%$ & $100 \%$ \\
\hline
\end{tabular}

Tabla 129: \% de FG según jugadores implicados por localización en B.Masculino.

Por último, en relación al reparto de FG según QT (tabla 130), a pesar de tener porcentajes similares, encontramos diferentes dinámicas. En Norteamérica se da un descenso en el número de FG según avanza el encuentro, mientras que en Europa se da una mayor incidencia en el primer QT, estabilizándose para los siguientes.

\begin{tabular}{|l|c|c|c|c|c|}
\cline { 2 - 5 } \multicolumn{1}{c|}{} & 10 QT & 20 QT & 30 QT & 40 QT & TOTAL \\
\hline B.MASC. (EU) & $25,84 \%$ & $24,66 \%$ & $24,78 \%$ & $24,73 \%$ & $100 \%$ \\
\hline B.MASC. (EEUU) & $25,94 \%$ & $25,54 \%$ & $24,66 \%$ & $23,86 \%$ & $100 \%$ \\
\hline
\end{tabular}

Tabla 130: \% de FG según periodo de juego por localización en B.Masculino.

\subsubsection{Baloncesto femenino en EU y EEUU}

A continuación se recogen los datos obtenidos para el baloncesto femenino europeo y norteamericano, pudiendo así comparar los resultados de ambos. En la tabla 131 observamos los porcentajes relativos a las zonas de ejecución del FG, no apreciándose ningún patrón diferenciador claro entre ambas localizaciones. La mayor diferencia se da en la zona 1, en la cual en baloncesto europeo ejecuta un 2,77\% más de FG. En las zonas 1, 6 y 7 se da un mayor porcentaje por parte de Europa, y en la 2, 3, 4 y 5 por parte de Norteamérica.

\begin{tabular}{|l|c|c|c|c|c|c|c|c|}
\cline { 2 - 9 } \multicolumn{1}{c|}{} & ZONA 1 & ZONA 2 & ZONA 3 & ZONA 4 & ZONA 5 & ZONA 6 & ZONA 7 & TOTAL \\
\hline B.FEM. (EU) & $51,63 \%$ & $6,52 \%$ & $6,75 \%$ & $8,76 \%$ & $4,63 \%$ & $4,58 \%$ & $17,13 \%$ & $100 \%$ \\
\hline B.FEM. (EEUU) & $48,86 \%$ & $8,94 \%$ & $6,89 \%$ & $10,42 \%$ & $5,01 \%$ & $3,36 \%$ & $16,51 \%$ & $100 \%$ \\
\hline
\end{tabular}

Tabla 131: \% de FG según zona del campo por localización en B.Femenino. 
En relación a los resultados del FG (tabla 132) podemos ver como el baloncesto femenino en EEUU tiene mayores porcentajes en canastas de 2 y 3 puntos, además de un menor porcentaje de fallos en los mismos. En los resultados que conllevan tiros adicionales, encontramos una superioridad del baloncesto europeo en los relativos a lanzamientos de 3 puntos, y del norteamericano en los lanzamientos de 2 puntos. En cuanto a los tapones, estos tienen una mayor incidencia en el baloncesto norteamericano.

\begin{tabular}{|c|c|c|c|c|c|c|c|c|c|c|}
\hline & 3p. + adicional & 3puntos & Falta +3 adic. & 2p. + adicional & 2puntos & Falta +2 adic. & Tapón & Fallo $3 p$. & Fallo $2 p$. & TOTAL \\
\hline B.FEM. (EU) & $0,13 \%$ & $7,66 \%$ & $0,10 \%$ & $1,96 \%$ & $27,75 \%$ & $5,86 \%$ & $3,54 \%$ & $18,33 \%$ & $34,67 \%$ & $100 \%$ \\
\hline B.FEM. (EEUU) & $0 \%$ & $7,80 \%$ & $0,06 \%$ & $2,45 \%$ & $28,19 \%$ & $7,74 \%$ & $4,10 \%$ & $16,74 \%$ & $32,92 \%$ & $100 \%$ \\
\hline
\end{tabular}

Tabla 132: \% de FG según resultado por localización en B.Femenino.

En cuanto al tiempo de posesión utilizado antes de un FG (tabla 133) ambas localizaciones coindicen en la mayor utilización de la franja intermedia, seguida de la última, y finalmente la primera. En comparación, el baloncesto femenino norteamericano utiliza más la primera franja y la intermedia, siendo por tanto algo más rápido, mientras que el europeo utiliza más la franja final, demostrando un juego más pausado.

\begin{tabular}{|l|c|c|c|c|}
\cline { 2 - 5 } \multicolumn{1}{c|}{} & $\mathbf{0 - \mathbf { 8 }}$ & $\mathbf{9 - 1 6}$ & $\mathbf{1 7 - 2 4}$ & TOTAL \\
\hline B.FEM. (EU) & $36,07 \%$ & $47,94 \%$ & $15,99 \%$ & $100 \%$ \\
\hline B.FEM. (EEUU) & $25,74 \%$ & $53,19 \%$ & $21,07 \%$ & $100 \%$ \\
\hline
\end{tabular}

Tabla 133: \% de FG según tiempo de posesión por localización en B.Femenino.

Respecto al tipo de tiro en baloncesto femenino (tabla 134), encontramos porcentajes muy similares entre ambas localizaciones. El porcentaje de tiros normales es muy semejante, con una ligera superioridad por parte del baloncesto europeo. Por su parte, el baloncesto norteamericano muestra una mayor incidencia en los malos tiros, y menor en los buenos. Por tanto, el baloncesto femenino europeo genera mejores opciones de FG.

\begin{tabular}{|l|c|c|c|c|}
\cline { 2 - 5 } \multicolumn{1}{c|}{} & Buen tiro & Tiro normal & Mal tiro & TOTAL \\
\hline B.FEM. (EU) & $38,72 \%$ & $49,57 \%$ & $11,71 \%$ & $100 \%$ \\
\hline B.FEM. (EEUU) & $35,99 \%$ & $49,09 \%$ & $14,92 \%$ & $100 \%$ \\
\hline
\end{tabular}

Tabla 134: \% de FG según tipo de tiro por localización en B.Femenino.

Por su parte, los resultados en función del marcador (tabla 135) no nos aportan datos fiables, por lo que nos los analizaremos. 


\begin{tabular}{|l|c|c|c|c|c|c|}
\cline { 2 - 7 } \multicolumn{1}{c|}{} & $(\mathbf{+}) \mathbf{1 1}-\mathbf{2 0}$ & $\mathbf{( + )} \mathbf{1}-\mathbf{1 0}$ & Empate & $(-) \mathbf{1}-\mathbf{1 0}$ & $(-\mathbf{)} \mathbf{1 1}-\mathbf{2 0}$ & TOTAL \\
\hline B.FEM. (EU) & $1,91 \%$ & $36,89 \%$ & $7,59 \%$ & $47,45 \%$ & $6,16 \%$ & $100 \%$ \\
\hline B.FEM. (EEUU) & $1,99 \%$ & $31,09 \%$ & $7,57 \%$ & $49,43 \%$ & $9,91 \%$ & $100 \%$ \\
\hline
\end{tabular}

Tabla 135: \% de FG según ventaja/desventaja por localización en B.Femenino.

En la tabla 136 se recogen los porcentajes del FG en función del precedente. El pase y la jugada personal vuelven a ser los precedentes más utilizados, pero mientras que en el baloncesto femenino europeo incide más el pase que la jugada personal, en el norteamericano ocurre lo contrario. El bloqueo directo se muestra como tercer precedente, siendo más utilizado por parte de las norteamericanas. El baloncesto femenino europeo tiene proporcionalmente una mayor incidencia en el robo y el rebote, pero menor en el contraataque.

\begin{tabular}{|l|c|c|c|c|c|c|c|}
\cline { 2 - 7 } \multicolumn{1}{c|}{} & Contraataque & Bloqueo Directo & Pase & Jugada Personal & Robo & Rebote & TOTAL \\
\hline B.FEM. (EU) & $2,70 \%$ & $13,98 \%$ & $39,10 \%$ & $35,36 \%$ & $2,90 \%$ & $5,96 \%$ & $100 \%$ \\
\hline B.FEM. (EEUU) & $3,36 \%$ & $17,31 \%$ & $33,43 \%$ & $37,70 \%$ & $2,73 \%$ & $5,47 \%$ & $100 \%$ \\
\hline
\end{tabular}

Tabla 136: \% de FG según precedente por localización en B.Femenino.

El porcentaje de jugadoras implicados antes de ejecutar el FG (tabla 137) nos muestra como a pesar de que para ambas localizaciones la intervención de dos y tres jugadoras es lo más común, en el baloncesto femenino europeo se da una mayor incidencia de tres que de dos, al contrario que en el norteamericano. En comparación, en Europa se da una intervención de más jugadoras, mostrando mayores porcentajes en tres, cuatro y cinco; y menor de uno y dos. Lo cual podría estar influenciado por la distinta utilización de los tiempos de posesión antes de un FG.

\begin{tabular}{|l|c|c|c|c|c|c|}
\cline { 2 - 7 } \multicolumn{1}{c|}{} & Uno & Dos & Tres & Cuatro & Cinco & TOTAL \\
\hline B.FEM. (EU) & $16,37 \%$ & $29,76 \%$ & $31,06 \%$ & $18,13 \%$ & $4,68 \%$ & $100 \%$ \\
\hline B.FEM. (EEUU) & $20,67 \%$ & $35,31 \%$ & $28,99 \%$ & $12,47 \%$ & $2,56 \%$ & $100 \%$ \\
\hline
\end{tabular}

Tabla 137: \% de FG según jugadores implicados por localización en B.Femenino.

Por último, en cuanto al reparto de porcentajes del FG en función del QT (tabla 138) obtenemos porcentajes muy similares. El baloncesto europeo ejecuta proporcionalmente más FG en la primera mitad del encuentro, y el norteamericano en la segunda.

\begin{tabular}{|l|c|c|c|c|c|}
\cline { 2 - 6 } \multicolumn{1}{c|}{} & 19 QT & 20 QT & 39 QT & 40 QT & TOTAL \\
\hline B.FEM. (EU) & $26,50 \%$ & $25,66 \%$ & $23,80 \%$ & $24,03 \%$ & $100 \%$ \\
\hline B.FEM. (EEUU) & $25,68 \%$ & $25,34 \%$ & $24,15 \%$ & $24,83 \%$ & $100 \%$ \\
\hline
\end{tabular}

Tabla 138: \% de FG según periodo de juego por localización en B.Femenino. 


\section{SINTESIS DE RESULTADOS}

\section{Zona del campo:}

- La zona 1 del campo es donde más FG se realizan con casi un 50\%.

- Las zonas más centradas (zona 1, 4 y 7) respecto al aro tienen mayores porcentajes de FG que las zonas laterales.

- En relación a la lateralidad, se realizan más FG desde el lado izquierdo.

- El orden de mayor a menor porcentaje de FG en cada zona del campo es: ○ Zona $1>$ Zona $7>$ Zona $4>$ Zona $2>$ Zona $5>$ Zona $3>$ Zona 6 .

\section{Zona del campo y resultado de la acción:}

- La única zona desde la que se dan más resultados positivos que negativos en cuanto al FG, es la zona 1.

- En la zona 1 es donde más tapones, faltas+2 adic. y $2 p$.+adic. se producen, con mucha diferencia sobre el resto de zonas del campo.

- Dividiendo los resultados en positivos (3p.+adic., 3p., falta+3adic., 2p.+adic., 2p., falta+2adic.) o negativos (tapón, fallo 3p. y fallo 2p.), el orden de mayor a menor eficacia dentro de cada zona es:

- Zona $1>$ Zona $4>$ Zona $3>$ Zona $5>$ Zona $2>$ Zona $6>$ Zona 7 .

- En relación a la lateralidad, en el exterior del perímetro si coincide el lado desde el que más se lanza con el más efectivo (lado izquierdo), pero en el interior del perímetro no, siendo el derecho el más efectivo.

- La zona 1 es la más efectiva y desde la que más se lanza. Mientras que la zona 4, a pesar de ser la segunda más efectiva, ocupa el tercer lugar en cuanto a zona más utilizada.

- La zona 7 es la zona exterior más utilizada y la que menor eficacia tiene.

\section{Zona del campo y tiempo de posesión:}

- En todas las zonas del campo la franja de posesión más común en la que se realizan los FG es "9-16".

- Sobre el reparto total de porcentajes de FG entre ambas variables, el porcentaje en la zona 1 y franja "9-16" es muy superior al resto, con más de un $24 \%$ sobre 
el total. Estamos hablando de que casi uno de cada cuatro FG se realizan en esa zona y franja de posesión.

- En todas las zonas del campo las franjas con mayores porcentajes de FG son la "9-16", "0-8" y "17-24" en este orden, pero en el caso de la zona 1, los valores entre las dos últimas son mucho más cercanos que en el resto de zonas.

\section{Zona del campo y tipo de tiro:}

- Analizando el reparto del porcentaje de FG dentro de cada zona, y comparando las zonas del campo entre sí, observamos como la zonas 2, 3 y 1, en ese orden, son las que menores porcentajes de buenos tiros tienen. Siendo además las zonas 2 y 3 , con diferencia sobre el resto, las que mayores porcentajes de malos tiros acumulan.

- Dentro de la línea de 3 puntos, en la zona 4 se produce casi un $49 \%$ de buenos tiros y tan solo un 7,24\% de malos tiros, lo que unido a ser la segunda zona más efectiva, la convierte en una zona clave para la futura aplicación práctica. En el exterior del perímetro son las zonas 5 y 6 las que destacan por sus altos porcentajes de buenos tiros, en torno al $67 \%$ y $69 \%$, y bajos porcentajes de malos tiros, entre $4 \%$ y $5 \%$.

- Las zonas exteriores a la línea de 3 puntos cuentan con los mayores porcentajes de buenos tiros, superando en las tres el 56\%, incluso cerca del 69\% en las zonas laterales.

- El orden de mayor a menor porcentaje de buenos y malos FG dentro de cada zona es:

○ Buen tiro: Zona $5>$ Zona $6>$ Zona $7>$ Zona $4>$ Zona $1>$ Zona $3>$ Zona 2.

○ Mal tiro: Zona $2>$ Zona $3>$ Zona $7>$ Zona $1>$ Zona $4>$ Zona $6>$ Zona 5 .

- Los porcentajes de FG de los buenos tiros siguen la dinámica de las zonas centrales, donde se dan los mayores porcentajes, aunque las zonas laterales del exterior de la línea de 3 puntos (zona 5 y 6 ) son muy similares a los valores de la zona 4. 
- Analizando como se reparten los porcentajes de cada categoría de la variable "tipo de tiro" en las zonas del campo, vemos como en las zonas 2 y 3 apenas se realizan buenos tiros, y en las zonas 5 y 6 el porcentaje de malos tiros es mínimo, seguidas de la zona 4.

\section{Zona del campo y ventaja / desventaja:}

- En todas las situaciones del marcador, las zonas más utilizadas para ejecutar el FG son respectivamente la 1, 7 y 4; pero cuando se va por debajo en el marcador el porcentaje de FG realizados desde la zona 1 y 7 es superior al del resto de situaciones.

\section{Zona del campo y precedente:}

- Respecto del porcentaje global de estas dos variables, la mayor incidencia de FG se da en la combinación de la categoría "zona 1" con todas las categorías de la variable precedente, a excepción de la categoría "pase", que tiene su mayor incidencia en la zona 7. Es decir, sobre el $100 \%$ de los FG analizados, la combinación de las categorías de la variable precedente con la categoría "zona 1" de la variable zona del campo suma un total de un $49,5 \%$.

- Los precedentes "jugada personal" y "pase" tienen la mayor incidencia sobre el total de FG ejecutados, sumando cada uno más de un 35\%. El bloqueo directo se encuentra en la tercera posición con algo más de un $16 \%$.

- Analizando los FG dentro de cada zona se observa como en las zonas 1, 2 y 3 destaca la jugada personal como precedente, mientras que en las zonas exteriores (zona 5, 6 y 7) lo hace el pase.

- Comparando las 3 zonas exteriores se observa una misma dinámica de reparto para las zonas 5 y 6 , existiendo una diferencia significativa con la zona 7 , en la cual se da un menor porcentaje del precedente "pase", y mayor de "jugada personal" y "bloqueo directo".

- En la zona 4 se da un mayor equilibrio entre los precedentes "jugada personal", "bloqueo directo" y "pase" respectivamente.

- En las zonas 5 y 6 apenas se utilizan los precedentes "jugada personal" y "bloqueo directo". 
- El bloqueo directo tiende a usarse en las zonas centrales.

\section{Zona del campo y jugadores implicados:}

- En todas las zonas del campo los mayores porcentajes de FG se dan con la intervención de dos o tres jugadores.

- En la zona 1 también se dan unos porcentajes altos de un jugador, lo cual es debido a los FG tras rebote.

- En las zonas 5 y 6 apenas se realizan FG en los que solo haya entrado en contacto con el balón un jugador.

- La intervención de los cinco jugadores es muy escasa, casi anecdótica, en todas las zonas.

\section{Zona del campo y periodo de juego:}

- Según avanzan los QT se van produciendo menos FG desde las zonas interiores.

- En las zonas exteriores se mantiene cierta constancia en el número de FG realizados, teniendo la zona 7 mayores porcentajes en los segundos cuartos de cada mitad $\left(2^{\circ}\right.$ y $\left.4^{\circ} \mathrm{QT}\right)$.

- Se da un aumento significativo del porcentaje de FG desde la zona 7 entre el primer y el último QT.

\section{Zona del campo y momento especial:}

- Los FG tras momento especial siguen los mismos patrones que el resto respecto a la zona del campo desde donde se realizan (zonas centrales), siendo las zonas con mayores porcentajes la zona 1 y 7 , seguidas de lejos por la zona 4 . Pero los valores de esos porcentajes de las zonas 1 y 7 se encuentran invertidos. Mientras que tras tiempo muerto el mayor número de FG se ejecutan desde la zona 1, seguidos de la zona 7; los FG en las últimas jugadas tienden a ejecutarse desde la zona 7, seguidos de la zona 1.

\section{Resultado:}

- Los resultados del FG que más se dan son los fallos de 2 puntos y las canastas de 2 puntos, seguidos del fallo de 3 puntos y canasta de 3 puntos en este orden. 
- Los FG con resultado de "canasta y adicional" o "falta y adicionales" tienen porcentajes bajos, siendo los relativos al lanzamiento de dos los únicos con valores no insignificantes, especialmente el de "falta y dos adicionales" con casi un $6,5 \%$ sobre el total de FG.

- A pesar de haber el doble de categorías positivas que negativas, los resultados negativos del FG prevalecen sobre los positivos con un 52,77\%.

\section{Resultado y tiempo de posesión:}

- Todos los resultados del FG tienen su mayor porcentaje de incidencia en la franja de posesión intermedia (9-16).

- Analizando como se reparten los FG de cada resultado en las distintas franjas de tiempo de posesión se observa como el 71,43\% de los triples y adicional se producen en la franja intermedia (9-16), repartiéndose el resto por igual entre las otras dos franjas.

También se aprecia como los resultados negativos (tapón, fallo de 2p. y fallo de 3

p.) tienen mayor presencia en la última franja (0-8) en comparación al resto de resultados, con tan solo una excepción, la canasta de 3 puntos, la cual cuenta con porcentajes similares a los resultados negativos en esa última franja.

Por otro lado, los resultados "2p.+adicional", "2p.", "falta+2adicionales" y "tapones" cuentan con porcentajes más altos que el resto en la primera franja de posesión.

- Analizando como se reparten los FG de cada franja de posesión en los distintos resultados, y comparando las tres franjas entre sí, se observa como la "canasta de 3 p.", "2p+adicional", "canasta de 2 p"y "falta+2 adicionales" se da en mayor porcentaje cuanto de más tiempo de posesión se dispone.

En los resultados de fallo de 2 y 3 puntos ocurre lo contrario, su porcentaje aumenta cuanto de menos tiempo de posesión se dispone.

Por su parte, los tapones muestran cierta constancia entre las tres franjas.

- La franja "17-24" es la única con mayor porcentaje de resultados positivos que negativos. La franja intermedia tiene porcentajes cercanos entre ambos resultados, y la última franja tiene un predominio de los resultados negativos. 


\section{$\underline{\text { Resultado y tipo de tiro: }}$}

- La mayoría de los posibles resultados del FG tienen su mayor porcentaje en la categoría "tiro normal". Tan solo el triple y su fallo tienen mayores porcentajes en la categoría "buen tiro". El resultado de canasta de 2 puntos muestra porcentajes muy similares entre los normales y los buenos tiros.

- Todos los resultados con lanzamientos adicionales se dan en mayor medida en los tiros normales.

- Analizando cada posible resultado en función del tipo de tiro, se observa como los FG cuyos resultados son triples o canastas de dos se ejecutan en su mayoría en un buen tiro o tiro normal. Pero, mientras que en las canastas de dos los porcentajes entre estas dos categorías son similares, en el caso del triple el porcentaje en la categoría "buen tiro" es mucho mayor que en el "tiro normal".

- Los buenos tiros son los únicos con mayor porcentaje de resultados positivos que negativos. En los tiros normales se dan más resultados negativos, pero con porcentajes similares a los positivos. En el caso de los malos tiros, los resultados negativos superan con creces a los positivos.

- Los malos tiros acaban en fallo de 2 o 3 puntos en más del $70 \%$ de las ocasiones, mientras que en los buenos tiros no superan el $43 \%$.

- Los malos tiros, en comparación a los buenos, tienen porcentajes más altos de tapones y fallo de 2 puntos, y menor de canastas de 2 y 3 puntos.

\section{$\underline{\text { Resultado y ventaja/desventaja: }}$}

- Los resultados de los FG cuando se va por encima en el marcador tienden a ser más negativos que cuando se va empate o por debajo en el marcador.

- Analizando como se reparten los porcentajes de los FG de cada situación del marcador entre los posibles resultados, y comparándolos entre ellos, se observa como cuando se va por encima en el marcador se meten menos triples y canastas, se reciben más tapones y se falla más de dos y tres puntos.

\section{$\underline{\text { Resultado y precedente: }}$}

- De los seis posibles precedentes al FG, tan solo el contraataque, el robo y el rebote tienen mayor porcentaje de resultados positivos que negativos, especialmente el 
contraataque y el robo, con valores superiores al 72,1\% y $68,5 \%$ de resultados positivos respectivamente.

- Analizando como se reparten los porcentajes de cada precedente del FG entre los posibles resultados, se observa como el contraataque, el robo y el rebote tienen su mayor incidencia en el lanzamiento de 2 puntos, tanto en canastas como en fallos, predominando claramente la primera sobre la segunda. Esto es extensible a la jugada personal, pero con la predominancia invertida, siendo superior el porcentaje de fallos que de aciertos.

- Los porcentajes de bloqueos directos y pases como precedentes del FG se reparten principalmente entre los fallos y aciertos de 2 y 3 puntos.

- En todos los resultados de FG destacan los mismos tres precedentes: el pase, la jugada personal y el bloqueo directo. En las zonas exteriores del perímetro es el pase el precedente con mayor porcentaje, mientras que en las interiores es la jugada personal.

\section{$\underline{\text { Resultado y jugadores implicados: }}$}

- Las FG en cuya jugada han entrado en contacto con el balón uno, tres y dos jugadores, son las más efectivas, seguidas de cinco y cuatro jugadores en ese orden.

- Tan solo la categoría de un jugador muestra más resultados positivos que negativos, algo muy relacionado con el FG tras rebote, el cual tiene un buen porcentaje de efectividad.

- La intervención de los 5 jugadores para la ejecución de un FG es casi anecdótica sobre el total de FG.

- Analizando como se reparten los porcentajes de cada posible resultado del FG en función del número de jugadores, se observa como en todos predomina la intervención de dos o tres. Además, los resultados relacionados con el FG de 2 puntos (fallo, falta+2 adic., canasta, canasta+adic.) y el tapón, también muestran altos porcentajes en la intervención de un solo jugador. 


\section{Resultado y QT:}

- Analizando el reparto de los porcentajes de FG de cada cuarto entre los posibles resultados, y comparándolos entre sí, se observa una dinámica similar en todos los cuartos.

- Si analizamos el reparto de los porcentajes de cada resultado de FG en función de los QT encontramos mayores diferencias.

- Los 3p.+adicional se producen mayoritariamente y con gran diferencia en el último cuarto del partido.

- En las canastas y fallos de 3 puntos, y en las faltas+2adic., los porcentajes se ven aumentados en los segundos cuartos de cada mitad $\left(2^{\circ}\right.$ y $\left.4^{\circ} \mathrm{QT}\right)$.

- En las canastas y fallos de 2 puntos se ve un descenso de los porcentajes entre el primer QT y el último.

- Los porcentajes de resultados positivos del FG va decreciendo según avanzan los QT.

\section{Resultado y momento especial:}

- Los resultados del FG tras un tiempo muerto son en su mayoría tiros de 2 y 3 puntos, donde se falla más que se convierte, pero con unos buenos porcentajes de eficacia.

- En las últimas jugadas los resultados de FG que más se dan son los fallos de 2 y 3 puntos.

- En cuanto a resultados positivos o negativos, el FG tras tiempo muerto tiene unos porcentajes de resultado positivo aceptables, estando cerca del porcentaje de media de todos los FG. En cuanto a las últimas jugadas, los resultados negativos del FG son superiores al $71 \%$.

\section{Tiempo de posesión:}

- La franja de posesión intermedia (9-16) es en la que más FG se ejecutan, acumulando casi el 50\% de los realizados, concretamente un 48,83\%.

- La última franja (0-8) es la segunda más utilizada, con un 33,19\%, y la primera franja (17-24) la menos utilizada, con un 17,99 \% de los FG realizados. 


\section{Tiempo de posesión y tipo de tiro:}

- Analizando el reparto de cada categoría de la variable "tipo de tiro" entre las franjas de posesión, se observa como los mayores porcentajes de buenos tiros y normales se producen en la posesión intermedia, mientras que en los malos tiros se produce en la última franja de posesión.

- Si nos centramos en el reparto de cada franja de posesión entre las categorías de la variable "tipo de tiro", y las comparamos entre sí, podemos ver como proporcionalmente se realizan más buenos tiros en la primera franja y menos en la última; ocurriendo lo contrario en cuanto a los malos tiros.

En la primera franja los tiros normales tienen porcentajes cercanos a los buenos tiros, y en las otras dos franjas cuentan con los mayores porcentajes.

\section{Tiempo de posesión y ventaja/desventaja:}

- Sea cual sea la situación del marcador, vayamos empate, ganando o perdiendo, la posesión en la que más FG se realizan es la intermedia, seguida de la última y la primera respectivamente.

- Los porcentajes entre las franjas de posesión cuando se va empatados o por encima en el marcador son muy similares, sin embargo, cuando se va perdiendo se producen menos FG en la última franja y más en la intermedia.

\section{Tiempo de posesión y precedente:}

- El análisis de los porcentajes de FG dentro de cada franja de posesión en función del precedente muestra como en todas las franjas los precedentes con mayores porcentajes son el pase y la jugada personal, aunque la superioridad de un precedente sobre el otro varía. En la primera franja se mantiene un equilibrio, en la franja intermedia el pase se encuentra por encima, y en la última es la jugada personal quien domina.

- El bloqueo directo se muestra como tercer precedente en la franja intermedia y final, pero en la primera se ve relegado al quinto puesto, pues es esta franja se dan grandes porcentajes de FG tras robo y contraataque, ocupando el tercer y cuarto lugar respectivamente. 
- Si nos centramos en como se reparten los porcentajes de cada precedente en función de las franjas de posesión podemos ver como:

- El FG tras contraataque o robo se da casi exclusivamente en la franja 1724.

- El bloqueo directo, el pase y la jugada personal tienen sus mayores porcentajes en la franja intermedia, seguidas de la franja 0-8, y por último la 17-24. En el caso de la jugada personal, los porcentajes entre la franja intermedia y la final son mucho más cercanos que en los otros dos precedentes.

○ Los datos en cuanto al rebote y el tiempo de posesión se vieron afectados por un cambio normativo, por lo que no son útiles.

\section{Tiempo de posesión y jugadores implicados:}

- Existen diferencias en el número de jugadores implicados en el FG en función del tiempo de posesión consumido. Mientras que los FG realizados en la primera franja tienden a contar con uno o dos jugadores, cuanto más tiempo de posesión va trascurriendo más jugadores intervienen en el FG. En la franja intermedia se tiende a contar con uno, dos y tres jugadores, y en la última, con dos, tres y cuatro.

- Los porcentajes de implicación en elFG de uno y dos jugadores van disminuyendo según avanza la posesión, mientras que los porcentajes de tres, cuatro y cinco van aumentado.

\section{Tiempo de posesión y QT:}

- En cuanto al reparto de los porcentajes del FG dentro de cada periodo de juego en función de las franjas de posesión, y comparándolas entre sí, observamos como se van realizando más FG en la última franja según avanza el encuentro.

En la primera franja se dan mayores porcentajes en los primeros cuartos de cada $\operatorname{mitad}\left(1^{\circ}\right.$ y $\left.3^{\circ} \mathrm{QT}\right)$.

- Si analizamos los porcentajes de FG de cada franja de posesión en función de los periodos de juego, volvemos a observar el aumento de los FG realizados en la última franja según avanza el encuentro, pero en la primera franja observamos 
diferencias, produciéndose un descenso de sus porcentajes según transcurre el partido.

\section{Tiempo de posesión y momento especial:}

- La categoría "última jugada" está unida por definición a la franja de posesión 08, por lo que todos los FG de esta se producen en dicha franja.

- Los FG tras tiempo muerto se producen principalmente entre la franja intermedia $(44,22 \%)$ y la última (46,94\%); no llegando ni siquiera al $9 \%$ los realizados en la primera.

\section{Tipo de tiro:}

- El mayor porcentaje de FG ejecutados se da en la categoría "tiro normal", con casi un 50\% del total, seguido de los buenos tiros con $37,74 \%$, y los malos tiros con $12,5 \%$.

\section{Tipo de tiro y ventaja/desventaja:}

- Cuando los equipos están empatados realizan mayor porcentaje de buenos tiros, y menor de tiros normales y malos, que en las situaciones en las que se va por encima o por debajo en el marcador.

- Comparando los porcentajes de la variable tipo de tiro en función de si se va ganando o perdiendo, se ha visto como con desventaja en el marcador se realizan mayor porcentaje de buenos tiros y tiros normales, y menor de malos tiros, que cuando se va por encima en el marcador.

\section{Tipo de tiro y precedente:}

- En el análisis del reparto de los porcentajes de cada precedente entre las categorías de la variable "tipo de tiro" se observa:

- En los FG tras contraataques, robos y pases se dan unos porcentajes muy altos de buenos tiros, superando en todos el 60\%, y en el caso concreto del contraataque, superando el $70 \%$.

- En los FG tras rebote, jugada personal y bloqueo directo se dan los mayores porcentajes en la categoría "tiro normal". 
- Los FG tras jugada personal también muestran un porcentaje elevado en los malos tiros, convirtiéndose en el precedente con mayor porcentaje en esa categoría con un $22,65 \%$. Además, también es el precedente con menor porcentaje en la categoría "buen tiro", por lo que se muestra como el precedente menos efectivo para la consecución de ventajas en el FG.

- En cuanto a como se reparte el porcentaje entre los precedentes dentro de cada tipo de tiro, se observa como el mayor porcentaje de buenos tiros se produce tras pase y bloqueo directo con un $57,39 \%$ y $17,73 \%$ respectivamente.

\section{Tipo de tiro y jugadores implicados:}

- Sobre el total de FG realizados, en todas las categorías de la variable "tipo de tiro" se muestra un ascenso de los porcentajes de incidencia entre la participación de uno y dos jugadores, siendo esta última categoría el pico de incidencia a partir del cual los porcentajes van disminuyendo a medida que se van implicando jugadores. Este descenso es más pronunciado a partir del tercer jugador.

- Centrándonos en el reparto de los porcentajes de cada tipo de tiro entre las categorías de la variable "jugadores implicados" vemos como:

- En los tres tipos de tiros los mayores porcentajes se dan con la implicación de dos o tres jugadores.

- Los malos tiros y los normales también muestran un elevado porcentaje en los FG con un solo jugador implicado.

- Más del 68\% de buenos tiros se realizan con la intervención de dos y tres jugadores.

- La intervención de los cinco jugadores es muy escasa en los tres tipos de tiros.

\section{Tipo de tiro y periodo de juego:}

- Comparando como se reparten los porcentajes de cada tipo de tiro entre los cuatro QT, se observa como la incidencia de los buenos tiros y de los tiros normales va disminuyendo según avanza el encuentro, dándose en el caso de los tiros normales una estabilización en los dos últimos cuartos. 
- Los porcentajes de malos tiros tienen un repunte en los segundos cuartos de cada mitad.

\section{Tipo de tiro y momento especial:}

- Los FG tras tiempo muerto muestran su mayor porcentaje en la categoría de "tiro normal" $(47,96 \%)$, con un porcentaje de buenos tiros de $34,18 \%$, el cual no llega a la media descrita anteriormente de $37,74 \%$.

- Los FG ejecutados en las últimas posesiones de QT tienen su mayor porcentaje en los malos tiros con un 43,37\%.

\section{Ventaja/desventaja:}

- Los datos de esta variable por si sola tan solo nos indican que de los FG analizados este estudio, el $36,85 \%$ se realizaron cuando se iba por encima en el marcador, el $55,77 \%$ cuando se iba por debajo, y el 7,38\% cuando se iba empatados. No pudiendo extrapolar, ni generalizar, resultados a partir de ellos.

\section{Ventaja/desventaja y precedente:}

- En las tres posibles situaciones del marcador los precedentes del FG más utilizados son la jugada personal y el pase respectivamente, siendo ocupado el tercer lugar por el bloqueo directo.

- En las situaciones de desventaja en el marcador se realiza menor porcentaje de FG tras pase, y más tras jugada personal, en comparación con las situaciones de empate o ventaja en el marcador.

- Cuando se va por encima en el marcador se produce mayor porcentaje de FG tras contraataque y robo que en las otras dos situaciones del marcador, pero menor tras rebote.

\section{Ventaja/desventaja y jugadores implicados:}

- En las tres posibles situaciones del marcador los FG con dos y tres jugadores implicados cuentan con los mayores porcentajes. En el caso de empate se tiende más a tres que a dos, mientras que con ventaja o desventaja se tiende a lo contrario. 
- Cuando se va por debajo en el marcador se realiza mayor porcentaje de FG con la intervención de un solo jugador, y menos con la de cuatro, que en el resto de situaciones del marcador.

- La intervención de los cinco jugadores es muy escasa en todas las situaciones del marcador.

- Cuando hay tablas en el marcador se dan menores porcentajes en la intervención de uno $\mathrm{Y}$ dos jugadores en comparación con las situaciones de ventaja o desventaja, pero mayores porcentajes de tres, cuatro y cinco.

\section{Ventaja/desventaja y QT:}

- El porcentaje de FG con el marcador empatado va disminuyendo según avanza el partido, pues esa igualdad inicial va desapareciendo.

- Con el marcador a favor se muestra un descenso del porcentaje de FG en los dos últimos cuartos, coincidiendo con un aumento de los porcentajes de los FG realizados con el marcador en contra.

\section{Precedente:}

- Ante la ejecución de un FG los porcentajes de los precedentes jugada personal y pase están muy por encima del resto, sumando entre ambos más de un $73 \%$ del total.

- El bloqueo directo es el tercer precedente con mayor porcentaje, seguido del rebote, el robo y el contraataque respectivamente, siendo la incidencia de los dos últimos muy escasa.

\section{Precedente y jugadores implicados:}

- Analizando los porcentajes de cada precedente del FG según el número de jugadores implicados vemos como en todos los precedentes, a excepción del robo y el rebote, los mayores porcentajes se dan en la intervención de dos y tres jugadores.

- El FG tras contraataque se produce casi en su totalidad con dos o tres jugadores, sumando entre ambas categorías más del $88 \%$. Hemos de destacar la categoría 
“dos jugadores”, la cual cuenta por si sola con más del 60\%. La intervención de los cinco jugadores nunca se llega a producir, y la de cuatro casi nunca.

- El FG tras bloqueo directo o jugada personal reparte sus porcentajes entre la intervención de dos, tres y un jugador, sumando entre dichas categorías más del $83 \%$.

- El FG tras pase se reparte casi por igual entre la intervención de dos y tres jugadores respectivamente, siendo ocupada la tercera posición por la intervención de cuatro.

- El FG tras robo se reparte casi exclusivamente entre dos y un jugador, acumulando entre ambos más del 90\%.

- El FG tras rebote, por su propia definición, se da exclusivamente bajo la intervención de un jugador.

- La intervención de cinco jugadores es muy baja o inexistente en todos los precedentes, y la de cuatro es escasa en comparación al resto. La única excepción se da en el pase, que cuenta con un $21 \%$ en la implicación de cuatro jugadores, lo cual se ve influenciado por que la categoría "uno" para este precedente no es posible, teniendo que repartir los porcentajes entre cuatro categorías. Es decir, el pase es el único precedente que por sí mismo obliga a la intervención como mínimo de dos jugadores, lo cual facilita que con su uso se aumente el número de estos.

\section{Precedente y QT:}

- Los precedentes del FG con mayores porcentajes en todos los periodos son el pase y la jugada personal respectivamente, sumando entre ambos más del $71 \%$. El bloqueo directo se muestra como tercer precedente, pero alejado de los valores de los dos anteriores.

- Analizando los porcentajes de cada precedente del FG en función del periodo en el que se ejecutan podemos ver como:

- El contraataque va reduciendo su porcentaje de incidencia según avanza el encuentro, dándose una gran diferencia entre los valores del primer y último QT. 
○ En los porcentajes del pase se aprecia también una dinámica negativa, pero mucho más gradual.

- En relación al bloqueo directo, en el primer QT se observa una mayor incidencia, tras el cual disminuye un poco y se mantiene constante durante los tres QT restantes.

- En cuanto a los FG tras jugada personal, a pesar de que en todos los cuartos los valores son similares, se aprecia un mayor porcentaje en los dos primeros QT, y además, una dominancia de los segundos cuartos de cada mitad sobre los primeros.

- En el rebote también se observa esa dinámica de dominancia del segundo sobre el primero y del cuarto sobre el tercero.

- En el caso del robo, se da una dinámica inversa, dominado el primer cuarto de cata mitad sobre los segundos, dándose en este caso la mayor diferencia entre pares.

\section{Precedente y momento especial:}

- Tanto el FG tras tiempo muerto, como el de última jugada de cuarto, acumulan sus mayores porcentajes en los precedentes "jugada personal" y "pase" respectivamente, con más del $82 \%$.

- Tras tiempo muerto no se pueden producir los precedentes contraataque, robo y rebote, por lo que sus porcentajes se reparten entre tan solo 3 categorías. Estas son “jugada personal", "pase”, y en tercera posición, con valores alejados de las dos anteriores, el "bloqueo directo".

- En el FG en la última jugada tiene mucha incidencia el precedente "jugada personal", con más de un 52\% por sí solo. Le siguen los precedentes "pase”, con más de un 30\%, "bloqueo directo" con algo más de un $11 \%$ y "robo" y "contraataque" con porcentajes muy bajos.

\section{Jugadores implicados:}

- En la realización de un FG:

○ En más del $63 \%$ de las ocasiones intervienen dos $(33,92 \%)$ o tres $(29,10 \%)$ jugadores. 
○ Les siguen de lejos las categorías "uno" (19,70\%), "cuatro" (14,38\%) y “cinco" $(2,89 \%)$ respectivamente, siendo esta última casi anecdótica.

\section{Jugadores implicados y QT:}

- Analizando el reparto de los porcentajes de cada QT en función de los jugadores implicados, y comparándolos entre sí, se observa como:

- En todos los QT los mayores porcentajes se dan en dos y tres jugadores respectivamente, con gran diferencia sobre el resto.

○ Las categorías "uno" y "cuatro" ocupan la tercera y cuarta posición.

- La intervención de cinco jugadores es muy escasa, no llegando en ningún QT al 3\%.

- Según avanzan los QT se van produciendo más FG con la intervención de un solo jugador.

○ La intervención en el FG de tres jugadores va disminuyendo según avanza el encuentro.

○ En el último cuarto se reducen los porcentajes de intervención de tres y cuatro jugadores en comparación a los periodos anteriores, compensándose con un aumento en la intervención de dos, y el ya mencionado aumento de un jugador.

\section{Jugadores implicados y momento especial:}

- En los FG tras tiempo muerto los mayores porcentajes en cuanto a jugadores implicados son las categorías "dos" y "tres", seguidas de "cuatro" y "uno" respectivamente, pero con valores muy por debajo. La intervención de los cinco jugadores no llega a alcanzar ni el $6 \%$.

- En los FG ejecutados en las últimas posesiones de cuarto se da en más de un $82 \%$ la implicación de uno o dos jugadores. El porcentaje va disminuyendo a medida que se van sumando jugadores, incluso, dándose un $0 \%$ para la intervención de todo el equipo.

\section{QT:}

- Se realizan mayor número de FG en el primer cuarto del partido.

- El número de FG se va reduciendo progresivamente según avanza el encuentro. 


\section{QT y momento especial:}

- Los FG tras tiempo muerto se producen en mayor porcentaje en los segundos cuartos de cada mitad ( $2^{\circ}$ y $\left.4^{\circ} \mathrm{QT}\right)$, existiendo una gran diferencia con el primer y tercer QT.

- Los FG tras tiempo muerto alcanzan su mayor porcentaje de incidencia, y de forma muy destacada, en el último QT del encuentro, superando el $43 \%$.

- En los FG realizados en las últimas posesiones de QT no se aprecia un patrón claro, tan solo un fuerte descenso en el porcentaje de incidencia sobre el último QT.

\section{Momento especial:}

- El porcentaje de FG tras los momentos especiales (tiempo muerto y última posesión de cuarto) sobre el total de FG analizados no alcanza ni el 6\%, por lo que su incidencia sobre el juego no es decisiva.

\section{Comparativa baloncesto masculino y femenino:}

- El baloncesto masculino tiene mayor incidencia en las zonas exteriores de la línea de 3 puntos (zona 5, 6 y 7), mientras que el baloncesto femenino la tiene en las zonas interiores (zona 1, 2, 3 y 4).

- La mayor diferencia en relación a la variable "zona del campo" se da en la zona 7, desde donde los hombres lanzan proporcionalmente un 7\% más.

- Los hombres tienen mayores porcentajes en los resultados relativos al lanzamiento de 3 puntos, mientras que en los relativos al lanzamiento de 2 puntos son más similares, teniendo como excepción el fallo de $2 \mathrm{p}$., donde las mujeres tienen un $9 \%$ más.

- El porcentaje de tapones es similar para ambos géneros.

- En relación a la variable "tiempo de posesión", los valores son muy similares, observándose una mayor incidencia por parte de los hombres en las franjas inicial (17-24) y final (0-8), mientras que el baloncesto femenino tiene mayor porcentaje en la intermedia (9-16).

- En la variable "tipo de tiro" no se han encontrado diferencias significativas. 
- En los precedentes antes del FG, el baloncesto femenino acumula mayores porcentajes en el contraataque, el pase y el rebote, mientras que los hombres utilizan proporcionalmente más el bloqueo directo y la jugada personal. En cuanto a los robos, los valores son similares.

- En ambos géneros los dos principales precedentes son el pase y la jugada personal, pero en el baloncesto femenino el pase está por encima de la jugada personal, y en el masculino es al contrario.

- En cuanto al número de jugadores implicados, para ambos los mayores porcentajes se recogen en dos y tres jugadores, pero proporcionalmente las mujeres tienen mayores porcentajes en tres, cuatro y cinco, mientras que los hombres en uno y dos.

- Por último, en cuanto a los periodos de juego, las diferencias no son significativas.

\section{Comparativa baloncesto europeo y americano:}

- A pesar de que los porcentajes en cuanto a la variable "zona del campo" son similares para ambas localizaciones, se dan ciertas diferencias. Más allá de la línea de 3 puntos se observan mayores porcentajes del baloncesto europeo en las zonas laterales (zona 5 y 6) y menor en la zona central (zona 7). En el interior, el baloncesto norteamericano tiene mayores porcentajes en las zonas 2 y 4 , mientras que el europeo en la zona 1 y 3.

- En la variable "resultado de la acción" los resultados también son similares, pudiendo destacar como los europeos tienen mayores porcentajes en fallos, tanto de 2 como de 3 puntos, y superioridad en la consecución de triples, pero no en canastas de 2 puntos.

- En cuanto a los porcentajes en tapones, los norteamericanos están ligeramente por encima.

- Para la variable "tiempo de posesión" se dan mayores diferencias en los porcentajes. En la posesión intermedia (9-16) el baloncesto norteamericano está por encima, pero con mucha menos diferencia que la existente en las otras dos franjas. Los norteamericanos destacan en la franja 17-24 mientras que los europeos en la 0-8. 
- En la variable "tipo de tiro" se observan valores similares para los malos tiros, superioridad de los europeos en los buenos tiros, y de los norteamericanos en los tiros normales.

- El baloncesto europeo tiene mayor porcentaje en el precedente "pase", mientras que el norteamericano lo tiene en la jugada personal. En cuanto a los bloqueos directos, los europeos cuentan con una ligera superioridad.

- En relación al número de jugadores implicados, los europeos tienen superioridad en las categorías "tres", "cuatro" y "cinco"; e inferioridad en "uno" y "dos".

- Por último, los porcentajes según periodo de juego son similares, siendo lo más destacable el mayor porcentaje en el primer QT por parte del baloncesto europeo.

\section{Baloncesto masculino y femenino en EU:}

- El baloncesto femenino ejecuta proporcionalmente más FG desde las zonas interiores, y el masculino desde el exterior del perímetro.

- Las mayores diferencias en cuanto a zona del campo se dan en la 4, con una superioridad femenina de un $4,13 \%$, y en la 7 , con una superioridad masculina de $7,85 \%$.

- El baloncesto masculino tiene mayor incidencia en los resultados relativos al FG de tres puntos, con la excepción del lanzamiento de 3 puntos más adicional, el cual se da un poco más en el femenino.

- En los resultados relativos al FG de dos puntos las mujeres muestran una mayor incidencia en el fallo, dándose en el resto porcentajes muy similares.

- Los hombres muestran un mayor porcentaje en cuanto a los tapones, pero con una diferencia mínima.

- Las mujeres ejecutan proporcionalmente más FG en las dos primeras franjas, mientras que los hombres tienden a agotar más la posesión.

- Los hombres realizan proporcionalmente más buenos y malos tiros. Las mujeres por su parte efectúan más tiros normales.

- Para ambos géneros los precedentes más utilizados son el pase, la jugada personal y el bloqueo directo respectivamente.

- Las mujeres realizan más FG tras contraataque, jugada personal, pase y rebote. Los hombres tras bloqueo directo y robo. 
- La intervención de dos y tres jugadores antes de un FG es la más común para ambos, pero en el caso de las mujeres prevalece tres jugadores sobre dos, al contrario que para los hombres.

- En el baloncesto masculino se ejecutan más FG con la intervención de uno y dos jugadores, mientras que en el caso de las mujeres lo hacen con la intervención de tres, cuatro y cinco.

- En cuanto a los QT, se da un mayor porcentaje de FG por parte de las mujeres en la primera mitad, y de los hombres en la segunda.

\section{Baloncesto masculino y femenino en EEUU:}

- Se da una mayor incidencia de FG desde las zonas interiores en el baloncesto femenino, y desde las exteriores en el masculino, siendo las zonas 7 y 4 las que mayores diferencias muestran.

- Los hombres cuentan con mayores porcentajes en los FG relativos a lanzamientos de tres puntos; y las mujeres en los relativos a lanzamientos de 2 puntos, con excepción de las canastas, donde se da una igualdad.

- En el baloncesto femenino se da proporcionalmente un mayor número de tapones en los FG.

- Los hombres muestran mayores porcentajes en los FG ejecutados en la primera y última franja de posesión en comparación con las mujeres, las cuales realizan más en la intermedia.

- El baloncesto femenino cuanto con mayores porcentajes en los malos y buenos tiros que los hombres, los cuales tienen superioridad en los normales.

- El baloncesto femenino tiene una superioridad porcentual en todos los precedentes a excepción de la jugada personal, la cual se da en mayor grado en el baloncesto masculino.

- Para ambos sexos los precedentes más utilizados son la jugada personal, el pase y el bloqueo directo en ese orden.

- Tanto el baloncesto masculino como femenino los mayores porcentajes de intervención de jugadores antes de un FG se dan con dos y tres jugadores.

- En el baloncesto femenino tienden a intervenir más jugadoras que en el masculino. 
- Los hombres realizan más FG que las mujeres en los tres primeros QT, y menos en el último.

\section{Baloncesto masculino en EU y EEUU:}

- El baloncesto masculino europeo tiene una mayor incidencia de los FG desde la zona $1 \mathrm{y}$ las tres zonas exteriores del perímetro que el norteamericano, el cual sobrepasa al europeo en las zonas 2, 3 y 4.

- Proporcionalmente, en Europa se encesta y falla más desde más allá de la línea de 3 puntos, y se anota y falla menos desde el interior.

- Se da una ligera mayor incidencia de los tapones ante un FG en Europa.

- El baloncesto europeo agota más el tiempo de posesión, acumulando el 87\% de sus FG en las dos últimas franjas, mientras que el norteamericano es más rápido con un $73 \%$ de los FG en las dos primeras franjas.

- En Europa se dan mayores porcentajes en los buenos y malos tiros que en Norteamérica.

- Para ambas localizaciones el pase y la jugada personal son los precedentes más usados. Pero mientras en Europa se ejecutan más pases que jugadas personales, en Norteamérica ocurre lo contrario.

- El tercer precedente más usado es el bloqueo directo, con una ligera superioridad porcentual del baloncesto europeo, el cual también cuenta con mayor porcentaje en los FG tras contraataque y robo, pero menor tras rebote.

- En cuanto al número de jugadores que intervienen antes del FG, tanto en Europa como en Norteamérica, la mayor incidencia se da en dos, tres, uno, cuatro y cinco respectivamente.

- En Europa se da proporcionalmente más la implicación de tres, cuatro y cinco jugadores, mientras que en Norteamérica se da más la de uno y dos.

- En el baloncesto norteamericano el número de FG va disminuyendo según avanza el encuentro, mientras que en el europeo se da el mayor porcentaje en el primer QT, tras el cual se estabilizan. 


\section{Baloncesto femenino en EU y EEUU:}

- En cuanto a las zonas del campo desde la que se ejecutan los FG, no se aprecia ningún patrón diferenciador claro. La mayor diferencia se da en la zona 1, donde el baloncesto europeo muestra un 2,77\% más de FG.

- En Norteamérica se dan mayores porcentajes de canasta y menores de fallo en los FG de 2 y 3 puntos.

- En los FG que conllevan tiros adicionales se da una superioridad norteamericana en los relativos a lanzamientos de 2 puntos, y Europa en los de 3 puntos.

- En Norteamérica se da una mayor incidencia de tapones ante la ejecución de un FG.

- El baloncesto norteamericano es más rápido, utilizando la franja inicial e intermedia más que el europeo, y menos la final.

- El porcentaje de FG ejecutados en unas condiciones normales es muy similar, dándose una ligera superioridad en Europa, la cual cuenta con mayores porcentajes en los buenos tiros y menores en los malos.

- El pase y la jugada personal son los precedentes que más se dan para ambas localizaciones. En Europa se da más el pase que la jugada personal, y en Norteamérica ocurre lo contrario.

- El bloqueo directo es el tercer precedente más común, siendo algo más utilizado por parte de las norteamericanas.

- El baloncesto femenino europeo tiene proporcionalmente una mayor incidencia en el robo y el rebote, pero menor en el contraataque.

- Para ambas localizaciones el número más común de jugadoras implicadas antes de un FG es dos y tres. En el caso de Europa se dan más tres que dos jugadoras, y en Norteamérica al contrario.

- En Europa se tiende a dar una intervención de más jugadoras.

- En Europa se realizan proporcionalmente más FG en la primera mitad del encuentro, mientras que en Norteamérica se realizan más en la segunda. 


\section{DISCUSIÓN DE LOS RESULTADOS}

Como hemos mostrado, el FG como la acción necesaria para la consecución de puntos, y por tanto, de la victoria, ha sido estudiado desde muchas perspectivas (fisiológicas, psicológicas, biomecánicas...), pero la realidad es que dada la complejidad normativa y la lógica interna del juego se hace necesario un estudio mucho más global, teniendo en cuenta todas las variables influyentes en la ejecución. El análisis del FG desde un punto de vista multidimensional ya ha sido abordado en distintos trabajos por autores como Tsitskaris et al. (2002) en la liga griega, Ibáñez et al. (2007) en la ACB, García et al. (2008) en la liga EBA, Ibáñez et al. (2009a) en la NBA, o Robles (2016) en un campeonato de España cadete. Contribuciones que no invalidan, sino que por el contrario refuerzan, la necesidad de acometer un estudio que contemple el conjunto tan amplio de variables y relaciones que pretende nuestra contribución. De los anteriores trabajos hemos de destacar el trabajo de Ibáñez et al. (2009a), pues tiene un planteamiento similar a nuestro estudio al relacionar la eficacia del FG de 2 y 3 puntos con hasta 7 variables: I) Periodo, II) Cuarto, III) Gestoforma, IV) Presión defensiva, V) Zona del lanzamiento, VI) Rol y VII) Acción previa; y defender la necesidad de la aplicación práctica desde ejercicios más semejantes al juego real, una de los objetivos de nuestro trabajo.

La zona de ejecución del FG es una de las variables más estudiadas. Ibáñez et al. (2009a) encuentran que las zonas más eficaces son las próximas a canasta, concretamente dentro de su estudio, la zona 1 y la 5, lo que se correspondería con la parte más cercana al aro de nuestra zona 1, coincidiendo así con los resultados obtenidos por otros autores como Mexas et al. (2005), Lapresa et al. (2014), Muñoz et al. (2015) y Noguera y Camerino (2013), siendo la zona con mayor eficacia el área restringida. Cuanto más se aumente la distancia del FG, más se incrementa el porcentaje de errores. De hecho, para Lapresa et al. (2014) tan solo los FG ejecutados desde la pintura obtienen una relación positiva entre consecuencias favorables y desfavorables con un 53,3\%, lo cual se corrobora en nuestro estudio, siendo la zona 1 la única con mayor porcentaje de resultados positivos con un $58,68 \%$. Esa mayor eficacia de las zonas cercanas al aro crea la necesidad por parte del equipo defensor de intensificar su oposición ante los atacantes cuanto más cerca del aro estén. En este sentido Ibáñez et al. (2019a) advierten como la proporción de faltas y tapones disminuye tanto en cuanto la ejecución del FG se aleja del aro. Nuestros 
resultados apoyan esta afirmación, concentrándose casi el 88\% de los tapones y algo más del $90 \%$ en las respectivas categorías asociadas a faltas, a excepción de las ligadas al triple, en la zona 1. En el caso de los tapones, las zonas 5 y la 4 respectivamente han mostrado valores muy bajos.

En cuanto a la zona exterior, Lapresa et al. (2014) encuentran un escaso porcentaje de FG con resultado favorable $(21,9 \%)$. Este resultado tan bajo es seguramente debido a la categoría analizada en dicho estudio, la infantil, pues como el mismo comenta, su resultado difiere mucho de los encontrados en otros estudios. De hecho, se puede observar cierta mejora en los porcentajes exteriores según se avanza de categoría debido a la madurez física y perfeccionamiento técnico que se va produciendo, ya que para la categoría juvenil es algo mayor con un 27,95\% (Ortega y Gómez, 2009), y aún más en ligas profesionales, pues Sautu et al. (2009) en la ACB encuentran un 35,87\%, Fernández y Ortiz (2017) encuentran un $32 \%$ en las semifinales y final de la liga uruguaya de baloncesto y Arjonilla (2009) entorno a un 30,10\% en la ACB y un $31 \%$ en la liga femenina. En nuestro caso la media de efectividad entre las tres zonas exteriores es de $35,5 \%$.

Además de esa diferencia en la eficacia, también se da un dispar reparto de porcentajes de FG ejecutados desde la zona de 3 puntos en función de la categoría. En categoría infantil Lapresa et al. (2014) encontraron un 11,9\% de FG ejecutados desde la zona exterior, mientras que en la élite del baloncesto otros autores como Fernández et al. (2009), Mexas et al. (2005) o Sautu et al. (2009) encontraron respectivamente un 37,7\%, $33 \%$ y $30 \%$. Centrándonos en la proporción de lanzamientos por zonas, varios autores defienden que la mayor parte de FG se ejecutan en las zonas con valor de 2 puntos (Noguera y Camerino, 2013; Mexas et al., 2005; Sautu et al., 2009; Fernández et al., 2009), lo cual concuerda con nuestros resultados con un $68,14 \%$ de los FG desde la zona de 2 puntos, aunque algunos otros autores como Muñoz et al. (2015) afirman lo contrario. Noguera y Camerino (2013) encontraron un 38,79\% desde la pintura, un 38,20\% desde la zona y tan solo un 23,02\% desde la zona exterior. Por otro lado, Sautu et al. (2009) recogieron que casi el 70\% de los FG se ejecutan desde la zona de dos puntos, lo cual relaciona con el porcentaje de acierto, un $50,11 \%$, frente al $35,87 \%$ de los tiros de 3 puntos. Aun así advierte que teniendo en cuenta los porcentajes de acierto de ambos, y el 
valor de cada uno, deberían realizarse más tiros de tres puntos.

Sin embargo, si se valora el porcentaje de aciertos y el valor de la puntuación de los tiros, se podría considerar que el número de Tiros de Tres debería de ser mayor, si se mantuvieran con estos porcentajes de acierto. (Sautu et al. 2009, p.69)

Respecto a la lateralidad, Noguera y Camerino (2013) señalan que las zonas centrales son desde las que más FG se ejecutan, ocurriendo lo mismo en la zona exterior del perímetro a pesar de no ser la más efectiva. Los datos obtenidos en nuestro estudio coinciden con estos resultados, siendo las zonas centrales (zona 1, 4 y 7) las que mayores porcentajes de FG tienen. En cuanto al exterior del perímetro, a pesar de que la zona 7 tiene un porcentaje mucho mayor de FG realizados que sus contiguas con un 21,25\%, respecto del 5,61\% de la zona 5 y del 5,01\% de la zona 6, la eficacia no va acorde, siendo las zonas laterales 5 y 6 , con respectivamente $37,10 \%$ y 35,57\%, más eficaces que la zona central (zona 7) que cuenta con un $33,89 \%$.

El resultado del FG por su importancia sobre el marcador, y por tanto en la victoria, también es una de las variables que más interés despierta. Noguera y Camerino (2013) encontraron una efectividad en los FG del 51,73\%, algo más alta que la recogida en nuestro estudio (47,23\%), seguramente debido a que en el suyo tienen en cuenta los tiros libres, de ahí ese aumento de efectividad.

Por otro lado, el tiempo de posesión como limitación reglamentaria influye de forma muy directa sobre el FG. Fernández y Ortiz (2017) encuentran que la franja de 5 a 0 segundos es la menos eficaz, a pesar de lo cual se da en ella cierto aumento del número de FG influenciado por la presión del límite temporal. En el caso de nuestro estudio la franja temporal es algo más amplia (0-8), pero los resultados van en la misma línea, pues a pesar de tener el menor porcentaje de resultados positivos con un 42,03\%, los FG efectuados en dicha franja suman el 33,19\%, solo por debajo de la franja intermedia (9-16), la cual es la más utilizada. El FG tiende a ejecutarse de media entre los 11 (Barrios, 2003) y 13 segundos (Lorenzo et al., 2003; Madejón, 2002). Barrios (2003) obtiene que la mayoría de FG se producen en los 15 primeros segundos $(71,4 \%)$, dejando tan solo un 28,6\% para los últimos 9 segundos. Estos resultados difieren un poco de los obtenidos en nuestro estudio debido a que son previos a la modificación reglamentaria que obliga a reiniciar la posesión desde 14 segundos en lugar de 24. 
En cuanto a los periodos de juego, Robles (2016) encuentra en su estudio sobre el lanzamiento de 3 puntos que en los segundos periodos de cada mitad se producen más lanzamientos y son más efectivos, siendo el último QT en el que más se lanza y el primero en el que menos. Esa misma idea es compartida por Ibáñez et al. (2009a) quienes comentan que "se aprecia una tendencia a incrementar el valor del lanzamiento riesgo, cuando se acerca el final del partido. Los equipos intentan recortar o incrementar las diferencias en el marcador con lanzamientos de un valor superior" (p.42). Tras la interpretación de nuestros resultados si se advierte un mayor porcentaje de FG de 3 puntos en la zona 7 en el segundo y cuarto QT, especialmente en este último, aunque no con mayor eficacia. En relación a los FG de dos puntos encontramos un mayor porcentaje en los dos primeros QT, y en el último QT un porcentaje significativamente menor que en el resto. En líneas generales, nuestros resultados coinciden con Ibáñez et al. (2009a) señalando que según avanza el encuentro se van produciendo menor número de FG de 2 y más de 3 puntos. Sin embargo, Lorenzo et al. (2003) encontraron una mayor ejecución de FG de 3 puntos en los dos primeros QT, y en cuanto a los FG de dos puntos señalaron que el primer y tercer QT son en los que más se realizan, siendo el último en el que menos.

En relación a las faltas y tapones, Ibáñez et al. (2009a) apreciaron un aumento en la segunda parte ( $3^{\circ}$ y $4^{\circ}$ QT), destacando en el caso de las faltas el último QT. Nuestros resultados coinciden en cuanto a los tapones, mostrándose los mayores porcentajes en el $3^{\circ}$ y especialmente en el $4^{\circ} \mathrm{QT}$, pero respecto a las faltas no encontramos un patrón claro.

De la mano del periodo de juego, el tanteo del marcador también tiene influencia sobre el FG, pues el número de lanzamientos de 3 puntos aumenta cuanto más avanza el encuentro y más ajustado está el marcador (Robles, 2016).

Por su parte, los precedentes del FG, como acciones inmediatamente previas al mismo, cuenta con numerosos estudios, pero por lo general, se centran en el bloqueo directo, el pase y el bote. Remmert (2003) obtuvo el bloqueo directo como la acción de finalización más usada, pero tan solo analizando las jugadas tácticas grupales. Por ello sus resultados no pueden extrapolarse a nuestro estudio, de hecho, hay estudios en desacuerdo con esa afirmación (Muñoz et al., 2015; Romarís et al 2012). En general, los bloqueos directos tienden a realizarse en las zonas centrales, donde son algo más eficientes; y entre los segundos 9 y 16, a pesar de lo cual, los realizados en los últimos segundos muestran la 
mayor eficiencia (Battaglia et al., 2009; Nunes et al., 2016). Esto coincide con nuestros resultados, produciéndose el $86,77 \%$ de los FG tras bloqueo directo en las zonas centrales y el 60,32\% en la franja intermedia. En cuanto a la eficacia, Nuñes e Iglesias obtuvieron que el 42,6\% de los lanzamientos tras bloqueo directo terminaron en canasta. (Nuñes e Iglesias, 2010, como se citó en Muñoz et al., 2015). En nuestro estudio ese porcentaje es algo menor con un $39,32 \%$, pero si lo ampliamos a todo resultado positivo, no solo canasta, este porcentaje asciende hasta 46,74\%. En relación al bloqueo directo debemos destacar el estudio de Nunes et al. (2016) donde advierten que hay un reparto similar entre cuartos, pero algo más en el segundo cuarto de cada parte $\left(2^{\circ}\right.$ y $\left.4^{\circ}\right)$, lo cual relaciona con el juego más conservador que se produce en dichos cuartos. Nuestros resultados no respaldan dicha afirmación, siendo el $1^{\circ}$ QT donde más se realizan y mostrando cierta igualdad en los posteriores. Por su parte, el contraataque, dada la superioridad que lleva implícita, es el precedente más eficaz a pesar de no ser el más utilizado, algo con lo que coinciden Noguera y Camerino (2013), pues solo ponen por delante al tiro libre, el cual no es analizado en este estudio. La eficacia encontrada en su estudio, 62,25\%, es algo menor a la encontrada en el nuestro, 72,19\%. En cuanto a su finalización, Refoyo et al. (2009) afirman que más del $75 \%$ de los contraataques finalizan en la zona interior, siendo este porcentaje incluso mayor en nuestro estudio con más del $82 \%$.

Centrándonos en los precedentes del FG más comunes, el pase y la jugada personal, Robles (2016) en su estudio sobre el lanzamiento de tres, a pesar de no estudiar los mismos precedentes que los utilizados en este estudio, si realiza una comparación entre los FG ejecutados tras un pase o tras bote, encontrando que los realizados tras pase predominan, y de forma muy destacada, pero la eficacia tras bote $(28,57 \%)$ es mayor que tras pase (22,16\%). Estos resultados difieren de los hallados por Ibáñez et al. (2009a), los cuales afirman que los FG tras pase son de los más eficaces, a pesar de lo cual hay mayor porcentaje de finalizaciones tras bote $(44,9 \%)$ que tras pase $(42,9 \%)$; y también, de los encontrados por Fernández y Ortiz (2017), los cuales encuentran una superioridad de la eficacia del FG tras pase (35\%) sobre el bote (25\%), además, advierten que en los FG tras pase se producen menor número de faltas en relación a los FG tras bote. En nuestros resultados se observa un mayor porcentaje de FG $(37,4 \%)$ y eficacia $(45,74 \%)$ tras jugada personal que tras pase, el cual cuenta con el 35,65\% de los FG y un 43,88\% de eficacia. Sin embargo, debemos recordar que en nuestro estudio se recoge la eficacia como todo 
resultado positivo, pues si lo redujéramos a la consecución o no de canasta, estos porcentajes disminuirían hasta $36,31 \%$ tras jugada personal y $40,89 \%$ tras pase. Es decir, el pase como precedente de un FG es más eficaz para la consecución de canasta que la jugada personal, pero como forma de obtener un resultado positivo (Triple y adicional, triple, falta y 3 tiros libres, canasta y adicional, canasta, canasta y 2 tiros libres) es la jugada personal quien está por encima. En cuanto a la afirmación de Fernández y Ortiz (2017) acerca de las faltas, nuestros resultados corroboran ese mayor porcentaje de faltas en los FG tras jugada personal (12,59\%) que tras pase (4,35\%), sin embargo, en la zona exterior, por la mayor circulación de balón, es el pase el precedente que tiene mayor porcentaje de faltas. Ibáñez et al. (2009a) también señalan la gran eficacia del rebote como precedente en el FG, teniendo además una alta probabilidad de recibir una falta. En nuestro estudio el rebote ha resultado ser el tercer precedente más efectivo, sólo por detrás del contraataque y el robo.

Por otro lado, el baloncesto actual, como hemos demostrado, tiende a "resumir" la carga táctica de las jugadas en un 2x2 o 3x3. Sáenz-López et al. (2007) afirma que las jugadoras prefieren el trabajo de $2 \times 2$ y $3 \times 3$ al considerarlo mejor y más eficaz.

En cuanto a la oposición encontrada a la hora de efectuar los FG, la gran mayoría de los lanzamientos de un partido se ejecutan con cierta oposición (Ibáñez et al., 2009a; Ortega et al., 2006, como se citó en Cañadas et al., 2009). Coincidiendo con nuestro estudio, Robles (2016) advierte que la oposición parcial es la que más se da, seguida de los FG sin oposición, y por último, los ejecutados contra una oposición total. En relación a la efectividad, a mayor grado de oposición en la ejecución del FG, la proporción de errores aumenta de forma significativa (Ibáñez et al, 2009a). En el caso concreto de nuestro estudio la efectividad disminuye desde un 57,36\% en los FG sin oposición, hasta el $18,54 \%$ en los FG efectuados bajo condiciones totalmente adversas.

En referencia a las diferencias existentes entre el baloncesto europeo y norteamericano, Fierro (2002) en su estudio de la NBA y la ACB encontró que los FG de la ACB tienen mayor efectividad que los de la NBA, tanto en los lanzamientos de 3 como de 2, pero especialmente en los últimos. La diferencia en los FG de 2 puntos la achaca al juego más rápido y precipitado llevado a cabo en la NBA, y en los FG de tres puntos a la diferencia en la distancia de anotación. Estos resultados van en la línea de los encontrados por Ibáñez 
et al. (2019a), quienes encuentran un mayor porcentaje de lanzamientos de 3 en la liga ACB y EBA en comparación con la NBA, lo cual también asocian a la diferencia de distancias reglamentarias. En cuanto al porcentaje de lanzamientos de 2 puntos encuentran una superioridad por parte de los norteamericanos, lo cual no choca con los datos aportados por Fierro, pues el hacía alusión a la efectividad. Los datos obtenidos en este estudio respaldan los resultados obtenidos por Ibáñez, con un mayor porcentaje de FG de tres puntos y menor en FG de dos puntos por parte de las ligas europeas respecto de las americanas. En cuanto a la efectividad, encontramos mayor efectividad por parte de las ligas europeas en los FG de tres puntos, y menor en los FG de dos puntos, discrepando por tanto con los resultados de Fierro.

A cerca de la forma de juego, Fierro (2002) señala que el juego más físico desarrollado por los norteamericanos desemboca en un mayor número de tapones, lo cual también se observa en nuestro estudio, siendo el porcentaje de tapones respecto del total de FG un 0,12\% mayor en las ligas norteamericanas. Ibáñez et al (2019a) también encuentra diferencias en el estilo, dándose en la NBA un ritmo de juego que no se dan en otras ligas.

Durante el 1er cuarto la eficacia de los equipos es superior, provocada por una menor presión defensiva (faltas y tapones). En el $2^{\circ}$ cuarto comienza a incrementarse la presión defensiva, disminuyendo la eficacia y aumentando los errores. El 3er cuarto, los equipos comienzan a pensar en ganar el partido, el incremento de la presión defensiva es notorio (aumento de los tapones), y los equipos comienzan a asegurar sus ataques (menos errores). El último cuarto es el desenlace del partido, el aumento de la presión defensiva y el cansancio provocan una mayor aparición de faltas, disminuyendo el porcentaje de aciertos. En estudios precedentes en las ligas ACB y EBA (Ibáñez et al., 2007; Ibáñez et al., 2008), este hecho no ocurre, se lanza de forma similar a lo largo del partido, pues no se encuentran relaciones entre la eficacia y el período y cuarto. (Ibáñez, 2019a, p. 43)

En lo que concierne al baloncesto masculino y femenino también se dan discrepancias, algunas de las cuales están directamente relacionadas con las diferencias antropométricas entre ambos sexos, como por ejemplo, el mayor número de tapones en el baloncesto masculino, y el mayor número de robos en el baloncesto femenino (Sampaio et al. 2004), 
lo cual también se observa en nuestro estudio.

La forma de juego es diferente, pues como recogen Romarís et al. (2012), en la ACB predominan las finalizaciones tras bloqueo directo, mientras que, en el caso de la Liga Femenina, lo hacen la circulación de balón, los movimientos sin balón y las jugadas individuales. La ejecución de los contraataques también difiere en función del sexo, Refoyo et al. (2009) encuentran diferencias estadísticamente significativas entre hombres y mujeres en cuanto al contraataque en función del tiempo de duración, la zona y oposición defensiva de la finalización. En el baloncesto masculino se realizan menos pases, intervienen menos jugadores y son más rápidos.

Montaner y Montaner (2004) en su estudio comparativo entre sexos en equipos de élite concluyen que:

- En el baloncesto masculino se tiende a largar más las posesiones en comparación al femenino.

- Para ambos sexos la acción positiva que se da con mayor frecuencia es la canasta de dos puntos.

- En el baloncesto masculino la acción negativa que más se produce es el fallo de 3, y en caso del femenino, el fallo de dos puntos. En nuestro estudio no ha sido así, siendo la acción negativa que más se produce en ambos sexos el fallo de 2 puntos.

- Las chicas anotan un $22 \%$ menos que los chicos en los últimos 7 segundos de posesión.

- En cuanto al FG de 3 puntos, los hombres consiguen su mejor porcentaje de acierto en los últimos 7 segundos, mientras que las chicas muestran sus peores porcentajes en esta última franja.

- Los porcentajes de acierto en los FG de dos puntos disminuyen en ambos sexos según avanza la posesión, siendo el de los chicos superior en las tres franjas o intervalos

- Los hombres en los 7 primeros segundos muestran una altísima eficacia en los FG de dos puntos. 


\section{APLICACIÓN PRÁCTICA}

El entrenamiento técnico en baloncesto es algo esencial, no cabe duda, pero como deporte de colaboración oposición, la táctica también lo es, tanto individual como colectiva. Los estudios sobre el entrenamiento táctico son numerosos, desde su aplicación en categorías inferiores como Cárdenas (2006) desde la perspectiva constructivista, hasta senior o profesionales como Alarcón et al. (2010) mediante el uso de pre-test y post-test, Chicote et al. (2009) con su análisis táctico de las acciones ofensivas a través del software de video análisis VA-Sports o muchos otros como Altavilla y Raiola (2015) o Kozina et al. (2017), y como es lógico, se van adaptando a los avances tecnológicos, empezándose a usar la realidad virtual como complemento al ya más que respaldado uso de videos como herramienta para recopilar feedbacks/aprendizajes y realizar scoutings. En este ámbito podríamos destacar el trabajo de Pagé et al. (2019), quienes comparan los resultados de aprendizaje entre tres grupos, el de control, en el que se usan fotografías como herramienta, otro en el que se usa el video, y por último, uno que utiliza un casco de VR. En su análisis diferencia entre aprendizajes o mejoras transferibles del "laboratorio" al campo de juego, y generalizables de los ejercicios o jugadas ensayadas a las no entrenadas. Sus resultados muestran como el video como herramienta es capaz de generar mejoras transferibles, pero no generalizables, mientras que la realidad virtual genera mejoras transferibles y generalizadas, superando ambas herramientas al grupo control. Esto apunta a que la VR será una herramienta fundamental en la formación deportiva, y seguramente aplicable a cualquier otro ámbito, algo que ya hace años Yao et al. (2012) anunciaban, insistiendo en como con el paso del tiempo la tecnología sería más accesible económicamente, pudiendo así implantarse para la enseñanza y formación de jugadores. Hay otros autores que también han utilizado esta tecnología aplicada al baloncesto como Zhang y Wang (2011), Tsai et al. (2017) y Tsai (2018) para la mejora de la táctica, o Covaci et al. (2012) que la utilizaron para la mejora de la técnica en el tiro libre.

Centrándonos en el presente estudio, se ha tenido como objeto encontrar unos patrones de juego y/o variables influyentes en el FG. Pero el conocimiento conseguido tras el análisis no debe quedarse tan solo en una recopilación de datos e información. Debemos analizar los resultados para poder extraer las claves que nos ayuden a entender el juego, más concretamente, los factores influyentes en la realización de este gesto técnico/táctico, sin duda el más importante, pues se trata del objetivo final del deporte, encestar. 
Con apoyo empírico en los resultados, hemos podido generar una batería de ejercicios para trabajar los puntos clave en la mejora del FG o su defensa, alguno de los cuales detallamos a continuación, pudiendo ser aplicados directamente en los ejercicios o usados como explicaciones complementarias para mejorar el entendimiento táctico de los jugadores.

Debemos trabajar ofensiva y defensivamente:

- Las zonas centrales por ser donde más FG se realizan, especialmente las zonas 1 y 4 por ser las más efectivas.

- La zona 4 por ser un área clave que cuenta con muy buen porcentaje de buenos tiros y es la segunda zona más eficaz.

- En el exterior del perímetro, en concreto las zonas 5 y 6 por ser las más efectivas y contar con mayor número de buenos tiros.

- La zona 7 por ser la zona exterior desde la que más FG se ejecutan, sufriendo incrementos en los segundos periodos de cada mitad, sobre todo en el último cuarto.

- La finalización en la zona 1 por ser muy utilizada en la última franja de posesión $\mathrm{y}$ tras precedentes muy efectivos como el contraataque o el robo.

- Los precedentes más comunes en función de las zonas: jugada personal para las zonas 1, 2 y 3; el pase en las zonas 5 y 6 ; y para las zonas 7 y 4 el pase, la jugada personal y el bloqueo directo.

- Las posesiones intermedias por ser las más utilizadas.

- Los precedentes "pase", "jugada personal” y "bloqueo directo" por ser los más utilizados.

- Los precedentes "contraataque", "robo" y "pase" por contar con altos porcentajes de buenos tiros; y en cuanto a los mejores resultados, trabajar el rebote, el contraataque y el robo.

- La intervención de dos y tres jugadores por ser lo más común, siendo la intervención de los cinco jugadores algo muy raro. Tras robo o contraataque tender más a ejercicios de dos que de tres jugadores.

A nivel defensivo, debemos de ser muy conscientes de las situaciones menos ventajosas para los atacantes, tratando así de llevarlos hacia ellas. Algunas de estas situaciones son: 
- Los FG en las zonas 2 y 3 cuentan con una eficacia muy baja y un gran número de malos tiros.

- Según les va quedando menos tiempo de posesión a los atacantes el porcentaje de fallo va aumentando.

- La jugada personal es el peor precedente para generar ventajas en el FG, pues es el precedente con mayor porcentaje de malos tiros y menor de buenos.

Debemos dar a conocer a los jugadores información complementaria a los ejercicios, siendo así conscientes de las dinámicas de juego. Debemos hacerles entender que en función de ciertas situaciones como el periodo de juego o el marcador, se dan diferencias en el juego:

- Según avanza el encuentro:

- Se dan más FG en la última franja de posesión.

○ Se producen menos contraataques.

○ Los FG tienen menos resultados positivos.

○ El número de FG va disminuyendo.

- En los segundos cuartos de cada mitad se producen más malos tiros.

- En los primeros cuartos de cada mitad se producen más robos y se ejecutan más FG en la primera franja de posesión.

- En el último cuarto aumenta el porcentaje de FG con dos y un jugador implicados en comparación al resto de cuartos, y disminuye de tres y cuatro.

- Cuando se va por debajo en el marcador:

- Se producen menos FG en la última franja de posesión y más en la intermedia.

- Se ejecutan más FG en los dos últimos cuartos.

- Se dan mejores resultados del FG, y mayor porcentaje de buenos tiros y normales.

- Se dan más FG tras jugada personal que tras pase.

- Cuando se va ganando se produce mayor porcentaje de FG tras contraataque o robo que cuando se va perdiendo.

- Cuando se va empate se producen menos FG con la intervención de tan solo uno o dos jugadores en comparación a cuándo se va ganando o perdiendo. 
En cuanto al trabajo de los momentos especiales, estos solo representan un $6 \%$ sobre el total de FG analizados, pero no dejan de ser una posible área de mejora, pues en mayor o menor medida influyen sobre el juego, siendo necesario diseñar y poner en práctica distintos ejercicios para aprender a controlar y gestionar esa crisis psicológica que pueden llegar a generar. Por ello debemos tener en cuenta para su trabajo que:

- Para el FG tras tiempo muerto:

○ Los precedentes más utilizados son la jugada personal y el pase.

○ Las zonas más utilizadas son la 1 y la 7.

- El porcentaje de resultados positivos y buenos tiros es aceptable, pero inferior a la media del FG.

- El número de jugadores que intervienen tiende a ser dos o tres.

- Se producen en su mayoría en la última franja o en la intermedia.

- Se producen más en los segundos cuartos de cada mitad, sobre todo en el último.

- Para el FG en última jugada:

○ Los precedentes más utilizados son la jugada personal y el pase.

○ Las zonas más utilizadas son la 7 y la 1.

○ Los resultados y tipos de tiro son muy negativos.

○ Por definición se producen en la última franja de posesión.

\subsection{EJERCICIOS PRÁCTICOS}

La fecundidad heurística de los resultados nos conduce de manera inmediata a considerar sus aplicaciones prácticas. Conscientes de la potencia que nos proporciona la apropiación cabal y refinada de la teoría, afrontamos el reto de construir secuencias no solo nomológicas, sino también nomopragmáticas de conducta en la práctica del baloncesto, resueltos a construir, con cierta originalidad, nuevas formas de entender y practicar el FG.

Antes de abordar la batería de ejercicios debemos de ser conscientes de que en cada ejercicio no se entrena tan solo un concepto de forma analítica, si no que a menudo se engloban distintos conceptos con distintas importancias o incidencias sobre el ejercicio. En ocasiones podremos "jugar" entre diferentes objetivos de entrenamiento mediante la modificación o limitación de los ejercicios a través de premisas o pautas, orientando así 
el ejercicio en función de las necesidades del equipo. Debemos buscar la complejidad contextual de situaciones reales de partido, mejorando así la toma de decisiones y eficacia de los jugadores a través de la comprensión de la lógica interna del juego e intervenciones reflexivas. Es de vital importancia que los jugadores sean conscientes de sus virtudes y limitaciones, así como las de sus compañeros, pues en el ámbito competitivo debemos generar situaciones de FG adecuadas a las características de cada finalizador, no sirviendo de nada, por ejemplo, generar una ventaja para un triple cómodo si el balón le ha llegado a un jugador con muy mal tiro, o un balón interior para un jugador con poco físico y técnica en la pintura. Por ello habrá ejercicios en los que se den unos roles específicos, pudiendo ser ocupadas dichas posiciones tan solo por ciertos tipos de jugadores.

La batería de ejercicios de este estudio consta de 36 fichas cuya estructura se sustenta en tres apartados de vital importancia (objetivos, ejercicio y representación gráfica), con la posibilidad de otros dos en los casos que así lo requieren (rotación y modificación mediante premisas). Dentro de los objetivos se hace distinción entre objetivos primarios, es decir, los fines o propósitos a la hora de diseñar el ejercicio; y objetivos secundarios, aquellos que aparecen de forma colateral y son aprovechados. La explicación del ejercicio de forma escrita es apoyada por la representación gráfica, cuya simbología está recogida al inicio de este trabajo. Por su parte, el apartado de rotación explica como han de reorganizarse los jugadores entre las distintas posiciones tras la realización del ejercicio; y el de modificación mediante premisas, como su propio nombre indica, recoge algunos ejemplos de variaciones en la lógica o ejecución del ejercicio. 


\section{FICHA No 1}

Objetivo/s primario/s: Rebote defensivo / Rebote ofensivo.

Objetivo/s secundario/s: FG tras pase.

\section{EJERCICIO:}

El jugador en la fila del balón realiza un pase a uno de los lados, donde el jugador que lo recibe ejecuta el FG. La pareja situada en el lado contario, atacante y defensor, lucharán por el rebote.

\section{ROTACIÓN:}

$1^{\circ}$ De la fila con balón, al lado contrario de donde se efectué el pase. $2^{\circ}$ El que ejecuta el FG luchara por el rebote ofensivo en la próxima jugada.

$3^{\circ}$ Del par que luchan por el rebote (ofensivo y defensivo), el que lo coja irá por fuera del campo de nuevo a la fila inicial, siendo el otro quien pase a luchar por el rebote defensivo en la próxima jugada en el lado contario.

\section{MODIFICACIÓN MEDIANTE PREMISAS:}

El lanzamiento tras el pase puede efectuarse desde cualquier zona del campo en función de las necesidades del equipo:

Premisa 1: Efectuar el lanzamiento desde las zonas 5 y 6 por contar con gran eficacia y alto porcentaje de buenos tiros.

Premisa 2: Efectuar el FG desde la zona 7 para mejorar la efectividad dado que es una de las zonas desde dónde más se lanza.

Si queremos incidir de forma más concreta sobre el bloqueo de rebote:

Premisa 3: El jugador que lucha por el rebote defensivo debe bloquear el rebote al atacante de tal forma que el balón bote dos veces sin que este pueda llegar a tocarlo, entonces, se considerará rebote defensivo. 


\section{FICHA N $\mathbf{N}^{0} 2$}

Objetivo/s primario/s: Rebote defensivo / Rebote ofensivo.

Objetivo/s secundario/s: 2x1 (contraataque).

\section{EJERCICIO:}

Tras el FG, las parejas lucharán por el rebote. La pareja que lo consiga contraatacará en el lado contrario.

El ejercicio no finaliza hasta que los atacantes en contraataque encesten o el defensor coja el rebote.

El defensor debe realizar fintas defensivas y ser agresivo para incomodar el contraataque.

\section{ROTACIÓN:}

$1^{\circ}$ La pareja que no coja el rebote luchará por el rebote defensivo en la siguiente jugada.

$2^{\circ}$ La pareja que lo coja realiza el contraataque.

$3^{\circ} \mathrm{El}$ defensor del contraataque seguirá defendiendo hasta que consiga un rebote, siendo entonces uno de los dos atacantes quien se quedará para defender el siguiente contraataque. Los otros dos volverán a las filas iniciales.

\section{MODIFICACIÓN MEDIANTE PREMISAS:}

Si queremos incidir de forma más concreta sobre el bloqueo de rebote:

Premisa 1: La pareja que lucha por el rebote defensivo debe bloquear el rebote a los atacantes de tal forma que el balón bote dos veces sin que estos puedan llegar a tocarlo.

En el contraataque:

Premisa 2: Obligar a finalizar en la zona 1 por su alta efectividad y ser la más común para este precedente.

Premisa 3: La pareja en contraataque no puede botar, por lo que debe finalizar a través de pases.

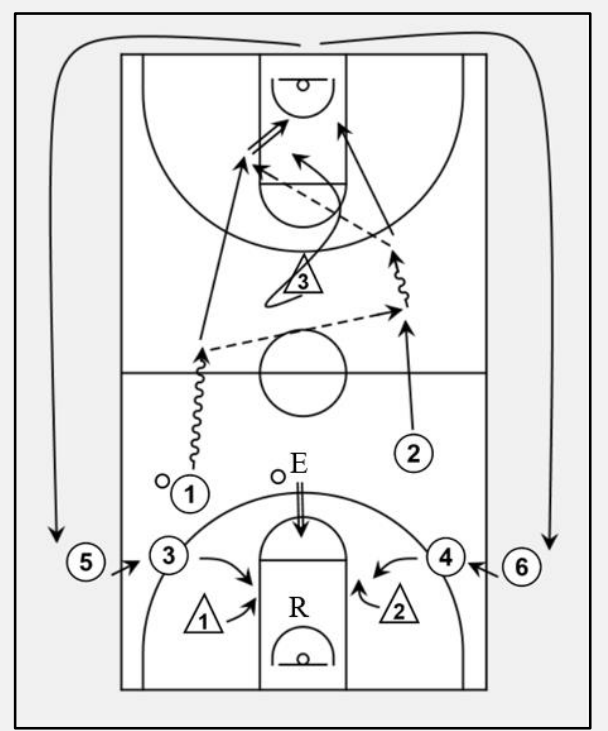




\section{FICHA N 3}

Objetivo/s primario/s: Toma de decisiones.

Objetivo/s secundario/s: Bloqueo indirecto y directo.

\section{EJERCICIO:}

El atacante y su defensor se colocan de espaldas bajo canasta, el atacante mirando hacia medio campo. Cuando él decida, arrancará hacia cualquiera de los obstáculos, dando así la salida al defensor.

El atacante utilizará los obstáculos como bloqueos indirectos para recibir mientras lee la defensa que le están realizando, para así, decidir la finalización más ventajosa.

Si el defensor le sigue por detrás, según recibe echará el balón al suelo para penetrar a canasta. Los mismo ocurriría si el defensor ataja por el lado contrario y le sigue, en cuyo caso la penetración se haría por el lado por el que ha venido, utilizando el obstáculo como un bloqueo directo. Sin embargo, si por lo contrario, el defensor le espera tras el bloqueo, este tendrá tiempo y espacio para ejecutar un buen FG.

La defensa también debe de ser consciente de las características técnico tácticas de su atacante, tratando de llevarle a la ejecución en la que menos cómodo se sienta o en mayor desventaja esté.

\section{ROTACIÓN:}

Fila de ataque a fila de defensa.

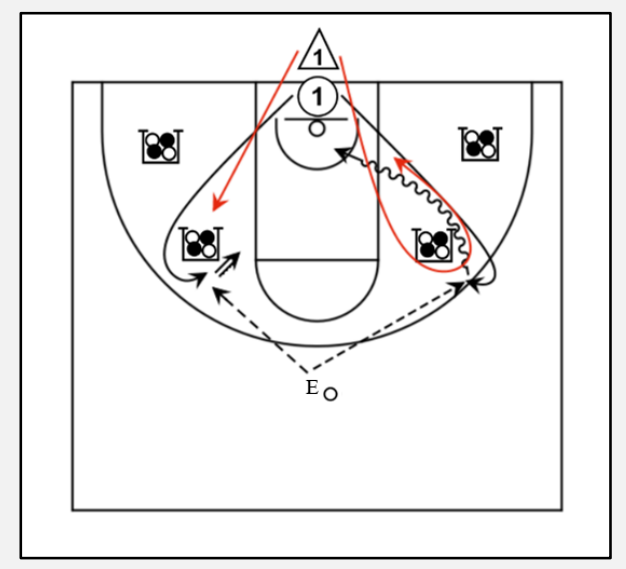




\section{FICHA N $\mathbf{N}^{\circ}$}

Objetivo/s primario/s: Fintas de recepción y líneas de pase.

Objetivo/s secundario/s: 2x2 y bloqueo directo.

\section{EJERCICIO:}

Cada pareja atacante debe realizar fintas de recepción (cortes en $\mathrm{V}$ o puertas atrás) para zafarse de sus defensores y recibir. Los defensores por su parte deben de ser muy agresivos sobre las líneas de pase para impedir o robar el pase.

En caso de que la recepción sea en el exterior, comenzaríamos un 2x2 obligando a realizar un bloqueo directo (diagrama 2).

\section{ROTACIÓN:}

De ataque a defensa y de defensa a la fila de ataque.

\section{MODIFICACIÓN MEDIANTE PREMISAS:}

Podemos aprovechar el ejercicio para trabajar las distintas opciones del bloqueo directo (pick and roll, pick and pop) y sus defensas (de segundo, tercero, push, cambio...) en función de lo que nos interese.
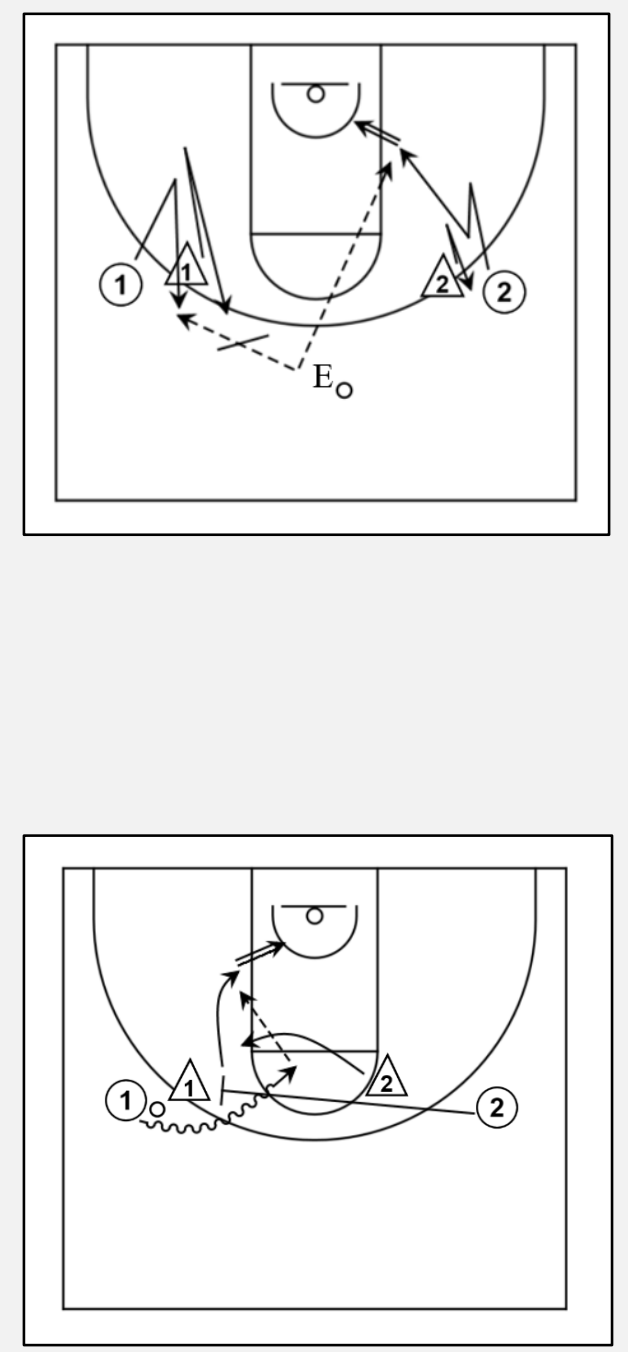


\section{FICHA N 5}

Objetivo/s primario/s: Ayudas defensivas.

Objetivo/s secundario/s: Ataque en superioridad.

\section{EJERCICIO:}

El atacante 1 dice a su defensor un lado, teniendo este que tocar dicho cono. El atacante aprovecha esa ventaja para iniciar el ataque, tras lo cual tiene que finalizar o buscar la finalización de un compañero.

Los defensores deben realizar las sucesivas ayudas para bloquear la ventaja atacante y dar tiempo al compañero a recuperar el desajuste defensivo.

Para el trabajo defensivo de ayudas en indispensable que los jugadores tengan interiorizado el concepto de lado fuerte y lado débil para trabajar de forma adecuada la defensa de las líneas de pase.

El ejercicio continúa hasta que los atacantes anoten o los defensores cojan el rebote.

\section{ROTACIÓN:}

En el sentido de las agujas del reloj dentro de la defensa y el ataque, es decir, de la posición 1 ofensiva a la 2 , a la 3 y a la 4 , tras lo cual se pasa a la posición 1 defensiva, a la 2 , a la 3 y a la 4 para volver a empezar de nuevo. 


\section{FICHA N ${ }^{\circ} 6$}

\section{Objetivo/s primario/s: Pase.}

Objetivo/s secundario/s: Moverse tras pase.

\section{EJERCICIO:}

Ejercicio de pase continúo.

Todos los jugadores realizan los mismos movimientos: pase al jugador del centro, desplazamiento al medio, recepción, pase al frente y desplazamiento a la siguiente fila.

\section{ROTACIÓN:}

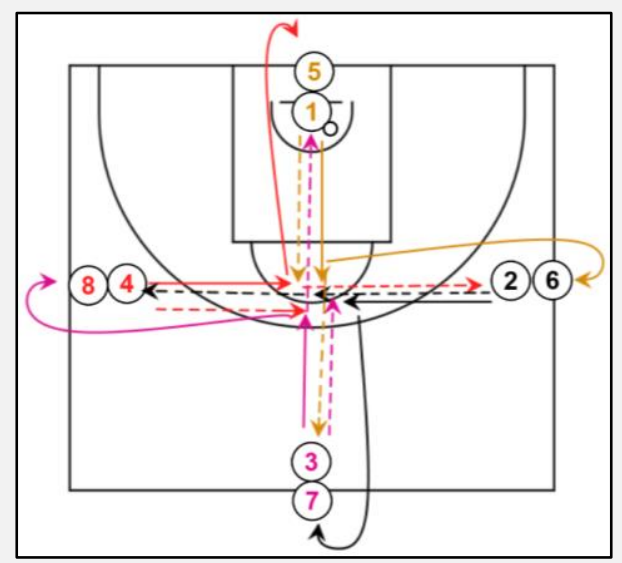

En el sentido de las agujas del reloj. 


\section{FICHA N 7}

Objetivo/s primario/s: FG tras pase.

Objetivo/s secundario/s:

\section{EJERCICIO:}

Cada jugador en ataque sale de un fondo hacia el contrario y antes de llegar a este, realiza un cambio de ritmo para recepcionar el balón y ejecutar el FG. El tirador va a por su rebote y se coloca en el fondo. El lanzamiento debe ejecutarse inmediatamente después del pase.

\section{ROTACIÓN:}

El jugador que lanza, cogerá su rebote y se colocará en la línea de fondo, para que el jugador que le ha pasado salga hacía el otro campo, y así de forma sucesiva.

\section{MODIFICACIÓN MEDIANTE PREMISAS:}

Premisa 1: Lanzamiento desde las zonas exteriores (5, 6 y 7$)$

Premisa 2: Lanzamiento desde las zonas interiores (2,3 y 4)

Premisa 3: Obligar al jugador en ataque a realizar el desplazamiento entre fondos antes de recibir en sprint, así entrenaremos el FG en condiciones de fatiga.
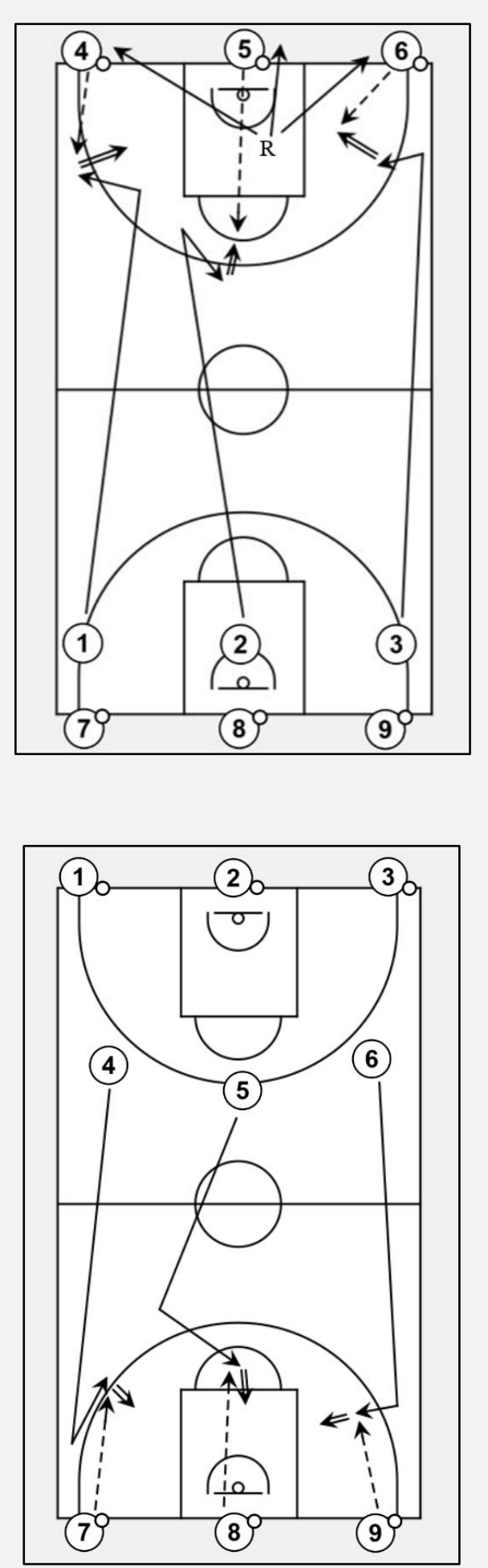


\section{FICHA No 8}

Objetivo/s primario/s: Pase interior y trabajo en el poste bajo.

Objetivo/s secundario/s: Dentro-fuera.

\section{EJERCICIO:}

$5 \times 5$ en el que se busca meter un balón interior para el 4 o el 5, tras lo cual buscará la jugada personal para encestar en la pintura.

Debemos insistir en el trabajo defensivo para evitar ese pase interior.

Diagrama2: en caso de no producirse el pase interior del diagrama 1, se invierte el balón para tratar de meter el pase al interior que ha realizado el bloqueo indirecto (5). Si no se pudiera realizar este tampoco, se seguiría la dinámica ya creada, realizando un bloqueo indirecto el 5 para el 4 y volviendo a empezar el proceso.

\section{ROTACIÓN:}

Si el equipo atacante consigue la canasta tras el pase interior sigue atacando, si no, pasa a defender.

Las posiciones son específicas, por lo que se mantienen.

\section{MODIFICACIÓN MEDIANTE PREMISAS:}

En lugar de buscar la finalización en el poste, podemos trabajar:

Premisa 1: dentro-fuera

Premisa 2: cortes para acompañar el 1x1 en el poste bajo

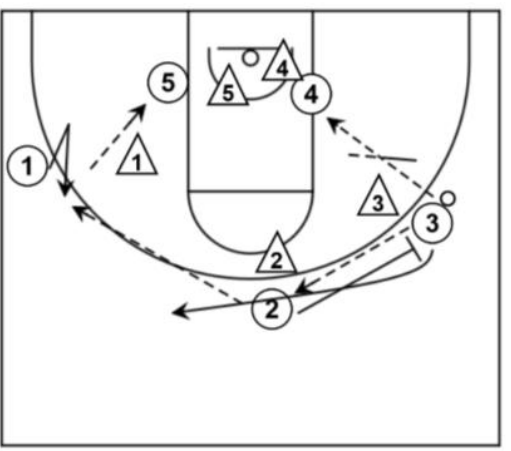




\section{FICHA No 9}

Objetivo/s primario/s: $1 \times 1$ y $1 \times 1$ con pasador.

Objetivo/s secundario/s:

\section{EJERCICIO:}

Dividimos cada campo de ataque en dos partes. El atacante con balón debe atacar al aro en un 1x1 dentro de esa media cancha.

Puede tratar de realizar una jugada personal o utilizar al pasador para generarse un tiro exterior o una puerta atrás.

\section{ROTACIÓN:}

Cada grupo de jugadores rota dentro de su media cancha. De ataque a defensa, de defensa a la fila de pasadores, y de la fila de pasadores al ataque.

\section{MODIFICACIÓN MEDIANTE PREMISAS:}

Premisa 1: Limitar el número de botes para obligar a un ataque más vertical.

Premisa 2: Limitar la finalización según zona. Para las zonas exteriores y la zona 4 tiene que finalizarse en FG tras pase. En las zonas 1 y 2 o 1 y 3 debe finalizarse en jugada personal. 


\section{FICHA N $\mathbf{N}^{\mathbf{0}} 10$}

Objetivo/s primario/s: 1x1 y dribling.

Objetivo/s secundario/s: Desplazamiento defensivo.

\section{EJERCICIO:}

Trabajo de 1x1 hasta medio campo a través de cross over, reversos, fintas u otros recursos técnicos de cambio de mano.

El defensor debe realizar un buen desplazamiento lateral defensivo.

Una vez superando el medio campo se realizará un ataque en 1x1 muy vertical buscando el aro con rapidez. En un lado este trabajo se hace a través de una jugada personal y en el otro con la posibilidad de utilizar un pasador.

\section{ROTACIÓN:}

Ejercicio por parejas. Cada miembro de la pareja da una vuelta entera atacando y luego cambia a defensa.

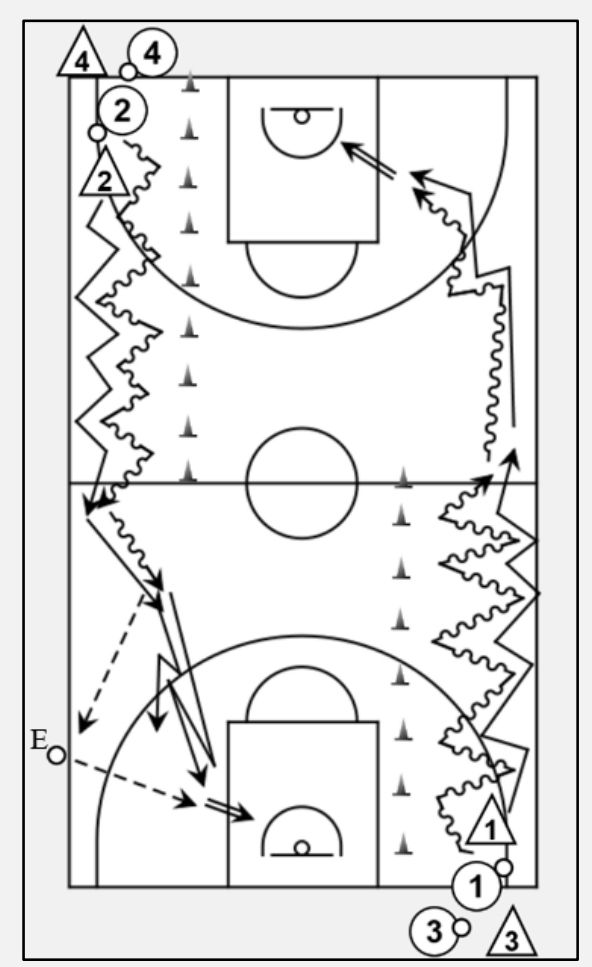


FICHA No 11

Objetivo/s primario/s: 1x1 y recuperación defensiva.

Objetivo/s secundario/s: Bote de velocidad.

\section{EJERCICIO:}

Los jugadores se colocan por parejas en filas enfrentadas en el medio campo. Cuando le toca a una pareja, comienzan a realizarse pases de pecho de forma continua hasta que en el entrenador realice una señal acústica. Entonces, el jugador con la posesión del balón deberá decidir a cuál de las dos canastas atacar y penetrar en bote de velocidad para finalizar antes de que recupere el defensor.

El ejercicio continúa hasta la canasta o rebote defensivo.

\section{ROTACIÓN:}

Ejercicio por parejas de las mismas características o posiciones.

Tras finalizar vuelven a sus respectivas filas.

\section{MODIFICACIÓN MEDIANTE PREMISAS:}

Premisa 1: permitir fintas de salida o cambios de dirección.

Premisa 2: limitar el número de botes.
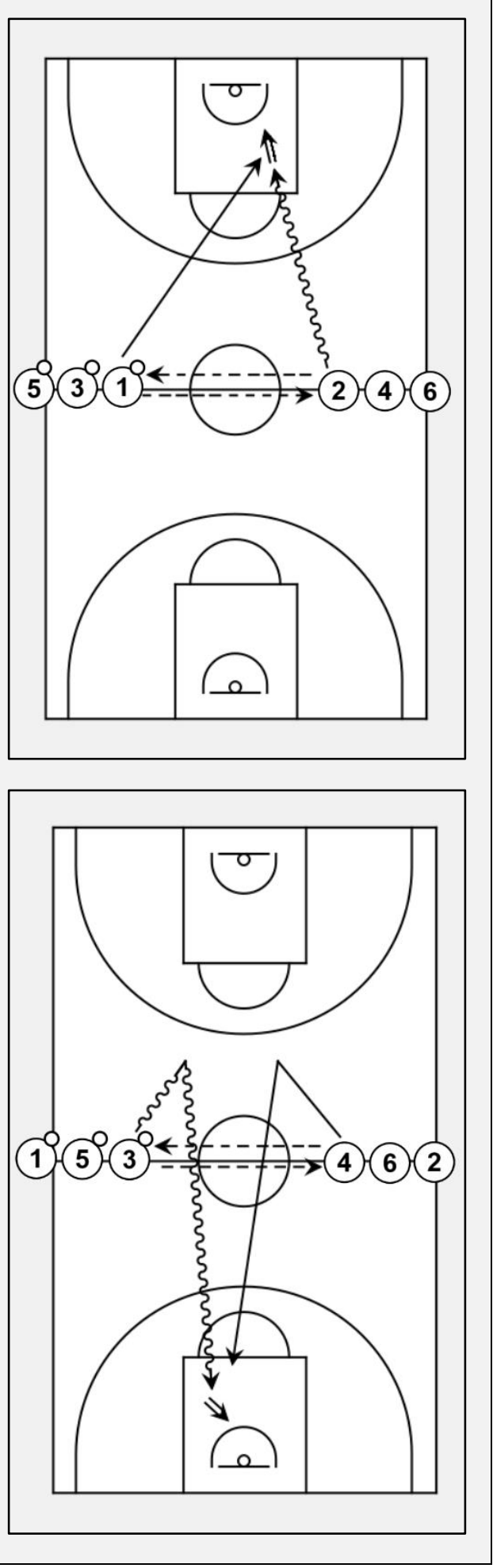


\section{FICHA $\mathbf{N}^{\circ} 12$}

Objetivo/s primario/s: $2 \times 1$ y bloqueo directo.

Objetivo/s secundario/s: Pick and roll y pick and pop.

\section{EJERCICIO:}

Práctica del bloqueo directo donde se aprovecha la superioridad numérica para clarificar los conceptos de la ejecución del pick and roll (diagrama 1) y pick and pop (diagrama 2).

\section{ROTACIÓN:}

Rotación entre filas en el sentido de las agujas del reloj.

\section{MODIFICACIÓN MEDIANTE PREMISAS:}

Una vez claros los conceptos y ejecución, podemos dar un paso en cuanto a nivel de dificultad introduciendo un segundo defensor (diagrama3), aprovechando así para también trabajar la defensa del bloqueo directo.

Buscamos que los jugadores sean capaces de leer e interpretar la jugada, ya sea en ataque o en defensa, para responder de la forma más adecuada.
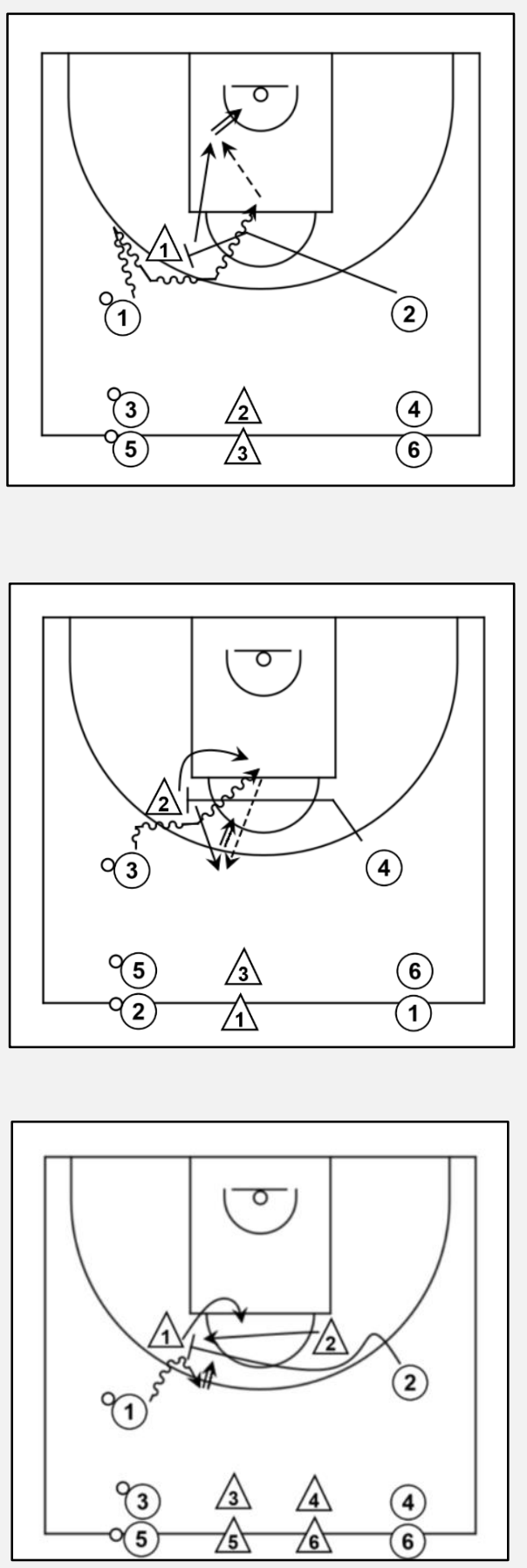
FICHA No 13

Objetivo/s primario/s: $2 \times 2$ y balance defensivo.

Objetivo/s secundario/s: Bloqueo directo.

\section{EJERCICIO:}

Una vez que el balón llega al segundo atacante comienza el 2x2 libre desde la posición de triple amenaza. En el caso de que el balance defensivo no sea rápido y se generé una ventaja para el atacante, este podrá aprovecharla.

\section{ROTACIÓN:}

Entre filas en el sentido de las agujas del reloj.

\section{MODIFICACIÓN MEDIANTE PREMISAS:}

El 2x2 puede realizarse de forma libre o limitándolo mediante premisas: Premisa 1: Al menos un bloqueo directo, tratando de optar a través de la lectura de la defensa por la opción más ventajosa, ya sea un FG tras salida del bloqueo, penetrar en dribling, pick and roll $u$ otras opciones.

*Ante un bloqueo directo se pueden realizar distintas defensas: pasando de segundo, como tercero, como cuarto (push), con cambio entre defensores, negando el bloqueo, realizando un flash o un trap. Estas defensas no deben elegirse de forma aleatoria, si no en función de las características de los jugadores de los que se disponen y/o de los jugadores contra los que nos enfrentamos.

Más allá del tipo de defensa que queramos trabajar, la clave ante la defensa de un bloqueo directo siempre será la comunicación entre los defensores, no pudiendo ser remplazada por simples automatismos.

Premisa 2: Limitar el tiempo de posesión o el número de pases en ataque para trabajar el control de estrés. 
FICHA No 14

Objetivo/s primario/s: $2 \times 2$ libre y balance defensivo.

Objetivo/s secundario/s:

\section{EJERCICIO:}

En el diagrama 1 y 2 se ven distintas disposiciones en función de donde nos interese que se inicie el $2 \times 2$. Tras los pases y el balance defensivo comenzaría el ataque.

El equipo atacante debe hacerlo hasta conseguir canasta, en cuyo caso volverán atacar en $2 \times 2$ hacia la canasta contraria (ejemplo en diagrama 3 , en rojo los movimientos defensivos). Si el balón es robado o la defensa coge el rebote, será la pareja defensora la que ataque en $2 \times 2$ hacia la canasta contaría.

\section{ROTACIÓN:}

Entre filas en el sentido de las agujas del reloj.

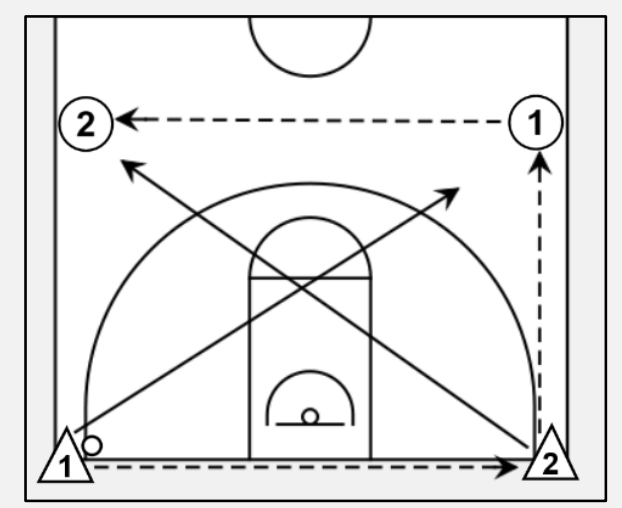

\section{MODIFICACIÓN MEDIANTE PREMISAS:}

Si queremos trabajar el bloqueo directo:

Premisa 1: En ambos ataques debe producirse un bloqueo directo.

Si queremos incidir de forma más concreta sobre el bloqueo de rebote:

Premisa 2: El jugador que lucha por el rebote defensivo debe bloquear el rebote al atacante de tal forma que el balón bote dos veces sin que este pueda llegar a tocarlo.

En el ataque de campo entero podemos introducir premisas limitando el bote o número de pases en busca de una mayor verticalidad del mismo.

Premisa 3: No se puede botar

Premisa 4: No se puede botar y máximo 5 pases.

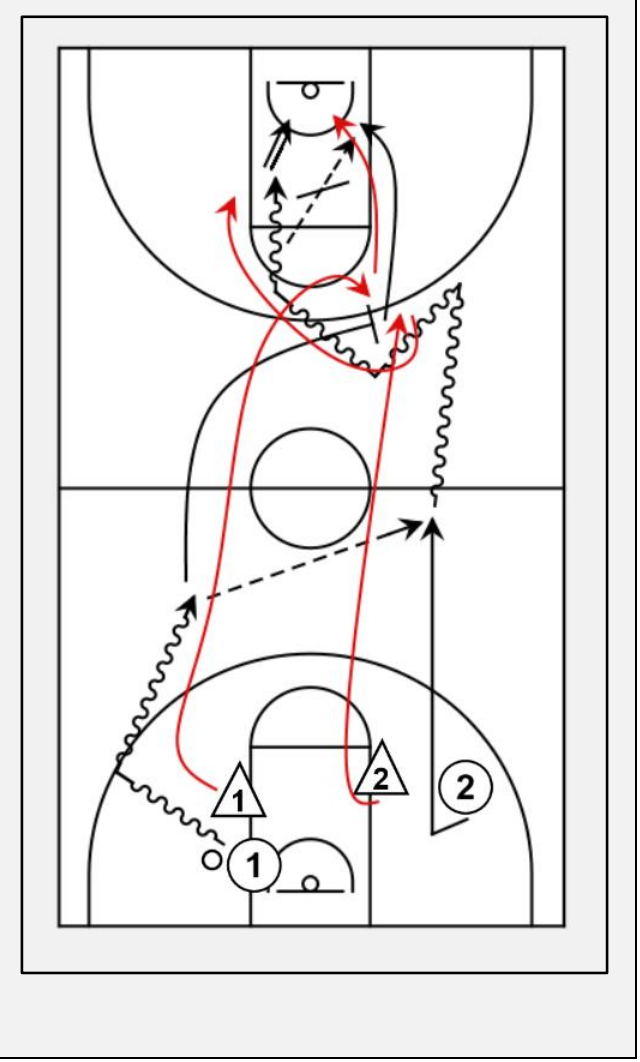




\section{FICHA $\mathbf{N}^{\circ} 15$}

Objetivo/s primario/s: $2 \times 2$ y defensa en tandem.

Objetivo/s secundario/s: Balance defensivo.

\section{EJERCICIO:}

El inicio lo marca la arrancada en dribling del atacante con balón, yendo cada jugador a superar su cono para ocupar su posición en el campo.

Desde ahí parte el 2x2 con ataque libre y defensa en tándem.

\section{ROTACIÓN:}

En el sentido de las agujas del reloj.

\section{MODIFICACIÓN MEDIANTE PREMISAS:}

Podemos obligar a realizar un bloqueo directo, limitar el número de pases o de botes, incluso no permitir el bote en función de lo que busquemos trabajar.
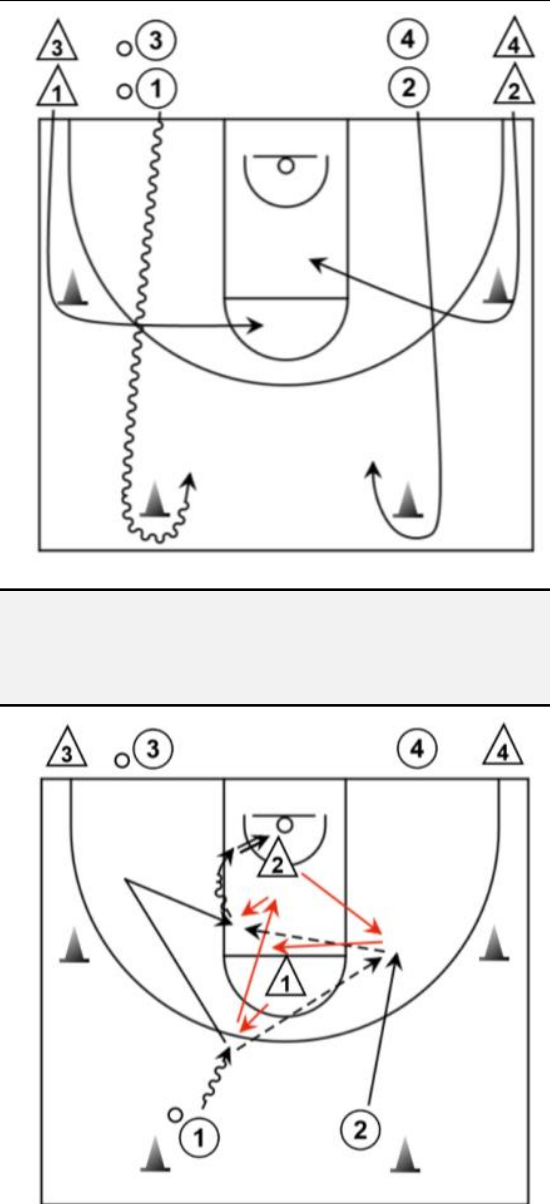
FICHA $\mathbf{N}^{\circ} 16$

Objetivo/s primario/s: $3 \times 0$ y $1 \times 2$.

Objetivo/s secundario/s: Trap.

\section{EJERCICIO:}

Ataque trenzado en el que jugador que finaliza el $3 \times 0$ atacará en $1 \times 2$ hacia el campo contrario. La defensa debe tratar de aprovechar su superioridad llevando al atacante hacia la línea de banda para poder realizar un buen trap e impedir el ataque.

\section{ROTACIÓN:}

En el sentido de las agujas del reloj.

\section{MODIFICACIÓN MEDIANTE PREMISAS:}

Se trata de un ejercicio muy común en el que se pueden trabajar todo tipo de superioridades o inferioridades.

Se basa en un ataque trenzado, ya sea 3, 4 o 5 x 0 para volver con superioridad o inferioridad en el ataque.

Por ejemplo podríamos modificar el 1x2 y convertirlo en un $2 \times 1$ donde trabajemos el contrataque, pudiendo limitar el número de botes, de pases, etcétera.
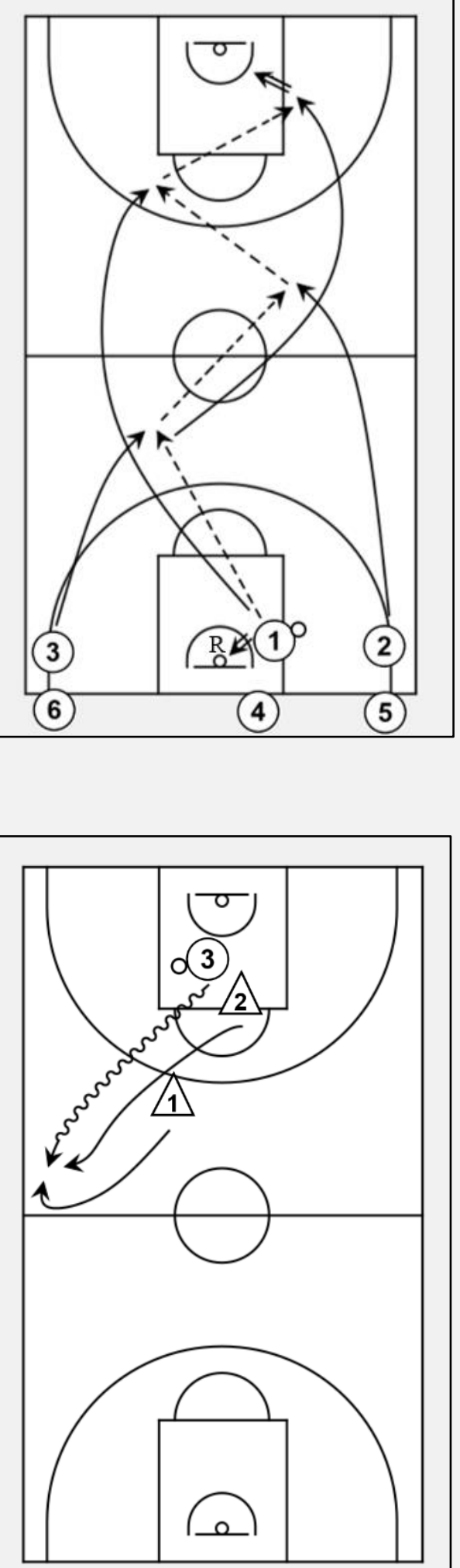
FICHA No 17

Objetivo/s primario/s: $3 \times 2$ y defensa en tándem.

Objetivo/s secundario/s:

\section{EJERCICIO:}

Contraataque $3 \times 2$ en trenzas donde se debe finalizar rápidamente.

La defensa debe de ser muy comunicativa.

\section{ROTACIÓN:}

La pareja defensora se cambia cada cierto tiempo o número de ataques.

La rotación entre filas se hace en el sentido de las agujas del reloj.

\section{MODIFICACIÓN MEDIANTE PREMISAS:}

Premisa 1: No se permite el bote

Premisa 2: No se permite el bote y máximo 5 pases.

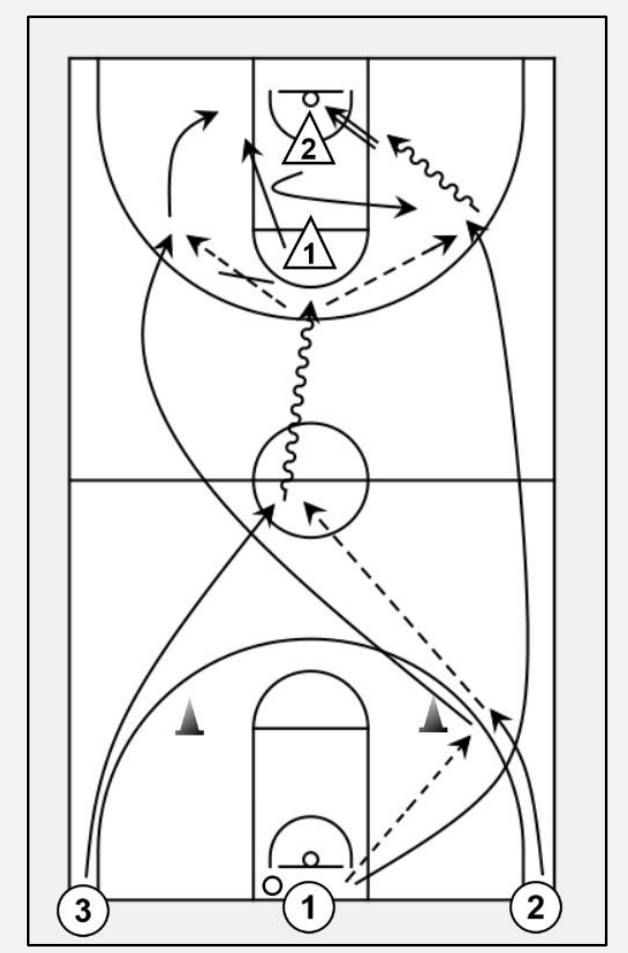


FICHA $\mathbf{N}^{\circ} 18$

Objetivo/s primario/s: $3 \times 2$ continuo (Once).

Objetivo/s secundario/s: Defensa en tándem.

\section{EJERCICIO:}

Ataque continuo rápido en superioridad.

La defensa en tándem debe comunicarse constantemente para ir remplazando sus posiciones según salgan al balón.

\section{ROTACIÓN:}

El atacante que enceste, o el defensor que robe o coja el rebote, atacará en el campo contrario junto con los dos atacantes de las filas exteriores. Los defensores tendrán prioridad para ponerse en las filas exteriores tras la defensa, uno a cada una. En el caso de los atacantes, dos se quedarán para la defensa de la jugada siguiente.

\section{MODIFICACIÓN MEDIANTE PREMISAS:}

Nos interesa la verticalidad y rapidez en el ataque para poder aprovechar la superioridad existente, por lo que todas las premisas irán en esa línea, ya sea limitación temporal, de bote o número de pases.
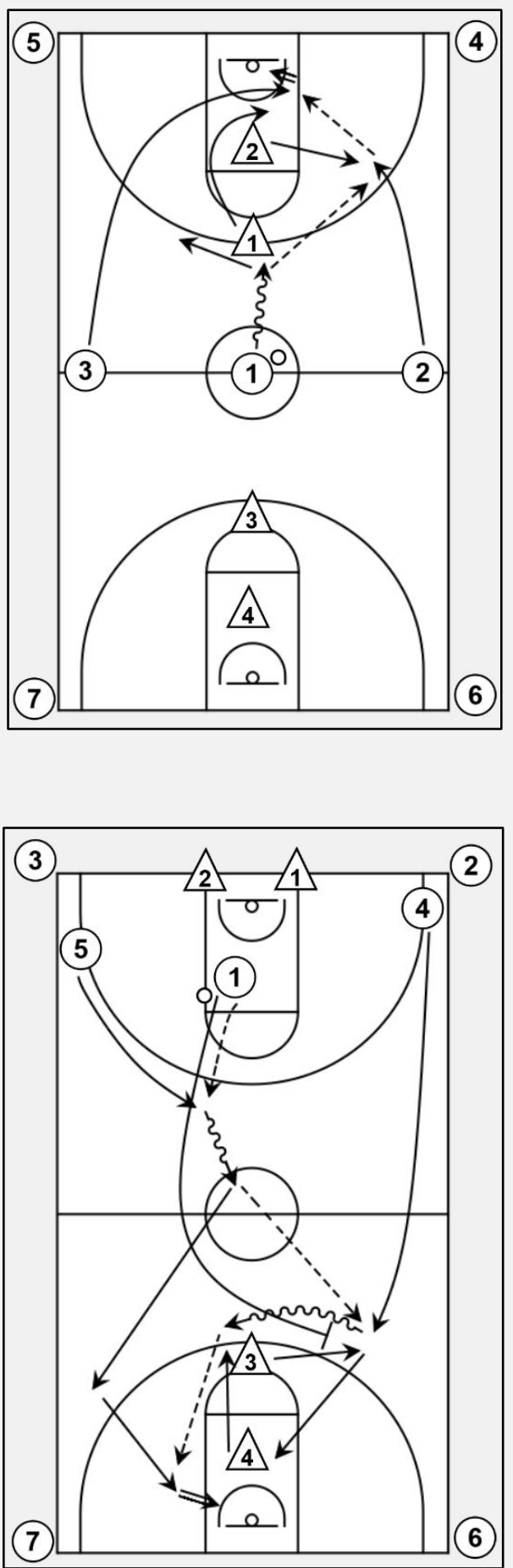


\section{FICHA N ${ }^{0} 19$}

\section{Objetivo/s primario/s: $3 \times 3$.}

Objetivo/s secundario/s: Extra pass.

\section{EJERCICIO:}

Trabajo de $3 \times 3$ en el cual buscamos conseguir la situación más ventajosa para el FG a través del extra pass o pase extra.

El ataque es libre, pudiendo utilizarse todo tipo de fintas, puertas atrás, bloqueos indirectos $\mathrm{u}$ otros recursos ofensivos.

\section{ROTACIÓN:}

En el sentido de las agujas del reloj tras ciclo ataque-defensa. 


\section{FICHA N 20}

Objetivo/s primario/s: $3 \times 3$, pasar y cortar.

Objetivo/s secundario/s: Defensa de líneas de pase.

\section{EJERCICIO:}

Ejercicio de $3 \times 3$ a través del pase y el corte. Los jugadores no deben utilizar ningún otro recurso más que las fintas para la recepción y los cortes.

Se trata de pasar y cortar para generar una opción de pase y finalización a la vez que el otro compañero se mueve en busca del espacio libre para acompañar la penetración o generar otra opción de pase, continuando así con el juego.

En este ejercicio es muy importante el trabajo defensivo de las líneas de pase.

En los diagramas se muestran ejemplos de los posibles movimientos en ataque.

\section{ROTACIÓN:}

En el sentido de las agujas del reloj tras ciclo ataque-defensa.

\section{MODIFICACIÓN MEDIANTE PREMISAS:}

Para incidir aún más en la importancia del pasar y cortar, podemos:

Premisa 1: Limitar a uno o dos botes cada vez que se recibe el balón.

Premisa 2: No permitir el bote. 
FICHA No 21

Objetivo/s primario/s: $3 \times 3$.

Objetivo/s secundario/s: Según premisas.

\section{EJERCICIO:}

Consiste en un $3 \times 3$ libre continuo.

\section{ROTACIÓN:}

Si el equipo atacante mete canasta seguirá atacando en el otro campo, si no, se quedarán en ese campo para la siguiente defensa y será el trio que defendía quien ataque en el lado contrario.

\section{MODIFICACIÓN MEDIANTE PREMISAS:}

Podemos limitar el 3x3 libre en función del objetivo que deseemos trabajar. Podemos obligar a realizar bloqueos directos, indirectos, aclarados, jugar dentro fuera o cualquier otra opción a través de la inclusión de premisas.

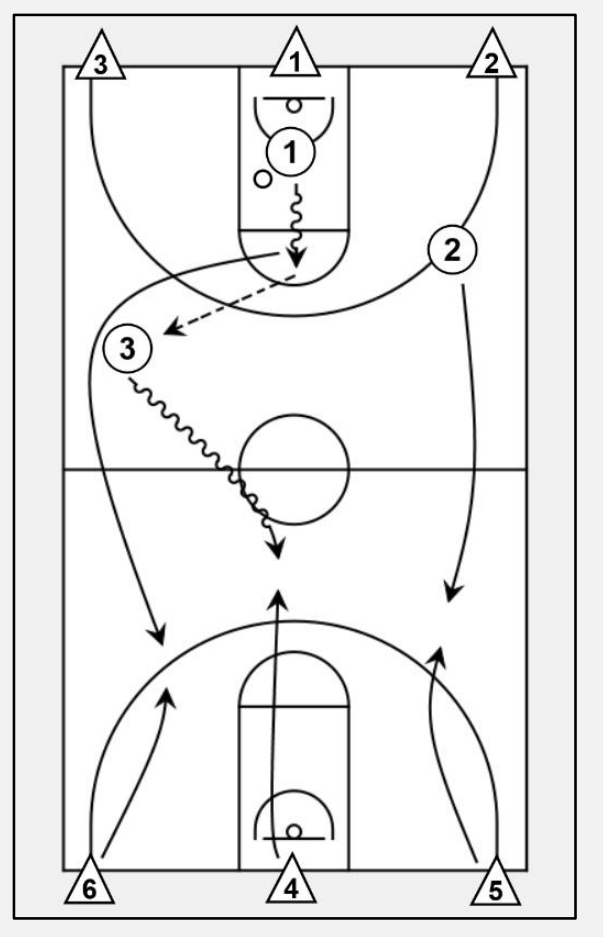




\section{FICHA No 22}

Objetivo/s primario/s: Pasar y cortar, defensa líneas de pase.

Objetivo/s secundario/s: Bloqueos indirectos.

\section{EJERCICIO:}

El equipo que inicie con el balón debe conseguir realizar 10 pases entre sus jugadores antes de poder atacar. El bote no está permitido, por lo que los jugadores deberán pasar y moverse para generar opciones de continuidad.

En caso de que el balón salga de banda o fondo, y el equipo mantenga la posesión, el conteo de pases se reiniciará.

Si el equipo defensor se hiciera con el balón, sería el quien debe realizar los 10 pases para poder atacar.

Debemos insistir a los atacantes en la necesidad de las fintas de recepción, en el movimiento tras pase para la ocupación de espacios libres, y la utilización del bloqueo indirecto como recursos para generar ventajas. Por su parte, el equipo defensor debe ser muy agresivo en las líneas de pase para conseguir el robo. 
FICHA No 23

Objetivo/s primario/s: Juego libre con premisas.

Objetivo/s secundario/s: Según premisas.

\section{EJERCICIO:}

El juego libre nos dará la posibilidad de ver la comprensión e interiorización de los conceptos que hemos trabajado, pudiendo introducir premisas para trabajar aquellos que consideremos que aún no están todo lo claro que deberían.

El objetivo final debe de ser generar jugadores totalmente autónomos en la toma de decisiones, sabiendo leer las situaciones y gozando de recursos suficientes para poder superarlas.

\section{FICHA No 24}

Objetivo/s primario/s: Contraataque con zonas defensivas.

Objetivo/s secundario/s:

\section{EJERCICIO:}

Contraataque en trenzas con zonas defensivas.

\section{ROTACIÓN:}

La rotación entre filas se hace según las agujas del reloj.

Los defensores se cambian cada cierto tiempo o número de ataques.

\section{MODIFICACIÓN MEDIANTE PREMISAS:}

Premisa 1: No se permite el bote.

Premisa 2: Máximo 5 pases.

Premisa 3: Aumento a dos defensores por zona.

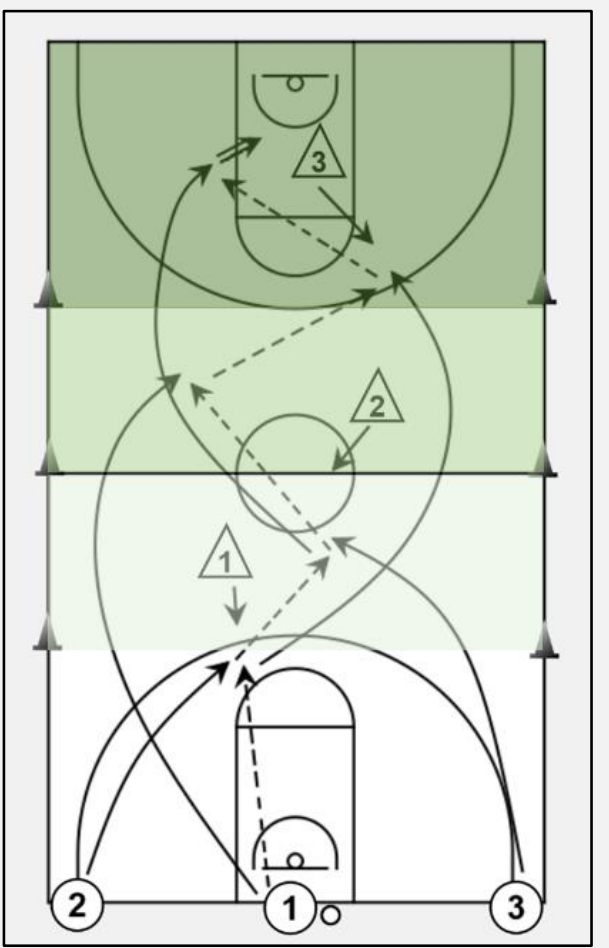




\section{FICHA N $\mathbf{N}^{\circ} 25$}

Objetivo/s primario/s: Pase largo para contraataque.

Objetivo/s secundario/s:

\section{EJERCICIO:}

Ambos diagramas representan ejercicios de ataque en últimos segundos o contraataque mediante el uso del pase largo o de béisbol.

En el primer diagrama los jugadores de las filas centrales se colocan bajo canasta, lanzan el balón a tablero (señal de salida para los jugadores de la banda), saltan para recoger el rebote, y pivotan sobre un pie para realizar un pase en largo al jugador que corre por la banda para que finalice.

En el diagrama dos se trabaja con unos pases previos al pase largo.

\section{ROTACIÓN:}

Rotación entre filas en el sentido de las agujas del reloj.
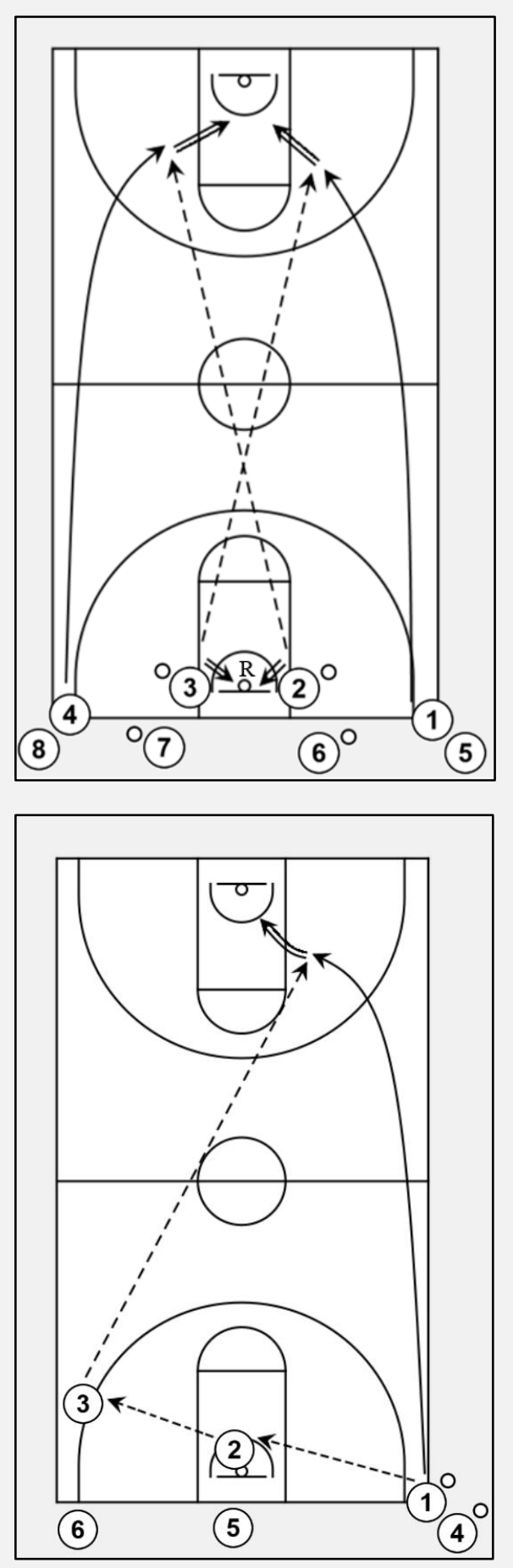


\section{FICHA N 26}

Objetivo/s primario/s: Presión todo el campo y trap.

Objetivo/s secundario/s:

\section{EJERCICIO:}

Ejercicio de presión en todo el campo en busca de un trap. Por su parte, el equipo atacante debe mejorar la salida de presión.

En el primer diagrama se observan las mejores zonas para realizar el trap, pues se utilizan las líneas del campo como defensores.

En el caso de las esquinas, el atacante se ve encerrado por las líneas de fondo, banda y los dos defensores.

En cuanto al medio campo hay dos opciones en función del objetivo. Por un lado, antes de que sobrepase la mitad del campo, cerrándolo así con la línea de banda y bloqueando con la defensa el avance hacia adelante y hacia el centro del campo, obligándolo a retroceder y por tanto posiblemente a superar los 8 segundos. Por otro lado, la opción de realizarlo tras superar la mitad del campo, donde quedaría totalmente encerrado por las líneas de banda, medio campo y los dos defensores.

En los otros dos diagramas se observan dos defensas para trap tratando de agotar los 8 segundos. Es importante que el defensor 1 nunca deje ganar medio al atacante con balón, y que los defensores 4 y 5 eviten el pase en largo para superar la presión.

\section{ROTACIÓN:}

Tras varias repeticiones y correcciones, cambio entre equipo atacante y defensor. 


\section{MODIFICACIÓN MEDIANTE PREMISAS:}

En el caso del ataque, podemos introducir un poste repetidor $u$ otras estrategias en función de las características de nuestro equipo para mejorar la salida de balón.

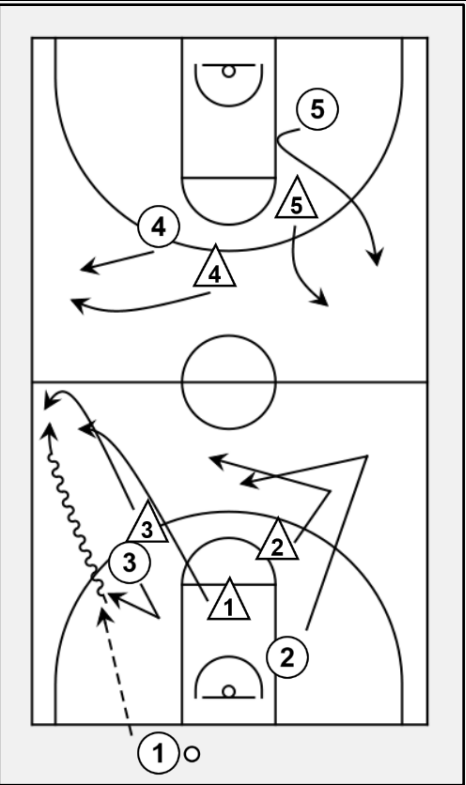

\section{FICHA No 27}

Objetivo/s primario/s: Ataque en últimos segundos (cuernos).

Objetivo/s secundario/s: Bloqueo directo y ocupación de espacios.

\section{EJERCICIO:}

Ataque en últimos segundos basado en un doble bloqueo para el atacante con balón y tiradores abiertos para generar espacio y una opción de pase a la penetración.

Por su parte la defensa debe comunicarse para tratar de anular la ventaja de los bloqueos directos y conseguir impedir un ataque cómodo. Los defensores 2 y 3 deben estar pendientes de sus compañeros por si hiciera falta realizar una ayuda defensiva.

Debemos trasmitir a los jugadores la importancia del tiempo de posesión para controlar el timing en el uso de los recursos u opciones ofensivas.

\section{ROTACIÓN:}

Se trata de un ejercicio con roles específicos, por lo que rotaremos entre ataque y defensa según posiciones.
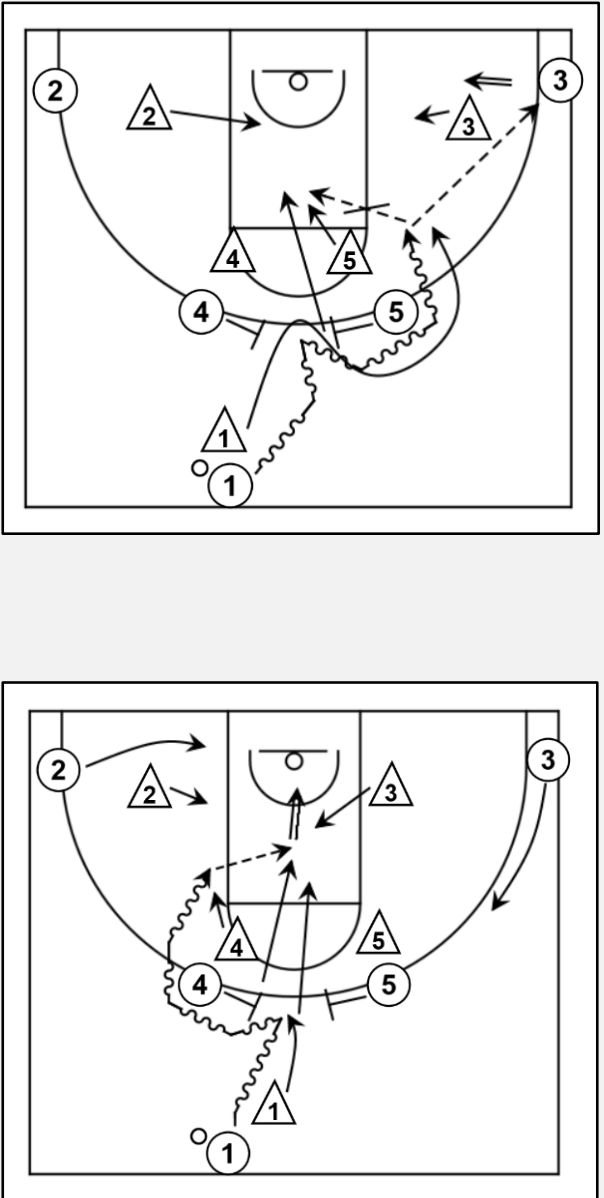


\section{FICHA $\mathbf{N}^{\circ} 28$}

Objetivo/s primario/s: Ataque en últimos segundos (aclarado).

Objetivo/s secundario/s: Bloqueo directo y ayudas defensivas.

\section{EJERCICIO:}

En esta ocasión se trabaja un aclarado (diagrama 1) o un aclarado con bloqueo directo (diagrama 2). El resto de los jugadores atacantes siempre deben ocupar los espacios para acompañar la penetración y ofrecerse ante un posible pase.

El equipo defensor deberá mantener una buena comunicación para poder realizar las ayudas defensivas en caso de ser necesario.

\section{ROTACIÓN:}

Se trata de un ejercicio con roles específicos, por lo que rotaremos entre ataque y defensa según posiciones.

\section{MODIFICACIÓN MEDIANTE PREMISAS:}

La segunda opción, aclarado con bloqueo directo, es una buena opción para trabajar las distintas posibilidades para la defensa del bloqueo directo, sobre todo la negación, pues en una situación de ataque en últimos segundos en la que se busca un bloqueo, es muy desconcertante que la defensa te lo imposibilite, pudiendo con ello desestabilizar el ataque. 


\section{FICHA No 29}

Objetivo/s primario/s: Ataque en últimos segundos campo entero.

Objetivo/s secundario/s: Poste repetidor.

\section{EJERCICIO:}

Ejercicio de salida de balón en últimos segundos ante una posible presión. En este ejercicio trabajamos los cortes en $\mathrm{V}$ para recibir, además de trabajar con un poste repetidor para la salida de balón o el bloqueo directo sobre el hombre con balón si fuera necesario.

Buscamos trabajar la ocupación de espacios para ofrecer opciones de pase al hombre con balón, llegando así al campo de ataque lo más rápido y en las mejores condiciones posibles.

Los diagramas muestran ejemplos, pero en este ejercicio lo más importante es que los jugadores interioricen la ocupación de espacios para generar líneas de pase.

\section{ROTACIÓN:}

Se trata de un ejercicio con roles específicos, por lo que rotaremos entre ataque y defensa según posiciones.
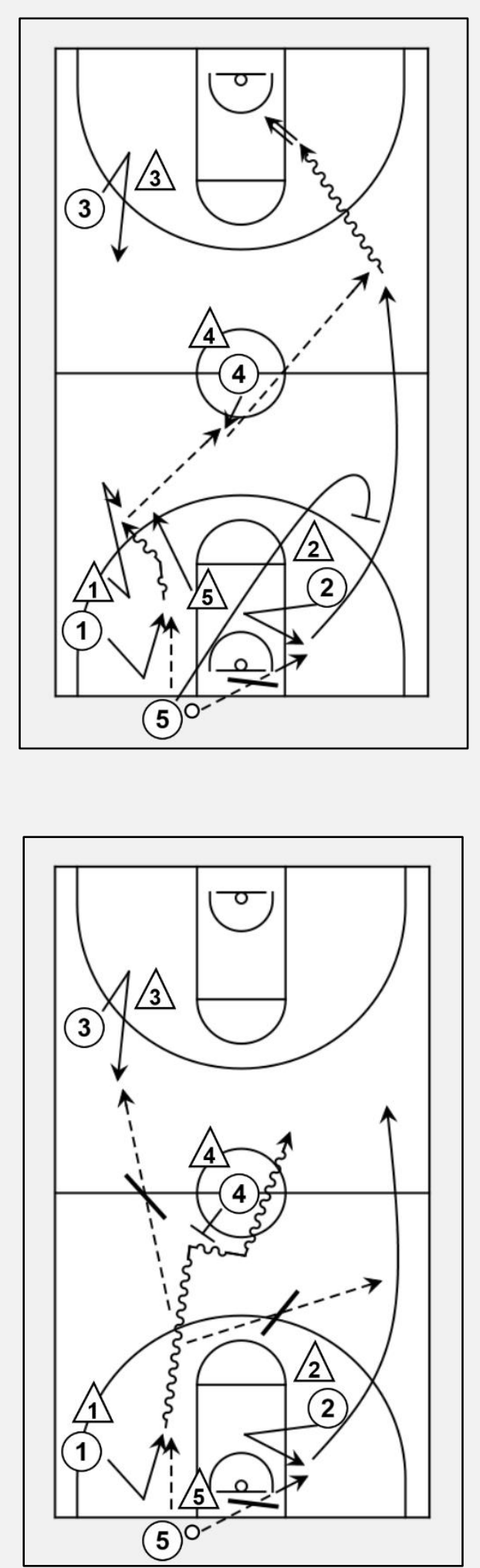


\section{FICHA No 30}

Objetivo/s primario/s: Preparación física (circuito).

\section{Objetivo/s secundario/s:}

\section{EJERCICIO:}

Se parte de un skipping estático hasta la señal del entrenador. Iniciamos con multisaltos y sprint al acabar estos hasta medio campo.

Continuamos con desplazamiento defensivo entre los conos. Al llegar a línea de fondo, skipping bajo con los aros o escalera de coordinación si disponemos de ella, y para finalizar cruzamos al campo de ataque para recibir y lanzar tras un bloqueo indirecto. Cogemos el rebote y se lo devolvemos al entrenador. Una vez acabado, volvemos por fuera del campo al inicio del circuito.

\section{ROTACIÓN:}

Circuito circular.

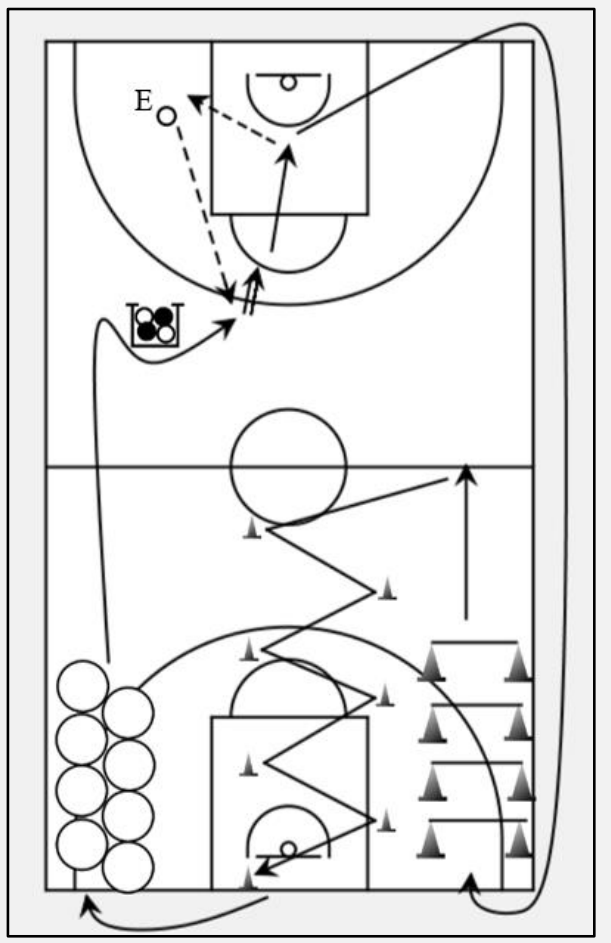




\section{FICHA No 31}

Objetivo/s primario/s: Preparación física y dribling (1).

Objetivo/s secundario/s: FG tras pase.

\section{EJERCICIO:}

En este circuito unimos la preparación física con la mejora en el manejo del balón.

Iniciamos con un zig-zag a alta velocidad con distintos cambios de mano, al llegar al medio campo realizamos un desplazamiento lateral en bote hasta la banda, donde comenzamos un bote de velocidad hasta línea de fondo.

Recuperamos aire con un desplazamiento en bote relajado hasta volver a iniciar un intenso zigzag en bote con cambios de mano. Una vez superando el medio campo, buscamos al entrenador para pasarle el balón, cortar en $\mathrm{V}$, recibir y lanzar. Este lanzamiento se produce en unas condiciones reales de fatiga, lo que nos ayudará a mejorar el FG para situaciones reales de partido.

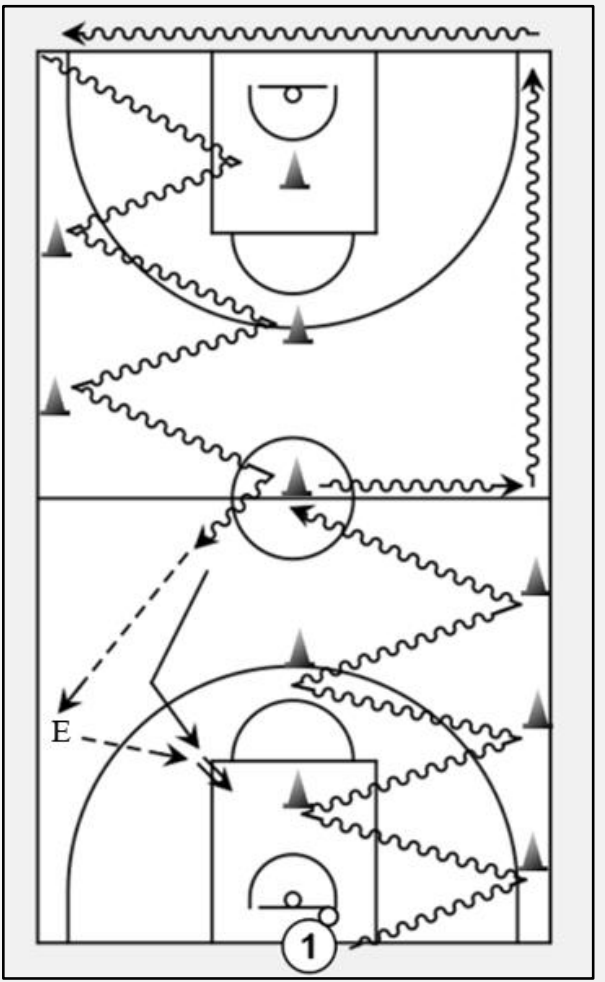

\section{ROTACIÓN:}

Circuito circular.

\section{MODIFICACIÓN MEDIANTE PREMISAS:}

Premisa 1: Sustituir un cono en cada uno de los zig-zag por un defensor muy activo en el trabajo de manos. Así obligaremos a realizar los cambios de mano técnicamente bien. 


\section{FICHA No 32}

Objetivo/s primario/s: Preparación física y dribling (2).

Objetivo/s secundario/s:

\section{EJERCICIO:}

Los jugadores con balón inician con una escalera de coordinación en bote, seguida de un bote en velocidad hasta la altura del aro donde realizan un pase a las filas laterales para colocarse posteriormente en ellas.

La fila lateral recibe y sale en dribling con cambios de mano y ritmo para finalizar en la cancha contraria y colocarse, tras coger el rebote, en la fila inicial.

\section{ROTACIÓN:}

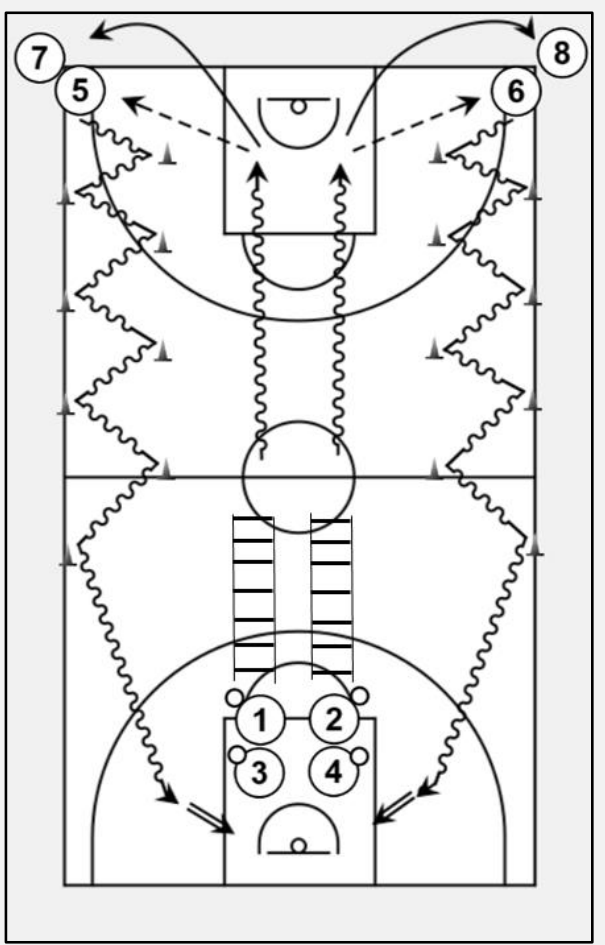

Circuito circular.

\section{FICHA No 33}

Objetivo/s primario/s: Preparación física (líneas).

\section{Objetivo/s secundario/s:}

\section{EJERCICIO:}

Los jugadores se sitúan en la línea de fondo, y tras la señal del entrenador corren hasta la primera línea, la tocan con la mano, y vuelven hasta la línea de fondo marcha atrás, tocan con la mano, y corren hacia la siguiente línea para seguir con el proceso hasta finalizar.

Las líneas a tocar están a la altura del tiro libre, zona más alejada del triple, medio campo, zona más alejada del triple del lado campo contario, tiro libre y fondo del lado contario.

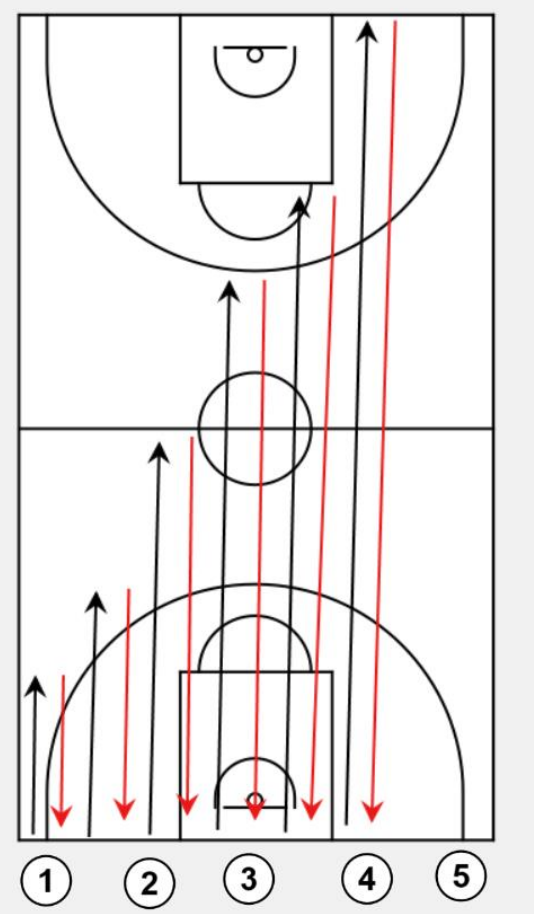




\section{FICHA N $\mathbf{N}^{0} 34$}

Objetivo/s primario/s: Preparación física (trenzas).

Objetivo/s secundario/s:

\section{EJERCICIO:}

Ataque en trenzas de $5 \times 0$ continuo donde se deben conseguir 10 canastas de forma consecutiva.

En caso de fallar alguna de las finalizaciones el marcador volverá a 0. La velocidad de las transiciones debe ser alta y con finalizaciones agresivas.

Mientras un grupo de 5 lo está realizando, el resto de jugadores pueden estar realizando ejercicios físicos como planchas, flexiones, lumbares....

\section{ROTACIÓN:}

Tras conseguir las 10 finalizaciones se cambiará de quinteto. 


\section{FICHA N $\mathbf{N}^{0} 35$}

Objetivo/s primario/s: Preparación física.

Objetivo/s secundario/s: Pase y finalización.

\section{EJERCICIO:}

El jugador con balón se desplaza mediante pases con las tres filas para finalizar en el campo contrario. Los pasadores cruzan corriendo el campo para volver a colocarse (el del medio cruza al otro lado y los laterales cruzan en X) y se repite la acción en el otro campo.

\section{ROTACIÓN:}

De la fila de balón a la primera posición de pasador, luego a la segunda, a la tercera, y de vuelta a la inicial.
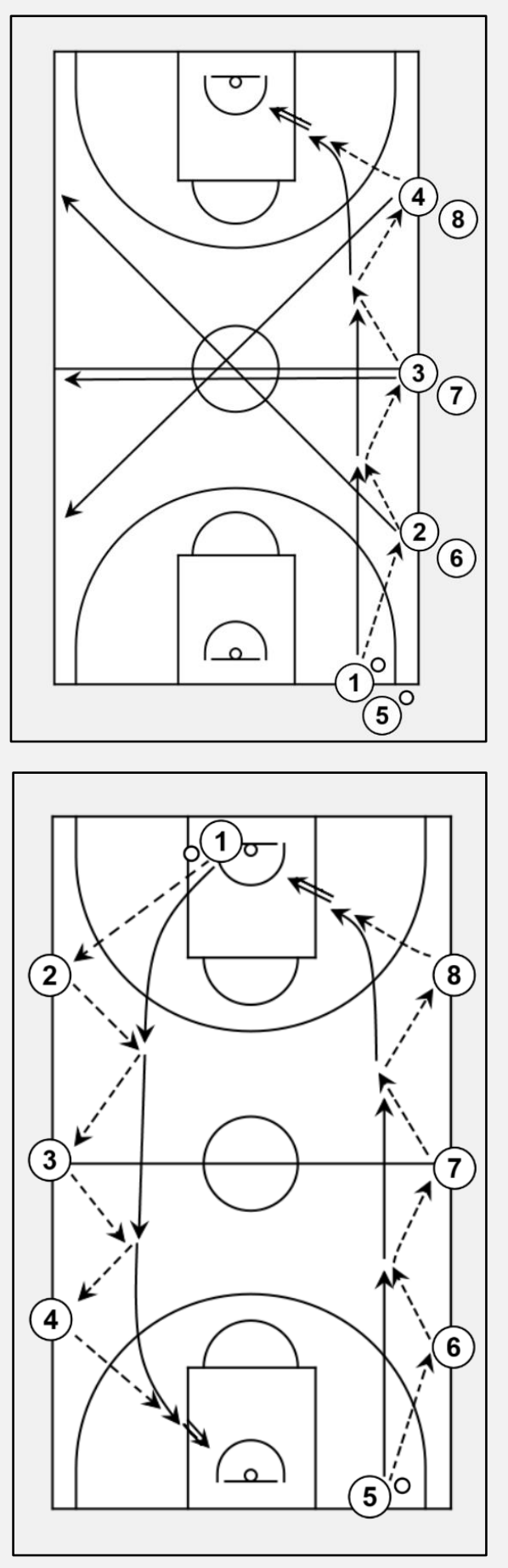


\section{FICHA No 36}

Objetivo/s primario/s: Preparación física (palmeos).

Objetivo/s secundario/s:

\section{EJERCICIO:}

Los jugadores se colocan en fila mirando a la canasta. El jugador con balón lanza el balón contra el tablero, salta, y en el aire vuelve a lanzarlo contra el tablero. El resto de jugadores deberán ir cogiéndolo en el aire y volviéndolo a lanzar contra el tablero para que el compañero que viene detrás continúe con la dinámica.

Tras el palmeo, los jugadores deberán correr para superar el cono y volver a la fila para continuar con los palmeos, impidiendo así que se corte la dinámica.

En caso de querer aumentar la intensidad, podemos ir alejando el cono. Para finalizar, cuando el entrenador haga una señal acústica, el siguiente en palmear deberá meter canasta. En caso de no conseguirlo, se volverá a iniciar el ejercicio. 


\section{BIBLIOGRAFÍA}

- Abénza, L., Alarcón, F., Leite, N., Ureña, N., y Piñar, M. (2009). Relación entre la ansiedad y la eficacia de un equipo de baloncesto durante la competición. Cuadernos de Psicología del Deporte, 9, 51. Recuperado de https://revistas.um.es/cpd/article/view/85651/82471

- Alarcón, F., Cárdenas, D., Miranda, M. T., Ureña, N., y Piñar, M. I. (2010). La influencia de un modelo constructivista para la enseñanza de la táctica en baloncesto sobre la eficacia del juego durante la competición. Retos. Nuevas tendencias en Educación Física, Deporte y Recreación, (17), 15-20. Recuperado de https://www.redalyc.org/pdf/3457/345732283003.pdf

- Alarcón, F., Ureña, N., y Cárdenas, D. (2017). La fatiga mental deteriora el rendimiento en el tiro libre en baloncesto. Revista de Psicología del Deporte, 26(1), 33-36. Recuperado de https://www.redalyc.org/pdf/2351/235150578006.pdf

- Almeida, E. L. (2017). Análisis comparativo de los niveles subjetivos de estrésrecuperación entre deportistas practicantes de deportes individuales y colectivos (Tesis doctoral). Pontificia Universidad Católica del Ecuador, Quito, Ecuador. Recuperado de http://repositorio.puce.edu.ec/bitstream/handle/22000/12871/TESIS\%20MEDICIN $\underline{\text { A\%20DEPORTIVA.pdf?sequence }=1 \& \text { is Allowed }=\mathrm{y}}$

- Altavilla, G., y Raiola, G. (2015). Sports game tactic in basketball. Sport Science, 8(1), 43-46. Recuperado de http://www.sposci.com/PDFS/BR0801/SVEE/04\%20CL\%2007\%20GA.pdf

- Álvaro, J., Dorado, A., González Badillo, J.J., González, J.L., Navarro, F., Molina, J.J., Portolés, J., y Sánchez, F. (1995). Modelo de análisis de los deportes colectivos basado en el rendimiento en competición. Infocoes, 1(0), 21-40.

- Andrade, E.M., Lois, G., y Arce, C. (2007). Propiedades psicométricas de la versión española de ansiedad competitiva CSAI-2R en deportistas. Psicothema, 19 (1), 150-155. Recuperado de https://www.redalyc.org/pdf/727/72719122.pdf

- Anguera, M. T. (1986). La investigación cualitativa. Educar, (10), 23-50. Recuperado de https://ddd.uab.cat/pub/educar/0211819Xn10/0211819Xn10p23.pdf

- Anguera, M.T. (1988). Observación en la escuela. Barcelona: Graó. 
- Anguera, M.T., Blanco, A., Hernández, A., y Losada, J.L. (2011). Diseños observacionales: ajuste y aplicación en psicología del deporte. Cuadernos de Psicología del Deporte, 11(2), 63-76. Recuperado de https://revistas.um.es/cpd/article/view/133241/122911

- Anguera, M. T., Blanco, A., Losada, J. L., y Portell, M. (2018). Pautas para elaborar trabajos que utilizan la metodología observacional. Anuario de psicología, 48(1), 9-17. Recuperado de https://revistes.ub.edu/index.php/Anuariopsicologia/article/download/27476/28415

- Anguera, M. T., y Hernández, A. (2013). La metodología observacional en el ámbito del deporte. E-balonmano.com: Revista de Ciencias del Deporte, 9(3), 135160. Recuperado de https://www.redalyc.org/pdf/865/86528863001.pdf

- Arent, S. M., y Landers, D. M. (2003). Arousal, anxiety, and performance: A reexamination of the inverted-U hypothesis. Research quarterly for exercise and sport, 74(4), 436-444.

- Arjonilla, N. (2009). Incidencia de los factores distancia, tiempo, fatiga y concentración de la efectividad en el baloncesto (Tesis doctoral). Universidad de Las Palmas de Gran Canaria, Las Palmas de Gran Canaria, España. Recuperado de https://accedacris.ulpgc.es/bitstream/10553/4778/1/0619919_00000_0000.pdf

- Bar-Eli, M., y Tractinsky, N. (2000). Criticality of game situations and decision making in basketball: an application of performance crisis perspective. Psychology of sport and exercise, 1(1), 27-39. Recuperado de https://www.academia.edu/download/52990500/s1469-0292 28002900005 420170504-8164-1i5d07o.pdf

- Barrios, R. (2003). Estudio del parámetro tiempo en baloncesto. Jgbasket. Recuperado de http://jgbasket.com/doc_pdf/estudio_parametro_tiempo_en_baloncesto_v2_jgbaske t.pdf

- Battaglia, O., Sánchez, J. M., Borrás, P. J., y Jiménez, S. (2009). Análisis de la táctica en la defensa de los bloqueos directos en la liga profesional española. Cuadernos de Psicología del Deporte, 9, 78. Recuperado en https://revistas.um.es/cpd/article/view/86021/82811 
- Belem, I. C., Caruzzo, N. M., Nascimento Junior, J. R. A., Vieira, J. L. L., y Vieira, L. F. (2014). Impact of coping strategies on resilience of elite beach volleyball athletes. Revista Brasileira de Cineantropometria \& Desempenho Humano, 16(4), 447-455. Recuperado de http://www.scielo.br/pdf/rbcdh/v16n4/1980-0037-rbcdh16-04-00447.pdf

- Benítez, V.; Joaquín, M.; Vázquez, I.R; García, D. M. y Arbinaga, F. (Noviembre de 2013). Motivación e identificación con el ejercicio en deporte base Colectivo vs individual. XIV Congreso Andaluz y I ${ }^{\circ}$ Congreso Internacional Luso-Andaluz de Psicología del Deporte y la Actividad Física, Huelva.

- Bonato, M., Benis, R., y La Torre, A. (2018). Neuromuscular training reduces lower limb injuries in elite female basketball players. A cluster randomized controlled trial. Scandinavian journal of medicine \& science in sports, 28(4), 14511460.

- Bonvecchio de Aruani, M., y Maggioni, B.E. (2006). Evaluación de los aprendizajes. Buenos Aires: Ediciones Novedades Educativas.

- Bray, S.R., y Widmeyer, W.N. (2000). Athletes' perceptions of the home advantage: an investigation of perceived casual factors. Journal of Sport Behaviour, 23(1), 1-10.

- Cagigal, J.M. (1975). El deporte en la sociedad actual. Madrid: Editorial nacional.

- Calleja-González, J., Terrados, N., Mielgo-Ayuso, J., Delextrat, A., Jukic, I., Vaquera, A., Torres, L., Schelling, X., Stojanovic, M. y Ostojic, S. M. (2016). Evidence-based post-exercise recovery strategies in basketball. The Physician and sportsmedicine, 44(1), 74-78.

- Cañadas, M., Parejo, I., Ibáñez, S. J., García, J., y Feu, S. (2009). Relación entre las variables pedagógicas de entrenamiento de un equipo de minibasket. Cuadernos de Psicología del Deporte, 9, 50. Recuperado de https://revistas.um.es/cpd/article/download/85641/82461/0

- Cárdenas, D. (2006). El proceso de formación táctica colectiva en el baloncesto desde la perspectiva constructivista. Lecturas: Educación física y deportes, (94). Recuperado de https://www.efdeportes.com/efd94/balonces.htm 
- Cárdenas, D., y Rojas, J. (1997). Determinación de la incidencia del tiro libre en el resultado final a través del análisis estadístico. European Journal of Human Movement, (3), 177-186. Recuperado de https://dialnet.unirioja.es/descarga/articulo/2278208.pdf

- Carron, A. V., Loughhead, T. M., y Bray, S. R. (2005). The home advantage in sport competitions: Courneya and Carron's (1992) conceptual framework a decade later. Journal of sports sciences, 23(4), 395-407.

- Castañer, M., Camerino, O., y Anguera, M. T. (2013). Métodos mixtos en la investigación de las ciencias de la actividad física y el deporte. Apunts. Educación Física y Deportes, (112), 11-66. Recuperado de http://diposit.ub.edu/dspace/bitstream/2445/103622/1/629242.pdf

- Chicote, J., Morante, J. C., y Vaquera, A. (2009). Propuesta metodológica para el análisis táctico de las acciones ofensivas en equipos profesionales de baloncesto. Cuadernos de Psicología del Deporte, 9, 75. Recuperado de https://revistas.um.es/cpd/article/view/85951/82751

- Cohen, J. A. (1960). A Coefficient of agreement for nominal scales. Educational and Psychological Measurement, 20(1), 37-46. Recuperado de http://www.ric.edu/faculty/organic/coge/cohen1960.pdf

- Collado-Mateo, D., Villafaina, S., Fernández-González, E., Gozalo, M., Fuentes, J. P., y Gusi, N. (2019). Efectos de la tarea dual sobre el tiro libre en baloncesto. Revista Iberoamericana de Ciencias de la Actividad Física y el Deporte, 8(2), 68-78. Recuperado de http://www.revistas.uma.es/index.php/riccafd/article/viewFile/6447/6181

- Comisión Europea (2007). Libro blanco del deporte. Bruselas: Comisión de las comunidades Europeas. Recuperado de https://eur-lex.europa.eu/legalcontent/ES/TXT/PDF/?uri=CELEX:52007DC0391\&from=EN

- Cortes generales (1978) Constitución española. BOE, 311. Recuperado de https://www.boe.es/buscar/pdf/1978/BOE-A-1978-31229-consolidado.pdf

- Courneya, K. S., y Carron, A. V. (1992). The home advantage in sport competitions: A literature review. Journal of Sport and Exercise Psychology, 14(1), 13-27. 
- Covaci, A., Postelnicu, C. C., Panfir, A. N., y Talaba, D. (Febrero de 2012). A virtual reality simulator for basketball free-throw skills development. In Doctoral Conference on Computing, Electrical and Industrial Systems (pp. 105-112). Springer, Berlin, Heidelberg. Recuperado de https://link.springer.com/content/pdf/10.1007/978-3-642-28255-3_12.pdf

- Csataljay, G., O’Donoghue, P., Hughes, M., y Dancs, H. (2009). Performance indicators that distinguish winning and losing teams in basketball. International Journal of Performance Analysis in Sport, 9(1), 60-66. Recuperado de https://www.researchgate.net/profile/Gabor_Csataljay2/publication/233682287_Per formance_indicators that_distinguish_winning_and_losing_teams_in_basketball/li nks/57396dc708aea45ee83ed38c.pdf

- Dabnichki, P., y Baca, A. (2008). Computers in sport. Southampton: WIT Press.

- De Rose, D. (2004). Statistical analysis of basketball performance indicators according to home/away games and winning and losing teams. Journal of Human Movement Studies, 47(4), 327-336.

- Elias, N., y Dunning, E. (1992). Deporte y ocio en el proceso de la civilización. Madrid: Fondo de Cultura Económica (FCE)

- Fernández, G., y Ortiz, L. (2017). Análisis de las variables intervinientes en función de la eficacia del tiro de tres puntos en la Liga Uruguaya de Básquetbol 2016/2017 (Trabajo fin de grado) Instituto Universitario Asociación Cristiana de Jóvenes, Montevideo, Uruguay. Recuperado de https://core.ac.uk/download/pdf/288314187.pdf

- Fernández, J., Camerino, O., Anguera, M. T., y Jonsson, G. K. (2009). Identifying and analyzing the construction and effectiveness of offensive plays in basketball by using systematic observation. Behavior Research Methods, 41(3), 719-730. Recuperado de https://link.springer.com/content/pdf/10.3758/BRM.41.3.719.pdf

- Ferreira, A. P., Ibáñez, S. J., y Sampaio, J. (2009). Las reglas y la casualidad en baloncesto: una aproximación histórica. Retos. Nuevas tendencias en Educación Física, Deporte y Recreación, (15), 9-13. Recuperado de http://www.retos.org/numero 15/retos\%2015-2.pdf 
- Fierro, C. (2002). Variables relacionadas con el éxito deportivo en las ligas NBA y ACB de baloncesto. Revista de psicología del deporte, 11(2), 247-255. Recuperado de https://ddd.uab.cat/pub/revpsidep/19885636v11n2/19885636v11n2p247.pdf

- Fleiss, J. L. (1971). Measuring nominal scale agreement among many raters. Psychological bulletin, 76(5), 378-382. Recuperado de http://www.wpic.pitt.edu/research/biometrics/Publications/Biometrics\%20Archives \%20PDF/395-1971\%20Fleiss0001.pdf

- Fort, R. (2019). Diferencias entre el deporte europeo y el norteamericano: una mirada retrospectiva. Papeles de Economía Española, (159), 61-71.

- Fort, R. (2000). European and North American Sports Diferrences. Scottish journal of political economy, 47(4), 431-455.

- Freyre, F., y Fernández, A. (2009). La Preparación Física en el entrenamiento técnico-táctico del Baloncesto. Ciencias Holguín, 15(1), 1-10. Recuperado de http://www.ciencias.holguin.cu/index.php/cienciasholguin/article/viewFile/477/349

- García, D.M.; Benítez, V.; Joaquín, M.; Vázquez, I. R. y Arbinaga, F. (2013a) Influencia de la familia en deportes individuales vs colectivos y el tipo de motivación en el joven deportista. XIV Congreso Andaluz de Psicología de la actividad física y deporte, Huelva.

- García, J., Ibáñez, S. J., Feu, S., Cañadas, M., y Parejo, I. (2008). Estudio de la gestoforma del lanzamiento a canasta en la liga EBA. Retos. Nuevas tendencias en Educación Física, Deporte y Recreación, (14), 17-21. Recuperado de https://www.redalyc.org/pdf/3457/345732279003.pdf

- García, J., Ibáñez, S. J., Martínez de Santos, R., Leite, N., y Sampaio, J. (2013b). Identifying basketball performance indicators in regular season and playoff games. Journal of human kinetics, 36(1), 161-168. Recuperado de https://content.sciendo.com/downloadpdf/journals/hukin/36/1/article-p161.pdf

- García, J., Sáez, J., Ibáñez, S. J., Parejo, I., y Cañadas, M. (2009). Estudio del efecto de jugar en casa en la liga ACB, temporada 2007-2008. Cuadernos de Psicología del Deporte, 9, 39. Recuperado de https://revistas.um.es/cpd/article/view/85451/82301 
- García, M. (2006). Veinticinco años de análisis del comportamiento deportivo de la población española (1980-2005). Revista internacional de sociología, 64(44), 15-

38. Recuperado de

http://revintsociologia.revistas.csic.es/index.php/revintsociologia/article/viewFile/2 $\underline{6 / 26}$

- García, R. (2016). Revisión sobre las diferencias de las variables psicológicas en deportes individuales vs. deportes de equipo (Trabajo fin de grado). Universidad de Cádiz, Cádiz, España. Recuperado de https://rodin.uca.es/xmlui/bitstream/handle/10498/18512/Garc\%C3\%ADaBert\%C3 \%B3_Raquel_TFG.pdf?sequence $=1 \&$ is Allowed $=y$

- Garzón, B., Lapresa, D., Anguera, M. T., y Arana, J. (2011). Análisis observacional del lanzamiento de tiro libre en jugadores de baloncesto base. Psicothema, 23(4), 851-857. Recuperado de https://www.redalyc.org/pdf/727/72722232049.pdf

- González-García, H., y Pelegrín, A. (Octubre de 2016). Diferencias en los Niveles de Ira en los Deportes Individuales y Colectivos. Actas II Congreso Internacional de la Sociedad Científica Española de Psicología Social, Elche. Recuperado de https://www.researchgate.net/profile/Higinio_Gonzalez-

Garcia/publication/309589164_Diferencias_en_los_Niveles_de_Ira_en_los_Deport es_Individuales_y_Colectivos/links/581895d008ae50812f5da267.pdf

- Gómez, J. (2013). La politización del deporte en los medios escritos especializados. Razón y Palabra, (84), 602-617. Recuperado de http://revistarazonypalabra.com/index.php/ryp/article/view/440/472

- Gómez, M. Á., y Lorenzo, A. (2006). Análisis de los procesos perceptivos y de toma de decisión en jugadores cadetes de baloncesto. Lecturas: Educación física y deportes, (95). Recuperado de https://www.efdeportes.com/efd95/balonc.htm

- Gómez, M. Á., Lorenzo, A., Ibáñez, S. J., y Sampaio, J. (2013). Ball possession effectiveness in men's and women's elite basketball according to situational variables in different game periods. Journal of sports sciences, 31(14), 1578-1587. 
- Gómez, M. Á., Lorenzo, A., Ortega, E., y Olmedilla, A. (2007b). Diferencias de los indicadores de rendimiento en baloncesto femenino entre ganadores y perdedores en función de jugar como local o como visitante. Revista de Psicología del Deporte, 16(1), 41-54. Recuperado de https://www.rpdonline.com/article/viewFile/24/24

- Gómez, M. Á., Lorenzo, A., Ortega, E., Sampaio, J., y Ibáñez, S. J. (2007a). Diferencias en las estadísticas de juego entre bases, aleros y pívots en baloncesto femenino. Cultura, Ciencia y deporte, 2(6), 139-144. Recuperado de http://repositorio.ucam.edu/bitstream/handle/10952/222/pag139_144.pdf?sequence $=1 \&$ is Allowed $=\mathrm{y}$

- Gómez, M.Á., Lorenzo, A., Sampaio, J., Ibáñez, S.J., y Ortega, E. (2008). Gamerelated statistics that discriminated winning and losing teams from the Spanish men's professional basketball teams. Collegium antropologicum, 32(2), 451-456. Recuperado de https://hrcak.srce.hr/file/43020

- Gréhaigne, J. F., Godbout, P., y Bouthier, D. (1999). The foundations of tactics and strategy in team sports. Journal of teaching in physical education, 18(2), 159-174.

- Gréhaigne, J. F., Wallian, N., y Godbout, P. (2005). Tactical-decision learning model and students' practices. Physical Education and Sport Pedagogy, 10(3), 255269. Recuperado de https://www.researchgate.net/profile/JeanFrancis_Grehaigne/publication/243666767_Tacticaldecision learning model and students' practices/links/55e5bdfc08aec74dbe74c85 2.pdf

- Guerra, J. R., Goosdenovich, D.A., Angulo, C. H., Singre, J. C., Campoverde, P. D. R., y Vargas, D. (2018). Potenciación de la efectividad en tiros libres de basquetbolistas juveniles: vinculación biomecánica. Revista Cubana de Investigaciones Biomédicas, 37(2), 1-14. Recuperado de http://www.revibiomedica.sld.cu/index.php/ibi/article/viewFile/56/55 
- Hoffmann, M. D., Loughead, T. M., Dixon, J. C., y Crozier, A. J. (2017). Examining the home advantage in the National Hockey League: Comparisons among regulation, overtime, and the shootout. Psychology of Sport and Exercise, 28, 24-30. Recuperado de https://www.researchgate.net/profile/Matt_Hoffmann/publication/308598549_Exa mining the home advantage in the National Hockey League Comparisons am ong regulation_overtime_and the shootout/links/59d96d2baca272e60966d4f0/Ex amining-the-home-advantage-in-the-National-Hockey-League-Comparisonsamong-regulation-overtime-and-the-shootout.pdf

- Ibáñez, S. J., Feu, S., y Dorado, G. (Noviembre de 2003). Análisis de las diferencias en el juego en función del género y categoría de los jugadores. Comunicación presentada en el II Congreso Ibérico de Baloncesto, Cáceres.

- Ibáñez, S. J., Feu, S., García, J., Cañadas, M., y Parejo, I. (2007). Multifactorial study of shot efficacy in the Spanish professional basketball league. Iberian Congress on Basketball Research, 4, 54-57.

- Ibáñez, S. J., Feu, S., García, J., Parejo, I., y Cañadas, M. (2009b). Shot differences between professional (ACB) and amateur (EBA) basketball teams. Multifactorial study. Revista de psicología del deporte, 18(3), 313-317. Recuperado de https://www.redalyc.org/pdf/2351/235116466005.pdf

- Ibáñez, S. J., García, J., Feu, S., Parejo, I., y Cañadas, M. (2009a). La eficacia del lanzamiento a canasta en la NBA: Análisis multifactorial. Cultura, Ciencia y Deporte, 4(10), 39-47. Recuperado de http://repositorio.ucam.edu/bitstream/handle/10952/180/articulo\%206.pdf?sequenc $\underline{\mathrm{e}=1 \& \text { isAllowed }=\mathrm{y}}$

- Ibáñez, S.J., Martínez, B., Feu, S., y Lozano, A. (2002). Estudio de los gestos técnico-tácticos en situación real de juego en baloncesto. Trabajo presentado en el II Congreso de Ciencias del Deporte, Madrid. Recuperado de http://cienciadeporte.com/images/congresos/madrid/Rendimiento\%20Deportivo/En trenamiento\%20Deportivo/Estudio\%20de\%20los\%20gestos.PDF 
- Iglesias, D., Sanz, D., García, T., Cervelló, E.M. y Del Villar, F. (2005). Influencia de un programa de supervisión reflexiva sobre la toma de decisiones y la ejecución del pase en jóvenes jugadores de baloncesto. Revista de Psicología del Deporte, 14(2), 209-223. Recuperado de https://www.rpdonline.com/article/viewFile/182/182

- Jiménez, A. C. (2007). Análisis de la toma de decisión en los deportes colectivos: Estrategias de las jugadoras aleros de baloncesto en posesión del balón. Sevilla: Wanceulen SL.

- Jiménez, A. C. (2017). Percepción de los entrenadores sobre la toma de decisión de los jugadores en la iniciación al baloncesto. SPORT TK-Revista EuroAmericana de Ciencias del Deporte, 6(1), 175-182. Recuperado de https://revistas.um.es/sportk/article/download/293641/211681

- Jiménez, M. G., y López, C. J. (2012). El acierto en el tiro libre en baloncesto: cómo influye el minuto de partido, el estado del marcador y ser equipo local o visitante. Cuadernos de Psicología del Deporte, 12(2), 25-38. Recuperado de http://scielo.isciii.es/pdf/cpd/v12n2/articulo03.pdf

- Kioumourtzoglou, E., Kourtessis, T., Michalopoulou, M., y Derri, V. (1998). Differences in several perceptual abilities between experts and novices in basketball, volleyball and water-polo. Perceptual and motor skills, 86(3), 899-912.

- Koning, R. H. (2011). Home advantage in professional tennis. Journal of Sports Sciences, 29(1), 19-27.

- Kozina, Z. L., Sobko, I. N., Bazilyuk, T. A., Barybina, L. M., y Borovskaya, O. Y. (2017). Interactive technologies as a means of tactical training of athletes in student basketball. Health, sport, rehabilitation, 3(1), 22-33. Recuperado de http://sportsscience.org/index.php/health/article/viewFile/568/756

- Landis, J. R., y Koch, G. G. (1977). The measurement of observer agreement for categorical data. Biometrics, 33(1), 159-174. Recuperado de https://pdfs.semanticscholar.org/7e73/43a5608fff1c68c5259db0c77b9193f1546d.pd $\mathrm{f}$ 
- Lapresa, D., Alsasua, R., Arana, J., Anguera, M. T., y Garzón, B. (2014). Análisis observacional de la construcción de las secuencias ofensivas que acaban en lanzamiento en baloncesto de categoría infantil. Revista de Psicología del Deporte 23(2), 365-376. Recuperado de https://www.redalyc.org/pdf/2351/235131674016.pdf

- Link, D., y Lames, M. (2009). Sport Informatics-Historical roots, interdisciplinarity and future developments. International Journal of Computer Science in Sport, 8(2), 68-87. Recuperado de https://cms.unikonstanz.de/fileadmin/archive/informatik-saupe/fileadmin/informatik/agsaupe/Lehre/WS_11_12/IS3/CSandSports/SportinformaticsLinkLamesIJCSS.pdf

- López, C. J., y Jiménez, M. G. (2013). El tiro libre en baloncesto: aciertos en cada minuto de juego. Revista Internacional de Medicina y Ciencias de la Actividad Física y del Deporte, 13(50), 307-327. Recuperado de https://www.redalyc.org/pdf/542/54227414007.pdf

- Lorenzo, A. (2000). Búsqueda de nuevas variables en la detección de talentos en los deportes colectivos: aplicación al baloncesto (tesis doctoral). Universidad Politécnica de Madrid, Madrid, España. Recuperado de http://oa.upm.es/98/1/ALBERTO_LORENZO_CALVO.pdf

- Lorenzo, A., Gómez, M. Á., Ortega, E., Ibáñez, S. J., y Sampaio, J. (2010). Game related statistics which discriminate between winning and losing under-16 male basketball games. Journal of sports science \& medicine, 9(4), 664-668. Recuperado de http://oa.upm.es/8396/1/INVE_MEM_2010_82180.pdf

- Lorenzo, A., Gómez, M. A., y Sampaio, A. J. (2003). Análisis descriptivo de las posesiones de 24 segundos en baloncesto. Lecturas: Educación Física y Deportes, (67). Recuperado de http://www.efdeportes.com/efd67/balonc.htm

- Lorenzo, J., Navarro, R., Rivilla, J. y Lorenzo A. (2013). The analysis of the basketball coach speech during the moments of game and pause in relation to the performance in competition. Revista de Psicología del Deporte, 22(1), 227-230. Recuperado de http://oa.upm.es/29374/1/INVE MEM 2013 170642.pdf

- Madejón, M. (2002). La evolución del modelo comparativo. Clinic: Revista técnica de baloncesto, (57), 22-24.

- Martens, R. (1977). Sport competition anxiety test. Champaign: Human Kinetics. 
- Martínez, J. A., y García, J. (2017). Una segunda oportunidad para ganar. Retos: nuevas tendencias en educación física, deporte y recreación, (31), 151-156.

Recuperado de https://dialnet.unirioja.es/descarga/articulo/5841363.pdf

- Mexas, K., Tsitskaris, G., Kyriakou, D., y Garefis, A. (2005). Comparison of effectiveness of organized offences between two different championships in high level basketball. International Journal of Performance Analysis in Sport, 5(1), 7282.

- Ministerio de Cultura y Deporte (2019). Estadística del deporte federado. Recuperado el 2 de julio de 2020, de https://www.culturaydeporte.gob.es/dam/jcr:6b7e9a1a-e3e5-4b45-8ae56f187b50235f/nota-resumen-estadistica-deporte-federado-2019.pdf

- Montaner, C., y Montaner, A.M. (2004). Estudio comparativo del tiempo de posesión y sus efectos en el juego entre un equipo masculino y uno femenino de baloncesto de élite. RendimientoDeportivo.com, 9.

- Morales, B. H., Pérez, M. E., Pillajo, M. A., Bonilla, A. R., Romero, E., y Morán, L. (2018). Diferencias biomecánicas y efectividad del tiro libre del baloncesto en estado óptimo y en fatiga. Revista Cubana de Investigaciones Biomédicas, 37(4), 19. Recuperado de http://scielo.sld.cu/pdf/ibi/v37n4/ibi05418.pdf

- Morante, J.C. (2009). Análisis del rendimiento en Deportes de Equipo: del Registro Estadístico al Análisis Táctico. Actas del II Congreso Internacional de Deportes de Equipo, A Coruña.

- Muñoz, V., Serna, J., Daza, G., y Hileno, R. (2015). Influencia del bloqueo directo y el uno contra uno en el éxito del lanzamiento en baloncesto. Apunts. Educación física y deportes, 1(119), 80-86. Recuperado de https://www.raco.cat/index.php/ApuntsEFD/article/view/291498/379979

- Navarro, R.M., Gómez, M.A, Lorenzo, J., Lorenzo, A., y Jiménez, S. (2012). La influencia del "home advantage" en el resultado de los momentos críticos en los partidos de baloncesto. Revista española de educación física y deportes, (396), 49-

63. Recuperado de http://oa.upm.es/29379/4/INVE_MEM_2013_170631.pdf 
- Navarro, R. M., Jiménez, S. L., Lorenzo, J., Lorenzo, A., y Gómez, M. Á. (2017). Análisis cualitativo de los momentos críticos en baloncesto, la visión del jugador. Revista de Psicología del Deporte, 26(1), 109-112. Recuperado de https://abacus.universidadeuropea.es/bitstream/handle/11268/6439/RPD_26_3_109 -112.pdf? sequence $=2 \&$ isAllowed $=y$

- Navarro, R. M., Lorenzo, A., Gómez, M. A., y Sampaio, J. (2009). Análisis de los momentos críticos en la liga ACB 2007-08. Cuadernos de Psicología del Deporte, 9, 37. Recuperado de https://revistas.um.es/cpd/article/view/85421/82271

- Nicholls, A. R., y Polman, R. C.J. (2007). Coping in sport: A systematic review. Journal of sports sciences, 25(1), 11-31. Recuperado de http://citeseerx.ist.psu.edu/viewdoc/download?doi=10.1.1.828.5091\&rep=rep1\&typ $\underline{\mathrm{e}=\mathrm{pdf}}$

- Noguera, O., y Camerino, O. (2013). La eficacia del ataque en baloncesto, ejemplo de un estudio observacional con T-patterns. Retos. Nuevas tendencias en Educación Física, Deporte y Recreación, (24), 67-71.Recuperado de https://www.redalyc.org/pdf/3457/345732290015.pdf

- Nunes, H., Iglesias, X., Daza, G., Irurtia, A., Caparrós, T., y Anguera, M. T. (2016). Influencia del pick and roll en el juego de ataque en baloncesto de alto nivel. Cuadernos de Psicología del Deporte, 16(1), 129-142. Recuperado de https://revistas.um.es/cpd/article/view/254431/192111

- Olivera, J. (2006). Hacia una nueva comprensión del deporte. Factores endógenos y exógenos. Apunts. Educación física y deportes, 4(86), 3-6. Recuperado de https://www.raco.cat/index.php/ApuntsEFD/article/download/300864/390309/

- Orta, A., Pino, J., y Moreno, I. (2000). Propuesta de un método de entrenamiento universal para deportes de equipo basándose en el análisis observacional de la competición. Lecturas: Educación Física y Deportes, (27). Recuperado de https://www.efdeportes.com/efd27a/de.htm

- Ortega, E., y García, A. (2009) Análisis de los sistemas de ataque en un equipo de baloncesto de alto de rendimiento. Lecturas: Educación física y deportes, (133). Recuperado de https://www.efdeportes.com/efd133/analisis-de-los-sistemas-deataque-en-baloncesto.htm 
- Ortega, E. y Gómez, M. A. (2009). Metodología observacional en baloncesto de formación. Murcia: Diego Marín.

- Otero, L. E. (2003). Ocio y deporte en el nacimiento de la sociedad de masas. La socialización del deporte como práctica y espectáculo en la España del primer tercio del siglo XX. Cuadernos de historia contemporánea, 25, 169-198. Recuperado de https://eprints.ucm.es/6157/1/CHCO0303120169A_ocio.pdf

- Pagé, C., Bernier, P. M., y Trempe, M. (2019). Using video simulations and virtual reality to improve decision-making skills in basketball. Journal of sports sciences, 37(21), 2403-2410.

- Patiño, Á., y López-Barrajón, M. (1998). Aplicacions de l'anàlisi i avaluació de la tècnica en bàsquet. Apunts. Educació física i esports, 4(54), 37-43. Recuperado de https://www.raco.cat/index.php/ApuntsEFE/article/view/307989/397955

- Perl, J. (2006). A computer science in sport: An overview of present fields and future applications (Part II). International Journal of Computer Science in Sport, 4(1), 36-45. Recuperado de https://cms.unikonstanz.de/fileadmin/archive/informatik-saupe/fileadmin/informatik/agsaupe/Lehre/WS_11_12/IS3/CSandSports/IJCSS_SP02_2006_Perl.pdf

- Pinto, I. E., Calero, S., Vaca, M. R., Sánchez, B., y Capote, G. (2018). Tiempo, ansiedad y concentración: influencia en la efectividad en tiros libres del baloncesto femenino. Revista Cubana de Investigaciones Biomédicas, 37(1), 75-84.

Recuperado de https://www.researchgate.net/profile/Santiago Calero Morales/publication/333965 831_Tiempo_ansiedad_y_concentracion_influencia_en_la_efectividad_en_tiros_lib res_del_baloncesto_femeninoTime_anxiety_and_concentration_influence_on_the effectiveness in free throws of women's basketball/links/5d0f1e69458515c11cf 0ed41/Tiempo-ansiedad-y-concentracion-influencia-en-la-efectividad-en-tiroslibres-del-baloncesto-femenino-Time-anxiety-and-concentration-influence-on-theeffectiveness-in-free-throws-of-womens-basketball.pdf 
- Piñar, M.I., Ortega, E., Ortega, V., y Palao, J.M. (2004). Incidencia de la modificación del tiempo de posesión de 30 a 24 segundos sobre el tanteo en baloncesto y propuesta de modificación en categorías de formación. Lecturas: Educación Física y Deportes, (79). Recuperado de https://www.efdeportes.com/efd79/balonc.htm

- Pojskic, H., Separovic, V., y Uzicanin, E. (2011). Modelling home advantage in basketball at different levels of competition. Acta Kinesiologica, 5(1), 25-30.

Recuperado de https://miun.divaportal.org/smash/get/diva2:954141/FULLTEXT01.pdf

- Policastro, F., Cattaruzza, V., Vittori, G., y Deodato, M. (2019). The postural impact on the prevention of injuries in young basketball players: A longitudinal preliminary study. Journal of Physical Health and Sports Medicine, 2(1), 1-11. Recuperado de https://arts.units.it/retrieve/handle/11368/2944626/272510/jphsm raft1004.pdf

- Pradas, F. y Reverter, J. (2011). La tecnificación en deportes individuales versus deportes colectivos. Movimiento Humano, (1), 75-99. Recuperado de http://www.didesp.udl.cat/wp-content/arxius/Movimiento-humano-1.pdf

- Prieto, J. M. (2015). Variables deportivas y personales en la ocurrencia de lesiones deportivas. Diferencias entre deportes individuales y colectivos. Retos. Nuevas tendencias en educación física, deporte y recreación, (28), 21-25. Recuperado de https://www.redalyc.org/pdf/3457/345741428004.pdf

- Ramis, Y., Torregrosa, M., Viladrich, C., y Cruz, J. (2010). Adaptación y validación de la versión española de la Escala de Ansiedad Competitiva SAS-2 para deportistas de iniciación. Psicothema, 22(4), 1004-1009. Recuperado de https://www.redalyc.org/pdf/727/72715515070.pdf

- Real Academia Española. (s.f.). Cultura. En Diccionario de la lengua española. Recuperado en 10 de febrero de 2019, de https://dle.rae.es/paradigma

- Refoyo, I., Romarís, I. U., y Sampedro, J. (2009). Analysis of men's and women's basketball fast-breaks. Revista de Psicología del deporte, 18(3), 439-444. Recuperado de https://www.rpd-online.com/article/viewFile/673/626 
- Remmert, H. (2003). Analysis of group-tactical offensive behavior in elite basketball on the basis of a process orientated model. European Journal of Sport Science, 3(3), 1-12. Recuperado en https://studydaddy.com/attachment/128437/Tact8ComputerizedTacticalAnalysisBasketball.pdf

- Riera, J. (1995). Análisis de la táctica deportiva. Apunts: Educación física y deportes, (40), 47-60. Recuperado de https://www.revistaapunts.com/apunts/articulos/40/es/040_047-060_es.pdf

- Rivera, Y. S. (2010). ¿Cómo se pueden aplicar los distintos paradigmas de la investigación científica a La Cultura Física y El Deporte?. PODIUM-Revista de Ciencia y Tecnología en la Cultura Física, 5(1), 1-10. Recuperado de http://podium.upr.edu.cu/index.php/podium/article/view/201/202

- Robles, A. (2016). Estudio del lanzamiento de tres en un campeonato de España de baloncesto cadete masculino. Lecturas: Educación Física y Deportes, (223). Recuperado de https://www.efdeportes.com/efd223/lanzamiento-de-tres-enbaloncesto-masculino.htm

- Rojas, F. J., Sánchez, A., Cepero, M., Soto, V. M., y Gutiérrez, M. (2000). Diferencias biomecánicas entre jugadores principiantes y de alto rendimiento en el lanzamiento en salto en baloncesto. Biomecánica, 8(1), 3-14. Recuperado de https://upcommons.upc.edu/bitstream/handle/2099/5419/02\%20\%20Diferencias\%20biomec\%C3\%A1nicas\%20entre\%20jugadores\%20principiante s\%20.pdf

- Romarís, I. U., Refoyo, I., y Coterón, J. (2012). La finalización de las posesiones en baloncesto: estudio de la acción de finalización. Cuadernos de Psicología del Deporte, 12(1), 45-50. Recuperado de https://revistas.um.es/cpd/article/view/169441/145631

- Rosado, A., Marques dos Santos, A., y Guillén, F. (2012). Estrategias de coping en jugadores de baloncesto de alta competición. Revista Iberoamericana de Psicología del Ejercicio y el Deporte, 7(1), 125-147. Recuperado de https://dialnet.unirioja.es/descarga/articulo/3967918.pdf 
- Sáenz-López, P., Jiménez, A. C., Giménez, F. J. e Ibáñez, S. J. (2007). La autopercepción de las jugadoras de baloncesto expertas respecto a sus procesos de formación. Cultura, Ciencia y Deporte, 3(7), 35-41. Recuperado de https://www.redalyc.org/pdf/1630/163017538005.pdf

- Sáez, G. A., y Ocampo, J. C. (2019). Características Psicológicas en Deporte Individual y Colectivo. Revista de Entrenamiento Deportivo, 33(4). Recuperado de https://g-se.com/caracteristicas-psicologicas-en-deporte-individual-y-colectivo2736-sa-J5dcedaefa432d

- Sampaio, J. (1998). Los indicadores estadísticos más determinantes en el resultado final en los partidos de Basquetbol. Lecturas: Educación Física y Deportes, 3(11). Recuperado de https://www.efdeportes.com/efd11/sampe.htm

- Sampaio, J., Ibáñez, S., y Feu, S. (2004). Discriminative power of basketball game-related statistics by level of competition and sex. Perceptual and motor Skills, 99, 1231-1238. Recuperado de https://www.researchgate.net/profile/Sergio Ibanez3/publication/7993770 Dis criminative_power_of basketball_gamerelated_statistics_by_level_of_competition_and_sex/links/09e4150c7613db79b 4000000.pdf

- Sampaio, J., Lorenzo, A., y Ribero, C. (2006). Momentos críticos en los partidos de baloncesto: metodología para identificación y análisis de los acontecimientos precedentes. Cultura, ciencia y deporte, 2(5), 83-88. Recuperado de https://www.redalyc.org/pdf/1630/163017530005.pdf

- Sampedro, J., y Prieto, J. (2012). El efecto de marcar primero y la ventaja de jugar en casa en la liga de fútbol y en la liga de fútbol sala de España. Revista de Psicología del Deporte. 21(2), 301-308. Recuperado de https://www.redalyc.org/pdf/2351/235126897010.pdf

- Sánchez, F., y Gómez, A. (2008). Epidemiología de las lesiones deportivas en baloncesto. International Journal of Medicine and Science of Physical Activity and Sport, 8(32), 270-281. Recuperado de https://repositorio.uam.es/bitstream/handle/10486/3554/25043_2.pdf?sequence $=1$ 
- Sánchez, M. (2007). El acondicionamiento físico en baloncesto. Apunts. Medicina de l'Esport, 42(154), 99-107. Recuperado de https://www.raco.cat/index.php/Apunts/article/download/73041/304631

- Sautu, L. M., Garay, J. O., y Hernández, A. (2009). Observación y análisis de las interacciones indirectas en el baloncesto ACB. Cuadernos de Psicología del Deporte, 9, 69. Recuperado de https://digitum.um.es/digitum/bitstream/10201/35065/1/32 Observac\%20y\%20 an\% $3 \%$ A1lisis.pdf

- Tashakkori, A., y Creswell, J.W. (2008). Mixed methodology across disciplines. Journal of Mixed Methods Research, 2(1), 3-6. Recuperado de https://journals.sagepub.com/doi/pdf/10.1177/1558689807309913

- Tashakkori, A., y Creswell, J. W. (2007). The New Era of Mixed Methods. Journal of Mixed Methods Research, 1(1), 3-7. Recuperado de https://journals.sagepub.com/doi/pdf/10.1177/2345678906293042

- Teramoto, M., Cross, C. L., Cushman, D. M., Maak, T. G., Petron, D. J., y Willick, S. E. (2017). Game injuries in relation to game schedules in the National Basketball Association. Journal of science and medicine in sport, 20(3), 230-235.

- Thibault, V., Guillaume, M., Berthelot, G., El Helou, N., Schaal, K., Quinquis, L., Nassif, H., Tafflet, M., Escolano, S., Hermine, O., y Toussaint, J. F. (2010). Women and men in sport performance: the gender gap has not evolved since 1983. Journal of sports science \& medicine, 9(2), 214-223. Recuperado de https://www.ncbi.nlm.nih.gov/pmc/articles/PMC3761733/

- Tran, C. M., y Silverberg, L. M. (2008). Optimal release conditions for the free throw in men's basketball. Journal of sports sciences, 26(11), 1147-1155.

- Trninić, S., Dizdar, D., y Lukšić, E. (2002). Differences between winning and defeated top quality basketball teams in final tournaments of European club championship. Collegium antropologicum, 26(2), 521-531. Recuperado de https://hrcak.srce.hr/file/44431 
- Tsai, W. L. (Junio de 2018). Personal basketball coach: tactic training through wireless virtual reality. In Proceedings of the 2018 ACM on International Conference on Multimedia Retrieval, 481-484. Recuperado de https://dl.acm.org/doi/pdf/10.1145/3206025.3206084

- Tsai, W. L., Chung, M. F., Pan, T. Y., y Hu, M. C. (Octubre de 2017). Train in virtual court: basketball tactic training via virtual reality. In Proceedings of the 2017 ACM Workshop on Multimedia-based Educational and Knowledge Technologies for Personalized and Social Online Training, 3-10.Recuperado de https://dl.acm.org/doi/pdf/10.1145/3132390.3132394

- Tsitskaris, G., Theoharopoulos, A, Galanis, D., y Nikopoulou, M. (2002). Types of shots used at the Greek National Basketball Championship according to the division and position of players. Journal of Human Movement Studies, 42(1), 4352.

- Van Bottenburg, M. (2011). Why are the European and American Sports Worlds so Different? Path-dependence in European and American Sports History. In Tomlinson, I., Young, C. \& Holt, R. (Ed.) Sport and the Transformation of Modern Europe: States, Media and Markets 1950-2010 (pp. 217-237). Abingdon, UK: Routledge.

- Vaquera, A., Cubillo, R., García-Tormo, J. V., y Morante, J. C. (2013). Validation of a tactical analysis methodology for the study of pick and roll in basketball. Revista de psicología del deporte, 22(1), 277-281. Recuperado de https://buleria.unileon.es/bitstream/handle/10612/10176/1345-3997-1PB.pdf? sequence $=1 \&$ is Allowed $=\mathrm{y}$

- Vaquera, A., Refoyo, I., Villa, J. G., Calleja, J., Rodríguez-Marroyo, J. A., GarcíaLópez, J., y Sampedro, J. (2008). Heart rate response to game-play in professional basketball players. Journal of human sport and exercise, 3(1), 1-9. Recuperado de https://www.redalyc.org/pdf/3010/301023501001.pdf

- Vaquera, A., Rodríguez, J. A., Villa, J. G., García, J., y Ávila, C. (2002). Cualidades Fisiológicas y Biomecánicas de Jugador Joven de Liga EBA. Motricidad: European Journal of Human Movement, (9), 43-63. Recuperado de https://dialnet.unirioja.es/descarga/articulo/2278435.pdf 
- Vaquera, A., Suárez-Iglesias, D., Guiu, X., Barroso, R., Thomas, G., y Renfree, A. (2018). Physiological responses to and athlete and coach perceptions of exertion during small-sided basketball games. The Journal of Strength \& Conditioning Research, 32(10), 2949-2953.

- Vignais, N., Kulpa, R., Brault, S., Presse, D., y Bideau, B. (2015). Which technology to investigate visual perception in sport: Video vs. virtual reality. Human movement science, 39, 12-26. Recuperado de http://people.rennes.inria.fr/Richard.Kulpa/papers/2015_Vignais_HMS.pdf

- Yao, H. P., Liu, Y. Z., y Han, C. S. (2012). Application expectation of virtual reality in basketball teaching. Procedia Engineering, 29, 4287-4291. Recuperado de https://www.sciencedirect.com/science/article/pii/S1877705812006698

- Zhang, L., y Wang, L. (2011). VR-based basketball movement simulation. In Pan, Z., Cheok, A.D., Müller, W. \& Yang, X. (Ed.) Transactions on edutainment V, 240250. Springer, Germany: Heidelberg.

- Zuckerman, S. L., Wegner, A. M., Roos, K. G., Djoko, A., Dompier, T. P., y Kerr, Z. Y. (2018). Injuries sustained in National Collegiate Athletic Association men's and women's basketball, 2009/2010-2014/2015. Brithis Journal of Sports Medicine, 52(4), 261-268.

"No intentes ser el mejor de tu equipo, intenta que tu equipo sea el mejor” Allen Iverson 


\section{ANEXOS}

\subsection{TABLAS INTRAOBSERVADOR}

\begin{tabular}{|c|c|c|c|c|c|c|c|c|c|}
\hline \multirow[t]{2}{*}{$N=61$} & & \multicolumn{8}{|c|}{ OBERVADOR A* } \\
\hline & & Zona 1 & Zona 2 & Zona 3 & Zona 4 & Zona 5 & Zona 6 & Zona 7 & Total \\
\hline \multirow{8}{*}{ OBERVADOR A } & Zona 1 & 40 & 0 & 0 & 0 & 0 & 0 & 0 & 40 \\
\hline & Zona 2 & 0 & 2 & 0 & 0 & 0 & 0 & 0 & 2 \\
\hline & Zona 3 & 0 & 0 & 1 & 0 & 0 & 0 & 0 & 1 \\
\hline & Zona 4 & 0 & 0 & 0 & 11 & 0 & 0 & 0 & 11 \\
\hline & Zona 5 & 0 & 0 & 0 & 0 & 2 & 0 & 0 & 2 \\
\hline & Zona 6 & 0 & 0 & 0 & 0 & 0 & 0 & 0 & 0 \\
\hline & Zona 7 & 0 & 0 & 0 & 0 & 0 & 0 & 5 & 5 \\
\hline & Total & 40 & 2 & 1 & 11 & 2 & 0 & 5 & 61 \\
\hline
\end{tabular}

\begin{tabular}{|c|c|c|c|c|c|c|c|c|c|c|c|}
\hline \multirow[t]{2}{*}{$N=61$} & & \multicolumn{10}{|c|}{ OBERVADOR A* } \\
\hline & & 3p. + adicional & 3puntos & Falta +3 adic. & $2 \mathrm{p} .+$ adicional & 2 puntos & Falta +2 adic. & Tapón & Fallo 3p. & Fallo 2p. & Tota \\
\hline \multirow{10}{*}{ OBERVADOR A } & 3p. + adicional & 0 & 0 & 0 & 0 & 0 & 0 & 0 & 0 & 0 & 0 \\
\hline & 3puntos & 0 & 3 & 0 & 0 & 0 & 0 & 0 & 0 & 0 & 3 \\
\hline & Falta +3 adic. & 0 & 0 & 0 & 0 & 0 & 0 & 0 & 0 & 0 & 0 \\
\hline & 2p. + adicional & 0 & 0 & 0 & 2 & 0 & 0 & 0 & 0 & 0 & 2 \\
\hline & 2 puntos & 0 & 0 & 0 & 0 & 15 & 0 & 0 & 0 & 0 & 15 \\
\hline & Falta +2 adic. & 0 & 0 & 0 & 0 & 0 & 2 & 0 & 0 & 0 & 2 \\
\hline & Tapón & 0 & 0 & 0 & 0 & 0 & 0 & 1 & 0 & 0 & 1 \\
\hline & Fallo 3p. & 0 & 0 & 0 & 0 & 0 & 0 & 0 & 4 & 0 & 4 \\
\hline & Fallo $2 \mathrm{p}$. & 0 & 0 & 0 & 0 & 0 & 0 & 0 & 0 & 34 & 34 \\
\hline & Total & 0 & 3 & 0 & 2 & 15 & 2 & 1 & 4 & 34 & 61 \\
\hline
\end{tabular}

\begin{tabular}{|c|l|c|c|c|c|c|c|}
\hline \multicolumn{2}{|c|}{$\mathbf{N = 6 1}$} & \multicolumn{7}{|c|}{ OBERVADOR A* } \\
\cline { 3 - 9 } & & Uno & Dos & Tres & Cuatro & Cinco & Total \\
\hline \multirow{4}{*}{ OBERVADOR A } & Uno & 9 & 0 & 0 & 0 & 0 & $\mathbf{9}$ \\
\cline { 2 - 9 } & Dos & 0 & 15 & 0 & 0 & 0 & $\mathbf{1 5}$ \\
\cline { 2 - 9 } & Tres & 0 & 0 & 23 & 0 & 0 & $\mathbf{2 3}$ \\
\cline { 2 - 9 } & Cuatro & 0 & 0 & 0 & 12 & 0 & $\mathbf{1 2}$ \\
\cline { 2 - 9 } & Cinco & 0 & 0 & 0 & 0 & 2 & $\mathbf{2}$ \\
\cline { 2 - 9 } & Total & $\mathbf{9}$ & $\mathbf{1 5}$ & $\mathbf{2 3}$ & $\mathbf{1 2}$ & $\mathbf{2}$ & $\mathbf{6 1}$ \\
\hline
\end{tabular}

\begin{tabular}{|l|l|c|c|c|c|}
\hline \multirow{2}{*}{$\mathbf{N = 6 1}$} & \multicolumn{4}{|c|}{ OBERVADOR A* } \\
\cline { 3 - 6 } & & $0-8$ & $9-16$ & $17-24$ & Total \\
\hline \multirow{4}{*}{ OBERVADOR A } & $0-8$ & 28 & 0 & 0 & $\mathbf{2 8}$ \\
\cline { 2 - 6 } & $9-16$ & 0 & 22 & 0 & $\mathbf{2 2}$ \\
\cline { 2 - 6 } & $17-24$ & 0 & 0 & 11 & $\mathbf{1 1}$ \\
\cline { 2 - 6 } & Total & $\mathbf{2 8}$ & $\mathbf{2 2}$ & $\mathbf{1 1}$ & $\mathbf{6 1}$ \\
\hline
\end{tabular}




\begin{tabular}{|l|l|c|c|c|c|}
\hline \multirow{2}{*}{$\mathbf{N = 6 1}$} & \multicolumn{4}{c|}{ OBERVADOR A* } \\
\cline { 3 - 6 } & & Buen tiro & Tiro normal & Mal tiro & Total \\
\hline \multirow{3}{*}{ OBERVADOR A A } & Buen tiro & 12 & 1 & 0 & $\mathbf{1 3}$ \\
\cline { 2 - 6 } & Tiro normal & 0 & 37 & 0 & $\mathbf{3 7}$ \\
\cline { 2 - 6 } & Mal tiro & 0 & 0 & 11 & $\mathbf{1 1}$ \\
\cline { 2 - 6 } & Total & $\mathbf{1 2}$ & $\mathbf{3 8}$ & $\mathbf{1 1}$ & $\mathbf{6 1}$ \\
\hline
\end{tabular}

\begin{tabular}{|c|c|c|c|c|c|c|c|}
\hline \multirow[t]{2}{*}{$N=61$} & & \multicolumn{6}{|c|}{ OBERVADOR A* } \\
\hline & & (+) $11-20$ & (+) $1-10$ & Empate & (-) $1-10$ & (-) $11-20$ & Total \\
\hline \multirow{6}{*}{ OBERVADOR A } & (+) $11-20$ & 0 & 0 & 0 & 0 & 0 & 0 \\
\hline & (+) $1-10$ & 0 & 5 & 0 & 0 & 0 & 5 \\
\hline & Empate & 0 & 0 & 3 & 0 & 0 & 3 \\
\hline & (-) $1-10$ & 0 & 0 & 0 & 53 & 0 & 53 \\
\hline & (-) $11-20$ & 0 & 0 & 0 & 0 & 0 & 0 \\
\hline & Total & 0 & 5 & 3 & 53 & 0 & 61 \\
\hline
\end{tabular}

\begin{tabular}{|c|c|c|c|c|c|c|c|c|}
\hline \multirow[t]{2}{*}{$N=61$} & & \multicolumn{7}{|c|}{ OBERVADOR A* } \\
\hline & & Contraataque & Bloqueo Directo & Pase & Jugada Personal & Robo & Rebote & Total \\
\hline \multirow{7}{*}{ OBERVADOR A } & Contraataque & 3 & 0 & 0 & 0 & 0 & 0 & 3 \\
\hline & Bloqueo Directo & 0 & 6 & 0 & 0 & 0 & 0 & 6 \\
\hline & Pase & 0 & 0 & 20 & 0 & 0 & 0 & 20 \\
\hline & Jugada Personal & 0 & 0 & 0 & 26 & 0 & 0 & 26 \\
\hline & Robo & 0 & 0 & 0 & 0 & 2 & 0 & 2 \\
\hline & Rebote & 0 & 0 & 0 & 0 & 0 & 4 & 4 \\
\hline & Total & 3 & 6 & 20 & 26 & 2 & 4 & 61 \\
\hline
\end{tabular}

\begin{tabular}{|c|c|c|c|c|c|c|}
\hline \multirow[t]{2}{*}{$N=61$} & & \multicolumn{5}{|c|}{ OBERVADOR A* } \\
\hline & & 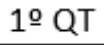 & 2ㅇ QT & 3ㅇ QT & 4으 QT & Total \\
\hline \multirow{5}{*}{ OBERVADOR A } & 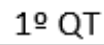 & 18 & 0 & 0 & 0 & 18 \\
\hline & $2 \cong Q T$ & 0 & 14 & 0 & 0 & 14 \\
\hline & зQ QT & 0 & 0 & 16 & 0 & 16 \\
\hline & 4ㅇ QT & 0 & 0 & 0 & 13 & 13 \\
\hline & Total & 18 & 14 & 16 & 13 & 61 \\
\hline
\end{tabular}

\begin{tabular}{|l|l|c|c|c|}
\hline \multirow{2}{*}{$\mathbf{N}=\mathbf{7}$} & \multicolumn{3}{|c|}{ OBERVADOR A* } \\
\cline { 3 - 5 } & & Tiempo Muerto & Última Jugada & Total \\
\hline \multirow{3}{*}{ OBERVADOR A A } & Tiempo Muerto & 4 & 0 & $\mathbf{4}$ \\
\cline { 2 - 5 } & Última Jugada & 0 & 3 & $\mathbf{3}$ \\
\cline { 2 - 5 } & Total & $\mathbf{4}$ & $\mathbf{3}$ & $\mathbf{7}$ \\
\hline
\end{tabular}




\subsection{TABLAS INTEROBSERVADOR}

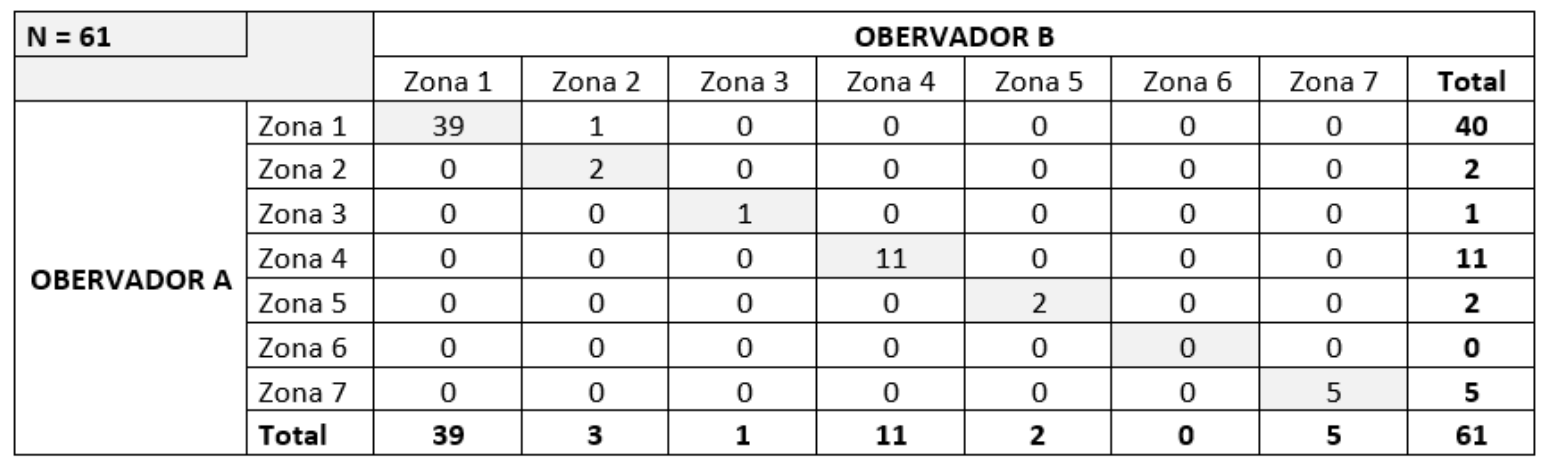

\begin{tabular}{|c|c|c|c|c|c|c|c|c|c|c|c|}
\hline \multirow[t]{2}{*}{$N=61$} & & \multicolumn{10}{|c|}{ OBERVADOR B } \\
\hline & & 3p. + adicional & 3puntos & Falta +3 adic. & $2 \mathrm{p} .+$ adicional & 2 puntos & Falta +2 adic. & Tapón & Fallo $3 p$. & Fallo $2 \mathrm{p}$. & Total \\
\hline \multirow{10}{*}{ OBERVADOR A } & 3p. + adicional & 0 & 0 & 0 & 0 & 0 & 0 & 0 & 0 & 0 & 0 \\
\hline & 3puntos & 0 & 3 & 0 & 0 & 0 & 0 & 0 & 0 & 0 & 3 \\
\hline & Falta +3 adic. & 0 & 0 & 0 & 0 & 0 & 0 & 0 & 0 & 0 & 0 \\
\hline & $2 \mathrm{p} .+$ adicional & 0 & 0 & 0 & 2 & 0 & 0 & 0 & 0 & 0 & 2 \\
\hline & 2 puntos & 0 & 0 & 0 & 0 & 15 & 0 & 0 & 0 & 0 & 15 \\
\hline & Falta +2 adic. & 0 & 0 & 0 & 0 & 0 & 2 & 0 & 0 & 0 & 2 \\
\hline & Tapón & 0 & 0 & 0 & 0 & 0 & 0 & 1 & 0 & 0 & 1 \\
\hline & Fallo 3p. & 0 & 0 & 0 & 0 & 0 & 0 & 0 & 4 & 0 & 4 \\
\hline & Fallo $2 \mathrm{p}$. & 0 & 0 & 0 & 0 & 0 & 0 & 0 & 0 & 34 & 34 \\
\hline & Total & 0 & 3 & 0 & 2 & 15 & 2 & 1 & 4 & 34 & 61 \\
\hline
\end{tabular}

\begin{tabular}{|c|c|c|c|c|c|c|c|}
\hline \multirow[t]{2}{*}{$N=61$} & & \multicolumn{6}{|c|}{ OBERVADOR B } \\
\hline & & Uno & Dos & Tres & Cuatro & Cinco & Total \\
\hline \multirow{6}{*}{ OBERVADOR A } & Uno & 9 & 0 & 0 & 0 & 0 & 9 \\
\hline & Dos & 0 & 15 & 0 & 0 & 0 & 15 \\
\hline & Tres & 0 & 0 & 23 & 0 & 0 & 23 \\
\hline & Cuatro & 0 & 0 & 0 & 12 & 0 & 12 \\
\hline & Cinco & 0 & 0 & 0 & 0 & 2 & 2 \\
\hline & Total & 9 & 15 & 23 & 12 & 2 & 61 \\
\hline
\end{tabular}

\begin{tabular}{|l|l|c|c|c|c|}
\hline \multicolumn{2}{|c|}{$\mathbf{N = 6 1}$} & \multicolumn{4}{c|}{ OBERVADOR B } \\
\cline { 3 - 6 } \multicolumn{2}{|c|}{} & $0-8$ & $9-16$ & $17-24$ & Total \\
\hline \multirow{4}{*}{ OBERVADOR A A } & $0-8$ & 27 & 1 & 0 & $\mathbf{2 8}$ \\
\cline { 2 - 6 } & $9-16$ & 0 & 22 & 0 & $\mathbf{2 2}$ \\
\cline { 2 - 6 } & $17-24$ & 0 & 0 & 11 & $\mathbf{1 1}$ \\
\cline { 2 - 6 } & Total & $\mathbf{2 7}$ & $\mathbf{2 3}$ & $\mathbf{1 1}$ & $\mathbf{6 1}$ \\
\hline
\end{tabular}

\begin{tabular}{|l|l|c|c|c|c|}
\hline \multirow{2}{*}{$\mathbf{N}=\mathbf{6 1}$} & \multicolumn{4}{|c|}{ OBERVADOR B } \\
\cline { 3 - 6 } & & Buen tiro & Tiro normal & Mal tiro & Total \\
\hline \multirow{3}{*}{ OBERVADOR A A } & Buen tiro & 12 & 1 & 0 & $\mathbf{1 3}$ \\
\cline { 2 - 6 } & Tiro normal & 1 & 36 & 0 & $\mathbf{3 7}$ \\
\cline { 2 - 6 } & Mal tiro & 0 & 0 & 11 & $\mathbf{1 1}$ \\
\cline { 2 - 6 } & Total & $\mathbf{1 3}$ & $\mathbf{3 7}$ & $\mathbf{1 1}$ & $\mathbf{6 1}$ \\
\hline
\end{tabular}




\begin{tabular}{|l|l|c|c|c|c|c|c|}
\hline \multicolumn{2}{|c|}{$\mathbf{N = 6 1}$} & \multicolumn{7}{|c|}{ OBERVADOR B } \\
\cline { 3 - 8 } & $(+) 11-20$ & $(+) 1-10$ & Empate & $(-) 1-10$ & $(-) 11-20$ & Total \\
\hline \multirow{4}{*}{ OBERVADOR A } & $(+) 11-20$ & 0 & 0 & 0 & 0 & 0 & $\mathbf{0}$ \\
\cline { 2 - 8 } & $(+) 1-10$ & 0 & 5 & 0 & 0 & 0 & $\mathbf{5}$ \\
\cline { 2 - 8 } & Empate & 0 & 0 & 3 & 0 & 0 & $\mathbf{3}$ \\
\cline { 2 - 8 } & $(-) 1-10$ & 0 & 0 & 0 & 53 & 0 & $\mathbf{5 3}$ \\
\cline { 2 - 8 } & $(-) 11-20$ & 0 & 0 & 0 & 0 & 0 & $\mathbf{0}$ \\
\cline { 2 - 8 } & Total & $\mathbf{0}$ & $\mathbf{5}$ & $\mathbf{3}$ & $\mathbf{5 3}$ & $\mathbf{0}$ & $\mathbf{6 1}$ \\
\hline
\end{tabular}

\begin{tabular}{|c|c|c|c|c|c|c|c|c|}
\hline \multirow[t]{2}{*}{$N=61$} & & \multicolumn{7}{|c|}{ OBERVADOR B } \\
\hline & & Contraataque & Bloqueo Directo & Pase & Jugada Personal & Robo & Rebote & Total \\
\hline \multirow{7}{*}{ OBERVADOR A } & Contraataque & 3 & 0 & 0 & 0 & 0 & 0 & 3 \\
\hline & Bloqueo Directo & 0 & 6 & 0 & 0 & 0 & 0 & 6 \\
\hline & Pase & 0 & 0 & 20 & 0 & 0 & 0 & 20 \\
\hline & Jugada Personal & 0 & 0 & 1 & 25 & 0 & 0 & 26 \\
\hline & Robo & 0 & 0 & 0 & 0 & 2 & 0 & 2 \\
\hline & Rebote & 0 & 0 & 0 & 0 & 0 & 4 & 4 \\
\hline & Total & 3 & 6 & 21 & 25 & 2 & 4 & 61 \\
\hline
\end{tabular}

\begin{tabular}{|c|c|c|c|c|c|c|}
\hline \multirow[t]{2}{*}{$N=61$} & & \multicolumn{5}{|c|}{ OBERVADOR B } \\
\hline & & 19 QT & 2Q QT & Зㅇ QT & 4ㅇ QT & Total \\
\hline \multirow{5}{*}{ OBERVADOR A } & 10 QT & 18 & 0 & 0 & 0 & 18 \\
\hline & 2QT & 0 & 14 & 0 & 0 & 14 \\
\hline & 3ㅇT & 0 & 0 & 16 & 0 & 16 \\
\hline & 4ㅇ QT & 0 & 0 & 0 & 13 & 13 \\
\hline & Total & 18 & 14 & 16 & 13 & 61 \\
\hline
\end{tabular}

\begin{tabular}{|l|l|c|c|c|}
\hline \multirow{2}{*}{$\mathbf{N = 7}$} & \multicolumn{3}{|c|}{ OBERVADOR B } \\
\cline { 3 - 5 } & & Tiempo Muerto & Última Jugada & Total \\
\hline \multirow{3}{*}{ OBERVADOR A } & Tiempo Muerto & 4 & 0 & $\mathbf{4}$ \\
\cline { 2 - 5 } & Última Jugada & 0 & 3 & $\mathbf{3}$ \\
\cline { 2 - 5 } & Total & $\mathbf{4}$ & $\mathbf{3}$ & $\mathbf{7}$ \\
\hline
\end{tabular}




\subsection{ENCUENTROS ANALIZADOS}

\begin{tabular}{|c|c|c|c|}
\hline \multicolumn{2}{|r|}{ LIGA ENDESA 2017/18 } & \multicolumn{2}{|r|}{ LIGA ENDESA 2018/19 } \\
\hline & Barca - KIROLBET Baskonia & & Monbus Obradoiro - KIROLBET Baskonia \\
\hline 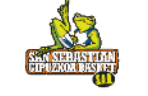 & C. Joventut Badalona - Delteco GBC & $\frac{15}{15}$ & Valencia Basket Club - Delteco GBC \\
\hline 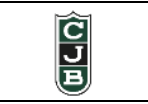 & Monbus Obradoiro - C. Joventut Badalona & $\begin{array}{l}\mathbf{C} \\
\text { J } \\
\end{array}$ & Herbalife Gran Canaria - C. Joventut Badalona \\
\hline A & C. Joventut Badalona - Barca & 蹒 & Unicaja - Barca \\
\hline & UCAM Murcia - Herbalife Gran Canaria & & Casademont Zaragoza - Herbalife G. Canaria \\
\hline 98 & Montakit Fuenlabrada - Iberostar Tenerife & & Barca - Iberostar Tenerife \\
\hline $\begin{array}{l}\text { MONuSA } \\
\text { OBRA } \\
\text { DOIRA }\end{array}$ & UCAM Murcia - Monbus Obradoiro & $\begin{array}{l}\text { Mow } \\
\text { OB }\end{array}$ & Cafés Candelas Breogán - Monbus Obradoiro \\
\hline 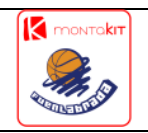 & Coosur Real Betis - Montakit Fuenlabrada & 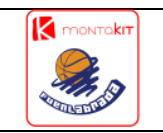 & Herbalife G. Canaria - Montakit Fuenlabrada \\
\hline 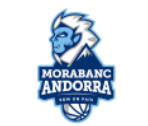 & Movistar Estudiantes - MoraBanc Andorra & & Barca - MoraBanc Andorra \\
\hline & Real Madrid - Movistar Estudiantes & & Herbalife Gran Canaria - Movistar Estudiantes \\
\hline 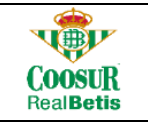 & C. Joventut Badalona - Coosur Real Betis & & Barca - Cafés Candelas Breogán \\
\hline & San Pablo Burgos - Real Madrid & & Barca - Real Madrid \\
\hline & UCAM Murcia - RETAbet Bilbao Basket & & MoraBanc Andorra - BAXI Manresa \\
\hline Burcos & Casademont Zaragoza - San Pablo Burgos & Burcos & Monbus Obradoiro - San Pablo Burgos \\
\hline & Monbus Obradoiro - Casademont Zaragoza & & Iberostar Tenerife - Casademont Zaragoza \\
\hline $\begin{array}{l}\text { VIFe } \\
\text { Unicaja }\end{array}$ & RETAbet Bilbao Basket - Unicaja & $\begin{array}{l}W / 1 / 2 \\
\text { Unicaja }\end{array}$ & Real Madrid - Unicaja \\
\hline 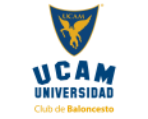 & Casademont Zaragoza - UCAM Murcia & $\underset{\text { ULIVESSIOAO }}{C}$ & MoraBanc Andorra - UCAM Murcia CB \\
\hline 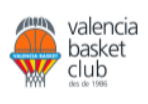 & Movistar Estudiantes - Valencia Basket Club & $\begin{array}{l}\text { valiancia } \\
\text { basket } \\
\text { cilub } \\
\text { calub }\end{array}$ & C. Joventut Badalona - Valencia Basket Club \\
\hline
\end{tabular}




\begin{tabular}{|c|c|c|c|}
\hline \multicolumn{2}{|r|}{ L.F ENDESA 2017/18 } & \multicolumn{2}{|r|}{ L.F ENDESA 2018/19 } \\
\hline 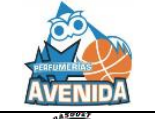 & Campus Promete - Perfumerías Avenida & $A$ & Duran Maquinaria Ensino - Perfumerías Avenida \\
\hline Qund & IDK Gipuzkoa - Spar Citylift Girona & & IDK Gipuzkoa - Spar Citylift Girona \\
\hline & Quesos El Pastor - Star Center-Uni Ferrol & & IDK Gipuzkoa - Star Center-Uni Ferrol \\
\hline & IDK Gipuzkoa - Mann-Filter Casablanca & & IDK Gipuzkoa - Mann-Filter Casablanca \\
\hline IDK GIPUZKKOA & Snatt’s Femení Sant Adriá - IDK Gipuzkoa & IDK GIPUzKOA & Nissan Al-Qázeres - IDK Gipuzkoa \\
\hline & CadÍ la Seu - Lointek Guernika Bizkaia & & IDK Gipuzkoa - Lointek Guernika Bizkaia \\
\hline & Cadí la Seu - Snatt's Femení Sant Adriá & & Valencia B.C. - Snatt's Femení Sant Adriá \\
\hline & IDK Gipuzkoa - Cadí la Seu & & Mann-Filter Casablanca - Cadí la Seu \\
\hline & Mann-Filter Casablanca - Nissan Al-Qázeres & & E. Pajariel Bembibre PDM - Nissan Al-Qázeres \\
\hline & Lointek Guernika Bizkaia - RPK Araski & & Star Center-Uni Ferrol - RPK Araski \\
\hline & IDK Gipuzkoa - E. Pajariel Bembibre & & Duran Maquinaria Ensino - E. Pajariel Bembibre \\
\hline & RPK Araski - Quesos El Pastor & & IDK Gipuzkoa - Quesos El Pastor \\
\hline & RPK Araski - Campus Promete & & IDK Gipuzkoa - Valencia B.C. \\
\hline & Star Center-Uni Ferrol - Movistar Estudiantes & 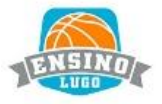 & RPK Araski - Duran Maquinaria Ensino \\
\hline
\end{tabular}




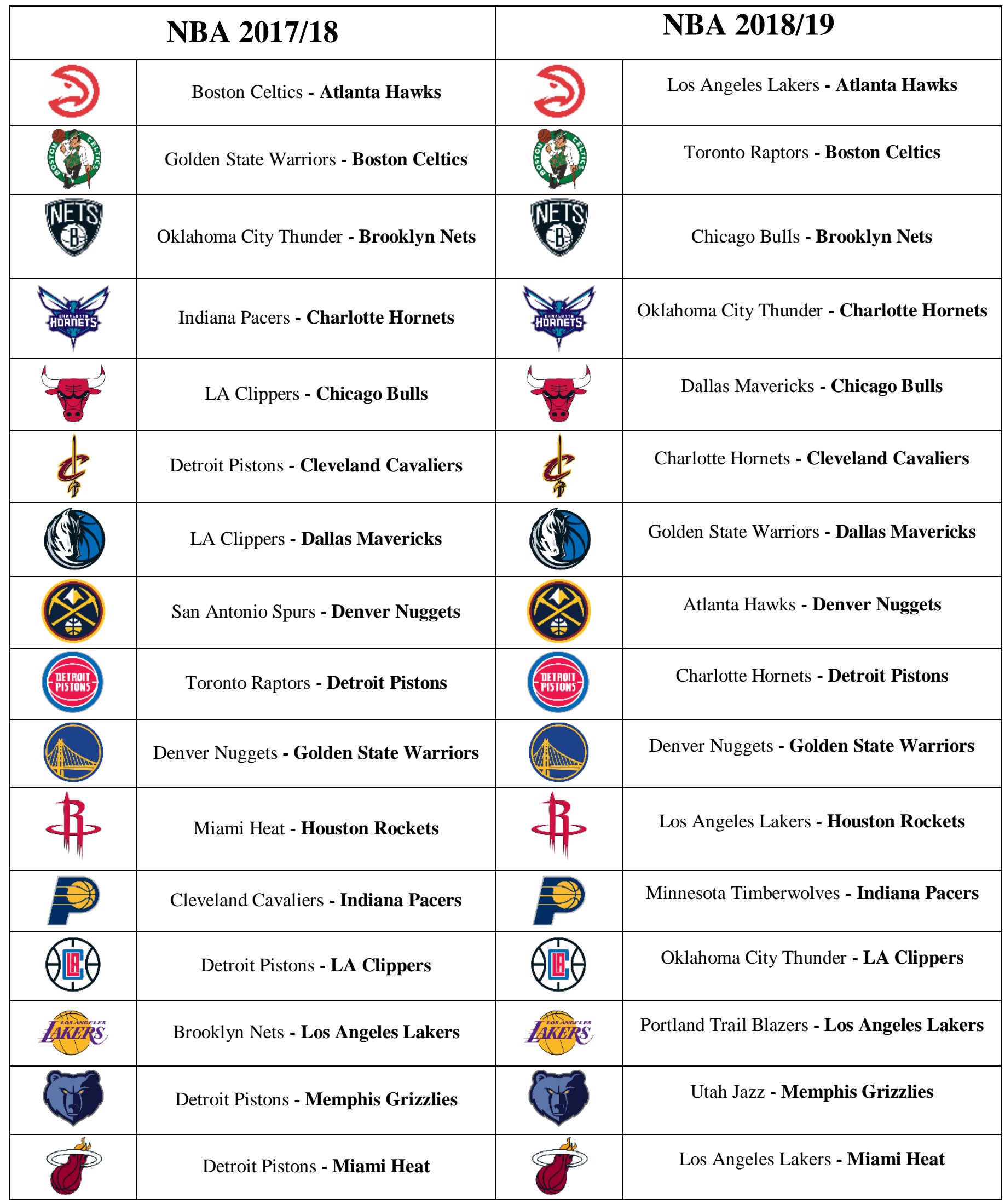




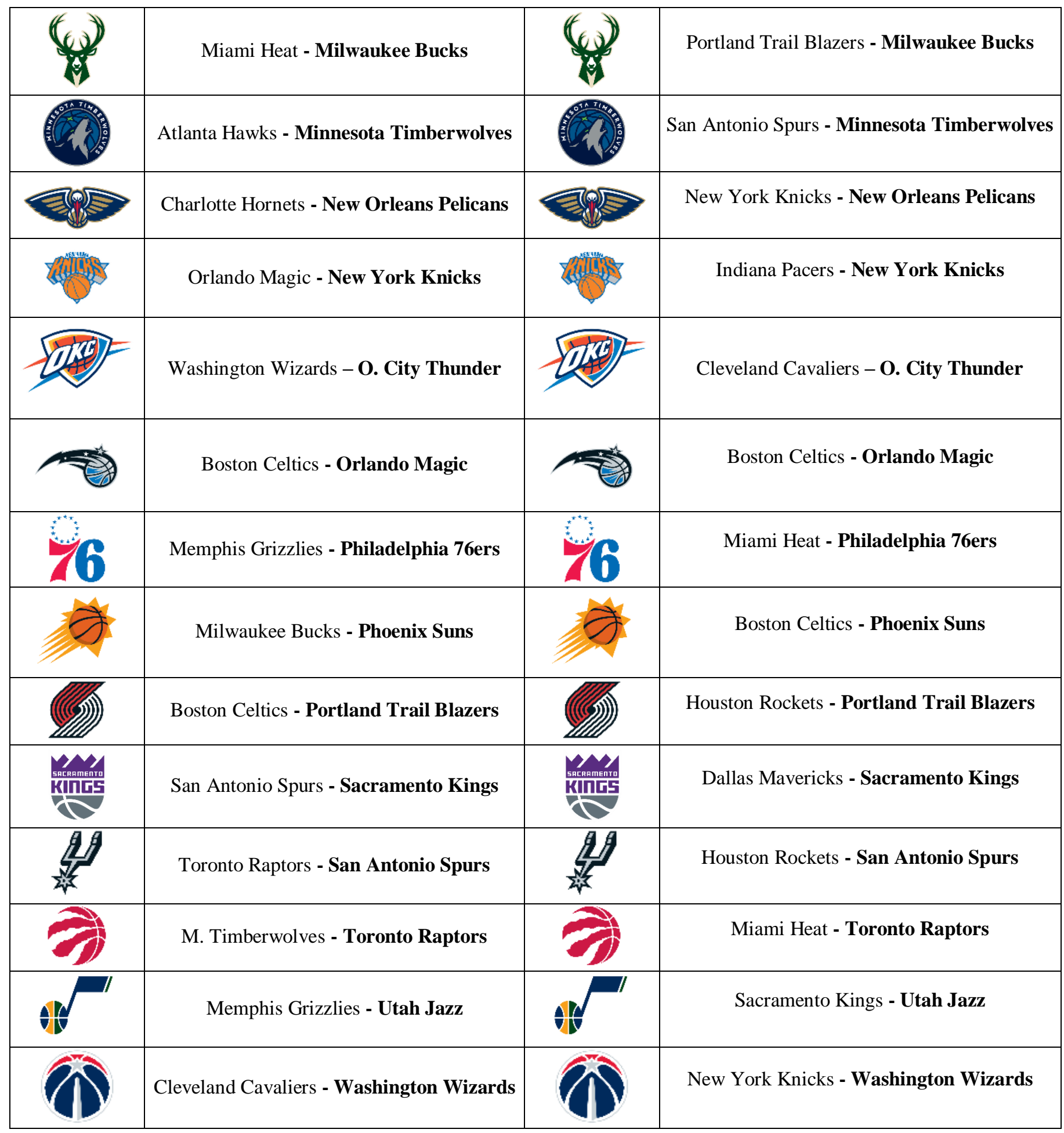




\begin{tabular}{|c|c|c|c|}
\hline \multicolumn{2}{|r|}{ WNBA 2017/18 } & \multicolumn{2}{|r|}{ WNBA 2018/19 } \\
\hline 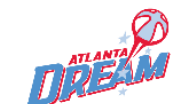 & Los Angeles Sparks - Atlanta Dream & 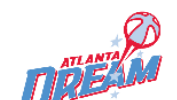 & Dallas Wings - Atlanta Dream \\
\hline & Indiana Fever - Chicago Sky & & Las Vegas Aces - Chicago Sky \\
\hline & Atlanta Dream - Connecticut Sun & & Los Angeles Sparks - Connecticut Sun \\
\hline & Phoenix Mercury - Dallas Wings & & New York Liberty - Dallas Wings \\
\hline & Washington Mystics - Indiana Fever & & Connecticut Sun - Indiana Fever \\
\hline & Phoenix Mercury - Las Vegas Aces & & Phoenix Mercury - Las Vegas Aces \\
\hline & Minnesota Lynx - Los Angeles Sparks & & Las Vegas Aces - Los Angeles Sparks \\
\hline & New York Liberty - Minnesota Lynx & & Connecticut Sun - Minnesota Lynx \\
\hline & Chicago Sky - New York Liberty & & Seattle Storm - New York Liberty \\
\hline & Seattle Storm - Phoenix Mercury & & Seattle Storm - Phoenix Mercury \\
\hline & Phoenix Mercury - Seattle Storm & & Washington Mystics - Seattle Storm \\
\hline (iingics & Indiana Fever - Washington Mystics & (iinstics & Chicago Sky - Washington Mystics \\
\hline
\end{tabular}




\begin{tabular}{|c|c|c|c|}
\hline \multicolumn{2}{|c|}{ T.A. EUROLEAGUE 2017/18 } & \multicolumn{2}{|c|}{ T.A. EUROLEAGUE 2018/19 } \\
\hline & Barca - Anadolu Efes Istambul & & $\begin{array}{c}\text { Herbalife Gran Canaria - Anadolu Efes } \\
\text { Istambul }\end{array}$ \\
\hline $\begin{array}{l}\text { brose } \\
\text { bamberg }\end{array}$ & Crvena Zvezda mts Belgrade - Brose Bamberg & & Real Madrid - Herbalife Gran Canaria \\
\hline & Fenerbahce Dogus Istanbul - Barca & & Herbalife Gran Canaria - Barca \\
\hline & Unicaja - KIROLBET Baskonia & & Zalgiris Kaunas - KIROLBET Baskonia \\
\hline & Panathinaikos - CSKA Moscow & & KIROLBET Baskonia - CSKA Moscow \\
\hline & Zalgiris Kaunas - Crvena Zvezda mts Belgrade & & Barca - Bayern de Múnich \\
\hline & Unicaja - Fenerbahce Dogus Istanbul & & K. Baskonia - Fenerbahce Dogus Istanbul \\
\hline & Valencia Basket Club - Khimki Moscow Region & & Real Madrid - Khimki Moscow Region \\
\hline & Khimki Moscow Region - Maccabi F. Tel Aviv & & Real Madrid - Maccabi F. Tel Aviv \\
\hline & Barca - AX Armani Exchange Olimpia Milan & & Barca - AX A. Exchange Olimpia Milan \\
\hline & Maccabi FOX Tel Aviv - Olympiacos & & KIROLBET Baskonia - Olympiacos \\
\hline & KIROLBET Baskonia - Panathinaikos & & KIROLBET Baskonia - Panathinaikos \\
\hline & Unicaja - Real Madrid & & AX A. Exchange Olimpia Milan - Real Madrid \\
\hline Unicaja & Olympiacos - Unicaja & 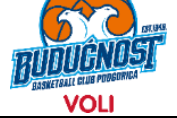 & Darussafaka S.K. - K.K. Buducnost Podgorica \\
\hline $\begin{array}{l}\text { valencia } \\
\text { basket } \\
\text { club }\end{array}$ & Khimki Moscow Region - Valencia B. Club & & Panathinaikos - Darussafaka S.K. \\
\hline & Crvena Zvezda mts Belgrade - Zalgiris Kaunas & & Herbalife Gran Canaria - Zalgiris Kaunas \\
\hline
\end{tabular}




\begin{tabular}{|c|c|c|c|}
\hline \multicolumn{2}{|c|}{ EUROLEAGUE W. $2017 / 18$} & \multicolumn{2}{|c|}{ EUROLEAGUE W. 2018/19 } \\
\hline 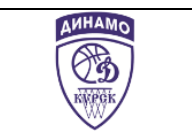 & ESB Villeneuve-d'Ascq - Dynamo Kursk & 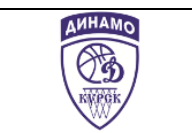 & TTT Riga - Dynamo Kursk \\
\hline 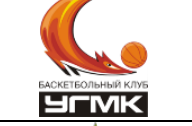 & Perfumerías Avenida - UMMC Ekaterinburg & 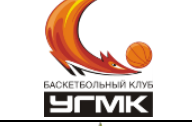 & Famila B. Schio - UMMC Ekaterinburg \\
\hline & CCC Polkowice - Sopron Basket & & Perfumerías Avenida - Sopron Basket \\
\hline & Mithra Castors Braine - USK Praha & & Nadezhda - USK Praha \\
\hline & Wisla Can-Pack Krakow - Fenerbahce & & Dynamo Kursk - Fenerbahce \\
\hline & Sopron Basket - CJM Bourges Basket & & USK Praha - CJM Bourges Basket \\
\hline $\begin{array}{l}\text { mithra } \\
\text { CASTOA } \\
\text { *A*** BRAIII }\end{array}$ & USK Praha - Mithra Castors Braine & 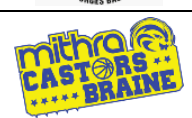 & ESB Villeneuve-d'Ascq - M. Castors Braine \\
\hline & ESB Villeneuve-d'Ascq - CCC Polkowice & & UMMC Ekaterinburg - CCC Polkowice \\
\hline & Perfumerías Avenida - Famila B. Schio & & Mithra Castors Braine - Famila B. Schio \\
\hline & Fenerbahce - Nadezhda & & CJM Bourges Basket - Nadezhda \\
\hline & Galatasaray - ESB Villeneuve-d'Ascq & & Famila Basket Schio - ESB Villeneuve-d'Ascq \\
\hline & Famila Basket Schio - Yakin Dogu U. & & Hatay - Olympiacos \\
\hline & Perf. Avenida - Wisla Can-Pack Krakow & & Sopron Basket - TTT Riga \\
\hline GAZELIIES & Famila B. Schio - B. Lattes Montpellier A. & & Flammes Carolo - Hatay \\
\hline & Mithra Castors Braine - Galatasaray & & Fenerbahce - Flammes Carolo \\
\hline Aven & Wisla Can-Pack Krakow - Perf. Avenida & & TTT Riga - Perfumerías Avenida \\
\hline
\end{tabular}




\subsection{DATOS OBTENIDOS}

\subsubsection{Totales}

\begin{tabular}{|c|c|c|c|c|c|c|c|}
\cline { 2 - 8 } \multicolumn{1}{c|}{} & ZONA 1 & ZONA 2 & ZONA 3 & ZONA 4 & ZONA 5 & ZONA 6 & ZONA 7 \\
\hline 3p. + adicional & 0 & 0 & 0 & 0 & 4 & 3 & 7 \\
\hline 3puntos & 0 & 0 & 0 & 0 & 308 & 264 & 1071 \\
\hline Falta + 3 adic. & 0 & 0 & 0 & 0 & 10 & 9 & 37 \\
\hline 2p. + adicional & 310 & 19 & 7 & 2 & 0 & 0 & 0 \\
\hline 2puntos & 3287 & 272 & 283 & 426 & 0 & 0 & 0 \\
\hline Falta + 2 adic. & 901 & 33 & 32 & 29 & 0 & 0 & 0 \\
\hline Tapón & 522 & 21 & 14 & 9 & 4 & 12 & 13 \\
\hline Fallo 3p. & 0 & 0 & 0 & 0 & 542 & 488 & 2162 \\
\hline Fallo 2p. & 2645 & 562 & 510 & 667 & 0 & 0 & 0 \\
\hline
\end{tabular}

\begin{tabular}{|c|c|c|c|c|c|c|c|}
\cline { 2 - 8 } \multicolumn{1}{c|}{} & ZONA 1 & ZONA 2 & ZONA 3 & ZONA 4 & ZONA 5 & ZONA 6 & ZONA 7 \\
\hline $\mathbf{0 - \mathbf { 8 }}$ & 2278 & 389 & 345 & 381 & 283 & 306 & 1157 \\
\hline $\mathbf{9 - 1 6}$ & 3771 & 435 & 397 & 626 & 432 & 343 & 1557 \\
\hline $\mathbf{1 7}-\mathbf{2 4}$ & 1616 & 83 & 104 & 126 & 153 & 127 & 576 \\
\hline
\end{tabular}

\begin{tabular}{|c|c|c|c|c|c|c|c|}
\cline { 2 - 8 } \multicolumn{1}{c|}{} & ZONA 1 & ZONA 2 & ZONA 3 & ZONA 4 & ZONA 5 & ZONA 6 & ZONA 7 \\
\hline Buen tiro & 1904 & 209 & 205 & 555 & 596 & 520 & 1855 \\
\hline Tiro normal & 4818 & 473 & 465 & 496 & 235 & 217 & 1001 \\
\hline Mal tiro & 943 & 225 & 176 & 82 & 37 & 39 & 434 \\
\hline
\end{tabular}

\begin{tabular}{|c|c|c|c|c|c|c|c|}
\cline { 2 - 9 } \multicolumn{1}{c|}{} & ZONA 1 & ZONA 2 & ZONA 3 & ZONA 4 & ZONA 5 & ZONA 6 & ZONA 7 \\
\hline (+) 11 - 20 & 159 & 18 & 16 & 24 & 13 & 11 & 80 \\
\hline (+) 1 - 10 & 2610 & 350 & 299 & 428 & 306 & 297 & 1095 \\
\hline Empate & 557 & 66 & 66 & 87 & 73 & 64 & 230 \\
\hline (-) $\mathbf{1}-\mathbf{1 0}$ & 3662 & 418 & 412 & 499 & 403 & 343 & 1579 \\
\hline (-) 11 - 20 & 677 & 55 & 53 & 95 & 73 & 61 & 306 \\
\hline
\end{tabular}

\begin{tabular}{|c|c|c|c|c|c|c|c|}
\cline { 2 - 8 } \multicolumn{1}{c|}{} & ZONA 1 & ZONA 2 & ZONA 3 & ZONA 4 & ZONA 5 & ZONA 6 & ZONA 7 \\
\hline Contraataque & 310 & 2 & 6 & 4 & 13 & 11 & 28 \\
\hline Bloqueo Directo & 1126 & 140 & 145 & 407 & 33 & 17 & 665 \\
\hline Pase & 1378 & 224 & 246 & 306 & 722 & 659 & 1985 \\
\hline Jugada Personal & 3698 & 525 & 433 & 410 & 83 & 78 & 565 \\
\hline Robo & 373 & 6 & 8 & 3 & 15 & 5 & 29 \\
\hline Rebote & 780 & 10 & 8 & 3 & 2 & 6 & 18 \\
\hline
\end{tabular}

\begin{tabular}{|c|c|c|c|c|c|c|c|}
\cline { 2 - 8 } \multicolumn{1}{c|}{} & ZONA 1 & ZONA 2 & ZONA 3 & ZONA 4 & ZONA 5 & ZONA 6 & ZONA 7 \\
\hline Uno & 2122 & 118 & 149 & 191 & 18 & 29 & 424 \\
\hline Dos & 2411 & 298 & 269 & 368 & 332 & 270 & 1305 \\
\hline Tres & 2031 & 307 & 273 & 378 & 299 & 257 & 961 \\
\hline Cuatro & 910 & 154 & 130 & 162 & 177 & 188 & 506 \\
\hline Cinco & 191 & 30 & 25 & 34 & 42 & 32 & 94 \\
\hline
\end{tabular}




\begin{tabular}{|l|c|c|c|c|c|c|c|}
\cline { 2 - 8 } \multicolumn{1}{c|}{} & ZONA 1 & ZONA 2 & ZONA 3 & ZONA 4 & ZONA 5 & ZONA 6 & ZONA 7 \\
\hline 10 QT & 2003 & 256 & 229 & 367 & 250 & 192 & 733 \\
\hline 20 QT & 1938 & 240 & 219 & 274 & 216 & 194 & 837 \\
\hline 30 QT & 1878 & 219 & 204 & 269 & 200 & 200 & 811 \\
\hline 40 QT & 1846 & 192 & 194 & 223 & 202 & 190 & 909 \\
\hline
\end{tabular}

\begin{tabular}{|c|c|c|c|c|c|c|c|}
\cline { 2 - 8 } \multicolumn{1}{c|}{} & ZONA 1 & ZONA 2 & ZONA 3 & ZONA 4 & ZONA 5 & ZONA 6 & ZONA 7 \\
\hline Tiempo Muerto & 267 & 41 & 31 & 42 & 35 & 29 & 143 \\
\hline Última Jugada & 92 & 12 & 16 & 26 & 18 & 13 & 132 \\
\hline
\end{tabular}

\begin{tabular}{|c|c|c|c|c|c|c|c|c|c|}
\hline & 3p. + adicional & 3puntos & Falta +3 adic. & 2p. + adicional & 2puntos & Falta +2 adic. & Tapón & Fallo 3p. & Fallo 2p. \\
\hline $0-8$ & 2 & 524 & 16 & 80 & 1248 & 290 & 193 & 1189 & 1597 \\
\hline $9-16$ & 10 & 804 & 30 & 177 & 2101 & 491 & 281 & 1479 & 2188 \\
\hline $17-24$ & 2 & 315 & 10 & 81 & 919 & 214 & 121 & 524 & 599 \\
\hline & 3p. + adicional & 3puntos & Falta +3 adic. & 2 p. + adicional & 2puntos & Falta +2 adic. & Tapón & Fallo 3p. & Fallo 2p. \\
\hline Buen tiro & 5 & 1200 & 11 & 76 & 2025 & 35 & 9 & 1755 & 728 \\
\hline Tiro normal & 8 & 378 & 38 & 244 & 2075 & 860 & 423 & 1012 & 2667 \\
\hline Mal tiro & 1 & 65 & 7 & 18 & 168 & 100 & 163 & 425 & 989 \\
\hline
\end{tabular}

\begin{tabular}{|c|c|c|c|c|c|c|c|c|c|}
\hline & 3p. + adicional & 3puntos & Falta +3 adic. & 2p. + adicional & 2 puntos & Falta +2 adic. & Tapón & Fallo 3p. & Fallo 2p. \\
\hline (+) $11-20$ & 0 & 29 & 2 & 7 & 86 & 11 & 15 & 72 & 99 \\
\hline$(+) 1-10$ & 3 & 507 & 21 & 86 & 1437 & 373 & 229 & 1154 & 1575 \\
\hline Empate & 2 & 136 & 2 & 23 & 333 & 60 & 35 & 227 & 325 \\
\hline$(-) 1-10$ & 5 & 778 & 27 & 180 & 2049 & 456 & 270 & 1503 & 2048 \\
\hline$(-) 11-20$ & 4 & 193 & 4 & 42 & 363 & 95 & 46 & 236 & 337 \\
\hline
\end{tabular}

\begin{tabular}{|c|c|c|c|c|c|c|c|c|c|}
\cline { 2 - 9 } \multicolumn{1}{c|}{} & 3p. + adicional & 3puntos & Falta + 3 adic. & 2p. + adicional & 2puntos & Falta + 2 adic. & Tapón & Fallo 3p. & Fallo 2p. \\
\hline Contraataque & 0 & 21 & 0 & 20 & 201 & 28 & 11 & 31 & 62 \\
\hline Bloqueo Directo & 1 & 242 & 14 & 32 & 721 & 174 & 80 & 454 & 815 \\
\hline Pase & 9 & 1140 & 30 & 66 & 1042 & 135 & 104 & 2169 & 825 \\
\hline Jugada Personal & 4 & 215 & 12 & 179 & 1705 & 534 & 332 & 489 & 2322 \\
\hline Robo & 0 & 19 & 0 & 12 & 233 & 37 & 28 & 29 & 81 \\
\hline Rebote & 0 & 6 & 0 & 29 & 366 & 87 & 40 & 20 & 279 \\
\hline
\end{tabular}

\begin{tabular}{|c|c|c|c|c|c|c|c|c|c|}
\hline & 3p. + adicional & 3puntos & Falta +3 adic. & 2p. + adicional & 2 puntos & Falta +2 adic. & Tapón & Fallo 3p. & Fallo 2p. \\
\hline Uno & 2 & 142 & 11 & 93 & 1001 & 291 & 163 & 312 & 1036 \\
\hline Dos & 5 & 645 & 24 & 117 & 1361 & 308 & 188 & 1220 & 1385 \\
\hline Tres & 5 & 507 & 13 & 90 & 1228 & 269 & 163 & 984 & 1247 \\
\hline Cuatro & 2 & 290 & 7 & 27 & 573 & 100 & 66 & 568 & 594 \\
\hline Cinco & 0 & 59 & 1 & 11 & 105 & 27 & 15 & 108 & 122 \\
\hline
\end{tabular}

\begin{tabular}{|c|c|c|c|c|c|c|c|c|c|}
\hline & 3p. + adicional & 3puntos & Falta +3 adic. & 2 p. + adicional & 2puntos & Falta +2 adic. & Tapón & Fallo 3p. & Fallo $2 p$ \\
\hline 10 QT & 3 & 400 & 16 & 84 & 1246 & 217 & 143 & 753 & 1168 \\
\hline 20 QT & 3 & 417 & 10 & 81 & 1068 & 268 & 135 & 810 & 1126 \\
\hline 3ㅇ QT & 2 & 406 & 15 & 87 & 1021 & 231 & 147 & 781 & 1091 \\
\hline 40 QT & 6 & 420 & 15 & 86 & 933 & 279 & 170 & 848 & 999 \\
\hline
\end{tabular}

\begin{tabular}{|c|c|c|c|c|c|c|c|c|c|}
\hline & 3p. + adicional & 3puntos & Falta +3 adic. & 2p. + adicional & 2puntos & Falta +2 adic. & Tapón & Fallo 3p. & Fallo 2p. \\
\hline Tiempo Muerto & 1 & 63 & 3 & 16 & 144 & 31 & 22 & 137 & 171 \\
\hline Última Jugada & 0 & 23 & 1 & 3 & 53 & 7 & 15 & 137 & 70 \\
\hline
\end{tabular}

\begin{tabular}{|c|c|c|c|}
\cline { 2 - 4 } \multicolumn{1}{c|}{} & $\mathbf{0 - \mathbf { 8 }}$ & $\mathbf{9 - 1 6}$ & $\mathbf{1 7 - 2 4}$ \\
\hline Buen tiro & 1498 & 2930 & 1416 \\
\hline Tiro normal & 2557 & 3974 & 1174 \\
\hline Mal tiro & 1084 & 657 & 195 \\
\hline
\end{tabular}




\begin{tabular}{|c|c|c|c|}
\cline { 2 - 4 } \multicolumn{1}{c|}{} & $\mathbf{0 - 8}$ & $\mathbf{9 - 1 6}$ & $\mathbf{1 7 - 2 4}$ \\
\hline (+) $\mathbf{1 1 - 2 0}$ & 110 & 150 & 61 \\
\hline (+) $\mathbf{1}-\mathbf{1 0}$ & 1874 & 2545 & 966 \\
\hline Empate & 393 & 546 & 204 \\
\hline (-) $\mathbf{1}-\mathbf{1 0}$ & 2352 & 3619 & 1345 \\
\hline (-) $\mathbf{1 1}-\mathbf{2 0}$ & 410 & 701 & $\mathbf{2 0 9}$ \\
\hline
\end{tabular}

\begin{tabular}{|c|c|c|c|}
\cline { 2 - 4 } \multicolumn{1}{c|}{} & $\mathbf{0 - 8}$ & $\mathbf{9 - 1 6}$ & $\mathbf{1 7 - 2 4}$ \\
\hline Contraataque & 9 & 2 & 363 \\
\hline Bloqueo Directo & 732 & 1528 & 273 \\
\hline Pase & 1862 & 2860 & 798 \\
\hline Jugada Personal & 2423 & 2567 & 802 \\
\hline Robo & 14 & 6 & 419 \\
\hline Rebote & 99 & 598 & 130 \\
\hline
\end{tabular}

\begin{tabular}{|c|c|c|c|}
\cline { 2 - 4 } \multicolumn{1}{c|}{} & $\mathbf{0 - 8}$ & $\mathbf{9 - 1 6}$ & $\mathbf{1 7 - 2 4}$ \\
\hline Uno & 468 & 1452 & 1131 \\
\hline Dos & 1213 & 2762 & 1278 \\
\hline Tres & 1776 & 2385 & 345 \\
\hline Cuatro & 1333 & 865 & 29 \\
\hline Cinco & 349 & 97 & 2 \\
\hline
\end{tabular}

\begin{tabular}{|l|c|c|c|}
\cline { 2 - 4 } \multicolumn{1}{c|}{} & $\mathbf{0 - \mathbf { 8 }}$ & $\mathbf{9 - 1 6}$ & $\mathbf{1 7 - 2 4}$ \\
\hline 10 QT & 1213 & 2042 & 775 \\
\hline 20 QT & 1299 & 1915 & 704 \\
\hline 3 QT & 1302 & 1785 & 694 \\
\hline 40 QT & 1325 & 1819 & 612 \\
\hline
\end{tabular}

\begin{tabular}{|c|c|c|c|}
\cline { 2 - 4 } \multicolumn{1}{c|}{} & $\mathbf{0 - 8}$ & $\mathbf{9 - 1 6}$ & $\mathbf{1 7 - 2 4}$ \\
\hline Tiempo Muerto & 276 & 260 & 52 \\
\hline Última Jugada & 309 & 0 & 0 \\
\hline
\end{tabular}

\begin{tabular}{|c|c|c|c|}
\cline { 2 - 4 } \multicolumn{1}{c|}{} & Buen tiro & Tiro normal & Mal tiro \\
\hline (+) $\mathbf{1 1}-\mathbf{2 0}$ & 111 & 171 & 39 \\
\hline (+) $\mathbf{1}-\mathbf{1 0}$ & 2001 & 2648 & 736 \\
\hline Empate & 472 & 555 & 116 \\
\hline (-) $\mathbf{1}-\mathbf{1 0}$ & 2770 & 3664 & 882 \\
\hline (-) $\mathbf{1 1}-\mathbf{2 0}$ & 490 & 667 & 163 \\
\hline
\end{tabular}




\begin{tabular}{|c|c|c|c|}
\cline { 2 - 4 } \multicolumn{1}{c|}{} & Buen tiro & Tiro normal & Mal tiro \\
\hline Contraataque & 263 & 102 & 9 \\
\hline Bloqueo Directo & 1036 & 1282 & 215 \\
\hline Pase & 3354 & 1822 & 344 \\
\hline Jugada Personal & 692 & 3788 & 1312 \\
\hline Robo & 278 & 144 & 17 \\
\hline Rebote & 221 & 567 & 39 \\
\hline
\end{tabular}

\begin{tabular}{|c|c|c|c|}
\cline { 2 - 4 } \multicolumn{1}{c|}{} & Buen tiro & Tiro normal & Mal tiro \\
\hline Uno & 789 & 1831 & 431 \\
\hline Dos & 2178 & 2444 & 631 \\
\hline Tres & 1800 & 2205 & 501 \\
\hline Cuatro & 914 & 1008 & 305 \\
\hline Cinco & 163 & 217 & 68 \\
\hline
\end{tabular}

\begin{tabular}{|c|c|c|c|}
\cline { 2 - 4 } \multicolumn{1}{c|}{} & Buen tiro & Tiro normal & Mal tiro \\
\hline 10 QT & 1588 & 2016 & 426 \\
\hline 20 QT & 1504 & 1913 & 501 \\
\hline 30 QT & 1431 & 1887 & 463 \\
\hline 40 QT & 1321 & 1889 & 546 \\
\hline
\end{tabular}

\begin{tabular}{|c|c|c|c|}
\cline { 2 - 4 } \multicolumn{1}{c|}{} & Buen tiro & Tiro normal & Mal tiro \\
\hline Tiempo Muerto & 201 & 282 & 105 \\
\hline Última Jugada & 62 & 113 & 134 \\
\hline
\end{tabular}

\begin{tabular}{|c|c|c|c|c|c|}
\cline { 2 - 6 } \multicolumn{1}{c|}{} & $(\boldsymbol{+}) \mathbf{1 1}-\mathbf{2 0}$ & $(\mathbf{+}) \mathbf{1}-\mathbf{1 0}$ & Empate & $(-) \mathbf{1}-\mathbf{1 0}$ & $(-\mathbf{)} \mathbf{1 1}-\mathbf{2 0}$ \\
\hline Contraataque & 12 & 146 & 23 & 173 & 20 \\
\hline Bloqueo Directo & 57 & 881 & 185 & 1199 & 211 \\
\hline Pase & 106 & 1959 & 420 & 2590 & 445 \\
\hline Jugada Personal & 115 & 1965 & 421 & 2779 & 512 \\
\hline Robo & 8 & 170 & 31 & 189 & 41 \\
\hline Rebote & 23 & 264 & 63 & 386 & 91 \\
\hline
\end{tabular}

\begin{tabular}{|c|c|c|c|c|c|}
\cline { 2 - 6 } \multicolumn{1}{c|}{} & $(\mathbf{+}) \mathbf{1 1}-\mathbf{2 0}$ & $(\mathbf{+}) \mathbf{1} \mathbf{- 1 0}$ & Empate & $(-) \mathbf{1}-\mathbf{1 0}$ & $(-) \mathbf{1 1}-\mathbf{2 0}$ \\
\hline Uno & 61 & 1012 & 204 & 1487 & $\mathbf{2 8 7}$ \\
\hline Dos & 128 & 1829 & 347 & 2487 & 462 \\
\hline Tres & 87 & 1568 & 357 & 2139 & 355 \\
\hline Cuatro & 35 & 839 & 183 & 984 & 186 \\
\hline Cinco & 10 & 137 & 52 & 219 & 30 \\
\hline
\end{tabular}




\begin{tabular}{|c|c|c|c|c|c|}
\cline { 2 - 6 } \multicolumn{1}{c|}{} & $\mathbf{( + )} \mathbf{1 1 - 2 0}$ & $\mathbf{( + )} \mathbf{1}-\mathbf{1 0}$ & Empate & $\mathbf{( - )} \mathbf{1}-\mathbf{1 0}$ & $(\mathbf{-}) \mathbf{1 1}-\mathbf{2 0}$ \\
\hline 10 QT & 32 & 1425 & 506 & 1985 & 82 \\
\hline 20 QT & 82 & 1529 & 276 & 1795 & 236 \\
\hline 39 QT & 97 & 1245 & 214 & 1814 & 411 \\
\hline 40 QT & 110 & 1186 & 147 & 1722 & 591 \\
\hline
\end{tabular}

\begin{tabular}{|c|c|c|c|c|c|}
\cline { 2 - 6 } \multicolumn{1}{c|}{} & $(\mathbf{+}) \mathbf{1 1}-\mathbf{2 0}$ & $\mathbf{( + )} \mathbf{1}-\mathbf{1 0}$ & Empate & $(-) \mathbf{1}-\mathbf{1 0}$ & $(-) \mathbf{1 1}-\mathbf{2 0}$ \\
\hline Tiempo Muerto & 13 & 148 & 28 & 332 & 67 \\
\hline Última Jugada & 9 & 107 & 13 & 151 & 29 \\
\hline
\end{tabular}

\begin{tabular}{|c|c|c|c|c|c|c|}
\cline { 2 - 7 } \multicolumn{1}{c|}{} & Contraataque & Bloqueo Directo & Pase & Jugada Personal & Robo & Rebote \\
\hline Uno & 29 & 592 & 0 & 1409 & 194 & 827 \\
\hline Dos & 225 & 931 & 2126 & 1769 & 202 & 0 \\
\hline Tres & 107 & 722 & 1967 & 1670 & 40 & 0 \\
\hline Cuatro & 13 & 242 & 1159 & 810 & 3 & 0 \\
\hline Cinco & 0 & 46 & 268 & 134 & 0 & 0 \\
\hline
\end{tabular}

\begin{tabular}{|c|c|c|c|c|c|c|}
\cline { 2 - 7 } \multicolumn{1}{c|}{} & Contraataque & Bloqueo Directo & Pase & Jugada Personal & Robo & Rebote \\
\hline 19 QT & 112 & 702 & 1420 & 1468 & 121 & 207 \\
\hline 20 QT & 105 & 617 & 1390 & 1483 & 103 & 220 \\
\hline 39 QT & 89 & 593 & 1390 & 1400 & 115 & 194 \\
\hline 40 QT & 68 & 621 & 1320 & 1441 & 100 & 206 \\
\hline
\end{tabular}

\begin{tabular}{|c|c|c|c|c|c|c|}
\cline { 2 - 7 } \multicolumn{1}{c|}{} & Contraataque & Bloqueo Directo & Pase & Jugada Personal & Robo & Rebote \\
\hline Tiempo Muerto & 0 & 90 & 238 & 260 & 0 & 0 \\
\hline Última Jugada & 6 & 36 & 94 & 162 & 11 & 0 \\
\hline
\end{tabular}

\begin{tabular}{|l|c|c|c|c|c|}
\cline { 2 - 6 } \multicolumn{1}{c|}{} & Uno & Dos & Tres & Cuatro & Cinco \\
\hline 10 QT & 760 & 1346 & 1215 & 590 & 119 \\
\hline 20 QT & 756 & 1311 & 1163 & 579 & 109 \\
\hline 3 QT & 759 & 1237 & 1102 & 572 & 111 \\
\hline 40 QT & 776 & 1359 & 1026 & 486 & 109 \\
\hline
\end{tabular}

\begin{tabular}{|c|c|c|c|c|c|}
\cline { 2 - 6 } \multicolumn{1}{c|}{} & Uno & Dos & Tres & Cuatro & Cinco \\
\hline Tiempo Muerto & 66 & 200 & 179 & 109 & 34 \\
\hline Última Jugada & 136 & 120 & 40 & 13 & 0 \\
\hline
\end{tabular}

\begin{tabular}{|l|c|c|c|c|}
\cline { 2 - 5 } \multicolumn{1}{c|}{} & 10 QT & 20 QT & 30 QT & 4ㅇ QT \\
\hline Tiempo Muerto & 88 & 146 & 101 & 253 \\
\hline Última Jugada & 81 & 79 & 96 & 53 \\
\hline
\end{tabular}


12.4.2. Baloncesto masculino (ACB, Euroliga y NBA)

\begin{tabular}{|c|c|c|c|c|c|c|c|}
\cline { 2 - 8 } \multicolumn{1}{c|}{} & ZONA 1 & ZONA 2 & ZONA 3 & ZONA 4 & ZONA 5 & ZONA 6 & ZONA 7 \\
\hline 3p. + adicional & 0 & 0 & 0 & 0 & 3 & 2 & 4 \\
\hline 3puntos & 0 & 0 & 0 & 0 & 222 & 197 & 786 \\
\hline Falta + 3 adic. & 0 & 0 & 0 & 0 & 9 & 8 & 34 \\
\hline 2p. + adicional & 201 & 13 & 3 & 1 & 0 & 0 & 0 \\
\hline 2puntos & 2163 & 143 & 146 & 231 & 0 & 0 & 0 \\
\hline Falta + 2 adic. & 569 & 22 & 21 & 17 & 0 & 0 & 0 \\
\hline Tapón & 345 & 9 & 9 & 2 & 2 & 7 & 10 \\
\hline Fallo 3p. & 0 & 0 & 0 & 0 & 362 & 323 & 1493 \\
\hline Fallo 2p. & 1501 & 307 & 281 & 355 & 0 & 0 & 0 \\
\hline
\end{tabular}

\begin{tabular}{|c|c|c|c|c|c|c|c|}
\cline { 2 - 8 } \multicolumn{1}{c|}{} & ZONA 1 & ZONA 2 & ZONA 3 & ZONA 4 & ZONA 5 & ZONA 6 & ZONA 7 \\
\hline $\mathbf{0 - \mathbf { 8 }}$ & 1414 & 227 & 195 & 208 & 204 & 211 & 811 \\
\hline $\mathbf{9 - 1 6}$ & 2337 & 231 & 210 & 337 & 289 & 238 & 1102 \\
\hline $\mathbf{1 7}-\mathbf{2 4}$ & 1028 & 36 & 55 & 61 & 105 & 88 & 414 \\
\hline
\end{tabular}

\begin{tabular}{|c|c|c|c|c|c|c|c|}
\cline { 2 - 8 } \multicolumn{1}{c|}{} & ZONA 1 & ZONA 2 & ZONA 3 & ZONA 4 & ZONA 5 & ZONA 6 & ZONA 7 \\
\hline Buen tiro & 1261 & 85 & 88 & 262 & 401 & 355 & 1239 \\
\hline Tiro normal & 2951 & 278 & 264 & 296 & 168 & 155 & 784 \\
\hline Mal tiro & 567 & 131 & 108 & 48 & 29 & 27 & 304 \\
\hline
\end{tabular}

\begin{tabular}{|c|c|c|c|c|c|c|c|}
\cline { 2 - 8 } \multicolumn{1}{c|}{} & ZONA 1 & ZONA 2 & ZONA 3 & ZONA 4 & ZONA 5 & ZONA 6 & ZONA 7 \\
\hline (+) 11 - 20 & 99 & 11 & 8 & 17 & 8 & 7 & 61 \\
\hline (+) $\mathbf{1}-\mathbf{1 0}$ & 1624 & 203 & 161 & 225 & 213 & 197 & 767 \\
\hline Empate & 338 & 30 & 33 & 50 & 48 & 43 & 170 \\
\hline (-) $\mathbf{1}-\mathbf{1 0}$ & 2256 & 216 & 229 & 268 & 274 & 245 & 1096 \\
\hline (-) $\mathbf{1 1}-\mathbf{2 0}$ & 462 & 34 & 29 & 46 & 55 & 45 & 233 \\
\hline
\end{tabular}

\begin{tabular}{|c|c|c|c|c|c|c|c|}
\cline { 2 - 8 } \multicolumn{1}{c|}{} & ZONA 1 & ZONA 2 & ZONA 3 & ZONA 4 & ZONA 5 & ZONA 6 & ZONA 7 \\
\hline Contraataque & 167 & 0 & 1 & 3 & 9 & 9 & 20 \\
\hline Bloqueo Directo & 776 & 86 & 85 & 207 & 25 & 13 & 488 \\
\hline Pase & 829 & 69 & 100 & 120 & 481 & 455 & 1343 \\
\hline Jugada Personal & 2303 & 329 & 267 & 273 & 69 & 57 & 443 \\
\hline Robo & 232 & 5 & 3 & 2 & 12 & 2 & 21 \\
\hline Rebote & 472 & 5 & 4 & 1 & 2 & 1 & 12 \\
\hline
\end{tabular}

\begin{tabular}{|c|c|c|c|c|c|c|c|}
\cline { 2 - 8 } \multicolumn{1}{c|}{} & ZONA 1 & ZONA 2 & ZONA 3 & ZONA 4 & ZONA 5 & ZONA 6 & ZONA 7 \\
\hline Uno & 1397 & 78 & 101 & 118 & 15 & 18 & 318 \\
\hline Dos & 1563 & 167 & 147 & 203 & 242 & 196 & 946 \\
\hline Tres & 1229 & 159 & 143 & 177 & 206 & 181 & 682 \\
\hline Cuatro & 510 & 76 & 58 & 94 & 110 & 122 & 326 \\
\hline Cinco & 80 & 14 & 11 & 14 & 25 & 20 & 55 \\
\hline
\end{tabular}




\begin{tabular}{|c|c|c|c|c|c|c|c|}
\cline { 2 - 8 } \multicolumn{1}{c|}{} & ZONA 1 & ZONA 2 & ZONA 3 & ZONA 4 & ZONA 5 & ZONA 6 & ZONA 7 \\
\hline 10 QT & 1255 & 138 & 134 & 190 & 168 & 131 & 522 \\
\hline 20 QT & 1181 & 141 & 109 & 152 & 146 & 134 & 602 \\
\hline 30 QT & 1199 & 118 & 116 & 149 & 137 & 140 & 563 \\
\hline 40 QT & 1144 & 97 & 101 & 115 & 147 & 132 & 640 \\
\hline
\end{tabular}

\begin{tabular}{|c|c|c|c|c|c|c|c|c|c|}
\hline & 3p. + adicional & 3puntos & Falta +3 adic. & $2 p .+$ adicional & 2 puntos & Falta +2 adic. & Tapón & Fallo 3p. & Fallo 2p. \\
\hline $0-8$ & 1 & 393 & 15 & 54 & 776 & 184 & 127 & 807 & 913 \\
\hline $9-16$ & 6 & 574 & 28 & 108 & 1331 & 306 & 177 & 1013 & 1201 \\
\hline 17 - 24 & 2 & 238 & 8 & 56 & 576 & 139 & 80 & 358 & 330 \\
\hline & 3p. + adicional & 3puntos & Falta +3 adic. & 2p. + adicional & 2puntos & Falta +2 adic. & Tapón & Fallo 3p. & Fallo $2 p$. \\
\hline Buen tiro & 2 & 860 & 10 & 56 & 1256 & 29 & 9 & 1123 & 346 \\
\hline Tiro normal & 6 & 299 & 35 & 149 & 1318 & 535 & 278 & 756 & 1520 \\
\hline Mal tiro & 1 & 46 & 6 & 13 & 109 & 65 & 97 & 299 & 578 \\
\hline
\end{tabular}

\begin{tabular}{|c|c|c|c|c|c|c|c|c|c|}
\multicolumn{1}{c|}{} & 3p.+ adicional & 3puntos & Falta + 3 adic. & 2p. + adicional & 2puntos & Falta + 2 adic. & Tapón & Fallo 3p. & Fallo 2p. \\
\hline (+) 11 - 20 & 0 & 15 & 2 & 4 & 58 & 8 & 9 & 58 & 57 \\
\hline (+) 1 - 10 & 2 & 357 & 19 & 58 & 871 & 238 & 137 & 791 & 917 \\
\hline Empate & 1 & 100 & 2 & 14 & 207 & 35 & 21 & 158 & 174 \\
\hline (-) 1 - 10 & 4 & 581 & 24 & 112 & 1291 & 284 & 181 & 998 & 1109 \\
\hline (-) 11 - 20 & 2 & 152 & 4 & 30 & 256 & 64 & 36 & 173 & 187 \\
\hline
\end{tabular}

\begin{tabular}{|c|c|c|c|c|c|c|c|c|c|}
\cline { 2 - 9 } \multicolumn{1}{c|}{} & 3p. + adicional & 3puntos & Falta + 3 adic. & 2p. + adicional & 2puntos & Falta + 2 adic. & Tapón & Fallo 3p. & Fallo 2p. \\
\hline Contraataque & 0 & 15 & 0 & 12 & 112 & 15 & 7 & 23 & 25 \\
\hline Bloqueo Directo & 1 & 185 & 12 & 21 & 483 & 107 & 50 & 324 & 497 \\
\hline Pase & 4 & 807 & 28 & 42 & 556 & 92 & 75 & 1428 & 365 \\
\hline Jugada Personal & 4 & 178 & 11 & 117 & 1140 & 345 & 208 & 373 & 1365 \\
\hline Robo & 0 & 16 & 0 & 9 & 142 & 24 & 18 & 19 & 49 \\
\hline Rebote & 0 & 4 & 0 & 17 & 250 & 46 & 26 & 11 & 143 \\
\hline
\end{tabular}

\begin{tabular}{|c|c|c|c|c|c|c|c|c|c|}
\hline & 3p. + adicional & 3puntos & Falta +3 adic. & 2p. + adicional & 2 puntos & Falta +2 adic. & Tapón & Fallo 3p. & Fallo $2 p$. \\
\hline Uno & 2 & 113 & 11 & 65 & 695 & 191 & 109 & 222 & 637 \\
\hline Dos & 3 & 486 & 21 & 76 & 888 & 201 & 124 & 865 & 800 \\
\hline Tres & 3 & 365 & 11 & 56 & 733 & 163 & 103 & 686 & 657 \\
\hline Cuatro & 1 & 200 & 7 & 17 & 325 & 60 & 40 & 347 & 299 \\
\hline Cinco & 0 & 41 & 1 & 4 & 42 & 14 & 8 & 58 & 51 \\
\hline
\end{tabular}

\begin{tabular}{|c|c|c|c|c|c|c|c|c|c|}
\hline & 3p. + adicional & 3puntos & Falta +3 adic. & 2p. + adicional & 2puntos & Falta +2 adic. & Tapón & Fallo 3p. & Fallo $2 p$. \\
\hline 1QT & 1 & 291 & 15 & 55 & 777 & 136 & 95 & 512 & 656 \\
\hline 2०QT & 2 & 306 & 9 & 51 & 680 & 172 & 77 & 560 & 608 \\
\hline 3 QT & 2 & 293 & 14 & 54 & 652 & 151 & 100 & 528 & 628 \\
\hline 4 QT & 4 & 315 & 13 & 58 & 574 & 170 & 112 & 578 & 552 \\
\hline
\end{tabular}

\begin{tabular}{|c|c|c|c|c|c|c|c|c|c|}
\hline & 3p. + adicional & 3puntos & Falta +3 adic. & 2 p. + adicional & 2puntos & Falta +2 adic. & Tapón & Fallo 3p. & Fallo 2p. \\
\hline Tiempo Muerto & 0 & 45 & 3 & 12 & 96 & 20 & 16 & 92 & 109 \\
\hline Última Jugada & 0 & 20 & 1 & 3 & 33 & 2 & 8 & 94 & 32 \\
\hline
\end{tabular}

\begin{tabular}{|c|c|c|c|}
\cline { 2 - 4 } \multicolumn{1}{c|}{} & $\mathbf{0 - \mathbf { 8 }}$ & $\mathbf{9 - 1 6}$ & $\mathbf{1 7 - 2 4}$ \\
\hline Buen tiro & 954 & 1825 & 912 \\
\hline Tiro normal & 1632 & 2509 & 755 \\
\hline Mal tiro & 684 & 410 & 120 \\
\hline
\end{tabular}




\begin{tabular}{|c|c|c|c|}
\cline { 2 - 4 } \multicolumn{1}{c|}{} & $\mathbf{0 - 8}$ & $\mathbf{9 - 1 6}$ & $\mathbf{1 7 - 2 4}$ \\
\hline$(+) \mathbf{1 1}-\mathbf{2 0}$ & 83 & 88 & 40 \\
\hline (+) $\mathbf{1}-\mathbf{1 0}$ & 1181 & 1588 & 621 \\
\hline Empate & 248 & 335 & 129 \\
\hline (-) $\mathbf{1}-\mathbf{1 0}$ & 1479 & 2253 & 852 \\
\hline$(-) \mathbf{1 1}-\mathbf{2 0}$ & 279 & 480 & 145 \\
\hline
\end{tabular}

\begin{tabular}{|c|c|c|c|}
\cline { 2 - 4 } \multicolumn{1}{c|}{} & $\mathbf{0 - \mathbf { 8 }}$ & $\mathbf{9 - 1 6}$ & $\mathbf{1 7 - 2 4}$ \\
\hline Contraataque & 5 & 1 & 203 \\
\hline Bloqueo Directo & 473 & 1036 & 171 \\
\hline Pase & 1146 & 1740 & 511 \\
\hline Jugada Personal & 1583 & 1636 & 522 \\
\hline Robo & 12 & 5 & 260 \\
\hline Rebote & 51 & 326 & 120 \\
\hline
\end{tabular}

\begin{tabular}{|c|c|c|c|}
\cline { 2 - 4 } \multicolumn{1}{c|}{} & $\mathbf{0 - 8}$ & $\mathbf{9 - 1 6}$ & $\mathbf{1 7 - 2 4}$ \\
\hline Uno & 318 & 947 & 780 \\
\hline Dos & 831 & 1829 & 804 \\
\hline Tres & 1154 & 1435 & 188 \\
\hline Cuatro & 795 & 487 & 14 \\
\hline Cinco & 172 & 46 & 1 \\
\hline
\end{tabular}

\begin{tabular}{|l|c|c|c|}
\cline { 2 - 4 } \multicolumn{1}{c|}{} & $\mathbf{0 - \mathbf { 8 }}$ & $\mathbf{9 - 1 6}$ & $\mathbf{1 7 - 2 4}$ \\
\hline 10 QT & 765 & 1285 & 488 \\
\hline 20 QT & 805 & 1207 & 453 \\
\hline 30 QT & 838 & 1136 & 448 \\
\hline 40 QT & 862 & 1116 & 398 \\
\hline
\end{tabular}

\begin{tabular}{|c|c|c|c|}
\cline { 2 - 4 } \multicolumn{1}{c|}{} & $\mathbf{0 - 8}$ & $\mathbf{9 - 1 6}$ & $\mathbf{1 7 - 2 4}$ \\
\hline Tiempo Muerto & 188 & 175 & 30 \\
\hline Última Jugada & 193 & 0 & 0 \\
\hline
\end{tabular}

\begin{tabular}{|c|c|c|c|}
\cline { 2 - 4 } \multicolumn{1}{c|}{} & Buen tiro & Tiro normal & Mal tiro \\
\hline (+) $\mathbf{1 1}-\mathbf{2 0}$ & $\mathbf{7 3}$ & 107 & 31 \\
\hline (+) $\mathbf{1}-\mathbf{1 0}$ & 1213 & 1706 & 471 \\
\hline Empate & 292 & 343 & 77 \\
\hline (-) $\mathbf{1}-\mathbf{1 0}$ & 1762 & 2298 & 524 \\
\hline (-) $\mathbf{1 1}-\mathbf{2 0}$ & 351 & 442 & 111 \\
\hline
\end{tabular}




\begin{tabular}{|c|c|c|c|}
\cline { 2 - 4 } \multicolumn{1}{c|}{} & Buen tiro & Tiro normal & Mal tiro \\
\hline Contraataque & 160 & 44 & 5 \\
\hline Bloqueo Directo & 664 & 856 & 160 \\
\hline Pase & 2059 & 1115 & 223 \\
\hline Jugada Personal & 486 & 2461 & 794 \\
\hline Robo & 175 & 91 & 11 \\
\hline Rebote & 147 & 329 & 21 \\
\hline
\end{tabular}

\begin{tabular}{|c|c|c|c|}
\cline { 2 - 4 } \multicolumn{1}{c|}{} & Buen tiro & Tiro normal & Mal tiro \\
\hline Uno & 519 & 1246 & 280 \\
\hline Dos & 1424 & 1632 & 408 \\
\hline Tres & 1116 & 1353 & 308 \\
\hline Cuatro & 537 & 571 & 188 \\
\hline Cinco & 95 & 94 & 30 \\
\hline
\end{tabular}

\begin{tabular}{|c|c|c|c|}
\cline { 2 - 4 } \multicolumn{1}{c|}{} & Buen tiro & Tiro normal & Mal tiro \\
\hline 19 QT & 988 & 1281 & 269 \\
\hline 2\% QT & 960 & 1207 & 298 \\
\hline 39 QT & 923 & 1197 & 302 \\
\hline 4 QT & 820 & 1211 & 345 \\
\hline
\end{tabular}

\begin{tabular}{|c|c|c|c|}
\cline { 2 - 4 } \multicolumn{1}{c|}{} & Buen tiro & Tiro normal & Mal tiro \\
\hline Tiempo Muerto & 127 & 194 & 72 \\
\hline Última Jugada & 45 & 73 & 75 \\
\hline
\end{tabular}

\begin{tabular}{|c|c|c|c|c|c|}
\cline { 2 - 6 } \multicolumn{1}{c|}{} & $(\mathbf{+}) \mathbf{1 1} \mathbf{- 2 0}$ & $\mathbf{( + )} \mathbf{1} \mathbf{- 1 0}$ & Empate & $\mathbf{( - )} \mathbf{1} \mathbf{- 1 0}$ & $\mathbf{( - )} \mathbf{1 1} \mathbf{- 2 0}$ \\
\hline Contraataque & 7 & 80 & 13 & 97 & 12 \\
\hline Bloqueo Directo & 42 & 587 & 124 & 777 & 150 \\
\hline Pase & 62 & 1166 & 254 & 1597 & 318 \\
\hline Jugada Personal & 79 & 1291 & 268 & 1769 & 334 \\
\hline Robo & 7 & 106 & 18 & 119 & 27 \\
\hline Rebote & 14 & 160 & 35 & 225 & 63 \\
\hline
\end{tabular}




\begin{tabular}{|c|c|c|c|c|c|}
\cline { 2 - 6 } \multicolumn{1}{c|}{} & $(\mathbf{+}) \mathbf{1 1} \mathbf{- 2 0}$ & $\mathbf{( + )} \mathbf{1} \mathbf{- 1 0}$ & Empate & $(\mathbf{-}) \mathbf{1}-\mathbf{1 0}$ & $\mathbf{( - )} \mathbf{1 1} \mathbf{- 2 0}$ \\
\hline Uno & 48 & 697 & 138 & 968 & 194 \\
\hline Dos & 80 & 1207 & 223 & 1629 & 325 \\
\hline Tres & 55 & 941 & 220 & 1318 & 243 \\
\hline Cuatro & 21 & 484 & 105 & 563 & 123 \\
\hline Cinco & 7 & 61 & 26 & 106 & 19 \\
\hline
\end{tabular}

\begin{tabular}{|c|c|c|c|c|c|}
\hline & $(+) 11-20$ & (+) 1 - 10 & Empate & (-) $1-10$ & (-) $11-20$ \\
\hline 10 QT & 23 & 965 & 296 & 1182 & 72 \\
\hline 2ㅇT & 51 & 921 & 162 & 1166 & 165 \\
\hline 3 QT & 73 & 771 & 164 & 1153 & 261 \\
\hline 4 QT & 64 & 733 & 90 & 1083 & 406 \\
\hline
\end{tabular}

\begin{tabular}{|c|c|c|c|c|c|}
\cline { 2 - 6 } \multicolumn{1}{c|}{} & $(\boldsymbol{+}) \mathbf{1 1} \mathbf{- 2 0}$ & $\mathbf{( + )} \mathbf{1}$ - $\mathbf{1 0}$ & Empate & $\mathbf{( - )} \mathbf{1}$ - $\mathbf{1 0}$ & $\mathbf{( - )} \mathbf{1 1} \mathbf{- 2 0}$ \\
\hline Tiempo Muerto & 8 & 88 & 18 & 231 & 48 \\
\hline Última Jugada & 7 & 64 & 8 & 95 & 19 \\
\hline
\end{tabular}

\begin{tabular}{|c|c|c|c|c|c|c|}
\cline { 2 - 7 } \multicolumn{1}{c|}{} & Contraataque & Bloqueo Directo & Pase & Jugada Personal & Robo & Rebote \\
\hline Uno & 15 & 408 & 0 & 1004 & 121 & 497 \\
\hline Dos & 126 & 628 & 1418 & 1162 & 130 & 0 \\
\hline Tres & 60 & 466 & 1201 & 1025 & 25 & 0 \\
\hline Cuatro & 8 & 148 & 648 & 491 & 1 & 0 \\
\hline Cinco & 0 & 30 & 130 & 59 & 0 & 0 \\
\hline
\end{tabular}

\begin{tabular}{|c|c|c|c|c|c|c|}
\cline { 2 - 7 } \multicolumn{1}{c|}{} & Contraataque & Bloqueo Directo & Pase & Jugada Personal & Robo & Rebote \\
\hline 10 QT & 57 & 454 & 859 & 968 & 71 & 129 \\
\hline 20 QT & 61 & 410 & 868 & 934 & 66 & 126 \\
\hline 30 QT & 54 & 401 & 859 & 902 & 73 & 133 \\
\hline 40 QT & 37 & 415 & 811 & 937 & 67 & 109 \\
\hline
\end{tabular}

\begin{tabular}{|c|c|c|c|c|c|c|}
\cline { 2 - 7 } \multicolumn{1}{c|}{} & Contraataque & Bloqueo Directo & Pase & Jugada Personal & Robo & Rebote \\
\hline Tiempo Muerto & 0 & 70 & 145 & 178 & 0 & 0 \\
\hline Última Jugada & 3 & 20 & 65 & 96 & 9 & 0 \\
\hline
\end{tabular}

\begin{tabular}{|l|c|c|c|c|c|}
\cline { 2 - 5 } \multicolumn{1}{c|}{} & Uno & Dos & Tres & Cuatro & Cinco \\
\hline 19 QT & 512 & 869 & 746 & 355 & 56 \\
\hline 29 QT & 487 & 859 & 733 & 332 & 54 \\
\hline 3 QT & 530 & 827 & 663 & 344 & 58 \\
\hline 4 QT & 516 & 909 & 635 & 265 & 51 \\
\hline
\end{tabular}




\begin{tabular}{|c|c|c|c|c|c|}
\cline { 2 - 6 } \multicolumn{1}{c|}{} & Uno & Dos & Tres & Cuatro & Cinco \\
\hline Tiempo Muerto & 44 & 135 & 133 & 61 & 20 \\
\hline Última Jugada & 88 & 79 & 17 & 9 & 0 \\
\hline
\end{tabular}

\begin{tabular}{|c|c|c|c|c|}
\cline { 2 - 5 } \multicolumn{1}{c|}{} & 19 QT & 20 QT & 3 QT & 40 QT \\
\hline Tiempo Muerto & 67 & 90 & 72 & 164 \\
\hline Última Jugada & 49 & 50 & 56 & 38 \\
\hline
\end{tabular}




\subsubsection{Baloncesto femenino (DÍA, WEuroliga y WNBA)}

\begin{tabular}{|c|c|c|c|c|c|c|c|}
\cline { 2 - 8 } \multicolumn{1}{c|}{} & ZONA 1 & ZONA 2 & ZONA 3 & ZONA 4 & ZONA 5 & ZONA 6 & ZONA 7 \\
\hline 3p. + adicional & 0 & 0 & 0 & 0 & 1 & 1 & 3 \\
\hline 3puntos & 0 & 0 & 0 & 0 & 86 & 67 & 285 \\
\hline Falta + 3 adic. & 0 & 0 & 0 & 0 & 1 & 1 & 3 \\
\hline 2p. + adicional & 109 & 6 & 4 & 1 & 0 & 0 & 0 \\
\hline 2puntos & 1124 & 129 & 137 & 195 & 0 & 0 & 0 \\
\hline Falta + 2 adic. & 332 & 11 & 11 & 12 & 0 & 0 & 0 \\
\hline Tapón & 177 & 12 & 5 & 7 & 2 & 5 & 3 \\
\hline Fallo 3p. & 0 & 0 & 0 & 0 & 180 & 165 & 669 \\
\hline Fallo 2p. & 1144 & 255 & 229 & 312 & 0 & 0 & 0 \\
\hline
\end{tabular}

\begin{tabular}{|c|c|c|c|c|c|c|c|}
\cline { 2 - 8 } \multicolumn{1}{c|}{} & ZONA 1 & ZONA 2 & ZONA 3 & ZONA 4 & ZONA 5 & ZONA 6 & ZONA 7 \\
\hline $\mathbf{0 - \mathbf { 8 }}$ & 864 & 162 & 150 & 173 & 79 & 95 & 346 \\
\hline $\mathbf{9 - 1 6}$ & 1434 & 204 & 187 & 289 & 143 & 105 & 455 \\
\hline $\mathbf{1 7}-\mathbf{2 4}$ & 588 & 47 & 49 & 65 & 48 & 39 & 162 \\
\hline
\end{tabular}

\begin{tabular}{|c|c|c|c|c|c|c|c|}
\cline { 2 - 8 } \multicolumn{1}{c|}{} & ZONA 1 & ZONA 2 & ZONA 3 & ZONA 4 & ZONA 5 & ZONA 6 & ZONA 7 \\
\hline Buen tiro & 643 & 124 & 117 & 293 & 195 & 165 & 616 \\
\hline Tiro normal & 1867 & 195 & 201 & 200 & 67 & 62 & 217 \\
\hline Mal tiro & 376 & 94 & 68 & 34 & 8 & 12 & 130 \\
\hline
\end{tabular}

\begin{tabular}{|c|c|c|c|c|c|c|c|}
\cline { 2 - 8 } \multicolumn{1}{c|}{} & ZONA 1 & ZONA 2 & ZONA 3 & ZONA 4 & ZONA 5 & ZONA 6 & ZONA 7 \\
\hline$(+) \mathbf{1 1}-\mathbf{2 0}$ & 60 & 7 & 8 & 7 & 5 & 4 & 19 \\
\hline (+) $\mathbf{1}-\mathbf{1 0}$ & 986 & 147 & 138 & 203 & 93 & 100 & 328 \\
\hline Empate & 219 & 36 & 33 & 37 & 25 & 21 & 60 \\
\hline $\mathbf{( - )} \mathbf{1}-\mathbf{1 0}$ & 1406 & 202 & 183 & 231 & 129 & 98 & 483 \\
\hline$(-) \mathbf{1 1}-\mathbf{2 0}$ & 215 & 21 & 24 & 49 & 18 & 16 & 73 \\
\hline
\end{tabular}

\begin{tabular}{|c|c|c|c|c|c|c|c|}
\cline { 2 - 8 } \multicolumn{1}{c|}{} & ZONA 1 & ZONA 2 & ZONA 3 & ZONA 4 & ZONA 5 & ZONA 6 & ZONA 7 \\
\hline Contraataque & 143 & 2 & 5 & 1 & 4 & 2 & 8 \\
\hline Bloqueo Directo & 350 & 54 & 60 & 200 & 8 & 4 & 177 \\
\hline Pase & 549 & 155 & 146 & 186 & 241 & 204 & 642 \\
\hline Jugada Personal & 1395 & 196 & 166 & 137 & 14 & 21 & 122 \\
\hline Robo & 141 & 1 & 5 & 1 & 3 & 3 & 8 \\
\hline Rebote & 308 & 5 & 4 & 2 & 0 & 5 & 6 \\
\hline
\end{tabular}

\begin{tabular}{|c|c|c|c|c|c|c|c|}
\cline { 2 - 8 } \multicolumn{1}{c|}{} & ZONA 1 & ZONA 2 & ZONA 3 & ZONA 4 & ZONA 5 & ZONA 6 & ZONA 7 \\
\hline Uno & 725 & 40 & 48 & 73 & 3 & 11 & 106 \\
\hline Dos & 848 & 131 & 122 & 165 & 90 & 74 & 359 \\
\hline Tres & 802 & 148 & 130 & 201 & 93 & 76 & 279 \\
\hline Cuatro & 400 & 78 & 72 & 68 & 67 & 66 & 180 \\
\hline Cinco & 111 & 16 & 14 & 20 & 17 & 12 & 39 \\
\hline
\end{tabular}




\begin{tabular}{|c|c|c|c|c|c|c|c|}
\hline & ZONA 1 & ZONA 2 & ZONA 3 & ZONA 4 & ZONA 5 & ZONA 6 & ZONA 7 \\
\hline 1 QT & 748 & 118 & 95 & 177 & 82 & 61 & 211 \\
\hline 2 QT & 757 & 99 & 110 & 122 & 70 & 60 & 235 \\
\hline 3 QT & 679 & 101 & 88 & 120 & 63 & 60 & 248 \\
\hline 4 QT & 702 & 95 & 93 & 108 & 55 & 58 & 269 \\
\hline & ZONA 1 & ZONA 2 & ZONA 3 & ZONA 4 & ZONA 5 & ZONA 6 & ZONA 7 \\
\hline Tiempo Muerto & 82 & 18 & 15 & 14 & 10 & 15 & 41 \\
\hline Última Jugada & 37 & 7 & 9 & 16 & 3 & 1 & 43 \\
\hline
\end{tabular}

\begin{tabular}{|c|c|c|c|c|c|c|c|c|c|}
\hline & 3p. + adicional & 3puntos & Falta +3 adic. & 2p. + adicional & 2puntos & Falta +2 adic. & Tapón & Fallo 3p. & Fallo 2p. \\
\hline $0-8$ & 1 & 131 & 1 & 26 & 472 & 106 & 66 & 382 & 684 \\
\hline $9-16$ & 4 & 230 & 2 & 69 & 770 & 185 & 104 & 466 & 987 \\
\hline $17-24$ & 0 & 77 & 2 & 25 & 343 & 75 & 41 & 166 & 269 \\
\hline
\end{tabular}

\begin{tabular}{|c|c|c|c|c|c|c|c|c|c|}
\cline { 2 - 9 } \multicolumn{1}{c|}{} & 3p. + adicional & 3puntos & Falta + 3 adic. & 2p. + adicional & 2puntos & Falta + 2 adic. & Tapón & Fallo 3p. & Fallo 2p. \\
\hline Buen tiro & 3 & 340 & 1 & 20 & 769 & 6 & 0 & 632 & 382 \\
\hline Tiro normal & 2 & 79 & 3 & 95 & 757 & 325 & 145 & 256 & 1147 \\
\hline Mal tiro & 0 & 19 & 1 & 5 & 59 & 35 & 66 & 126 & 411 \\
\hline
\end{tabular}

\begin{tabular}{|c|c|c|c|c|c|c|c|c|c|}
\hline & 3p. + adicional & 3puntos & Falta +3 adic. & 2p. + adicional & 2puntos & Falta +2 adic. & Tapón & Fallo 3p. & Fallo 2p. \\
\hline (+) $11-20$ & 0 & 14 & 0 & 3 & 28 & 3 & 6 & 14 & 42 \\
\hline$(+) 1-10$ & 1 & 150 & 2 & 28 & 566 & 135 & 92 & 363 & 658 \\
\hline Empate & 1 & 36 & 0 & 9 & 126 & 25 & 14 & 69 & 151 \\
\hline$(-) 1-10$ & 1 & 197 & 3 & 68 & 758 & 172 & 89 & 505 & 939 \\
\hline$(-) 11-20$ & 2 & 41 & 0 & 12 & 107 & 31 & 10 & 63 & 150 \\
\hline
\end{tabular}

\begin{tabular}{|c|c|c|c|c|c|c|c|c|c|}
\hline & 3p. + adicional & 3puntos & Falta +3 adic. & 2p. + adicional & 2 puntos & Falta +2 adic. & Tapón & Fallo 3p. & Fallo 2p. \\
\hline Contraataque & 0 & 6 & 0 & 8 & 89 & 13 & 4 & 8 & 37 \\
\hline Bloqueo Directo & 0 & 57 & 2 & 11 & 238 & 67 & 30 & 130 & 318 \\
\hline Pase & 5 & 333 & 2 & 24 & 486 & 43 & 29 & 741 & 460 \\
\hline Jugada Personal & 0 & 37 & 1 & 62 & 565 & 189 & 124 & 116 & 957 \\
\hline Robo & 0 & 3 & 0 & 3 & 91 & 13 & 10 & 10 & 32 \\
\hline Rebote & 0 & 2 & 0 & 12 & 116 & 41 & 14 & 9 & 136 \\
\hline
\end{tabular}

\begin{tabular}{|c|c|c|c|c|c|c|c|c|c|}
\hline & 3p. + adicional & 3puntos & Falta +3 adic. & 2 p. + adicional & 2 puntos & Falta +2 adic. & Tapón & Fallo 3p. & Fallo 2p. \\
\hline Uno & 0 & 29 & 0 & 28 & 306 & 100 & 54 & 90 & 399 \\
\hline Dos & 2 & 159 & 3 & 41 & 473 & 107 & 64 & 355 & 585 \\
\hline Tres & 2 & 142 & 2 & 34 & 495 & 106 & 60 & 298 & 590 \\
\hline Cuatro & 1 & 90 & 0 & 10 & 248 & 40 & 26 & 221 & 295 \\
\hline Cinco & 0 & 18 & 0 & 7 & 63 & 13 & 7 & 50 & 71 \\
\hline
\end{tabular}

\begin{tabular}{|c|c|c|c|c|c|c|c|c|c|}
\hline & 3p. + adicional & 3puntos & Falta +3 adic. & 2 p. + adicional & 2puntos & Falta +2 adic. & Tapón & Fallo 3p. & Fallo 2p. \\
\hline 10QT & 2 & 109 & 1 & 29 & 469 & 81 & 48 & 241 & 512 \\
\hline 2QT & 1 & 111 & 1 & 30 & 388 & 96 & 58 & 250 & 518 \\
\hline 3ㅇ QT & 0 & 113 & 1 & 33 & 369 & 80 & 47 & 253 & 463 \\
\hline 40 QT & 2 & 105 & 2 & 28 & 359 & 109 & 58 & 270 & 447 \\
\hline
\end{tabular}

\begin{tabular}{|c|c|c|c|c|c|c|c|c|c|}
\hline & 3p. + adicional & 3puntos & Falta +3 adic. & $2 p .+$ adicional & 2 puntos & Falta +2 adic. & Tapón & Fallo 3p. & Fallo 2p. \\
\hline Tiempo Muerto & 1 & 18 & 0 & 4 & 48 & 11 & 6 & 45 & 62 \\
\hline Última Jugada & 0 & 3 & 0 & 0 & 20 & 5 & 7 & 43 & 38 \\
\hline
\end{tabular}

\begin{tabular}{|c|c|c|c|}
\cline { 2 - 4 } \multicolumn{1}{c|}{} & $\mathbf{0 - \mathbf { 8 }}$ & $\mathbf{9 - 1 6}$ & $\mathbf{1 7 - 2 4}$ \\
\hline Buen tiro & 544 & 1105 & 504 \\
\hline Tiro normal & 925 & 1465 & 419 \\
\hline Mal tiro & 400 & 247 & 75 \\
\hline
\end{tabular}




\begin{tabular}{|c|c|c|c|}
\multicolumn{1}{c|}{} & $\mathbf{0 - 8}$ & $\mathbf{9 - 1 6}$ & $\mathbf{1 7 - 2 4}$ \\
\hline $\mathbf{( + )} \mathbf{1 1}-\mathbf{2 0}$ & 27 & 62 & 21 \\
\hline (+) $\mathbf{1}-\mathbf{1 0}$ & 693 & 957 & 345 \\
\hline Empate & 145 & 211 & 75 \\
\hline (-) $\mathbf{1}-\mathbf{1 0}$ & 873 & 1366 & 493 \\
\hline (-) $\mathbf{1 1}-\mathbf{2 0}$ & 131 & 221 & 64 \\
\hline
\end{tabular}

\begin{tabular}{|c|c|c|c|}
\cline { 2 - 4 } \multicolumn{1}{c|}{} & $\mathbf{0 - \mathbf { 8 }}$ & $\mathbf{9 - 1 6}$ & $\mathbf{1 7 - 2 4}$ \\
\hline Contraataque & 4 & 1 & 160 \\
\hline Bloqueo Directo & 259 & 492 & 102 \\
\hline Pase & 716 & 1120 & 287 \\
\hline Jugada Personal & 840 & 931 & 280 \\
\hline Robo & 2 & 1 & 159 \\
\hline Rebote & 48 & 272 & 10 \\
\hline
\end{tabular}

\begin{tabular}{|c|c|c|c|}
\cline { 2 - 4 } \multicolumn{1}{c|}{} & $\mathbf{0 - \mathbf { 8 }}$ & $\mathbf{9 - 1 6}$ & $\mathbf{1 7 - 2 4}$ \\
\hline Uno & 150 & 505 & 351 \\
\hline Dos & 382 & 933 & 474 \\
\hline Tres & 622 & 950 & 157 \\
\hline Cuatro & 538 & 378 & 15 \\
\hline Cinco & 177 & 51 & 1 \\
\hline
\end{tabular}

\begin{tabular}{|l|c|c|c|}
\cline { 2 - 4 } \multicolumn{1}{c|}{} & $\mathbf{0 - 8}$ & $\mathbf{9 - 1 6}$ & $\mathbf{1 7 - 2 4}$ \\
\hline 10 QT & 448 & 757 & 287 \\
\hline 20 QT & 494 & 708 & 251 \\
\hline 30 QT & 464 & 649 & 246 \\
\hline 40 QT & 463 & 703 & 214 \\
\hline
\end{tabular}

\begin{tabular}{|c|c|c|c|}
\cline { 2 - 4 } \multicolumn{1}{c|}{} & $\mathbf{0 - \mathbf { 8 }}$ & $\mathbf{9 - 1 6}$ & $\mathbf{1 7 - 2 4}$ \\
\hline Tiempo Muerto & 88 & 85 & 22 \\
\hline Última Jugada & 116 & 0 & 0 \\
\hline
\end{tabular}

\begin{tabular}{|c|c|c|c|}
\cline { 2 - 4 } \multicolumn{1}{c|}{} & Buen tiro & Tiro normal & Mal tiro \\
\hline (+) $\mathbf{1 1}-\mathbf{2 0}$ & 38 & 64 & 8 \\
\hline (+) $\mathbf{1}-\mathbf{1 0}$ & 788 & 942 & 265 \\
\hline Empate & 180 & 212 & 39 \\
\hline (-) $\mathbf{1}-\mathbf{1 0}$ & 1008 & 1366 & 358 \\
\hline (-) $\mathbf{1 1}-\mathbf{2 0}$ & 139 & 225 & 52 \\
\hline
\end{tabular}




\begin{tabular}{|c|c|c|c|}
\cline { 2 - 4 } \multicolumn{1}{c|}{} & Buen tiro & Tiro normal & Mal tiro \\
\hline Contraataque & 103 & 58 & 4 \\
\hline Bloqueo Directo & 372 & 426 & 55 \\
\hline Pase & 1295 & 707 & 121 \\
\hline Jugada Personal & 206 & 1327 & 518 \\
\hline Robo & 103 & 53 & 6 \\
\hline Rebote & 74 & 238 & 18 \\
\hline
\end{tabular}

\begin{tabular}{|c|c|c|c|}
\cline { 2 - 4 } \multicolumn{1}{c|}{} & Buen tiro & Tiro normal & Mal tiro \\
\hline Uno & 270 & 585 & 151 \\
\hline Dos & 754 & 812 & 223 \\
\hline Tres & 684 & 852 & 193 \\
\hline Cuatro & 377 & 437 & 117 \\
\hline Cinco & 68 & 123 & 38 \\
\hline
\end{tabular}

\begin{tabular}{|c|c|c|c|}
\cline { 2 - 4 } \multicolumn{1}{c|}{} & Buen tiro & Tiro normal & Mal tiro \\
\hline 10 QT & 600 & 735 & 157 \\
\hline 20 QT & 544 & 706 & 203 \\
\hline 30 QT & 508 & 690 & 161 \\
\hline 40 QT & 501 & 678 & 201 \\
\hline
\end{tabular}

\begin{tabular}{|c|c|c|c|}
\cline { 2 - 4 } \multicolumn{1}{c|}{} & Buen tiro & Tiro normal & Mal tiro \\
\hline Tiempo Muerto & 74 & 88 & 33 \\
\hline Última Jugada & 17 & 40 & 59 \\
\hline
\end{tabular}

\begin{tabular}{|c|c|c|c|c|c|}
\hline & $(+) 11-20$ & $(+) 1-10$ & Empate & $(-) 1-10$ & $(-) 11-20$ \\
\hline Contraataque & 5 & 66 & 10 & 76 & 8 \\
\hline Bloqueo Directo & 15 & 294 & 61 & 422 & 61 \\
\hline Pase & 44 & 793 & 166 & 993 & 127 \\
\hline Jugada Personal & 36 & 674 & 153 & 1010 & 178 \\
\hline Robo & 1 & 64 & 13 & 70 & 14 \\
\hline Rebote & 9 & 104 & 28 & 161 & 28 \\
\hline
\end{tabular}

\begin{tabular}{|c|c|c|c|c|c|}
\cline { 2 - 6 } \multicolumn{1}{c|}{} & $(\mathbf{+}) \mathbf{1 1} \mathbf{- 2 0}$ & $\mathbf{( + )} \mathbf{1} \mathbf{- 1 0}$ & Empate & $\mathbf{( - )} \mathbf{1} \mathbf{- 1 0}$ & $\mathbf{( - )} \mathbf{1 1} \mathbf{- 2 0}$ \\
\hline Uno & 13 & 315 & 66 & 519 & 93 \\
\hline Dos & 48 & 622 & 124 & 858 & 137 \\
\hline Tres & 32 & 627 & 137 & 821 & 112 \\
\hline Cuatro & 14 & 355 & 78 & 421 & 63 \\
\hline Cinco & 3 & 76 & 26 & 113 & 11 \\
\hline
\end{tabular}




\begin{tabular}{|c|c|c|c|c|c|}
\cline { 2 - 6 } \multicolumn{1}{c|}{} & $\mathbf{( + )} \mathbf{1 1} \mathbf{- 2 0}$ & $\mathbf{( + )} \mathbf{1}-\mathbf{1 0}$ & Empate & $\mathbf{( - )} \mathbf{1}-\mathbf{1 0}$ & $\mathbf{( - )} \mathbf{1 1} \mathbf{- 2 0}$ \\
\hline 10 QT & 9 & 460 & 210 & 803 & 10 \\
\hline 20 QT & 31 & 608 & 114 & 629 & 71 \\
\hline 30 QT & 24 & 474 & 50 & 661 & 150 \\
\hline 40 QT & 46 & 453 & 57 & 639 & 185 \\
\hline
\end{tabular}

\begin{tabular}{|c|c|c|c|c|c|}
\cline { 2 - 6 } \multicolumn{1}{c|}{} & $(\mathbf{+}) \mathbf{1 1} \mathbf{- 2 0}$ & $\mathbf{( + )} \mathbf{1} \mathbf{- 1 0}$ & Empate & $\mathbf{( - )} \mathbf{1}-\mathbf{1 0}$ & $\mathbf{( - )} \mathbf{1 1} \mathbf{- 2 0}$ \\
\hline Tiempo Muerto & 5 & 60 & 10 & 101 & 19 \\
\hline Última Jugada & 2 & 43 & 5 & 56 & 10 \\
\hline
\end{tabular}

\begin{tabular}{|c|c|c|c|c|c|c|}
\cline { 2 - 7 } \multicolumn{1}{c|}{} & Contraataque & Bloqueo Directo & Pase & Jugada Personal & Robo & Rebote \\
\hline Uno & 14 & 184 & 0 & 405 & 73 & 330 \\
\hline Dos & 99 & 303 & 708 & 607 & 72 & 0 \\
\hline Tres & 47 & 256 & 766 & 645 & 15 & 0 \\
\hline Cuatro & 5 & 94 & 511 & 319 & 2 & 0 \\
\hline Cinco & 0 & 16 & 138 & 75 & 0 & 0 \\
\hline
\end{tabular}

\begin{tabular}{|l|c|c|c|c|c|c|}
\cline { 2 - 7 } \multicolumn{1}{c|}{} & Contraataque & Bloqueo Directo & Pase & Jugada Personal & Robo & Rebote \\
\hline 10 QT & 55 & 248 & 561 & 500 & 50 & 78 \\
\hline 20 QT & 44 & 207 & 522 & 549 & 37 & 94 \\
\hline 30 QT & 35 & 192 & 531 & 498 & 42 & 61 \\
\hline 40 QT & 31 & 206 & 509 & 504 & 33 & 97 \\
\hline
\end{tabular}

\begin{tabular}{|c|c|c|c|c|c|c|}
\cline { 2 - 7 } \multicolumn{1}{c|}{} & Contraataque & Bloqueo Directo & Pase & Jugada Personal & Robo & Rebote \\
\hline Tiempo Muerto & 0 & 20 & 93 & 82 & 0 & 0 \\
\hline Última Jugada & 3 & 16 & 29 & 66 & 2 & 0 \\
\hline
\end{tabular}

\begin{tabular}{|c|c|c|c|c|c|}
\cline { 2 - 6 } \multicolumn{1}{c|}{} & Uno & Dos & Tres & Cuatro & Cinco \\
\hline 10 QT & 248 & 477 & 469 & 235 & 63 \\
\hline 20 QT & 269 & 452 & 430 & 247 & 55 \\
\hline 30 QT & 229 & 410 & 439 & 228 & 53 \\
\hline 40 QT & 260 & 450 & 391 & 221 & 58 \\
\hline
\end{tabular}

\begin{tabular}{|c|c|c|c|c|c|}
\cline { 2 - 6 } \multicolumn{1}{c|}{} & Uno & Dos & Tres & Cuatro & Cinco \\
\hline Tiempo Muerto & 22 & 65 & 46 & 48 & 14 \\
\hline Última Jugada & 48 & 41 & 23 & 4 & 0 \\
\hline
\end{tabular}

\begin{tabular}{|c|c|c|c|c|}
\cline { 2 - 5 } \multicolumn{1}{c|}{} & 10 QT & 20 QT & 3 QT & 4ㅇ QT \\
\hline Tiempo Muerto & 21 & 56 & 29 & 89 \\
\hline Última Jugada & 32 & 29 & 40 & 15 \\
\hline
\end{tabular}




\subsubsection{Europa (Euroliga y WEuroliga)}

\begin{tabular}{|c|c|c|c|c|c|c|c|}
\cline { 2 - 8 } \multicolumn{1}{c|}{} & ZONA 1 & ZONA 2 & ZONA 3 & ZONA 4 & ZONA 5 & ZONA 6 & ZONA 7 \\
\hline 3p. + adicional & 0 & 0 & 0 & 0 & 1 & 1 & 2 \\
\hline 3puntos & 0 & 0 & 0 & 0 & 82 & 83 & 282 \\
\hline Falta + 3 adic. & 0 & 0 & 0 & 0 & 1 & 3 & 8 \\
\hline 2p. + adicional & 82 & 6 & 2 & 2 & 0 & 0 & 0 \\
\hline 2puntos & 864 & 61 & 95 & 105 & 0 & 0 & 0 \\
\hline Falta + 2 adic. & 226 & 5 & 6 & 8 & 0 & 0 & 0 \\
\hline Tapón & 135 & 9 & 5 & 5 & 0 & 2 & 1 \\
\hline Fallo 3p. & 0 & 0 & 0 & 0 & 147 & 142 & 554 \\
\hline Fallo 2p. & 714 & 131 & 140 & 189 & 0 & 0 & 0 \\
\hline
\end{tabular}

\begin{tabular}{|c|c|c|c|c|c|c|c|}
\cline { 2 - 8 } \multicolumn{1}{c|}{} & ZONA 1 & ZONA 2 & ZONA 3 & ZONA 4 & ZONA 5 & ZONA 6 & ZONA 7 \\
\hline $\mathbf{0 - \mathbf { 8 }}$ & 717 & 99 & 106 & 133 & 84 & 104 & 381 \\
\hline $\mathbf{9}-\mathbf{1 6}$ & 983 & 94 & 119 & 147 & 121 & 96 & 370 \\
\hline $\mathbf{1 7}-\mathbf{2 4}$ & 321 & 19 & 23 & 29 & 26 & 31 & 96 \\
\hline
\end{tabular}

\begin{tabular}{|c|c|c|c|c|c|c|c|}
\cline { 2 - 8 } \multicolumn{1}{c|}{} & ZONA 1 & ZONA 2 & ZONA 3 & ZONA 4 & ZONA 5 & ZONA 6 & ZONA 7 \\
\hline Buen tiro & 520 & 65 & 84 & 169 & 171 & 169 & 513 \\
\hline Tiro normal & 1264 & 91 & 119 & 115 & 58 & 49 & 216 \\
\hline Mal tiro & 237 & 56 & 45 & 25 & 2 & 13 & 118 \\
\hline
\end{tabular}

\begin{tabular}{|c|c|c|c|c|c|c|c|}
\cline { 2 - 8 } \multicolumn{1}{c|}{} & ZONA 1 & ZONA 2 & ZONA 3 & ZONA 4 & ZONA 5 & ZONA 6 & ZONA 7 \\
\hline $\mathbf{( + )} \mathbf{1 1}-\mathbf{2 0}$ & 52 & 6 & 5 & 5 & 3 & 5 & 24 \\
\hline $\mathbf{( + )} \mathbf{1}-\mathbf{1 0}$ & 669 & 67 & 87 & 115 & 78 & 89 & 255 \\
\hline Empate & 151 & 17 & 12 & 16 & 19 & 19 & 60 \\
\hline $\mathbf{( - )} \mathbf{1}-\mathbf{1 0}$ & 969 & 106 & 130 & 151 & 110 & 101 & 437 \\
\hline $\mathbf{( - )} \mathbf{1 1}-\mathbf{2 0}$ & 180 & 16 & 14 & 22 & 21 & 17 & 71 \\
\hline
\end{tabular}

\begin{tabular}{|c|c|c|c|c|c|c|c|}
\cline { 2 - 8 } \multicolumn{1}{c|}{} & ZONA 1 & ZONA 2 & ZONA 3 & ZONA 4 & ZONA 5 & ZONA 6 & ZONA 7 \\
\hline Contraataque & 80 & 2 & 1 & 1 & 1 & 2 & 3 \\
\hline Bloqueo Directo & 338 & 27 & 36 & 96 & 10 & 5 & 200 \\
\hline Pase & 398 & 70 & 95 & 95 & 198 & 201 & 498 \\
\hline Jugada Personal & 884 & 111 & 113 & 116 & 21 & 21 & 135 \\
\hline Robo & 104 & 1 & 2 & 1 & 1 & 1 & 8 \\
\hline Rebote & 217 & 1 & 1 & 0 & 0 & 1 & 3 \\
\hline
\end{tabular}

\begin{tabular}{|c|c|c|c|c|c|c|c|}
\cline { 2 - 8 } \multicolumn{1}{c|}{} & ZONA 1 & ZONA 2 & ZONA 3 & ZONA 4 & ZONA 5 & ZONA 6 & ZONA 7 \\
\hline Uno & 508 & 19 & 35 & 50 & 2 & 7 & 107 \\
\hline Dos & 599 & 71 & 90 & 97 & 81 & 79 & 301 \\
\hline Tres & 582 & 84 & 76 & 105 & 85 & 74 & 260 \\
\hline Cuatro & 269 & 31 & 41 & 48 & 51 & 60 & 151 \\
\hline Cinco & 63 & 7 & 6 & 9 & 12 & 11 & 28 \\
\hline
\end{tabular}




\begin{tabular}{|c|c|c|c|c|c|c|c|}
\cline { 2 - 8 } \multicolumn{1}{c|}{} & ZONA 1 & ZONA 2 & ZONA 3 & ZONA 4 & ZONA 5 & ZONA 6 & ZONA 7 \\
\hline 10 QT & 540 & 65 & 64 & 103 & 79 & 57 & 180 \\
\hline 20 QT & 521 & 55 & 68 & 66 & 54 & 54 & 211 \\
\hline 30 QT & 487 & 49 & 49 & 76 & 57 & 58 & 213 \\
\hline 40 QT & 473 & 43 & 67 & 64 & 41 & 62 & 243 \\
\hline
\end{tabular}

\begin{tabular}{|c|c|c|c|c|c|c|c|c|c|}
\hline & 3p. + adicional & 3puntos & Falta +3 adic. & 2p. + adicional & 2puntos & Falta +2 adic. & Tapón & Fallo 3p. & Fallo 2p. \\
\hline $0-8$ & 0 & 183 & 3 & 26 & 406 & 88 & 60 & 381 & 477 \\
\hline $9-16$ & 4 & 208 & 4 & 52 & 534 & 115 & 71 & 370 & 572 \\
\hline $17-24$ & 0 & 56 & 5 & 14 & 185 & 42 & 26 & 92 & 125 \\
\hline & 3p. + adicional & 3puntos & Falta +3 adic. & 2 p. + adicional & 2puntos & Falta +2 adic. & Tapón & Fallo 3p. & Fallo 2p. \\
\hline Buen tiro & 3 & 335 & 4 & 18 & 562 & 10 & 3 & 511 & 245 \\
\hline Tiro normal & 1 & 94 & 7 & 69 & 517 & 213 & 107 & 219 & 685 \\
\hline Mal tiro & 0 & 18 & 1 & 5 & 46 & 22 & 47 & 113 & 244 \\
\hline
\end{tabular}

\begin{tabular}{|c|c|c|c|c|c|c|c|c|c|}
\hline & 3p. + adicional & 3puntos & Falta +3 adic. & 2p. + adicional & 2puntos & Falta +2 adic. & Tapón & Fallo 3p. & Fallo 2p. \\
\hline$(+) 11-20$ & 0 & 12 & 1 & 4 & 22 & 2 & 4 & 19 & 36 \\
\hline$(+) 1-10$ & 0 & 141 & 2 & 28 & 366 & 87 & 62 & 277 & 397 \\
\hline Empate & 1 & 35 & 0 & 4 & 86 & 19 & 8 & 62 & 79 \\
\hline$(-) 1-10$ & 1 & 212 & 7 & 43 & 559 & 110 & 71 & 427 & 574 \\
\hline$(-) 11-20$ & 2 & 47 & 2 & 13 & 92 & 27 & 12 & 58 & 88 \\
\hline
\end{tabular}

\begin{tabular}{|c|c|c|c|c|c|c|c|c|c|}
\hline & 3p. + adicional & 3puntos & Falta +3 adic. & 2p. + adicional & 2puntos & Falta +2 adic. & Tapón & Fallo 3p. & Fallo 2p. \\
\hline Contraataque & 0 & 4 & 0 & 7 & 48 & 7 & 4 & 2 & 18 \\
\hline Bloqueo Directo & 0 & 70 & 4 & 11 & 188 & 44 & 25 & 141 & 229 \\
\hline Pase & 4 & 308 & 5 & 20 & 319 & 38 & 21 & 578 & 262 \\
\hline Jugada Personal & 0 & 58 & 3 & 44 & 413 & 119 & 84 & 115 & 565 \\
\hline Robo & 0 & 6 & 0 & 3 & 65 & 11 & 11 & 4 & 18 \\
\hline Rebote & 0 & 1 & 0 & 7 & 92 & 26 & 12 & 3 & 82 \\
\hline
\end{tabular}

\begin{tabular}{|c|c|c|c|c|c|c|c|c|c|}
\hline & 3p. + adicional & 3puntos & Falta +3 adic. & 2 p. + adicional & 2 puntos & Falta +2 adic. & Tapón & Fallo 3p. & Fallo 2p. \\
\hline Uno & 0 & 44 & 3 & 15 & 212 & 69 & 42 & 69 & 274 \\
\hline Dos & 2 & 145 & 4 & 34 & 347 & 63 & 43 & 309 & 371 \\
\hline Tres & 2 & 149 & 4 & 26 & 367 & 72 & 44 & 263 & 339 \\
\hline Cuatro & 0 & 95 & 1 & 12 & 170 & 31 & 23 & 165 & 154 \\
\hline Cinco & 0 & 14 & 0 & 5 & 29 & 10 & 5 & 37 & 36 \\
\hline
\end{tabular}

\begin{tabular}{|c|c|c|c|c|c|c|c|c|c|}
\hline & 3p. + adicional & 3puntos & Falta +3 adic. & 2p. + adicional & 2puntos & Falta +2 adic. & Tapón & Fallo 3p. & Fallo 2p. \\
\hline 10 QT & 2 & 120 & 2 & 24 & 333 & 46 & 41 & 192 & 328 \\
\hline 20 QT & 0 & 112 & 3 & 25 & 282 & 63 & 37 & 204 & 303 \\
\hline 3 QT & 0 & 112 & 2 & 20 & 268 & 56 & 44 & 214 & 273 \\
\hline 40 QT & 2 & 103 & 5 & 23 & 242 & 80 & 35 & 233 & 270 \\
\hline
\end{tabular}

\begin{tabular}{|c|c|c|c|c|c|c|c|c|c|}
\hline & 3p. + adicional & 3puntos & Falta +3 adic. & 2p. + adicional & 2 puntos & Falta +2 adic. & Tapón & Fallo 3p. & Fallo 2p. \\
\hline Tiempo Muerto & 1 & 18 & 1 & 3 & 28 & 9 & 7 & 35 & 42 \\
\hline Última Jugada & 0 & 6 & 0 & 0 & 19 & 2 & 5 & 40 & 23 \\
\hline
\end{tabular}

\begin{tabular}{|c|c|c|c|}
\cline { 2 - 4 } \multicolumn{1}{c|}{} & $\mathbf{0 - \mathbf { 8 }}$ & $\mathbf{9 - 1 6}$ & $\mathbf{1 7 - 2 4}$ \\
\hline Buen tiro & 551 & 830 & 310 \\
\hline Tiro normal & 754 & 957 & 201 \\
\hline Mal tiro & 319 & 143 & 34 \\
\hline
\end{tabular}




\begin{tabular}{|c|c|c|c|}
\cline { 2 - 4 } \multicolumn{1}{c|}{} & $\mathbf{0 - 8}$ & $\mathbf{9 - 1 6}$ & $\mathbf{1 7 - 2 4}$ \\
\hline (+) $\mathbf{1 1}-\mathbf{2 0}$ & 37 & 51 & 12 \\
\hline (+) $\mathbf{1}-\mathbf{1 0}$ & 555 & 617 & 188 \\
\hline Empate & 128 & 126 & 40 \\
\hline (-) $\mathbf{1}-\mathbf{1 0}$ & 775 & 961 & 268 \\
\hline (-) $\mathbf{1 1}-\mathbf{2 0}$ & 129 & 175 & 37 \\
\hline
\end{tabular}

\begin{tabular}{|c|c|c|c|}
\cline { 2 - 4 } \multicolumn{1}{c|}{} & $\mathbf{0 - \mathbf { 8 }}$ & $\mathbf{9 - 1 6}$ & $\mathbf{1 7 - 2 4}$ \\
\hline Contraataque & 2 & 1 & 87 \\
\hline Bloqueo Directo & 265 & 389 & 58 \\
\hline Pase & 625 & 780 & 150 \\
\hline Jugada Personal & 693 & 573 & 135 \\
\hline Robo & 5 & 1 & 112 \\
\hline Rebote & 34 & 186 & 3 \\
\hline
\end{tabular}

\begin{tabular}{|c|c|c|c|}
\cline { 2 - 4 } \multicolumn{1}{c|}{} & $\mathbf{0 - 8}$ & $\mathbf{9 - 1 6}$ & $\mathbf{1 7 - 2 4}$ \\
\hline Uno & 127 & 398 & 203 \\
\hline Dos & 364 & 698 & 256 \\
\hline Tres & 604 & 584 & 78 \\
\hline Cuatro & 425 & 220 & 6 \\
\hline Cinco & 104 & 30 & 2 \\
\hline
\end{tabular}

\begin{tabular}{|l|c|c|c|}
\cline { 2 - 4 } \multicolumn{1}{c|}{} & $\mathbf{0 - 8}$ & $\mathbf{9 - 1 6}$ & $\mathbf{1 7}-\mathbf{2 4}$ \\
\hline 10 QT & 419 & 508 & 161 \\
\hline 20 QT & 388 & 505 & 136 \\
\hline 30 QT & 389 & 474 & 126 \\
\hline 40 QT & 428 & 443 & 122 \\
\hline
\end{tabular}

\begin{tabular}{|c|c|c|c|}
\cline { 2 - 4 } \multicolumn{1}{c|}{} & $\mathbf{0 - \mathbf { 8 }}$ & $\mathbf{9 - \mathbf { 1 6 }}$ & $\mathbf{1 7 - \mathbf { 2 4 }}$ \\
\hline Tiempo Muerto & 74 & 55 & 15 \\
\hline Última Jugada & 95 & 0 & 0 \\
\hline
\end{tabular}

\begin{tabular}{|c|c|c|c|}
\cline { 2 - 4 } \multicolumn{1}{c|}{} & Buen tiro & Tiro normal & Mal tiro \\
\hline$(+) \mathbf{1 1}-\mathbf{2 0}$ & $\mathbf{2 9}$ & 58 & 13 \\
\hline$(+) \mathbf{1}-\mathbf{1 0}$ & 590 & 596 & 174 \\
\hline Empate & 129 & 141 & 24 \\
\hline (-) $\mathbf{1}-\mathbf{1 0}$ & 828 & 937 & 239 \\
\hline (-) $\mathbf{1 1}-\mathbf{2 0}$ & 115 & 180 & 46 \\
\hline
\end{tabular}




\begin{tabular}{|c|c|c|c|}
\cline { 2 - 4 } \multicolumn{1}{c|}{} & Buen tiro & Tiro normal & Mal tiro \\
\hline Contraataque & 62 & 26 & 2 \\
\hline Bloqueo Directo & 307 & 355 & 50 \\
\hline Pase & 1041 & 427 & 87 \\
\hline Jugada Personal & 168 & 900 & 333 \\
\hline Robo & 70 & 41 & 7 \\
\hline Rebote & 43 & 163 & 17 \\
\hline
\end{tabular}

\begin{tabular}{|c|c|c|c|}
\cline { 2 - 4 } \multicolumn{1}{c|}{} & Buen tiro & Tiro normal & Mal tiro \\
\hline Uno & 199 & 422 & 107 \\
\hline Dos & 597 & 577 & 144 \\
\hline Tres & 546 & 587 & 133 \\
\hline Cuatro & 304 & 263 & 84 \\
\hline Cinco & 45 & 63 & 28 \\
\hline
\end{tabular}

\begin{tabular}{|c|c|c|c|}
\cline { 2 - 4 } \multicolumn{1}{c|}{} & Buen tiro & Tiro normal & Mal tiro \\
\hline 10 QT & 469 & 520 & 99 \\
\hline 20 QT & 417 & 481 & 131 \\
\hline 30 QT & 421 & 455 & 113 \\
\hline 4\% QT & 384 & 456 & 153 \\
\hline
\end{tabular}

\begin{tabular}{|c|c|c|c|}
\cline { 2 - 4 } \multicolumn{1}{c|}{} & Buen tiro & Tiro normal & Mal tiro \\
\hline Tiempo Muerto & 58 & 55 & 31 \\
\hline Última Jugada & 23 & 35 & 37 \\
\hline
\end{tabular}

\begin{tabular}{|c|c|c|c|c|c|}
\cline { 2 - 6 } \multicolumn{1}{c|}{} & $(\mathbf{+}) \mathbf{1 1}-\mathbf{2 0}$ & $\mathbf{( + )} \mathbf{1}-\mathbf{1 0}$ & Empate & $\mathbf{( - )} \mathbf{1}-\mathbf{1 0}$ & $\mathbf{( - )} \mathbf{1 1}-\mathbf{2 0}$ \\
\hline Contraataque & 2 & 36 & 8 & 39 & 5 \\
\hline Bloqueo Directo & 17 & 222 & 49 & 369 & 55 \\
\hline Pase & 40 & 535 & 111 & 761 & 108 \\
\hline Jugada Personal & 29 & 451 & 106 & 681 & 134 \\
\hline Robo & 2 & 46 & 7 & 48 & 15 \\
\hline Rebote & 10 & 70 & 13 & 106 & 24 \\
\hline
\end{tabular}

\begin{tabular}{|c|c|c|c|c|c|}
\cline { 2 - 6 } \multicolumn{1}{c|}{} & $\mathbf{( + )} \mathbf{1 1}-\mathbf{2 0}$ & $\mathbf{( + )} \mathbf{1} \mathbf{- 1 0}$ & Empate & $\mathbf{( - )} \mathbf{1}-\mathbf{1 0}$ & $\mathbf{( - )} \mathbf{1 1}-\mathbf{2 0}$ \\
\hline Uno & 16 & 239 & 48 & 354 & $\mathbf{7 1}$ \\
\hline Dos & 36 & 414 & 83 & 667 & 118 \\
\hline Tres & 31 & 405 & 97 & 638 & 95 \\
\hline Cuatro & 12 & 254 & 53 & 285 & 47 \\
\hline Cinco & 5 & 48 & 13 & 60 & 10 \\
\hline
\end{tabular}




\begin{tabular}{|c|c|c|c|c|c|}
\hline & $(+) 11-20$ & $(+) 1-10$ & Empate & $(-) 1-10$ & (-) $11-20$ \\
\hline 1QT & 9 & 344 & 134 & 576 & 25 \\
\hline 2० QT & 31 & 402 & 71 & 471 & 54 \\
\hline 3 QT & 15 & 320 & 58 & 487 & 109 \\
\hline \multirow[t]{2}{*}{ 4ㅇT QT } & 45 & 294 & 31 & 470 & 153 \\
\hline & (+) $11-20$ & $(+) 1-10$ & Empate & (-) $1-10$ & (-) $11-20$ \\
\hline Tiempo Muerto & 5 & 36 & 7 & 79 & 17 \\
\hline Última Jugada & 2 & 36 & 5 & 42 & 10 \\
\hline
\end{tabular}

\begin{tabular}{|c|c|c|c|c|c|c|}
\cline { 2 - 7 } \multicolumn{1}{c|}{} & Contraataque & Bloqueo Directo & Pase & Jugada Personal & Robo & Rebote \\
\hline Uno & 7 & 155 & 0 & 288 & 55 & 223 \\
\hline Dos & 50 & 251 & 538 & 427 & 52 & 0 \\
\hline Tres & 31 & 222 & 563 & 441 & 9 & 0 \\
\hline Cuatro & 2 & 69 & 375 & 203 & 2 & 0 \\
\hline Cinco & 0 & 15 & 79 & 42 & 0 & 0 \\
\hline
\end{tabular}

\begin{tabular}{|c|c|c|c|c|c|c|}
\cline { 2 - 7 } \multicolumn{1}{c|}{} & Contraataque & Bloqueo Directo & Pase & Jugada Personal & Robo & Rebote \\
\hline 10 QT & 37 & 183 & 397 & 377 & 32 & 62 \\
\hline 20 QT & 20 & 190 & 371 & 362 & 25 & 61 \\
\hline 3 QT & 18 & 156 & 417 & 317 & 32 & 49 \\
\hline 4 QT & 15 & 183 & 370 & 345 & 29 & 51 \\
\hline
\end{tabular}

\begin{tabular}{|c|c|c|c|c|c|c|}
\cline { 2 - 7 } \multicolumn{1}{c|}{} & Contraataque & Bloqueo Directo & Pase & Jugada Personal & Robo & Rebote \\
\hline Tiempo Muerto & 0 & 21 & 65 & 58 & 0 & 0 \\
\hline Última Jugada & 1 & 12 & 31 & 47 & 4 & 0 \\
\hline
\end{tabular}

\begin{tabular}{|l|c|c|c|c|c|}
\cline { 2 - 6 } \multicolumn{1}{c|}{} & Uno & Dos & Tres & Cuatro & Cinco \\
\hline 10 QT & 192 & 352 & 338 & 172 & 34 \\
\hline 20 QT & 198 & 321 & 306 & 168 & 36 \\
\hline 30 QT & 160 & 316 & 318 & 162 & 33 \\
\hline 40 QT & 178 & 329 & 304 & 149 & 33 \\
\hline
\end{tabular}

\begin{tabular}{|c|c|c|c|c|c|}
\cline { 2 - 6 } \multicolumn{1}{c|}{} & Uno & Dos & Tres & Cuatro & Cinco \\
\hline Tiempo Muerto & 16 & 55 & 43 & 25 & 5 \\
\hline Última Jugada & 38 & 41 & 12 & 4 & 0 \\
\hline
\end{tabular}

\begin{tabular}{|c|c|c|c|c|}
\cline { 2 - 5 } \multicolumn{1}{c|}{} & 10 QT & 20 QT & 3 QT & 4 QT \\
\hline Tiempo Muerto & 18 & 42 & 22 & 62 \\
\hline Última Jugada & 30 & 19 & 28 & 18 \\
\hline
\end{tabular}




\subsubsection{EEUU (NBA y WNBA)}

\begin{tabular}{|c|c|c|c|c|c|c|c|}
\cline { 2 - 8 } \multicolumn{1}{c|}{} & ZONA 1 & ZONA 2 & ZONA 3 & ZONA 4 & ZONA 5 & ZONA 6 & ZONA 7 \\
\hline 3p. + adicional & 0 & 0 & 0 & 0 & 2 & 1 & 4 \\
\hline 3puntos & 0 & 0 & 0 & 0 & 147 & 102 & 516 \\
\hline Falta + 3 adic. & 0 & 0 & 0 & 0 & 6 & 3 & 21 \\
\hline 2p. + adicional & 145 & 11 & 1 & 0 & 0 & 0 & 0 \\
\hline 2puntos & 1519 & 147 & 124 & 245 & 0 & 0 & 0 \\
\hline Falta + 2 adic. & 438 & 21 & 20 & 19 & 0 & 0 & 0 \\
\hline Tapón & 253 & 8 & 6 & 2 & 3 & 7 & 6 \\
\hline Fallo 3p. & 0 & 0 & 0 & 0 & 244 & 195 & 986 \\
\hline Fallo 2p. & 1155 & 305 & 234 & 322 & 0 & 0 & 0 \\
\hline
\end{tabular}

\begin{tabular}{|c|c|c|c|c|c|c|c|}
\cline { 2 - 8 } \multicolumn{1}{c|}{} & ZONA 1 & ZONA 2 & ZONA 3 & ZONA 4 & ZONA 5 & ZONA 6 & ZONA 7 \\
\hline $\mathbf{0 - \mathbf { 8 }}$ & 817 & 187 & 138 & 146 & 112 & 91 & 414 \\
\hline $\mathbf{9}-\mathbf{1 6}$ & 1792 & 260 & 190 & 365 & 201 & 151 & 754 \\
\hline $\mathbf{1 7}-\mathbf{2 4}$ & 901 & 45 & 57 & 77 & 89 & 66 & 365 \\
\hline
\end{tabular}

\begin{tabular}{|c|c|c|c|c|c|c|c|}
\cline { 2 - 8 } \multicolumn{1}{c|}{} & ZONA 1 & ZONA 2 & ZONA 3 & ZONA 4 & ZONA 5 & ZONA 6 & ZONA 7 \\
\hline Buen tiro & 839 & 89 & 66 & 283 & 259 & 186 & 841 \\
\hline Tiro normal & 2217 & 278 & 233 & 271 & 120 & 113 & 518 \\
\hline Mal tiro & 454 & 125 & 86 & 34 & 23 & 9 & 174 \\
\hline
\end{tabular}

\begin{tabular}{|c|c|c|c|c|c|c|c|}
\cline { 2 - 8 } \multicolumn{1}{c|}{} & ZONA 1 & ZONA 2 & ZONA 3 & ZONA 4 & ZONA 5 & ZONA 6 & ZONA 7 \\
\hline$(+) \mathbf{1 1}-\mathbf{2 0}$ & 81 & 9 & 9 & 15 & 8 & 4 & 43 \\
\hline (+) $\mathbf{1}-\mathbf{1 0}$ & 1232 & 199 & 132 & 215 & 152 & 124 & 551 \\
\hline Empate & 265 & 35 & 36 & 49 & 29 & 27 & 113 \\
\hline$(-) \mathbf{1}-\mathbf{1 0}$ & 1618 & 220 & 182 & 258 & 184 & 131 & 693 \\
\hline$(-) \mathbf{1 1}-\mathbf{2 0}$ & 314 & 29 & 26 & 51 & 29 & 22 & 133 \\
\hline
\end{tabular}

\begin{tabular}{|c|c|c|c|c|c|c|c|}
\cline { 2 - 8 } \multicolumn{1}{c|}{} & ZONA 1 & ZONA 2 & ZONA 3 & ZONA 4 & ZONA 5 & ZONA 6 & ZONA 7 \\
\hline Contraataque & 130 & 0 & 4 & 2 & 7 & 6 & 18 \\
\hline Bloqueo Directo & 494 & 94 & 81 & 235 & 14 & 9 & 283 \\
\hline Pase & 550 & 82 & 73 & 133 & 330 & 256 & 910 \\
\hline Jugada Personal & 1812 & 306 & 221 & 215 & 40 & 33 & 301 \\
\hline Robo & 161 & 5 & 3 & 0 & 9 & 3 & 11 \\
\hline Rebote & 363 & 5 & 3 & 3 & 2 & 1 & 10 \\
\hline
\end{tabular}

\begin{tabular}{|c|c|c|c|c|c|c|c|}
\cline { 2 - 8 } \multicolumn{1}{c|}{} & ZONA 1 & ZONA 2 & ZONA 3 & ZONA 4 & ZONA 5 & ZONA 6 & ZONA 7 \\
\hline Uno & 1113 & 81 & 94 & 111 & 13 & 12 & 224 \\
\hline Dos & 1154 & 171 & 119 & 201 & 170 & 115 & 636 \\
\hline Tres & 838 & 151 & 123 & 184 & 133 & 106 & 438 \\
\hline Cuatro & 349 & 77 & 43 & 79 & 69 & 65 & 200 \\
\hline Cinco & 56 & 12 & 6 & 13 & 17 & 10 & 35 \\
\hline
\end{tabular}




\begin{tabular}{|l|c|c|c|c|c|c|c|}
\cline { 2 - 8 } \multicolumn{1}{c|}{} & ZONA 1 & ZONA 2 & ZONA 3 & ZONA 4 & ZONA 5 & ZONA 6 & ZONA 7 \\
\hline 10 QT & 896 & 135 & 111 & 187 & 110 & 85 & 344 \\
\hline 20 QT & 895 & 136 & 95 & 142 & 97 & 70 & 405 \\
\hline 30 QT & 856 & 120 & 106 & 148 & 93 & 87 & 361 \\
\hline 40 QT & 863 & 101 & 73 & 111 & 102 & 66 & 423 \\
\hline
\end{tabular}

\begin{tabular}{|c|c|c|c|c|c|c|c|}
\cline { 2 - 8 } \multicolumn{1}{c|}{} & ZONA 1 & ZONA 2 & ZONA 3 & ZONA 4 & ZONA 5 & ZONA 6 & ZONA 7 \\
\hline Tiempo Muerto & 125 & 23 & 14 & 20 & 20 & 7 & 61 \\
\hline Última Jugada & 33 & 3 & 6 & 9 & 10 & 5 & 51 \\
\hline
\end{tabular}

\begin{tabular}{|c|c|c|c|c|c|c|c|c|c|}
\cline { 2 - 10 } \multicolumn{1}{c|}{} & 3p. + adicional & 3puntos & Falta + 3 adic. & 2p. + adicional & 2puntos & Falta + 2 adic. & Tapón & Fallo 3p. & Fallo 2p. \\
\hline $\mathbf{0 - 8}$ & 1 & 188 & 7 & 33 & 477 & 116 & 68 & 416 & 599 \\
\hline $\mathbf{9 - 1 6}$ & 4 & 383 & 19 & 73 & 1056 & 259 & 141 & 693 & 1085 \\
\hline $\mathbf{1 7 - 2 4}$ & 2 & 194 & 4 & 51 & 502 & 123 & 76 & 316 & 332 \\
\hline
\end{tabular}

\begin{tabular}{|c|c|c|c|c|c|c|c|c|c|}
\hline & 3p. + adicional & 3puntos & Falta +3 adic. & 2p. + adicional & 2puntos & Falta +2 adic. & Tapón & Fallo 3p. & Fallo 2p. \\
\hline Buen tiro & 2 & 549 & 3 & 39 & 929 & 14 & 4 & 732 & 291 \\
\hline Tiro normal & 4 & 189 & 22 & 106 & 1019 & 426 & 206 & 524 & 1254 \\
\hline Mal tiro & 1 & 27 & 5 & 12 & 87 & 58 & 75 & 169 & 471 \\
\hline
\end{tabular}

\begin{tabular}{|c|c|c|c|c|c|c|c|c|c|}
\hline & 3p. + adicional & 3 puntos & Falta +3 adic. & 2p. + adicional & 2puntos & Falta +2 adic. & Tapón & Fallo 3p. & Fallo 2p. \\
\hline (+) $11-20$ & 0 & 15 & 1 & 2 & 47 & 8 & 8 & 38 & 50 \\
\hline$(+) 1-10$ & 2 & 237 & 15 & 39 & 697 & 199 & 115 & 564 & 737 \\
\hline Empate & 1 & 64 & 2 & 12 & 169 & 36 & 18 & 102 & 150 \\
\hline$(-) 1-10$ & 3 & 362 & 12 & 85 & 948 & 208 & 117 & 627 & 924 \\
\hline (-) $11-20$ & 1 & 87 & 0 & 19 & 174 & 47 & 27 & 94 & 155 \\
\hline
\end{tabular}

\begin{tabular}{|c|c|c|c|c|c|c|c|c|c|}
\hline & 3p. + adicional & 3puntos & Falta +3 adic. & 2p. + adicional & 2puntos & Falta +2 adic. & Tapón & Fallo 3p. & Fallo 2p. \\
\hline Contraataque & 0 & 11 & 0 & 8 & 84 & 13 & 1 & 20 & 30 \\
\hline Bloqueo Directo & 1 & 101 & 10 & 16 & 378 & 82 & 35 & 190 & 397 \\
\hline Pase & 3 & 529 & 13 & 25 & 424 & 61 & 52 & 940 & 287 \\
\hline Jugada Personal & 3 & 113 & 7 & 91 & 877 & 287 & 162 & 250 & 1138 \\
\hline Robo & 0 & 7 & 0 & 5 & 98 & 15 & 15 & 16 & 36 \\
\hline Rebote & 0 & 4 & 0 & 12 & 174 & 40 & 20 & 9 & 128 \\
\hline
\end{tabular}

\begin{tabular}{|c|c|c|c|c|c|c|c|c|c|}
\hline & 3p. + adicional & 3puntos & Falta +3 adic. & 2p. + adicional & 2puntos & Falta +2 adic. & Tapón & Fallo 3p. & Fallo 2p. \\
\hline Uno & 2 & 69 & 7 & 56 & 560 & 160 & 92 & 169 & 533 \\
\hline Dos & 2 & 335 & 14 & 51 & 676 & 167 & 98 & 562 & 661 \\
\hline Tres & 3 & 225 & 5 & 38 & 523 & 122 & 72 & 439 & 546 \\
\hline Cuatro & 0 & 113 & 3 & 11 & 234 & 42 & 20 & 217 & 242 \\
\hline Cinco & 0 & 23 & 1 & 1 & 42 & 7 & 3 & 38 & 34 \\
\hline
\end{tabular}

\begin{tabular}{|c|c|c|c|c|c|c|c|c|c|}
\hline & 3p. + adicional & 3puntos & Falta +3 adic. & 2p. + adicional & 2puntos & Falta +2 adic. & Tapón & Fallo 3p. & Fallo 2p. \\
\hline $19 Q T$ & 1 & 179 & 10 & 38 & 597 & 113 & 66 & 348 & 516 \\
\hline $2 \div Q T$ & 2 & 198 & 6 & 41 & 511 & 136 & 67 & 363 & 516 \\
\hline 3 QT & 1 & 177 & 8 & 41 & 480 & 121 & 68 & 349 & 526 \\
\hline $4 \circ Q T$ & 3 & 211 & 6 & 37 & 447 & 128 & 84 & 365 & 458 \\
\hline
\end{tabular}

\begin{tabular}{|c|c|c|c|c|c|c|c|c|c|}
\hline & 3p. + adicional & 3puntos & Falta +3 adic. & 2p. + adicional & 2puntos & Falta +2 adic. & Tapón & Fallo 3p. & Fallo 2p. \\
\hline Tiempo Muerto & 0 & 28 & 1 & 9 & 72 & 12 & 9 & 58 & 81 \\
\hline Última Jugada & 0 & 8 & 0 & 2 & 23 & 1 & 9 & 56 & 18 \\
\hline
\end{tabular}

\begin{tabular}{|c|c|c|c|}
\cline { 2 - 4 } \multicolumn{1}{c|}{} & $\mathbf{0 - \mathbf { 8 }}$ & $\mathbf{9 - 1 6}$ & $\mathbf{1 7 - 2 4}$ \\
\hline Buen tiro & 471 & 1336 & 756 \\
\hline Tiro normal & 1015 & 2011 & 724 \\
\hline Mal tiro & 419 & 366 & 120 \\
\hline
\end{tabular}




\begin{tabular}{|c|c|c|c|}
\cline { 2 - 4 } \multicolumn{1}{c|}{} & $\mathbf{0 - 8}$ & $\mathbf{9 - 1 6}$ & $\mathbf{1 7 - 2 4}$ \\
\hline (+) $\mathbf{1 1}-\mathbf{2 0}$ & 57 & 73 & 39 \\
\hline (+) $\mathbf{1}-\mathbf{1 0}$ & 763 & 1278 & 564 \\
\hline Empate & 154 & 286 & 114 \\
\hline (-) $\mathbf{1}-\mathbf{1 0}$ & $\mathbf{7 9 9}$ & 1741 & 746 \\
\hline (-) $\mathbf{1 1}-\mathbf{2 0}$ & 132 & 335 & 137 \\
\hline
\end{tabular}

\begin{tabular}{|c|c|c|c|}
\cline { 2 - 4 } \multicolumn{1}{c|}{} & $\mathbf{0 - \mathbf { 8 }}$ & $\mathbf{9 - 1 6}$ & $\mathbf{1 7 - 2 4}$ \\
\hline Contraataque & 4 & 0 & 163 \\
\hline Bloqueo Directo & 245 & 795 & 170 \\
\hline Pase & 600 & 1276 & 458 \\
\hline Jugada Personal & 1017 & 1407 & 504 \\
\hline Robo & 7 & 2 & 183 \\
\hline Rebote & 32 & 233 & 122 \\
\hline
\end{tabular}

\begin{tabular}{|c|c|c|c|}
\cline { 2 - 4 } \multicolumn{1}{c|}{} & $\mathbf{0 - \mathbf { 8 }}$ & $\mathbf{9 - 1 6}$ & $\mathbf{1 7 - 2 4}$ \\
\hline Uno & 221 & $\mathbf{7 2 2}$ & $\mathbf{7 0 5}$ \\
\hline Dos & 487 & 1369 & 710 \\
\hline Tres & 627 & 1174 & 172 \\
\hline Cuatro & 460 & 409 & 13 \\
\hline Cinco & 110 & 39 & 0 \\
\hline
\end{tabular}

\begin{tabular}{|l|c|c|c|}
\cline { 2 - 4 } \multicolumn{1}{c|}{} & $\mathbf{0 - 8}$ & $\mathbf{9 - 1 6}$ & $\mathbf{1 7}-\mathbf{2 4}$ \\
\hline 10 QT & 437 & 1001 & 430 \\
\hline 20 QT & 491 & 933 & 416 \\
\hline 30 QT & 497 & 887 & 387 \\
\hline 40 QT & 480 & 892 & 367 \\
\hline
\end{tabular}

\begin{tabular}{|c|c|c|c|}
\cline { 2 - 4 } \multicolumn{1}{c|}{} & $\mathbf{0 - 8}$ & $\mathbf{9 - 1 6}$ & $\mathbf{1 7 - 2 4}$ \\
\hline Tiempo Muerto & 108 & 135 & 27 \\
\hline Última Jugada & 117 & 0 & 0 \\
\hline
\end{tabular}

\begin{tabular}{|c|c|c|c|}
\cline { 2 - 4 } \multicolumn{1}{c|}{} & Buen tiro & Tiro normal & Mal tiro \\
\hline (+) $\mathbf{1 1}-\mathbf{2 0}$ & 62 & 86 & 21 \\
\hline (+) $\mathbf{1}-\mathbf{1 0}$ & 884 & 1352 & 369 \\
\hline Empate & 217 & 275 & 62 \\
\hline (-) $\mathbf{1}-\mathbf{1 0}$ & 1181 & 1716 & 389 \\
\hline (-) $\mathbf{1 1}-\mathbf{2 0}$ & 219 & 321 & 64 \\
\hline
\end{tabular}




\begin{tabular}{|c|c|c|c|}
\cline { 2 - 4 } \multicolumn{1}{c|}{} & Buen tiro & Tiro normal & Mal tiro \\
\hline Contraataque & 118 & 43 & 6 \\
\hline Bloqueo Directo & 487 & 620 & 103 \\
\hline Pase & 1370 & 828 & 136 \\
\hline Jugada Personal & 356 & 1932 & 640 \\
\hline Robo & 119 & 67 & 6 \\
\hline Rebote & 113 & 260 & 14 \\
\hline
\end{tabular}

\begin{tabular}{|c|c|c|c|}
\cline { 2 - 4 } \multicolumn{1}{c|}{} & Buen tiro & Tiro normal & Mal tiro \\
\hline Uno & 396 & 1028 & 224 \\
\hline Dos & 1025 & 1230 & 311 \\
\hline Tres & 747 & 1004 & 222 \\
\hline Cuatro & 337 & 415 & 130 \\
\hline Cinco & 58 & 73 & 18 \\
\hline
\end{tabular}

\begin{tabular}{|c|c|c|c|}
\cline { 2 - 4 } \multicolumn{1}{c|}{} & Buen tiro & Tiro normal & Mal tiro \\
\hline 10 QT & 712 & 962 & 194 \\
\hline 2o QT & 678 & 932 & 230 \\
\hline 3o QT & 615 & 924 & 232 \\
\hline 40 QT & 558 & 932 & 249 \\
\hline
\end{tabular}

\begin{tabular}{|c|c|c|c|}
\cline { 2 - 4 } \multicolumn{1}{c|}{} & Buen tiro & Tiro normal & Mal tiro \\
\hline Tiempo Muerto & 85 & 143 & 42 \\
\hline Última Jugada & 22 & 45 & 50 \\
\hline
\end{tabular}

\begin{tabular}{|c|c|c|c|c|c|}
\cline { 2 - 6 } \multicolumn{1}{c|}{} & $(\mathbf{+}) \mathbf{1 1}-\mathbf{2 0}$ & $\mathbf{( + )} \mathbf{1}-\mathbf{1 0}$ & Empate & $\mathbf{( - )} \mathbf{1}-\mathbf{1 0}$ & $\mathbf{( - )} \mathbf{1 1}-\mathbf{2 0}$ \\
\hline Contraataque & 8 & 62 & 7 & 78 & 12 \\
\hline Bloqueo Directo & 29 & 433 & 95 & 548 & 105 \\
\hline Pase & 48 & 883 & 187 & 1024 & 192 \\
\hline Jugada Personal & 68 & 1032 & 220 & 1368 & 240 \\
\hline Robo & 6 & 80 & 11 & 81 & 14 \\
\hline Rebote & 10 & 115 & 34 & 187 & 41 \\
\hline
\end{tabular}




\begin{tabular}{|c|c|c|c|c|c|}
\cline { 2 - 6 } \multicolumn{1}{c|}{} & $\mathbf{( + )} \mathbf{1 1}-\mathbf{2 0}$ & $\mathbf{( + )} \mathbf{1}-\mathbf{1 0}$ & Empate & $\mathbf{( - )} \mathbf{1}-\mathbf{1 0}$ & $\mathbf{( - )} \mathbf{1 1}-\mathbf{2 0}$ \\
\hline Uno & 37 & 555 & 118 & 794 & 144 \\
\hline Dos & 71 & 957 & 179 & 1151 & $\mathbf{2 0 8}$ \\
\hline Tres & 41 & 722 & 162 & 893 & 155 \\
\hline Cuatro & 17 & 327 & 73 & 377 & 88 \\
\hline Cinco & 3 & 44 & 22 & 71 & 9 \\
\hline
\end{tabular}

\begin{tabular}{|c|c|c|c|c|c|}
\cline { 2 - 6 } \multicolumn{1}{c|}{} & $\mathbf{( + )} \mathbf{1 1}-\mathbf{2 0}$ & $\mathbf{( + )} \mathbf{1}-\mathbf{1 0}$ & Empate & $\mathbf{( - )} \mathbf{1}-\mathbf{1 0}$ & $\mathbf{( - )} \mathbf{1 1}-\mathbf{2 0}$ \\
\hline 10 QT & 19 & 687 & 221 & 906 & 35 \\
\hline 20 QT & 32 & 763 & 145 & 826 & 74 \\
\hline 39 QT & 62 & 603 & 117 & 784 & 205 \\
\hline 40 QT & 56 & 552 & 71 & 770 & 290 \\
\hline
\end{tabular}

\begin{tabular}{|c|c|c|c|c|c|}
\hline & (+) $11-20$ & (+) $1-10$ & Empate & $(-) 1-10$ & (-) $11-20$ \\
\hline Tiempo Muerto & 6 & 68 & 16 & 153 & 27 \\
\hline Última Jugada & 6 & 42 & 5 & 57 & 7 \\
\hline
\end{tabular}

\begin{tabular}{|c|c|c|c|c|c|c|}
\cline { 2 - 7 } \multicolumn{1}{c|}{} & Contraataque & Bloqueo Directo & Pase & Jugada Personal & Robo & Rebote \\
\hline Uno & 11 & 330 & 0 & 836 & 84 & 387 \\
\hline Dos & 100 & 445 & 1025 & 905 & 91 & 0 \\
\hline Tres & 50 & 314 & 816 & 777 & 16 & 0 \\
\hline Cuatro & 6 & 105 & 405 & 365 & 1 & 0 \\
\hline Cinco & 0 & 16 & 88 & 45 & 0 & 0 \\
\hline
\end{tabular}

\begin{tabular}{|c|c|c|c|c|c|c|}
\cline { 2 - 7 } \multicolumn{1}{c|}{} & Contraataque & Bloqueo Directo & Pase & Jugada Personal & Robo & Rebote \\
\hline 10 QT & 45 & 342 & 621 & 723 & 50 & 87 \\
\hline 20 QT & 55 & 294 & 585 & 761 & 48 & 97 \\
\hline 30 QT & 37 & 290 & 584 & 710 & 47 & 103 \\
\hline 40 QT & 30 & 284 & 544 & 734 & 47 & 100 \\
\hline
\end{tabular}

\begin{tabular}{|c|c|c|c|c|c|c|}
\cline { 2 - 7 } \multicolumn{1}{c|}{} & Contraataque & Bloqueo Directo & Pase & Jugada Personal & Robo & Rebote \\
\hline Tiempo Muerto & 0 & 39 & 106 & 125 & 0 & 0 \\
\hline Última Jugada & 2 & 15 & 34 & 61 & 5 & 0 \\
\hline
\end{tabular}

\begin{tabular}{|l|c|c|c|c|c|}
\cline { 2 - 5 } \multicolumn{1}{c|}{} & Uno & Dos & Tres & Cuatro & Cinco \\
\hline 10 QT & 391 & 653 & 545 & 232 & 47 \\
\hline 20 QT & 394 & 649 & 543 & 216 & 38 \\
\hline 3 QT & 429 & 592 & 471 & 248 & 31 \\
\hline 40 QT & 434 & 672 & 414 & 186 & 33 \\
\hline
\end{tabular}




\begin{tabular}{|c|c|c|c|c|c|}
\cline { 2 - 6 } \multicolumn{1}{c|}{} & Uno & Dos & Tres & Cuatro & Cinco \\
\hline Tiempo Muerto & 30 & 87 & 88 & 45 & 20 \\
\hline Última Jugada & 59 & 44 & 11 & 3 & 0 \\
\hline
\end{tabular}

\begin{tabular}{|c|c|c|c|c|}
\cline { 2 - 5 } \multicolumn{1}{c|}{} & 10 QT & 20 QT & 30 QT & 40 QT \\
\hline Tiempo Muerto & 44 & 63 & 45 & 118 \\
\hline Última Jugada & 28 & 31 & 41 & 17 \\
\hline
\end{tabular}




\subsubsection{Baloncesto masculino europeo (ACB Y Euroliga)}

\begin{tabular}{|c|c|c|c|c|c|c|c|}
\cline { 2 - 8 } \multicolumn{1}{c|}{} & ZONA 1 & ZONA 2 & ZONA 3 & ZONA 4 & ZONA 5 & ZONA 6 & ZONA 7 \\
\hline 3p. + adicional & 0 & 0 & 0 & 0 & 1 & 1 & 0 \\
\hline 3puntos & 0 & 0 & 0 & 0 & 105 & 109 & 363 \\
\hline Falta + 3 adic. & 0 & 0 & 0 & 0 & 4 & 5 & 13 \\
\hline 2p. + adicional & 96 & 5 & 2 & 1 & 0 & 0 & 0 \\
\hline 2puntos & 973 & 47 & 61 & 62 & 0 & 0 & 0 \\
\hline Falta + 2 adic. & 247 & 8 & 8 & 4 & 0 & 0 & 0 \\
\hline Tapón & 154 & 3 & 5 & 1 & 1 & 3 & 4 \\
\hline Fallo 3p. & 0 & 0 & 0 & 0 & 173 & 170 & 704 \\
\hline Fallo 2p. & 657 & 96 & 120 & 133 & 0 & 0 & 0 \\
\hline
\end{tabular}

\begin{tabular}{|c|c|c|c|c|c|c|c|}
\cline { 2 - 8 } \multicolumn{1}{c|}{} & ZONA 1 & ZONA 2 & ZONA 3 & ZONA 4 & ZONA 5 & ZONA 6 & ZONA 7 \\
\hline $\mathbf{0 - \mathbf { 8 }}$ & 790 & 92 & 99 & 101 & 118 & 138 & 479 \\
\hline $\mathbf{9}-\mathbf{1 6}$ & 1004 & 60 & 79 & 84 & 138 & 119 & 481 \\
\hline $\mathbf{1 7}-\mathbf{2 4}$ & 333 & 7 & 18 & 16 & 28 & 31 & 124 \\
\hline
\end{tabular}

\begin{tabular}{|c|c|c|c|c|c|c|c|}
\cline { 2 - 8 } \multicolumn{1}{c|}{} & ZONA 1 & ZONA 2 & ZONA 3 & ZONA 4 & ZONA 5 & ZONA 6 & ZONA 7 \\
\hline Buen tiro & 604 & 35 & 47 & 94 & 196 & 206 & 578 \\
\hline Tiro normal & 1276 & 81 & 104 & 85 & 76 & 63 & 323 \\
\hline Mal tiro & 247 & 43 & 45 & 22 & 12 & 19 & 183 \\
\hline
\end{tabular}

\begin{tabular}{|c|c|c|c|c|c|c|c|}
\cline { 2 - 8 } \multicolumn{1}{c|}{} & ZONA 1 & ZONA 2 & ZONA 3 & ZONA 4 & ZONA 5 & ZONA 6 & ZONA 7 \\
\hline $\mathbf{( + )} \mathbf{1 1}-\mathbf{2 0}$ & 37 & 5 & 0 & 5 & 2 & 4 & 24 \\
\hline $\mathbf{( + )} \mathbf{1}-\mathbf{1 0}$ & 645 & 56 & 67 & 76 & 85 & 93 & 309 \\
\hline Empate & 136 & 7 & 9 & 12 & 26 & 23 & 78 \\
\hline $\mathbf{( - )} \mathbf{1}-\mathbf{1 0}$ & 1071 & 76 & 106 & 87 & 137 & 141 & 548 \\
\hline$(-) \mathbf{1 1}-\mathbf{2 0}$ & 238 & 15 & 14 & 21 & 34 & 27 & 125 \\
\hline
\end{tabular}

\begin{tabular}{|c|c|c|c|c|c|c|c|}
\cline { 2 - 8 } \multicolumn{1}{c|}{} & ZONA 1 & ZONA 2 & ZONA 3 & ZONA 4 & ZONA 5 & ZONA 6 & ZONA 7 \\
\hline Contraataque & 84 & 0 & 0 & 2 & 3 & 5 & 7 \\
\hline Bloqueo Directo & 394 & 20 & 30 & 54 & 16 & 5 & 255 \\
\hline Pase & 412 & 29 & 55 & 50 & 227 & 250 & 627 \\
\hline Jugada Personal & 924 & 108 & 108 & 93 & 34 & 27 & 181 \\
\hline Robo & 115 & 0 & 1 & 2 & 4 & 0 & 11 \\
\hline Rebote & 198 & 2 & 2 & 0 & 0 & 1 & 3 \\
\hline
\end{tabular}

\begin{tabular}{|c|c|c|c|c|c|c|c|}
\cline { 2 - 8 } \multicolumn{1}{c|}{} & ZONA 1 & ZONA 2 & ZONA 3 & ZONA 4 & ZONA 5 & ZONA 6 & ZONA 7 \\
\hline Uno & 524 & 18 & 35 & 37 & 3 & 9 & 134 \\
\hline Dos & 693 & 51 & 66 & 67 & 107 & 99 & 435 \\
\hline Tres & 617 & 59 & 58 & 62 & 103 & 96 & 318 \\
\hline Cuatro & 251 & 24 & 30 & 31 & 58 & 71 & 168 \\
\hline Cinco & 42 & 7 & 7 & 4 & 13 & 13 & 29 \\
\hline
\end{tabular}




\begin{tabular}{|c|c|c|c|c|c|c|c|}
\cline { 2 - 8 } \multicolumn{1}{c|}{} & ZONA 1 & ZONA 2 & ZONA 3 & ZONA 4 & ZONA 5 & ZONA 6 & ZONA 7 \\
\hline 10 QT & 571 & 50 & 53 & 58 & 81 & 63 & 245 \\
\hline 20 QT & 514 & 37 & 49 & 52 & 70 & 78 & 270 \\
\hline 3운 & 536 & 38 & 43 & 51 & 65 & 72 & 270 \\
\hline 40 QT & 506 & 34 & 51 & 40 & 68 & 75 & 299 \\
\hline
\end{tabular}

\begin{tabular}{|c|c|c|c|c|c|c|c|}
\cline { 2 - 8 } \multicolumn{1}{c|}{} & ZONA 1 & ZONA 2 & ZONA 3 & ZONA 4 & ZONA 5 & ZONA 6 & ZONA 7 \\
\hline Tiempo Muerto & 90 & 9 & 4 & 14 & 10 & 11 & 52 \\
\hline Última Jugada & 28 & 2 & 5 & 4 & 7 & 7 & 51 \\
\hline
\end{tabular}

\begin{tabular}{|c|c|c|c|c|c|c|c|c|c|}
\hline & 3p. + adicional & 3puntos & Falta +3 adic. & 2p. + adicional & 2puntos & Falta +2 adic. & Tapón & Fallo 3p. & Fallo 2p. \\
\hline $0-8$ & 0 & 238 & 8 & 30 & 413 & 98 & 77 & 482 & 471 \\
\hline $9-16$ & 2 & 267 & 10 & 55 & 538 & 125 & 70 & 458 & 440 \\
\hline $17-24$ & 0 & 72 & 4 & 19 & 192 & 44 & 24 & 107 & 95 \\
\hline
\end{tabular}

\begin{tabular}{|c|c|c|c|c|c|c|c|c|c|}
\hline & 3p. + adicional & 3puntos & Falta +3 adic. & 2p. + adicional & 2 puntos & Falta +2 adic. & Tapón & Fallo 3p. & Fallo 2p. \\
\hline Buen tiro & 0 & 415 & 7 & 23 & 574 & 16 & 5 & 558 & 162 \\
\hline Tiro normal & 2 & 134 & 14 & 77 & 525 & 228 & 124 & 309 & 595 \\
\hline Mal tiro & 0 & 28 & 1 & 4 & 44 & 23 & 42 & 180 & 249 \\
\hline
\end{tabular}

\begin{tabular}{|c|c|c|c|c|c|c|c|c|c|}
\hline & 3p. + adicional & 3puntos & Falta +3 adic. & 2p. + adicional & 2 puntos & Falta +2 adic. & Tapón & Fallo 3p. & Fallo 2p. \\
\hline$(+) 11-20$ & 0 & 5 & 1 & 3 & 23 & 2 & 2 & 24 & 17 \\
\hline$(+) 1-10$ & 0 & 152 & 5 & 24 & 340 & 89 & 54 & 329 & 338 \\
\hline Empate & 0 & 46 & 0 & 7 & 75 & 10 & 8 & 81 & 64 \\
\hline$(-) 1-10$ & 1 & 294 & 12 & 53 & 577 & 133 & 94 & 513 & 489 \\
\hline (-) $11-20$ & 1 & 80 & 4 & 17 & 128 & 33 & 13 & 100 & 98 \\
\hline
\end{tabular}

\begin{tabular}{|c|c|c|c|c|c|c|c|c|c|}
\cline { 2 - 9 } \multicolumn{1}{c|}{} & 3p. + adicional & 3puntos & Falta + 3 adic. & 2p. + adicional & 2puntos & Falta + 2 adic. & Tapón & Fallo 3p. & Fallo 2p. \\
\hline Contraataque & 0 & 7 & 0 & 6 & 57 & 8 & 6 & 8 & 9 \\
\hline Bloqueo Directo & 0 & 102 & 3 & 10 & 204 & 49 & 26 & 171 & 209 \\
\hline Pase & 1 & 383 & 15 & 24 & 264 & 41 & 35 & 699 & 188 \\
\hline Jugada Personal & 1 & 76 & 4 & 52 & 434 & 140 & 86 & 159 & 523 \\
\hline Robo & 0 & 9 & 0 & 5 & 73 & 11 & 6 & 6 \\
\hline Rebote & 0 & 0 & 0 & 7 & 111 & 18 & 12 & 4 & 54 \\
\hline
\end{tabular}

\begin{tabular}{|c|c|c|c|c|c|c|c|c|c|}
\cline { 2 - 10 } \multicolumn{1}{c|}{} & 3p. + adicional & 3puntos & Falta + 3 adic. & 2p. + adicional & 2puntos & Falta + 2 adic. & Tapón & Fallo 3p. & Fallo 2p. \\
\hline Uno & 0 & 50 & 4 & 21 & 254 & 73 & 33 & 91 & 234 \\
\hline Dos & 1 & 217 & 8 & 40 & 379 & 71 & 57 & 412 & 333 \\
\hline Tres & 0 & 182 & 6 & 31 & 348 & 81 & 52 & 327 & 286 \\
\hline Cuatro & 1 & 106 & 4 & 9 & 144 & 33 & 24 & 184 & 128 \\
\hline Cinco & 0 & 22 & 0 & 3 & 18 & 9 & 5 & 33 & 25 \\
\hline
\end{tabular}

\begin{tabular}{|c|c|c|c|c|c|c|c|c|c|}
\hline & 3p. + adicional & 3puntos & Falta +3 adic. & 2p. + adicional & 2 puntos & Falta +2 adic. & Tapón & Fallo 3p. & Fallo 2p. \\
\hline 10 QT & 0 & 146 & 5 & 29 & 329 & 51 & 41 & 237 & 283 \\
\hline 20 QT & 0 & 145 & 3 & 17 & 288 & 72 & 35 & 268 & 242 \\
\hline 30 QT & 1 & 142 & 7 & 23 & 283 & 62 & 47 & 256 & 254 \\
\hline 4० QT & 1 & 144 & 7 & 35 & 243 & 82 & 48 & 286 & 227 \\
\hline
\end{tabular}




\begin{tabular}{|c|c|c|c|c|c|c|c|c|c|}
\cline { 2 - 9 } \multicolumn{1}{c|}{} & 3p. + adicional & 3puntos & Falta + 3 adic. & 2p. + adicional & 2puntos & Falta + 2 adic. & Tapón & Fallo 3p. & Fallo 2p. \\
\hline Tiempo Muerto & 0 & 24 & 2 & 4 & 43 & 11 & 10 & 46 & 50 \\
\hline Última Jugada & 0 & 12 & 1 & 1 & 16 & 2 & 1 & 52 & 19 \\
\hline
\end{tabular}

\begin{tabular}{|c|c|c|c|}
\cline { 2 - 4 } \multicolumn{1}{c|}{} & $\mathbf{0 - 8}$ & $\mathbf{9 - 1 6}$ & $\mathbf{1 7 - 2 4}$ \\
\hline Buen tiro & 597 & 838 & 325 \\
\hline Tiro normal & 832 & 985 & 191 \\
\hline Mal tiro & 388 & 142 & 41 \\
\hline
\end{tabular}

\begin{tabular}{|c|c|c|c|}
\cline { 2 - 4 } \multicolumn{1}{c|}{} & $\mathbf{0 - 8}$ & $\mathbf{9 - 1 6}$ & $\mathbf{1 7 - 2 4}$ \\
\hline $\mathbf{( + )} \mathbf{1 1}-\mathbf{2 0}$ & $\mathbf{3 6}$ & $\mathbf{3 2}$ & 9 \\
\hline (+) $\mathbf{1}-\mathbf{1 0}$ & 572 & 584 & 175 \\
\hline Empate & 131 & 121 & 39 \\
\hline (-) $\mathbf{1}-\mathbf{1 0}$ & 898 & 982 & $\mathbf{2 8 6}$ \\
\hline (-) $\mathbf{1 1}-\mathbf{2 0}$ & 180 & 246 & 48 \\
\hline
\end{tabular}

\begin{tabular}{|c|c|c|c|}
\cline { 2 - 4 } \multicolumn{1}{c|}{} & $\mathbf{0 - \mathbf { 8 }}$ & $\mathbf{9 - 1 6}$ & $\mathbf{1 7 - 2 4}$ \\
\hline Contraataque & 1 & 1 & 99 \\
\hline Bloqueo Directo & 289 & 428 & 57 \\
\hline Pase & 709 & 799 & 142 \\
\hline Jugada Personal & 783 & 559 & 133 \\
\hline Robo & 5 & 3 & 125 \\
\hline Rebote & 30 & 175 & 1 \\
\hline
\end{tabular}

\begin{tabular}{|c|c|c|c|}
\cline { 2 - 4 } \multicolumn{1}{c|}{} & $\mathbf{0 - 8}$ & $\mathbf{9 - 1 6}$ & $\mathbf{1 7 - 2 4}$ \\
\hline Uno & 142 & 405 & 213 \\
\hline Dos & 448 & 803 & 267 \\
\hline Tres & 688 & 553 & 72 \\
\hline Cuatro & 443 & 186 & 4 \\
\hline Cinco & 96 & 18 & 1 \\
\hline
\end{tabular}

\begin{tabular}{|l|c|c|c|}
\cline { 2 - 4 } \multicolumn{1}{c|}{} & $\mathbf{0 - 8}$ & $\mathbf{9 - 1 6}$ & $\mathbf{1 7 - 2 4}$ \\
\hline 10 QT & 432 & 538 & 151 \\
\hline 20 QT & 449 & 490 & 131 \\
\hline 3o QT & 453 & 469 & 153 \\
\hline 40 QT & 483 & 468 & 122 \\
\hline
\end{tabular}




\begin{tabular}{|c|c|c|c|}
\cline { 2 - 4 } \multicolumn{1}{c|}{} & $\mathbf{0 - \mathbf { 8 }}$ & $\mathbf{9 - \mathbf { 1 6 }}$ & $\mathbf{1 7 - \mathbf { 2 4 }}$ \\
\hline Tiempo Muerto & 104 & 76 & 10 \\
\hline Última Jugada & 104 & 0 & 0 \\
\hline
\end{tabular}

\begin{tabular}{|c|c|c|c|}
\cline { 2 - 4 } \multicolumn{1}{c|}{} & Buen tiro & Tiro normal & Mal tiro \\
\hline (+) $\mathbf{1 1}-\mathbf{2 0}$ & $\mathbf{2 4}$ & 41 & 12 \\
\hline (+) $\mathbf{1}-\mathbf{1 0}$ & 533 & 606 & 192 \\
\hline Empate & 135 & 125 & 31 \\
\hline (-) $\mathbf{1}-\mathbf{1 0}$ & 881 & 1021 & 264 \\
\hline (-) $\mathbf{1 1}-\mathbf{2 0}$ & 187 & 215 & 72 \\
\hline
\end{tabular}

\begin{tabular}{|c|c|c|c|}
\cline { 2 - 4 } \multicolumn{1}{c|}{} & Buen tiro & Tiro normal & Mal tiro \\
\hline Contraataque & 75 & 24 & 2 \\
\hline Bloqueo Directo & 320 & 371 & 83 \\
\hline Pase & 1028 & 489 & 133 \\
\hline Jugada Personal & 190 & 947 & 338 \\
\hline Robo & 88 & 40 & 5 \\
\hline Rebote & 59 & 137 & 10 \\
\hline
\end{tabular}

\begin{tabular}{|c|c|c|c|}
\cline { 2 - 4 } \multicolumn{1}{c|}{} & Buen tiro & Tiro normal & Mal tiro \\
\hline Uno & 224 & 424 & 112 \\
\hline Dos & 649 & 674 & 195 \\
\hline Tres & 553 & 606 & 154 \\
\hline Cuatro & 278 & 264 & 91 \\
\hline Cinco & 56 & 40 & 19 \\
\hline
\end{tabular}

\begin{tabular}{|l|c|c|c|}
\cline { 2 - 4 } \multicolumn{1}{c|}{} & Buen tiro & Tiro normal & Mal tiro \\
\hline 10 QT & 460 & 528 & 133 \\
\hline 2o QT & 444 & 488 & 138 \\
\hline 3o QT & 454 & 487 & 134 \\
\hline 40 QT & 402 & 505 & 166 \\
\hline
\end{tabular}




\begin{tabular}{|c|c|c|c|}
\cline { 2 - 4 } \multicolumn{1}{c|}{} & Buen tiro & Tiro normal & Mal tiro \\
\hline Tiempo Muerto & 63 & 87 & 40 \\
\hline Última Jugada & 28 & 34 & 42 \\
\hline
\end{tabular}

\begin{tabular}{|c|c|c|c|c|c|}
\cline { 2 - 6 } \multicolumn{1}{c|}{} & $(\mathbf{+}) \mathbf{1 1} \mathbf{- 2 0}$ & $(\mathbf{+}) \mathbf{1}-\mathbf{1 0}$ & Empate & $(-) \mathbf{1}-\mathbf{1 0}$ & $(-\mathbf{)} \mathbf{1 1} \mathbf{- 2 0}$ \\
\hline Contraataque & 2 & 35 & 8 & 51 & 5 \\
\hline Bloqueo Directo & 18 & 253 & 50 & 380 & 73 \\
\hline Pase & 24 & 481 & 120 & 849 & 176 \\
\hline Jugada Personal & 25 & 452 & 95 & 736 & 167 \\
\hline Robo & 2 & 47 & 9 & 57 & 18 \\
\hline Rebote & 6 & 63 & 9 & 93 & 35 \\
\hline
\end{tabular}

\begin{tabular}{|c|c|c|c|c|c|}
\cline { 2 - 6 } \multicolumn{1}{c|}{} & $(\boldsymbol{+}) \mathbf{1 1} \mathbf{- 2 0}$ & $(\boldsymbol{+}) \mathbf{1} \mathbf{- 1 0}$ & Empate & $(\boldsymbol{-}) \mathbf{1} \mathbf{- 1 0}$ & $(\boldsymbol{-}) \mathbf{1 1} \mathbf{- 2 0}$ \\
\hline Uno & 14 & 247 & 42 & 367 & 90 \\
\hline Dos & 27 & 433 & 84 & 785 & 189 \\
\hline Tres & 23 & 390 & 105 & 664 & 131 \\
\hline Cuatro & 8 & 231 & 48 & 292 & 54 \\
\hline Cinco & 5 & 30 & 12 & 58 & 10 \\
\hline
\end{tabular}

\begin{tabular}{|c|c|c|c|c|c|}
\hline & $(+) 11-20$ & $(+) 1-10$ & Empate & $(-) 1-10$ & $(-) 11-20$ \\
\hline 10 QT & 7 & 410 & 135 & 529 & 40 \\
\hline 20 QT & 19 & 335 & 65 & 541 & 110 \\
\hline 3ㅇ QT & 21 & 302 & 57 & 556 & 139 \\
\hline 4ㅇ QT & 30 & 284 & 34 & 540 & 185 \\
\hline
\end{tabular}

\begin{tabular}{|c|c|c|c|c|c|}
\cline { 2 - 6 } \multicolumn{1}{c|}{} & $\mathbf{( + )} \mathbf{1 1} \mathbf{- 2 0}$ & $\mathbf{( + )} \mathbf{1} \mathbf{- 1 0}$ & Empate & $\mathbf{( - )} \mathbf{1} \mathbf{- 1 0}$ & $\mathbf{( - )} \mathbf{1 1} \mathbf{- 2 0}$ \\
\hline Tiempo Muerto & 4 & 35 & 6 & 116 & $\mathbf{2 9}$ \\
\hline Última Jugada & 1 & 32 & 5 & 51 & 15 \\
\hline
\end{tabular}

\begin{tabular}{|c|c|c|c|c|c|c|}
\cline { 2 - 7 } \multicolumn{1}{c|}{} & Contraataque & Bloqueo Directo & Pase & Jugada Personal & Robo & Rebote \\
\hline Uno & 9 & 163 & 0 & 325 & 57 & 206 \\
\hline Dos & 59 & 296 & 628 & 472 & 63 & 0 \\
\hline Tres & 30 & 230 & 594 & 446 & 13 & 0 \\
\hline Cuatro & 3 & 68 & 355 & 207 & 0 & 0 \\
\hline Cinco & 0 & 17 & 73 & 25 & 0 & 0 \\
\hline
\end{tabular}




\begin{tabular}{|l|c|c|c|c|c|c|}
\cline { 2 - 7 } \multicolumn{1}{c|}{} & Contraataque & Bloqueo Directo & Pase & Jugada Personal & Robo & Rebote \\
\hline 10 QT & 27 & 199 & 404 & 395 & 35 & 61 \\
\hline 29 QT & 21 & 193 & 418 & 356 & 28 & 54 \\
\hline 39 QT & 30 & 184 & 428 & 348 & 38 & 47 \\
\hline 40 QT & 23 & 198 & 400 & 376 & 32 & 44 \\
\hline
\end{tabular}

\begin{tabular}{|c|c|c|c|c|c|c|}
\cline { 2 - 7 } \multicolumn{1}{c|}{} & Contraataque & Bloqueo Directo & Pase & Jugada Personal & Robo & Rebote \\
\hline Tiempo Muerto & 0 & 36 & 71 & 83 & 0 & 0 \\
\hline Última Jugada & 1 & 11 & 40 & 48 & 4 & 0 \\
\hline
\end{tabular}

\begin{tabular}{|l|l|l|l|c|c|}
\cline { 2 - 6 } \multicolumn{1}{c|}{} & Uno & Dos & Tres & Cuatro & Cinco \\
\hline 10 QT & 201 & 373 & 344 & 177 & 26 \\
\hline 20 QT & 186 & 363 & 325 & 169 & 27 \\
\hline 3o QT & 188 & 382 & 313 & 156 & 36 \\
\hline 40 QT & 185 & 400 & 331 & 131 & 26 \\
\hline
\end{tabular}

\begin{tabular}{|c|c|c|c|c|c|}
\cline { 2 - 6 } \multicolumn{1}{c|}{} & Uno & Dos & Tres & Cuatro & Cinco \\
\hline Tiempo Muerto & 23 & 72 & 64 & 27 & 4 \\
\hline Última Jugada & 41 & 45 & 12 & 6 & 0 \\
\hline
\end{tabular}

\begin{tabular}{|c|c|c|c|c|}
\cline { 2 - 5 } \multicolumn{1}{c|}{} & 10 QT & 20 QT & 30 QT & 40 QT \\
\hline Tiempo Muerto & 31 & 42 & 38 & 79 \\
\hline Última Jugada & 26 & 27 & 28 & 23 \\
\hline
\end{tabular}


12.4.7. Baloncesto femenino europeo (L.Fem. y WEuroliga)

\begin{tabular}{|c|c|c|c|c|c|c|c|}
\cline { 2 - 8 } \multicolumn{1}{c|}{} & ZONA 1 & ZONA 2 & ZONA 3 & ZONA 4 & ZONA 5 & ZONA 6 & ZONA 7 \\
\hline 3p. + adicional & 0 & 0 & 0 & 0 & 1 & 1 & 3 \\
\hline 3puntos & 0 & 0 & 0 & 0 & 56 & 53 & 192 \\
\hline Falta + 3 adic. & 0 & 0 & 0 & 0 & 0 & 1 & 3 \\
\hline 2p. + adicional & 69 & 3 & 4 & 1 & 0 & 0 & 0 \\
\hline 2puntos & 795 & 78 & 98 & 119 & 0 & 0 & 0 \\
\hline Falta + 2 adic. & 216 & 4 & 4 & 6 & 0 & 0 & 0 \\
\hline Tapón & 115 & 10 & 3 & 6 & 0 & 2 & 3 \\
\hline Fallo 3p. & 0 & 0 & 0 & 0 & 125 & 123 & 472 \\
\hline Fallo 2p. & 833 & 161 & 156 & 212 & 0 & 0 & 0 \\
\hline
\end{tabular}

\begin{tabular}{|c|c|c|c|c|c|c|c|}
\cline { 2 - 8 } \multicolumn{1}{c|}{} & ZONA 1 & ZONA 2 & ZONA 3 & ZONA 4 & ZONA 5 & ZONA 6 & ZONA 7 \\
\hline $\mathbf{0 - \mathbf { 8 }}$ & 671 & 110 & 108 & 134 & 53 & 77 & 264 \\
\hline $\mathbf{9 - 1 6}$ & 975 & 115 & 128 & 177 & 93 & 73 & 322 \\
\hline $\mathbf{1 7}-\mathbf{2 4}$ & 382 & 31 & 29 & 33 & 36 & 30 & 87 \\
\hline
\end{tabular}

\begin{tabular}{|c|c|c|c|c|c|c|c|}
\cline { 2 - 8 } \multicolumn{1}{c|}{} & ZONA 1 & ZONA 2 & ZONA 3 & ZONA 4 & ZONA 5 & ZONA 6 & ZONA 7 \\
\hline Buen tiro & 461 & 85 & 92 & 178 & 141 & 128 & 436 \\
\hline Tiro normal & 1325 & 114 & 128 & 140 & 39 & 41 & 160 \\
\hline Mal tiro & 242 & 57 & 45 & 26 & 2 & 11 & 77 \\
\hline
\end{tabular}

\begin{tabular}{|c|c|c|c|c|c|c|c|}
\cline { 2 - 8 } \multicolumn{1}{c|}{} & ZONA 1 & ZONA 2 & ZONA 3 & ZONA 4 & ZONA 5 & ZONA 6 & ZONA 7 \\
\hline $\mathbf{( + )} \mathbf{1 1}-\mathbf{2 0}$ & 41 & 4 & 7 & 4 & 3 & 3 & 13 \\
\hline $\mathbf{( + )} \mathbf{1}-\mathbf{1 0}$ & 733 & 95 & 100 & 137 & 69 & 80 & 235 \\
\hline Empate & 156 & 24 & 21 & 26 & 18 & 14 & 39 \\
\hline $\mathbf{( - )} \mathbf{1}-\mathbf{1 0}$ & 973 & 122 & 124 & 154 & 82 & 71 & 338 \\
\hline $\mathbf{( - )} \mathbf{1 1}-\mathbf{2 0}$ & 125 & 11 & 13 & 23 & 10 & 12 & 48 \\
\hline
\end{tabular}

\begin{tabular}{|c|c|c|c|c|c|c|c|}
\cline { 2 - 8 } \multicolumn{1}{c|}{} & ZONA 1 & ZONA 2 & ZONA 3 & ZONA 4 & ZONA 5 & ZONA 6 & ZONA 7 \\
\hline Contraataque & 96 & 2 & 2 & 0 & 3 & 0 & 3 \\
\hline Bloqueo Directo & 238 & 26 & 34 & 118 & 3 & 3 & 127 \\
\hline Pase & 416 & 113 & 118 & 123 & 165 & 153 & 448 \\
\hline Jugada Personal & 962 & 111 & 104 & 102 & 9 & 18 & 83 \\
\hline Robo & 97 & 1 & 4 & 1 & 2 & 2 & 7 \\
\hline Rebote & 219 & 3 & 3 & 0 & 0 & 4 & 5 \\
\hline
\end{tabular}

\begin{tabular}{|c|c|c|c|c|c|c|c|}
\cline { 2 - 8 } \multicolumn{1}{c|}{} & ZONA 1 & ZONA 2 & ZONA 3 & ZONA 4 & ZONA 5 & ZONA 6 & ZONA 7 \\
\hline Uno & 485 & 19 & 20 & 43 & 2 & 8 & 66 \\
\hline Dos & 564 & 76 & 84 & 100 & 55 & 56 & 234 \\
\hline Tres & 576 & 97 & 92 & 132 & 63 & 55 & 205 \\
\hline Cuatro & 310 & 53 & 57 & 52 & 50 & 52 & 138 \\
\hline Cinco & 93 & 11 & 12 & 17 & 12 & 9 & 30 \\
\hline
\end{tabular}




\begin{tabular}{|l|c|c|c|c|c|c|c|}
\cline { 2 - 8 } \multicolumn{1}{c|}{} & ZONA 1 & ZONA 2 & ZONA 3 & ZONA 4 & ZONA 5 & ZONA 6 & ZONA 7 \\
\hline 10 QT & 536 & 71 & 65 & 122 & 59 & 44 & 144 \\
\hline 20 QT & 529 & 67 & 75 & 80 & 49 & 46 & 162 \\
\hline 30 QT & 486 & 61 & 55 & 70 & 42 & 41 & 180 \\
\hline 40 QT & 477 & 57 & 70 & 72 & 32 & 49 & 187 \\
\hline
\end{tabular}

\begin{tabular}{|c|c|c|c|c|c|c|c|}
\cline { 2 - 8 } \multicolumn{1}{c|}{} & ZONA 1 & ZONA 2 & ZONA 3 & ZONA 4 & ZONA 5 & ZONA 6 & ZONA 7 \\
\hline Tiempo Muerto & 52 & 9 & 13 & 8 & 5 & 11 & 30 \\
\hline Última Jugada & 31 & 7 & 5 & 13 & 1 & 1 & 30 \\
\hline
\end{tabular}

\begin{tabular}{|c|c|c|c|c|c|c|c|c|c|}
\hline & 3p. + adicional & 3puntos & Falta +3 adic. & 2 p. + adicional & 2puntos & Falta +2 adic. & Tapón & Fallo 3p. & Fallo 2p. \\
\hline $0-8$ & 1 & 98 & 1 & 17 & 358 & 76 & 48 & 291 & 527 \\
\hline $9-16$ & 4 & 154 & 1 & 49 & 507 & 107 & 70 & 328 & 663 \\
\hline $17-24$ & 0 & 49 & 2 & 11 & 225 & 47 & 21 & 101 & 172 \\
\hline
\end{tabular}

\begin{tabular}{|c|c|c|c|c|c|c|c|c|c|}
\hline & 3p. + adicional & 3puntos & Falta +3 adic. & 2 p. + adicional & 2puntos & Falta +2 adic. & Tapón & Fallo 3p. & Fallo 2p. \\
\hline Buen tiro & 3 & 236 & 1 & 14 & 522 & 5 & 0 & 465 & 275 \\
\hline Tiro normal & 2 & 55 & 2 & 61 & 531 & 206 & 93 & 179 & 818 \\
\hline Mal tiro & 0 & 10 & 1 & 2 & 37 & 19 & 46 & 76 & 269 \\
\hline
\end{tabular}

\begin{tabular}{|c|c|c|c|c|c|c|c|c|c|}
\cline { 2 - 9 } \multicolumn{1}{c|}{} & 3p. + adicional & 3puntos & Falta + 3 adic. & 2p. + adicional & 2puntos & Falta + 2 adic. & Tapón & Fallo 3p. & Fallo 2p. \\
\hline (+) $\mathbf{1 1}-\mathbf{2 0}$ & 0 & 9 & 0 & 2 & 16 & 1 & 5 & 10 & 32 \\
\hline (+) $\mathbf{1}-\mathbf{1 0}$ & 1 & 118 & 1 & 23 & 400 & 85 & 60 & 261 & 500 \\
\hline Empate & 1 & 26 & 0 & 4 & 89 & 14 & 9 & 44 & 111 \\
\hline (-) $\mathbf{1}-\mathbf{1 0}$ & 1 & 122 & 3 & 42 & 524 & 115 & 59 & 363 & 635 \\
\hline (-) $\mathbf{1 1}-\mathbf{2 0}$ & 2 & 26 & 0 & 6 & 61 & 15 & 6 & 42 & 84 \\
\hline
\end{tabular}

\begin{tabular}{|c|c|c|c|c|c|c|c|c|c|}
\cline { 2 - 9 } \multicolumn{1}{c|}{} & 3p. + adicional & 3puntos & Falta + 3 adic. & 2p. + adicional & 2puntos & Falta + 2 adic. & Tapón & Fallo 3p. & Fallo 2p. \\
\hline Contraataque & 0 & 3 & 0 & 6 & 60 & 7 & 4 & 3 & 23 \\
\hline Bloqueo Directo & 0 & 39 & 1 & 6 & 139 & 43 & 19 & 93 & 209 \\
\hline Pase & 5 & 228 & 2 & 17 & 354 & 33 & 17 & 530 & 350 \\
\hline Jugada Personal & 0 & 26 & 1 & 36 & 394 & 107 & 84 & 80 & 661 \\
\hline Robo & 0 & 3 & 0 & 2 & 62 & 11 & 7 & 7 & 22 \\
\hline Rebote & 0 & 2 & 0 & 10 & 81 & 29 & 8 & 7 & 97 \\
\hline
\end{tabular}

\begin{tabular}{|c|c|c|c|c|c|c|c|c|c|}
\cline { 2 - 9 } \multicolumn{1}{c|}{} & 3p. + adicional & 3puntos & Falta + 3 adic. & 2p. + adicional & 2puntos & Falta + 2 adic. & Tapón & Fallo 3p. & Fallo 2p. \\
\hline Uno & 0 & 23 & 0 & 16 & 187 & 58 & 38 & 52 & 269 \\
\hline Dos & 2 & 93 & 2 & 26 & 306 & 70 & 33 & 246 & 391 \\
\hline Tres & 2 & 100 & 2 & 21 & 357 & 66 & 39 & 218 & 415 \\
\hline Cuatro & 1 & 71 & 0 & 7 & 195 & 25 & 22 & 167 & 224 \\
\hline Cinco & 0 & 14 & 0 & 7 & 45 & 11 & 7 & 37 & 63 \\
\hline
\end{tabular}

\begin{tabular}{|c|c|c|c|c|c|c|c|c|c|}
\hline & 3p. + adicional & 3puntos & Falta +3 adic. & 2p. + adicional & 2puntos & Falta +2 adic. & Tapón & Fallo 3p. & Fallo 2p. \\
\hline 10 QT & 2 & 75 & 1 & 17 & 320 & 53 & 36 & 168 & 369 \\
\hline 20 QT & 1 & 74 & 1 & 23 & 269 & 60 & 33 & 179 & 368 \\
\hline 3ㅇ QT & 0 & 87 & 0 & 23 & 258 & 48 & 32 & 176 & 311 \\
\hline 40 QT & 2 & 65 & 2 & 14 & 243 & 69 & 38 & 197 & 314 \\
\hline
\end{tabular}




\begin{tabular}{|c|c|c|c|c|c|c|c|c|c|}
\hline & 3p. + adicional & 3puntos & Falta +3 adic. & 2p. + adicional & 2 puntos & Falta +2 adic. & Tapón & Fallo 3p. & Fallo 2p. \\
\hline Tiempo Muerto & 1 & 11 & 0 & 3 & 29 & 8 & 3 & 33 & 40 \\
\hline Última Jugada & 0 & 3 & 0 & 0 & 14 & 4 & 5 & 29 & 33 \\
\hline
\end{tabular}

\begin{tabular}{|c|c|c|c|}
\cline { 2 - 4 } \multicolumn{1}{c|}{} & $\mathbf{0 - 8}$ & $\mathbf{9 - 1 6}$ & $\mathbf{1 7 - 2 4}$ \\
\hline Buen tiro & 430 & 756 & 335 \\
\hline Tiro normal & 710 & 978 & 259 \\
\hline Mal tiro & 277 & 149 & 34 \\
\hline
\end{tabular}

\begin{tabular}{|c|c|c|c|}
\cline { 2 - 4 } \multicolumn{1}{c|}{} & $\mathbf{0 - \mathbf { 8 }}$ & $\mathbf{9 - 1 6}$ & $\mathbf{1 7 - 2 4}$ \\
\hline $\mathbf{( + )} \mathbf{1 1}-\mathbf{2 0}$ & 17 & 45 & 13 \\
\hline $\mathbf{( + )} \mathbf{1}-\mathbf{1 0}$ & 539 & 683 & 227 \\
\hline Empate & 108 & 139 & 51 \\
\hline (-) $\mathbf{1}-\mathbf{1 0}$ & 655 & 896 & 313 \\
\hline (-) $\mathbf{1 1}-\mathbf{2 0}$ & 98 & 120 & 24 \\
\hline
\end{tabular}

\begin{tabular}{|c|c|c|c|}
\cline { 2 - 4 } \multicolumn{1}{c|}{} & $\mathbf{0 - \mathbf { 8 }}$ & $\mathbf{9 - \mathbf { 1 6 }}$ & $\mathbf{1 7 - 2 4}$ \\
\hline Contraataque & 4 & 1 & 101 \\
\hline Bloqueo Directo & 198 & 305 & 46 \\
\hline Pase & 553 & 785 & 198 \\
\hline Jugada Personal & 623 & 601 & 165 \\
\hline Robo & 2 & 1 & 111 \\
\hline Rebote & 37 & 190 & 7 \\
\hline
\end{tabular}

\begin{tabular}{|c|c|c|c|}
\cline { 2 - 4 } \multicolumn{1}{c|}{} & $\mathbf{0 - 8}$ & $\mathbf{9 - 1 6}$ & $\mathbf{1 7 - 2 4}$ \\
\hline Uno & 105 & 325 & 213 \\
\hline Dos & 278 & 590 & 301 \\
\hline Tres & 461 & 658 & 101 \\
\hline Cuatro & 430 & 270 & 12 \\
\hline Cinco & 143 & 40 & 1 \\
\hline
\end{tabular}




\begin{tabular}{|l|c|c|c|}
\cline { 2 - 4 } \multicolumn{1}{c|}{} & $\mathbf{0 - \mathbf { 8 }}$ & $\mathbf{9 - 1 6}$ & $\mathbf{1 7}-\mathbf{2 4}$ \\
\hline 10 QT & 344 & 503 & 194 \\
\hline 20 QT & 359 & 492 & 157 \\
\hline 3o QT & 352 & 429 & 154 \\
\hline 40 QT & 362 & 459 & 123 \\
\hline
\end{tabular}

\begin{tabular}{|c|c|c|c|}
\cline { 2 - 4 } \multicolumn{1}{c|}{} & $\mathbf{0 - \mathbf { 8 }}$ & $\mathbf{9 - 1 6}$ & $\mathbf{1 7 - 2 4}$ \\
\hline Tiempo Muerto & 64 & 49 & 15 \\
\hline Última Jugada & 88 & 0 & 0 \\
\hline
\end{tabular}

\begin{tabular}{|c|c|c|c|}
\cline { 2 - 4 } \multicolumn{1}{c|}{} & Buen tiro & Tiro normal & Mal tiro \\
\hline (+) $\mathbf{1 1}-\mathbf{2 0}$ & 25 & 44 & 6 \\
\hline (+) $\mathbf{1}-\mathbf{1 0}$ & 584 & 690 & 175 \\
\hline Empate & 120 & 155 & 23 \\
\hline (-) $\mathbf{1}-\mathbf{1 0}$ & 708 & 927 & 229 \\
\hline (-) $\mathbf{1 1}-\mathbf{2 0}$ & 84 & 131 & 27 \\
\hline
\end{tabular}

\begin{tabular}{|c|c|c|c|}
\cline { 2 - 4 } \multicolumn{1}{c|}{} & Buen tiro & Tiro normal & Mal tiro \\
\hline Contraataque & 70 & 35 & 1 \\
\hline Bloqueo Directo & 229 & 291 & 29 \\
\hline Pase & 956 & 505 & 75 \\
\hline Jugada Personal & 146 & 909 & 334 \\
\hline Robo & 71 & 37 & 6 \\
\hline Rebote & 49 & 170 & 15 \\
\hline
\end{tabular}

\begin{tabular}{|c|c|c|c|}
\cline { 2 - 4 } \multicolumn{1}{c|}{} & Buen tiro & Tiro normal & Mal tiro \\
\hline Uno & 169 & 379 & 95 \\
\hline Dos & 504 & 540 & 125 \\
\hline Tres & 500 & 595 & 125 \\
\hline Cuatro & 299 & 329 & 84 \\
\hline Cinco & 49 & 104 & 31 \\
\hline
\end{tabular}




\begin{tabular}{|l|c|c|c|}
\cline { 2 - 4 } \multicolumn{1}{c|}{} & Buen tiro & Tiro normal & Mal tiro \\
\hline 10 QT & 416 & 526 & 99 \\
\hline 2o QT & 382 & 493 & 133 \\
\hline 3o QT & 362 & 476 & 97 \\
\hline 40 QT & 361 & 452 & 131 \\
\hline
\end{tabular}

\begin{tabular}{|c|c|c|c|}
\cline { 2 - 4 } \multicolumn{1}{c|}{} & Buen tiro & Tiro normal & Mal tiro \\
\hline Tiempo Muerto & 53 & 52 & 23 \\
\hline Última Jugada & 12 & 34 & 42 \\
\hline
\end{tabular}

\begin{tabular}{|c|c|c|c|c|c|}
\cline { 2 - 6 } \multicolumn{1}{c|}{} & $(\mathbf{+}) \mathbf{1 1} \mathbf{- 2 0}$ & $\mathbf{( + )} \mathbf{1} \mathbf{- 1 0}$ & Empate & $\mathbf{( - )} \mathbf{1}-\mathbf{1 0}$ & $\mathbf{( - )} \mathbf{1 1} \mathbf{- 2 0}$ \\
\hline Contraataque & 2 & 49 & 8 & 44 & 3 \\
\hline Bloqueo Directo & 10 & 195 & 40 & 271 & 33 \\
\hline Pase & 34 & 595 & 113 & 717 & 77 \\
\hline Jugada Personal & 22 & 481 & 106 & 675 & 105 \\
\hline Robo & 0 & 43 & 11 & 51 & 9 \\
\hline Rebote & 7 & 86 & 20 & 106 & 15 \\
\hline
\end{tabular}

\begin{tabular}{|c|c|c|c|c|c|}
\cline { 2 - 6 } \multicolumn{1}{c|}{} & $(\boldsymbol{+}) \mathbf{1 1} \mathbf{- 2 0}$ & $(\mathbf{+}) \mathbf{1}-\mathbf{1 0}$ & Empate & $\mathbf{( - )} \mathbf{1}-\mathbf{1 0}$ & $(\boldsymbol{-}) \mathbf{1 1}-\mathbf{2 0}$ \\
\hline Uno & 10 & 210 & 44 & 326 & 53 \\
\hline Dos & 30 & 439 & 84 & 551 & 65 \\
\hline Tres & 23 & 456 & 90 & 582 & 69 \\
\hline Cuatro & 10 & 281 & 62 & 315 & 44 \\
\hline Cinco & 2 & 63 & 18 & 90 & 11 \\
\hline
\end{tabular}

\begin{tabular}{|c|c|c|c|c|c|}
\cline { 2 - 6 } \multicolumn{1}{c|}{} & (+) 11 - 20 & (+) 1 - 10 & Empate & (-) 1 - 10 & (-) $\mathbf{1 1 ~ - ~ 2 0 ~}$ \\
\hline 10 QT & 6 & 328 & 150 & 550 & 7 \\
\hline 20 QT & 31 & 431 & 66 & 428 & 52 \\
\hline 30 QT & 14 & 340 & 40 & 474 & 67 \\
\hline 40 QT & 24 & 350 & 42 & 412 & 116 \\
\hline
\end{tabular}

\begin{tabular}{|c|c|c|c|c|c|}
\cline { 2 - 6 } \multicolumn{1}{c|}{} & $(\mathbf{+}) \mathbf{1 1} \mathbf{- 2 0}$ & $\mathbf{( + )} \mathbf{1} \mathbf{- 1 0}$ & Empate & $\mathbf{( - )} \mathbf{1} \mathbf{- 1 0}$ & $\mathbf{( - )} \mathbf{1 1} \mathbf{- 2 0}$ \\
\hline Tiempo Muerto & 3 & 45 & 6 & 63 & 11 \\
\hline Última Jugada & 2 & 33 & 3 & 43 & 7 \\
\hline
\end{tabular}




\begin{tabular}{|c|c|c|c|c|c|c|}
\cline { 2 - 7 } \multicolumn{1}{c|}{} & Contraataque & Bloqueo Directo & Pase & Jugada Personal & Robo & Rebote \\
\hline Uno & 9 & 99 & 0 & 248 & 53 & 234 \\
\hline Dos & 66 & 190 & 473 & 392 & 48 & 0 \\
\hline Tres & 27 & 178 & 557 & 447 & 11 & 0 \\
\hline Cuatro & 4 & 69 & 399 & 238 & 2 & 0 \\
\hline Cinco & 0 & 13 & 107 & 64 & 0 & 0 \\
\hline
\end{tabular}

\begin{tabular}{|l|c|c|c|c|c|c|}
\cline { 2 - 7 } \multicolumn{1}{c|}{} & Contraataque & Bloqueo Directo & Pase & Jugada Personal & Robo & Rebote \\
\hline 10 QT & 40 & 161 & 395 & 350 & 36 & 59 \\
\hline 20 QT & 29 & 130 & 387 & 366 & 27 & 69 \\
\hline 30 QT & 22 & 119 & 378 & 342 & 30 & 44 \\
\hline 40 QT & 15 & 139 & 376 & 331 & 21 & 62 \\
\hline
\end{tabular}

\begin{tabular}{|c|c|c|c|c|c|c|}
\cline { 2 - 7 } \multicolumn{1}{c|}{} & Contraataque & Bloqueo Directo & Pase & Jugada Personal & Robo & Rebote \\
\hline Tiempo Muerto & 0 & 15 & 61 & 52 & 0 & 0 \\
\hline Última Jugada & 3 & 10 & 20 & 53 & 2 & 0 \\
\hline
\end{tabular}

\begin{tabular}{|l|l|l|l|c|c|}
\cline { 2 - 6 } \multicolumn{1}{c|}{} & Uno & Dos & Tres & Cuatro & Cinco \\
\hline 10 QT & 168 & 320 & 326 & 181 & 46 \\
\hline 20 QT & 176 & 299 & 295 & 194 & 44 \\
\hline 3o QT & 142 & 263 & 318 & 168 & 44 \\
\hline 40 QT & 157 & 287 & 281 & 169 & 50 \\
\hline
\end{tabular}

\begin{tabular}{|c|c|c|c|c|c|}
\cline { 2 - 6 } \multicolumn{1}{c|}{} & Uno & Dos & Tres & Cuatro & Cinco \\
\hline Tiempo Muerto & 13 & 41 & 27 & 37 & 10 \\
\hline Última Jugada & 36 & 31 & 17 & 4 & 0 \\
\hline
\end{tabular}

\begin{tabular}{|c|c|c|c|c|}
\cline { 2 - 5 } \multicolumn{1}{c|}{} & 10 QT & 20 QT & 30 QT & 40 QT \\
\hline Tiempo Muerto & 13 & 41 & 18 & 56 \\
\hline Última Jugada & 27 & 21 & 27 & 13 \\
\hline
\end{tabular}




\subsubsection{Baloncesto masculino EEUU (NBA)}

\begin{tabular}{|c|c|c|c|c|c|c|c|}
\cline { 2 - 8 } \multicolumn{1}{c|}{} & ZONA 1 & ZONA 2 & ZONA 3 & ZONA 4 & ZONA 5 & ZONA 6 & ZONA 7 \\
\hline 3p. + adicional & 0 & 0 & 0 & 0 & 2 & 1 & 4 \\
\hline 3puntos & 0 & 0 & 0 & 0 & 117 & 88 & 423 \\
\hline Falta + 3 adic. & 0 & 0 & 0 & 0 & 5 & 3 & 21 \\
\hline 2p. + adicional & 105 & 8 & 1 & 0 & 0 & 0 & 0 \\
\hline 2puntos & 1190 & 96 & 85 & 169 & 0 & 0 & 0 \\
\hline Falta + 2 adic. & 322 & 14 & 13 & 13 & 0 & 0 & 0 \\
\hline Tapón & 191 & 6 & 4 & 1 & 1 & 4 & 6 \\
\hline Fallo 3p. & 0 & 0 & 0 & 0 & 189 & 153 & 789 \\
\hline Fallo 2p. & 844 & 211 & 161 & 222 & 0 & 0 & 0 \\
\hline
\end{tabular}

\begin{tabular}{|c|c|c|c|c|c|c|c|}
\cline { 2 - 8 } \multicolumn{1}{c|}{} & ZONA 1 & ZONA 2 & ZONA 3 & ZONA 4 & ZONA 5 & ZONA 6 & ZONA 7 \\
\hline $\mathbf{0 - \mathbf { 8 }}$ & 624 & 135 & 96 & 107 & 86 & 73 & 332 \\
\hline $\mathbf{9}-\mathbf{1 6}$ & 1333 & 171 & 131 & 253 & 151 & 119 & 621 \\
\hline $\mathbf{1 7}-\mathbf{2 4}$ & 695 & 29 & 37 & 45 & 77 & 57 & 290 \\
\hline
\end{tabular}

\begin{tabular}{|c|c|c|c|c|c|c|c|}
\cline { 2 - 8 } \multicolumn{1}{c|}{} & ZONA 1 & ZONA 2 & ZONA 3 & ZONA 4 & ZONA 5 & ZONA 6 & ZONA 7 \\
\hline Buen tiro & 657 & 50 & 41 & 168 & 205 & 149 & 661 \\
\hline Tiro normal & 1675 & 197 & 160 & 211 & 92 & 92 & 461 \\
\hline Mal tiro & 320 & 88 & 63 & 26 & 17 & 8 & 121 \\
\hline
\end{tabular}

\begin{tabular}{|c|c|c|c|c|c|c|c|}
\cline { 2 - 8 } \multicolumn{1}{c|}{} & ZONA 1 & ZONA 2 & ZONA 3 & ZONA 4 & ZONA 5 & ZONA 6 & ZONA 7 \\
\hline (+) 11 - 20 & 62 & 6 & 8 & 12 & 6 & 3 & 37 \\
\hline (+) $\mathbf{1}-\mathbf{1 0}$ & 979 & 147 & 94 & 149 & 128 & 104 & 458 \\
\hline Empate & 202 & 23 & 24 & 38 & 22 & 20 & 92 \\
\hline$(-) \mathbf{1}-\mathbf{1 0}$ & 1185 & 140 & 123 & 181 & 137 & 104 & 548 \\
\hline$(-) \mathbf{1 1}-\mathbf{2 0}$ & 224 & 19 & 15 & 25 & 21 & 18 & 108 \\
\hline
\end{tabular}

\begin{tabular}{|c|c|c|c|c|c|c|c|}
\cline { 2 - 8 } \multicolumn{1}{c|}{} & ZONA 1 & ZONA 2 & ZONA 3 & ZONA 4 & ZONA 5 & ZONA 6 & ZONA 7 \\
\hline Contraataque & 83 & 0 & 1 & 1 & 6 & 4 & 13 \\
\hline Bloqueo Directo & 382 & 66 & 55 & 153 & 9 & 8 & 233 \\
\hline Pase & 417 & 40 & 45 & 70 & 254 & 205 & 716 \\
\hline Jugada Personal & 1379 & 221 & 159 & 180 & 35 & 30 & 262 \\
\hline Robo & 117 & 5 & 2 & 0 & 8 & 2 & 10 \\
\hline Rebote & 274 & 3 & 2 & 1 & 2 & 0 & 9 \\
\hline
\end{tabular}




\begin{tabular}{|c|c|c|c|c|c|c|c|}
\cline { 2 - 8 } \multicolumn{1}{c|}{} & ZONA 1 & ZONA 2 & ZONA 3 & ZONA 4 & ZONA 5 & ZONA 6 & ZONA 7 \\
\hline Uno & 873 & 60 & 66 & 81 & 12 & 9 & 184 \\
\hline Dos & 870 & 116 & 81 & 136 & 135 & 97 & 511 \\
\hline Tres & 612 & 100 & 85 & 115 & 103 & 85 & 364 \\
\hline Cuatro & 259 & 52 & 28 & 63 & 52 & 51 & 158 \\
\hline Cinco & 38 & 7 & 4 & 10 & 12 & 7 & 26 \\
\hline
\end{tabular}

\begin{tabular}{|c|c|c|c|c|c|c|c|}
\cline { 2 - 8 } \multicolumn{1}{c|}{} & ZONA 1 & ZONA 2 & ZONA 3 & ZONA 4 & ZONA 5 & ZONA 6 & ZONA 7 \\
\hline 10 QT & 684 & 88 & 81 & 132 & 87 & 68 & 277 \\
\hline 20 QT & 667 & 104 & 60 & 100 & 76 & 56 & 332 \\
\hline 3o QT & 663 & 80 & 73 & 98 & 72 & 68 & 293 \\
\hline 40 QT & 638 & 63 & 50 & 75 & 79 & 57 & 341 \\
\hline
\end{tabular}

\begin{tabular}{|c|c|c|c|c|c|c|c|}
\cline { 2 - 8 } \multicolumn{1}{c|}{} & ZONA 1 & ZONA 2 & ZONA 3 & ZONA 4 & ZONA 5 & ZONA 6 & ZONA 7 \\
\hline Tiempo Muerto & 95 & 14 & 12 & 14 & 15 & 3 & 50 \\
\hline Última Jugada & 27 & 3 & 2 & 6 & 8 & 5 & 38 \\
\hline
\end{tabular}

\begin{tabular}{|c|c|c|c|c|c|c|c|c|c|}
\cline { 2 - 10 } \multicolumn{1}{c|}{} & 3p. + adicional & 3puntos & Falta + 3 adic. & 2p. + adicional & 2puntos & Falta + 2 adic. & Tapón & Fallo 3p. & Fallo 2p. \\
\hline $\mathbf{0 - 8}$ & 1 & 155 & 7 & 24 & 363 & 86 & 50 & 325 & 442 \\
\hline $\mathbf{9 - 1 6}$ & 4 & 307 & 18 & 53 & 793 & 181 & 107 & 555 & 761 \\
\hline $\mathbf{1 7 - 2 4}$ & 2 & 166 & 4 & 37 & 384 & 95 & 56 & 251 & 235 \\
\hline
\end{tabular}

\begin{tabular}{|c|c|c|c|c|c|c|c|c|c|}
\cline { 2 - 10 } \multicolumn{1}{c|}{} & 3p. + adicional & 3puntos & Falta + 3 adic. & 2p. + adicional & 2puntos & Falta + 2 adic. & Tapón & Fallo 3p. & Fallo 2p. \\
\hline Buen tiro & 2 & 445 & 3 & 33 & 682 & 13 & 4 & 565 & 184 \\
\hline Tiro normal & 4 & 165 & 21 & 72 & 793 & 307 & 154 & 447 & 925 \\
\hline Mal tiro & 1 & 18 & 5 & 9 & 65 & 42 & 55 & 119 & 329 \\
\hline
\end{tabular}

\begin{tabular}{|c|c|c|c|c|c|c|c|c|c|}
\cline { 2 - 10 } \multicolumn{1}{c|}{} & 3p. + adicional & 3puntos & Falta + 3 adic. & 2p. + adicional & 2puntos & Falta + 2 adic. & Tapón & Fallo 3p. & Fallo 2p. \\
\hline (+) $\mathbf{1 1 - 2 0}$ & 0 & 10 & 1 & 1 & 35 & 6 & 7 & 34 & 40 \\
\hline (+) $\mathbf{1}-\mathbf{1 0}$ & 2 & 205 & 14 & 34 & 531 & 149 & 83 & 462 & 579 \\
\hline Empate & 1 & 54 & 2 & 7 & 132 & 25 & 13 & 77 & 110 \\
\hline (-) $\mathbf{1}-\mathbf{1 0}$ & 3 & 287 & 12 & 59 & 714 & 151 & 87 & 485 & 620 \\
\hline (-) $\mathbf{1 1}-\mathbf{2 0}$ & 1 & 72 & 0 & 13 & 128 & 31 & 23 & 73 & 89 \\
\hline
\end{tabular}

\begin{tabular}{|c|c|c|c|c|c|c|c|c|c|}
\cline { 2 - 11 } \multicolumn{1}{c|}{} & 3p. + adicional & 3puntos & Falta + 3 adic. & 2p. + adicional & 2puntos & Falta + 2 adic. & Tapón & Fallo 3p. & Fallo 2p. \\
\hline Contraataque & 0 & 8 & 0 & 6 & 55 & 7 & 1 & 15 & 16 \\
\hline Bloqueo Directo & 1 & 83 & 9 & 11 & 279 & 58 & 24 & 153 & 288 \\
\hline Pase & 3 & 424 & 13 & 18 & 292 & 51 & 40 & 729 & 177 \\
\hline Jugada Personal & 3 & 102 & 7 & 65 & 706 & 205 & 122 & 214 & 842 \\
\hline Robo & 0 & 7 & 0 & 4 & 69 & 13 & 12 & 13 & 26 \\
\hline Rebote & 0 & 4 & 0 & 10 & 139 & 28 & 14 & 7 & 89 \\
\hline
\end{tabular}




\begin{tabular}{|c|c|c|c|c|c|c|c|c|c|}
\hline & 3p. + adicional & 3puntos & Falta +3 adic. & 2p. + adicional & 2 puntos & Falta +2 adic. & Tapón & Fallo 3p. & Fallo 2p. \\
\hline Uno & 2 & 63 & 7 & 44 & 441 & 118 & 76 & 131 & 403 \\
\hline Dos & 2 & 269 & 13 & 36 & 509 & 130 & 67 & 453 & 467 \\
\hline Tres & 3 & 183 & 5 & 25 & 385 & 82 & 51 & 359 & 371 \\
\hline Cuatro & 0 & 94 & 3 & 8 & 181 & 27 & 16 & 163 & 171 \\
\hline Cinco & 0 & 19 & 1 & 1 & 24 & 5 & 3 & 25 & 26 \\
\hline
\end{tabular}

\begin{tabular}{|c|c|c|c|c|c|c|c|c|c|}
\hline & 3p. + adicional & 3puntos & Falta +3 adic. & 2p. + adicional & 2puntos & Falta +2 adic. & Tapón & Fallo 3p. & Fallo 2p. \\
\hline 10 QT & 1 & 145 & 10 & 26 & 448 & 85 & 54 & 275 & 373 \\
\hline 2० QT & 2 & 161 & 6 & 34 & 392 & 100 & 42 & 292 & 366 \\
\hline 3 QT & 1 & 151 & 7 & 31 & 369 & 89 & 53 & 272 & 374 \\
\hline 40 QT & 3 & 171 & 6 & 23 & 331 & 88 & 64 & 292 & 325 \\
\hline
\end{tabular}

\begin{tabular}{|c|c|c|c|c|c|c|c|c|c|}
\hline & 3p. + adicional & 3puntos & Falta +3 adic. & 2p. + adicional & 2puntos & Falta +2 adic. & Tapón & Fallo 3p. & Fallo 2p. \\
\hline Tiempo Muerto & 0 & 21 & 1 & 8 & 53 & 9 & 6 & 46 & 59 \\
\hline Última Jugada & 0 & 8 & 0 & 2 & 17 & 0 & 7 & 42 & 13 \\
\hline
\end{tabular}

\begin{tabular}{|c|c|c|c|}
\cline { 2 - 4 } \multicolumn{1}{c|}{} & $\mathbf{0 - \mathbf { 8 }}$ & $\mathbf{9 - 1 6}$ & $\mathbf{1 7 - 2 4}$ \\
\hline Buen tiro & 357 & 987 & 587 \\
\hline Tiro normal & 800 & 1524 & 564 \\
\hline Mal tiro & 296 & 268 & 79 \\
\hline
\end{tabular}

\begin{tabular}{|c|c|c|c|}
\cline { 2 - 4 } \multicolumn{1}{c|}{} & $\mathbf{0 - 8}$ & $\mathbf{9 - 1 6}$ & $\mathbf{1 7 - 2 4}$ \\
\hline $\mathbf{( + )} \mathbf{1 1}-\mathbf{2 0}$ & 47 & 56 & 31 \\
\hline (+) $\mathbf{1}-\mathbf{1 0}$ & 609 & 1004 & 446 \\
\hline Empate & 117 & 214 & 90 \\
\hline$(-) \mathbf{1}-\mathbf{1 0}$ & 581 & 1271 & 566 \\
\hline (-) $\mathbf{1 1}-\mathbf{2 0}$ & 99 & 234 & 97 \\
\hline
\end{tabular}

\begin{tabular}{|c|c|c|c|}
\cline { 2 - 4 } \multicolumn{1}{c|}{} & $\mathbf{0 - \mathbf { 8 }}$ & $\mathbf{9 - \mathbf { 1 6 }}$ & $\mathbf{1 7 - 2 4}$ \\
\hline Contraataque & 4 & 0 & 104 \\
\hline Bloqueo Directo & 184 & 608 & 114 \\
\hline Pase & 437 & 941 & 369 \\
\hline Jugada Personal & 800 & 1077 & 389 \\
\hline Robo & 7 & 2 & 135 \\
\hline Rebote & 21 & 151 & 119 \\
\hline
\end{tabular}




\begin{tabular}{|c|c|c|c|}
\cline { 2 - 4 } \multicolumn{1}{c|}{} & $\mathbf{0 - 8}$ & $\mathbf{9 - 1 6}$ & $\mathbf{1 7 - 2 4}$ \\
\hline Uno & 176 & 542 & 567 \\
\hline Dos & 383 & 1026 & 537 \\
\hline Tres & 466 & 882 & 116 \\
\hline Cuatro & 352 & 301 & 10 \\
\hline Cinco & 76 & 28 & 0 \\
\hline
\end{tabular}

\begin{tabular}{|l|c|c|c|}
\cline { 2 - 4 } \multicolumn{1}{c|}{} & $\mathbf{0 ~ - ~ 8}$ & $\mathbf{9 - 1 6}$ & $\mathbf{1 7 - 2 4}$ \\
\hline 10 QT & 333 & 747 & 337 \\
\hline 20 QT & 356 & 717 & 322 \\
\hline 30 QT & 385 & 667 & 295 \\
\hline 40 QT & 379 & 648 & 276 \\
\hline
\end{tabular}

\begin{tabular}{|c|c|c|c|}
\cline { 2 - 4 } \multicolumn{1}{c|}{} & $\mathbf{0 - 8}$ & $\mathbf{9 - 1 6}$ & $\mathbf{1 7 - 2 4}$ \\
\hline Tiempo Muerto & 84 & 99 & 20 \\
\hline Última Jugada & 89 & 0 & 0 \\
\hline
\end{tabular}

\begin{tabular}{|c|c|c|c|}
\cline { 2 - 4 } \multicolumn{1}{c|}{} & Buen tiro & Tiro normal & Mal tiro \\
\hline (+) $\mathbf{1 1}-\mathbf{2 0}$ & 49 & 66 & 19 \\
\hline (+) $\mathbf{1}-\mathbf{1 0}$ & 680 & 1100 & 279 \\
\hline Empate & 157 & 218 & 46 \\
\hline (-) $\mathbf{1}-\mathbf{1 0}$ & 881 & 1277 & 260 \\
\hline (-) $\mathbf{1 1}-\mathbf{2 0}$ & 164 & 227 & 39 \\
\hline
\end{tabular}

\begin{tabular}{|c|c|c|c|}
\cline { 2 - 4 } \multicolumn{1}{c|}{} & Buen tiro & Tiro normal & Mal tiro \\
\hline Contraataque & 85 & 20 & 3 \\
\hline Bloqueo Directo & 344 & 485 & 77 \\
\hline Pase & 1031 & 626 & 90 \\
\hline Jugada Personal & 296 & 1514 & 456 \\
\hline Robo & 87 & 51 & 6 \\
\hline Rebote & 88 & 192 & 11 \\
\hline
\end{tabular}




\begin{tabular}{|c|c|c|c|}
\cline { 2 - 4 } \multicolumn{1}{c|}{} & Buen tiro & Tiro normal & Mal tiro \\
\hline Uno & 295 & 822 & 168 \\
\hline Dos & 775 & 958 & 213 \\
\hline Tres & 563 & 747 & 154 \\
\hline Cuatro & 259 & 307 & 97 \\
\hline Cinco & 39 & 54 & 11 \\
\hline
\end{tabular}

\begin{tabular}{|l|c|c|c|}
\cline { 2 - 4 } \multicolumn{1}{c|}{} & Buen tiro & Tiro normal & Mal tiro \\
\hline 10 QT & 528 & 753 & 136 \\
\hline 2o QT & 516 & 719 & 160 \\
\hline 3o QT & 469 & 710 & 168 \\
\hline 40 QT & 418 & 706 & 179 \\
\hline
\end{tabular}

\begin{tabular}{|c|c|c|c|}
\cline { 2 - 4 } \multicolumn{1}{c|}{} & Buen tiro & Tiro normal & Mal tiro \\
\hline Tiempo Muerto & 64 & 107 & 32 \\
\hline Última Jugada & 17 & 39 & 33 \\
\hline
\end{tabular}

\begin{tabular}{|c|c|c|c|c|c|}
\cline { 2 - 6 } \multicolumn{1}{c|}{} & $(\mathbf{+}) \mathbf{1 1} \mathbf{- 2 0}$ & $\mathbf{( + )} \mathbf{1} \mathbf{- 1 0}$ & Empate & $\mathbf{( - )} \mathbf{1} \mathbf{- 1 0}$ & $\mathbf{( - )} \mathbf{1 1} \mathbf{- 2 0}$ \\
\hline Contraataque & 5 & 45 & 5 & 46 & 7 \\
\hline Bloqueo Directo & 24 & 334 & 74 & 397 & 77 \\
\hline Pase & 38 & 685 & 134 & 748 & 142 \\
\hline Jugada Personal & 54 & 839 & 173 & 1033 & 167 \\
\hline Robo & 5 & 59 & 9 & 62 & 9 \\
\hline Rebote & 8 & 97 & 26 & 132 & 28 \\
\hline
\end{tabular}

\begin{tabular}{|c|c|c|c|c|c|}
\cline { 2 - 6 } \multicolumn{1}{c|}{} & $\mathbf{( + )} \mathbf{1 1}-\mathbf{2 0}$ & $\mathbf{( + )} \mathbf{1}-\mathbf{1 0}$ & Empate & $\mathbf{( - )} \mathbf{1}-\mathbf{1 0}$ & $\mathbf{( - )} \mathbf{1 1}-\mathbf{2 0}$ \\
\hline Uno & 34 & 450 & 96 & 601 & 104 \\
\hline Dos & 53 & 774 & 139 & 844 & 136 \\
\hline Tres & 32 & 551 & 115 & 654 & 112 \\
\hline Cuatro & 13 & 253 & 57 & 271 & 69 \\
\hline Cinco & 2 & 31 & 14 & 48 & 9 \\
\hline
\end{tabular}




\begin{tabular}{|l|c|c|c|c|c|}
\cline { 2 - 6 } \multicolumn{1}{c|}{} & $\mathbf{( + )} \mathbf{1 1}-\mathbf{2 0}$ & $\mathbf{( + )} \mathbf{1}-\mathbf{1 0}$ & Empate & $\mathbf{( - )} \mathbf{1}-\mathbf{1 0}$ & $(\mathbf{-}) \mathbf{1 1}-\mathbf{2 0}$ \\
\hline 10 QT & 16 & 555 & 161 & 653 & 32 \\
\hline 20 QT & 32 & 586 & 97 & 625 & 55 \\
\hline 30 QT & 52 & 469 & 107 & 597 & 122 \\
\hline 40 QT & 34 & 449 & 56 & 543 & 221 \\
\hline
\end{tabular}

\begin{tabular}{|c|c|c|c|c|c|}
\cline { 2 - 6 } \multicolumn{1}{c|}{} & $(\mathbf{+}) \mathbf{1 1} \mathbf{- 2 0}$ & $\mathbf{( + )} \mathbf{1} \mathbf{- 1 0}$ & Empate & $\mathbf{( - )} \mathbf{1} \mathbf{- 1 0}$ & $\mathbf{( - )} \mathbf{1 1} \mathbf{- 2 0}$ \\
\hline Tiempo Muerto & 4 & 53 & 12 & 115 & 19 \\
\hline Última Jugada & 6 & 32 & 3 & 44 & 4 \\
\hline
\end{tabular}

\begin{tabular}{|c|c|c|c|c|c|c|}
\cline { 2 - 7 } \multicolumn{1}{c|}{} & Contraataque & Bloqueo Directo & Pase & Jugada Personal & Robo & Rebote \\
\hline Uno & 6 & 245 & 0 & 679 & 64 & 291 \\
\hline Dos & 67 & 332 & 790 & 690 & 67 & 0 \\
\hline Tres & 30 & 236 & 607 & 579 & 12 & 0 \\
\hline Cuatro & 5 & 80 & 293 & 284 & 1 & 0 \\
\hline Cinco & 0 & 13 & 57 & 34 & 0 & 0 \\
\hline
\end{tabular}

\begin{tabular}{|c|c|c|c|c|c|c|}
\cline { 2 - 7 } \multicolumn{1}{c|}{} & Contraataque & Bloqueo Directo & Pase & Jugada Personal & Robo & Rebote \\
\hline 10 QT & 30 & 255 & 455 & 573 & 36 & 68 \\
\hline 20 QT & 40 & 217 & 450 & 578 & 38 & 72 \\
\hline 3o QT & 24 & 217 & 431 & 554 & 35 & 86 \\
\hline 40 QT & 14 & 217 & 411 & 561 & 35 & 65 \\
\hline
\end{tabular}

\begin{tabular}{|c|c|c|c|c|c|c|}
\cline { 2 - 7 } \multicolumn{1}{c|}{} & Contraataque & Bloqueo Directo & Pase & Jugada Personal & Robo & Rebote \\
\hline Tiempo Muerto & 0 & 34 & 74 & 95 & 0 & 0 \\
\hline Última Jugada & 2 & 9 & 25 & 48 & 5 & 0 \\
\hline
\end{tabular}

\begin{tabular}{|l|c|c|c|c|c|}
\cline { 2 - 6 } \multicolumn{1}{c|}{} & Uno & Dos & Tres & Cuatro & Cinco \\
\hline 10 QT & 311 & 496 & 402 & 178 & 30 \\
\hline 20 QT & 301 & 496 & 408 & 163 & 27 \\
\hline 30 QT & 342 & 445 & 350 & 188 & 22 \\
\hline 40 QT & 331 & 509 & 304 & 134 & 25 \\
\hline
\end{tabular}

\begin{tabular}{|c|c|c|c|c|c|}
\cline { 2 - 6 } \multicolumn{1}{c|}{} & Uno & Dos & Tres & Cuatro & Cinco \\
\hline Tiempo Muerto & 21 & 63 & 69 & 34 & 16 \\
\hline Última Jugada & 47 & 34 & 5 & 3 & 0 \\
\hline
\end{tabular}




\begin{tabular}{|c|c|c|c|c|}
\cline { 2 - 5 } \multicolumn{1}{c|}{} & 10 QT & 20 QT & 30 QT & 40 QT \\
\hline Tiempo Muerto & 36 & 48 & 34 & 85 \\
\hline Última Jugada & 23 & 23 & 28 & 15 \\
\hline
\end{tabular}




\subsubsection{Baloncesto femenino EEUU (WNBA)}

\begin{tabular}{|c|c|c|c|c|c|c|c|}
\cline { 2 - 8 } \multicolumn{1}{c|}{} & ZONA 1 & ZONA 2 & ZONA 3 & ZONA 4 & ZONA 5 & ZONA 6 & ZONA 7 \\
\hline 3p. + adicional & 0 & 0 & 0 & 0 & 0 & 0 & 0 \\
\hline 3puntos & 0 & 0 & 0 & 0 & 30 & 14 & 93 \\
\hline Falta + 3 adic. & 0 & 0 & 0 & 0 & 1 & 0 & 0 \\
\hline 2p. + adicional & 40 & 3 & 0 & 0 & 0 & 0 & 0 \\
\hline 2puntos & 329 & 51 & 39 & 76 & 0 & 0 & 0 \\
\hline Falta + 2 adic. & 116 & 7 & 7 & 6 & 0 & 0 & 0 \\
\hline Tapón & 62 & 2 & 2 & 1 & 2 & 3 & 0 \\
\hline Fallo 3p. & 0 & 0 & 0 & 0 & 55 & 42 & 197 \\
\hline Fallo 2p. & 311 & 94 & 73 & 100 & 0 & 0 & 0 \\
\hline
\end{tabular}

\begin{tabular}{|c|c|c|c|c|c|c|c|}
\cline { 2 - 8 } \multicolumn{1}{c|}{} & ZONA 1 & ZONA 2 & ZONA 3 & ZONA 4 & ZONA 5 & ZONA 6 & ZONA 7 \\
\hline $\mathbf{0 - \mathbf { 8 }}$ & 193 & 52 & 42 & 39 & 26 & 18 & 82 \\
\hline $\mathbf{9 - 1 6}$ & 459 & 89 & 59 & 112 & 50 & 32 & 133 \\
\hline $\mathbf{1 7}-\mathbf{2 4}$ & 206 & 16 & 20 & 32 & 12 & 9 & 75 \\
\hline
\end{tabular}

\begin{tabular}{|c|c|c|c|c|c|c|c|}
\cline { 2 - 8 } \multicolumn{1}{c|}{} & ZONA 1 & ZONA 2 & ZONA 3 & ZONA 4 & ZONA 5 & ZONA 6 & ZONA 7 \\
\hline Buen tiro & 182 & 39 & 25 & 115 & 54 & 37 & 180 \\
\hline Tiro normal & 542 & 81 & 73 & 60 & 28 & 21 & 57 \\
\hline Mal tiro & 134 & 37 & 23 & 8 & 6 & 1 & 53 \\
\hline
\end{tabular}

\begin{tabular}{|c|c|c|c|c|c|c|c|}
\cline { 2 - 8 } \multicolumn{1}{c|}{} & ZONA 1 & ZONA 2 & ZONA 3 & ZONA 4 & ZONA 5 & ZONA 6 & ZONA 7 \\
\hline (+) $\mathbf{1 1}-\mathbf{2 0}$ & 19 & 3 & 1 & 3 & 2 & 1 & 6 \\
\hline$(+) \mathbf{1}-\mathbf{1 0}$ & 253 & 52 & 38 & 66 & 24 & 20 & 93 \\
\hline Empate & 63 & 12 & 12 & 11 & 7 & 7 & 21 \\
\hline $\mathbf{( - )} \mathbf{1}-\mathbf{1 0}$ & 433 & 80 & 59 & 77 & 47 & 27 & 145 \\
\hline$(-) \mathbf{1 1}-\mathbf{2 0}$ & 90 & 10 & 11 & 26 & 8 & 4 & 25 \\
\hline
\end{tabular}

\begin{tabular}{|c|c|c|c|c|c|c|c|}
\cline { 2 - 8 } \multicolumn{1}{c|}{} & ZONA 1 & ZONA 2 & ZONA 3 & ZONA 4 & ZONA 5 & ZONA 6 & ZONA 7 \\
\hline Contraataque & 47 & 0 & 3 & 1 & 1 & 2 & 5 \\
\hline Bloqueo Directo & 112 & 28 & 26 & 82 & 5 & 1 & 50 \\
\hline Pase & 133 & 42 & 28 & 63 & 76 & 51 & 194 \\
\hline Jugada Personal & 433 & 85 & 62 & 35 & 5 & 3 & 39 \\
\hline Robo & 44 & 0 & 1 & 0 & 1 & 1 & 1 \\
\hline Rebote & 89 & 2 & 1 & 2 & 0 & 1 & 1 \\
\hline
\end{tabular}

\begin{tabular}{|c|c|c|c|c|c|c|c|}
\cline { 2 - 8 } \multicolumn{1}{c|}{} & ZONA 1 & ZONA 2 & ZONA 3 & ZONA 4 & ZONA 5 & ZONA 6 & ZONA 7 \\
\hline Uno & 240 & 21 & 28 & 30 & 1 & 3 & 40 \\
\hline Dos & 284 & 55 & 38 & 65 & 35 & 18 & 125 \\
\hline Tres & 226 & 51 & 38 & 69 & 30 & 21 & 74 \\
\hline Cuatro & 90 & 25 & 15 & 16 & 17 & 14 & 42 \\
\hline Cinco & 18 & 5 & 2 & 3 & 5 & 3 & 9 \\
\hline
\end{tabular}




\begin{tabular}{|l|c|c|c|c|c|c|c|}
\cline { 2 - 8 } \multicolumn{1}{c|}{} & ZONA 1 & ZONA 2 & ZONA 3 & ZONA 4 & ZONA 5 & ZONA 6 & ZONA 7 \\
\hline 10 QT & 212 & 47 & 30 & 55 & 23 & 17 & 67 \\
\hline 20 QT & 228 & 32 & 35 & 42 & 21 & 14 & 73 \\
\hline 30 QT & 193 & 40 & 33 & 50 & 21 & 19 & 68 \\
\hline 40 QT & 225 & 38 & 23 & 36 & 23 & 9 & 82 \\
\hline
\end{tabular}

\begin{tabular}{|c|c|c|c|c|c|c|c|}
\cline { 2 - 8 } \multicolumn{1}{c|}{} & ZONA 1 & ZONA 2 & ZONA 3 & ZONA 4 & ZONA 5 & ZONA 6 & ZONA 7 \\
\hline Tiempo Muerto & 30 & 9 & 2 & 6 & 5 & 4 & 11 \\
\hline Última Jugada & 6 & 0 & 4 & 3 & 2 & 0 & 13 \\
\hline
\end{tabular}

\begin{tabular}{|c|c|c|c|c|c|c|c|c|c|}
\cline { 2 - 8 } \multicolumn{1}{c|}{} & 3p. + adicional & 3puntos & Falta + 3 adic. & 2p. + adicional & 2puntos & Falta + 2 adic. & Tapón & Fallo 3p. & Fallo 2p. \\
\hline $\mathbf{0 - 8}$ & 0 & 33 & 0 & 9 & 114 & 30 & 18 & 91 & 157 \\
\hline $\mathbf{9 - 1 6}$ & 0 & 76 & 1 & 20 & 263 & 78 & 34 & 138 & 324 \\
\hline $\mathbf{1 7 - 2 4}$ & 0 & 28 & 0 & 14 & 118 & 28 & 20 & 65 & 97 \\
\hline
\end{tabular}

\begin{tabular}{|c|c|c|c|c|c|c|c|c|c|}
\hline & 3p. + adicional & 3puntos & Falta $+\mathbf{3}$ adic. & 2p. + adicional & 2puntos & Falta +2 adic. & Tapón & Fallo 3p. & Fallo 2p. \\
\hline$(+) 11-20$ & 0 & 5 & 0 & 1 & 12 & 2 & 1 & 4 & 10 \\
\hline$(+) 1-10$ & 0 & 32 & 1 & 5 & 166 & 50 & 32 & 102 & 158 \\
\hline Empate & 0 & 10 & 0 & 5 & 37 & 11 & 5 & 25 & 40 \\
\hline$(-) 1-10$ & 0 & 75 & 0 & 26 & 234 & 57 & 30 & 142 & 304 \\
\hline$(-) 11-20$ & 0 & 15 & 0 & 6 & 46 & 16 & 4 & 21 & 66 \\
\hline
\end{tabular}

\begin{tabular}{|c|c|c|c|c|c|c|c|c|c|}
\cline { 2 - 9 } \multicolumn{1}{c|}{} & 3p. + adicional & 3puntos & Falta + 3 adic. & 2p. + adicional & 2puntos & Falta + 2 adic. & Tapón & Fallo 3p. & Fallo 2p. \\
\hline Contraataque & 0 & 3 & 0 & 2 & 29 & 6 & 0 & 5 \\
\hline Bloqueo Directo & 0 & 18 & 1 & 5 & 99 & 24 & 11 & 37 \\
\hline Pase & 0 & 105 & 0 & 7 & 132 & 10 & 12 & 211 & 110 \\
\hline Jugada Personal & 0 & 11 & 0 & 26 & 171 & 82 & 40 & 36 & 296 \\
\hline Robo & 0 & 0 & 0 & 1 & 29 & 2 & 3 & 3 \\
\hline Rebote & 0 & 0 & 0 & 2 & 35 & 12 & 6 & 2 \\
\hline
\end{tabular}

\begin{tabular}{|c|c|c|c|c|c|c|c|c|c|}
\cline { 2 - 9 } \multicolumn{1}{c|}{} & 3p. + adicional & 3puntos & Falta + 3 adic. & 2p. + adicional & 2puntos & Falta + 2 adic. & Tapón & Fallo 3p. & Fallo 2p. \\
\hline Uno & 0 & 6 & 0 & 12 & 119 & 42 & 16 & 38 & 130 \\
\hline Dos & 0 & 66 & 1 & 15 & 167 & 37 & 31 & 109 & 194 \\
\hline Tres & 0 & 42 & 0 & 13 & 138 & 40 & 21 & 80 & 175 \\
\hline Cuatro & 0 & 19 & 0 & 3 & 53 & 15 & 4 & 54 & 71 \\
\hline Cinco & 0 & 4 & 0 & 0 & 18 & 2 & 0 \\
\hline
\end{tabular}

\begin{tabular}{|c|c|c|c|c|c|c|c|c|c|}
\hline & 3p. + adicional & 3puntos & Falta +3 adic. & 2p. + adicional & 2puntos & Falta +2 adic. & Tapón & Fallo 3p. & Fallo 2p. \\
\hline 10 QT & 0 & 34 & 0 & 12 & 149 & 28 & 12 & 73 & 143 \\
\hline 20 QT & 0 & 37 & 0 & 7 & 119 & 36 & 25 & 71 & 150 \\
\hline 30 QT & 0 & 26 & 1 & 10 & 111 & 32 & 15 & 77 & 152 \\
\hline 40 QT & 0 & 40 & 0 & 14 & 116 & 40 & 20 & 73 & 133 \\
\hline
\end{tabular}

\begin{tabular}{|c|c|c|c|c|c|c|c|c|c|}
\hline & 3p. + adicional & 3puntos & Falta +3 adic. & $2 p .+$ adicional & 2 puntos & Falta +2 adic. & Tapón & Fallo 3p. & Fallo 2p. \\
\hline Tiempo Muerto & 0 & 7 & 0 & 1 & 19 & 3 & 3 & 12 & 22 \\
\hline Última Jugada & 0 & 0 & 0 & 0 & 6 & 1 & 2 & 14 & 5 \\
\hline
\end{tabular}

\begin{tabular}{|c|c|c|c|}
\cline { 2 - 4 } \multicolumn{1}{c|}{} & $\mathbf{0 - \mathbf { 8 }}$ & $\mathbf{9 - 1 6}$ & $\mathbf{1 7 - 2 4}$ \\
\hline Buen tiro & 114 & 349 & 169 \\
\hline Tiro normal & 215 & 487 & 160 \\
\hline Mal tiro & 123 & 98 & 41 \\
\hline
\end{tabular}




\begin{tabular}{|c|c|c|c|}
\cline { 2 - 4 } \multicolumn{1}{c|}{} & $\mathbf{0 - 8}$ & $\mathbf{9 - 1 6}$ & $\mathbf{1 7 - 2 4}$ \\
\hline$(+) \mathbf{1 1}-\mathbf{2 0}$ & 10 & 17 & 8 \\
\hline (+) $\mathbf{1}-\mathbf{1 0}$ & 154 & 274 & 118 \\
\hline Empate & 37 & 72 & 24 \\
\hline$(-) \mathbf{1}-\mathbf{1 0}$ & 218 & 470 & 180 \\
\hline (-) $\mathbf{1 1}-\mathbf{2 0}$ & 33 & 101 & 40 \\
\hline
\end{tabular}

\begin{tabular}{|c|c|c|c|}
\cline { 2 - 4 } \multicolumn{1}{c|}{} & $\mathbf{0 - \mathbf { 8 }}$ & $\mathbf{9 - 1 6}$ & $\mathbf{1 7 - 2 4}$ \\
\hline Contraataque & 0 & 0 & 59 \\
\hline Bloqueo Directo & 61 & 187 & 56 \\
\hline Pase & 163 & 335 & 89 \\
\hline Jugada Personal & 217 & 330 & 115 \\
\hline Robo & 0 & 0 & 48 \\
\hline Rebote & 11 & 82 & 3 \\
\hline
\end{tabular}

\begin{tabular}{|c|c|c|c|}
\cline { 2 - 4 } \multicolumn{1}{c|}{} & $\mathbf{0 - 8}$ & $\mathbf{9 - 1 6}$ & $\mathbf{1 7 - 2 4}$ \\
\hline Uno & 45 & 180 & 138 \\
\hline Dos & 104 & 343 & 173 \\
\hline Tres & 161 & 292 & 56 \\
\hline Cuatro & 108 & 108 & 3 \\
\hline Cinco & 34 & 11 & 0 \\
\hline
\end{tabular}

\begin{tabular}{|l|c|c|c|}
\cline { 2 - 4 } \multicolumn{1}{c|}{} & $\mathbf{0 - 8}$ & $\mathbf{9 - 1 6}$ & $\mathbf{1 7 - 2 4}$ \\
\hline 10 QT & 104 & 254 & 93 \\
\hline 20 QT & 135 & 216 & 94 \\
\hline 3o QT & 112 & 220 & 92 \\
\hline 40 QT & 101 & 244 & 91 \\
\hline
\end{tabular}

\begin{tabular}{|c|c|c|c|}
\cline { 2 - 4 } \multicolumn{1}{c|}{} & $\mathbf{0 - 8}$ & $\mathbf{9 - 1 6}$ & $\mathbf{1 7 - 2 4}$ \\
\hline Tiempo Muerto & 24 & 36 & 7 \\
\hline Última Jugada & 28 & 0 & 0 \\
\hline
\end{tabular}




\begin{tabular}{|c|c|c|c|}
\cline { 2 - 4 } \multicolumn{1}{c|}{} & Buen tiro & Tiro normal & Mal tiro \\
\hline (+) $\mathbf{1 1}-\mathbf{2 0}$ & 13 & 20 & 2 \\
\hline (+) $\mathbf{1}-\mathbf{1 0}$ & 204 & 252 & 90 \\
\hline Empate & 60 & 57 & 16 \\
\hline (-) $\mathbf{1}-\mathbf{1 0}$ & 300 & 439 & 129 \\
\hline (-) $\mathbf{1 1}-\mathbf{2 0}$ & 55 & 94 & $\mathbf{2 5}$ \\
\hline
\end{tabular}

\begin{tabular}{|c|c|c|c|}
\cline { 2 - 4 } \multicolumn{1}{c|}{} & Buen tiro & Tiro normal & Mal tiro \\
\hline Contraataque & 33 & 23 & 3 \\
\hline Bloqueo Directo & 143 & 135 & 26 \\
\hline Pase & 339 & 202 & 46 \\
\hline Jugada Personal & 60 & 418 & 184 \\
\hline Robo & 32 & 16 & 0 \\
\hline Rebote & 25 & 68 & 3 \\
\hline
\end{tabular}

\begin{tabular}{|c|c|c|c|}
\cline { 2 - 4 } \multicolumn{1}{c|}{} & Buen tiro & Tiro normal & Mal tiro \\
\hline Uno & 101 & 206 & 56 \\
\hline Dos & 250 & 272 & 98 \\
\hline Tres & 184 & 257 & 68 \\
\hline Cuatro & 78 & 108 & 33 \\
\hline Cinco & 19 & 19 & 7 \\
\hline
\end{tabular}

\begin{tabular}{|l|c|c|c|}
\cline { 2 - 4 } \multicolumn{1}{c|}{} & Buen tiro & Tiro normal & Mal tiro \\
\hline 10 QT & 184 & 209 & 58 \\
\hline 20 QT & 162 & 213 & 70 \\
\hline 30 QT & 146 & 214 & 64 \\
\hline 40 QT & 140 & 226 & 70 \\
\hline
\end{tabular}

\begin{tabular}{|c|c|c|c|}
\cline { 2 - 4 } \multicolumn{1}{c|}{} & Buen tiro & Tiro normal & Mal tiro \\
\hline Tiempo Muerto & 21 & 36 & 10 \\
\hline Última Jugada & 5 & 6 & 17 \\
\hline
\end{tabular}




\begin{tabular}{|c|c|c|c|c|c|}
\cline { 2 - 6 } \multicolumn{1}{c|}{} & $\mathbf{( + )} \mathbf{1 1} \mathbf{- 2 0}$ & $\mathbf{( + )} \mathbf{1}-\mathbf{1 0}$ & Empate & $\mathbf{( - )} \mathbf{1}-\mathbf{1 0}$ & $\mathbf{( - )} \mathbf{1 1} \mathbf{- 2 0}$ \\
\hline Contraataque & 3 & 17 & 2 & 32 & 5 \\
\hline Bloqueo Directo & 5 & 99 & 21 & 151 & $\mathbf{2 8}$ \\
\hline Pase & 10 & 198 & 53 & 276 & 50 \\
\hline Jugada Personal & 14 & 193 & 47 & 335 & 73 \\
\hline Robo & 1 & 21 & 2 & 19 & 5 \\
\hline Rebote & 2 & 18 & 8 & 55 & 13 \\
\hline
\end{tabular}

\begin{tabular}{|c|c|c|c|c|c|}
\cline { 2 - 6 } \multicolumn{1}{c|}{} & $\mathbf{( + )} \mathbf{1 1}-\mathbf{2 0}$ & $\mathbf{( + )} \mathbf{1}-\mathbf{1 0}$ & Empate & $\mathbf{( - )} \mathbf{1}-\mathbf{1 0}$ & $\mathbf{( - )} \mathbf{1 1}-\mathbf{2 0}$ \\
\hline Uno & 3 & 105 & 22 & 193 & 40 \\
\hline Dos & 18 & 183 & 40 & 307 & 72 \\
\hline Tres & 9 & 171 & 47 & 239 & 43 \\
\hline Cuatro & 4 & 74 & 16 & 106 & 19 \\
\hline Cinco & 1 & 13 & 8 & 23 & 0 \\
\hline
\end{tabular}

\begin{tabular}{|l|c|c|c|c|c|}
\cline { 2 - 6 } \multicolumn{1}{c|}{} & $\mathbf{( + )} \mathbf{1 1}-\mathbf{2 0}$ & $\mathbf{( + )} \mathbf{1}-\mathbf{1 0}$ & Empate & $\mathbf{( - )} \mathbf{1}-\mathbf{1 0}$ & $(\mathbf{-}) \mathbf{1 1}-\mathbf{2 0}$ \\
\hline 10 QT & 3 & 132 & 60 & 253 & 3 \\
\hline 20 QT & 0 & 177 & 48 & 201 & 19 \\
\hline 30 QT & 10 & 134 & 10 & 187 & 83 \\
\hline 40 QT & 22 & 103 & 15 & 227 & 69 \\
\hline
\end{tabular}

\begin{tabular}{|c|c|c|c|c|c|}
\cline { 2 - 6 } \multicolumn{1}{c|}{} & $\mathbf{( + )} \mathbf{1 1} \mathbf{- 2 0}$ & $\mathbf{( + )} \mathbf{1}-\mathbf{1 0}$ & Empate & $\mathbf{( - )} \mathbf{1}-\mathbf{1 0}$ & $\mathbf{( - )} \mathbf{1 1} \mathbf{- 2 0}$ \\
\hline Tiempo Muerto & 2 & 15 & 4 & 38 & 8 \\
\hline Última Jugada & 0 & 10 & 2 & 13 & 3 \\
\hline
\end{tabular}

\begin{tabular}{|c|c|c|c|c|c|c|}
\cline { 2 - 7 } \multicolumn{1}{c|}{} & Contraataque & Bloqueo Directo & Pase & Jugada Personal & Robo & Rebote \\
\hline Uno & 5 & 85 & 0 & 157 & 20 & 96 \\
\hline Dos & 33 & 113 & 235 & 215 & 24 & 0 \\
\hline Tres & 20 & 78 & 209 & 198 & 4 & 0 \\
\hline Cuatro & 1 & 25 & 112 & 81 & 0 & 0 \\
\hline Cinco & 0 & 3 & 31 & 11 & 0 & 0 \\
\hline
\end{tabular}

\begin{tabular}{|c|c|c|c|c|c|c|}
\cline { 2 - 7 } \multicolumn{1}{c|}{} & Contraataque & Bloqueo Directo & Pase & Jugada Personal & Robo & Rebote \\
\hline 10 QT & 15 & 87 & 166 & 150 & 14 & 19 \\
\hline 2o QT & 15 & 77 & 135 & 183 & 10 & 25 \\
\hline 3o QT & 13 & 73 & 153 & 156 & 12 & 17 \\
\hline 4o QT & 16 & 67 & 133 & 173 & 12 & 35 \\
\hline
\end{tabular}

\begin{tabular}{|c|c|c|c|c|c|c|}
\cline { 2 - 7 } \multicolumn{1}{c|}{} & Contraataque & Bloqueo Directo & Pase & Jugada Personal & Robo & Rebote \\
\hline Tiempo Muerto & 0 & 5 & 32 & 30 & 0 & 0 \\
\hline Última Jugada & 0 & 6 & 9 & 13 & 0 & 0 \\
\hline
\end{tabular}




\begin{tabular}{|c|c|c|c|c|c|}
\cline { 2 - 6 } \multicolumn{1}{c|}{} & Uno & Dos & Tres & Cuatro & Cinco \\
\hline 10 QT & 80 & 157 & 143 & 54 & 17 \\
\hline 20 QT & 93 & 153 & 135 & 53 & 11 \\
\hline 30 QT & 87 & 147 & 121 & 60 & 9 \\
\hline 40 QT & 103 & 163 & 110 & 52 & 8 \\
\hline
\end{tabular}

\begin{tabular}{|c|c|c|c|c|c|}
\cline { 2 - 6 } \multicolumn{1}{c|}{} & Uno & Dos & Tres & Cuatro & Cinco \\
\hline Tiempo Muerto & 9 & 24 & 19 & 11 & 4 \\
\hline Última Jugada & 12 & 10 & 6 & 0 & 0 \\
\hline
\end{tabular}

\begin{tabular}{|c|c|c|c|c|}
\cline { 2 - 5 } \multicolumn{1}{c|}{} & 10 QT & 20 QT & 30 QT & 40 QT \\
\hline Tiempo Muerto & 8 & 15 & 11 & 33 \\
\hline Última Jugada & 5 & 8 & 13 & 2 \\
\hline
\end{tabular}

